\title{
LISTA DE FIGURAS
}

Figura 1 Macro Visão Parcial dos Componentes do SPB …...................................

Figura 2 Micro Visão Parcial dos Componentes do SPB......................................... 4

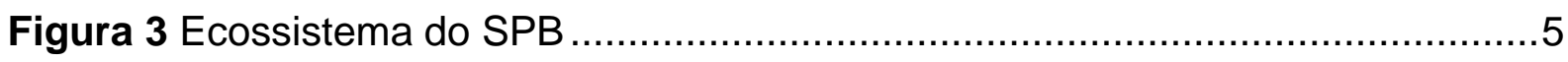

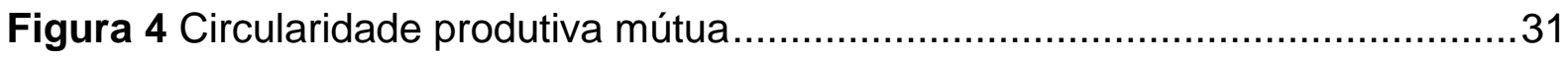

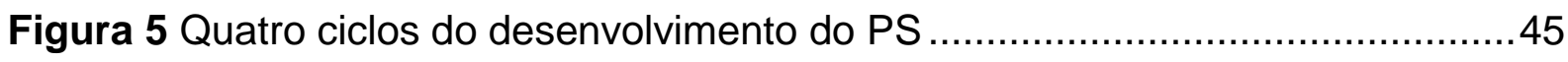

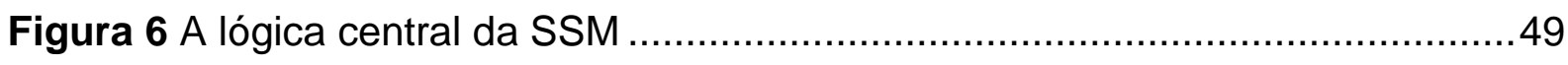

Figura 7 As fases da SSM Fonte: Checkland (1981).........................................52

Figura 8 Modelo genérico de um SAH Fonte: Checkland (1989) ..........................52

Figura 9 Padrão de organização sistêmico .....................................................5

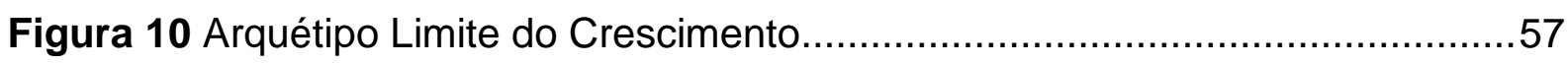

Figura 11 Arquétipo Transferência de Responsabilidade ......................................58

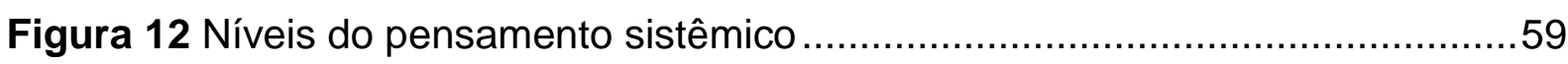

Figura 13 Conceitos básicos da melhoria de processo de software ........................78

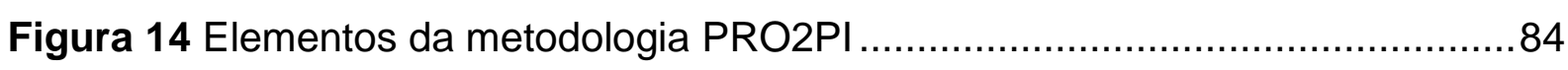

Figura 15 Sete práticas sequenciais do PRO2PI-MFMOD ....................................87

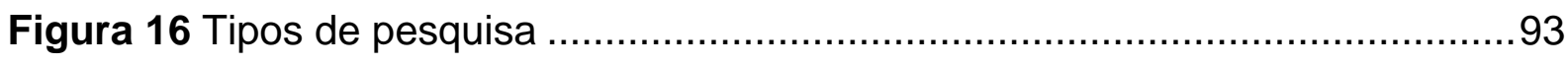

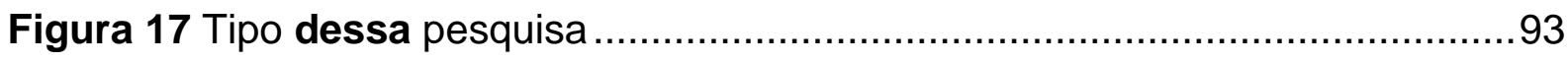

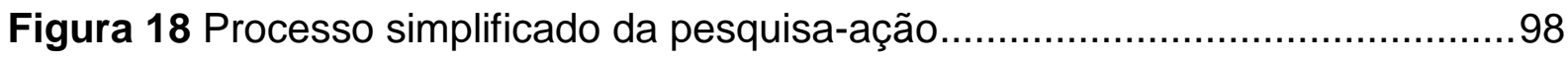

Figura 19 Processos das ciências naturais e da pesquisa-ação ..............................99

Figura 20 Processo "canônico" da pesquisa-ação...............................................101

Figura 21 Etapas do ciclo da pesquisa-ação .....................................................104

Figura 22 Criação do conhecimento oriundo das etapas do SSM ........................116

Figura 23 Natureza dual dos ciclos de pesquisa-ação .......................................117

Figura 24 Relacionamento entre núcleo de ação e pesquisa ................................119

Figura 25 Os quatro momentos da pesquisa................................................137

Figura 26 Novos paradigmas dos modelos de capacidade ….............................139

Figura 27 Representação do fluxo do sistema SPB .........................................149

Figura 28 Vetores de qualidade do SPB ....................................................151

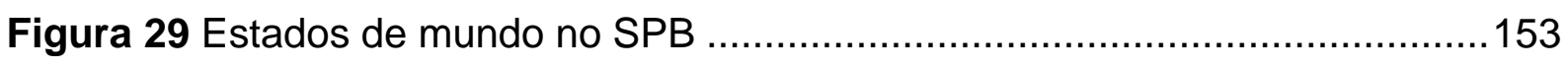

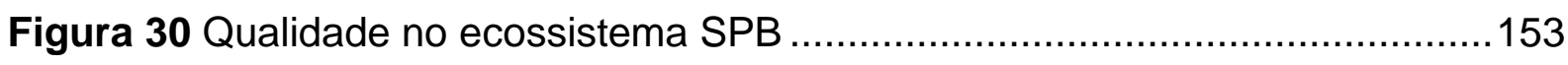

Figura 31 Membros da equipe do SPB baseados no CTI/Campinas ...................155

Figura 32 Representação do Ecossistema SPB e seu entorno .............................158 


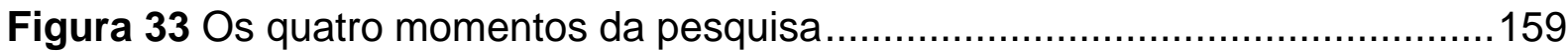

Figura 34 Representação do momento 01 da pesquisa .....................................160

Figura 35 Representação do esquema da dinâmica do "Café Mundial" ..................164

Figura 36 Representação do Momento 02 da pesquisa ......................................169

Figura 37 Arcabouço estrutural do Ecossistema SPB .....................................178

Figura 38 Representação da reunião sobre a metodologia SSM .........................183

Figura 39 Representação da reunião de desafio visionário ..................................184

Figura 40 Representação da reunião sobre a história e os indicadores..................185

Figura 41 Representação da reunião de construção do mapa sistêmico ................188

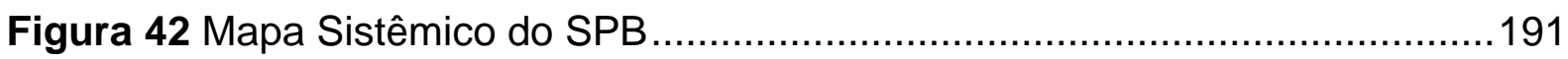

Figura 43 Representação da reunião sobre modelos mentais no SPB ..................192

Figura 44 Representação da reunião de cenários do SPB..................................194

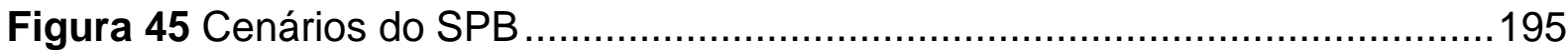

Figura 46 Representação da reunião de aprendizagem....................................198

Figura 47 Aspecto geral do modelo do SPB no ITHINK ....................................199

Figura 48 Representação da sétima reunião SSM ..........................................201

Figura 49 Modelo de referência do Ecossistema SPB .....................................217

Figura 50 Agrupamentos de variáveis críticas do SPB......................................224

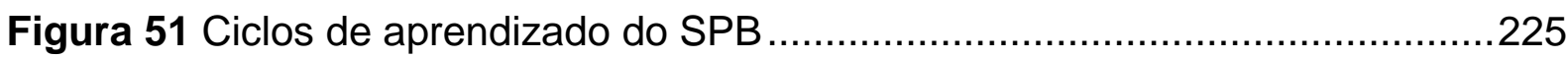

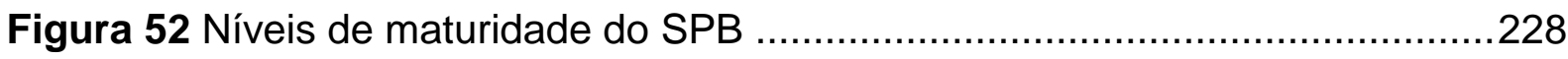

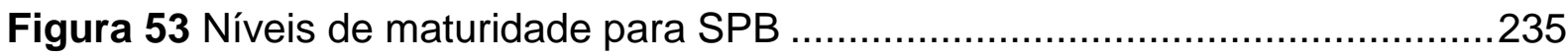

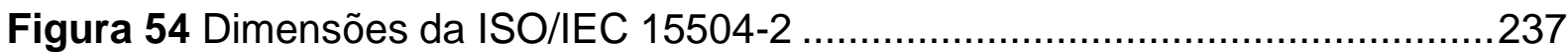

Figura 55 Nova dimensão para a estrutura de medição .....................................238

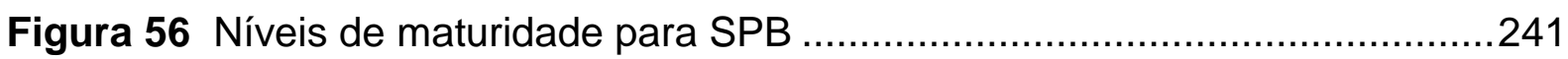

Figura 57 Percurso para construção dos níveis sistêmicos.................................243

Figura 58 Visão organizacional das áreas de capacidade do Modelo ....................252

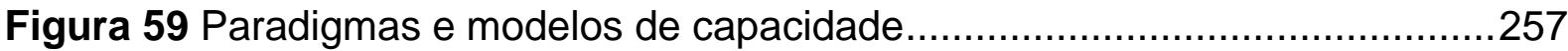




\section{LISTA DE TABELAS}

Tabela 1 Bases utilizadas na pesquisa sem refinamento ......................................322

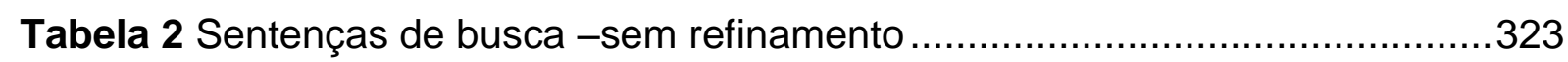

Tabela 3 Quantidade bruta de publicações por tema ..........................................323

Tabela 4 Bases do primeiro, segundo e terceiro refinamentos ...............................324

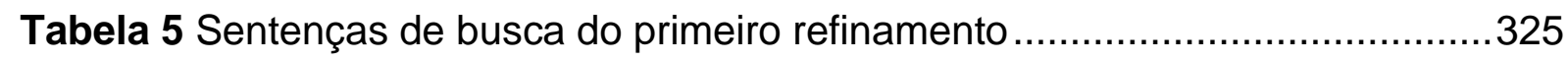

Tabela 6 Quantidade de publicações por tema na ES e na CC.............................325

Tabela 7 Sentença de busca do segundo refinamento ...........................................327

Tabela 8 Quantidade de publicações por tema na ES e CC ..................................327

Tabela 9 Sentença de busca do terceiro refinamento ............................................328 


\section{LISTA DE QUADROS}

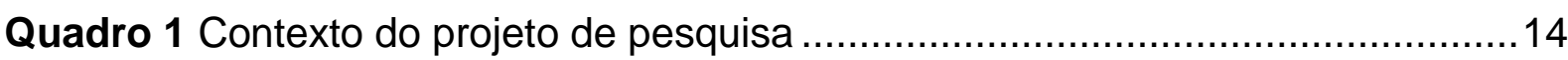

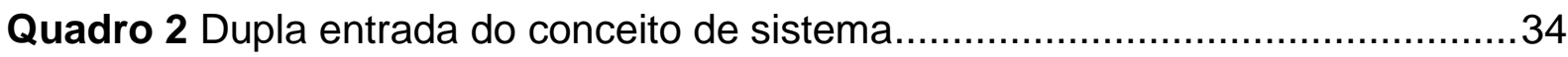

Quadro 3 Principais referências teóricas para sistemas complexos..........................36

Quadro 4 A forma do movimento sistêmico........................................................4 44

Quadro 5 Diferenças entre as abordagens hard e soft.........................................53

Quadro 6 Literatura de Referência sobre Pensamento Sistêmico.............................63

Quadro 7 Literatura de Referência sobre Ecossistemas Digitais.............................73

Quadro 8 Literatura de referência sobre Modelos de Maturidade ...........................83

Quadro 9 Sete práticas sequenciais do PRO2PI-MFMOD ......................................86

Quadro 10 Regras de customização do PRO2PI-MFMOD …………………......... 87

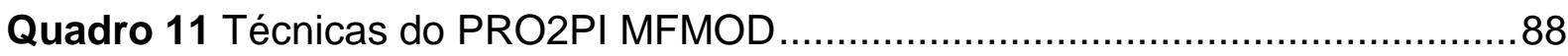

Quadro 12 Literatura de Referência sobre o PRO2PI-MFMOD................................89

Quadro 13 Principais métodos de pesquisa na EP ..............................................96

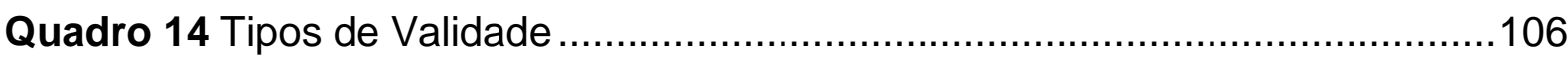

Quadro 15 Aspectos gerais de avaliação de Thiollent (2005) .............................108

Quadro 16 Objetivos de conhecimento alcançáveis de Thiollent (2005) ................108

Quadro 17 Critérios para avaliação da qualidade da pesquisa-ação ....................111

Quadro 18 Características principais da pesquisa-ação versus Tese ...................127

Quadro 19 Método Científico\&Pesquisa-ação\&Tese ........................................132

Quadro 20 Características da pesquisa ....................................................137

Quadro 21 Fases e técnicas da pesquisa .....................................................141

Quadro 22 Quadro-resumo para pesquisa-ação …………………………......144

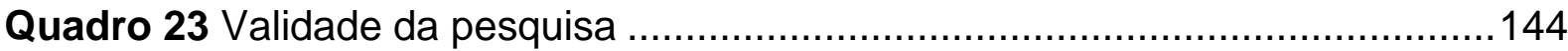

Quadro 24 Referência para avaliação versus tese ...........................................145

Quadro 25 Atividades, Regras, Práticas e Técnicas do MFMOD para o SPB........166

Quadro 26 Práticas e atividades do PRO2PI-MFMOD para o SPB - 01 ...............166

Quadro 27 Resumo do Momento de Pesquisa 01 ............................................168

Quadro 28 Entendendo o problema (FASE01) ……........................................175

Quadro 29 Atividades, Regras, Práticas e Técnicas do MFMOD para o SPB........176

Quadro 30 Práticas e atividades do PRO2PI-MFMOD para o SPB 02 ...................177

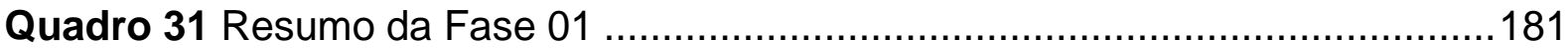

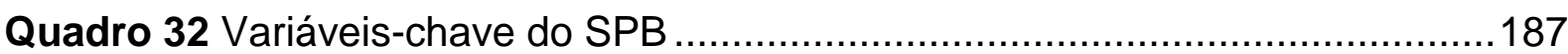


Quadro 33 Modelos mentais do SPB 193

Quadro 34 Dados e informações coletados durante os ciclos da SSM .................212

Quadro 35 Atividades, Regras, Práticas e Técnicas do MFMOD para o SPB........213

Quadro 36 Atividades, Regras, Práticas e Técnicas do MFMOD para o SPB........214

Quadro 37 Práticas e atividades do PRO2PI-MFMOD para o SPB - 03 ...............214

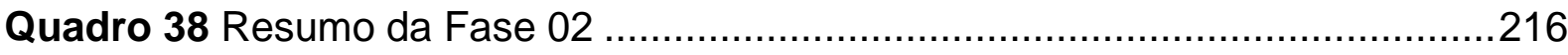

Quadro 39 Variáveis para a definição dos níveis de maturidade do SPB .............233

Quadro 40 Esboço dos atributos do ecossistema .............................................244

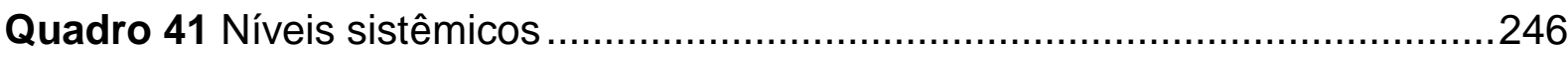

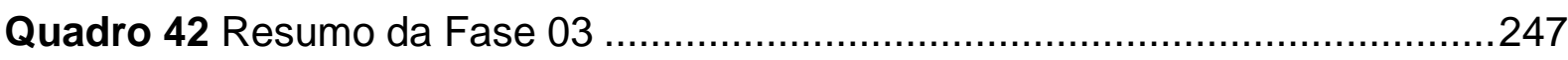

Quadro 43 Práticas e atividades do PRO2PI-MFMOD para o SPB.......................248

Quadro 44 Atividades, Regras, Práticas e Técnicas do MFMOD para o SPB......250

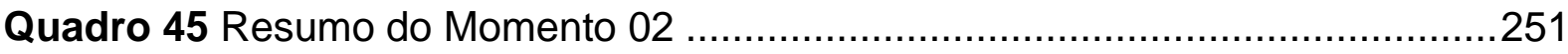

Quadro 46 Áreas de capacidade de processo do SPB .......................................252

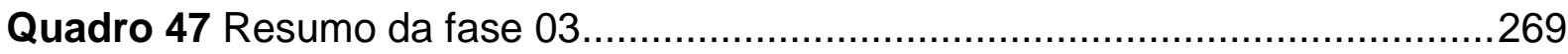

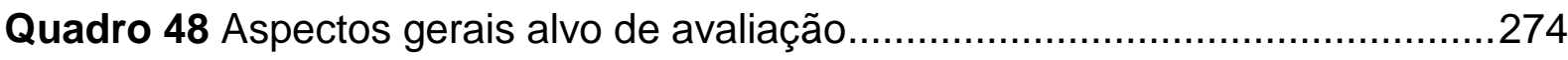

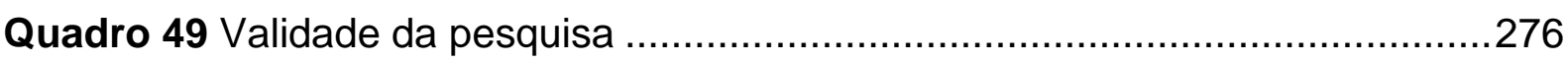




\section{LISTA DE ABREVIATURAS E SIGLAS}

$4 \mathrm{CMBr}$

Grupo de interesse para municípios brasileiros

$5 \mathrm{CQualiBr}$

Grupo de interesse para qualidade do SPB

ABEP

Associação das Entidades Estaduais de Tecnologia da Informação e Comunicação

APENACS Sistema de Arquitetura de Comunidades Aberto

ASSESPRO Associação das Empresas Brasileiras de Tecnologia da Informação, Software e Internet

CC Creactive Commons

CERTICS Certificação de Tecnologia Nacional de Software

CMM Modelo de maturidade de capacidade

CMMI Modelo Integrado de maturidade da capacidade

CMMI-DEV Modelo integrado de maturidade da capacidade desenvolvimento

COBIT

Objetivos de Controle para Tecnologias de Informação e Relacionadas

CTI Centro de Tecnologia da Informação Renato Archer

e-PROINFO Ambiente colaborativo de aprendizagem

EPS Escola do Pensamento sistêmico

FACTI Fundação de Apoio à Capacitação em Tecnologia da Informação

FANAINFO Federação Nacional das Empresas de Serviços Técnicos de Informática e Similares

FINEP Financiadora de estudos e projetos

GPL Licença Pública Geral

GSAN Sistema integrado de gestão de serviços de saneamento

I3GEO Sistema de referenciamento geográfico

IEEE 610.12 IEEE Standard Glossary of Software Engineering Terminology

InVesalius Sistema de diagnóstico e planejamento cirúrgico

ISO $20.000 \quad$ Norma de gerenciamento de serviços

MARES-MPE Método de Avaliação Rápida para Empresas de Software

MCTI Ministério da Ciência Tecnologia e Inovação

MDIC Ministério do Desenvolvimento, Indústria e Comércio Exterior

MOPROSOFT Modelo de Processos para a Indústria de Software 


\begin{tabular}{|c|c|}
\hline MPOG & Ministério do Planejamento Orçamento e Gestão \\
\hline MR-MPS & Modelo de Referência para Melhoria de Processo de Software \\
\hline OPENACS & O Sistema de Arquitetura de Comunidades Aberto \\
\hline PMBOK & Corpo de Conhecimento de Gerência de Projeto \\
\hline PNUD & Programa das Nações Unidas para o Desenvolvimento \\
\hline PROCERGS & $\begin{array}{l}\text { Companhia de Processamento de Dados do Estado do Rio } \\
\text { Grande do Sul }\end{array}$ \\
\hline PRODERJ & $\begin{array}{l}\text { Centro de Tecnologia da Informação e Comunicação do Estado } \\
\text { do Rio de Janeiro }\end{array}$ \\
\hline RUP & Processo Unificado Rational \\
\hline SAAS & Software como Serviço \\
\hline SEPIN & Secretaria de Política de Informática \\
\hline SIGATI & Sistema de administração de serviços de diretório \\
\hline SLTI & Secretaria de Logística e Tecnologia da Informação \\
\hline SP01 & Subprojeto ecossistemas do SPB \\
\hline SP02 & Subprojeto de interoperabilidade do SPB \\
\hline SP03 & Subprojeto para produtos de software no SPB \\
\hline SP04 & Subprojeto desenvolvimento de software no SPB \\
\hline SP05 & Subprojeto para prestadores de serviços do SPB \\
\hline SP06 & Subprojeto de testes de software do SPB \\
\hline SP07 & Subprojeto de disseminação e sustentabilidade do SPB \\
\hline SPB & Software Público Brasileiro \\
\hline SPICE & $\begin{array}{l}\text { Melhoria de Processo de Software e Determinação da } \\
\text { Capacidade }\end{array}$ \\
\hline SUCESU & Associação de Usuários de Informática e Telecomunicações \\
\hline SWEBOK & Corpo de Conhecimento de Engenharia de Software \\
\hline UFMG & Universidade Federal de Minas Gerais \\
\hline UNB & Universidade de Brasília \\
\hline
\end{tabular}




\section{SUMÁRIO}

1. INTRODUÇÃO

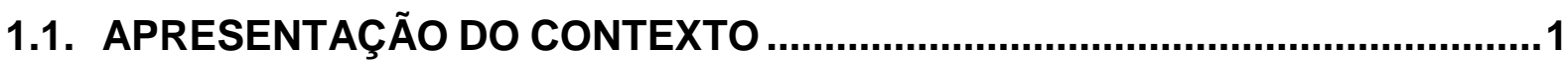

1.2. MOTIVAÇÃO

1.3. OBJETIVOS

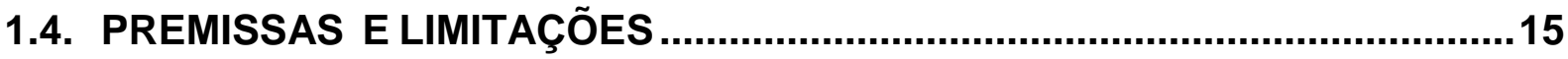

1.5. ESTRUTURAÇÃO DO TRABALHO

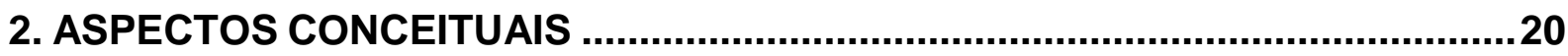

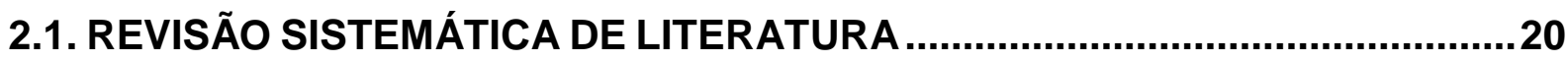

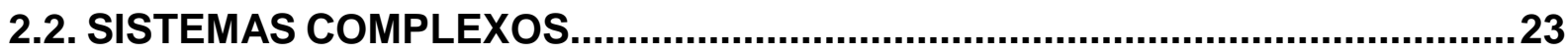

2.2.1. SISTEMA ...............................................................................................................23

2.2.2. COMPLEXIDADE

2.2.3. SISTEMAS COMPLEXOS .....................................................................................25

2.2.4. SISTEMA COMO PARADIGMA DO PENSAMENTO COMPLEXO ….................................27

2.2.5. SISTEMAS ADAPTATIVOS COMPLEXOS ………….................................................35

2.2.6. CONCLUSÃO DA REVISÃO DE LITERATURA - SISTEMAS COMPLEXOS........................36

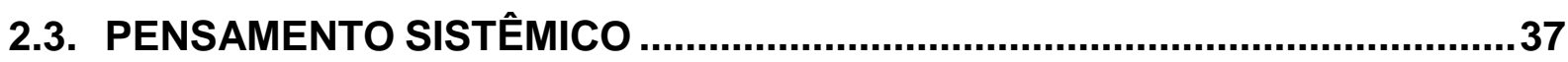

2.3.1. CONSIDERAÇÕES SOBRE A SITUAÇÃO DO MOVIMENTO SISTÊMICO …………...........42

2.3.2. DIVERSAS FORMAS DE ORDENAMENTO DO PENSAMENTO SISTÊMICO.....................43

2.3.3. TÓPICOS DE INVESTIGAÇÃO DAS ABORDAGENS ……..........................................45

2.3.4. AS ABORDAGENS SISTÊMICAS APLICADAS A ORGANIZAÇÕES ..............................47

2.3.5. CONCLUSÃO DA REVISÃO DE LITERATURA-PENSAMENTO SISTÊMICO......................63

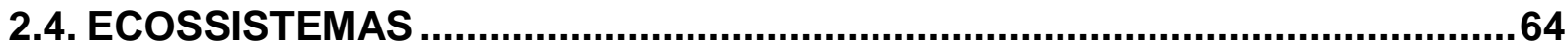

2.4.1. MACROECOSSISTEMA

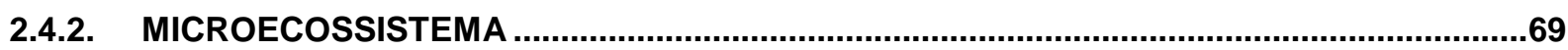

2.4.3. ECOSSISTEMAS TECNOLÓGICOS VERSUS ECONÔMICOS …………………………......69

2.4.4. OUTRO TIPO DE ECOSSISTEMA.............................................................................70

2.4.5. CONCLUSÃO DA REVISÃO DE LITERATURA - ECOSSISTEMAS DIGITAIS ....................73

2.5. A CAPACIDADE, A MATURIDADE E OS MODELOS …...............................75

2.5.1. DEFINIÇÕES E CONCEITOS.......................................................................................78

2.5.2. CONCLUSÃO DA REVISÃO DE LITERATURA - MOD. DE MATURIDADE........................83

2.6. PRO2PI-MFMOD

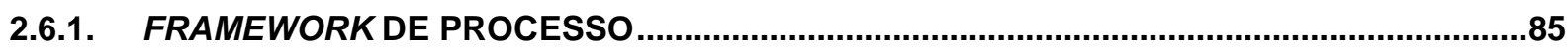

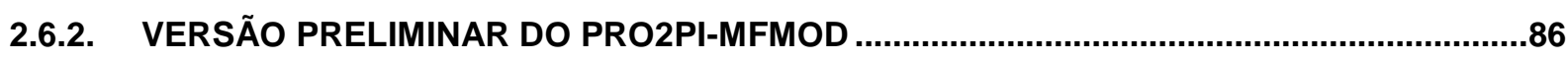

2.6.3. CONCLUSÃO DA A REVISÃO DE LITERATURA - PRO2PI-MFMOD...............................8 
2.7. CONSIDERAÇÕES FINAIS DOS ASPECTOS CONCEITUAIS .89

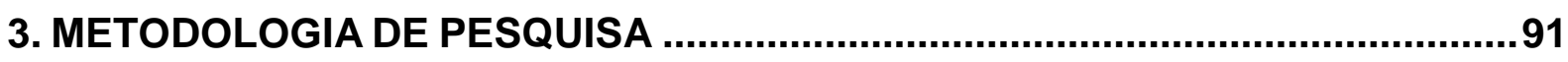

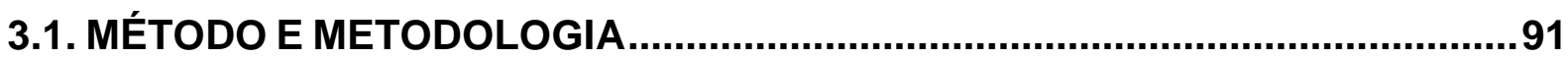

3.1.1. A METODOLOGIA

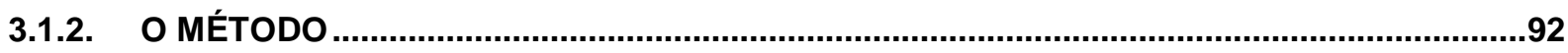

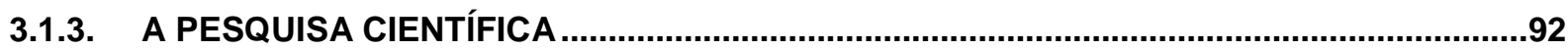

3.1.4. A TAXONOMIA DA PESQUISA CIENTÍFICA........................................................92

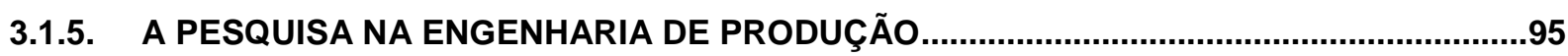

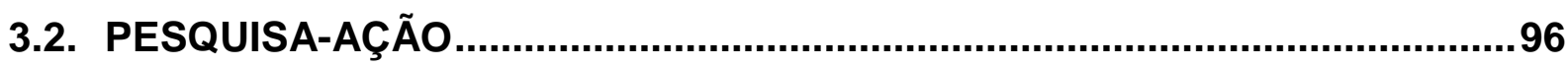

3.2.1. PRINCÍPIOS DA PESQUISA-AÇÃO

3.2.2. 0 processo da pesquisa-ação ...................................................................................98

3.2.3. A CONDUÇÃO DO PROCESSO DE PESQUISA-AÇÃO …………................................100

3.2.4. QUALIDADE E VALIDAÇÃO DA PESQUISA-AÇÃO ……….........................................105

3.2.5. PESQUISA-AÇÃO E SSM ................................................................................115

3.3. PROJETO DE PESQUISA-AÇÃO E TESE............................................117

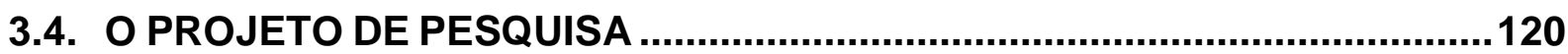

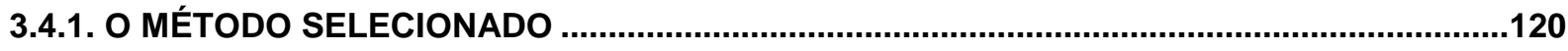

3.4.2. A PESQUISA-AÇÃO, O MÉTODO CIENTÍFICO TRADICIONAL E A TESE.........................128

3.4.3. AS QUESTÕES DE PESQUISA...........................................................................135

3.4.4 DELINEAMENTO DA PESQUISA ............................................................................136

3.4.5. PROTOCOLO DE PESQUISA ...............................................................................140

3.4.6. DA COLETA E ANÁLISE DE DADOS NESTA PESQUISA ..........................................141

3.4.7. A VALIDAÇÃO DA PESQUISA.....................................................................142

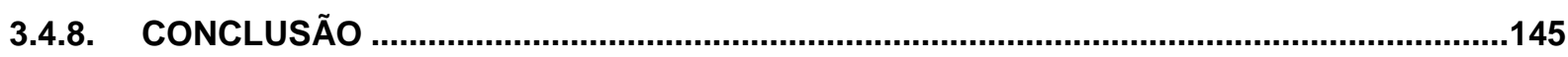

4. PROBLEMA E AMBIENTE REAL DA PESQUISA .............................................

4.1. CONTEXTO DO AMBIENTE REAL .......................................................146

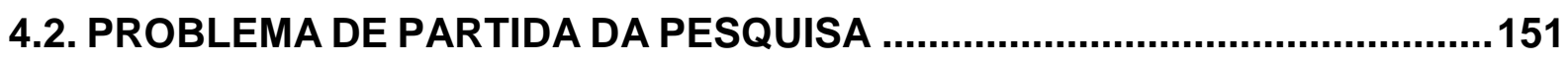

4.3. RECURSOS PARA A REALIZAÇÃO DA PESQUISA …..............................154

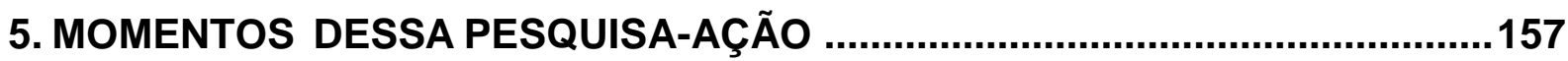

5.1. UMA VISÃO GERAL DOS MOMENTOS DESTA PESQUISA-AÇÂO ..............157

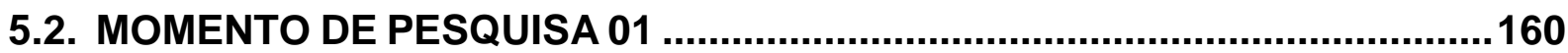

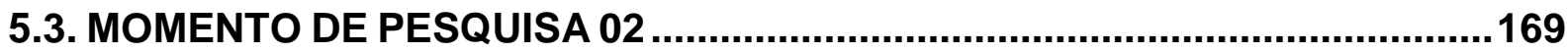

5.3.1. MOMENTO DE PESQUISA 02 - FASE 01- ENTENDENDO O PROBLEMA...........................170

5.3.2. MOMENTO DE PESQUISA 02-FASE 02-APLICANDO A SSM .......................................181

5.3.3. MOMENTO DE PESQUISA 02 - FASE 03 - OS MODELOS DE REFERÊNCIA.....................216

5.3.4. CONCLUSÃO DO MOMENTO DE PESQUISA 02 ……................................................247

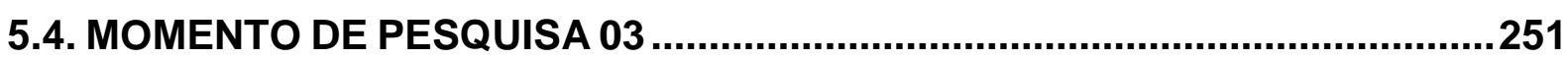


5.4.1. Atividade 24 - Seleção de processos para a prova de conceito .251

5.4.2. ATIVIDADE 25 - PROVA DE CONCEITO DOS NÍVEIS SISTÊMICOS. .256

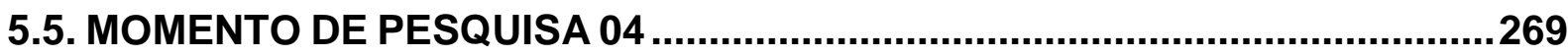

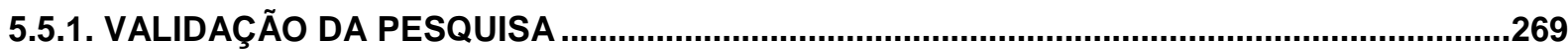

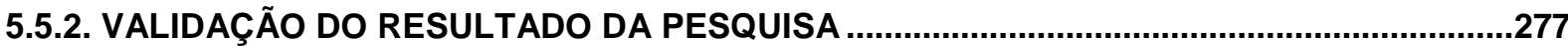

6. CONSIDERAÇÕES FINAIS .....................................................................281

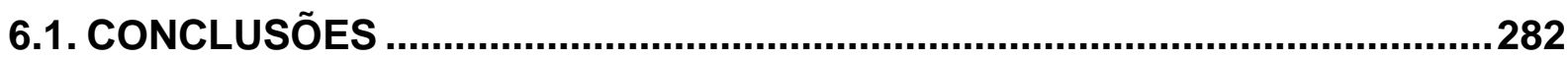

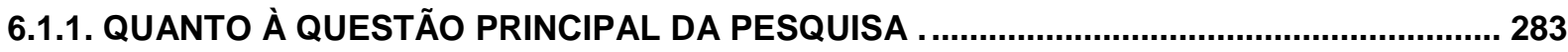

6.1.2. QUANTO ÀS QUESTÕES SECUNDÁRIAS DA PESQUISA. ......................................... 284

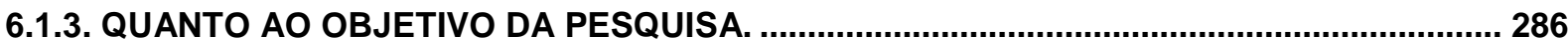

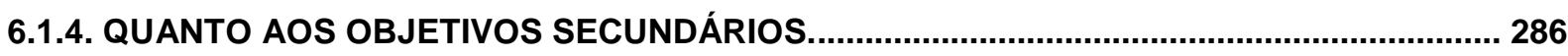

6.2. CONTRIBUIÇÕES .....................................................................................287

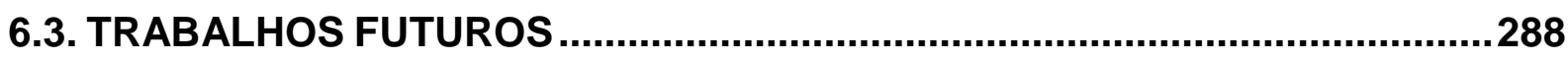

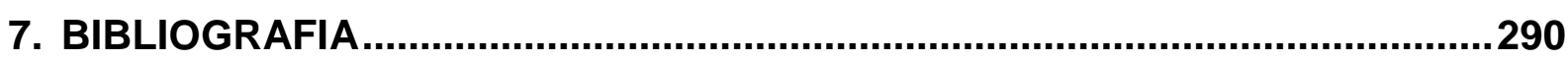

ANEXO I - LISTA DE PUBLICAÇÕES ................................................... 316

ANEXO II - REVISÃO SISTEMÁTICA DE LITERATURA......................... 321

ANEXO III - ROTEIRO PARA ENTREVISTAS PRELIMINARES ................. 332

ANEXO IV -CONSTRUÇÃO DO PROPÓSITO E VISÃO DO SPB ............... 336

ANEXO V - GRUPO CONSULTIVO E EXECUTIVO ............................... 341

ANEXO VI - PLANO DE DESENVOLVIMENTO SISTÊMICO DO SPB ....... 343 


\section{INTRODUÇÃO}

\subsection{APRESENTAÇÃO DO CONTEXTO}

A troca de informações é própria da natureza das relações entre os homens e, portanto, a sociedade humana pode ser definida como uma rede de trocas de informações, hoje potencializada pela Tecnologia da Informação (TI). Entre as recentes mudanças ocasionadas pela $\mathrm{TI}$, a produção colaborativa em redes virtuais chama a atenção da sociedade, pelos impactos causados nas diversas esferas do conhecimento e, em especial, pela sua elevada produtividade e pelo seu comportamento não linear. Ao contrário do que ocorria na maioria dos sistemas produtivos que predominaram no século $\mathrm{XX}$, as redes atuais baseiam-se na colaboração voluntária, na descentralização de sua gestão e em processos de autoorganização. Sua estrutura e seus comportamentos resultantes assemelham-se aos de um organismo vivo (CAPRA, 1996).

O Software ${ }^{1}$ Público Brasileiro (SPB) é uma rede de produção colaborativa virtual, que apresenta, em certa medida, as mesmas características presentes em um sistema vivo. Esta rede se formou utilizando como base o modelo de produção do software livre, que é o de uma rede que se auto-organiza e que tem seu eixo de produção caracterizado pela intensa participação voluntária (REIS, 2003). Esse modelo de produção vem reformulando a indústria internacional de software e as próprias bases tecnológicas da Internet. A partir dos conceitos e princípios contidos nesse tipo de produção, outras redes têm se estruturado (LÉON, 2008). Embora haja nuances entre os modelos em que estas redes se organizam, há determinados princípios comuns, como a tendência da descentralização na tomada de decisões, o intenso compartilhamento de informações e, os processos de retroalimentação decorrente do uso dos artefatos produzidos. Como resultado, observa-se que os impactos decorrentes desse modelo de produção emergem principalmente destas interações, ao invés de decorrerem de uma planificação. A trajetória de evolução de

\footnotetext{
${ }^{1}$ Os programas de computador, ou softwares, formam uma categoria singular de produto tecnológico. São criações intelectuais, conjuntos de dados, conhecimentos e modos de fazer sistematizados, passíveis de serem descritos em uma linguagem simbólica e aplicados à solução de problemas. Ao mesmo tempo são ferramentas de produção que possibilitam a execução de tarefas pertinentes a praticamente todas as formas de atividade humana.
} 
um software cujo código é construído colaborativamente não é definida a priori, mas decorre das diversas interações com o meio.

Desde que os recursos da área de TI se tornaram presentes e imprescindíveis em todas as atividades da administração pública, a busca realizada por esse setor na direção de compartilhar recursos de informática se confirmou como um desafio. Tal empenho tem como justificativa a necessidade de promover a sinergia dos esforços realizados pelos entes públicos, com objetivo de racionalizar a gestão dos recursos de informática, diminuir custos e atividades redundantes, reaproveitar soluções existentes e usufruir dos benefícios de ações cooperadas.

O conceito de software público no Brasil tem seus primeiros registros de discussão nos anos 90 (PSPB, 2011). As primeiras experiências sustentaram nuances conceituais em diferentes escalas: vão desde o software para compartilhamento somente no setor público até a sua total liberação para a sociedade. Em 1995 as empresas estaduais de informática, capitaneadas pela Associação das Entidades Estaduais de Tecnologia da Informação e Comunicação (ABEP) iniciaram um processo de discussão sobre o software público brasileiro. Naquela época a intenção era acelerar a colaboração no meio governamental, com a orientação de redução de esforços de desenvolvimento, rateamento dos custos e racionalização de recursos (MEFFE, 2006b). Práticas de compartilhamento de software por entes públicos e destes com a sociedade são ainda esporádicas, no Brasil e, até onde se pode enxergar, no mundo (MEFFE, 2006a). Entre as restrições para tornar cotidianas tais práticas, há aspectos financeiros, culturais, tecnológicos e mesmo jurídicos. Segundo Meffe (2006b), de forma não exaustiva, podem ser citados os receios da instituição desenvolvedora quanto a: a) Sobrecarga por demandas de serviços de suporte e customização por parte dos demais usuários da solução, sem contrapartidas; b) Possíveis restrições jurídicas decorrentes da cessão e do uso do bem produzido no âmbito do setor público; c) Riscos à segurança das informações governamentais tratadas pela solução decorrentes da publicação de seu códigofonte; d) Apropriação do código por instituições privadas, com o consequente "fechamento" do acesso a melhorias produzidas; e) Manutenção do nível de qualidade da solução para atender as demandas crescentes; f) Receio de potenciais usuários quanto a mudanças nas regras de acesso ao software e, quanto à descontinuidade da solução; g) Inexistência de padrões universais para produzir e 
documentar programas; h) Desconhecimento de boas práticas aplicáveis a casos similares; i) Complexidade da relação existente entre os setores público e privado, o terceiro setor e o colaborador individual, na qual todos os atores precisam ter os seus papéis compreendidos para o pleno funcionamento de uma Comunidade.

A consolidação das principais modalidades de licenciamento associadas ao software livre estabelece, em tese, o ambiente propício à superação de boa parte dos limitadores listados, em especial os que se referem aos "receios de instituições desenvolvedoras e de potenciais usuários". Finalmente, várias das garantias pretendidas poderiam se tornar possíveis por meio da adoção de licenciamento em modalidade Licença Geral de Uso (GPL) do software a ser publicizado². Questões como o não fechamento futuro de códigos derivados da versão originalmente livre, a impossibilidade de alteração na modalidade de licenciamento de determinada versão e o direito público às melhorias produzidas em softwares livres são diretamente tratadas pela modalidade de licenciamento referida. Em 2004 foi publicada versão em português dessa licença, com o reconhecimento formal das autoras da concepção mundialmente aceita: Creative Commons e Free Software Foundation (MEFFE, 2010). Nesse contexto, foi formulado o conceito de Software Público Brasileiro (PROCERGS, 2001), associado a estratégias para a ampla publicização de softwares desenvolvidos pelo governo com previsão de tratamento para o conjunto das restrições mencionadas anteriormente. A plataforma e o ecossistema SPB constituem uma experiência bem sucedida (MEFFE, 2010).

O conceito de software público diferencia-se do de software livre em alguns aspectos, destacando-se a atribuição da natureza de bem público ao software. Resumidamente, isto significa a assunção de algumas responsabilidades por parte do Governo, no caso, mais precisamente o Ministério de Planejamento, Orçamento e Gestão (MPOG), que garantam ao usuário do software condições adequadas de uso. Assim, acrescenta às condições previstas na GPL, algumas obrigações para a entidade que libera o software no portal, indicadas a seguir: a) Prover um software com documentação completa de instalação e preparado para funcionar; b) Disponibilizar um ponto focal ou uma equipe que possa fazer interlocução com a sociedade e encaminhar suas demandas; c) Fornecer um ambiente virtual que

\footnotetext{
${ }^{2}$ É um neologismo e o significado é: se tornar público.
} 
operacionalize a comunicação com o usuário (fórum, controle de versão); d) Realizar ações para incentivar a colaboração e a gestão do conhecimento produzido, além da gestão da comunidade virtual associada ao software liberado.

A equipe que cunhou o termo Software Público em 2001, trabalhava com o conceito de plataforma ${ }^{3}$, que foi sendo gradualmente substituído por "ecossistema" , conceito que envolve a cadeia produtiva do Portal que constitui o centro da iniciativa. A Figura 1 e a Figura 2 apresentam um esquema ilustrativo de partes desse ecossistema.

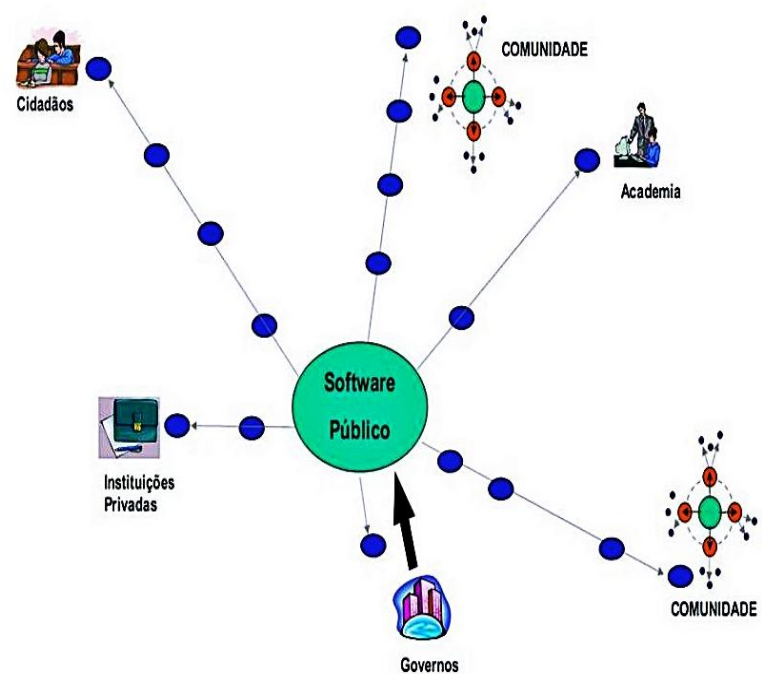

Figura 1 Macro Visão Parcial dos Componentes do SPB Fonte: Meffe (2009)

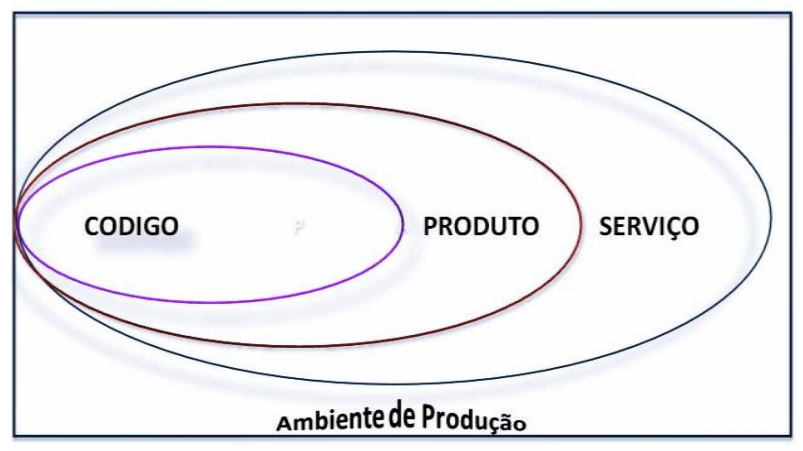

Prestadores de Serviço

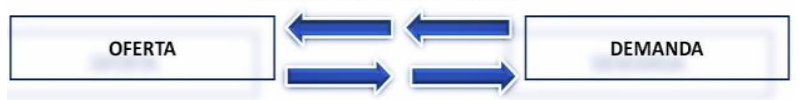

Figura 2 Micro Visão Parcial dos Componentes do SPB Fonte: Freitas (2008)

A evolução do conceito de plataforma para o conceito de ecossistema se deu a partir da participação do Centro de Tecnologia da Informação Renato Archer (CTI) no projeto de desenvolvimento do arcabouço estrutural do SPB (CTI, 2007). A adoção deste novo conceito, para o até então Portal do Software Público Brasileiro, leva em consideração que a produção econômica, a transformação nos padrões estabelecidos de produção econômica, o relacionamento social, e a organização política estão sendo viabilizados por meio da TI e do ecossistema criado em torno delas (CASTELLS, 2008; CRYSTAL, 2001; ESCOBAR, 1994; JONES, 1995 e 1998; KELTY, 2008; LESSIG, 1999, 2004 e 2008; FREITAS \& MEFFE, 2008; MOGLEN,

${ }^{3} E m$ jargão informático, plataforma significa o conjunto de equipamentos (plataforma de hardware) ou programas (plataforma de software) usados por uma pessoa ou instituição para executar uma dada solução. 
1999; RAYMOND, 1997, 1998; 1999 2000; STALLMAN, 2000, 2001; TAPSCOTT, 2006).

O código aberto é apenas uma das condições necessárias para a produção de software público, uma variante do software livre. Além disso, existe um complexo sistema de redes sociais que se expandem no contexto do software como produto e como produtor - e ofertante - de serviços, conforme ilustrado na Figura 3. Os sistemas social, político, econômico e cultural que se organizam com base nessa configuração existente são constituídos por diferentes atores: a) Representantes de órgãos governamentais - responsáveis formais pela iniciativa do software público; b) Setores empresarial e de mercado - na figura dos prestadores de serviços, que podem ser, empresas ou usuários interessados; c) Organizações de ensino superior e de pesquisas envolvidas; d) Representantes do terceiro setor e da sociedade civil de forma abrangente (usuários-cidadãos).

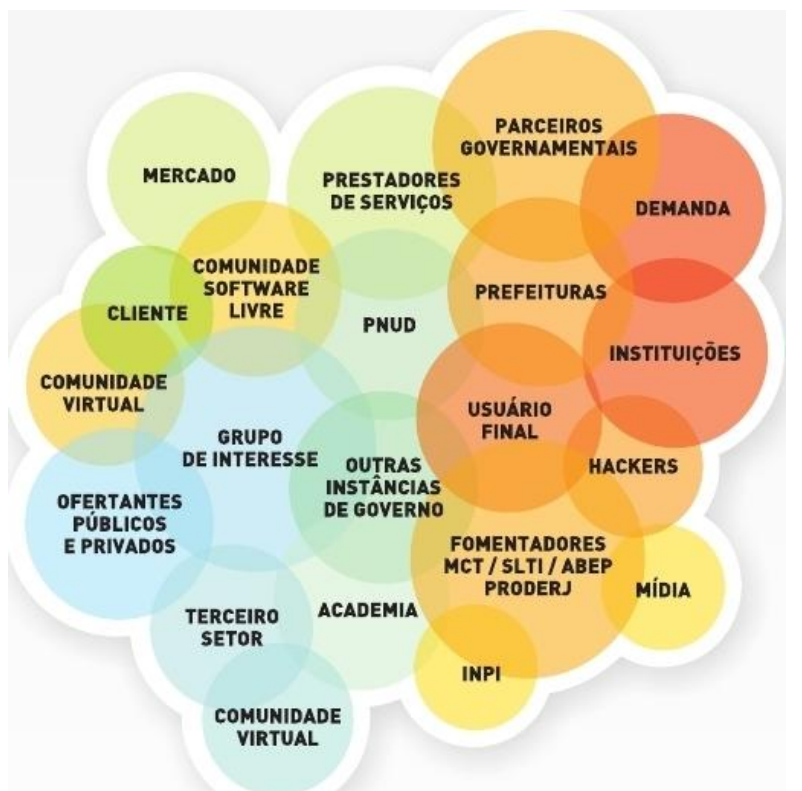

Figura 3 Ecossistema do SPB

O conceito do SPB é utilizado como um dos alicerces das políticas de uso e desenvolvimento de software pelo setor público no Brasil, de relacionamento entre os diferentes entes públicos - seja entre os níveis (municipal, estadual, federal) de governo, seja entre os poderes (executivo, legislativo, judiciário) - e de relacionamento desses com as empresas e a sociedade. Esse conceito adota 0 exemplo do padrão de desenvolvimento vigente para software livre em que os participantes cooperam intensivamente e sem restrições, pelo menos aparentes. 
O modelo de software público confere aos artefatos (software, modelos, metodologias, certificações, qualificações, documentos de referência e planos) desenvolvidos, financiados e geridos pelo governo o princípio inerente a qualquer bem público, que é ser passível de compartilhamento entre entidades governamentais, bem como com a sociedade, o que os torna, portanto, objetos de aplicação de políticas públicas. Seguindo o exemplo do padrão de desenvolvimento vigente para software livre, O SPB propõe um modelo de desenvolvimento compartilhado de software, acrescido de um conjunto de serviços públicos oferecidos pelas entidades que disponibilizam a solução, ou são interessadas em assumir o compromisso público de liderança do projeto. Esse conjunto de serviço deve incluir: manual de usuário, manual de instalação, listas de discussão, fóruns, modelo de gestão e algum nível de suporte. O conceito e o respectivo arcabouço do SPB também possibilitam a inclusão de software produzido originalmente como privado (proprietary), mas cuja abertura de código evidencie a apropriabilidade pública do conhecimento associado.

Em seu estado atual, o SPB tem como sua janela mais visível o Portal do Software Público Brasileiro (http://goo.gl/p02pp ), espaço virtual, onde estão disponibilizadas aproximadamente 60 soluções e hospedadas as comunidades de desenvolvimento e uso das mesmas. No total são aproximadamente 150.000 participantes. As soluções disponibilizadas cobrem as mais diversas áreas: de software médico (InVesalius) até soluções integradas para gestão municipal (e-Cidades), passando pelo middleware 4 para TV digital (Ginga). O Portal conta ainda com um ambiente para as empresas, o Mercado Público Virtual, e três grupos de interesse ou temáticos.

Os grupos temáticos são representados pelos ambientes denominados 4C Colaboração, Comunidade, Conhecimento e Compartilhamento. As comunidades temáticas do ambiente são: $4 \mathrm{CMBr}$, cujo tema é Tecnologia da Informação para os municípios; $5 \mathrm{CqualiBr}$, que agrega o " $\mathrm{C}$ " de Confiança e trata do tema da qualidade no ecossistema e $4 \mathrm{CAcadBr}$, que agrega as soluções e ideias que são criadas dentro das universidades e centros de pesquisa. Nesses ambientes temáticos estão disponíveis ferramentas para a interação entre os usuários, tais como: fóruns, chats,

\footnotetext{
${ }^{4}$ No caso, programas que tratam da interação entre o equipamento de TV e os fornecedores de
} serviço. O Ginga deve ser adotado pela Argentina, Paraguai e Peru, além do Brasil. 
listas e ambientes de colaboração. $O$ grupo de interesse municipal é destinado às administrações públicas municipais brasileiras e disponibiliza documentos ligados à Tecnologia da Informação na esfera municipal, bem como soluções livres de interesse da gestão municipal. O grupo dedicado à qualidade trabalha para melhorar a qualidade do software público e do conhecimento em TI no país.

Embora o SPB tenha adotado em sua formulação o modelo de produção de software livre para maior democratização do conhecimento, os resultados obtidos na formação de comunidades virtuais desembocaram na formação de um sistema com dinâmica própria, com mais identidade e autonomia da indução governamental do que o inicialmente previsto. Esse sistema vem crescentemente se auto-organizando, incorporando novos atores, novas parcerias e ensejando o surgimento de uma inteligência e de padrões de comportamento sistêmicos o que resultou na incorporação do conceito de ecossistema.

O modelo de negócio do Software Público Brasileiro contempla as seguintes características básicas: a) 0 produto - o software é tratado como um produto acabado, que chega para a sociedade com documentação completa de instalação e preparado para funcionar, como qualquer software de prateleira; b) Os serviços associados - é organizado um conjunto de serviços básicos, tais como: página na internet, fórum e lista de discussão para desenvolvimento, suporte a projetos, ferramenta de controle de versão e documentação; c) A prestação de serviços adota-se um procedimento simplificado para a relação do governo com o cidadão que acessa o serviço, no qual o cidadão pode conhecer as informações da comunidade, como resolver as questões relacionadas ao software e os responsáveis pelos serviços, inclui a disponibilização, por parte do governo, de uma equipe de atendimento para a comunidade; d) A gestão da colaboração - incentiva-se a colaboração entre os diversos usuários e desenvolvedores da ferramenta, sejam eles pessoa físicas ou jurídicas, de qualquer setor da economia, por meio de ações indutoras; procura-se estruturar instrumentos de gestão e controle mais rigorosos para estabelecer a periodicidade do lançamento de novas versões e definir parâmetros de controle de qualidade no desenvolvimento das soluções (grifo da autora); e) A licença - o modelo de licença segue os princípios do software livre. As soluções recebem a General Public License (Licença Pública Geral) na sua versão 2.0 em português; f) A licença pública de marca - Versão GPL que permite 
também que as marcas sejam usadas livremente pelo público em geral. Esse modelo se propõe a fomentar o surgimento de novos modelos econômicos e políticos para a sociedade (MEFFE, 2009). O modelo prático desenvolvido no Brasil pode criar condições para viabilizar uma experiência de coprodução de bens e serviços públicos.

Esta pesquisa faz parte de um projeto que envolve a consolidação de um framework de qualidade para o SPB (MCT, 2007). Uma parte desse projeto é o a Definição do Arcabouço Estrutural e Gerencial do Ecossistema SPB, subprojeto cujo objetivo é a modelagem do ecossistema como um todo, de forma a encontrar um framework que o represente na sua dinâmica em seus componentes e que possa ser apresentado e comunicado aos seus usuários e stakeholders. Nesta representação, o framework deverá considerar conceitos de qualidade, que neste subprojeto especifico, referese à qualidade do ecossistema. O desafio desta pesquisa é observar, no âmbito do ecossistema, a realidade resultante das ações, dinâmicas, interações e propriedades emergentes e então, propor elementos de um framework de maturidade que possa orientar sua evolução.

\subsection{MOTIVAÇÃO}

O portal do SPB é um espaço virtual para a disseminação e o aprimoramento de soluções de software. Em algumas comunidades acontecem atividades de desenvolvimento de novas funcionalidades ou mesmo de novas versões das soluções. Portanto, acontecem processos de desenvolvimento de software, porém ainda sem um processo de qualidade instituído.

As abordagens mais usuais de verificação da qualidade têm como base as organizações formalmente estabelecidas, com processos de produção que podem ser decompostos em unidades menores de maneira linear. Assim, a maturidade de uma organização é diretamente proporcional ao controle de seus processos e à capacidade de atingir as metas previstas. Segundo o Software Engineering Institute (SEI) da Carnegie Mellon University, um processo de software pode ser definido como um conjunto de atividades, métodos, práticas e transformações utilizado para desenvolver e manter um software e os seus produtos associados (por exemplo: planos e documentos de projeto, código, casos de teste e manuais de usuário). À medida que uma organização se torna madura, seu processo de software fica mais 
definido, possibilitando que o mesmo seja implementado de modo mais consistente em toda a organização. Ainda segundo o SEl, a maturidade do processo de software é a extensão com a qual um processo específico é explicitamente definido, gerenciado, medido, controlado e efetivado. Esta abordagem é conhecida como a maturidade com base na capacidade (HUMPHREY, 1989), (PAULK et al., 1994), (SEI, 1993). A maturidade representa o potencial de crescimento de capacidade (conjunto de resultados esperados que podem ser obtidos pela aplicação do processo de software) e indica a riqueza do processo de software da organização e a consistência com que o mesmo é aplicado em todos os seus projetos. Em uma organização madura, o processo de software é bem registrado e compreendido por meio de documentação e treinamento, e é continuamente monitorado e melhorado pelos seus usuários. A maturidade de processo de software implica que a produtividade e a qualidade resultantes do processo podem ser continuamente melhoradas por meio de ganhos consistentes na disciplina alcançada com a sua utilização. O modelo de maturidade do SEI define então cinco níveis de maturidade para avaliação dos processos de software de uma dada unidade organizacional. Essa definição dos níveis de maturidade tem por base a formalização dos processos de software dentro da unidade organizacional e a sua integração com a organização como um todo.

No ecossistema SPB, observa-se uma estrutura fluida, com processos de software com dinâmicas variadas, que se alteram ao longo do tempo. Aqui, processos de software padrão da organização e metas da qualidade são conceitos dos modelos convencionais de maturidade que conflitam com a dinâmica do ecossistema.

A motivação para a realização desta pesquisa foi desenvolver elementos de um framework de maturidade para um sistema complexo, uma rede virtual cujo desenho se aproxima de uma nuvem com limites não definidos, papéis que se alteram e configurações mutantes, que se baseiam na colaboração voluntária, na descentralização da gestão, estabelecida por processos de auto-organização, pelo intenso compartilhamento de informações e por processos de retroalimentação decorrente do uso dos artefatos produzidos. Esse sistema, o SPB, é o objeto desta pesquisa. $O$ processo de construção de uma visão de qualidade para redes virtuais deve incorporar a complexidade desses sistemas. Os modelos de maturidade baseados em capacidade existentes foram criados a partir da avaliação de 
estruturas precisamente definidas, com processos definidos e interfaces com o ambiente externo quantificadas e qualificadas. Para um sistema como o SPB, com limites indefinidos, relacionamentos e dinâmicas não lineares, o caminho para construir um modelo de maturidade deve ser diferente e inovador.

A versão atual da Norma ISO/IEC 15504 (ISO/IEC, 2008) estabelece a capacidade do processo como o caminho para a sua melhoria. A maturidade de uma determinada organização é medida com relação à capacidade dos processos definidos por um determinado framework, por exemplo, o CMMI (Modelo Integrado de Maturidade da Capacidade) e o SPICE ( Melhoria de Processo de Software e Determinação da Capacidade).

O pensamento sistêmico indica um caminho para a maturidade diferente daquele definido com base na capacidade. Este achado é consistente com a evolução atual do SPICE (série ISO/IEC 33000) (DORLING, 2009) que concluiu que a capacidade, antes de ser um único caminho para a maturidade, é somente um caso particular dos muitos caminhos possíveis. O grupo SPICE encontra-se atualmente elaborando os requisitos básicos que devem ser considerados quando da elaboração de um novo framework de medição que orientará a criação dessas diferentes formas (DORLING 2009).

Esta pesquisa apresenta referências para um framework de modelo de maturidade que permite avaliar e acompanhar a evolução do ecossistema público de software considerando o recorte da qualidade. A definição dessas referências considera as metodologias baseadas no pensamento sistêmico para obter evidências empíricas de que o ecossistema SPB evolui em ciclos de aprendizado que podem representar um modelo de maturidade sistêmica e constituir uma referência para entender e melhorar O SPB e outros ecossistemas de Software Público. O framework desenvolvido nesta pesquisa poderá ser considerado pelo SPICE como uma alternativa de maturidade para ecossistemas digitais. Os dados do Quadro 1 sumarizam o contexto do projeto de pesquisa deste trabalho. 


\subsection{OBJETIVOS}

O objetivo desta pesquisa é:

Criar uma estrutura de medição da qualidade do Software Público Brasileiro que considere as questões de maturidade e do pensamento sistêmico.

Os objetivos secundários desta pesquisa são:

1. Proporcionar uma experiência que poderá ser usada como subsídio para os requisitos do framework de medição de processos para a nova norma ISO/IEC 33000 que está sucedendo a ISO/IEC 15504.

2. Verificar a possibilidade de generalização do modelo do caso particular, o ecossistema SPB, para casos genéricos de ecossistemas digitais de natureza semelhante.

3. Avaliar a pertinência do uso dos conceitos e características das teorias de ecossistemas digitais, modelos de maturidade/capacidade, pensamento sistêmico e sistemas complexos;

4. Aprender com a aplicação dos modelos conceituais Metodologia de Sistema Soft (SSM) e Metodologia de Melhoria de Processo Multimodelo Orientada por Perfis de Capacidade de Processo - Framework de Métodos para a Construção de Modelos de Capacidade de processo (PRO2PI-MFMOD) no processo de construção dos elementos do framework;

5. Planejar, estruturar e executar uma pesquisa-ação para concretizar os objetivos definidos.

A pesquisa oferece uma contribuição de cunho empírico, mapeando e definindo elementos de um framework de maturidade que pode ser utilizado por ecossistemas digitais de produção de software, buscando o entendimento e a descrição do fenômeno por meio das lentes teóricas da Teoria da Complexidade, do Pensamento Sistêmico, dos Ecossistemas Digitais e dos Modelos de Maturidade. O objetivo para o pesquisador, no caso a autora da pesquisa, é avançar o conhecimento no âmbito da melhoria de processos de software, estendendo o conceito de capacidade, e contribuir como referência para estudos relacionados à maturidade, que considerem outros conceitos, diferentes do de capacidade de processo (process capability). 


\begin{tabular}{|c|c|}
\hline Componente & Contexto do projeto de pesquisa \\
\hline Metodologia & $\begin{array}{l}\text { Pesquisa-ação segundo os ciclos da Soft System Methodology-SSM, acompanhados pelas fases do } \\
\text { PRO2PI-MFMOD. }\end{array}$ \\
\hline Propósito & $\begin{array}{l}\text { Elaboração de referências para um framework de maturidade para o domínio de ecossistemas digitais } \\
\text { de produção de software. }\end{array}$ \\
\hline $\begin{array}{l}\text { Temática da } \\
\text { Pesquisa }\end{array}$ & $\begin{array}{l}\text { Formas alternativas à capacidade de processos em frameworks de construção de modelos de } \\
\text { maturidade. }\end{array}$ \\
\hline Objeto de análise & O ecossistema de produção de software SPB. \\
\hline $\begin{array}{l}\text { Tipologia dos } \\
\text { dados }\end{array}$ & Tipicamente qualitativo, com uso limitado de dados quantitativos. \\
\hline Coleta dos dados & $\begin{array}{l}\text { Uso de diário de pesquisa (wiki, blog, grupos), participação nas reuniões de projeto, análise } \\
\text { documental (registro de projetos, relatórios, atas e outros), entrevistas, realização de surveys e oficinas } \\
\text { de trabalho. }\end{array}$ \\
\hline Análise de dados & $\begin{array}{l}\text { Interpretação de dados qualitativos; lógica indutiva; reflexões com base nas anotações do diário de } \\
\text { pesquisa; e interpretação de dados quantitativos oriundos das séries históricas do ecossistema em } \\
\text { foco. }\end{array}$ \\
\hline $\begin{array}{l}\text { Qualidade e } \\
\text { validade da } \\
\text { pesquisa }\end{array}$ & $\begin{array}{l}\text { Apresentações públicas dos resultados da pesquisa; diferenciação da pesquisa-ação de um projeto } \\
\text { simples de solução de um problema. }\end{array}$ \\
\hline Questão primária & É possível definir um framework de modelos de maturidade para ecossistemas digitais públicos de \\
\hline
\end{tabular}




\begin{tabular}{|c|c|}
\hline Componente & Contexto do projeto de pesquisa \\
\hline de estudo & rodução colaborativa de software? \\
\hline Proposições & $\begin{array}{l}\text { É possível definir elementos de um framework de modelos de maturidade para ecossistemas digitais } \\
\text { públicos de produção de software considerando referências como: P1: frameworks de modelos de } \\
\text { capacidade/maturidade existentes (CMMI e ISO/IEC15504), P2: framework de métodos para a } \\
\text { construção de modelos de capacidade de processo (PRO2PI - MFMOD), P3: Soft System } \\
\text { Methodology (SSM) e P4: referências teóricas dos ecossistemas digitais, do pensamento sistêmico e } \\
\text { de sistemas complexos. }\end{array}$ \\
\hline $\begin{array}{l}\text { Unidade(s) de } \\
\text { Análise }\end{array}$ & $\begin{array}{l}\text { 1.Identificação } \\
\text { Ecossistema do Software Público Brasileiro, cujo modelo de negócio é composto por um modelo de } \\
\text { licenciamento, de gestão e por regras de disponibilização das soluções desenvolvidas definidos pela } \\
\text { Administração Pública (representada pelo MPOG/SLTI) e pela rede de parceiros da sociedade } \\
\text { (empresas, universidades, organizações governamentais e sociedade em geral) } \\
\text { 2.Características gerais } \\
\text { Ambiente organizado com as características de um ecossistema, multifuncional, multidisciplinar, } \\
\text { multiplataforma, com diversidade de atores envolvidos, diversidade de infraestruturas de hardware e } \\
\text { de software, com funcionamento segundo a lógica de rede e gestão compartilhada, com diferentes } \\
\text { interesses e objetivos. A dimensão de melhoria, tanto das aplicações quanto das comunidades e de } \\
\text { todo o ambiente é difusa. O objetivo do ecossistema é facilitar a implantação de novas ferramentas } \\
\text { nos diversos setores administrativos, promover a integração entre as unidades federativas e oferecer } \\
\text { um conjunto de serviços públicos para a sociedade com base no bem software. Conta hoje com } 60\end{array}$ \\
\hline
\end{tabular}




\begin{tabular}{|l|l|}
\hline Componente & Contexto do projeto de pesquisa \\
\hline & $\begin{array}{l}\text { soluções disponíveis, 150.000 membros, um Mercado Público Virtual, e 3 Grupos de Interesse: 4CMBr, } \\
5 \mathrm{CQ} \text { ualiBr e 4CAcadBr. } \\
\text { 3. Unidades de análise } \\
\text { 3.1.Unidade 1: Modelo conceitual do ecossistema SPB } \\
\text { 3.2.Unidade 2: Mapeamento das dinâmicas e criação da taxonomia dos elementos do sistema } \\
\text { 3.3.Unidade 3: Qualidade no ecossistema SPB }\end{array}$ \\
\hline Envolvidos na & $\begin{array}{l}\text { Pesquisadores e técnicos do SLTI/MPOG, técnicos e tecno-politicos da SEPIN/MCTI, coordenadores } \\
\text { de comunidade, membros de comunidade, coordenadores dos grupos de interesse,representantes de } \\
\text { empresas. }\end{array}$ \\
\hline $\begin{array}{l}\text { Interessados nos } \\
\text { resultados }\end{array}$ & $\begin{array}{l}\text { SLTI/MPOG, SEPIN/MCTI, comunidades e empresas com soluções de software disponibilizadas no } \\
\text { ambiente SPB, usuários do ambiente , empresas produtoras de software, empresas prestadoras de } \\
\text { serviços em software, desenvolvedores de software, técnicos de software, prefeituras, especialistas em } \\
\text { qualidade de software, pesquisadores das áreas de melhoria de processos de software, eGOV e } \\
\text { eCidadania. }\end{array}$ \\
\hline
\end{tabular}

Quadro 1 Contexto do projeto de pesquisa

Fonte: Estrutura adaptada de Nomura (2008) 


\subsection{PREMISSAS E LIMITAÇÕES}

Esta pesquisa foi conduzida sob a área de conhecimento de Engenharia de Produção e, segundo a classificação da ABEPRO (2013), no escopo da subárea Engenharia da Qualidade, pois aborda tópicos de planejamento, projeto e controle de sistemas de gestão da qualidade que consideram o gerenciamento por processos, a abordagem factual para a tomada de decisão e a utilização de ferramentas da qualidade. Quanto às influências teóricas mais significativas que moldaram esta tese, são identificados dois grupos distintos.

O primeiro grupo está relacionado diretamente ao tema da tese e refere-se à melhoria de processo de software. Neste grupo, as referências teóricas são de Humphrey (1988, 1989), de Paulk et al. (1994) e do SEI (1993). O conceito de capacidade nasceu da necessidade do governo americano de comprar software de empresas que tivessem uma capacidade mínima de entregar os produtos contratados. Humphrey utilizou uma forma sistemática para organizar o conhecimento existente à época sobre melhores práticas de construção de software e elaborou o SW-CMM. O SW-CMM evoluiu para um framework de modelos integrados denominado Modelo Integrado de Maturidade da Capacidade (CMMI). Esse framework é baseado na capacidade dos processos e maturidade das unidades organizacionais. Segundo esse conceito a maturidade do processo de software é a extensão com a qual um processo específico é explicitamente definido, gerenciado, medido, controlado e efetivado. Neste grupo está também o modelo de capacidade de processo para engenharia de software da norma NBR ISO/IEC 15504 (ABNT, 2008). Esse modelo foi concebido pelo grupo SPICE que ofereceu uma alternativa ao formato proposto por Humphrey. O modelo é bidimensional, sendo a primeira dimensão de processos e a segunda a capacidade dos processos, e tem por objetivo a realização de avaliações de processos com o foco na melhoria dos processos. Ele permite que seja gerado um perfil de capacidade dos processos, identificando os pontos fracos e fortes dos processos executados na empresa. Essas informações podem então ser utilizadas para a elaboração de um plano de melhorias.

O segundo grupo está relacionado a um contexto teórico mais amplo, que se refere às teorias do pensamento complexo, do pensamento sistêmico e dos ecossistemas digitais. 
A teoria do pensamento complexo (TPC) é uma nova abordagem que busca o entendimento da realidade e de suas relações complexas. As principais referências teóricas utilizadas neste trabalho foram Prigogine (1984), por apresentar o fenômeno da emergência ou auto-organização nos sistemas dinâmicos complexos, Bar-Yan (1970), por apresentar os conceitos operacionais de emergência, auto-organização e dinâmica evolucionária e o transição de fase e Morin (1992), que apresenta o conceito de sistema ao nível paradigmático, como conceito-chave para avançar a construção de um conhecimento complexo; o conceito de que a complexidade implica o reconhecimento de que a complicação e a obscuridade são desafios incontornáveis da realidade; um novo conteúdo para o termo organização, na perspectiva sistêmica, que é substancialmente distinto da perspectiva clássica, um conjunto de princípios relativos ao caráter complexo das relações que, segundo o autor, devem conformar o conceito de sistema como noção nuclear de um novo paradigma do conhecimento.

O pensamento sistêmico, cuja definição adotada neste trabalho foi apresentada por Flood e Carlson (1988), consiste em uma nova estrutura de pensamento para lidar com a complexidade e conta com as referências teóricas de Checkland, Capra e Senge. Checkland $(1979,1981)$ apresenta uma taxonomia para os desenvolvimentos sistêmicos que considera em um primeiro momento o desenvolvimento teórico do pensamento sistêmico (cibernética) e o desenvolvimento das aplicações em outras áreas ou disciplinas. A partir desta classificação o autor sugere um segundo nível de refinamento, ou seja, o desenvolvimento teórico puro (Teoria Geral dos Sistemas) e o desenvolvimento teórico, a partir de problemas do mundo real (engenharia de sistemas, análise de sistemas da RAND Corporation, e Metodologia de Sistemas SOFT - SSM). A SSM desenvolvida por Checkland é um método de estruturação de problemas, capaz de guiar os questionamentos e ações ao se lidar com situações problemáticas.

Capra (1982) apresenta as primeiras ideias sobre a síntese do movimento sistêmico na ciência, na tecnologia e na sociedade e introduz a visão mecanicista e a visão sistêmica de áreas do conhecimento. Em 1996, o mesmo autor apresenta uma compreensão científica dos sistemas vivos e em 2002 apresenta uma visão de sustentabilidade e um amplo espectro de experiências mundiais em direção ao paradigma sistêmico. 
Senge, em 1990, apresenta o núcleo de uma abordagem que consiste na utilização do pensamento sistêmico como ferramenta (disciplina) para examinar e testar os modelos mentais de grupos e indivíduos, e que é chave para as decisões organizacionais e para a aprendizagem individual e em equipe e meio de construir visões e objetivos comuns. Para Senge, o pensamento sistêmico é a pedra fundamental para constituir uma nova mentalidade que torne possível construir organizações com capacidade de aprendizagem duradoura. Em 1995 o mesmo autor apresenta uma descrição do método sistêmico como um conjunto de passos sistematizados que leva à aplicação do pensamento sistêmico de forma organizada, de modo que cada passo termina com resultados que são utilizados como entradas nos passos subsequentes. Com a evolução do processo, aprofunda-se a aprendizagem sobre uma situação de interesse. Com o método, mantém-se a direção nos objetivos intermediários e finais e alcança-se uma aprendizagem dos desafios aos modelos mentais.

As teorias sobre os ecossistemas digitais foram apresentadas a partir de Briscoe (2007) e Chang (2006), cujas referências eram os ecossistemas naturais e evoluíram para os ecossistemas digitais considerando os três campos mais importantes das ciências naturais: física, biologia e química. Hasdic (2007) caracteriza um ecossistema digital e Nischira, Dini e Indrawan (2002, 2005, 2007) apresentam a configuração de ecossistemas de negócios e caracterizam micro ecossistemas. Benkler (2001) apresenta uma metáfora envolvendo ecossistemas econômicos e ecossistemas digitais.

Quanto às delimitações de aplicação prática, a pesquisa foi realizada em um ecossistema digital implementado por um portal, o Portal do Software Público Brasileiro, hospedado na SLTI/MPOG, em Brasília. As comunidades pertencentes ao ecossistema estão distribuídas por todo o território nacional. Temporalmente, as atividades de pesquisa-ação em campo ocorreram em dois anos, com início em 2009, período este definido no âmbito do projeto "Modelo de Referência para o Software Público Brasileiro", financiado pela Financiadora de Estudos e Projetos (FINEP).

Não se objetivou a mensuração de indicadores no ecossistema antes e depois da pesquisa-ação uma vez que o interesse da investigação estava focado na modelagem do sistema, na descoberta/definição de suas variáveis críticas bem 
como na elaboração de elementos que pudessem ser utilizados para a construção de um framework que incorporasse os requisitos necessários para avaliar e melhorar a qualidade de sistemas dessa natureza. Além disso, a pesquisa está delimitada pelas informações e interpretações dadas por indivíduos com diferentes graus de visão sobre o objeto em estudo.

Quanto às limitações desta pesquisa, podem ser citados alguns pontos significativos. O primeiro refere-se ao material disponível sobre ecossistemas e especificamente sobre ecossistemas digitais. Os trabalhos citados são oriundos de publicações em conferências posteriores ao ano 2000. Não foram encontradas referências em journals quando a busca foi realizada para este trabalho (ANEXO II).

O segundo está relacionado ao tamanho das séries históricas utilizadas para o levantamento dos dados relativos às variáveis críticas. As séries são recentes, com início em 2006, quando iniciou a divulgação do conceito e do portal do SPB. Além disso, nem todos os dados que poderiam ser úteis para a pesquisa estavam no conjunto dos dados que foram coletados e preservados pelo ecossistema (pela plataforma tecnológica).

O terceiro ponto refere-se ao número de ciclos da metodologia de ação. ZuberSkerritt e Perry (2002) argumentam que uma tese de doutorado nas ciências sociais deveria apresentar, pelo menos, dois ciclos de ação para observar que a aprendizagem do grupo de trabalho proveniente do primeiro ciclo seja transferida para o segundo ciclo, de forma que se alcance um novo patamar de melhoria na situação problemática. Nesse sentido, os resultados obtidos nesta pesquisa com apenas um ciclo da SSM podem ser interpretados como limitadores para reflexões no que tange ao aprendizado ocorrido no sistema. Para mitigar esta limitação, existe a observação da autora, que acompanhou a evolução do ecossistema e reuniu dados empíricos que comprovam o aprendizado e o seu amadurecimento.

\subsection{ESTRUTURAÇÃO DO TRABALHO}

O trabalho está estruturado em seis capítulos, dos quais este é o Capítulo 1 INTRODUÇÃO, que apresenta o contexto do trabalho e o problema a ser pesquisado, a motivação para a pesquisa, bem como os limites e restrições que ela enfrenta na sua execução. 
O Capítulo 2 - ASPECTOS CONCEITUAIS - apresenta os resultados de uma revisão sistemática de literatura, que considerou os quatro eixos teóricos que constituem a base de sustentação da pesquisa. Além disso, esse capítulo discorre sobre os principais autores e teorias relativas à melhoria de processos baseada em capacidade/maturidade e sobre as definições e teorias relativas a Ecossistemas Digitais, Sistemas Complexos e Pensamento Sistêmico.

O Capítulo 3 - METODOLOGIA DE PESQUISA - apresenta uma revisão breve sobre os significados de conceitos como metodologia e método e, trata da pesquisa científica, da pesquisa na engenharia de produção e, mais especificamente, da pesquisa-ação. Também situa a pesquisa no contexto da pesquisa-ação e, finalmente, apresenta o projeto de pesquisa, definindo suas questões e o protocolo a ser utilizado.

O Capítulo 4 - PROBLEMA E AMBIENTE REAL DA PESQUISA - apresenta 0 problema geral que norteia esta pesquisa, a qualidade no ecossistema SPB, e o problema específico que dá início à pesquisa-ação, a dificuldade para desenvolver um framework de modelos de qualidade para o ambiente SPB.

O Capítulo 5 - MOMENTOS DESTA PESQUISA-AÇÃO - apresenta a pesquisaação realizada ao longo de um ano no ambiente do SPB e descreve os ciclos e momentos dessa pesquisa-ação.

O Capítulo 6 - CONSIDERAÇÕES FINAIS - apresenta a análise final dos resultados da pesquisa, as conclusões do trabalho, suas contribuições relevantes e sugestões para trabalhos futuros. No item que aborda as contribuições relevantes, serão tratadas as questões relativas às dificuldades encontradas pela autora na aplicação da metodologia adotada para a pesquisa. No final deste trabalho, são apresentados os anexos referentes aos artefatos gerados durante a pesquisa-ação, e as Referências Bibliográficas que nortearam a pesquisa. 


\section{ASPECTOS CONCEITUAIS}

Os modelos de capacidade convencionais visam tradicionalmente aprimorar a qualidade de um processo linear e bem delimitado. No caso de uma rede virtual, com limites não definidos, papéis que se alteram, configurações mutantes, a visão convencional de modelo de capacidade parece não ser adequada, uma vez que o controle do processo não é uma meta a ser atingida por essas redes. Considerando que as características ocorrem no SPB, para pensar elementos de um modelo de maturidade para esse ecossistema faz-se necessário elaborar uma fundamentação teórica nas diversas áreas que definem o objeto do trabalho. Considerando ainda o objetivo da pesquisa, cuja proposta é introduzir elementos de qualidade, baseados em melhoria de processo de software em ecossistemas digitais de produção de software, surge a necessidade de compreender tópicos como Teoria dos Sistemas Complexos, Pensamento Sistêmico, Ecossistemas Digitais e Modelos de Maturidade. Este capítulo busca, em um esforço de síntese, criar um arcabouço teórico que fundamente e oriente a pesquisa desenvolvida neste trabalho.

\subsection{REVISÃO SISTEMÁTICA DE LITERATURA}

Considerando que a revisão bibliográfica deve dar conta de quatro temas conceituais optou-se por executar essa revisão em três passos: Passo 01- Visão Panorâmica, Passo 02 - Visão Focada e Passo 03 - Visão Detalhada.

A visão panorâmica tem o objetivo de apresentar uma perspectiva dos recortes teóricos da pesquisa utilizando a metodologia de Revisão Sistemática de Literatura (RSL). A RSL é utilizada na medicina e o seu uso no domínio da engenharia de software teve inicio em 2004, com Kitchenham (2004). Para a execução da RSL, foram levantadas as questões de pesquisa bem como uma primeira seleção das bases a serem pesquisadas. As bases e catálogos foram selecionados considerando as bases específicas recomendadas por Kitchenham (2004) e Brereton (2007) para o domínio da engenharia de software. As questões de pesquisa têm o objetivo de apresentar a evolução e a tendência dos recortes teóricos, considerando o conjunto de bases selecionado. Nesta fase foram elaboradas noventa sentenças de busca e foram pesquisadas onze bases e dois catálogos. Neste passo, foi identificada uma revista específica para o tema "emergência" (Emergence: Complexity and Organization) e quatro para o tema "complexidade" (Journal of Systems Science and 
Complexity, Journal of Complexity, Computational Complexity e Complexity). O segundo passo, Visão Focada, tem como objetivo selecionar as bases que são utilizadas para a continuação e o aprofundamento do passo anterior. Essas bases foram escolhidas considerando os seguintes critérios: (1) cobertura significativa em todos os temas e (2) publicações dos trabalhos relacionados a esta pesquisa. Foram selecionadas duas bases e nessas bases foram pesquisados os trabalhos relacionados aos temas da pesquisa e selecionados aqueles considerados mais relevantes. A relevância foi avaliada segundo o índice $h^{5}$ do trabalho e a relevância do trabalho ou do autor no tema. O passo Visão Detalhada consistiu na seleção dos trabalhos utilizados como referência para a elaboração do arcabouço teórico da pesquisa, considerando os passos anteriores. Também foram selecionados trabalhos considerados relevantes para o tema, segundo o entendimento da autora da pesquisa. O detalhamento da revisão bibliográfica está disponível no ANEXO II.

Os objetivos da revisão de literatura foram atingidos após a execução do processo. O primeiro objetivo, a verificação do caráter inédito do trabalho proposto, ficou demonstrado pelos resultados exibidos no item 3.2.1.3 do ANEXO II. O resultado das análises descritas no item 3.2.3 do ANEXO II, fornecem subsídios para a elaboração deste capítulo que trata dos Aspectos Conceituais da pesquisa proposta.

Com os resultados obtidos na revisão (ANEXO II - Conclusão), percebe-se que o tema "complexidade" , é de longe, o tema com maior número de publicações em journals, seguido pelo tema "modelo de maturidade". O tema relativo ao pensamento sistêmico é o terceiro com maior número de publicações, enquanto que o tema "ecossistemas digitais" é o que tem menor número de publicações e estas se encontram em anais de conferências.

A ausência de trabalhos que tratam os quatro eixos teóricos simultaneamente indica que a questão proposta por esta pesquisa é original e inédita. Esses quatro eixos teóricos são apresentados nas seções 2.2, 2.3, 2.4 e 2.5.

O eixo apresentado na seção 2.2 trata da complexidade e dos sistemas complexos. A Teoria do Pensamento Complexo (TPC) é uma nova abordagem que busca o

${ }^{5}$ É uma proposta para quantificar a produtividade e o impacto de cientistas baseando-se nos seus artigos (papers) mais citados 
entendimento da realidade e suas relações complexas. A TPC surgiu a partir da constatação de que era necessária uma nova forma de apreciar o mundo e seus processos, uma vez que as abordagens tradicionais mostravam-se insuficientes para comportar a sua complexidade crescente. Mais que isto, a TPC busca unir os aspectos da ordem (linearidade) e da desordem (sistêmico).

A seção 2.3 apresenta o eixo do Pensamento Sistêmico, que segundo Ackoff (1981), se propõe a desenvolver uma nova estrutura intelectual para descrever a "complexidade organizada" como redes dinâmicas de interações, com base no conceito de sistema, Capra (1996) define o "pensamento sistêmico" como "a compreensão de um fenômeno dentro de um contexto", estabelecendo-se a totalidade das interações envolvidas, em oposição à busca das relações causais simples entre partes isoladas.

A seção 2.4 apresenta o eixo dos ecossistemas digitais, que são os ecossistemas ${ }^{6}$ onde o ambiente é digital e povoado por espécies digitais (componentes de software, aplicações, serviços online e outros). Há ecossistemas digitais voltados para produção de conteúdo, negócios, produção acadêmica, entre outros (KANNAN, 2010). Os valores éticos têm importante papel na auto regulação e na autoorganização desses ecossistemas e são, muitas vezes, o elemento atrativo que mobiliza a convergência de atores para esse ambiente virtual. Os ecossistemas digitais sinalizam na direção de um modelo aperfeiçoado de aprendizagem, ao convergir o fluxo de interações e a energia criativa para objetivos comuns, acordados entre os participantes. O modelo que inspira estes ecossistemas digitais é, por sua natureza, um sistema complexo e, assim, naturalmente induz modelos mentais, valores e processos decisórios alinhados com suas características (descentralização, autonomia, diversidade, acolhimento dos conflitos).

A seção 2.5 apresenta o eixo relativo aos frameworks de capacidade/maturidade, nos quais a maturidade representa o potencial de crescimento de capacidade

\footnotetext{
${ }^{6} \mathrm{O}$ conceito tradicional de ecossistema designa o conjunto formado por todas as comunidades (espécies) que vivem e interagem em determinada região e pelos fatores abióticos (água, etc.) que atuam sobre essas comunidades. Estas espécies são interconectadas com o ambiente e entre si, mantendo um equilíbrio nesta interconexão. As espécies interagem umas com as outras e balanceiam umas às outras, mesmo que algumas destas espécies assumam um papel de liderança por algum tempo. O meio ambiente suporta as necessidades das espécies que são continuadas, geração após geração. Estes princípios, por analogia, são emulados nos ecossistemas digitais. (CHANG, 2006).
} 
(gama de resultados esperados que podem ser obtidos pela aplicação do processo de software) e indica a riqueza do processo de software da organização e a consistência com que o mesmo é aplicado em todos os seus projetos. Em uma organização madura, o processo de software é bem compreendido - o que geralmente é conseguido por meio de documentação e treinamento - e é continuamente monitorado e melhorado pelos seus usuários. A maturidade de um processo de software implica que a produtividade e a qualidade resultantes do processo podem ser continuamente melhoradas por meio de ganhos consistentes na disciplina alcançada com a sua utilização.

\subsection{SISTEMAS COMPLEXOS}

Este item aborda a base teórica para o tratamento de sistemas complexos que é um dos eixos teóricos dessa pesquisa. Os conceitos são desenvolvidos a partir da conceituação de sistemas e são apresentados também o paradigma do pensamento complexo e os sistemas adaptativos complexos. O objetivo da revisão foi escolher, entre os vários autores que tratam da disciplina, os mais relevantes. Com a revisão, também foi possível decidir qual o suporte metodológico a ser utilizado para trabalhar a questão problemática da pesquisa.

\subsubsection{SISTEMA}

Segundo Jordan (1974) em todas as definições de sistema existe um padrão comum: um sistema é visto como um conjunto de entidades ou elementos unidos por alguma forma de interação ou interdependência regular, que constitui um todo integral.

Para tratar a questão de múltiplas definições Checkland (1994) aponta que o que torna o movimento sistêmico coerente é o compartilhamento do conceito de sistema. A partir desta ideia sintetiza, da seguinte forma os principais elementos que constituem o conceito de sistema: "[...] um todo adaptativo; uma entidade com propriedades emergentes; estruturado em níveis e processos de comunicação e controle que permitem a adaptação a um ambiente de mudança”.

Ao examinar o trabalho de Jordan (1974) e as definições de Checkland (1994) é possível perceber que existem três aspectos centrais, a partir dos quais o conceito de sistema pode ser discutido: a complexidade, a estrutura sistêmica e as propriedades emergentes, aspectos esses que serão considerados nessa revisão. 


\subsubsection{COMPLEXIDADE}

Não existe um consenso em torno da definição do que seja a complexidade (BORGATTI, 2008). Ainda segundo Borgatti (2008), no sentido funcionalista do termo, complexidade refere-se a um grande conjunto de variáveis cujas relações entre si não podem ser mapeadas ou controladas. Para Demo (2002), a complexidade está relacionada, não apenas com o número de variáveis no sentido da extensão, mas com um conjunto de propriedades que permitem interpretar um fenômeno como complexo.

A primeira propriedade destacada pelo autor é a dinamicidade. Não é complexo o que não é dinâmico. No entanto, para ser dinâmico, devem ser observadas no fenômeno as propriedades da emergência e da criação de novos eventos. Não é complexo o que é linear. A não linearidade implica irreversibilidade e, processos não controláveis, ou seja, equilíbrio em desequilíbrio. Entretanto Demo informa que "não cabe excluir a linearidade da realidade, porque também a integra" e contrapõe as noções de "complicado versus complexo", por meio de exemplos de sistemas sofisticados, como as máquinas e os aviões, em oposição à noção de complexidade presente nos organismos vivos. A complexidade é reconstrutiva, como na noção biológica que ao existir se reconfigura, "na natureza tudo é feito dos mesmos elementos e, mesmo assim, nada é propriamente igual" (DEMO, 2002). A complexidade é um processo dialético e evolutivo que está relacionado com a capacidade e conceito de aprender. A aprendizagem que decorre dos fenômenos complexos pode incluir criatividade autêntica no sentido de que produz modos de ser que são sempre de vir a ser. Comportam-se de maneira reconstrutiva: não se reproduzem linearmente e reconstroem-se não linearmente. Não é complexo o que é reversível. A irreversibilidade, como todo fenômeno complexo, é vir a ser, é incompleto. Com o passar do tempo, nada se repete, por mais que possa parecer o contrário; qualquer depois é diferente do antes; não se pode tomar como equação linear o que se estabelece entre antes e depois, mas sim como não linear.

A intensidade é outra característica da complexidade. A intensidade é uma característica ligada aos conceitos de dependência sensível e não linearidade, e requer uma maior valoração dos aspectos qualitativos em face dos aspectos quantitativos dos fenômenos. Não é complexo o que não é ambíguo/ambivalente (DEMO, 2002). A ambiguidade é típica da unidade de contrários, que se firma para 
salvaguardar a dialética de algo que ao mesmo tempo forma um todo aberto e relativamente unitário, mas que ultrapassa seu próprio limite (prende-se à estrutura caótica dos fenômenos complexos). Já a ambivalência liga-se mais à processualidade dos fenômenos complexos e, é mais facilmente visível, pois está vinculada a seus modos de vir a ser. Percebe-se a ambivalência em fenômenos de cunho qualitativo como participação, envolvimento, conhecimento, aprendizagem (DEMO, 2002).

\subsubsection{SISTEMAS COMPLEXOS}

Os sistemas complexos são entendidos por muitos autores como aqueles situados entre os sistemas que envolvem dinâmicas muito simples (normalmente envolvendo poucos elementos que interagem de forma simples, de modo que seu comportamento pode ser bem entendido com explicações lineares), e aqueles sistemas com grande quantidade de elementos que interagem com uma dinâmica que pode ser entendida como aleatória. Assim, é comum situar a complexidade entre a ordem e a desordem, ou seja, entre a ordem determinada linearmente e 0 caos indeterminado (CASTI, 1998; BYRNE, 1998).

Existem diversas denominações relacionadas aos estudos da dinâmica de sistemas complexos, como a teoria do caos e a teoria da complexidade, vindas da gestão organizacional. A teoria do caos é focada no conteúdo matemático para representação de uma dinâmica não linear em processos determinísticos, cujos resultados não podem ser exatamente previstos, em função da sensibilidade às condições iniciais do sistema. A teoria da complexidade, normalmente, mas nem sempre, é associada à dinâmica de modelos computacionais baseados em agentes (sistemas adaptativos complexos), de maneira tal que envolve muitos elementos em interação, incluindo interações não lineares, cujos padrões organizacionais emergentes não são previsíveis em muitos casos.

A teoria do caos é bem delimitada na sua proposta e existe uma concordância quanto à sua denominação e ao seu conteúdo. O mesmo não acontece quando no que se refere a uma teoria da complexidade, pois, sob essa denominação, muitas vezes são incluídas contribuições de outras áreas, tais como as dinâmicas de fenômenos biológicos e, em alguns casos, a própria teoria do caos. 
A teoria da complexidade estuda basicamente o fenômeno da emergência ou autoorganização, que é uma propriedade dos sistemas dinâmicos complexos. Por emergência entende-se o processo em que o resultado das interações entre os agentes relevantes de um sistema é em grande parte não intencional embora as ações individuais (pelo menos em sistemas sociais) possam ser consideradas racionais, no sentido de estarem voltadas para a preservação do auto-interesse (PRIGOGINE, 1984).

A complexidade sistêmica decorre do fato de que a interação entre os componentes de um sistema ocorre em loops de feedback negativos e positivos, em que causas e efeitos encontram-se afastados no tempo por delays. Nessas condições, as ações individuais em partes aparentemente isoladas dos sistemas podem dar origem a reações em outras partes em momentos posteriores, as quais alterarão as condições sob as quais os primeiros indivíduos tomaram as decisões que deram início ao processo. O resultado é que, em sistemas dinamicamente complexos, essas decisões produzirão, em geral, consequências não intencionais para quem as toma.

Um conceito central na discussão das ciências da complexidade é a interação nãolinear, a qual está associada à imprevisibilidade do sistema. Surgem como principais conceitos operacionais: emergência, auto-organização e dinâmica evolucionária, que podem ser entendidos como conceitos chaves nas ciências da complexidade (BARYAM, 1997).

Embora não exista uma definição ampla e consensual, os sistemas complexos são identificáveis por exibir uma série de comportamentos que são sistematicamente enumerados pela literatura e são eles: a) Emergência: um fenômeno é emergente quando surge como resultado da interação entre seus componentes; b) Transições de Fase: mudanças nas estatísticas de um sistema, dadas mudanças em parâmetros de controle, são denominadas transições de fase podem ser contínuas ou descontínuas; c) Universalidade: detalhes do comportamento dos constituintes de um sistema complexo frequentemente não são importantes para o comportamento agregado (médio); d) Adaptabilidade: a capacidade de modificar o próprio comportamento de acordo com mudanças no ambiente é uma característica comum em sistemas biológicos e socioeconômicos; e) Auto-referência: sistemas complexos, em particular sistemas socioeconômicos, respondem aos resultados de suas próprias ações; f) Auto-organização: interações locais produzem ordem em 
escala global; g) Imprevisibilidade: mesmo quando regido por equações inteiramente determinísticas, o comportamento de um sistema complexo pode ser imprevisível; h) Redes Complexas: sistemas complexos apresentam padrões de interação que não são inteiramente regulares, nem inteiramente irregulares. Em geral, redes de relações se auto-organizam localmente, de maneira aparentemente aleatória e, no entanto, apresentam uma ordenação global. Redes complexas apresentam alguns poucos nós com muitas conexões e diversos outros nós com poucas conexões, apresentam distâncias médias reduzidas entre nós, que redundam em uma capacidade de influência maior do que aparentam ter; i) Causas múltiplas, efeitos não lineares e retroalimentação: em fenômenos socioeconômicos e biológicos, suas causas são, em geral, múltiplas e interativas entre si. Uma pequena variação em uma ou mais das causas pode redundar em uma grande mudança nos efeitos observados $e$ os efeitos podem ser retroalimentados em causas futuras. As técnicas estatísticas que supõem comportamentos lineares dos sistemas não são capazes de lidar corretamente essas características; j) Invariância em Escala: padrões complexos podem ser obtidos pela aplicação repetida de regras simples em escalas diferentes (temporais ou espaciais).

\subsubsection{SISTEMA COMO PARADIGMA DO PENSAMENTO COMPLEXO}

Edgar Morin (1992) critica as abordagens sistêmicas que, segundo a sua leitura, se fixaram em demasia na noção genérica de sistema e deixaram de desenvolver o conteúdo radical que este conceito deve assumir. Morin propõe o desenvolvimento do conceito de sistema ao nível paradigmático, como conceito-chave para avançar na construção de um "conhecimento complexo". Segundo o autor, como noção paradigmática o conceito de sistema deve ser formulado como um macroconceito para a construção do conhecimento nos mais variados campos. Para tanto, entende Morin, o sistema não deve ser concebido como um conceito fechado, no sentido de completo. Deve somente fornecer as noções, os princípios e as relações para a construção de um novo tipo de conhecimento. Não deve ser concebido preso a uma teoria geral ${ }^{7}$ que, supostamente, serviria para entender e descrever todos os fenômenos complexos do mundo real.

\footnotetext{
${ }^{7}$ Crítica à Teoria Geral dos Sistemas
} 
Morin assinala como um dos principais problemas do desenvolvimento do conceito de sistema a pretensão de querer formular uma teoria sistêmica geral para impor à realidade complexa. Aponta esse equívoco assinalando que se as abordagens sistêmicas (teorias, modelos, metodologias), nas distintas áreas do conhecimento, forem, por exemplo, moldadas pela Teoria Geral dos Sistemas, a focalização dos fenômenos será reduzida à dimensão privilegiada por essa teoria - a abertura do sistema à transação de matéria, energia e informação com o meio. Segundo Morin, tentar abordar as diferentes formas de complexidade em função da sua abertura ao meio é insuficiente, pois cada fenômeno a ser descrito possui as suas próprias física, química, termodinâmica, natureza e organização. Assim, para o autor, o conceito de sistema ao invés de ser pensado como um termo geral para enquadrar a complexidade deve ser encarado como um conceito generativo de conhecimentos, tanto gerais como específicos, independente do domínio no qual vier a ser aplicado. Deve permanecer aberto ou incompleto fornecendo: "[...] as relações básicas de associação e/ou oposição entre um número limitado de noções que comandam e controlam nosso pensamento, discursos e teorias" (MORIN, 1992).

Como base de um novo paradigma, o conceito deve deixar de ter o caráter globalista, ou, nas palavras do autor, "sistema" deve deixar de ser uma "palavra-mestre para a totalidade" e converter-se na "palavra-raiz para a complexidade". O outro aspecto da crítica do autor dirige-se à crença de que a complexidade possa ser um substituto eficaz da simplificação que, à semelhança da simplificação do pensamento analítico, tornaria possível "programar e esclarecer" (MORIN, 1996). A suposição central que fundamenta essa perspectiva, segundo o autor, é a de que seria possível encontrar uma explicação para os fenômenos complexos a partir de alguns princípios simples responsáveis por um número infinito de combinações de alguns elementos (MORIN, 1992). Para Morin (1977; 1996), ao contrário, a complexidade implica o reconhecimento de que a complicação e a obscuridade são desafios incontornáveis da realidade. Ainda para Morin (1992) o desenvolvimento do conceito de sistema como novo paradigma de conhecimento envolve dois aspectos centrais: a) o desenvolvimento do conceito de organização como noção chave do conceito de sistema e b) o estabelecimento de um conjunto de princípios e regras que comandam as relações entre essas noções. Morin (1992) propõe a formulação do conceito de sistema em torno de três noções constitutivas básicas: a) o sistema 
como manifestação emergente da unidade complexa; b) o sistema como resultado de relações entre partes ou variáveis qualitativamente distintas, que mantêm interações, e não somente de interações de ações simples entre si; c) o sistema como configuração das interações, que constitui a organização sistêmica. O autor descreve do seguinte modo a relação entre as três noções:

De fato o conceito de sistema é um conceito de três lados: o sistema expressa a unidade complexa e a natureza fenomenal do todo bem como as relações entre o todo e as partes; interações, que expressam o conjunto de relações, ações e feedbacks que são entretecidas em um sistema; e a organização, que expressa o caráter formativo das interações por compor, proteger, regular, direcionar e renovar as interações, assim servindo como espinha dorsal ao conceito de sistema. (MORIN, 1992).

Ou seja, o sistema como forma descritiva de um fenômeno global origina-se de interações, cuja configuração constitui sua organização. O conceito de sistema é, portanto, inseparável da noção de organização que o produz. A organização é o "[...] nó que liga a ideia de interação à ideia de sistema", pois a organização "liga e transforma os elementos num sistema, produz e mantém esse sistema" Para Morin (1992) o conteúdo do termo organização, na perspectiva sistêmica, é substancialmente distinto do da perspectiva clássica. Nas ciências clássicas a organização é um conceito estático, de ordem e regras invariáveis, associado à noção de "estrutura" da visão mecanicista. Na perspectiva sistêmica é uma noção com características dinâmicas, que se refere a processos que se auto mantêm em sistemas naturais ou que são mantidos em sistemas construídos pelo homem. A organização como noção sistêmica central, segundo Morin (1992), engloba as seguintes características: a) a organização em sistemas físicos e em todos os biológicos ativos envolve suprimento, estoque, distribuição e controle de energia, bem como, consumo e dissipação de energia em seu trabalho; b) como consequência da característica anterior, a organização produz entropia - degradação do sistema e da própria organização - e negentropia ${ }^{8}$ - a regeneração do sistema, incluindo a reorganização permanente das relações que especificam a sua própria organização; c) a organização envolve interações que especificam a abertura do sistema (trocas com o seu ambiente) ao mesmo tempo em que mantém o

\footnotetext{
${ }^{8}$ Negentropia é o processo de obtenção de informação. O sistema precisa reabastecer-se de informação para manter sua estrutura. A negentropia utiliza a informação como meio de ordenação do sistema.
} 
"'fechamento organizacional" (manutenção de um padrão de interações fechadas, responsáveis pela autonomia e pela integridade do sistema); d) organização significa a criação de ordem onde impera o determinismo sistêmico. Entretanto, esta ordem pode ser flexível, contemplando zonas de incerteza, disputa e liberdade. A desordem é um ingrediente inevitável, gerado complementarmente à própria atividade organizacional; e) em função da característica anterior - a presença simultânea da ordem e desordem -, a organização envolve incertezas e antagonismos; f) o "ser" e a "'existência" são características relacionadas à organização sistêmica, quando esta assume a forma auto-organizadora. A auto-organização gera ser e existência.

A organização recorrente é vista como a característica fundamental da organização complexa (MORIN, 1977; 1992; 1996). Organização recorrente é definida como "um círculo produtivo ininterrupto" em que "os produtos são necessários à produção daquilo que os produz" (MORIN, 1996). Como exemplo o autor cita as sociedades humanas em que as interações entre os indivíduos geram o todo social, o qual, por sua vez, retroage sobre os indivíduos para co-produzi-los.

O princípio autorregulador da cibernética é visto por Morin (1977) como uma situação especial da causalidade complexa. A relação produto-produtor é apontada como a noção complexa mais geral. Para Morin (1977) a organização recorrente é responsável pela causalidade complexa. Segundo explica o autor, para o determinismo clássico causas são impingidas aos objetos a partir de uma perspectiva externa. O efeito não retroage sobre a causa que the deu origem que, nas mesmas condições, devem resultar no mesmo efeito. A organização baseada em interações recorrentes rompe com essa ideia de causalidade linear. Laços fechados, constituídos de redes de interações recorrentes, podem provocar efeitos locais distintos dos presumíveis a partir do determinismo clássico. A lógica causal dos processos circulares e recorrentes gera determinações locais, sem as quais entidades complexas não são concebíveis diante das múltiplas determinações externas.

A seguir são pontuadas duas implicações cruciais relacionada à noção de causalidade complexa, segundo Morin (1977): a) Causalidade finalista - ao opor-se à determinação externa a lógica causal interna envolve recursos que mantêm determinadas condições estáveis e preservam características de identidade do sistema, ou ainda, desdobram-no em uma forma modificada no transcorrer do tempo. 
Enquanto que para a causalidade determinista os efeitos são imediatos e diretos, os efeitos da causalidade complexa podem permanecer latentes e invisíveis. Podem demandar tempo e/ou condições favoráveis para manifestarem-se, revelando a sua plenitude somente quando o "fim" tiver sido realizado. Para um observador isso pode parecer como a busca ou a manutenção de um objetivo ou a realização de um propósito. Assim, a causalidade complexa (local) pode ser descrita como causalidade finalista; b) Causalidade generativa - processos circulares recorrentes estão na gênese de todo fenômeno organizacional. Sistemas complexos, ao mesmo tempo em que se relacionam com as causas externas - são abertos a fluxos de matéria, energia e informação do meio -, criam uma disjunção entre as determinações ou causas externas e seus efeitos locais, via processos circulares. Sua manutenção implica a geração e a manutenção de graus de autonomia organizacional em relação ao meio. É isso que permite compreender o desenvolvimento de estratégias e decisões. Nos sistemas biológicos, estratégias e decisões são imanentes aos processos físicos. são o resultado de um processo seletivo de milhões de anos. Nos sistemas humanos, estratégias são verbalizadas racionalmente na linguagem.
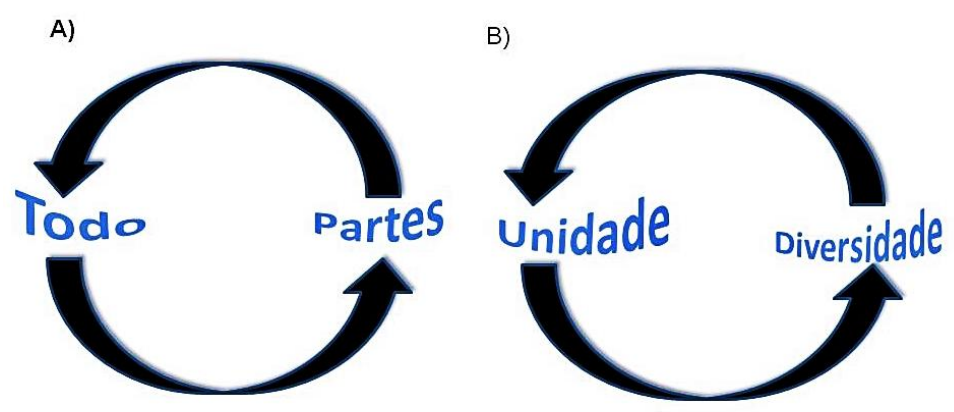

Figura 4 Circularidade produtiva mútua Fonte: Morin (1997)

Morin (1992) concebeu as regras e princípios que comandam as relações em sistemas complexos a partir de duas formas de "circularidade construtiva", apresentadas na Figura 4 onde "A" é a interação circular em que o todo é explicado pelas partes e as partes são explicadas em função do todo e "B" é a interação circular entre a unidade e a diversidade, em que as unidades complexas são constituídas a partir da diversidade e a diversidade é resultante da unidade.

Quanto à primeira forma de circularidade, Morin (1997) explica que o reconhecimento de um nível de oposição e disputa entre os dois processos de 
explicação - a explicação das partes pelo todo e do todo pelas partes - significa a introdução da complexidade ao nível paradigmático. Ou seja, a complexidade não deve ser vista apenas ao nível de fenômeno, mas, em primeiro lugar, como princípio explicativo.

Quanto à segunda forma de circularidade, Morin (1992) argumenta que o conceito de sistema, ao referir-se à descrição da complexidade, se refere à "unidade do diverso". A experiência mostra, segundo o autor, que as entidades físicas, biológicas e sociais não são somente unidades compostas a partir da diversidade, sendo a própria diversidade produto da unidade. As partes "possuem uma dupla identidade: uma identidade individual não redutível ao todo e uma identidade comum, como cidadão do sistema".

A partir da concepção anterior, Morin (1977; 1992) formulou um conjunto de princípios quanto ao caráter complexo das relações que, segundo seu entendimento, devem integrar o conceito de sistema como noção nuclear de um novo paradigma do conhecimento: a) $\mathrm{O}$ todo é maior que a soma das partes. Este princípio assinala que o todo possui propriedades globais - qualidades, propriedades, comportamentos não observáveis nos componentes em separado; b) O todo é inferior à soma das partes. Este princípio assinala que muitas qualidades e propriedades das partes desaparecem quando sob o efeito das restrições do todo; c) O todo é maior que o todo. Este princípio assinala que existe um "circuito construtivo" entre o todo e as partes em que são desenvolvidas potencialidades maiores que a realidade global do sistema revela; d) As partes são ao mesmo tempo mais e menos que as partes. Este princípio assinala que ao mesmo tempo em que a organização inibe propriedades potenciais das partes (por isso as partes são menores que as partes) ela pode criar condições que permitem os desvios e a expansão de novos potenciais nos seus componentes; e) O todo é menor que o todo. Este princípio assinala que sistemas comportam "zonas de sombra", desconhecimento mútuo, "brechas, rupturas entre o reprimido, o latente e o expresso, entre o imerso e o que emerge, entre o generativo e o fenomenal" (MORIN, 1992); f) O todo é insuficiente. Este princípio decorre do anterior. Totalidades são sempre incompletas, comportando insuficiências reconhecíveis, zonas desconhecidas, situações fora de controle, que incluem rupturas e conflitos; g) $O$ todo é incerto. Este princípio estabelece a relatividade do conceito. Não existe forma "certa" ou "absoluta" de isolar um sistema de outros 
sistemas aos quais está ligado; h) O todo é conflitivo. O todo contempla relações antagônicas, fontes de cisões, conflitos e riscos à sua perpetuação. Essas forças são permanentemente reprimidas por mecanismos de realimentação negativa ou mesmo usadas de modo positivo, construtivamente.

Para Morin (1992), o conceito de sistema, como base de um novo paradigma de construção do conhecimento, deverá substituir a concepção ontológica que está no núcleo do paradigma clássico, ou seja, a ideia de objeto substancial e elementar:

A noção se torna revolucionária quando substitui a noção de coisa ou objeto, que foi conceitualizada como tendo forma e substância, decomponível em elementos primários, nitidamente separados no espaço, e sujeitos às leis externas à 'natureza'. A nova noção deve romper a ontologia clássica do objeto. Devemos ver que o objeto da ciência clássica é um segmento, uma aparência, uma construção simplificada, mutilando e abstraindo uma realidade complexa que está enraizada simultaneamente na organização física e na organização psicocultural. (MORIN, 1992).

No novo paradigma, “...os objetos dão lugar ao sistema. Em lugar das essências e das substâncias, a organização; em lugar de unidades simples e elementares as unidades complexas; em lugar de agregados formando corpos, sistemas de sistemas de sistemas” (MORIN, 1977). Do ponto de vista epistemológico, o autor rejeita as duas alternativas, segundo as quais, no seu ponto de vista, a noção de sistema normalmente é apresentada: de um lado, a perspectiva realista/positivista em que o sistema reflete as características dos objetos da realidade empírica se impondo à percepção do observador, podendo ser descrito acuradamente como entidade física mensurável (MORIN, 1992) e, de outro, o sistema como um modelo ideal/formal abstrato (categoria mental) aplicável aos fenômenos - "uma heurística construída mentalmente e/ou um modelo pragmático usado para controlar, entender ou simular um fenômeno".

Como alternativa Morin (1992) propõe uma perspectiva epistemológica em que a noção de sistema possui uma dupla determinação ou "dupla entrada", conforme descrito no Quadro 2: uma '"entrada" física, experimentada empiricamente, em que são reconhecidos: (a) a existência de condições físicas de formação e existência das interações que mantêm o sistema; (b) limites físicos de existência fora dos quais o sistema se desintegra ou se transforma e (c) as características emergentes que tornam possível distinguir o sistema (MORIN, 1977). Ao mesmo tempo, outra entrada, que é experimentada como fenômeno, por mais evidente que pareça, 
depende também do "espírito" humano, do processo cognitivo através do qual o observador/conceptor opera as abstrações (MORIN, 1977).

\begin{tabular}{|c|c|}
\hline Física & Psíquica \\
\hline $\begin{array}{c}\text { Por formação e por existência (interações, } \\
\text { combinação de circunstâncias ecológicas, } \\
\text { condições energéticas e termodinâmicas e } \\
\text { operações). (Mesmo um sistema de } \\
\text { pensamento tem um componente físico- } \\
\text { bioquímico, relacionado à atividade cerebral). }\end{array}$ & $\begin{array}{c}\text { Por distinção e isolamento, pela escolha } \\
\text { de conceitos sucessivamente aninhados } \\
\text { (subsistema, sistema, suprassistema, } \\
\text { ecossistema). }\end{array}$ \\
\hline Um principio da arte (de diagnóstico) \\
\hline Um princípio de reflexão crítica (da relatividade da noção de fronteiras de um sistema) \\
\hline \multicolumn{2}{|c|}{ Um princípio de incerteza } \\
\hline
\end{tabular}

Quadro 2 Dupla entrada do conceito de sistema Fonte: Morin (1977)

O reconhecimento do caráter simultaneamente psíquico e físico do sistema, segundo Morin (1977), remete à indivisibilidade da relação sujeito/objeto. Isso significa que a distinção de algo é sempre uma transação (relação) entre o observador e o sistema observado. A importância do observador no processo de descrição de um modelo sistêmico pode ser avaliada pelas duas citações que a seguem:

A determinação do caráter sistêmico, subsistêmico, ecossistêmico, etc., depende de seleções, interesses, escolhas e decisões, que por sua vez dependem das condições culturais e sociais nas quais se inscreve o observador/conceptor. É sistema aquilo que o observador considera do ponto de vista da sua autonomia e das suas emergências (ocultando por isso mesmo as dependências que, sob outro ângulo, o definiram como subsistema). É subsistema aquilo que um observador considera do ponto de vista da sua integração e das suas dependências.

Há, portanto sempre, na extração, no isolamento, na definição de um sistema, alguma coisa de incerto ou arbitrário: há sempre decisão e escolha, o que introduz no conceito de sistema a categoria do sujeito. O sujeito intervém na definição do sistema nos e pelos seus interesses, seleções e finalidades, quer dizer que traz ao conceito de sistema, através de sua sobredeterminação subjetiva, a sobredeterminação cultural, social e antropológica. (MORIN, 1977)

Assim, mesmo que um modelo sistêmico se refira a uma entidade de natureza exclusivamente física, a sua descrição sempre envolve os interesses, a subjetividade e os valores culturais de quem seleciona e delimita o sistema. 


\subsubsection{SISTEMAS ADAPTATIVOS COMPLEXOS}

Para o caso dos ecossistemas é importante observar que eles são considerados como sistemas adaptativos complexos. Esses ecossistemas apresentam características próprias tais como: a) Complexidade versus. Simplicidade: apesar de serem sistemas globalmente complexo, são sistemas que apresentam simplicidade local; b) Grande número de componentes que interagem entre si e influenciam uns aos outros; c) São imunes aos métodos científicos de análise disponíveis. O método reducionista de análise não é utilizável para o estudo e previsão desses sistemas. Nesses sistemas, o todo é maior que a soma das partes e este fenômeno é chamado sinergia; d) Não são sistemas determinísticos ou previsíveis, sempre há aspectos aleatórios envolvidos; e) Ampla diversidade de componentes que se interrelacionam e que mantêm similaridades dentro da diversidade; f) São capazes de evoluir, de se adaptar e de aprender de acordo com mudanças nas características de seu ambiente; g) Inexistência de uma coordenação global, absoluta, efetiva e duradoura, embora vários mecanismos de coordenação mais fraca possam estar presentes.

Os sistemas adaptativos complexos apresentam a propriedade chamada transição de fases. A transição de fase é o estado intermediário entre dois períodos estáveis, periódicos, quiescentes, rotineiros (regime estável). A transição de fase é um estado de ebulição, caótico, do qual emerge uma nova realidade (GLEICK, 1990) (BARYAM, 1997). As principais características do regime de transição de fase são: a) Ele ocorre de forma auto-organizada no limiar da destruição do sistema; b) A transição de fase desenvolve-se com dualidade constante entre simplicidade e complexidade (STACEY, 1996) (BERTALANFFY, 1997). Stacey (1996) resume o cenário da seguinte forma:

A ciência da complexidade explora a natureza das redes determinísticas e adaptativas. Estas últimas - sistemas complexos adaptativos - são redes com grande número de agentes que interagem de acordo com esquemas que contêm ambas as partes dominante e recessiva. $\mathrm{A}$ principal descoberta que cientistas da complexidade fizeram sobre sistemas complexos adaptativos é que eles são criativos somente quando operam no que poderia ser chamado de espaço para novidades. Esta é uma transição de fase à beira do caos, isto é, no limiar da desintegração do sistema. É um estado paradoxal, pois é estável e instável ao mesmo tempo, orientado pela contraditória dinâmica da competição e cooperação, da amplificação e restrição, da exposição à tensão criativa e proteção dela. Tais sistemas evoluem dialeticamente com resultados radicalmente imprevisíveis. O processo coevolutivo é de 
destruição criativa auto-organizada e reconstrução em que um esquema recessivo depõe um dominante para produzir resultados emergentes. Estes são sistemas que aprendem de maneiras complexas e são naturalmente ubíquos".

"Organizações são sistemas adaptativos complexos e também são criativos e inovadores quando ocupam um espaço para novidade à beira do caos ou desintegração. Este é um estado em que as pessoas atuam num sistema à sombra da organização com conceitos e ações que acabam por descartar seu legítimo sistema a fim de mudá-lo. Organizações transformam-se através da tensão entre o sistema legítimo e sua sombra; esta é a essência do aprendizado organizacional ou gerenciamento extraordinário. Tal aprendizado em tempo real, ou auto-reflexo, é um processo auto-organizado que produz resultados emergentes radicalmente imprevisíveis. Ele opera sob tensão com o processo intencional do sistema legítimo - gerenciamento ordinário.

Uma forma de entender os sistemas adaptativos complexos é pela utilização de um dos operadores cognitivos de Morin, o Pensamento Sistêmico. O Quadro 3 apresenta uma compilação da revisão bibliográfica efetuada para sistemas complexos. As publicações foram selecionadas conforme o exposto no início deste capítulo.

\begin{tabular}{|l|l|l|}
\hline Autores & Ano & Contribuição Teórica \\
\hline Borgatti & 2008 & $\begin{array}{l}\text { Tese que explora duas abordagens gerais da complexidade: } \\
\text { ciência da complexidade e pensamento complexo. }\end{array}$ \\
\hline Morin & $\begin{array}{l}1996, \\
1998\end{array}$ & $\begin{array}{l}\text { Apresenta crítica às abordagens sistêmicas convencionais. } \\
\text { Propõe que os sistemas sejam um macro conceito para avançar } \\
\text { na construção de um conhecimento complexo. }\end{array}$ \\
\hline Checkland & 1994 & $\begin{array}{l}\text { Apresenta as diferentes definições de sistemas e propõe uma } \\
\text { forma de tratar esta variedade de definições. }\end{array}$ \\
\hline Prigogine & 1984 & $\begin{array}{l}\text { Introduz os conceitos de emergência e auto-organização na } \\
\text { teoria da complexidade. } \\
\text { Apresenta um levantamento exaustivo da definição do termo } \\
\text { sistema. }\end{array}$ \\
\hline Jordan & 1974 & \begin{tabular}{l} 
Principais referennas teOricas para sistemas complexos \\
\hline
\end{tabular}
\end{tabular}

Quadro 3 Principais referências teóricas para sistemas complexos

\subsubsection{CONCLUSÃO DA REVISÃO DE LITERATURA - SISTEMAS COMPLEXOS}

O pensamento complexo é uma nova abordagem que busca o entendimento da realidade e de suas relações complexas. O pensamento complexo surgiu a partir da constatação da necessidade de uma nova forma de apreciar o mundo e seus 
processos, uma vez que as abordagens tradicionais mostravam-se insuficientes para comportar sua complexidade crescente. Mais que isto, o pensamento complexo busca unir os aspectos da ordem (linearidade) e da desordem (sistêmico). Tomando como base a própria afirmação de Morin (MENDES, 2003, p. 77 apud BORGATTI, 2008): "O pensamento complexo é, portanto, essencialmente, o pensamento que lida com a incerteza e que é capaz de conceber a organização", sugere-se considerar o saber "enfrentar as incertezas" como central. Os trabalhos de Morin indicam a intenção de que sua proposta seja utilizada como uma ponte entre os discursos científicos e filosóficos: "O pensamento complexo não se reduz nem à ciência, nem à filosofia, mas permite comunicação mútua, fazendo o intercâmbio entre uma e outra" (MENDES, 2003, p. 77 apud BORGATTI, 2008). Ainda segundo Borgatti a proposta de pensamento complexo de Morin reflete sua forte relação histórica com a Cibernética e a Teoria Geral de Sistemas, com físicos quânticos e da termodinâmica do não equilíbrio (Prigogine) e ainda com a biologia de Maturana e Varela (2001).

O objetivo desta revisão foi identificar na literatura disponível as características de um sistema complexo com o objetivo de caracterizar e comprovar teoricamente que o ecossistema do SPB é um sistema de natureza complexa e que deve, portanto, ser abordado metodologicamente e conceitualmente como tal.

\subsection{PENSAMENTO SISTÊMICO}

Este item aborda a base teórica que sustenta o pensamento sistêmico que é um dos eixos desta pesquisa. São apresentadas questões relativas à situação do movimento sistêmico, as formas de ordenamento desse pensamento e, as abordagens do pensamento sistêmico relevantes para este trabalho. O objetivo da revisão é escolher, entre os vários autores que tratam da disciplina, os mais relevantes para esta pesquisa. Com a revisão também foi possível decidir qual o suporte metodológico a ser utilizado para trabalhar a questão problemática da pesquisa.

Segundo os diversos autores que tratam do tema, o pensamento sistêmico consiste em uma nova estrutura de pensamento para lidar com a complexidade (FLOOD e CARLSON, 1988); na busca do desenvolvimento de uma epistemologia para descrever a realidade e para elucidar alguns de seus problemas (CHECKLAND, 1981); em um processo de pensamento que vê algo como parte de um sistema 
maior e em termos do papel que cumpre no mesmo, invertendo a lógica que caracteriza o pensamento analítico (ACKOFF, 1981); em pensar em termos de contexto e em termos de padrões de interações dentro de padrões maiores de interações (CAPRA, 1996); em mudar o foco das partes para os processos, nos quais estruturas são concebidas como estabilizações temporárias de relações entre partes e processos (BUCKLEY, 1971). As variações, quanto ao significado da expressão pensamento sistêmico são frequentes na literatura, embora possam ser destacadas duas tendências relativas ao seu caráter: a) uma expressão que se refere a abordagens aplicadas, na forma de modelos teóricos, metodologias e técnicas, segundo enfoques específicos; b) um conjunto de noções e princípios básicos de uma nova organização intelectual do processo de conhecimento.

Lane (1994) aponta um exemplo do uso da expressão com o significado subordinado a uma abordagem específica, na Dinâmica de Sistemas (FORRESTER, 1961). Essa abordagem, segundo o autor, incorporou recentemente o termo pensamento sistêmico em sua linguagem, popularizando-o por meio de Senge (1990).

Senge (1990) define pensamento sistêmico como "[...] uma estrutura conceitual, um conjunto de conhecimentos e instrumentos desenvolvido nos últimos cinquenta anos, que tem por objetivo tornar mais claro o conjunto e nos mostrar as modificações a serem feitas para melhorá-lo".

$\mathrm{Na}$ interpretação de Lane (1994), o uso efetivo do termo, feito por Senge (1990), refere-se somente a aspectos qualitativos e modelagem de micromundos, restritos à visão particular da Dinâmica de Sistemas.

Forrester (1999) faz uma crítica ao uso qualitativo dos seus conceitos adotado por Senge (1990) e alerta sobre os riscos do uso do 'pensamento sistêmico' no campo da administração, sem a fundamentação de uma disciplina sistêmica rigorosa. Forrester (1999) reafirma a importância da construção rigorosa de modelos de simulação, na forma proposta pela Dinâmica de Sistemas.

Segundo Lane (1994), os argumentos de Forrester levam à conclusão de que ele vê o pensamento sistêmico como somente um elemento da Dinâmica de Sistemas, o que também depõe contra a aceitabilidade da posição de Senge (1990), embora seja inegável a contribuição da Dinâmica de Sistemas para a visão sistêmica como 
um todo, ela é apenas uma rica matriz de abordagens que conformam o pensamento sistêmico.

Para Capra (1996) que definiu pensamento sistêmico como uma nova forma de pensar, "[...] em termos de conexidade, de relações e de contexto", o pensamento sistêmico envolve a complementaridade entre pensamento contextual e pensamento processual. Como pensamento contextual, Capra aponta cinco aspectos que caracterizam o pensamento sistêmico: a) Mudança das partes para o todo. Um sistema surge das "[...] relações de organização [...] da configuração de relações ordenadas [...]"; b) Capacidade de deslocar a atenção entre níveis sistêmicos. É possível encontrar sistemas aninhados dentro de outros sistemas e aplicar os mesmos conceitos a diferentes níveis; c) Inversão da relação entre as partes e o todo. Para o pensamento sistêmico, as propriedades das partes somente podem ser entendidas dentro de um contexto maior, o que envolve explicá-las considerando o seu ambiente; d) Pensar em termos de redes de relações. Com o pensamento sistêmico, "a metáfora do conhecimento como um edifício, está sendo substituída pela da rede. Quando percebemos a realidade como uma rede de relações, nossas descrições também formam uma rede interconectada de concepções e modelos, na qual não há fundamentos"; e) Mudança epistemológica. A realidade concebida como uma rede de relações implica uma mudança epistemológica profunda em relação à concepção tradicional de objetividade científica. No paradigma sistêmico "[...] a epistemologia - a compreensão do processo de conhecimento - precisa ser explicitamente incluída na descrição dos fenômenos naturais".

As características contextuais do pensamento sistêmico são interdependentes. A visão de mundo que é apreendida a partir das características foi sintetizada por Capra do seguinte modo:

\footnotetext{
"A natureza é vista como uma teia interconexa de relações, na qual a identificação de padrões específicos como sendo 'objetos' depende do observador humano e do processo de conhecimento. Essa teia de relações é descrita por intermédio de uma rede correspondente de conceitos e de modelos, todos igualmente importantes" (CAPRA, 1996)
}

O aspecto processual do pensamento sistêmico é resultante da centralidade das interações. Para o pensamento sistêmico as estruturas são vistas como a manifestação de processos subjacentes (CAPRA, 1996), (JACKSON, 1991). Estruturas sistêmicas são estabilizações temporárias de relações e processos que 
persistem, e não o resultado das propriedades dos componentes estruturais isolados que lhes servem de suporte. Buckley (1971) descreve esse modo de conceber estruturas sistêmicas, no plano sociológico, do seguinte modo:

\footnotetext{
“A 'estrutura' é uma construção abstrata e não algo distinto do processo iterativo em marcha, mas a sua representação temporária e acomodativa em qualquer tempo. [...]. O foco no processo, portanto, são as ações e interações dos componentes do sistema em evolução, de maneira tal que surgem, persistem, desenvolvem-se, ou se alteram em graus variados de estruturação". (BUCKLEY,1971).
}

O pensamento processual está presente no trabalho de vários autores e pensadores que durante o século XX retomaram a ideia de "processo" como noção central para explicar inúmeros fenômenos (CAPRA, 1996). Em particular, está no núcleo das concepções sistêmicas contemporâneas, por meio do trabalho de Bertalanffy (1998) e dos padrões dinâmicos circulares da cibernética.

Do exposto acima pode-se concluir que o pensamento sistêmico contrapõe o cartesianismo e é uma forma de abordagem da realidade que surgiu no século $X X$, em contraposição ao pensamento reducionista, ou cartesiano, que visava a fragmentação. É visto como componente do paradigma emergente, que tem como representantes cientistas, pesquisadores, filósofos e intelectuais de vários campos. Por definição, o pensamento sistêmico inclui a interdisciplinaridade (BEHRENS, 2005). O pensamento sistêmico, de uma forma geral, pode ser definido como uma nova forma de percepção da realidade. Segundo Capra, quanto mais são estudados os problemas de nossa época, mais se percebe que eles não podem ser entendidos isoladamente. São problemas sistêmicos, o que significa que estão interligados e são interdependentes. Deve-se sempre partir do princípio de que o todo é mais que a soma das partes, sendo desta forma o sistema um todo integrado cujas propriedades essenciais surgem das inter-relações entre suas partes. Entender a realidade sistemicamente significa, literalmente, colocá-la dentro de um contexto e estabelecer a natureza de suas relações.

Capra (1996) apresenta a ideia de inter-relação entre os objetos e os seres vivos, segundo a qual, as coisas não são separadas, apenas ficam separadas momentaneamente ou mesmo aparentam estar separadas, no entanto é preciso ter cuidado com a ilusão, pois a realidade pode ser outra. Os objetos e os seres vivos estão em constante relação. Há uma troca tanto subjetiva como objetiva nessas 
relações, não podendo ser estudadas, vistas, analisadas ou, entendidas separadamente. A ciência deve estar mais aberta à realidade do todo e não a uma parte deste todo. A ciência sistêmica mostra que os sistemas não podem ser compreendidos por meio da analise individual. As propriedades das partes não são necessariamente propriedades extrínsecas, mas precisam ser vistas e entendidas dentro do contexto do todo. Nessa perspectiva o pensamento cartesiano, 0 pensamento holístico e o pensamento sistêmico apesar de cada qual possuir identidade, método e história diferentes, não são diretamente opostos, apenas tomaram caminhos diferentes, visando chegar a algo comum, pensando na busca da verdade do todo (CAPRA,1996).

Num sentido amplo, o pensamento sistêmico pode ser entendido como uma nova estrutura de referência conceitual ou metalinguagem em desenvolvimento, alternativa à estrutura conceitual clássica ou pensamento analítico. O pensamento sistêmico tem por objeto lidar com fenômenos e situações que requerem explicação baseada na inter-relação de múltiplas forças ou fatores. Contempla um conjunto de ideias sistêmicas gerais, bem como teorias e abordagens aplicadas. Envolve trabalho em inúmeros campos de investigação, como, por exemplo, biologia, cibernética, engenharia de sistemas, ciências da administração, economia, sociologia, neurociências, teorias cognitivas, aprendizagem, psicologia, matemática, ciências da complexidade e simulação computacional de um modo geral. pensamento sistêmico nasce do questionamento da aplicabilidade universal dos pressupostos do pensamento analítico, segundo o qual todos os fenômenos podem ser compreendidos pelo seu desmembramento partes componentes e a partir de relações causais lineares. Tais pressupostos são inadequados quando o objeto em questão é um todo organizado, que apresenta características e propriedades que emergem (propriedades emergentes) de um conjunto de interações simultâneas e constitutivas do todo. As propriedades emergentes pressupõem uma causalidade gerada localmente - formadora do todo - intrínseca à entidade, fenômeno ou situação complexa a explicar. Ao constituir o todo, a determinação local, ou contingente, delimita um espectro de mudanças ou variações toleráveis, para que não haja a transformação ou desconstituição do todo.

Outra mudança diz respeito à concepção da natureza da realidade. Para o pensamento sistêmico, a realidade pode ser concebida em termos de padrões de 
interações dentro de contextos maiores de múltiplos padrões de interações. Esse princípio supõe a existência de distintos níveis sistêmicos na realidade - sistemas aninhados e entrelaçados com outros sistemas - aos quais devem corresponder diferentes níveis descritivos de organização, em função de critérios delimitadores. $O$ pressuposto subjacente é que o tecido da realidade - a essência constitutiva dos fenômenos descritos a partir da experiência humana - constitui-se de fluxos de atividades e processos inter-relacionados e não de elementos últimos. Organizações complexas como átomos, moléculas, seres vivos, organizações, sociedades, ecossistemas e mesmo modelos conceituais abstratos, emergem de fatores interrelacionados e dos processos que os realizam. A noção central do pensamento sistêmico é a organização sistêmica ou estrutura sistêmica. Essa noção consiste em delimitar um padrão de interações como hipótese explicativa de uma propriedade de interesse ou emergente. Como configuração explicativa, a organização sistêmica distingue-se das ideias clássicas de organização e estrutura, pois se refere a padrões dinâmicos, e não estáticos, de interações. Pressupõe atividades processuais - fluxos de matéria, energia e informação - que realizam ou geram as interações que configuram a existência do todo. É por meio dos processos que se materializa ou realiza a lógica que origina a existência de uma situação, fenômeno ou entidade complexa.

\subsubsection{CONSIDERAÇÕES SOBRE A SITUAÇÃO DO MOVIMENTO SISTÊMICO}

Embora exista, genericamente, um compartilhamento do conceito de sistema, o movimento sistêmico tem como característica a ausência de uma perspectiva unificada (RICHARDSON, 1994), (CHECKLAND, 1994), (JACKSON, 1991). Checkland (1994) refere-se ao pensamento sistêmico nas ciências da administração somente como versões do pensamento sistêmico e não como algo único. O fato de não existir uma perspectiva teórica unificada foi destacada por Capra (1996), que constata, diferentemente do que foi idealizado por Bertalanffy (1999) que não houve a concretização de uma teoria geral dos sistemas, aplicável a diversos campos de investigação. Esta constatação levou o movimento sistêmico a um declínio nos anos setenta. A capacidade do movimento sistêmico de se tornar uma alternativa viável no âmbito da ciência foi questionada por teóricos como Berlinski e Liiendfild (CHECKLAND,1981). Entretanto, durante esse tempo, importantes movimentos estavam acontecendo. Pesquisadores preocupados com o uso prático das ideias 
sistêmicas vinham aplicando os conceitos iniciais em suas áreas específicas. Estavam sendo testados modelos teóricos e novas abordagens para a resolução de problemas em disciplinas específicas, como a teoria das estruturas dissipativas, na física, a autopoiese, na biologia e nas ciências cognitivas, o estudo de sistemas dinâmicos não lineares e as formulações da teoria do caos, na matemática e no campo das ciências da administração. Durante os anos setenta e oitenta, ocorreram importantes aprimoramentos e a formulação de novas abordagens aplicadas a problemas operacionais e gerenciais. A conclusão apresentada por Capra (1996) é que embora não exista uma teoria sistêmica formal, já existe uma série de modelos sistêmicos bem sucedidos assim como inúmeros modelos e metodologias aplicadas a temas específicos. Checkland (1994) aponta que o desenvolvimento de metodologias aplicadas a questões organizacionais e à administração, foi "a parte mais ativa do movimento sistêmico". Já Richardson (1994) aponta que os distintos modelos e abordagens configuram o movimento sistêmico como um movimento amplo, constituído de distintas comunidades sistêmicas, cada uma com sua própria linguagem e credo.

\subsubsection{DIVERSAS FORMAS DE ORDENAMENTO DO PENSAMENTO SISTÊMICO}

Os desdobramentos do movimento sistêmico contam com extenso e complexo conjunto de trabalhos teóricos e práticos em inúmeras áreas do conhecimento humano. De acordo com Checkland (1979), os desenvolvimentos sistêmicos podem ser separados em uma taxonomia considerando em um primeiro momento, o desenvolvimento teórico do pensamento sistêmico (cibernética) e o desenvolvimento das aplicações em outras áreas ou disciplinas (biologia, geografia, economia e psicologia). A partir dessa classificação o autor sugere um segundo nível de refinamento, ou seja, o desenvolvimento teórico puro (Teoria Geral dos Sistemas) e o desenvolvimento teórico a partir da aplicação a problemas do mundo real (Engenharia de Sistemas, Análise de Sistemas da RAND Corporation e Metodologia de Sistema Soft - SSM). O Quadro 4 ilustra a taxonomia proposta por Checkland.

Uma segunda taxonomia é proposta por Troncale (1988) que agrupa as ciências sistêmicas em quatro domínios: a) Teorias sistêmicas gerais - que consistem na construção de modelos genéricos, b) Teorias sistêmicas baseadas em disciplinas que consistem na construção de modelos teóricos sistêmicos através da "unificação de medidas reducionistas e modelos analíticos dentro de uma área limitada”; c) 
Análise de sistemas - que consiste na "construção de modelos empíricos de interações que estão firmemente acoplados a um sistema real singular humano ou não";d) Aplicações sistêmicas - que "buscam resolver e melhorar, ou redefinir um problema de um nível sistêmico particular em um sistema humano particular".

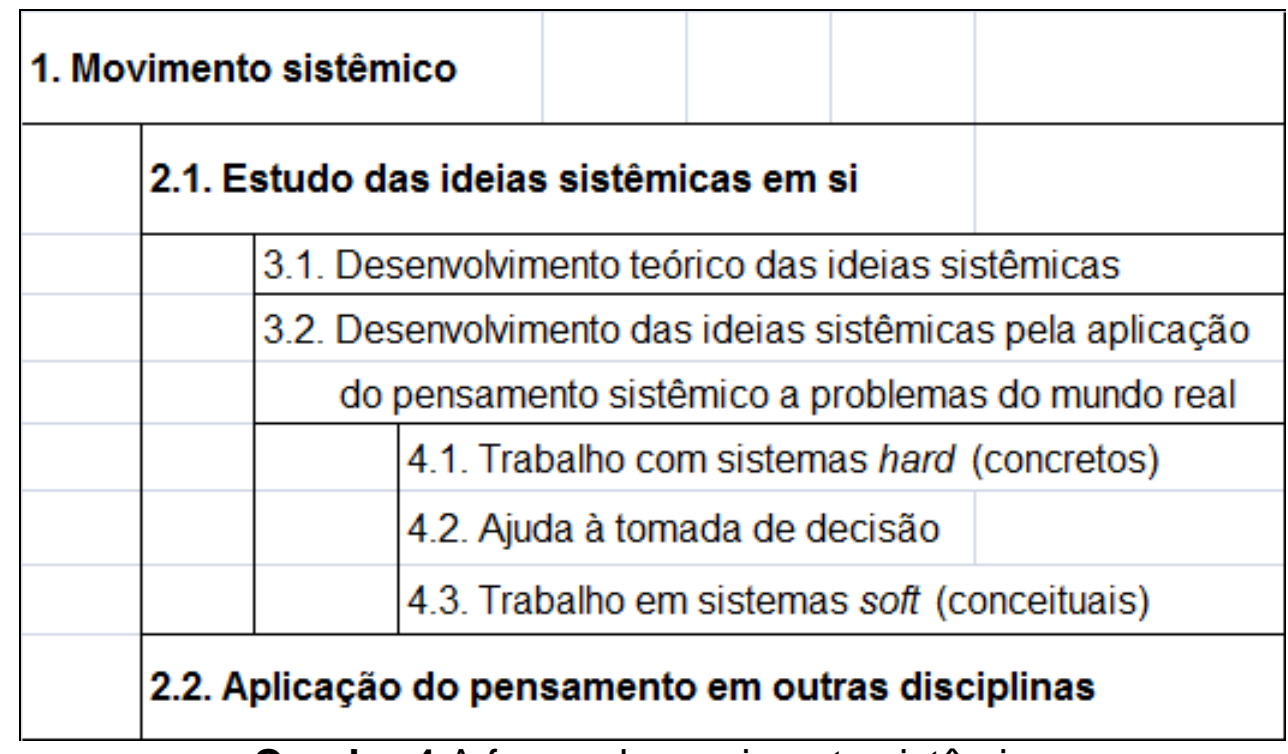

Quadro 4 A forma do movimento sistêmico

Fonte: Checkland (1983)

A diferença entre a taxonomia de Checkland (1979) e a de Troncale (1988) é que esta última separa a aplicação das concepções sistêmicas a problemas práticos do mundo real em duas categorias - análise de sistemas e aplicações sistêmicas, entretanto, excetuando-se esta questão, são similares.

A abordagem proposta por Flood \& Carlson (1988) para visualizar o processo de desenvolvimento do pensamento sistêmico foi um modelo dinâmico. Para os autores, o pensamento sistêmico pode ser descrito como um processo de quatro ciclos interligados que correspondem ao trabalho sistêmico nos níveis teórico e metodológico, em abordagens de resolução de problemas e de aplicação ao conteúdo de outras disciplinas, conforme pode ser visualizado na Figura 5. O primeiro ciclo promove o pensamento sistêmico por meio da sua formalização em teoria sistêmica. O segundo ciclo promove o pensamento sistêmico por meio da formulação de teorias sistêmicas para explanar a estrutura e o comportamento em outras disciplinas. O terceiro ciclo promove a eficiência administrativa em outras disciplinas via aplicação do pensamento sistêmico. O quarto e último ciclo promove o pensamento sistêmico, melhorando o gerenciamento de problemas, via aplicação das concepções sistêmicas. 
Considerando as três proposições anteriores, observa-se que as diversas formas de aplicações das concepções sistêmicas envolvem dois tipos de desenvolvimentos inter-relacionados e complementares: a) Formulações de modelos e abordagens sistêmicas aplicadas a fenômenos e situações complexas identificadas na realidade (como construção de teorias e modelos de inúmeros conteúdos disciplinares ou como fundamentação de metodologias de análise, resolução e estruturação de situações complexas) e b) Do desenvolvimento de concepções sistêmicas gerais como um novo quadro de referência intelectual. Esse desenvolvimento consiste na sedimentação de um conjunto de princípios e noções gerais que conformam uma nova concepção ou linguagem descritiva da realidade.

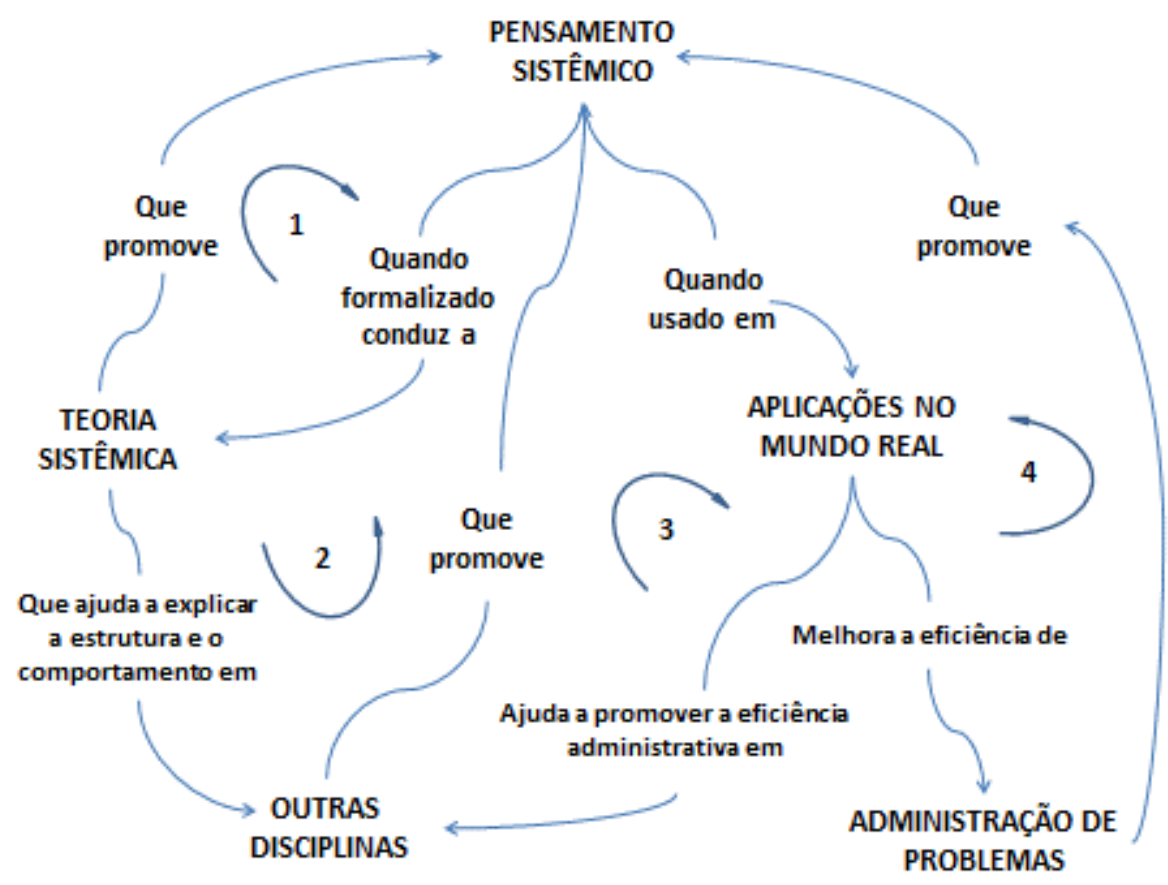

Figura 5 Quatro ciclos do desenvolvimento do PS Fonte: Flood \& Carlson (1988)

\subsubsection{TÓPICOS DE INVESTIGAÇÃO DAS ABORDAGENS}

As diferentes abordagens sistêmicas podem ser classificadas em torno de três tópicos centrais: a) Concepções sistêmicas gerais:-. referem-se às doutrinas básicas do pensamento sistêmico, que contemplam as suposições acerca da natureza da realidade, bem como às noções conceituais que tornam possível aplicar essas doutrinas a diferentes conteúdos; b) Concepções voltadas aos temas de interesse da abordagem:- consistem na distinção das concepções específicas que estão na origem do modelo, abordagem ou metodologia particular e c) 


\section{Pressupostos acerca da natureza do conhecimento e das interações:-.} consistem na distinção dos pressupostos assumidos quanto ao caráter do conhecimento obtido com a abordagem sistêmica e quanto à natureza das interações que conformam essa realidade, em especial quando se trata de contextos sociais.

As abordagens sistêmicas fundamentais são aquelas que estão na origem do movimento sistêmico. Entre as abordagens que se enquadram nessas características estão: a) Teoria Geral dos Sistemas - TGS, na perspectiva de Bertalanffy (1975); b) Cibernética I, que contempla a contribuição de Wiener (1970; 1984); c) Cibernética II, que contempla as concepções de Maruyama (1963); d) Cibernética III, que trata da contribuição fundamental de Ashby (1979) e f) Dinâmica de Sistemas que trata do modelo de Forrester $(1961,1990)$.

Embora as concepções iniciais da Dinâmica de Sistemas tenham sido formuladas para aplicação a corporações industriais, a sua inclusão entre as abordagens sistêmicas básicas deve-se às concepções básicas que contempla e à influência que exerce sobre toda uma tendência de desenvolvimento do pensamento sistêmico. As abordagens sistêmicas aplicadas a conteúdos científicos específicos comprovam a relevância do pensamento sistêmico como quadro de referência para o desenvolvimento do conhecimento em geral. Os modelos que representam essas abordagens são: a) A teoria das estruturas dissipativas; b) O estudo do caos determinístico e c) A teoria da autopoiese.

Essas abordagens são relevantes no que se refere a formulações que elas contemplam para as ciências contemporâneas e pela sua relação com as abordagens sistêmicas básicas: a teoria das estruturas dissipativas amplia a compreensão da natureza dos processos internos em sistemas físicos abertos; o caos determinístico contempla preocupações similares às da Dinâmica de Sistemas, quanto ao comportamento dinâmico de sistemas complexos; a teoria da autopoiese é um desdobramento das concepções cibernéticas, aplicadas à explicação do fenômeno vivo e do processo cognitivo.

As abordagens sistêmicas aplicadas a organizações consistem na aplicação das ideias sistêmicas, na forma de modelos teóricos e metodologias, ao tratamento de questões problemáticas e ao gerenciamento de organizações. são elas: a) As abordagens "clássicas" das ciências da administração; b) As organizações como 
sistemas abertos; c) O Modelo do Sistema Viável; d) A abordagem para organizações sociais de Russel Ackoff; e) A Metodologia de Sistemas Soft - SSM; f) O pensamento sistêmico e aprendizagem organizacional e g) As abordagens sistêmicas críticas das ciências da administração.

\subsubsection{AS ABORDAGENS SISTÊMICAS APLICADAS A ORGANIZAÇÕES}

Neste item são examinadas as abordagens que contemplam aplicações das concepções sistêmicas a questões e problemas relacionados à administração de organizações. A abordagem clássica da ciência da administração, bem como as abordagens mais recentes, organizações como sistemas abertos, Modelo do Sistema Viável, abordagem para organizações de Russel Ackoff e abordagens sistêmicas críticas, não serão tratadas nesta pesquisa. Nela serão tratadas as abordagens Metodologia de Sistemas Soft - SSM e o pensamento sistêmico e aprendizagem organizacional que foram consideradas adequadas ao tratamento do problema de pesquisa.

\subsubsection{A Metodologia de Sistemas Soft - SSM}

A Metodologia de Sistema Soft - SSM foi desenvolvida na Universidade de Lancaster, durante os anos setenta, por uma equipe coordenada pelo engenheiro Peter Checkland. Seu objeto é a intervenção em situações em que predominam atividades humanas propositais. O termo Soft denota que se trata de uma metodologia direcionada a uma variedade de problemas relacionados à administração de organizações sociais, onde predomina o fator humano como componente ativo no contexto (CHECKLAND, 1981). Trata-se de situações caracterizadas pela difícil definição de objetivos e nas quais as medidas de performance possíveis, na maioria das vezes, são de natureza qualitativa e as decisões envolvem um elevado grau de incerteza. A formulação dessa metodologia ocorreu como resultado da experiência com a tentativa de aplicação da Engenharia de Sistemas a situações-problema em que o fator humano era o elemento central. Checkland e sua equipe concluíram pela inadequação dos pressupostos, bem como pela insuficiência das técnicas e ferramentas das abordagens clássicas das ciências da administração para lidar com a ambiguidade dos contextos sociais em organizações. Assim, a nova metodologia desenvolvida com o objetivo de torná-la 
adequada à intervenção em sistemas de atividades humanas, foi radicalmente modificada em relação à Engenharia de Sistemas.

Checkland (1981) parte da constatação de que, diferentemente do que pressupõem as abordagens tradicionais das ciências da administração, na maioria das situações problemáticas do mundo real os objetivos e os meios de alcançar uma solução não estão dados. A definição dos objetivos é na maioria das vezes a parte essencial do problema a ser enfrentado. Isso se deve ao fato de que, em situações onde prepondera a atividade humana, sempre existem outras possibilidades de interpretação de uma mesma situação ou fenômeno. Muito frequentemente tentativas de melhorar uma situação requerem a busca da acomodação de pontos de vista distintos (ou mesmo conflitantes) quanto aos objetivos a serem alcançados (CHECKLAND, 1994). A posição geral adotada na SSM é a de que "problemas são endêmicos nas coisas humanas" e "não podem ser resolvidos de uma vez por todas", requerendo uma abordagem "orientada para processo ao invés de uma abordagem técnica" (CHECKLAND, 1988a). Quatro ideias centrais conformam o núcleo das concepções específicas da SSM: a) O conceito de sistema de atividades humanas; b) O lugar central da visão de mundo dos envolvidos na definição de uma situação; c) A concepção da metodologia como um processo de aprendizagem contínua e d) Os modelos de sistemas de atividades humanas como suporte a sistemas de informação. A seguir serão examinadas as três primeiras ideias. A quarta não será examinada, pois foge do escopo do presente trabalho.

Checkland (1981) desenvolveu o conceito de sistema de atividades humanas concebendo-o como um conjunto de atividades interligadas, conformando um todo, organizadas para o alcance de um propósito. Um sistema de atividades humanas distingue-se de outras classes de sistemas, como, por exemplo, dos sistemas naturais e dos sistemas físicos construídos pelo homem, pelo fato de que o primeiro poderia ser bem diferente do que é, em função da consciência humana e da possibilidade de diferentes escolhas que ela enseja (CHECKLAND,1981).

A segunda ideia central é a de que um modelo coerente de um sistema de atividades humanas somente pode ser construído se for declarada a visão de mundo que the dá significado (CHECKLAND 1994). A SSM admite que vários modelos sistêmicos, todos igualmente válidos, podem ser úteis na descrição de uma situação. As distintas interpretações consideradas relevantes, descritas em modelos 
conceituais, devem ser examinadas na busca de ações de melhoria. Em qualquer situação, as ações no mundo real são muito mais complexas do que as atividades estruturadas descritas nos modelos.

A ideia anterior conduz à terceira: a principal atividade da SSM é a aquisição de conhecimentos, via processo de aprendizagem contínua, para melhorar situações humanas problemáticas. A lógica da SSM consiste na implementação de um processo cíclico de aprendizagem, segundo o modelo geral da pesquisa-ação (KREHER, 1995). Esse modo de investigação faz interagir teoria e prática (CHECKLAND, 1981) e está estreitamente ligado ao exame dos pressupostos que são muitas vezes assumidos como dados (KREHER, 1995).

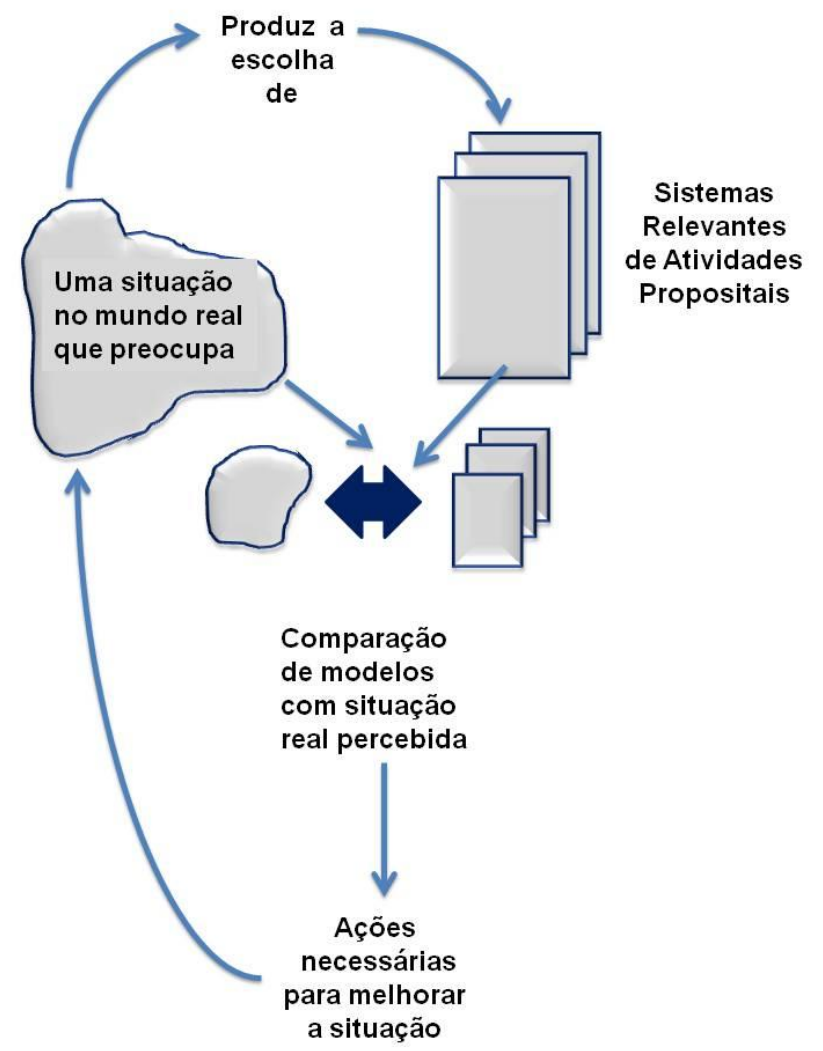

Figura 6 A lógica central da SSM

Fonte: Checkland \& Scholes (1990)

De um modo geral, conforme mostra a Figura 6, a abordagem consiste em formular alguns modelos relevantes sobre a situação investigada, confrontando-os com as percepções do mundo real. A comparação deve servir para estimular o debate entre os envolvidos na estruturação da situação-problema. Seu objetivo é conduzir a 
decisões sobre ações para melhorar a parte da realidade que está sendo examinada (CHECKLAND \& SCHOLES, 1990).

Para Checkland (1981) a SSM não é, entretanto, somente um sistema de aprendizagem da situação-problema. É também um processo de aprendizagem da própria metodologia. O processo cíclico das fases da metodologia além de gerar novas ideias sobre a situação específica contribui para o desenvolvimento das concepções sistêmicas e para o aprimoramento da abordagem. Checkland \& Scholes (1990) apontam o segundo aspecto - a sistemicidade do processo de investigação (o ciclo) - como o mais importante dentro da metodologia.

O domínio de aplicação da SSM é o mundo real (KREHER, 1995). O termo "mundo real" entretanto nada tem a ver com o realismo da ciência tradicional. Serve para distinguir as situações sociais problemáticas, onde predominam atividades humanas inter-relacionadas, do mundo artificial do laboratório, onde o pesquisador controla os procedimentos e influencia decisivamente os resultados (CHECKLAND, 1981). Em contraste com o mundo artificial do laboratório o "mundo real" envolve a complexidade das interações do cotidiano, onde existem incertezas quanto às metas e aos objetivos (CHECKLAND, 1981). São situações em que aspectos particulares, como percepções de valores e interesses de indivíduos e grupos, escapam do controle predeterminado do pesquisador (KREHER, 1995). Melhorias e mudanças não somente envolvem alterações nos procedimentos e em estados físicos, mas também, mudanças nas formas de percepção dos envolvidos na situação. 0 observador humano, como participante ativo no contexto, seja como ator, seja como investigador, pode alterar a lógica da situação ao mudar sua própria relação com a mesma (CHECKLAND, 1981). Assim, para a SSM, a complexidade não é algo preexistente num mundo independente do observador. Modelos conceituais que descrevem o mundo real, as relações e os componentes de um sistema de atividades humanas, são informados pela visão de mundo de quem descreve a situação.

Checkland (1988a) justifica a utilidade das ideias sistêmicas em função de que a experiência no 'mundo real' sugere que o mesmo é densamente conectado. Tanto a manutenção da estabilidade como as mudanças são vistas como problemáticas, tendo as ideias sistêmicas potencial para lidar com ambas as situações (CHECKLAND, 1988a). A metáfora que descreve a imagem sistêmica básica da 
SSM é a ideia de que o conceito de sistema descreve uma entidade total, que exibe propriedades emergentes, é estruturada em níveis hierárquicos e pode se adaptar a ambientes em mudança em função de processos de comunicação e controle. Checkland \& Scholes (1990) e Checkland (1994) identifica dois modos de utilização das concepções sistêmicas na SSM: a) Na metodologia como processo sistêmico de investigação e aprendizagem e b) $\mathrm{Na}$ construção de modelos sistêmicos de atividades humanas propositais.

$\mathrm{Na}$ primeira forma a sistemicidade aparece associada ao processo cíclico das sete fases da metodologia, apresentadas na Figura 7: a) Fase 1 - identificação de uma situação problemática no mundo real; b) Fase 2 - verbalização ou descrição da situação; c) Fase 3 - seleção de alguns sistemas de atividades humanas relevantes; d) Fase 4 - formalização em modelos conceituais; e) Fase 5 - uso dos modelos para questionar a situação do mundo real; f) Fase 6 - avaliação das mudanças culturalmente possíveis e sistemicamente desejáveis e g) Fase 7 - implementação das ações para tentar melhorar a situação-problema original. A realização de novas ações por si só irá mudar a situação, requerendo que um novo ciclo se reinicie (CHECKLAND \& SCHOLES, 1990).

A segunda forma de uso das concepções sistêmicas é na construção dos modelos conceituais de sistemas de atividades humanas (SAH). Esses modelos são construídos com base em atividades consideradas relevantes para a investigação da situação-problema (fase 4). Eles descrevem diferentes visões de mundo e servem para estruturar o debate participativo sobre ações para melhorar a situaçãoproblema (CHECKLAND, 1994). Modelos de sistemas de atividades humanas consistem de atividades estruturadas ou ligadas logicamente para realizar um propósito (CHECKLAND, 1994). Eles envolvem um subsistema de monitoramento e controle que possibilita ao sistema adaptar-se. Operacionalmente, cada atividade é vista como um processo de transformação efetivado pela ação humana. Sua descrição depende da percepção particular de cada ator envolvido.

Os modelos conceituais de Sistemas de Atividades Humanas (SAH), representados na Figura 8 estão fundados nas noções constitutivas gerais do conceito de sistema que, de acordo com a concepção de Checkland (1981), são emergência, hierarquia e processos de comunicação e controle. Checkland (1981) entende que, independentemente da forma particular assumida por um nível hierárquico, a 
organização do conjunto de elementos num nível pode ser vista como a imposição de restrições ao grau de liberdade dos elementos neste nível, o que torna possível a ocorrência de atividade significativa no nível superior. Ou seja, implica a existência de mecanismos de comunicação e controle operando entre níveis, que efetuam as restrições entre eles.

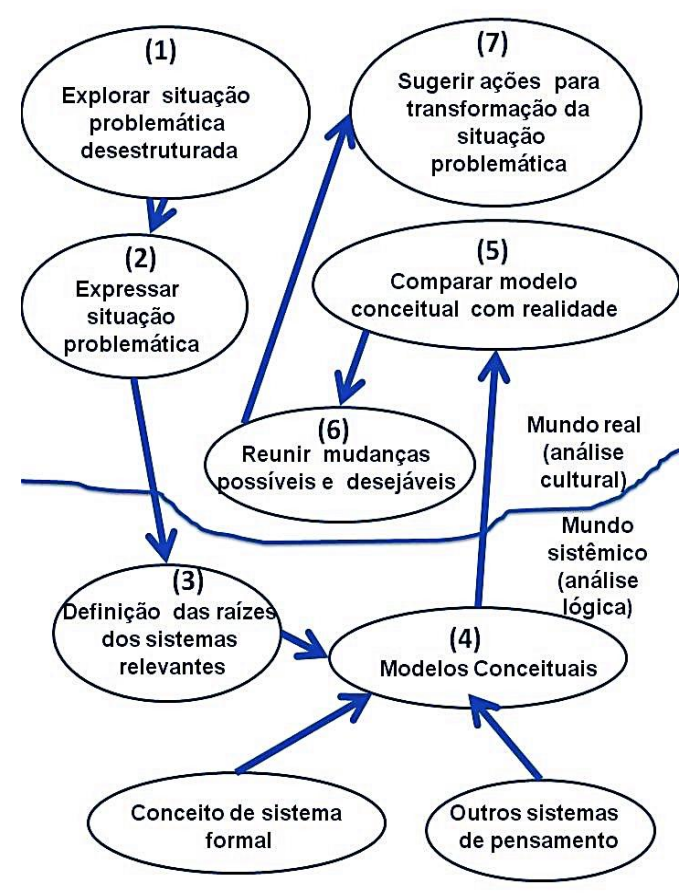

Figura 7 As fases da SSM Fonte: Checkland (1981)

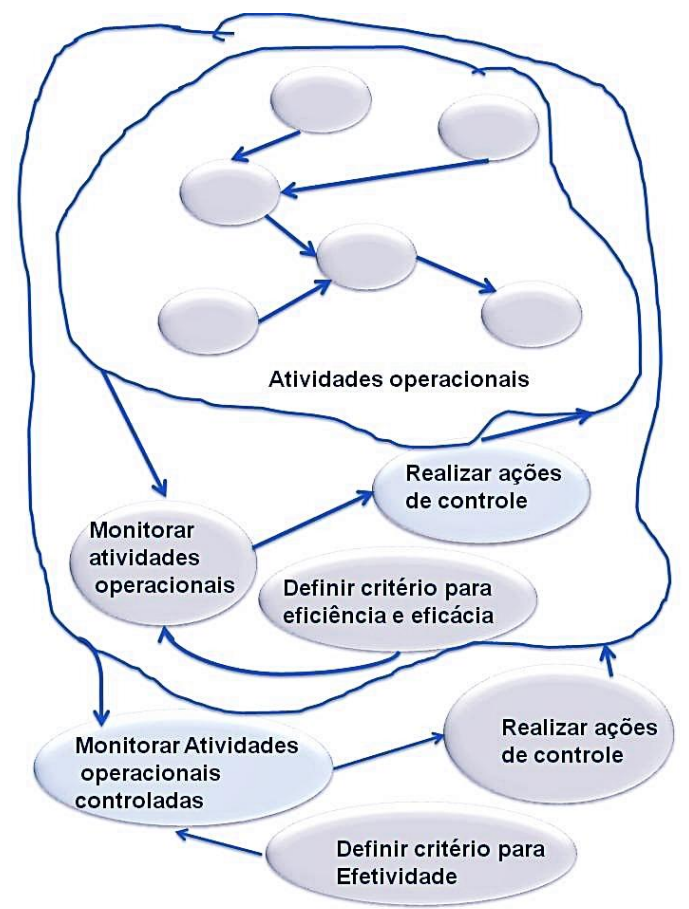

Figura 8 Modelo genérico de um SAH Fonte: Checkland (1989)

$\mathrm{Na}$ SSM, as noções constitutivas do conceito de sistema não são concebidas como entidades ontológicas representativas de entidades ou fenômenos que existem no mundo real. Elas são vistas como elementos de uma linguagem ou epistemologia (CHECKLAND, 1994). Como dispositivos epistemológicos ou intelectuais, sua utilidade está em contribuir para o aumento do entendimento sobre uma situação e para definir ações para melhorá-la. A principal implicação dessa posição é que a percepção da realidade é relativa à visão de mundo e à linguagem descritiva do observador. Segundo essa perspectiva, também conhecida como interpretativa, a problemática do mundo real caracteriza-se por envolver incertezas na definição de metas e objetivos globais, múltiplos valores e interesses, que conduzem a distintos julgamentos numa mesma situação problemática, e a influência de aspectos históricos na geração e na alteração da percepção. Consequentemente, uma vez sendo o observador um partícipe ativo da situação-problema, existem muitas 
possibilidades de interpretação da mesma. Embora os modelos sistêmicos da SSM não sejam entidades que representam um mundo objetivamente dado, isso não significa, entretanto, a negação de uma realidade ontológica da qual seres humanos são parte. Checkland \& Scholes (1990) deixam isso claro quando estabelecem como componentes básicos da epistemologia da SSM as noções de "mundo real" e de "mundo do pensamento sistêmico", para distinguir os dois mundos em que os homens vivem como observadores: "Mundo real: o desdobramento do fluxo interativo de eventos e ideias que experimentamos como vida cotidiana" e "Mundo do pensamento sistêmico: o mundo no qual a reflexão consciente sobre o 'mundo real', usando ideias sistêmicas, tem lugar" (CHECKLAND \& SCHOLES, 1990, p. 288). Assim, existe uma demarcação entre a SSM e as abordagens sistêmicas hard das ciências da administração. O pensamento sistêmico hard vê sistemas existindo ontologicamente. Ou seja, o sistema é tido como algo que corresponde a uma entidade objetiva e que pode ser manipulado pelo engenheiro ou administrador. $\mathrm{Na}$ SSM, o sistema é parte de um dispositivo epistemológico, sendo útil por tornar possível investigar alguns dos problemas da realidade. O Quadro 5 reproduz o sumário apresentado por Kreher (1995) sobre as diferenças de linguagens, em função das distintas epistemologias, que fundamentam respectivamente a abordagem da SSM e as abordagens tradicionais (hard) da administração.

\begin{tabular}{|c|c|}
\hline HARD & SOFT \\
\hline Bem definido/estruturado & Mal definido/não estruturado \\
Problema & Situação-problema \\
Objetivo & Problemático \\
Maximização/otimização & Aprendizagem/dar sentido \\
Projeto de gerenciamento & Projeto de investigação \\
Engenharia de um sistema & Sistema como dispositivo epistemológico \\
\hline
\end{tabular}

Quadro 5 Diferenças entre as abordagens hard e soft

Fonte: Kreher (1995)

\subsubsection{Pensamento sistêmico e aprendizagem organizacional}

Os desenvolvimentos mais recentes no campo das ciências da administração enfatizam uma nova visão do processo de modelagem. O papel dos modelos e da modelagem na nova perspectiva é o de capturar conhecimentos e apoiar a aprendizagem, como auxílio à tomada de decisão. Modelos, ao invés de serem 
utilizados para fazer previsões sobre o futuro, devem servir como instrumentos de apoio para que os próprios administradores aprendam as consequências do seu modo de enxergar a realidade (MORECROFT e STERMAN, 1994). Nesta nova visão, muda também o lugar do especialista. Este passa a ter o papel de facilitador da aprendizagem em equipes, ao invés de projetista de modelos que desconsidera o ponto de vista dos atores que influenciam a dinâmica da organização. O modelo sistêmico de aprendizagem organizacional formulado por Senge (1990) é um dos desenvolvimentos que se enquadram na perspectiva anteriormente descrita. Esse modelo tem como fundamento principal a crença de que a melhoria do desempenho em organizações envolve a criação de ambientes para que as pessoas possam aprender continuamente a partir do que realizam e do que pensam de suas organizações. O núcleo da abordagem consiste na utilização do pensamento sistêmico como ferramenta (disciplina) para examinar e testar os "modelos mentais" de grupos e indivíduos chave para as decisões organizacionais e, para a aprendizagem individual e em equipe, e como meio para construir visões e objetivos comuns. Para Senge (1990), o pensamento sistêmico é a "pedra fundamental" para constituir uma nova mentalidade que torne possível construir organizações com capacidade de aprendizagem duradoura. A suposição básica de Senge (1990) é a de que o pensamento sistêmico, por ser um quadro de referência para construir entendimentos sobre as estruturas profundas da realidade, desencadeará mudanças na forma como os indivíduos e os grupos pensam e interagem dentro das organizações, alavancando o processo de aprendizagem e mudança.

Quanto às concepções sistêmicas Senge adota na sua abordagem os conceitos, princípios e técnicas de modelagem da Dinâmica de Sistemas. Enfatiza especialmente a modelagem sistêmica qualitativa, utilizando principalmente diagramas de influência causal, baseados nas noções de realimentação negativa e positiva. Diagramas de estoque e fluxo e simulação computacional, na forma concebida pela Dinâmica de Sistemas (software Ithink) ${ }^{9}$ (CHECKLAND e SCHOLE, 1999) são utilizados como ferramentas auxiliares no teste de hipóteses e na aprendizagem iterativa das equipes. Para constituir uma organização para a

\footnotetext{
${ }^{9}$ Para simulação de sistemas complexos o modelo de aprendizagem de Senge utiliza o software de modelagem Ithink, versão contemporânea e aperfeiçoada do modelo de simulação da Dinâmica de Sistemas desenvolvido originalmente por Jay Forrester. Disponível em: http://goo.gl/xyNAS
} 
aprendizagem Senge (1990) defende que uma mudança profunda deve ser instituída nas estruturas subjacentes que comandam a lógica organizacional. Esse autor propõe a institucionalização da prática de cinco disciplinas - as cinco disciplinas da aprendizagem - para melhorar a forma como as pessoas pensam, se comunicam e tomam decisões nas organizações.

São as seguintes as disciplinas da aprendizagem organizacional : a) domínio pessoal: supõe que as pessoas só se engajam adequadamente nos objetivos coletivos se individualmente aprenderem a esclarecer e aprofundar seus objetivos pessoais; b) modelos mentais: promovem a abertura à aprendizagem ao permitir que as pessoas melhorem suas imagens da realidade, imagens estas que muitas vezes entram em choque com as tentativas de mudança nas organizações e as fazem fracassar; c) visão compartilhada: sugere que os indivíduos e grupos dentro da organização só se empenharão genuinamente se ajudarem a construir uma visão de futuro para a própria organização; d) aprendizagem em grupo: habilita formas melhores de comunicação que incrementam a capacidade e as habilidades coletivas das equipes e, por fim, e) pensamento sistêmico: a disciplina que integra as outras quatro, e que é a base para um novo tipo de pensamento dentro da organização (SENGE, 1990).

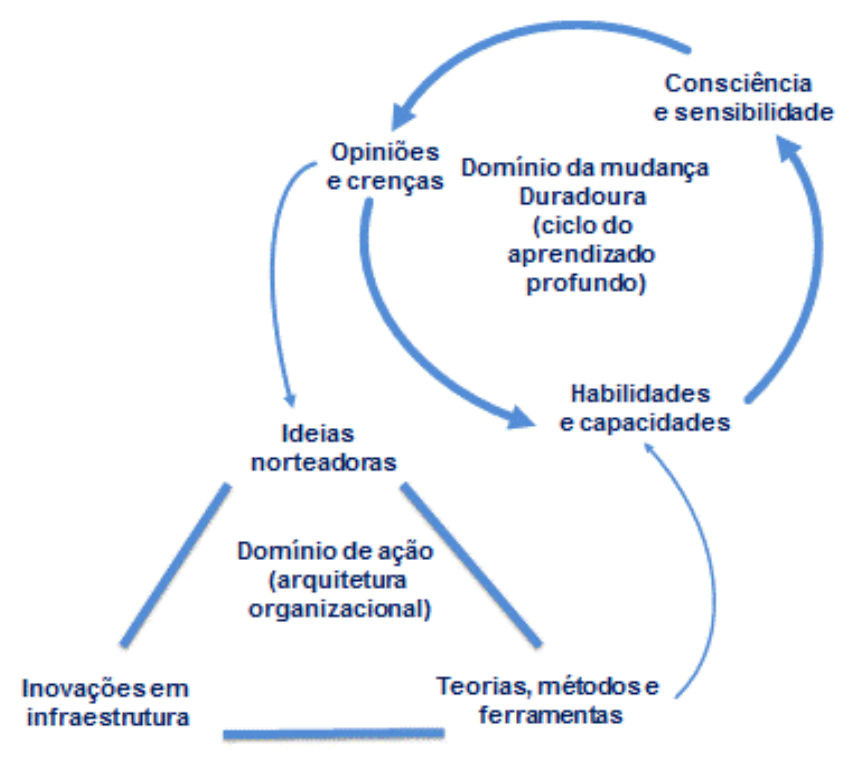

Figura 9 Padrão de organização sistêmico Fonte: Senge (1995)

Senge et al. (1995) formalizaram num modelo sistêmico seu modo de conceber a transformação de empresas em organizações para a aprendizagem. Conforme 
mostra a Figura 9 esse modelo envolve processos que ocorrem em dois domínios distintos, embora estreitamente inter-relacionados: o domínio da mudança duradoura ou ciclo da aprendizagem profunda representado pelo círculo e, o domínio da ação, a arquitetura organizacional, representado pelo triângulo. A origem das mudanças tem como causa central o círculo, que representa movimento contínuo e mudança. Entretanto, as mudanças devem se configurar no triângulo ou domínio da ação, introduzindo modificação na arquitetura organizacional. Os dois domínios, que se influenciam mutuamente, representam juntos, tanto as mudanças tangíveis como as mais sutis ou intangíveis (SENGE et al., 1995).

O ciclo de aprendizagem profunda envolve a aquisição de novas habilidades e capacidades pelas pessoas da organização. As habilidades e capacidades, as percepções e sensibilidades, e as opiniões e crenças de uma organização que aprende, segundo Senge (1990), derivam da institucionalização das cinco disciplinas da aprendizagem por ele propostas. Entretanto, embora a aprendizagem deva gerar mudanças ao nível dos aspectos intangíveis anteriormente mencionados, ela necessita ser concretizada numa arquitetura organizacional adequada - o molde no qual ocorrem as ações práticas. Para facilitar o uso do processo de pensamento sistêmico em organizações, Senge (1990) identificou e catalogou diversos arquétipos sistêmicos. Arquétipos sistêmicos são padrões sistêmicos que aparecem com frequência, tanto em fenômenos naturais como em contextos sociais. São também denominados de estruturas sistêmicas genéricas, de acordo com a linguagem da Dinâmica de Sistemas (LANE, 1998). A identificação de tais padrões teve por objetivo principal simplificar a comunicação e a compreensão dos modelos sistêmicos, especialmente para facilitar a utilização das ideias sistêmicas como uma nova linguagem e para a transmissão de informações em equipes gerenciais. A Figura 10 ilustra o arquétipo sistêmico Limite do Crescimento. No exemplo específico, serve como modelo de explicação para a estagnação das melhorias quando da implementação de um programa de qualidade. Esse arquétipo descreve um processo de crescimento exponencial que, num dado momento, é limitado por um enlace negativo que possui implícito um objetivo ou limite - a capacidade da organização de realizar melhorias nas condições dadas. Inicialmente, os recursos alocados para obtenção de melhorias na qualidade geram resultados animadores. 
Os resultados alcançados são o estímulo para o investimento em mais recursos para melhorias na qualidade.

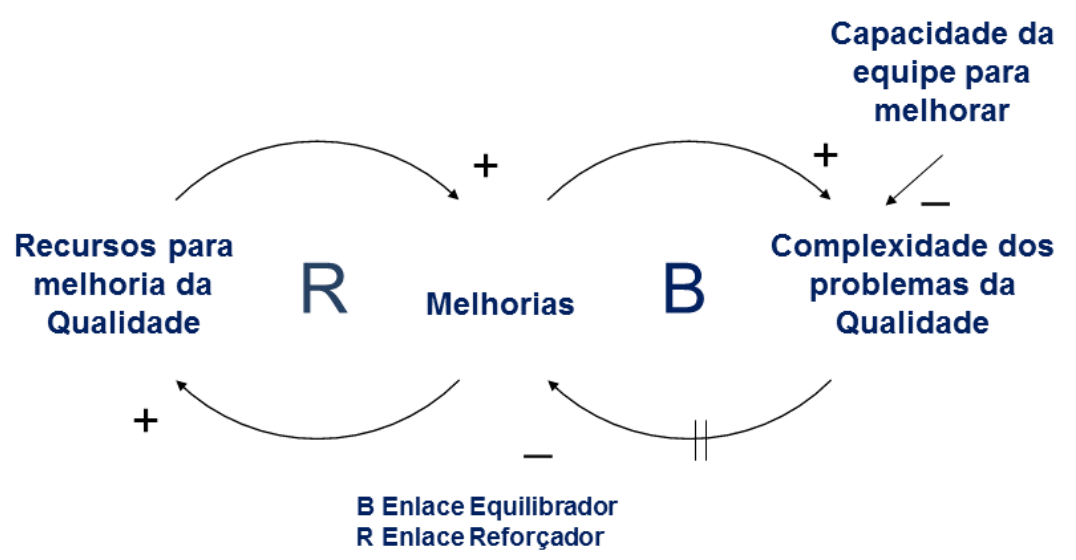

Figura 10 Arquétipo Limite do Crescimento Fonte:Senge (1995)

No entanto, as melhorias fáceis, obtidas no início da implementação do programa (a colheita dos frutos baixos), dão lugar à tentativa de resolver problemas mais complexos. Isso diminui o ritmo das melhorias. Na prática, o processo de crescimento passa a ser limitado pelos próprios limites da organização, em termos de capacitação, para resolver problemas mais complexos.

O exemplo da Figura 11 ilustra 0 arquétipo Transferência de Responsabilidade. Esse arquétipo refere-se a uma situação de crise em uma empresa em que o apelo a soluções heroicas substitui as soluções profundas duradouras. Diante da ameaça do não cumprimento de um prazo na entrega de um produto, uma grande flexibilidade é concedida aos gerentes ou responsáveis para tomarem as medidas que julgarem necessárias. Tudo vale em nome de fazer o produto sair a tempo e cumprir os prazos. Esse processo - que atua na correção do sintoma de um problema - é representado pelo enlace superior da Figura 11. Solucionada a crise momentânea, o responsável pela solução passa a ser visto como o herói da empresa. Outras soluções sugeridas por pessoas da organização, que atacam o problema num nível mais fundamental, como por exemplo, repensar o processo de gerência de projetos, examinar as barreiras decorrentes de regras e formalidades e avaliar os processos, recebem menos atenção, pois demandariam tempo para surtir efeito (as soluções fundamentais são representadas pelo enlace inferior na Figura 11. Assim, com o tempo, a prática do heroísmo como forma de enfrentar dificuldades gera como efeito colateral uma empresa viciada em heroísmo. A dependência da 
organização de soluções heroicas é reforçada, cada vez mais, pois o conjunto da organização passa a se comportar de acordo com o critério de recompensa implícito no estímulo às soluções heroicas.

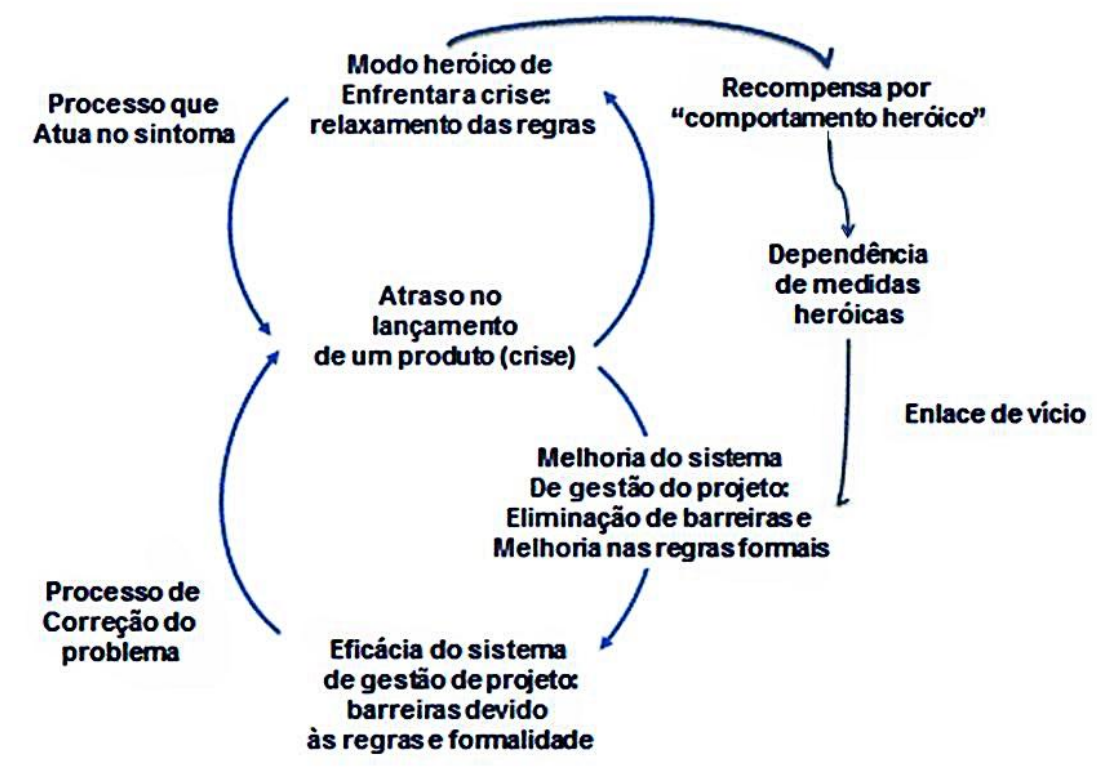

Figura 11 Arquétipo Transferência de Responsabilidade Fonte: Adaptado de Senge (1995)

Uma segunda contribuição importante do trabalho de Senge (1990) e Senge et al (1995), examinada por Andrade (1998), refere-se à caracterização dos distintos níveis em que podem ser descritas e compreendidas as situações complexas da realidade. Conforme mostra a Figura 12 , de acordo com Senge (1990), as situações ou fenômenos da realidade podem ser explicados em termos de quatro níveis distintos: eventos; padrões de comportamento; estrutura sistêmica e modelos mentais.

Eventos são os acontecimentos ou os fatos percebidos, que são visíveis, pelas pessoas. São exemplos de eventos: uma máquina com defeito, um acidente, um relatório que é escrito, as ações da empresa que caem, entre outros. Em geral é com base em eventos isolados que as pessoas explicam situações e tomam suas decisões.

Padrões de comportamento resultam da percepção de que uma situação não é o resultado de eventos esporádicos e desconexos. Eventos, quando examinados ao longo do tempo, podem revelar padrões de comportamento recorrentes ou 
tendências de longo prazo. A identificação de padrões recorrentes muitas vezes indica pistas valiosas que ajudam a melhorar a compreensão do comportamento futuro de um fenômeno.

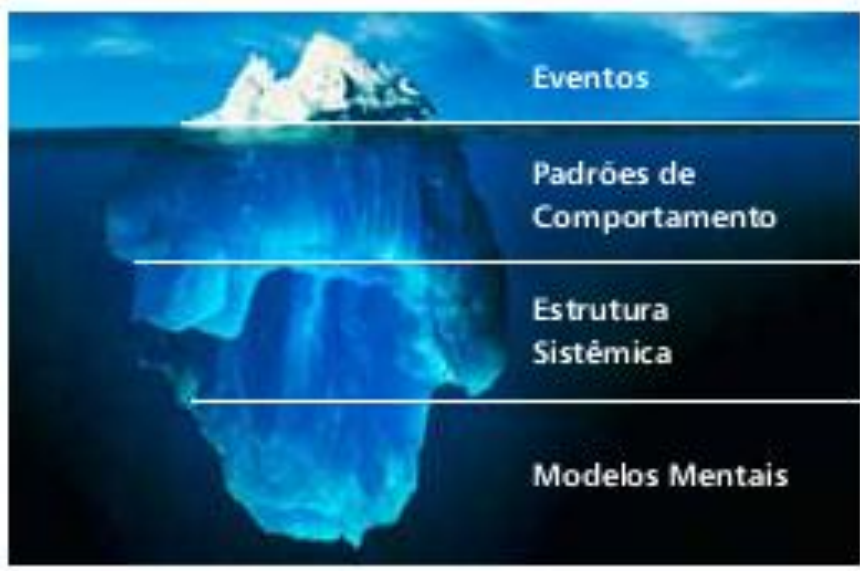

Figura 12 Níveis do pensamento sistêmico Fonte: Andrade et al (1998)

A estrutura sistêmica pode ser vista como a geradora de eventos e padrões de comportamento. Segundo Senge (1990), a importância das explicações estruturais está no fato de elas referirem-se a padrões de interconexões através dos quais são explicados como os comportamentos observados são gerados.

Modelos mentais geram o modo como a realidade é concebida. Segundo Senge (1990) e Senge et al (1995), quando se trata de sistemas sociais, sua criação ou mudança é o produto do modo como as pessoas pensam e interagem. Situações não desejadas em organizações, igualmente, são geradas pelos "modelos mentais" de indivíduos e grupos. Estes, por meio das suas ações, criam as estruturas sistêmicas da realidade. Assim, mudar uma determinada situação implica mudar a forma como as pessoas pensam e interagem. Desse modo, serão alterados os "modelos mentais" que possuem sobre uma situação, tornando possível ações que mudem as estruturas sistêmicas que geram o comportamento não desejado.

A partir da visualização da realidade por meio dos níveis anteriormente apresentados e a partir da experiência com a modelagem do comportamento de sistemas complexos, Senge (1990) apontou três princípios sistêmicos centrais que devem ser observados, especialmente, quando se trata de sistemas humanos. a) a estrutura influencia o comportamento:-. Em sistemas complexos, pessoas diferentes, quando imersas no mesmo padrão de interações, tendem a produzir 
resultados qualitativamente semelhantes; b) Em sistemas complexos existem ações potenciais de alavancagem:- Pontos de alavancagem são pontos em que pequenas mudanças podem gerar efeitos significativos. Esses pontos, quando se trata de sistemas humanos, não são acionados ou são ignorados, pois as pessoas habitualmente são treinadas para se concentrar nas suas próprias ações e ignoram como os fatores se inter-relacionam para gerar os comportamentos e c) Resistência à mudança de políticas:- Uma vez que é a estrutura de interações mais fundamental que controla o comportamento e na medida em que em sistemas humanos as políticas operacionais integram a estrutura, qualquer tentativa de mudança que não altere substancialmente os fatores relevantes na determinação do comportamento do sistema (que integram a estrutura sistêmica), tenderá a ser contrabalançada e anulada pelo sistema.

Senge (1990) distancia-se do positivismo científico da ciência clássica. O "realismo ingênuo", como denominou a perspectiva dominante na ciência é, segundo o autor:

"[...] a visão de mundo que sustenta posições rígidas como a primazia das partes e a natureza isolada do eu. [...] toma a realidade como uma entidade dada fora da nossa percepção e vê a linguagem como a ferramenta através da qual descrevemos essa realidade externa [...]." (SENGE et al, 1995).

Em oposição, a essa visão, Senge (1995) parte do pressuposto de que a linguagem modela a percepção e o pensamento. Segundo essa perspectiva, o que é descrito como um objeto da realidade não é uma entidade independente e objetivamente dada. As pessoas percebem o mundo por meio da sua articulação na linguagem. Quer dizer, através da linguagem os homens participam ativamente da configuração do mundo que descrevem (SENGE et al, 1995). O autor se utiliza de Heisenberg, o formulador do princípio da incerteza da física quântica, segundo o qual, jamais se terá um meio efetivo de saber o que é o "lá fora". O não reconhecimento disso, segundo Senge et al (1995), é um obstáculo efetivo à busca de formas alternativas de ação:

"Quando esquecemos o poder generativo da linguagem, rapidamente confundimos nossos mapas do território. Desenvolvemos um nível de certeza que nos rouba a capacidade de indagar, que reprime nossa capacidade de admitir novas interpretações e novas possibilidades de ação. Tais são as raízes de sistemas de crenças que se tornam rígidos, arraigados e finalmente auto protetores" (SENGE et al, 1995). 
Para Senge (1990), o pensamento sistêmico é uma nova linguagem que rompe com o "pensamento linear". Este último é um obstáculo que limita ou impede a percepção de situações que envolve complexidade. Como uma nova linguagem, o pensamento sistêmico modela uma nova forma de pensamento, que torna possíveis processos mentais mais efetivos, elevando o potencial das pessoas de entender e interagir com a realidade. Modelos sistêmicos, segundo essa visão, não têm a função de fazer previsões sobre o mundo percebido. Servem basicamente para aprender sobre os modelos mentais que os atores têm da realidade e construir micro mundos, modelos como laboratórios de aprendizagem, sobre as situações típicas percebidas em organizações, visando melhorar as decisões sem colocar em risco a empresa.

O Quadro 6 apresenta uma compilação da revisão bibliográfica efetuada para o operador cognitivo Pensamento Sistêmico.

\begin{tabular}{|l|l|l|}
\hline Autores & Ano & Contribuição Teórica \\
\hline HOSS & 2011 & $\begin{array}{l}\text { Apresenta a SSM como um processo de aprendizagem } \\
\text { atuando em uma situação problemática no processo de } \\
\text { estruturação da transformação de uma empresa. }\end{array}$ \\
\hline ANDRADE & 2006 & $\begin{array}{l}\text { Publicação sobre SSM e pensamento sistêmico apresentada } \\
\text { na forma de caderno de campo. }\end{array}$ \\
\hline KASPER & 2000 & $\begin{array}{l}\text { Fundamentos básicos, princípios doutrinários noções, } \\
\text { conceitos gerais e concepções específicas e outros aspectos } \\
\text { do processo de pensamento sistêmico, como quadro de } \\
\text { referência conceitual para a abordagem de questões e } \\
\text { problemas complexos. }\end{array}$ \\
\hline MORIN & 1997 & $\begin{array}{l}\text { Discute o conceito de sistema sob o ponto de vista } \\
\text { epistemológico como noção básica de um novo paradigma de } \\
\text { pensamento que dominou o pensamento complexo. }\end{array}$ \\
\hline CAPRA & 1996 & $\begin{array}{l}\text { Apresenta o pensamento sistêmico em termos de contexto e } \\
\text { em termos de padrões de interação dentro de padrões } \\
\text { maiores de interação. Apresenta os conceitos de pensamento } \\
\text { contextual e processual. }\end{array}$ \\
\hline SENGE & 1995, & $\begin{array}{l}\text { Descreve o método sistêmico como um conjunto de passos } \\
\text { sistematizados que leva aplicação do Pensamento Sistêmico } \\
\text { de forma organizada, de modo que cada passo termina com }\end{array}$ \\
\hline
\end{tabular}




\begin{tabular}{|c|c|c|}
\hline Autores & Ano & Contribuição Teórica \\
\hline & & $\begin{array}{l}\text { resultados que servem como entradas nos passos } \\
\text { subsequentes. Com a evolução do processo, aprofunda-se a } \\
\text { aprendizagem sobre uma situação de interesse. Com o } \\
\text { método, mantém-se a direção nos objetivos intermediários e } \\
\text { finais e alcança-se uma aprendizagem dos desafios aos } \\
\text { modelos mentais. Apresenta o pensamento sistêmico como } \\
\text { uma estrutura conceitual, um conjunto de conhecimentos e } \\
\text { instrumentos desenvolvido com o objetivo de tornar mais claro } \\
\text { o conjunto e apontar as modificações a serem feitas para } \\
\text { melhorá-lo. }\end{array}$ \\
\hline CARLSON & 1988 & $\begin{array}{l}\text { Apresenta o pensamento sistêmico como uma nova estrutura } \\
\text { de pensamento para lidar com a complexidade }\end{array}$ \\
\hline $\begin{array}{l}\text { FLOOD\& } \\
\text { CARLSON }\end{array}$ & 1988 & $\begin{array}{l}\text { Apresentam um modelo dinâmico para visualizar o processo } \\
\text { de desenvolvimento do pensamento sistêmico, composto por } \\
\text { quatro ciclos interligados que correspondem ao trabalho } \\
\text { sistêmico nos níveis teórico e metodológico, em abordagens } \\
\text { de resolução de problemas e em aplicação de conteúdo de } \\
\text { outras disciplinas. }\end{array}$ \\
\hline CAPRA & 1982 & $\begin{array}{l}\text { Obra seminal de Capra lança as primeiras ideias sobre a } \\
\text { síntese do movimento sistêmico na ciência, tecnologia e } \\
\text { sociedade. O livro é composto de duas partes: a visão } \\
\text { mecanicista e a visão sistêmica de áreas importantes do } \\
\text { conhecimento humano. }\end{array}$ \\
\hline CHECKLAND & $\begin{array}{l}1981 a \\
1981 b\end{array}$ & $\begin{array}{l}\text { Apresenta a SSM desenvolvida por Peter Checkland, com o } \\
\text { intuito de tentar resolver problemas em empresas, de maneira } \\
\text { sistêmica e em situações onde eles se mostravam pouco } \\
\text { estruturados ou mesmo obscuros. Segundo Checkland a } \\
\text { SSM é um processo baseado em modelos sistêmicos, que } \\
\text { leva à escolha de uma ação propositada. Apresenta a busca } \\
\text { do desenvolvimento de uma epistemologia para descrever a } \\
\text { realidade e elucidar alguns de seus problemas. }\end{array}$ \\
\hline ACROFF & 1981 & Apresenta o pensamento sistêmico como um processo de \\
\hline
\end{tabular}




\begin{tabular}{|c|c|c|}
\hline Autores & Ano & Contribuição Teórica \\
\hline & & $\begin{array}{l}\text { pensamento que vê algo como parte de um sistema maior e } \\
\text { em termos do papel que cumpre, invertendo a lógica do } \\
\text { pensamento analítico. }\end{array}$ \\
\hline BUCKLEY & 1971 & $\begin{array}{l}\text { Apresenta a mudança de foco das partes para os processos, } \\
\text { na qual as estruturas são concebidas como estabilizações } \\
\text { temporais de relações entre partes e processos. }\end{array}$ \\
\hline FORRESTER & 1961 & $\begin{array}{l}\text { Apresenta a visão do pensamento como um elemento da } \\
\text { Dinâmica de Sistemas. }\end{array}$ \\
\hline
\end{tabular}

Quadro 6 Literatura de Referência sobre Pensamento Sistêmico

\subsubsection{CONCLUSÃO DA REVISÃO DE LITERATURA-PENSAMENTO SISTÊMICO}

O objetivo desta revisão foi identificar na literatura disponível as características do pensamento sistêmico com o objetivo de caracterizar e comprovar teoricamente que o ecossistema do SPB deve ser abordado metodologicamente e conceitualmente com o recorte do pensamento sistêmico. A revisão de literatura apresentou algumas formulações quanto ao caráter do pensamento sistêmico. Verificou-se que, para a maioria dos autores revisados, trata-se de uma nova perspectiva ou quadro de organização intelectual do conhecimento. A lógica da metodologia SSM consiste na implementação de um processo cíclico de aprendizagem segundo o modelo geral da pesquisa-ação que é aderente à metodologia de pesquisa adotada neste trabalho. Além disso, durante sua aplicação, essa metodologia desenvolve a consciência dos envolvidos sobre a situação-problema ao mesmo tempo em que apresenta ferramentas para uma melhor compreensão dessa situação e para a elaboração de ações que possam alterá-la a ponto de introduzir mudanças no mundo real. 


\subsection{ECOSSISTEMAS}

Para a conceituação do termo nesta pesquisa, partiu-se do Briscoe (2007), que utilizou como base de sua teoria os ecossistemas naturais e definiu os ecossistemas digitais, considerando os três campos mais importantes das ciências naturais: a física, a biologia e a química. Os ecossistemas são descritos como sistemas complexos adaptativos e podem ser de dois tipos: os naturais e os digitais. Os ecossistemas naturais são entendidos a partir das ciências naturais e Chang (2006) define ecossistema como:

"[...]a loosely coupled, domain clustered environment where each species conserves the environment, is proactive and responsive for its own benefit. There are two key elements in an ecosystem, namely: the species and the environment. Species need to interact with each other and balance each other (even though some species may play a leading role at times) and an environment that supports ecological needs of species so it can continue generation after generation"

As ciências naturais estudam o universo por meio de regras e leis de ordem natural. O termo ciência natural é também utilizado para diferenciar o campo que utiliza o método cientifico para estudar a natureza em contraste com as ciências sociais, que utilizam o método científico aplicado ao comportamento humano. Os campos das ciências naturais são vastos e diversos, contemplando desde a ciência do solo até a astronomia.

Segundo Resnick (2007), o universo que era representado por pesquisadores como um mecanismo com funcionamento sob regras lineares de causa e efeito começou a ser representado como ecossistema, sendo, pois seus objetos de investigação representados por uma nova metáfora menos determinística.

Com o advento da web e sua presença ubíqua em todos os meios, o ambiente no qual vivemos não é mais somente ecológico, mas sim um ambiente dual: ecológico e digital. Este ambiente mudou a economia do mundo de uma economia conectada fisicamente para a economia digital em rede. Esse ambiente alterou o comportamento das pessoas e das organizações. Esse novo ambiente de redes colaborativas, dinâmicas e abertas, foi introduzido às sociedades da informação e da comunicação como ecossistema digital (DEST, 2007; CHANG; WEST, 2006; CHANG; GUETL, 2007; KÜSTER et al., 2007; UDEN; DAMIANI, 2007; INDRAWAN et al., 2007; HAZDIC et al., 2007) e segundo estes autores, um 
ecossistema digital é análogo às comunidades ecológicas naturais, pois são sistemas complexos, dinâmicos e adaptativos, que incluem componentes digitais interagindo entre si e com o meio digital.

A motivação principal para a pesquisa em ecossistemas digitais é explorar as propriedades de auto-organização presentes nos ecossistemas naturais. Ecossistemas biológicos são considerados robustos, com arquiteturas escaláveis que podem automaticamente resolver problemas complexos e dinâmicos. Propriedades biológicas, tais como a evolução de populações, ambientes complexos e dinâmicos e a distribuição espacial, que criam interações locais, contribuem para os aspectos auto-organizacionais de ecossistemas naturais (BRISCOE et al., 2007). Ecossistemas biológicos são fenômenos naturais ubíquos, cuja manutenção é essencial para a sobrevivência da espécie humana. $O$ desempenho de ecossistemas naturais é frequentemente medido com relação a sua estabilidade, complexidade e diversidade. Para Briscoe et al. (2007) ecossistemas digitais são tecnologias criadas para servir propósitos humanos específicos e 0 seu desempenho é avaliado relativamente à função para a qual eles foram projetados. Em alguns casos, o objetivo de um ecossistema digital é de resolver com alta eficiência problemas dinâmicos em paralelo. A vantagem de ecossistemas digitais em relação a outros modelos organizacionais complexos é seu potencial de auto-organização dinâmico e adaptativo. Porém, para garantir a utilidade de tais modelos, eles devem ser eficientes no sentido computacional, mas também devem resolver problemas significativos. Nesse sentido ecossistemas digitais devem ser atentos a demandas de usuários. Portanto, a construção de ecossistemas digitais úteis requer um equilíbrio entre a liberdade do sistema de se auto-organizar e a necessidade de geração de soluções significativas para os usuários (BRISCOE et al., 2007). Para Chang (2006) um ecossistema digital pode ser definido como:

\footnotetext{
"Digital ecosystems transcend the traditional, rigorously defined, collaborative environments from centralized, distributed or hybrid models into an open, flexible, domain cluster, demanddriven, interactive environment, where each specie is proactive and responsive for its own benefit or profit. A digital ecosystem is a new-networked architecture and collaborative environment that addresses the weakness of client-server, peer-to-peer, Grid and web services"
} 
Para Hazdic et al. (2007), um ecossistema digital é o complexo dinâmico e sinergético de comunidades digitais que consiste de espécies digitais com suas conexões, relações e dependências, situadas em um ambiente digital, que interagem como uma unidade funcional e são interligadas por meio de ações e, de fluxos de informação e de transação. Os autores afirmam que ecossistemas digitais estão no princípio da fase de implementação e que não há ainda uma metodologia clara para o projeto de tais sistemas. Esses autores então apresentam uma proposta de arcabouço (framework) metodológico para o desenvolvimento de ecossistemas digitais dividido em cinco fases que se concentram nos papéis dos componentes do ecossistema; na sua organização e colaboração e na inteligência e segurança do ecossistema todo. Para esses autores, uma espécie digital consiste de hardware (como o corpo de uma espécie biológica) junto com seu software associado (em analogia à vida de uma espécie biológica). Alguns exemplos de espécies digitais são os PDAs (Personal Digital Assistant), os telefones celulares ou os laptops. O ambiente digital corresponde ao ambiente biológico, pois nele vivem e funcionam as espécies digitais. O fluxo de informação pode ser uma ideia expressa em linguagem natural ou formal, digitalizada, transportada dentro do ecossistema e processada por computadores ou humanos. Um ecossistema digital é caracterizado pelas suas atividades e processos que atraem espécies digitais a participar e a se beneficiar do ambiente. A grande maioria destes processos se refere ao compartilhamento de conhecimento e à cooperação.

Um ecossistema digital é um sistema que apoia a cooperação, o compartilhamento do conhecimento, o desenvolvimento de tecnologias abertas e adaptativas e a evolução de ambientes ricos em conhecimentos (DINI, 2005; KÜSTER et al., 2007; UDEN; DAMIANI, 2007). Ecossistemas digitais capturam a essência do ambiente ecológico clássico e complexo, onde organismos formam um sistema dinâmico e inter-relacionado. Ecossistemas digitais são habitados por populações humanas e digitais e sua criação depende exclusivamente das interações entre humanos e sistemas digitais. Ecossistemas digitais não são apenas ambientes pervasivos habitados por componentes digitais que evoluem e se adaptam às condições locais graças à recombinação e evolução de seus componentes digitais, mas dependem da satisfação e do benefício de sua população humana 
(KÜSTER et al., 2007). Igualmente a um ambiente ecológico, um ecossistema digital consiste de espécies que criam e conservam recursos valiosos. O software, os bancos de dados e os serviços se referem a espécies digitais. As espécies econômicas são as entidades de negócios que formam um ecossistema complexo, dinâmico e inter-relacionado. Este pode ser definido como uma composição de entidades multiformes e heterogêneas, que participam de um domínio digital e conduzem interações multidisciplinares. Um ecossistema digital é um ambiente aberto, flexível, colaborativo, onde cada espécie é proativa e responsável por sua própria segurança enquanto contribui para o bem estar do ecossistema como um todo. O sistema é aberto, pois é um ambiente onde todos são convidados a participar exceto espécies perigosas que têm a intenção de causar danos à comunidade. O paradigma transcende a definição rigorosa de ambientes colaborativos centralizados (cliente-servidor), distribuídos ou híbridos (peer-topeer), e segue na direção de modelos de comunidades baseadas em agentes, abertas, orientadas a demandas interativas, que oferecem serviços digitais e atividades que atraem a participação de outros agentes para delas se beneficiar. (CHANG; WEST, 2006).

\subsubsection{MACROECOSSISTEMA}

Recentemente, as pesquisas conduzidas do ponto de vista tecnológico têm como foco as discussões centradas na ideia de criar ecossistemas digitais de negócios que englobam as pequenas e médias empresas como entidades dos sistemas (NACHIRA, 2002; DINI et al., 2005; INDRAWAN et al., 2007). A metáfora biológica é utilizada como modelo de interação entre pequenas e médias empresas e seu ambiente ou sua infraestrutura. Esta aplicação da metáfora de ecossistemas para a interação entre pequenas e médias empresas assume o ponto de vista de macro ecossistema.

Um ecossistema digital de negócios é uma inovação tecnológica e econômica. Especificamente, é uma infraestrutura de software cujo objetivo é apoiar um grande número de usuários de negócios e serviços interagindo entre si. Os indivíduos de um ecossistema digital de negócios são agentes de software que representam entidades de negócios ou serviços. Esses agentes interagem, evoluem e se adaptam ao ambiente dinâmico digital, atendendo, desta forma, os requisitos de negócios, que mudam constantemente e são impostos pela economia (BRISCOE et al., 2007). 
O uso da metáfora de ecossistemas e a sua aplicação em alguns ambientes têm sido relatados na literatura que define um ecossistema de negócios como a rede de compradores, fornecedores e fabricantes de um conjunto de produtos ou serviços junto com seu ambiente socioeconômico, a sua infraestrutura institucional e seus regulamentos (DIGITAL ECOSYSTEMS, 2007; UDEN; DAMIANI, 2007). Para Dini et al. (2005), ecossistemas digitais de negócios resultam da co-evolução de ecossistemas digitais e de ecossistemas de negócios. A rede de ecossistemas digitais oferece às pequenas e médias empresas, e às áreas menos desenvolvidas ou mais afastadas, a oportunidade de participar da economia global. As tecnologias de ecossistemas digitais permitem novas formas de interação dinâmica e novas formas de cooperação global entre organizações e comunidades de negócios, fomentando o crescimento econômico local. Com isto, o conhecimento, a cultura e a identidade locais são preservados e contribuem para superar as diferenças de acesso à tecnologia.

O conceito de ecossistema de negócios é oriundo do conceito de "ecossistemas digitais de negócios" (Digital Business Ecosystems - DBE), que por sua vez é uma extensão da teoria de sistemas econômicos complexos e evolucionários. Ele baseiase em uma analogia entre o conceito de ecossistema biológico e o de organizações de populações, nos quais se observa fenômenos como competição, cooperação e evolução dos indivíduos/componentes, tais como ocorrem em sistemas socioeconômicos (PELTONIEMI, 2005; MOORE, 2006). A análise de um mercado a partir do modelo de ecossistema de negócios propicia, portanto, uma visão sistêmica, a partir da descrição e compreensão do comportamento de uma organização populacional. lyer et al (2006) propõem o desenho de um ecossistema de negócios como uma ferramenta estratégica, que permite que os gestores possam examinar o papel de sua empresa, o da concorrência e o dos complementares em sistemas complexos. Cusomano e Gawer (2002) também destacam a importância do gerenciamento dos complementares para competir em mercados em rede e sugerem que as empresas que conseguem direcionar as inovações de uma dada indústria inserida em um ecossistema, têm maior chance de tornarem-se as líderes dessas plataformas tecnológicas.

A diferença entre os conceitos de plataforma tecnológica e de seus componentes em um ecossistema é esclarecida por Eisenmann (2007): a plataforma compreende os 
componentes e as regras gerais utilizadas pelos usuários das redes (incluindo consumidores e complementares), na maioria das suas interações, enquanto os componentes incluem hardwares, softwares, serviços e arquitetura. As regras em si se referem aos padrões que asseguram a compatibilidade técnica entre componentes, protocolos, políticas e contratos da plataforma e, portanto, do ecossistema como um todo. O posicionamento estratégico de empresas que atuam neste tipo de sistemas complexos, requer o que lyer et al (2006) denominam de capacidade de lidar com um "pequeno mundo" particular, através do gerenciamento não apenas dos complementares da rede, também de uma intrincada e mutante rede de cooperação e competição, regida por alianças e troca de informações diversas entre atores que se relacionam com pouco grau de separação entre si.

\subsubsection{MICROECOSSISTEMA}

É uma situação na qual a metáfora se refere a um micro ecossistema em que o conceito de ecossistema é proposto para gerenciar uma coleção de equipamentos inteligentes no âmbito de uma casa (Device Ecology). Neste caso, considera-se que os equipamentos elétricos podem ter comportamentos inteligentes e executar funções especificas para ambientes caseiros. O micro ecossistema proposto prevê a inclusão de três espécies: os usuários humanos, os equipamentos inteligentes e o servidor. O ambiente é constituído pela temperatura, a umidade e o tempo. Fatores ambientais influenciam a operação da ecologia de equipamentos. É possível, por exemplo, que um equipamento de ar-condicionado seja ligado se a temperatura interna da casa chega a um certo grau. As informações sobre o ambiente são coletadas por meio de um mecanismo de sensores. E, com conhecimento do perfil dos usuários, o servidor toma decisões apropriadas e ativa ou desativa equipamentos (INDRAWAN et al., 2007).

\subsubsection{ECOSSISTEMAS TECNOLÓGICOS VERSUS ECONÔMICOS}

Benkler (2001) se baseia na metáfora de ecossistema para explicar os desacordos, ocorridos nos anos 90, entre os ecossistemas tecnológicos e os ecossistemas econômicos no que diz respeito à produção de informação. Com a ampla divulgação e utilização da web, voluntários começaram a preencher a rede mundial com informação, conhecimento e trocas culturais. Para o autor, 0 advento do software livre é a peça central responsável pela emergência de espécies que 
produzem informações e código aberto. A produção voluntária e, muitas vezes, a produção cooperativa voluntária, organiza-se por meio de comunicação e não por mecanismos de mercado ou por hierarquias gerenciais. Nesse sentido, a comunidade de software livre tem provocado espontaneamente uma organização que busca um objetivo comum e uma eficiência mensurável. Essa organização e essa eficiência sugerem a possibilidade de sustentabilidade econômica e a potencial superioridade no novo modelo de produção de informação em relação ao antigo, regido por direitos autorais pertencentes a grandes empresas.

Um exemplo de ecossistema digital relatado por Küster et al. (2007), é o TextGrid, uma iniciativa de oito instituições alemãs, definida como um ecossistema digital cujo objetivo é a criação de uma comunidade para a edição colaborativa, a anotação, a análise e a publicação de textos científicos. O ecossistema envolve diferentes espécies: humanos e agentes de software, e consiste de alguns subsistemas que interagem entre si. Os subsistemas principais são: os usuários finais, os provedores de conteúdos e os desenvolvedores de software. Estes são igualmente necessários, porém suas motivações e condições de vida são diferentes. Usuários finais desejam a possibilidade de buscar informações das fontes armazenadas, desenvolvedores de software se preocupam com os benefícios tangíveis de suas aplicações, e os provedores de conteúdo se interessam pelo controle de sua propriedade intelectual. TextGrid é um ecossistema que deve fornecer boas condições de vida para seus habitantes, enquanto mantém o seu ambiente aberto para poder comunicar-se e interoperar com outros ecossistemas (KÜSTER et al., 2007).

\subsubsection{OUTRO TIPO DE ECOSSISTEMA}

A Rede como ecossistema e procomun define o novo entorno como um meio ambiente digital formado por espécies digitais (aplicações informáticas, sistemas operacionais, protocolos de comunicação, serviços online, modelos de negócio etc.) que se relacionam mutuamente por relações simbióticas de reforço mútuo ou dependência mútua (BENKLER, 2003 e 2006). Pode-se distinguir as relações entre positivas - baseadas na colaboração e orientadas ao benefício mútuo - ou negativas - de parasitismo ou depredação. Essas relações têm um papel fundamental na criação de novas espécies digitais que estão espalhando o centro do poder, levando o sistema de volta ao cidadão. Para que se leve adiante essa 
dinâmica positiva, um ecossistema digital deve desenvolver uma infraestrutura orientada a serviços que sejam recursos públicos. Nesse sentido, um ecossistema digital é definido como uma estrutura digital auto-organizativa orientada à criação de um ambiente digital distribuído em rede. Esse ecossistema é caracterizado por uma série de elementos: conhecimento compartilhado, tecnologias, padrões e protocolos abertos, cooperação solidária e novos modelos de negócios. A implementação desse ambiente digital tem a estrutura de um procomun, que Benkler define como um espaço institucional em que se podem exercer certas liberdades com respeito às restrições impostas pelos mercados. Essas restrições aparecem, frequentemente, na forma de relações de propriedade, que definem quem tem controle sobre quais recursos, e quais são as relações entre agentes em função da posse ou carência de um bem ou um recurso determinado. Isso não significa que os bens comuns sejam espaços anárquicos, mas que os agentes podem atuar neles com uma lógica diferente da do mercado, evitando os paradoxos que se produzem na teoria dos jogos quando um agente busca a maximização da utilidade esperada de suas decisões. Em outras palavras, é o que acontece quando se atua em ambientes estratégicos, em que vários agentes atuam de forma que as decisões de um dependem das decisões dos demais, seguindo as regras dos ambientes paramétricos, aqueles em que o mundo e o conjunto de possibilidades já dadas não são modificáveis pelas decisões de outros sujeitos. Os bens comuns podem ser usados através de normas sociais que não precisam de relação de propriedade. Os bens comuns podem ser abertos a todo mundo, como é o caso do ar que respiramos ou da água dos oceanos. Também podem ser de acesso limitado a uma comunidade, como os pastos comunais para o gado ou os campos de cultivo comuns.

Em outro ponto de vista, podem ser submetidos ou não à regulação. Um mesmo bem pode inclusive, ter uma dupla consideração. Benkler destaca o exemplo do ar: para respirar é livre e gratuito, mas a sua contaminação submetida à regulação e ao pagamento de taxas em alguns casos. Os procomuns abertos mais importantes e significativos são a ciência e a cultura até o século $X I X$. No século $X X$, uma parte significativa da cultura assim como algumas áreas de investigação científica deixou de ser livre. No século XXI, segundo Benkler, tanto a ciência quanto a cultura correm o risco de uma progressiva e ilimitada privatização. As intenções de patentear 
algoritmos matemáticos fundamentais para a produção de software e a de John Craig Venter de patentear desenhos de seres vivos são exemplos de até que ponto a ciência e a tecnologia estão submetidas a uma profunda pressão mercantilista. Essa progressiva apropriação pode supor um notável freio à inovação e à difusão cultural. Pelo contrário, o procomun supõe um ambiente de democratização da cultura e desenvolvimento da cidadania. Por ele, as redes devem se manter como bens comuns que garantam, segundo Lessig (2004), a liberdade dos usuários. Essa cidadania potencializada se manifesta através de redes sociais virtuais, blogs, videoblogs, comunidades de intercâmbio, movimentos Open Source e Conhecimento Livre (Free Knowledge) e outros. Mas também se manifesta a partir do poderoso movimento de deslocamento do poder do centro do sistema para a periferia, como fazem as chamadas comunidades de interesse. O Quadro 7 apresenta uma compilação da revisão bibliográfica efetuada para o eixo teórico dos ecossistemas digitais.

\begin{tabular}{|c|c|c|}
\hline Autores & Ano & Contribuição Teórica \\
\hline 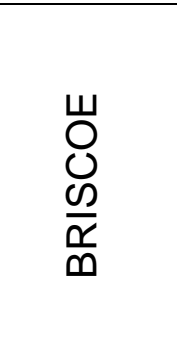 & 2010 & $\begin{array}{l}\text { Apresenta a definição de um Ecossistema Genérico, na } \\
\text { perspectiva da ciência da computação. Discute a transição de } \\
\text { ecossistemas biológicos para ecossistemas de software, } \\
\text { ecossistemas digitais, ecossistemas sociais, ecossistemas de } \\
\text { conhecimento e ecossistemas de negócio. }\end{array}$ \\
\hline ALVES & 2009 & $\begin{array}{l}\text { Apresenta os conceitos do ecossistema SPB e de ciclos de } \\
\text { aprendizado em um ecossistema emergente. }\end{array}$ \\
\hline 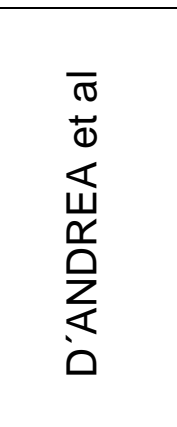 & 2009 & $\begin{array}{l}\text { Apresenta um conceito novo: Digital Organization Ecosystem } \\
\text { (DOE) e a análise das evoluções de uma organização de } \\
\text { pesquisa em um ecossistema na Itália. Trabalha os conceitos } \\
\text { de DOE e de evolução considerando o impacto que as TIC } \\
\text { tiveram na criação e manutenção de interações para a } \\
\text { organização. }\end{array}$ \\
\hline 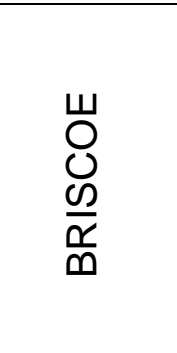 & 2009 & $\begin{array}{l}\text { Analisa os ecossistemas os ecossistemas digitais (DE) sob o } \\
\text { ponto de vista da auto-organização. O trabalho investiga os } \\
\text { aspectos de auto-organização dos ecossistemas digitais por } \\
\text { meio da aplicação da computação evolucionária a Multi-Agent } \\
\text { Systems (MASs). }\end{array}$ \\
\hline
\end{tabular}




\begin{tabular}{|c|c|c|}
\hline Autores & Ano & Contribuição Teórica \\
\hline DINI et al & 2008 & $\begin{array}{l}\text { Discute uma teoria de ecossistemas digitais autopoiética e } \\
\text { associativa. O trabalho endereça os domínios: ciência natural, } \\
\text { ciência social e ciência da computação. }\end{array}$ \\
\hline $\begin{array}{l}\text { BRSICOE } \\
\text { et al }\end{array}$ & 2007 & Apresenta os conceitos de auto organização \\
\hline BRISCOE & 2007 & $\begin{array}{l}\text { Apresenta os conceitos preliminares de um Digital Business } \\
\text { Ecosystem (DBE) }\end{array}$ \\
\hline CHANG & 2006 & Apresenta um detalhamento de ecossistemas digitais \\
\hline 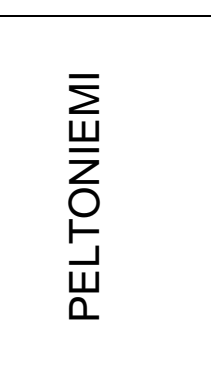 & 2005 & $\begin{array}{l}\text { Apresenta um framework para estudar como os Business } \\
\text { Ecosystem são construídos. Apresenta os conceitos de } \\
\text { coevolução, auto-organização, emergência, escolha consciente, } \\
\text { conhecimento limitado, interconexão, feedback, variação na } \\
\text { interação, seleção e desenvolvimento. }\end{array}$ \\
\hline$\frac{E}{\sum^{\infty}}$ & 2004 & $\begin{array}{l}\text { Os autores estendem o conceito de ecossistema. Apontam que } \\
\text { o sucesso de empresas como IBM e outras se deve aos seus } \\
\text { ecossistemas de negócio. }\end{array}$ \\
\hline$\underset{\bar{E}}{\sum_{\leq}}$ & 2002 & $\begin{array}{l}\text { Numa visão mais moderna do conceito, definem ecossistema de } \\
\text { negócios como um grande número de participantes } \\
\text { interconectados de maneira livre e que dependem uns dos } \\
\text { outros para sua mútua eficiência e sobrevivência. Isso implica } \\
\text { que, para a saúde e o bem-estar dos membros de um } \\
\text { ecossistema, o grupo como um todo deve estar em bom estado. }\end{array}$ \\
\hline
\end{tabular}

Quadro 7 Literatura de Referência sobre Ecossistemas Digitais

\subsubsection{CONCLUSÃO DA REVISÃO DE LITERATURA - ECOSSISTEMAS DIGITAIS}

O objetivo desta revisão foi identificar na literatura disponível as características de um ecossistema digital, com o objetivo de caracterizar e comprovar teoricamente que o ecossistema do SPB é um sistema também de natureza digital e que deve, portanto, ser abordado metodologicamente e conceitualmente como tal. Os ecossistemas digitais requerem uma epistemologia e ontologia própria, dependendo de sua natureza. Uma pequena parte da ontologia será proposta nesta pesquisa. 
Considerando a literatura exposta, é possível caracterizar o SPB como um ecossistema resultante de um conjunto de relacionamentos que elementos específicos mantêm entre si e que conduzem à interdependência. Os elementos do SPB são: entidades, artefatos e comunidades que podem ser expostos a vários graus de desagregação. Nessas desagregações podem ser estabelecidas hierarquias (formais ou informais) (ALVES, 2009). 


\subsection{A CAPACIDADE, A MATURIDADE E OS MODELOS}

A Engenharia de Software tem o seu corpo de conhecimento codificado no SWEBOK (Guide to the Software Engineering Body of Knowledge), que é uma caracterização, validada por consenso, da disciplina de Engenharia de Software e um guia para o corpo do conhecimento que apoia essa disciplina (ABRAN et al. 2004). O SWEBOK adotou a definição IEEE 610.12, que define Engenharia de Software como: "(i) a aplicação de uma abordagem sistemática, disciplinada e quantificável para o desenvolvimento, operação e manutenção de software; ou seja, a aplicação da engenharia ao software, (ii) o estudo das abordagens como em (i)".

A utilização mais sistemática de processos, foi iniciada nos anos trinta com Walter Shewhart (SHEWHART, 1980) que iniciou um trabalho em melhoria de processos com os princípios do controle estatístico de processo. Os princípios foram então refinados por W. Edwards Deming e Joseph Juran (DEMING, 1986) JURAN(1967). $\mathrm{O}$ foco dos trabalhos desses pesquisadores era a indústria de manufatura. $\mathrm{Na}$ década de setenta, outro pesquisador, Philip Crosby (CROSBY, 1979), passou a estudar as organizações com as quais trabalhava, conforme a qualidade de sua produção. A partir desses estudos definiu cinco estágios sequenciais e cumulativos do processo de produção, considerando fundamentalmente as atitudes gerenciais encontradas em cada estágio. Na década de oitenta, Ron Rodice adaptou os princípios de controle estatísticos e os estágios da qualidade ao desenvolvimento de software. Watts Humphrey estendeu esse trabalho e definiu cinco níveis de maturidade (CRISSIS et al, 2003).

Segundo Fuggeta (2000), ao concluir uma visão geral da história e os resultados da pesquisa de processo de software, "a utilização de processos para tratar a inerente complexidade de software como um processo vem auxiliando significativamente a identificação das diferentes dimensões do desenvolvimento de software e os problemas que devem ser tratados para estabelecer práticas efetivas". Ainda segundo Fuggetta, "nós temos de prestar atenção na complexa interpelação de numerosos fatores organizacionais, culturais, tecnológicos e econômicos [do desenvolvimento de software]". Osterweil $(1987,1997)$ reconheceu, em seus trabalhos de pesquisa, que os processos de software também são software.

A melhoria de processo de software tem se mostrado uma abordagem viável e 
efetiva para a melhoria das organizações intensivas em software. As abordagens para melhoria de processo, como, por exemplo, a abordagem IDEAL (MCFEELEY, 1996), a abordagem para Melhoria de Processo da ISO/IEC 15504 (ISO/IEC TR 15504-7 1998, ISO/IEC 15504-4, 2004), a abordagem baseada em problemas e metas (PORTERE SAKRY, 2002) e as orientações para a melhoria (O'TOOLE, 2000), utilizam como referência um modelo de processo que sistematiza e representa as melhores práticas, define uma medição para avaliação da capacidade dos processos e provê um roteiro racional para a melhoria dos processos. Exemplos de modelos mais utilizados são o SW-CMM versão 1.1 (Capability Maturity Model for Software) (PAULK et al., 1994), a Norma ISO/IEC 12207 (1998), a Norma ISO/IEC 15504 (ISO 15504, 2004), a evolução do SW-CMM lançada em 2000 o CMMI (Capability Maturity Model Integration) (CHRISSIS et al., 2003), e a aplicação para software da Norma ISO 9000, principalmente a versão 2000 com o par coerente 9001 e 9004 (ISO 9001 2000, ISO 9004, 2000). Essas metodologias, os modelos e considerações sobre o relacionamento entre modelos estão difundidas na comunidade e descritas em várias publicações (SHEARD, 2001).

Uma tendência atual é a ampliação da abrangência da melhoria de processo de software para a melhoria de processo de sistemas. Os dois principais modelos de capacidade de processo de software (SW-CMM e ISO/IEC TR 15504) evoluíram e suas novas versões (CMMI e ISO/IEC 15504) tratam de processos de sistema, que incluem processos de software. A melhoria de processo de software e de sistemas é parte da disciplina de engenharia de processo de sistema e software, que, por sua vez, é ao mesmo tempo uma disciplina autônoma e parte da disciplina de engenharia de software e sistemas. Existe uma tendência atual de generalizar as atividades de software para sistemas, cujos componentes podem ser implementados por diferentes engenharias, como, por exemplo, elétrica, eletrônica, e a de software. Com isto pode-se estender a abrangência a) dos processos da engenharia de software para os processos da engenharia de sistemas; e b) da engenharia de processo de software para a engenharia de processo de sistemas.

Os modelos da Norma ISO/IEC 15504 e CMMI são hoje os principiais modelos de referência para avaliação e melhoria dos processos de software e de sistemas. Outras normas, como, por exemplo, a Norma NBR ISO/IEC 12207, tratam de outros aspectos da engenharia de processo de software. A Norma ISO/IEC 12207 - 
Processos de Ciclo de Vida de Software (NBR1998, ISO 2002, Machado 2003) tem como objetivo principal o estabelecimento de uma estrutura comum para os processos de ciclo de vida de software, como forma de ajudar as organizações a compreender todos os componentes presentes na aquisição e fornecimento de software e, assim, conseguir firmar contratos e executar projetos de forma mais eficaz.

Segundo Salviano (2006) a utilização de modelos não é suficiente para garantir o sucesso da melhoria. Para a obtenção da melhoria, alguns fatores têm sido reconhecidos como fundamentais e, entre eles estão: a) o entendimento das características, limitações e implicações da utilização da abordagem baseada em melhoria de processo; b) a escolha, o entendimento, a utilização e a interpretação de um bom modelo de processo ou de um bom conjunto de modelos; c) o alinhamento dos esforços de melhoria com o contexto e os objetivos estratégicos da organização; d) o estabelecimento de metas relevantes, viáveis e mensuráveis; e) considerações dos aspectos gerenciais, técnicos e humanos da melhoria; f) o comprometimento da alta gerência, a condução por empreendedores e a participação de todos; g) a condução dos esforços de melhoria como um programa com base em uma abordagem; e h) o conhecimento do processo atual.

O destaque dado atualmente à área de melhoria e avaliação de processo de software se deve, em parte, ao sucesso e ao reconhecimento do conjunto de ações realizadas em função do modelo SW-CMM (Capability Maturity Model for Software). O SW-CMM organizou grande parte do conhecimento de engenharia software em um modelo, com base em um conjunto de premissas. Essas premissas incluem: a) As organizações de software estão sobrecarregadas de trabalho, reagindo a crises constantes e trabalhando de forma reativa, b) Os maiores problemas nas organizações de software são de natureza gerencial e não de natureza técnica; c) Sem uma disciplina de gerenciamento bem estabelecida, as atividades do processo de engenharia são as primeiras a serem desconsideradas; d) Os princípios da qualidade, definidos por autores como Juran e Deming, que revolucionaram a indústria de manufatura, também podem ser aplicados com sucesso na produção de software; e) As boas práticas existentes em algumas organizações de software são pouco disseminadas; e f) A qualidade do processo utilizado para o desenvolvimento e manutenção de um software tem influência na qualidade do software. 


\subsubsection{DEFINIÇÕES E CONCEITOS}

Salviano (2006) identifica em seu trabalho vinte e oito conceitos básicos e os principais relacionamentos entre esses conceitos para caracterizar a visão atual da área de melhoria de processo de software. Esses conceitos estão representados na Figura 13 .

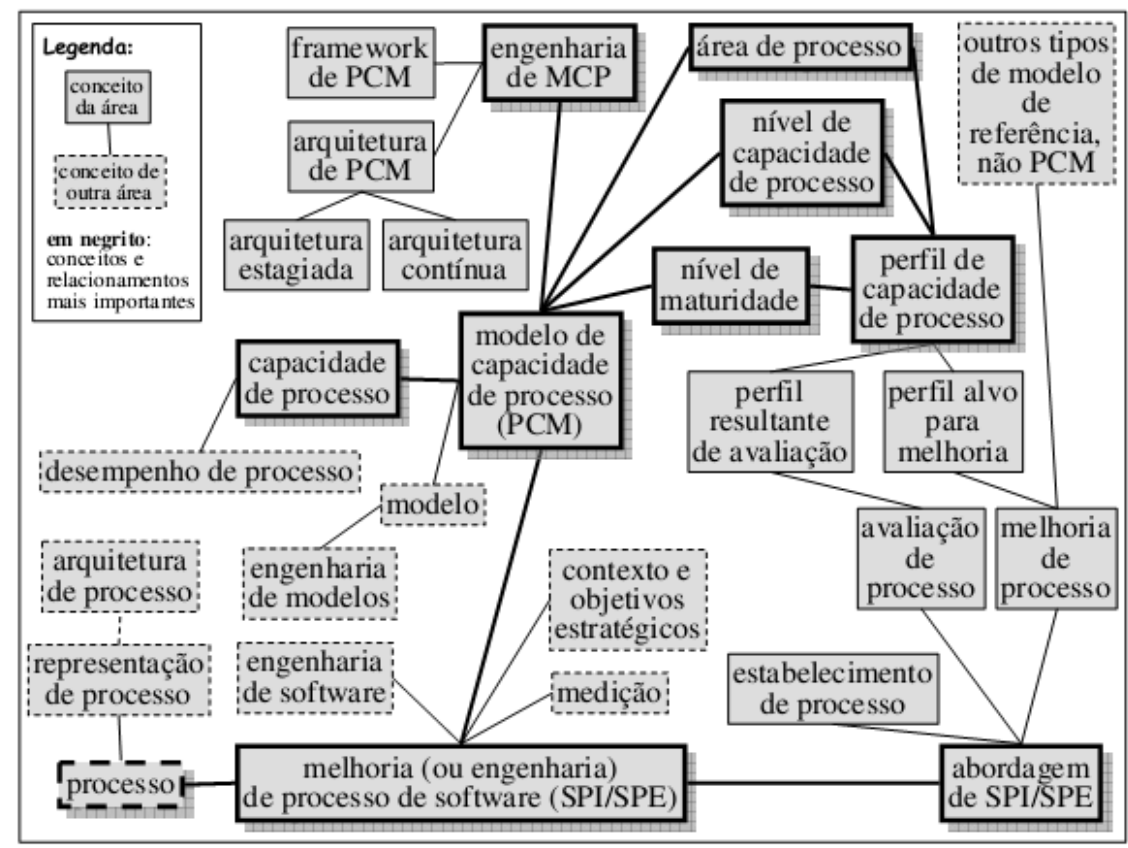

Figura 13 Conceitos básicos da melhoria de processo de software Fonte: Salviano (2006)

A seguir, serão definidos os conceitos utilizados para o desenvolvimento desta pesquisa. São eles: processo, processo de software, capacidade, maturidade, área de melhoria de processo de software, modelo de capacidade de processo, capacidade de processo, desempenho de processo e modelo de maturidade.

\subsubsection{Processo e processo de software}

Processo é uma atividade, ou um conjunto de atividades, com um determinado propósito, realizadas por pessoas que utilizam suas habilidades e seu conhecimento, com o apoio de artefatos, ferramentas e outros recursos. Processo de software é uma atividade, ou um conjunto de atividades, realizadas, com um determinado propósito, por pessoas que utilizam suas habilidades e seu conhecimento, com o apoio de artefatos, ferramentas e outros recursos, para produzir software e seus produtos associados (SALVIANO, 2006). 


\subsubsection{Capacidade}

A capacidade de processo é um conceito que nasceu no SEI com a organização dos conhecimentos ou melhores práticas observados nas empresas de software. Esse conceito nasceu da necessidade do governo americano de comprar software de empresas que tivessem uma capacidade mínima de entregar os produtos contratados (HUMPHREY, 1989). A forma de medir esta capacidade não foi definida na primeira versão do SW-CMM. Nessa primeira sabia-se que a capacidade estava ligada à maturidade, mas não foi explicitado como medi-la. Para o SEI, a maturidade sempre esteve ligada à capacidade dos processos, mas a literatura referente ao desenvolvimento de software da época não esclarecia a divisão ou as diferenças entre capacidade de processo e maturidade. Segundo Humphrey, o SEI e Paul et al., a versão 1.1 do modelo SW-CMM, lançada em 1993, estabeleceu a área de melhoria de processo de software com o objetivo de orientar a melhoria do processo de projetos de desenvolvimento de software por encomenda, como meio para a melhoria das organizações intensivas em software, tendo como referência níveis de maturidade (HUMPHREY,1989), (SEI,1993) e (PAULK et al, 1994).

Simultaneamente, na Europa, foi proposta uma nova arquitetura para modelo de maturidade: a ISO/IEC 15504. A ISO/IEC 15504 propõe modelos com duas dimensões: um conjunto de áreas de processo e uma sequência de níveis de capacidade de processo. Essa proposta definiu uma forma de medir a capacidade dos processos, ou seja, métricas claras, com controle de processo, que permitem dizer, por exemplo, que um conjunto de processos de uma determinada área de processo deve ter um determinado nível de capacidade para, então, a unidade ser considerada com um determinado nível de maturidade.

O SW-CMM evoluiu para um framework de modelos integrados (CMMI: Capability Maturity Model Integration) alinhado com a ISO/IEC 15504. Esta nova versão do CMM contempla esse conceito de capacidade, com métricas e controle e estabelece uma relação clara entre a capacidade dos processos e os níveis de maturidade.

\subsubsection{Maturidade}

Por volta de 1930, Walter Shewhart iniciou um trabalho em melhoria de processos com os princípios do controle estatístico. Esses princípios foram posteriormente melhorado por W. Edwards Deming (DEMING, 1986) e Joseph Juran (JURAN, 
1987), sempre focados na indústria de manufatura. Na década de setenta, Philip Crosby (CROSBY, 1979) observou que as organizações de manufatura nas quais trabalhou poderiam ser estudadas de acordo com a qualidade de sua produção e definiu cinco estágios sequenciais e cumulativos do processo de produção, baseados principalmente nas atitudes gerenciais encontradas em cada estágio. Esses estágios (Quality Management Maturity Grid) indicam a qualidade do processo de produção. Na década de oitenta, Ron Radice adaptou esses princípios de controle estatísticos e os estágios de qualidade ao desenvolvimento de software. Em seguida, Watts Humphrey estendeu esse trabalho e definiu cinco níveis de maturidade (CHRISSIS, 2007).

\subsubsection{Capacidade, maturidade e modelos de maturidade}

A versão 1.1 do modelo SW-CMM lançada em 1993, estabeleceu a área de melhoria de processo de software com o objetivo de orientar a melhoria do processo de projetos de desenvolvimento de software por encomenda, como meio para a melhoria das organizações intensivas em software, tendo como referência níveis de maturidade. O modelo SW-CMM define a arquitetura estagiada com cinco níveis de maturidade, com estágios sequenciais e cumulativos, que atuam como referência para a evolução do processo de imaturo, imprevisível e com baixa qualidade, para um processo maduro, sistemático e com qualidade (SALVIANO, 2006).

\subsubsection{5. Área de melhoria de processo de software}

O conceito de melhoria (ou engenharia) de processo de software é definido como uma abordagem para a melhoria de organizações intensivas em software, baseada em modelos de capacidade de processo de software. Essa melhoria das organizações é obtida por meio do estabelecimento, avaliação e melhoria da capacidade de seus processos mais importantes, relacionados às atividades de aquisição, fornecimento, operação, desenvolvimento, manutenção, gerência, melhoria e/ou apoio de sistemas de software, com o objetivo de satisfazer de forma mais eficiente e eficaz os seus objetivos estratégicos. Os objetivos estratégicos são uma seleção e composição de fatores como controle e redução dos prazos, custos, e outros recursos para desenvolvimento, manutenção e operação de sistemas intensivos em software, os quais devem satisfazer os usuários e a comunidade envolvida, com um número mínimo de erros na sua execução. O propósito do processo de melhoria de processo é "a melhoria contínua da eficiência e eficácia da 
organização por meio dos processos utilizados e mantidos de forma alinhada às necessidades de negócio" (ISO/IEC 15504-5 2006) (SALVIANO, 2006).

\subsubsection{Modelo de capacidade de processo}

Um modelo de capacidade de processo é um conjunto de boas práticas, organizadas de forma sistemática, segundo o conceito de capacidade de processo. Alguns modelos acrescentam o termo "maturidade" para indicar o uso dos níveis de maturidade, como, por exemplo, os modelos SW-CMM e CMMI-SE/SW. Como esses modelos definem maturidade em função da capacidade de processo, o termo "capacidade" é suficiente para caracterizar todos os modelos da área. (SALVIANO, 2006).

\subsubsection{Capacidade de processo}

O conceito-chave que caracteriza a melhoria de processo e a diferencia de outras abordagens relacionadas a processo é o de capacidade de processo. Na definição de melhoria de processo de Ahern et al. (2001), é realçado e definido o termo capacidade de processo: "Melhoria de processo (de software) baseada em modelo envolve o uso de um modelo (de capacidade de processo) para guiar a melhoria dos processos de uma organização (por meio do aumento da capacidade dos processos)".

"Essencialmente, capacidade de processo é a inerente habilidade do processo de produzir resultados planejados. Com o aumento da capacidade de um processo, ele se torna mais previsível e mensurável, e as causas mais significativas de baixa qualidade e produtividade são controladas e eliminadas. Uma organização torna-se mais "madura" à medida que ela melhora continuamente a capacidade de seus processos" (AHERN et al. 2001).

A ISO/IEC 15504-1 define capacidade de processo como "uma caracterização da habilidade de um processo em atender objetivos requeridos ou contribuir (juntamente com outros processos) para 0 atendimento de objetivos requeridos" (ISO/IEC 15504-1, 2004). Do ponto de vista do controle estatístico de processo, capacidade de processo refere-se à "previsibilidade do desempenho de um processo sob controle estatístico" (FLORAC e CARLETON, 1999). Desta forma, "quando um processo está sob controle estatístico em relação a um determinado conjunto de atributos, nós temos uma base válida para predizer, dentro de certos 
limites, como será o desempenho do processo no futuro, e enquanto o processo continuar dentro do mesmo estado de controle estatístico, praticamente todos os resultados de medições desses atributos estarão dentro dos seus limites de processo naturais, o que é definido como capacidade de processo" (FLORAC e CARLETON, 1999). Na visão da ISO/IEC 15504 e do CMMI, esta definição é apropriada apenas para os níveis 4 e 5 de capacidade. Assim capacidade de processo é considerada de uma forma mais ampla, desde o nível 0 até o nível 5 (SALVIANO, 2006).

\subsubsection{Desempenho de processo}

Desempenho de processo é "a extensão na qual a execução de um processo atinge seu propósito" (ISO/IEC 15504-1, 2004) e "uma medida dos resultados reais de um processo, que é caracterizada por medições de processo, como, por exemplo, esforço, tempo de ciclo, e eficiência em remover defeitos, e medições de produto como, por exemplo, confiabilidade, densidade de defeitos e tempo de resposta" (CHRISSIS et al., 2003).

\subsubsection{Perfil de capacidade de processo}

O conceito de perfil de capacidade de processo está relacionado a dois outros conceitos, que são os de áreas de processo e de níveis de capacidade de processo. Os dois últimos conceitos estão relacionados entre si. Uma área de processo descreve uma abstração de um conjunto de atividades, descritas no nível 1 de capacidade. Os níveis de capacidade apresentam uma medida de quanto estes conjuntos de atividades é bem realizado em relação a uma área de processo (SALVIANO, 2006). O perfil de capacidade de processo representa a combinação das duas categorias citadas: a área de processo e os níveis de capacidade.

\subsubsection{Modelo de maturidade}

Um modelo de maturidade é uma coleção estruturada de elementos que descreve certos aspectos da maturidade de uma unidade organizacional. Um modelo de maturidade fornece: a) Um ponto de partida; b) Os benefícios dos usuários em experiências anteriores; c) Um vocabulário comum e uma visão compartilhada; d) Um framework para priorizar ações e e) Uma forma de definir as melhorias mais significativas para uma organização. 
Um modelo de maturidade pode ser usado como base para avaliar diferentes unidades organizacionais e estabelecer comparações. O modelo descreve a maturidade de unidades organizacionais com base nos projetos que elas estão desenvolvendo e nos clientes relacionados. Os modelos de maturidade foram desenvolvidos para avaliar a qualidade dos processos de software aplicados em uma unidade organizacional. O modelo que primeiro agregou as boas práticas das empresas de software e definiu o conceito de processo de software foi o Capability Maturity Model (CMM) do Software Engineering Institute - SEI (HERBSLEB, 1997).

\subsubsection{CONCLUSÃO DA REVISÃO DE LITERATURA - MOD. DE MATURIDADE}

O objetivo desta revisão foi identificar na literatura disponível as características de modelos de maturidade para caracterizar e comprovar teoricamente que (1) o ecossistema do SPB é um sistema de natureza complexa, digital, que deve ser abordado segundo metodologias do pensamento sistêmico e, adicionalmente, (2) que os mecanismos de desenvolvimento de modelos de referência com base na maturidade, podem ser utilizados para a construção de modelos de referência para ecossistemas com a natureza do ecossistema SPB. O Quadro 8 apresenta uma compilação da revisão bibliográfica efetuada para o eixo teórico dos modelos de maturidade para ambientes de desenvolvimento de software.

\begin{tabular}{|c|c|c|}
\hline Autores & Ano & Contribuição Teórica \\
\hline CRISSIS & 2003 & $\begin{array}{l}\text { Apresenta um histórico do modelo de maturidade/capacidade } \\
\text { idealizado pelo SEI com a finalidade de introduzir questões de } \\
\text { qualidade nas compras públicas do governo americano. }\end{array}$ \\
\hline 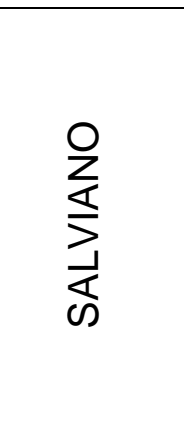 & 2006 & $\begin{array}{l}\text { Apresenta o PRO2PI (Process Capability Profile to drive } \\
\text { Process Improvement) que é uma metodologia de melhoria de } \\
\text { processo multimodelo orientada por perfis de capacidade de } \\
\text { processo. O PRO2PI apoia a melhoria de processos usando } \\
\text { elementos de múltiplos modelos de capacidade de processo e } \\
\text { de outras fontes. }\end{array}$ \\
\hline 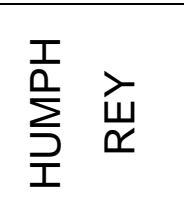 & 1998 & $\begin{array}{l}\text { Apresenta a gênese dos modelos de maturidade materializado } \\
\text { no CMM 1.1. Além disso, mostra o processo utilizado para se } \\
\text { chegar ao primeiro desses modelos. }\end{array}$ \\
\hline
\end{tabular}

Quadro 8 Literatura de referência sobre Modelos de Maturidade 


\subsection{PRO2PI-MFMOD}

PRO2PI (Process Capability Profile to drive Process Improvement) é uma metodologia de melhoria de processo multimodelo orientada por perfis de capacidade de processo. O PRO2PI apoia a melhoria de processos usando elementos de múltiplos modelos de capacidade de processo e de outras fontes. Estes elementos são selecionados ou definidos e integrados como um perfil de capacidade de processo (SALVIANO, 2006). Um perfil de capacidade de processo que orienta a melhoria de processo da metodologia PRO2PI também é chamado de PRO2PI. O PRO2PI é alinhado com os objetivos e estratégias da organização e pode ser alterado em função de mudanças de objetivos e mudanças estratégicas que possam ocorrer. A Figura 14 apresenta os elementos conceituais da metodologia PRO2PI, a relação entre eles e o nome de cada um destes elementos (SALVIANO, 2006).

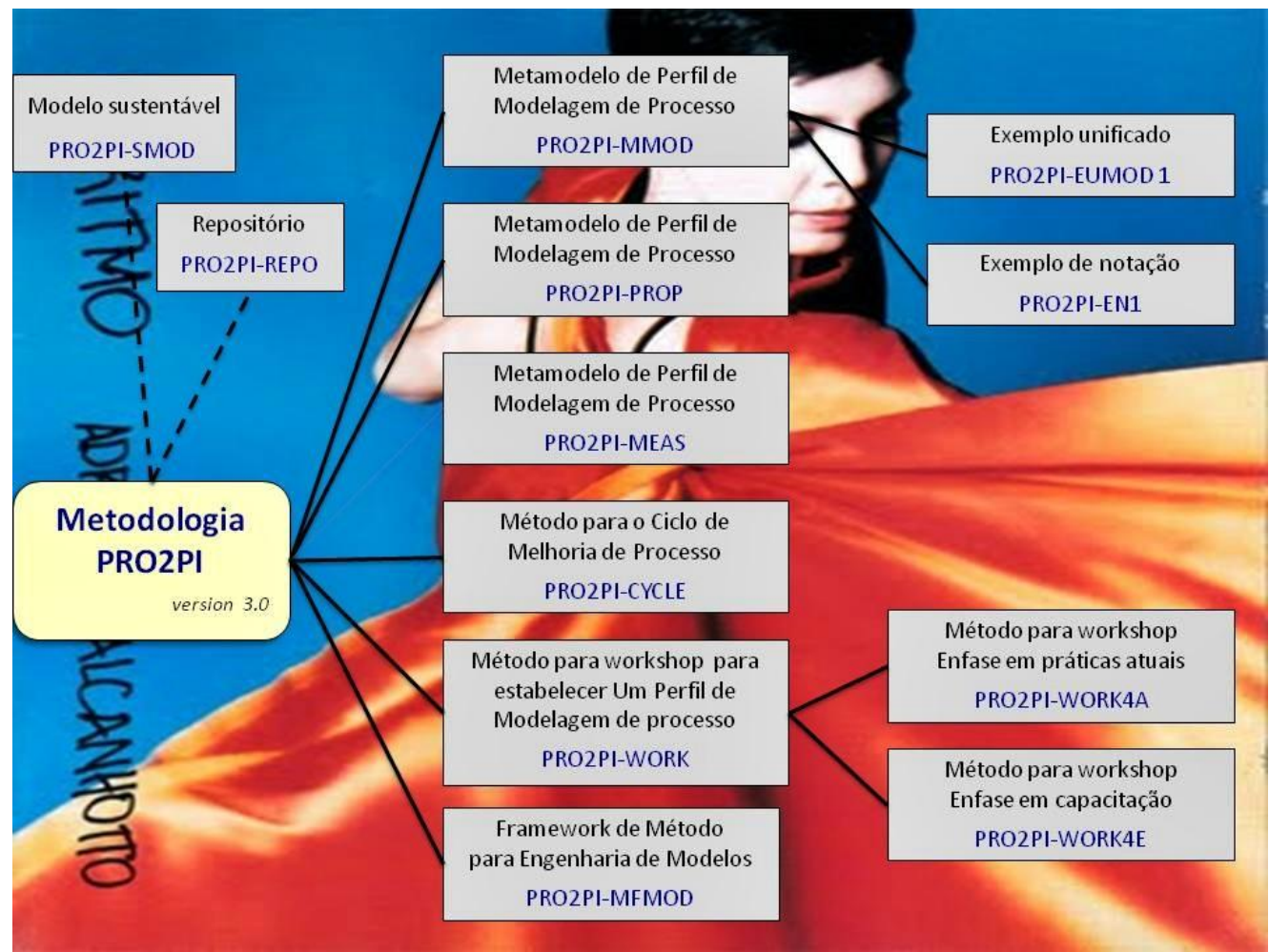

Figura 14 Elementos da metodologia PRO2PI

Fonte: Salviano (2006)

O PRO2PI-SMOD é um modelo sustentável para a disseminação e evolução da metodologia PRO2PI, o PRO2PI-REPO é um repositório para ativos do PRO2PI, o PRO2PI-MMOD é um meta modelo para um perfil de capacidade de processo e modelo de capacidade de processo, o PRO2PI-EUMOD1 é um exemplo unificado de 
modelo de capacidade de processo com elementos selecionados de modelos relevantes, o PRO2PI-EN1 é uma notação para representar um PRO2PI, o PRO2PI-PROP é um conjunto de propriedades para o PRO2PI como, por exemplo, relevante, dinâmico, viável, sistêmico, representativo, que são aplicadas ao perfil como um todo e, rastreável, específico e oportuno, que podem ou não ser aplicadas a uma parte do perfil de capacidade de processo (PCP), o PRO2PI-MEAS é um conjunto de medidas para qualificar um PRO2PI, o. PRO2PI-CYCLE é um processo para ciclos de melhoria de processo incluindo uma função para definir, atualizar ou usar um PRO2PI (SALVIANO, 2006) e o PRO2PI-WORK é um método para realizar workshop em uma empresa, ou grupo de empresas, para estabelecer um perfil de capacidade de processo e orientar um ciclo de melhoria processo. Este método foi desenvolvido para guiar a implementação da primeira das três fases do PRO2PICYCLE. O PRO2PI-WORK é alinhado aos objetivos de negócio da empresa, requer poucos recursos, é realizado em curto prazo e é voltado mais especificamente para micro e pequenas empresas. Além disso, duas variações customizadas deste método foram definidas. PRO2PI-WORK4A é um método para realizar workshop com ênfase na avaliação das práticas atuais e PRO2PI-WORK4E é um método para realizar workshop com ênfase na capacitação em melhoria de processo. O PRO2PIMFMOD é o framework de métodos para a construção de modelos de capacidade de processo (SALVIANO, 2006).

\subsubsection{FRAMEWORK DE PROCESSO}

Segundo Sommerville (2007), um framework de processo pode ser aplicado e adaptado para criar processos mais específicos de engenharia de software. Um framework de processo é instanciado para criar componentes de processo, que são usados para construir um processo real. Um framework de processo define regras para todo e qualquer processo que possa ser instanciado. As regras são tanto para a seleção e criação de componentes do processo, como para sua semântica e interconexões. Esta abordagem é essencialmente modular e fornece a base para a criação de um processo real a partir de componentes individuais disponíveis no framework de processos. Esse framework descreve componentes como, por exemplo, atividades e técnicas para a criação do novo processo. Os componentes do framework podem ser criados especialmente para o processo atual ou podem ser acumulados de processos anteriores e a partir de uma revisão bibliográfica. Assim, 
um framework de processo não é somente um processo, mas um processo para criar outros processos. Ele deve ser instanciado antes de ser utilizado como um processo real. Isto traz como consequência o custo de fazer a instanciação do framework, mas traz também a vantagem de que o resultado é tipicamente adequado à realidade do engenheiro de processos que está instanciando o framework.

\subsubsection{VERSÃO PRELIMINAR DO PRO2PI-MFMOD}

O PRO2PI-MFMOD define sete práticas sequenciais para orientar 0 desenvolvimento de um método ou processo de construção de modelos de capacidade de processo. Entretanto, essas práticas sequenciais apenas expressam o que deve ser feito por um método definido para construir um modelo de capacidade de processo, mas não explicitam como elas (as práticas) podem ser implementadas. Para orientar a implementação destas práticas sequenciais são apresentadas técnicas que têm seu uso detalhado passo a passo no framework. As práticas estão discriminadas no Quadro 9.

\section{Práticas Sequenciais}

\begin{tabular}{|l|l|}
\hline P1 & Decisões iniciais \\
\hline P2 & Análise de fontes \\
\hline P3 & Estratégia de desenvolvimento \\
\hline P4 & Projeto do modelo \\
\hline P5 & Desenvolvimento da versão preliminar do modelo \\
\hline P6 & Validação da versão preliminar do modelo \\
\hline P7 & Consolidação do modelo \\
\hline
\end{tabular}

Quadro 9 Sete práticas sequenciais do PRO2PI-MFMOD

Fonte: Zoucas (2010)

A Figura 15 apresenta um esquema que representa as sete práticas sequenciais do PRO2PI-MFMOD. Ela mostra que as práticas sequenciais podem ser executadas de 1 a $n$ vezes dependendo do interesse de quem estiver determinando o método de construção de modelos de capacidade de processo. Outra informação embutida nesta Figura é que o PRO2PI-MFMOD é um elemento da metodologia PRO2PI.

Como partes do framework de métodos, estas sete práticas sequenciais, devem ser customizadas como as atividades de um método ou mesmo de um processo. Esta 
customização é orientada por sete regras de customização (RC1 a RC7). O Quadro 10 a seguir, descreve essas sete regras de customização em termos dos relacionamentos entre uma ou mais práticas sequenciais do framework de métodos e uma ou mais práticas do método de construção de modelo de capacidade de processo.

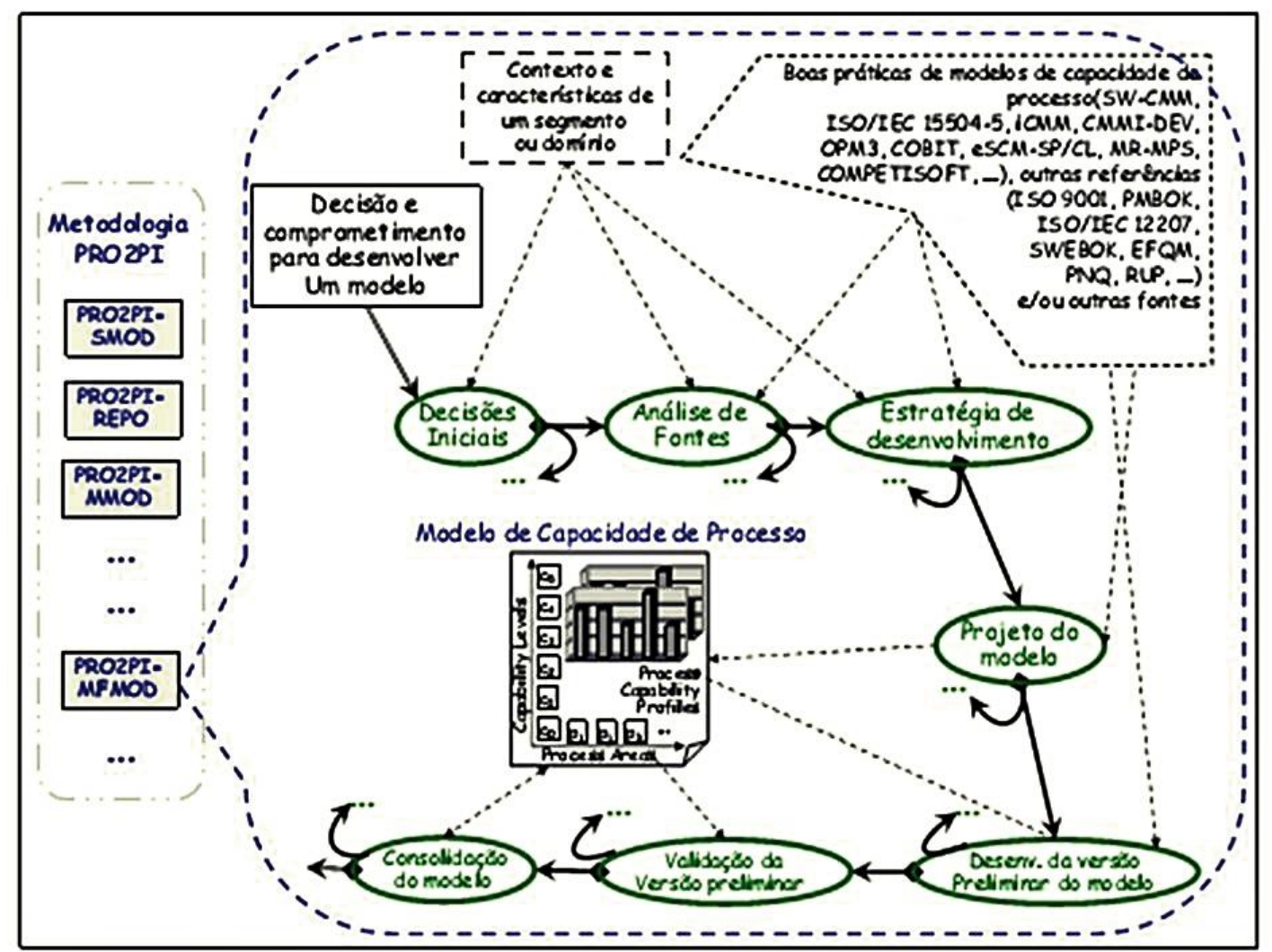

Figura 15 Sete práticas sequenciais do PRO2PI-MFMOD Fonte: Salviano (2006)

\begin{tabular}{|l|l|}
\hline \multicolumn{2}{|l|}{ Regra/Descrição } \\
\hline RC1 & Uma prática corresponde a uma atividade (uma prática para uma atividade). \\
\hline RC2 & Não existe atividade correspondente à prática. \\
\hline RC3 & $\begin{array}{l}\text { Não existem atividades que correspondam a uma ou mais práticas finais } \\
\text { consecutivas. }\end{array}$ \\
\hline RC4 & Duas ou mais atividades correspondem a uma prática. \\
\hline RC5 & Uma atividade corresponde a duas ou mais práticas consecutivas. \\
\hline RC6 & $\begin{array}{l}\text { Existem atividades consecutivas que correspondem a ciclos de práticas } \\
\text { consecutivas. }\end{array}$ \\
\hline RC7 & Existem uma ou mais técnicas especificadas para uma ou mais atividades. \\
\hline
\end{tabular}

Quadro 10 Regras de customização do PRO2PI-MFMOD

Fonte: (ZOUCAS, 2010) 
A versão atual do PRO2PI-MFMOD estabelece doze técnicas que podem ser selecionadas e usadas para implementar práticas sequenciais e, assim, apoiar a definição de métodos para a construção de modelos de capacidade de processo. Cada técnica é apresentada a partir da seguinte estrutura: a) Origem: indica o método de construção de modelos utilizado como base para a definição da técnica; b) Descrição: explica a técnica de modo geral, buscando também estabelecer seu propósito e c) Passos: detalham a técnica, indicando as atividades a serem executadas, bem como suas entradas e saídas. As doze técnicas da versão atual do PRO2PI-MFMOD são discriminadas no Quadro 11.

\begin{tabular}{|l|l|}
\hline \multicolumn{2}{|l|}{ Identificador da Técnica, Nome da Técnica } \\
\hline T1 & Tradução de áreas de processo \\
\hline T2 & Questionário \\
\hline T3 & Revisão da literatura \\
\hline T4 & Análise de trabalhos correlatos \\
\hline T5 & Estudo de caso \\
\hline T6 & Representação de domínio \\
\hline T7 & Abstração de processos \\
\hline T8 & Tradução de modelos no formato de requisitos \\
\hline T9 & Brainstorming (tempestade de ideias) \\
\hline T10 & Revisão pelos pares \\
\hline T11 & Entrevista \\
\hline T12 & Workshop (oficina) \\
\hline
\end{tabular}

Quadro 11 Técnicas do PRO2PI MFMOD Adaptado de ZOUCAS (2011)

\subsubsection{CONCLUSÃO DA A REVISÃO DE LITERATURA - PRO2PI-MFMOD}

O objetivo desta revisão foi apresentar o framework de modelos PRO2PI-MFMOD, que será utilizado neste trabalho para guiar a construção de elementos de um modelo de maturidade para o ecossistema SPB. O Quadro 12 apresenta uma compilação da revisão bibliográfica efetuada no eixo teórico dos frameworks de construção de métodos para modelos de capacidade.

\begin{tabular}{|l|l|l|}
\hline Autores & Ano & Contribuição Teórica \\
\hline SALVIANO & 2010 & $\begin{array}{l}\text { Apresenta as práticas para a engenharia de modelos de } \\
\text { capacidade de processo de software }\end{array}$ \\
\hline ZOUCAS & 2010 & $\begin{array}{l}\text { Apresenta o desenvolvimento de um modelo de qualidade } \\
\text { para os desenvolvedores de software do SPB. }\end{array}$ \\
\hline
\end{tabular}




\begin{tabular}{|l|l|l|}
\hline WANGENHEIM & 2010 & $\begin{array}{l}\text { Apresenta o processo de criação de modelos de } \\
\text { maturidade/capacidade }\end{array}$ \\
\hline SALVIANO & 2009 & $\begin{array}{l}\text { Apresenta o framework de modelo MFMOD com todos os } \\
\text { seus componentes: as práticas sequenciais, as regras de } \\
\text { customização, os exemplos de utilização e as técnicas. }\end{array}$ \\
\hline ZOUCAS & 2009 & $\begin{array}{l}\text { Apresenta as técnicas para a engenharia de modelos de } \\
\text { capacidade de processo de software }\end{array}$ \\
\hline SALVIANO & 2006 & $\begin{array}{l}\text { Apresenta o PRO2PI que é uma metodologia de melhoria } \\
\text { de processo multimodelo orientada por perfis de } \\
\text { capacidade de processo. O PRO2PI apoia a melhoria de } \\
\text { processos usando elementos de múltiplos modelos de } \\
\text { capacidade de processo e de outras fontes. }\end{array}$ \\
\hline
\end{tabular}

Quadro 12 Literatura de Referência sobre o PRO2PI-MFMOD

\subsection{CONSIDERAÇÕES FINAIS DOS ASPECTOS CONCEITUAIS}

A fundamentação teórica deste trabalho compreendeu o estudo de temas que permeiam os conceitos e a complexidade dos ambientes de produção de software, que são públicos e que fazem parte de um ecossistema. Para o desenvolvimento da pesquisa foi necessário investigar quais referenciais teóricos seriam úteis para o entendimento do problema a ser resolvido e quais ferramentas poderiam ser utilizadas para resolvê-lo. O problema em questão está associado a certo tipo de arranjo social e tecnológico. Para melhor entender esse arranjo foram realizadas pesquisas sobre os ecossistemas digitais. Além disso, verificou-se que a questão a ser resolvida apresentava-se no formato de um problema sem estruturação, sem o conhecimento de hipóteses iniciais e a natureza desse problema bem com suas possíveis soluções eram desconhecidas tanto dos atores que configuravam o SPB quanto da autora. Nesse cenário os recortes da complexidade e do pensamento sistêmico ofereceram a base teórica para sustentação do desenvolvimento realizado na pesquisa além de propiciar a escolha das ferramentas adequadas para a condução do trabalho.

O recorte teórico da melhoria de processo baseada em modelos de capacidade/maturidade ofereceu a base necessária para expandir os conceitos utilizados nas organizações convencionais considerando a nova definição do termo 
que agora leva em conta a complexidade e a natureza sistêmica que as organizações abrigam. A questão principal era como deveria ser abordado o problema apresentado. Para entender o problema foi necessário conhecer o ambiente onde ele estava inserido. Para tanto, foi necessário o suporte teórico dos ecossistemas digitais. Uma vez definido o objeto buscou-se a natureza do objeto. As buscas levaram, com o suporte teórico da complexidade, ao entendimento que o problema estava relacionado com um sistema complexo. A pergunta seguinte foi: “ como tratar este sistema complexo?" e a resposta veio por meio do recorte do pensamento sistêmico. $O$ recorte teórico que conduziu às questões anteriores e às demais desenvolvidas ao longo da pesquisa esteve sob o olhar da melhoria de processo de software utilizando como instrumentos os modelos de capacidade/maturidade. Esse recorte teve origem na demanda do cliente, que solicitou um modelo de referência para tratar a qualidade no âmbito do SPB bem como nas indagações e na área de pesquisa. 


\section{METODOLOGIA DE PESQUISA}

Este capítulo discute questões metodológicas com foco na Engenharia de Produção e apresenta a abordagem e a justificativa desta pesquisa. Ele também contém o projeto, o roteiro e, as decisões para o planejamento e o desenvolvimento do projeto de pesquisa cujo objetivo é a resolução da sua questão principal: - elaboração de uma estrutura conceitual para um modelo de maturidade cujo objetivo é abordar questões de qualidade em um ecossistema digital de produção de software utilizando para isso a pesquisa-ação como metodologia. O capítulo apresenta ainda um aprofundamento teórico da metodologia de pesquisa utilizada para a condução do trabalho: a pesquisa-ação. $O$ aprofundamento se faz necessário devido a diversas inquietações teóricas percebidas pela autora no momento da definição do protocolo e da preparação da aplicação da pesquisa. As primeiras incertezas estavam relacionadas à pertinência da aplicação da metodologia no presente trabalho. Como demonstrar esta pertinência de forma que outro pesquisador pudesse aplicar os mesmos critérios e chegar a um resultado semelhante? Também existiam incertezas relativas ao papel duplo do pesquisador no trabalho/pesquisa e dessas incertezas vieram questões relativas às ferramentas que deveriam ser usadas pelo pesquisador, enquanto realizador da pesquisa, e pelo membro da equipe do projeto, enquanto responsável pela resolução do problema do cliente. Questões quanto à qualidade de validação da pesquisa também foram objeto de reflexão durante a elaboração do projeto. Essas questões são tratadas neste capítulo e, para isso foi necessária uma investigação detalhada da metodologia pesquisa-ação procurando referências que pudessem auxiliar no entendimento do "como fazer" essa pesquisa. São poucos os autores encontrados que tratam a questão nesse nível de detalhe e todos eles são referidos neste trabalho. Em consequência das questões apontadas anteriormente, o problema da aplicação da pesquisa-ação será retomado no Capítulo 6.

\subsection{MÉTODO E METODOLOGIA}

Este item apresenta os conceitos de método e metodologia encontrados na literatura pesquisada bem como um aprofundamento desses dois conceitos. 


\subsubsection{A METODOLOGIA}

A confusão encontrada na literatura, relativa ao significado dos termos método e metodologia, ocorre devido a um equívoco terminológico entre o significado desses termos (THIOLLENT, 2005). Essa confusão decorre de um não entendimento do que seja o nível da efetiva abordagem da situação sob investigação, com métodos e técnicas particulares, e, o do meta-nível constituído pela metodologia enquanto instância de reflexão sobre o primeiro nível. A metodologia deve ser entendida como a disciplina que se relaciona com a epistemologia ou a filosofia da ciência. O objetivo da metodologia é analisar as características dos vários métodos disponíveis, avaliar suas capacidades, potencialidades, limitações ou distorções e criticar as implicações de sua aplicação. A metodologia também é considerada como um modo de conduzir a pesquisa e pode ser entendida como o conhecimento geral e a habilidade que são necessários ao pesquisador para se orientar no processo de investigação, tomar decisões oportunas, selecionar conceitos, hipóteses, técnicas e dados adequados.

\subsubsection{O MÉTODO}

Para Lakatos (2006), o método é um conjunto de atividades sistemáticas e racionais que, com maior segurança e economia, permite alcançar o objetivo - conhecimentos válidos e verdadeiros, traçando o caminho a ser seguido, detectando erros e auxiliando as decisões do cientista. A aplicação de um método específico, quando adequado às circunstancias e ao objeto de investigação, permite ao pesquisador percorrer o caminho mais seguro na definição das opções a serem adotadas, em outras palavras, permite o aproveitamento de experiências e conhecimentos acumulados sobre o próprio uso do método, contribuindo para aumentar a eficiência da investigação científica.

\subsubsection{A PESQUISA CIENTÍFICA}

A pesquisa científica pode ser entendida como um procedimentos reflexivo sistemático, controlado e crítico, que permite descobrir novos fatos ou dados, relações ou leis, em qualquer campo do conhecimento (LAKATOS, 2006).

\subsubsection{A TAXONOMIA DA PESQUISA CIENTÍFICA}

Dentre as diversas taxonomias utilizadas para caracterizar os tipos de pesquisa a Figura 16 apresenta a taxonomia sugerida por Miguel (2010) e a Figura 17 apresenta o tipo dessa pesquisa considerando a taxonomia apresentada. $\mathrm{O}$ autor 
apresenta três critérios para caracterizar a pesquisa científica. Esses critérios referem-se à natureza, aos objetivos, à abordagem metodológica e ao método de pesquisa.

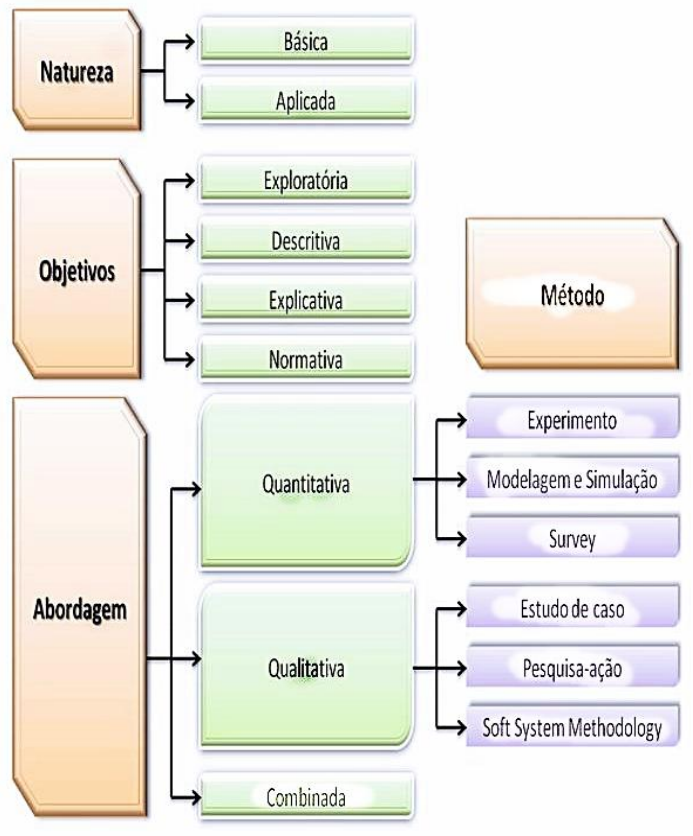

Figura 16 Tipos de pesquisa

Fonte: (MIGUEL, 2010)

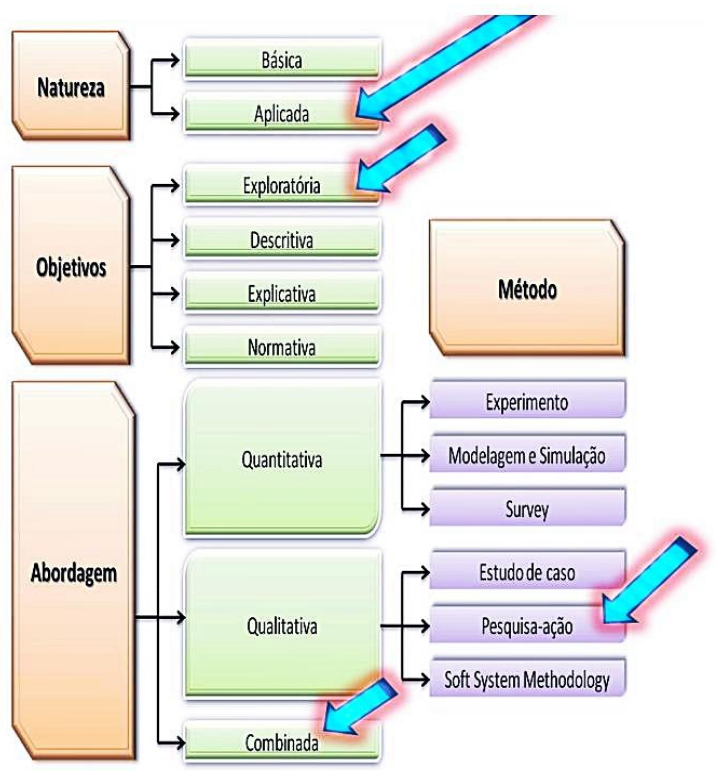

Figura 17 Tipo dessa pesquisa

Fonte: (MIGUEL, 2010)

Quanto á sua natureza, a pesquisa pode ser básica ou aplicada. É básica a pesquisa que procura o progresso científico, a ampliação de conhecimentos teóricos, sem a preocupação de utilização prática. É uma pesquisa formal que tem por meta generalizações, princípios e leis. É aplicada a pesquisa que se caracteriza por interesses práticos, ou seja, que visa resultados que sejam aplicados ou utilizados imediatamente na solução de problemas que ocorrem na realidade. Este segundo tipo de pesquisa pode ser suscitado por objetivos comerciais, por meio do desenvolvimento de novos produtos ou processos orientados para as necessidades do mercado (APPLOLINÁRIO, 2006).

Quanto aos seus objetivos, a pesquisa pode ser classificada de exploratória, descritiva, explicativa ou normativa. É uma pesquisa exploratória aquela que visa proporcionar uma maior familiaridade com um problema, com o objetivo de torná-lo explícito ou construir hipóteses, envolve levantamento bibliográfico, entrevistas, análise de exemplos. A pesquisa descritiva visa descrever as características de uma determinada população ou fenômeno ou o estabelecimento de relações entre 
variáveis, envolve o uso de técnicas de coleta de dados como questionário e observação sistemática. A pesquisa explicativa é definida como aquela cujo objetivo é identificar os fatores que determinam ou contribuem para a ocorrência dos fenômenos; aprofunda o conhecimento da realidade porque explica a razão das coisas, em ciências naturais, requer o uso de método experimental e, em ciências sociais, o uso do método observacional. Por outro lado, a pesquisa normativa tem como foco de interesse, primariamente, o desenvolvimento de políticas, estratégias e ações para aperfeiçoar os resultados disponíveis na literatura, para encontrar uma solução ótima para novas definições de problemas ou para comparar várias estratégias relativas a um dado problema (BERTRAND e FRANSOO, 2002).

Quanto à abordagem do problema, a pesquisa pode ser quantitativa, qualitativa ou combinada. A pesquisa quantitativa considera que tudo pode ser quantificável, ou seja, que se podem traduzir em números opiniões e informações, para classificá-las e analisá-las; requer o uso de recursos e técnicas estatísticas. A pesquisa é considerada qualitativa quando há uma relação dinâmica entre o mundo real e o sujeito ou, em outras palavras, um vínculo indissociável entre o mundo objetivo e a subjetividade do sujeito, que não pode ser traduzido em números, nesse tipo de pesquisa, a interpretação dos fenômenos e a atribuição de significados são básicas para o processo. Uma pesquisa é dita do tipo combinada quando considera que o pesquisador pode combinar aspectos das pesquisas qualitativa e quantitativa em todas ou em algumas das etapas do processo de pesquisa.

Quanto aos métodos utilizados, a pesquisa pode ser executada por meio de experimentos, levantamentos ou surveys, modelagem e simulação, estudo de caso, pesquisa-ação ou Soft System Methodology (SSM). O experimento é usado quando se determina um objeto de estudo, selecionam-se as variáveis que são capazes de influenciá-lo e, definem-se as formas de controle e de observação dos efeitos que cada variável produz no objeto. A pesquisa por levantamento ou survey é utilizada quando envolve a interrogação direta das pessoas cujo comportamento se deseja conhecer. Emprega-se a modelagem e simulação quando o objetivo da pesquisa é experimentar, por meio de um modelo, um sistema real, determinando-se como esse sistema responde a modificações que the são propostas. O estudo de caso envolve o estudo profundo e exaustivo de um ou poucos objetos, de maneira que se permita o seu conhecimento amplo e detalhado. 
A pesquisa-ação é concebida e realizada em estreita associação com uma ação ou com a resolução de um problema coletivo. Os pesquisadores e os participantes representativos da situação ou problema são envolvidos de modo cooperativo ou participativo. A metodologia SSM auxilia a formulação e estruturação do pensamento sobre os problemas em situações complexas. Seu princípio está na construção de modelos conceituais e na comparação desses modelos com o mundo real.

\subsubsection{A PESQUISA NA ENGENHARIA DE PRODUÇÃO}

As abordagens de pesquisa orientadas para a Engenharia de Produção (EP) são de cunho quantitativo, quando se referem a temas técnicos das engenharias, ou de cunho qualitativo, quando o tema está associado às ciências sociais (NAKANO, FLEURY, 1996). Nakano e Fleury realizam um estudo sobre os principais métodos de pesquisa aplicados à EP e apontam que apesar da classificação ser aparentemente simples, nem sempre é possível uma distinção clara entre eles. $\mathrm{Na}$ prática da pesquisa, encontram-se diversas situações em que há superposição de conceitos. Os métodos de pesquisa caracterizados no Quadro 13 são apontados como os principais na EP, sendo que os três métodos mais comuns de pesquisa qualitativa são o estudo de caso, a pesquisa-ação e a pesquisa participante.

\begin{tabular}{|l|l|l|l|}
\hline $\begin{array}{l}\text { Método de } \\
\text { Pesquisa }\end{array}$ & Descrição & $\begin{array}{l}\text { Abordagem } \\
\text { Principal }\end{array}$ & Instrumentos \\
\hline Experimental & $\begin{array}{l}\text { Teste de hipóteses de um } \\
\text { experimento controlado }\end{array}$ & Quantitativa & Experimentos \\
\hline Survey & $\begin{array}{l}\text { Coleta de dados por entrevistas ou } \\
\text { questionários. A análise dos dados } \\
\text { exige tratamento estatístico }\end{array}$ & Quantitativa & Questionários \\
\hline $\begin{array}{l}\text { Pesquisa } \\
\text { participante }\end{array}$ & $\begin{array}{l}\text { Tem como base as metodologias } \\
\text { de observação participante }\end{array}$ & Qualitativa & $\begin{array}{l}\text { Observação } \\
\text { direta }\end{array}$ \\
\hline $\begin{array}{l}\text { Pesquisa- } \\
\text { ação }\end{array}$ & $\begin{array}{l}\text { ação ou resolução de um problema. } \\
\text { Os pesquisadores desempenham } \\
\text { um papel ativo nessa resolução. }\end{array}$ & Qualitativa & $\begin{array}{l}\text { Observação e } \\
\text { participação } \\
\text { direta }\end{array}$ \\
\hline
\end{tabular}




\begin{tabular}{|c|c|c|c|}
\hline $\begin{array}{l}\text { Método de } \\
\text { Pesquisa }\end{array}$ & Descrição & $\begin{array}{l}\text { Abordagem } \\
\text { Principal }\end{array}$ & Instrumentos \\
\hline $\begin{array}{l}\text { Estudo de } \\
\text { caso }\end{array}$ & $\begin{array}{l}\text { Documenta e analisa as atividades } \\
\text { de uma organização ou de um } \\
\text { pequeno grupo dentro dela. A } \\
\text { unidade de análise é a organização } \\
\text { como um todo, um departamento } \\
\text { ou uma área. }\end{array}$ & Qualitativa & $\begin{array}{l}\text { Entrevistas e } \\
\text { outras fontes }\end{array}$ \\
\hline
\end{tabular}

Quadro 13 Principais métodos de pesquisa na EP Fonte: Nakano e Fleury (1996)

\subsection{PESQUISA-AÇÃO}

Nesta seção é apresentado o método de pesquisa adotado nesta tese. $\mathrm{Na}$ seção 3.2.1. é apresentada uma introdução sobre os princípios da pesquisa-ação. Uma vez conhecidos os princípios do método, na seção 3.2.2 é abordado o processo da pesquisa-ação. Em seguida, a seção 3.2.3 apresenta a condução do processo de pesquisa-ação. Em 3.2.4 são apresentadas as questões relativas à qualidade e à validação da pesquisa-ação.

\subsubsection{PRINCÍPIOS DA PESQUISA-AÇÃO}

Segundo Dick e Kock et al $(1993,1997)$ a pesquisa-ação é um método de pesquisa que tem o duplo objetivo de pesquisa e ação: a) pesquisa para ampliar o conhecimento científico e b) ação para promover uma melhoria na organização ou comunidade onde a pesquisa está sendo realizada.

O termo "organização" remete à pesquisa-ação realizada com um grupo de profissionais numa instituição, como uma empresa ou uma escola; enquanto o termo "comunidade" é usado em áreas que investigam grupos sociais, como moradores de um bairro ou crianças de uma determinada faixa etária. Nesta pesquisa, cujo objeto é um ambiente colaborativo de desenvolvimento de software adota-se o termo "organização".

A pesquisa-ação é um termo genérico, que cobre muitas formas de pesquisa orientada para a ação e indica uma diversidade na teoria e na prática observada entre os pesquisadores usuários desse método. Aos pesquisadores ele fornece várias opções para o que pode ser apropriado para suas questões de pesquisa 
(COUGHLAN e COGHLAN, 2002). Segundo Thiollent (2005), a pesquisa-ação é um tipo de pesquisa social com base empírica que é concebida e realizada em estreita associação com uma ação ou com a resolução de um problema coletivo, na qual os pesquisadores e os participantes representativos da situação ou do problema são envolvidos de modo cooperativo ou participativo. As variáveis envolvidas não são isoláveis, posto que todas elas interferem no que está sendo observado. Portanto, assim como nas outras pesquisas da linha interpretativista, a substancialidade dos pesquisadores não é total, pois o que cada pesquisador observa e interpreta nunca é independente da sua formação, de suas experiências anteriores e da própria imersão na situação investigada. Thiollent (2005) explica ainda que uma pesquisa pode ser qualificada de pesquisa-ação quando houver uma ação por parte das pessoas ou grupos implicados no problema sob observação. Além disso, é preciso que a ação seja não trivial, o que quer dizer uma ação problemática que merece investigação para ser elaborada e conduzida. Na pesquisa-ação, os pesquisadores desempenham um papel ativo no equacionamento dos problemas encontrados, no acompanhamento e na avaliação das ações desencadeadas em função desses problemas.

Oquist (1978) define a pesquisa-ação como a produção de conhecimento e ação e a modificação intencional de uma dada realidade. A ação implica consequências que modificam uma dada realidade, independentemente de essa ação ter ou não sucesso em termos da intenção de modificar a realidade em questão em uma dada direção. Bryman (1989) considera que a pesquisa-ação é uma abordagem à pesquisa social aplicada na qual o pesquisador e o cliente colaboram para 0 desenvolvimento de um diagnóstico e para a solução de um problema e por meio da qual as descobertas resultantes contribui para a base de conhecimento em um domínio empírico particular.

Portanto, a pesquisa-ação é uma estratégia de pesquisa válida na Engenharia de Produção que visa produzir conhecimento e resolver um problema prático. A relação entre essas duas preocupações é variável, porém é desejável que haja um equilíbrio entre elas. Thiollent (2005) define esses dois objetivos como: a) Objetivo técnico: contribuir para o melhor equacionamento possível do problema considerado como central da pesquisa, com levantamento de soluções e proposta de ações correspondentes às soluções para auxiliar o agente na sua atividade transformadora 
da situação e b) Objetivo científico: obter informações que seriam de difícil acesso por meio de outros procedimentos e, aumentar o conhecimento de determinadas situações.

\subsubsection{O processo da pesquisa-ação}

Em termos de processo, segundo Thiollent (2007), a essência da definição de pesquisa-ação pode ser pensada, de maneira simplificada, em duas fases, conforme a Figura 18. A primeira é a fase de diagnóstico, que envolve uma análise colaborativa da situação pelos pesquisadores e participantes da pesquisa. A partir desse diagnóstico, são formuladas teorias em relação ao domínio da pesquisa. Neste caso, teorias são referidas como sinônimos para conjecturas ou conhecimento especulativo e prático. Em uma segunda etapa, a fase terapêutica envolve experimentos e tentativas, realizados de forma colaborativa. Nessa fase, são introduzidas mudanças e seus efeitos são estudados. Iteram-se as duas fases até que o problema seja resolvido.

Argyris et al. (1985) fazem uma analogia de um processo semelhante a este com experimentação, afirmando que o conhecimento prático embutido na ação, representado pela identificação de fatores causais que podem ser manipulados para provocar as consequências desejadas dentro de uma conjunto de circunstâncias, é a hipótese sendo testada. Caso as consequências pretendidas ocorram, então a hipótese é confirmada, caso contrário, ela é refutada.

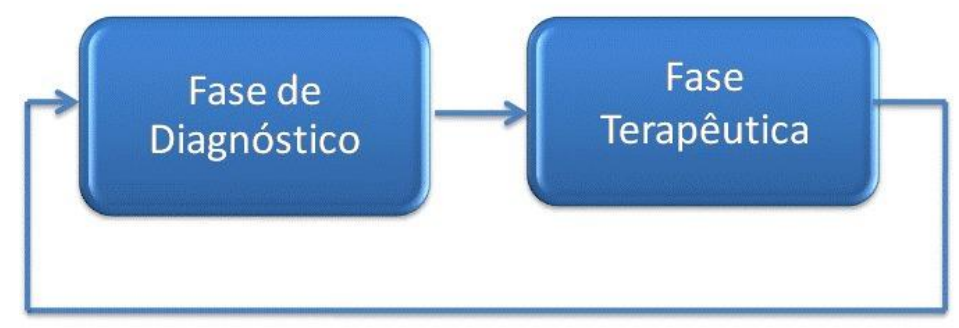

Figura 18 Processo simplificado da pesquisa-ação

Ainda que não haja neutralidade na observação e na manipulação do ambiente de estudo, exigida para a refutação de hipóteses, qualquer metodologia científica deve contribuir para o corpo de conhecimento científico de maneira válida e rigorosa. Além disso, a avaliação científica de qualquer afirmação dentro do corpo do conhecimento científico deve passar pela replicabilidade dos resultados 
encontrados. Como consequência, um processo de investigação semelhante ao apresentado na Figura 18 raramente é adotado na prática, pois não define qualquer tipo de orientação em relação a essas questões.

Para Checkland e Holwell (1988), qualquer modo de pesquisa pode ser pensado como vinculado aos seguintes elementos: um conjunto coeso de ideias formando um arcabouço conceitual F o qual é utilizado em uma metodologia $\mathbf{M}$ para investigar uma área de interesse A. Por exemplo, em Engenharia de Software poderia se pensar na seguinte pesquisa (simplificada) segundo a visão positivista: investigar se os ecossistemas digitais de produção de software (área de interesse A) podem ser avaliados e melhorados por meio dos modelos de maturidade convencionais (arcabouço conceitual F), a partir da aplicação da pesquisa-ação (metodologia M). Essa proposição é ilustrada na parte superior da Figura 19.

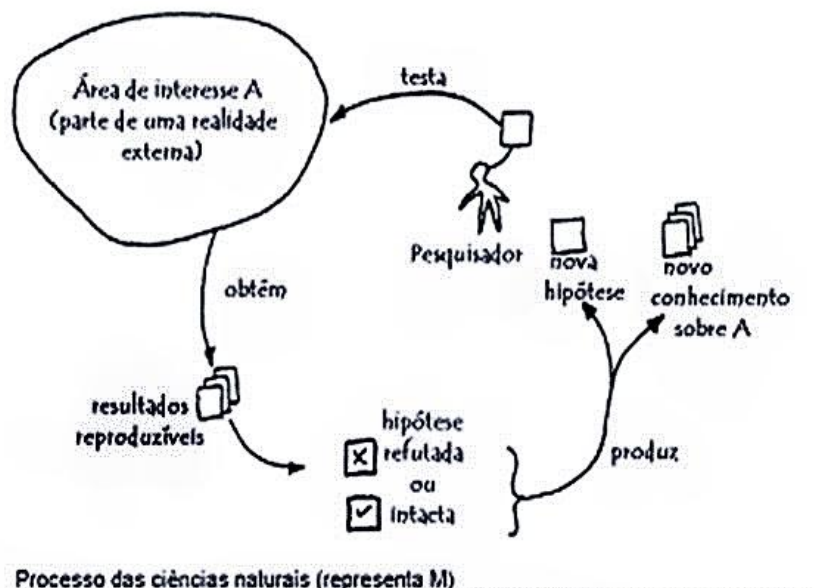

Processo das ciencias nalurais (representa I)

Processo da pesquisa-açăo (dectara $M)$

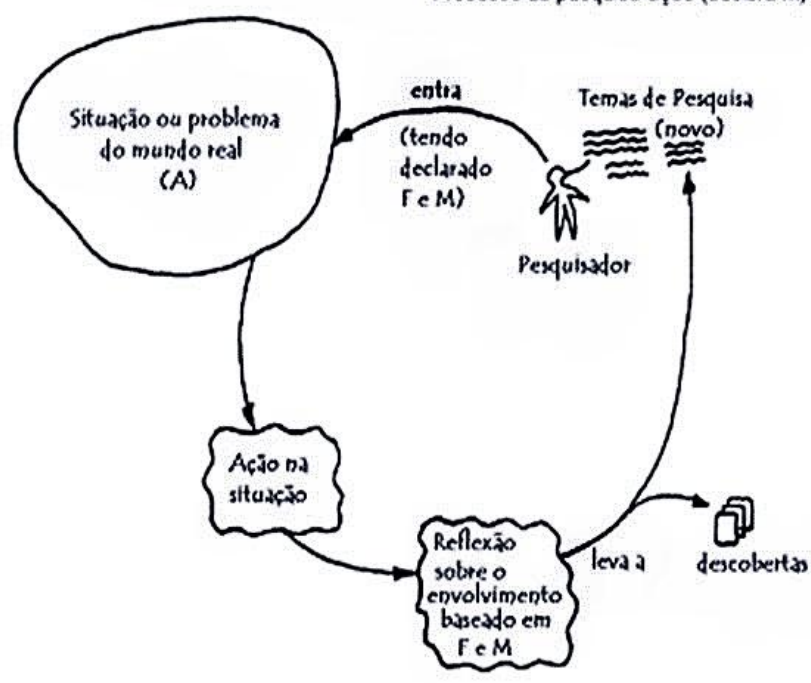

Figura 19 Processos das ciências naturais e da pesquisa-ação Fonte: Checkland e Holwell (1988) apud HOSS (2011) 
Para Checkland e Holwell (1998), a pesquisa-ação modifica os papeis de $\mathbf{F}$, de $\mathbf{M}$ e até mesmo de A, na medida em que o pesquisador passa a estar envolvido no fluxo de transformações que ocorrem em uma determinada situação. Neste caso, o pesquisador interessado em um tema de pesquisa, declara $\mathbf{F}$ e $\mathbf{M}$, e, então, entra em uma situação do mundo real em que aquele tema seja relevante. Como consequência, a pesquisa-ação não apenas representa $M$, como nas ciências naturais, mas também deve declarar um protocolo de pesquisa que permita que o processo de investigação seja recuperável por qualquer interessado em submeter a pesquisa à análise crítica, conforme ilustra a parte inferior da Figura 19.

Ainda que com isto a pesquisa-ação não atinja a repetibilidade alcançada nas ciências naturais, o método é suficiente para tornar claros os processos e modelos que permitiram ao pesquisador fazer suas interpretações e derivar suas conclusões. A importância de ter critérios explícitos antes que a pesquisa seja conduzida também é enfatizada por Avison et al. (1999), que afirmam que, sem isto, a avaliação dos resultados tende a ficar comprometida e, eventualmente, o que está sendo descrito pode ser ação, mas não pesquisa, ou pesquisa, mas não ação.

\subsubsection{A CONDUÇÃO DO PROCESSO DE PESQUISA-AÇÃO}

O processo apresentado na Figura 19 oferece indicações importantes de questões que devem ser tratadas para conferir rigor ao processo da pesquisa-ação, mas ainda assim não apresenta um guia explicativo de como a pesquisa deve ser conduzida. Com este propósito, outros pesquisadores expandiram a estrutura básica que guia o processo da pesquisa-ação. O processo mais comum, e que, segundo Davison et al. (2004), tem alcançado a condição de processo canônico, é de Susman e Evered (1978), o qual é composto por cinco fases, conforme mostra

\section{a Figura 20.}

A fase de Diagnóstico deve identificar um problema na organização e consiste em descobrir o campo de pesquisa, os interessados e suas expectativas de uma perspectiva holística. Nessa etapa, existe ainda a definição do tema de pesquisa o qual é representado através da designação do problema prático e da área do conhecimento a ser abordada. Os pesquisadores e alguns membros da organização na situação investigada começam a detectar os problemas, os atores, 
as capacidades de ação e os tipos de ação possíveis (diagnóstico para identificar o problema). Esta primeira etapa do processo de pesquisa-ação, que tem grande importância devido ao fato de encaminhar as fases subsequentes da pesquisa, possui um aspecto interno, que diz respeito ao diagnóstico da situação e das necessidades dos atores e à formação de equipes envolvendo pesquisadores e clientes, e um aspecto externo, que tem por objetivo divulgar essas propostas e obter o comprometimento dos participantes e interessados. Existem dois problemas a serem esclarecidos nessa etapa: o plano institucional e o plano metodológico. No que diz respeito ao institucional, destaca-se a necessidade de definir o grupo de pesquisadores e suas relações com os atores da situação.

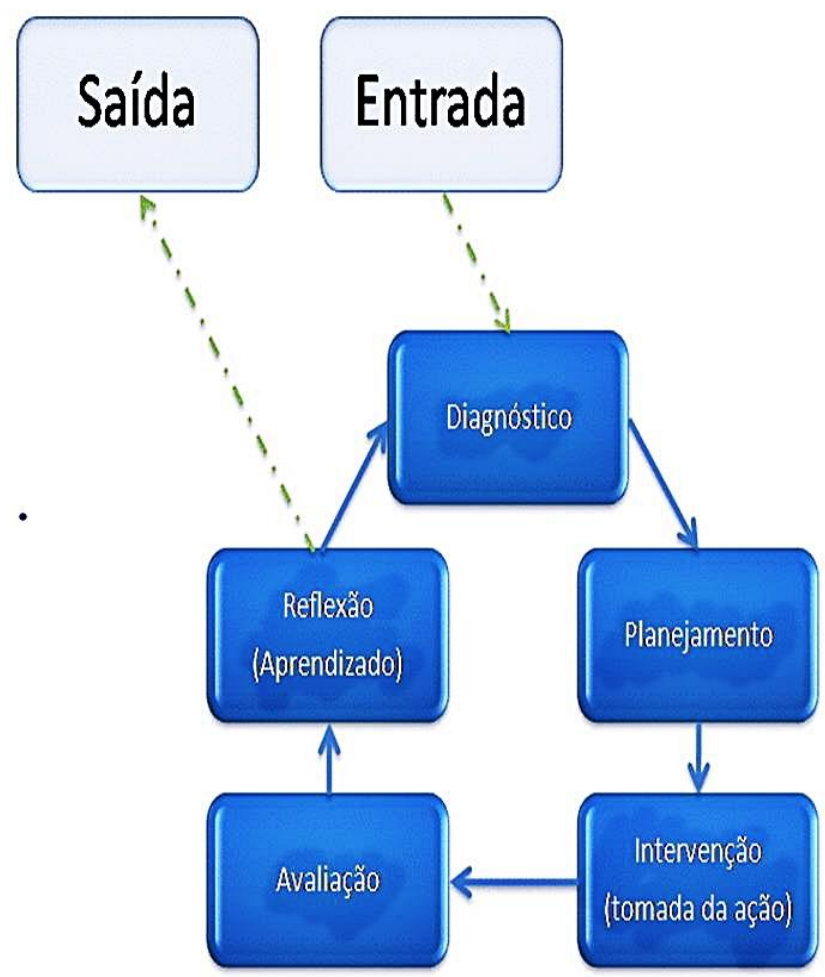

Figura 20 Processo "canônico" da pesquisa-ação

Fonte: (DAVISON et al., 2004)

É importante informar a todos os participantes sobre os objetivos do estudo e a metodologia empregada. O principal foco está em obter as informações significativas para elaborar o projeto. Deve-se utilizar um quadro conceitual, elaborado em conjunto com os pesquisadores e atores da situação, e pesquisa de campo de caráter diagnóstico, realizada por meio de entrevistas abertas, para detectar os 
principais problemas existentes (THIOLLENT, 2005). Os pesquisadores devem considerar a fase de diagnóstico como encerrada, e passar à fase seguinte, no momento em que concluírem que existe clareza e consenso em dois ou três pontos prioritários que darão base à pesquisa-ação.

A fase de Planejamento de ação deve considerar as ações alternativas para resolver o problema; é a etapa na qual são definidas as ações para o quadro diagnosticado. As definições são guiadas pelas hipóteses que representam as suposições formuladas pelo pesquisador a respeito de possíveis soluções e resultados. As hipóteses, por sua vez, devem ser acompanhadas de uma formulação teórica científica. A situação é pesquisada por meio de diversos tipos de instrumentos de coleta de dados, que são discutidos e progressivamente interpretados pelos grupos que participam da pesquisa. No momento em que se obtém um claro diagnóstico sobre a realidade da organização e os eventos ou pontos que se deseja pesquisar, os pesquisadores iniciam a prática, que ocorre por meio de atividades para guiar a ação. Os seminários em grupo são operacionalizados, sendo o grupo composto pelos promotores da pesquisa, por membros da gerência de diversas áreas e categorias profissionais e por consultores ou pesquisadores externos. As principais funções do grupo permanente que tem poder de decisão, são as seguintes: a) elaboração dos temas e problemas prioritários a serem investigados; b) elaboração da problemática na qual serão tratados os problemas e as correspondentes hipóteses de pesquisa; c) coordenação de atividades em sintonia com o trabalho dos outros grupos e com as ações de formação; d) centralização de informações provenientes de diversas fontes; e) interpretação dos resultados; f) busca de soluções e propostas de ação; g) acompanhamento de ações implementadas; h) avaliação de resultados; e i) divulgação de resultados pelos canais apropriados. Conforme resumido por Thiollent (2005), a fase de planejamento é composta por um grande conjunto de entrevistas individuais e coletivas ou questionários aplicados a pessoas-chaves da organização, que irão expor suas reclamações, constatações e sugestões a respeito do assunto em pauta. Todas estas informações coletadas entre os entrevistados servem como base para posterior debate.

A fase de Execução das ações, com seleção de um roteiro de ação corresponde á implantação das ações planejadas. Um elemento central nesta etapa, segundo 
Thiollent (2007), é a técnica de seminário, utilizada para examinar, discutir e tomar decisões acerca do processo de investigação. Essa fase consiste em, com base nas investigações em curso, difundir os resultados, definir objetivos alcançáveis por meio de ações concretas e apresentar propostas que poderão ser negociadas entre as parte interessadas. A fase de Execução engloba medidas práticas baseadas nas etapas anteriores: difusão de resultados, definição de objetivos alcançáveis por meio de ações concretas, apresentação de propostas a serem negociadas entre as partes interessadas e implementação de ações-piloto que posteriormente, após avaliação, podem ser assumidas pelos atores sem atuação dos pesquisadores (THIOLLENT, 2005).

A fase de Avaliação das consequências da ação é aquela na qual se realiza a análise dos efeitos das ações frente ao apoio teórico utilizado como ponto de partida para a definição das ações e que tem por objetivos: observar, redirecionar o que realmente acontece e resgatar o conhecimento produzido no decorrer do processo. Esta etapa final do processo de pesquisa-ação apresenta dois objetivos principais: verificar os resultados das ações no contexto organizacional da pesquisa e suas consequências a curto e médio prazos e extrair ensinamentos que serão úteis para continuar a experiência e aplicá-la em estudos futuros.

A fase de Reflexão trata da aprendizagem específica e da identificação dos ensinamentos da experiência, com retorno ao ponto de partida para evidenciar o conhecimento generalizável adquirido sobre o problema. Ela envolve a circulação de informação entre os participantes e outros setores da organização. A aprendizagem é facilitada pela colaboração temporária com especialistas em assuntos técnicos cujo conhecimento tenha sido útil ao grupo. A pesquisa-ação, como informam Kock et al (1997), é tipicamente realizada em ciclos iterativos que sucessivamente refinam o conhecimento adquirido nos ciclos anteriores. A execução de diversos ciclos é vista como uma forma de aumentar o rigor da pesquisa, uma vez que, a cada ciclo, ela passa por nova revisão crítica, o que possibilita encontrar erros, inconsistências ou vieses anteriormente não identificados. Segundo McKay e Marshall (2001), a representação usual do processo de pesquisa-ação é feita por meio de um ciclo. Na sua origem, as duas etapas essenciais da pesquisa-ação são a de refletir sobre o problema (estágio de diagnóstico) e a de agir sobre o problema (estágio terapêutico). Na literatura de pesquisa-ação são encontradas diferentes 
formas de apresentar os ciclos conforme observado em Kemmis e McTaggart (2005), Susman e Johnson (2004, 2008), Stringer (1999, apud BERG 2004) e Evered (1978, apud BASKERVILLE, 1999).

Esta pesquisa adotou ciclos com as quatro etapas - Planejar, Agir, Observar e, Refletir - de Kemmis e McTaggart (2004), esquematizadas na Figura 21. Esse tipo de ciclo é bem reportado na literatura por Berg, Herr e Anderson e Riel (2004, 2005, 2007) e possui um número de etapas que não é nem tão pequeno de tal forma que cada etapa contenha várias sub-etapas embutidas, nem tão grande que fragmente demais procedimentos que estejam fortemente relacionados.

$\mathrm{Na}$ etapa Planejar, planeja-se o ciclo da pesquisa-ação, definindo-se a solução a ser investigada, as ações a serem realizadas, os dados a serem coletados e a forma como será feita a análise desses dados

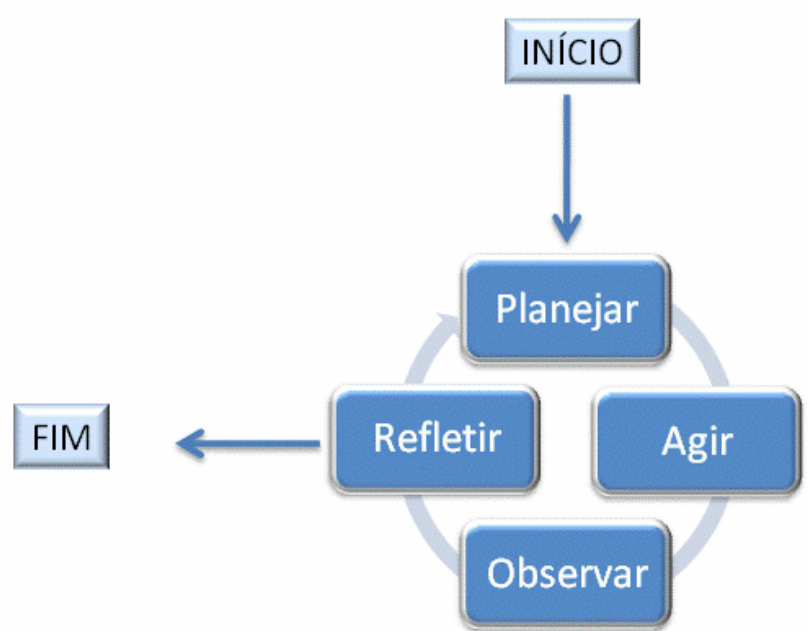

Figura 21 Etapas do ciclo da pesquisa-ação

$\mathrm{Na}$ etapa Agir, a solução é aplicada. No caso desta pesquisa, a etapa Agir consiste na implementação das etapas da metodologia SSM, em conjunto com a equipe de projeto/pesquisadores, e na disseminação do aprendizado em cada uma das etapas junto aos coordenadores do ecossistema SPB, conforme definido na etapa de Planejar.

$\mathrm{Na}$ etapa Observar, é feita a coleta dos dados quantitativos e qualitativos durante o período previamente definido na etapa Planejar. A coleta desses dados se dá tanto nos resultados das etapas da SSM quanto por meio de séries históricas, entrevistas, surveys e outras formas. 
Na etapa Refletir, é feita a análise dos dados resultantes da aplicação das etapas da SSM e, se necessário, de outras formas complementares, e uma reflexão sobre os resultados obtidos. Nessa reflexão, busca-se identificar os efeitos decorrentes da aplicação da etapa, verificar se o objetivo da etapa foi atingido e apropriado por todos os envolvidos e, também, a necessidade de ajustes e refinamentos para a aplicação da etapa seguinte. Nesta pesquisa, os casos de resultados de reflexão relacionados com seu tema, são submetidos a à avaliação por pares por meio da publicação de artigos.

\subsubsection{QUALIDADE E VALIDAÇÃO DA PESQUISA-AÇÃO}

A qualidade, a avaliação e a validação do processo foram preocupações constantes durante todo o desenvolvimento desta pesquisa. Essas preocupações têm como base o histórico da pesquisa-ação informado por autores como Bermejo, Thiollent, Coughlan e Coghlam e Thompson e Perry (2000, 2005, 2002, 2004). Durante as décadas iniciais da pesquisa-ação a tendência era avaliá-la aplicando métodos e critérios da pesquisa convencional. A pesquisa-ação era considerada um modelo de experimentação no qual a ação era submetida à prova e eram utilizadas as definições de um grupo a ser testado e de um outro grupo de controle ao qual não se aplicava a ação. Essa prática foi abandonada e a pesquisa-ação consolidou-se como um tipo determinado de pesquisa que enfatiza a participação e a mudança. Assim, a pesquisa-ação não deve ser avaliada com os mesmos critérios da pesquisa empírica tradicional mas deve ser avaliada com critérios já definidos que sejam adequados à sua natureza. Para a realização dessas verificações e avaliações nesta pesquisa foram escolhidos os métodos sugeridos pelos autores Snyder (apud DICK, 1997), Coughlan e Coghlam, Thiollent e Thompson\&Perry (2002, 2005, 2004) e Bermejo (2000).

\section{Qualidade, validação e rigor metodológico}

Para Coughlan e Coghlam, um dos aspectos importantes na condução de uma pesquisa-ação é seu o rigor metodológico. As maiores ameaças para o rigor metodológico podem ocorrer devido à não imparcialidade do pesquisador, a inferências indevidas, a avaliações tendenciosas, bem como a preconceitos levados para a condução da pesquisa. Assim buscando o máximo rigor metodológico, um maior cuidado deve ser considerado para observar como os dados são 
gerados, coletados, explorados e avaliados, bem como para verificar como os eventos são questionados e interpretados por meio dos múltiplos ciclos da pesquisaação.

Outra análise importante sobre a qualidade do trabalho é a que se faz em relação aos diversos tipos de validade presentes, com maior ou menor intensidade em qualquer tipo de pesquisa. O Quadro 14 indica, na primeira coluna, os diversos tipos de validade e na segunda coluna o seu significado.

\begin{tabular}{|l|l|}
\hline Validade & Aspectos do trabalho \\
\hline Interna & $\begin{array}{l}\text { Compreende o nível de confiança em relação a causa e efeito } \\
\text { entre as variáveis (um exemplo é a constatação de que as } \\
\text { conclusões são resultados das evidências). }\end{array}$ \\
\hline Externa & $\begin{array}{l}\text { Significa o grau de generalização das conclusões da pesquisa } \\
\text { (ou seja, a verificação de quão aplicáveis são os resultados } \\
\text { para outros objetos de análise). }\end{array}$ \\
\hline Construtiva & $\begin{array}{l}\text { Consiste na extensão com a qual uma observação mede o } \\
\text { conceito que se pretende medir. }\end{array}$ \\
\hline Descritiva & $\begin{array}{l}\text { É expressa pelo grau de exatidão do relatório da pesquisa, ou } \\
\text { seja, representa a situação pesquisada. }\end{array}$ \\
\hline Interpretativa & $\begin{array}{l}\text { Compreende a extensão com a qual a interpretação dada } \\
\text { representa o que está sendo estudado, como no caso da } \\
\text { pesquisa empírica. }\end{array}$ \\
\hline Teórica & $\begin{array}{l}\text { Consiste no grau de concordância dos dados com a teoria } \\
\text { postulada, ou seja, trata-se da constatação de que a } \\
\text { apresentados. }\end{array}$ \\
\hline
\end{tabular}

Quadro 14 Tipos de Validade

Fonte: Croom (2005)

Thiollent (2005) propõe duas abordagens de avaliação para uma pesquisa-ação. Na primeira, sugere alguns aspectos gerais que devem ser alvos de avaliação: pontos estratégicos, capacidade de mobilização, capacidade de propostas, continuidade do projeto, participação e qualidade do trabalho em equipe, efetividade das atividades de formação, conhecimento e informação, comunicação e, atividade de apoio. Esses aspectos estão caracterizados no Quadro 15. Na segunda abordagem, propõe que 
a pesquisa-ação seja avaliada considerando objetivos de conhecimentos alcançáveis e, entre eles, destaca a coleta de informação original, a concretização de conhecimentos teóricos, a comparação com interlocutores, a produção de material escrito, os ensinamentos que emergem durante a ação e as validações a partir de pesquisas semelhantes. O Quadro 16 apresenta esses objetivos com uma breve descrição.

\begin{tabular}{|c|c|}
\hline $\begin{array}{l}\text { Aspectos Gerais Alvos de } \\
\text { Avaliação }\end{array}$ & Descrição \\
\hline Pontos estratégicos & $\begin{array}{l}\text { Clareza de objetivos, identificação e resolução de } \\
\text { problemas, e negociação dos objetivos com } \\
\text { membros da diretoria }\end{array}$ \\
\hline Capacidade de mobilização & $\begin{array}{l}\text { Aceitação da iniciativa por diversas áreas da } \\
\text { organização e engajamento de um número } \\
\text { significativo de pessoas }\end{array}$ \\
\hline Capacidade de propostas & $\begin{array}{l}\text { Adequação, relevância e viabilidade das propostas } \\
\text { apresentadas e habilidade dos grupos no seu } \\
\text { encaminhamento. }\end{array}$ \\
\hline Continuidade do projeto & Harmonia no decorrer do tempo \\
\hline Participação & $\begin{array}{l}\text { Efetividade na participação entre diversos níveis } \\
\text { hierárquicos }\end{array}$ \\
\hline $\begin{array}{l}\text { Qualidade do trabalho em } \\
\text { equipe }\end{array}$ & $\begin{array}{l}\text { Habilidade no gerenciamento das relações e } \\
\text { qualidade nas relações interpessoais }\end{array}$ \\
\hline $\begin{array}{l}\text { Efetividade das atividades } \\
\text { de formação }\end{array}$ & $\begin{array}{l}\text { Efeito global de autoconhecimento da instituição e } \\
\text { capacidade de aprendizagem }\end{array}$ \\
\hline Conhecimento e informação & $\begin{array}{l}\text { Adequação do questionário e de outros instrumentos } \\
\text { de pesquisa, consistência e validade dos resultados } \\
\text { encontrados, qualidade dos relatórios, possibilidade } \\
\text { de publicação em revistas científicas e comparações } \\
\text { com outros estudos }\end{array}$ \\
\hline Comunicação & $\begin{array}{l}\text { Possibilidade de criação de mecanismos internos, } \\
\text { assembleias e reuniões com participantes, } \\
\text { adequação à linguagem utilizada na cultura } \\
\text { organizacional e adequação aos canais de difusão }\end{array}$ \\
\hline
\end{tabular}




\begin{tabular}{|l|l|}
\hline $\begin{array}{c}\text { Aspectos Gerais Alvos de } \\
\text { Avaliação }\end{array}$ & Descrição \\
\hline Atividade de apoio & $\begin{array}{l}\text { Qualidade, rapidez e eficácia no processamento de } \\
\text { dados e na produção de material de divulgação e } \\
\text { capacidade de obter o opoio de técnicos em } \\
\text { informática. }\end{array}$ \\
\hline
\end{tabular}

Quadro 15 Aspectos gerais de avaliação de Thiollent (2005)

\section{Objetivos Alcançáveis}

A coleta de informação original acerca de situações ou de atores em movimento

A concretização de conhecimentos teóricos, obtida de modo dialogado na relação entre pesquisadores e membros representativos das situações ou problemas investigados

A comparação das representações próprias aos vários interlocutores, com aspecto de cotejo entre saber formal e saber informal acerca da resolução de diversas categorias de problemas.

A produção de guias ou de regras práticas para resolver os problemas e planejar as correspondentes ações

Os ensinamentos positivos ou negativos quanto à conduta da ação e suas condições de êxito

Possíveis validações estabelecidas a partir de várias pesquisas semelhantes e com o aprimoramento da experiência dos pesquisadores

Quadro 16 Objetivos de conhecimento alcançáveis de Thiollent (2005)

Outros autores a tratar a questão da qualidade da pesquisa-ação são Thompson e Perry (2004). Para esses autores, a pesquisa-ação, assim como qualquer outro método de pesquisa científica, deve ser pautada na confiabilidade e na validade, características que medem sua qualidade ou rigor científico. A confiabilidade é definida por Yin (2005) como a capacidade de demonstrar que os procedimentos de uma pesquisa (por exemplo, as etapas para coleta ou análise de dados) podem ser repetidos apresentando os mesmos resultados. A validade de uma pesquisa é definida como a condição na qual suas conclusões ou inferências são verdadeiras. Yin (2005) ainda classifica a validade em interna, externa e de construto. Thompson 
e Perry (2004) também citam a validade contingente, que demonstra que um relatório científico denomina e descreve alguns mecanismos generativos gerais que explicam como os construtos podem operar dentro de seu contexto. Nesse tipo de validade, a pesquisa emprega diversas abordagens para assegurar que as incertas fronteiras dos sistemas sociais envolvidos e a natureza contemplativa dos atores participantes desses sistemas são consideradas no projeto.

Lembrando que a qualidade de uma pesquisa científica somente pode ser julgada em termos específicos do paradigma no qual o pesquisador trabalha, ou seja, os critérios para um paradigma podem ser quase insignificantes para um outro paradigma, Thompson e Perry (2004) sugerem seis critérios para avaliar a qualidade (validade e confiabilidade) da pesquisa-ação sob o paradigma do realismo: adequação ontológica, validade contingente, percepções múltiplas de participantes e pesquisadores associados, fidedignidade metodológica, generalização analítica e validade de construto. O Quadro 17 apresenta aspectos iniciais propostos para a validação do processo de pesquisa-ação. Os seis critérios são propostos para a análise da validade do processo científico. Em um primeiro instante, esses critérios propostos podem ser questionados, este, entretanto, não é o objetivo deste trabalho. Assim, considerando que os critérios propostos sejam válidos, pode-se discutir como conduzir a avaliação de cada uma das etapas da pesquisa-ação. 


\begin{tabular}{|c|c|c|c|}
\hline Critério & $\begin{array}{c}\text { Objetivo do critério e medidas } \\
\text { aplicadas }\end{array}$ & $\begin{array}{c}\text { Fase da pesquisa } \\
\text { utilizada }\end{array}$ & Medidas aplicadas na pesquisa \\
\hline $\begin{array}{l}\text { Adequação } \\
\text { ontológica }\end{array}$ & $\begin{array}{l}\text { O problema de pesquisa lida com o } \\
\text { complexo fenômeno das ciências } \\
\text { sociais envolvendo pessoas } \\
\text { conscientes. Demonstra que o mundo } \\
\text { que está sendo investigado é criação } \\
\text { independente de mentes e criaturas } \\
\text { vivas ou do mundo de ideias, arte, } \\
\text { ciências, linguagens, ética e } \\
\text { instituições. }\end{array}$ & $\begin{array}{l}\text { Projeto da } \\
\text { pesquisa e análise } \\
\text { de dados }\end{array}$ & $\begin{array}{l}\text { Formulação adequada da questão de pesquisa; } \\
\text { uso da teoria prévia; fundamentação teórica; } \\
\text { projeto da pesquisa-ação; triangulação de dados; } \\
\text { desenvolvimento da base de dados da pesquisa e } \\
\text { de evidências para avaliação. }\end{array}$ \\
\hline $\begin{array}{l}\text { Validade } \\
\text { contingente }\end{array}$ & $\begin{array}{l}\text { Estabelece a validade sobre os } \\
\text { mecanismos generativos que são } \\
\text { denominados e descobertos pela } \\
\text { pesquisa e os contextos que os } \\
\text { tornam contingentes (eventuais) }\end{array}$ & $\begin{array}{l}\text { Projeto da } \\
\text { pesquisa e análise } \\
\text { de dados }\end{array}$ & $\begin{array}{l}\text { Projeto da pesquisa-ação; detalhes das } \\
\text { circunstâncias organizacionais e do principal } \\
\text { contexto do projeto da pesquisa-ação; } \\
\text { desenvolvimento da base de dados da pesquisa e } \\
\text { de evidências para avaliação. }\end{array}$ \\
\hline $\begin{array}{l}\text { Percepções } \\
\text { múltiplas de } \\
\text { participantes e } \\
\text { pesquisadores } \\
\text { associados }\end{array}$ & $\begin{array}{l}\text { Demonstra como a pesquisa revela o } \\
\text { mundo real, embora de uma forma } \\
\text { que seja apenas imperfeita e } \\
\text { probabilisticamente compreensível. O } \\
\text { foco está na sensibilização dos } \\
\text { valores da pesquisa. }\end{array}$ & $\begin{array}{l}\text { Projeto da } \\
\text { pesquisa, coleta e } \\
\text { análise de dados, } \\
\text { posterior análise } \\
\text { de dados. }\end{array}$ & $\begin{array}{l}\text { Fontes de dados múltiplas; apresentação de } \\
\text { evidências de apoio; questionamento amplo em } \\
\text { entrevistas antes das questões exploratórias; } \\
\text { triangulação de dados; consciência dos valores } \\
\text { próprios e seu impacto na coleta de dados; } \\
\text { revisão por pares. }\end{array}$ \\
\hline
\end{tabular}




\begin{tabular}{|c|c|c|c|}
\hline $\begin{array}{l}\text { Fidedignidade } \\
\text { metodológica }\end{array}$ & $\begin{array}{l}\text { Estabelecimento de um relatório que } \\
\text { possa ser avaliado. }\end{array}$ & $\begin{array}{l}\text { Projeto da } \\
\text { pesquisa, coleta e } \\
\text { análise de dados }\end{array}$ & $\begin{array}{l}\text { Desenvolvimento da base de dados da pesquisa e } \\
\text { de evidências para avaliação; uso frequente de } \\
\text { citações relevantes no relatório para fundamentar } \\
\text { a construção da teoria; descrições de } \\
\text { procedimentos com detalhes de datas, } \\
\text { respondentes e tempo. }\end{array}$ \\
\hline $\begin{array}{l}\text { Generalização } \\
\text { analítica }\end{array}$ & $\begin{array}{l}\text { Estabelecimento da primazia da } \\
\text { construção da teoria no relatório. }\end{array}$ & $\begin{array}{l}\text { Projeto da } \\
\text { pesquisa, coleta e } \\
\text { análise de dados }\end{array}$ & $\begin{array}{l}\text { Identificação das questões de pesquisa antes da } \\
\text { coleta de dados; desenvolvimento da teoria por } \\
\text { meio da triangulação de dados; não utilização de } \\
\text { técnicas quantitativas. }\end{array}$ \\
\hline $\begin{array}{l}\text { Validade de } \\
\text { construto }\end{array}$ & $\begin{array}{l}\text { Determina quão bem os construtos na } \\
\text { teoria que está sendo construída são } \\
\text { mensuráveis pela pesquisa. }\end{array}$ & $\begin{array}{l}\text { Projeto da } \\
\text { pesquisa, coleta e } \\
\text { análise de dados }\end{array}$ & $\begin{array}{l}\text { Fundamentação teórica; entrevistas com } \\
\text { especialistas de diferentes áreas; } \\
\text { desenvolvimento e uso de protocolos de } \\
\text { entrevistas; avaliação de publicações e } \\
\text { documentos de origem interna das empresas; } \\
\text { desenvolvimento de uma base de dados } \\
\text { detalhando o encadeamento de evidências; } \\
\text { devolutivas das transcrições das entrevistas aos } \\
\text { informantes para confirmação e comentários; } \\
\text { revisão das versões rascunho do relatório pelos } \\
\text { pares. }\end{array}$ \\
\hline
\end{tabular}

Quadro 17 Critérios para avaliação da qualidade da pesquisa-ação Fonte: Adaptado de Thompson e Perry (2004) 
A adequação ontológica é obtida na fase preparatória do processo, quando se busca demonstrar que ela foi conduzida segundo as etapas previstas. A validade contingente trata da contextualização do processo. Nela, o pesquisador demonstra que o processo de pesquisa foi planejado visando uma contribuição científica e não a simples aplicação de uma determinada tecnologia para a solução de problemas, como acontece no caso de um projeto de consultoria.

Essa diferenciação acontece na etapa de coleta de dados, na qual o pesquisador se preocupa com a identificação de evidências que permitam a análise do fenômeno e a sua comparação com a teoria já estabelecida. Na etapa de coleta de dados também são validados os instrumentos de obtenção dos dados, ocasião em que se destaca o uso de fontes múltiplas que permite a triangulação dos dados, confrontando as interpretações do pesquisador, com as evidências documentais e a percepção dos pesquisados.

A fidedignidade metodológica garante que o trabalho apresenta dados confiáveis. $O$ relato necessita ser detalhado e estar o mais próximo possível do que foi planejado na etapa de planejamento (planejar a pesquisa-ação). Isso mostra o cuidado do pesquisador com a cientificidade do processo de pesquisa, de forma a permitir a generalização analítica.

A generalização analítica é a etapa do processo de validação proposto na qual, no relatório obtido, são apresentados os resultados que confirmam ou refutam a teoria e as condições em que foram obtidos, permitindo assim que outros pesquisadores continuem o processo de exploração do tema.

O último critério proposto, designado como validade do construto, busca a avaliação dos resultados obtidos. O pesquisador se utiliza, então, do encadeamento de evidências obtido e da discussão dos resultados com seus pares para caracterizar as contribuições do processo de pesquisa por meio da pesquisa-ação e identificar os problemas de pesquisa que ainda não tenham sido abordados.

De acordo com Snyder, existem três etapas no processo de avaliação. Cada uma delas oferece uma forma diferente de avaliar e cada etapa baseia-se na anterior. $A$ avaliação do processo ajuda, entre outros aspectos os participantes do projeto a compreender o processo, a relação entre os elementos do modelo, e a importância dos recursos e atividades desenvolvidas para alcançar as metas e ideais. Ela inclui o 
desenvolvimento de ideais, a definição de metas, a comparação das metas e ideais, a definição de atividades e efeitos imediatos, a comparação das metas e efeitos imediatos, a definição de recursos, a comparação de atividades e recursos e o planejamento das atividades ou mudanças nas atuais.

A avaliação dos resultados refere-se à sua medição. Com base na avaliação do processo, os participantes podem identificar indicadores válidos e objetivos para medir os resultados alcançados. Além disso, a avaliação dos resultados e uma maneira de revisar a avaliação do processo e mostrar a eficiência do projeto. Ela inclui, destacar metas mensuráveis, efeitos imediatos mensuráveis, atividades, e recursos mensuráveis, como também, desenvolver atividades de monitoração.

A avaliação cíclica utiliza os indicadores da avaliação dos resultados para desenvolver uma efetiva realimentação. Em outras palavras, a avaliação cíclica contribui para que o projeto se transforme em um sistema auto-desenvolvido com um aperfeiçoamento contínuo. Ela inclui, a identificação de critérios de avaliação, informações para a avaliação, fontes de informação, criação de sistemas de informação, revisão das avaliações de processo e dos resultados e, a criação de mecanismos de revisão.

$\mathrm{Na}$ avaliação de processo, é realizada uma análise do processo, na avaliação dos resultados, é efetuada a medição dos resultados, e na avaliação cíclica a preocupação é com o desenvolvimento contínuo do sistema. A avaliação também deve considerar três momentos importantes, que estão relacionados com a solução ou controle do problema que motivou o projeto, a melhoria da democracia no grupo e na comunidade, a aprendizagem dos participantes e, ainda, o desenvolvimento de resultados teóricos que apontem a mudança do grupo ou da organização. Os três momentos estão descritos a seguir.

- Avaliação do processo de solução ou controle do problema:- No início de um projeto coletivo, a meta está relativamente clara e refere-se à eliminação de um determinado problema. Nessa base, no fim do processo pode-se avaliar se essa meta foi alcançada ou não. Apesar de o objetivo inicial pode mudar, fruto das reuniões posteriores, sempre se conserva o fundamento do problema. Prática habitual da pesquisa-ação é que o grupo estime os resultados do projeto. Esse tipo de avaliação está em concordância com o 
espírito desse tipo de pesquisa, sendo o único meio eficiente para que o grupo determine o fim do projeto com um consenso sobre os resultados positivos e negativos do trabalho.Avaliação da aprendizagem dos participantes:- Um projeto de pesquisa-ação pode ser interessante e gratificante pelas novas formas de trabalhar e pensar desenvolvidas pelos participantes. Durante o projeto, o pesquisador aprende a conhecer os membros do grupo, o que lhe permite avaliar o desenvolvimento do pensamento, das habilidades e das atitudes desse grupo. Além disso, é possível avaliar o desenvolvimento da comunidade e o desafio seguinte é relativo ao desenvolvimento de capacidade suficiente para enfrentar, por conta própria, problemas semelhantes. A resposta a esta questão somente pode ser conhecida nas ações posteriores do grupo/organização.

- Avaliação de resultados teóricos:- Embora os problemas sejam diferentes entre os grupos dos diversos domínios onde a pesquisa-ação é realizada, existem aspectos que são invariáveis e que podem ser generalizados para outras situações. Convencionalmente, a validade dos fatos apresentados deve ser avaliada.

\section{Rigor metodológico}

Cabe destacar que o rigor da pesquisa-ação não se baseia nos princípios da pesquisa empírica e experimental tradicional. A pesquisa-ação utiliza diversas fontes de rigor características da pesquisa qualitativa como, por exemplo, o uso de metodologias, técnicas múltiplas, diversas fontes de informação e processos para coleta e análise das informações. A sua natureza cíclica, permite uma revisão constante das informações e interpretações realizadas. Pode-se identificar quatro elementos que contribuem para o rigor científico da pesquisa-ação:

- Participação:- Ainda na sua forma mais elementar é possível o uso de diversas fontes para a melhor compreensão de um fenômeno. As discussões em grupo podem resultar em um desafio para os participantes e os pesquisadores, que pode ter grandes benefícios para o processo.

- Qualitativa:- As informações obtidas por meio do diálogo, desenvolvidas em um clima apropriado, podem contribuir para 0 aprofundamento do 
conhecimento acumulado. A qualidade permite chegar à essência do fenômeno.

- A ação:- Considerando que a pesquisa é orientada para uma ação os planos são testados imediatamente. Também os pressupostos podem ser testados. Se se quer conhecer um sistema, deve-se tentar mudá-lo. A ação e a pesquisa informam-se mutuamente.

- Emergente:- De acordo com Dick (1999) este é um aspecto fundamental da pesquisa-ação. Na medida em que aumenta o conhecimento, a ação está mais bem informada. O mesmo acontece com a metodologia utilizada. É essa sensibilidade às informações, à situação e, às pessoas, que dá à pesquisaação a possibilidade de mudar programas.

\subsubsection{PESQUISA-AÇÃO E SSM}

Segundo Hoss (2011), existe um elo entre a capacidade de aprendizagem evolucionária e a sua operacionalização em organizações que buscam uma forma de estruturação de seus problemas e resultados semelhantes à teoria de criação de conhecimento. Yoshida (2002) apresenta uma resposta ao observar que a teorização de Nonaka e Takeuchi (1997) pode ser alcançada na prática pela execução do ciclo de melhoria da SSM desenvolvida por Checkland (1981) conforme mostra a Figura 22. Segundo Jackson (2008, 2009), embora a SSM seja uma metodologia com origem no pensamento sistêmico flexível, e não na teoria da criação de conhecimento, ambos os escopos teóricos possuem fundamentações na fenomenologia e na hermenêutica. Como a teoria da criação do conhecimento está ainda em fase de amadurecimento e muito longe de desenvolver metodologias e métodos explícitos que possam consistentemente criar conhecimento, as metodologias já amadurecidas do pensamento sistêmico podem ser aplicadas em suas questões de investigação. No seu ponto de vista, é apropriado alegar que a SSM é a articulação de um processo sistemático de aprendizagem que permite a criação de conhecimento. Desta forma uma capacidade de aprendizagem similar à evolucionária poderia ser operacionalizada através do uso da SSM. 
O SPB, entretanto, não realiza um processo de aprendizagem estruturado mesmo porque, devido a seu crescimento acelerado e ao seu formato inovador, a estrutura da organização não era compreendida pelos seus atores em seus diferentes níveis.

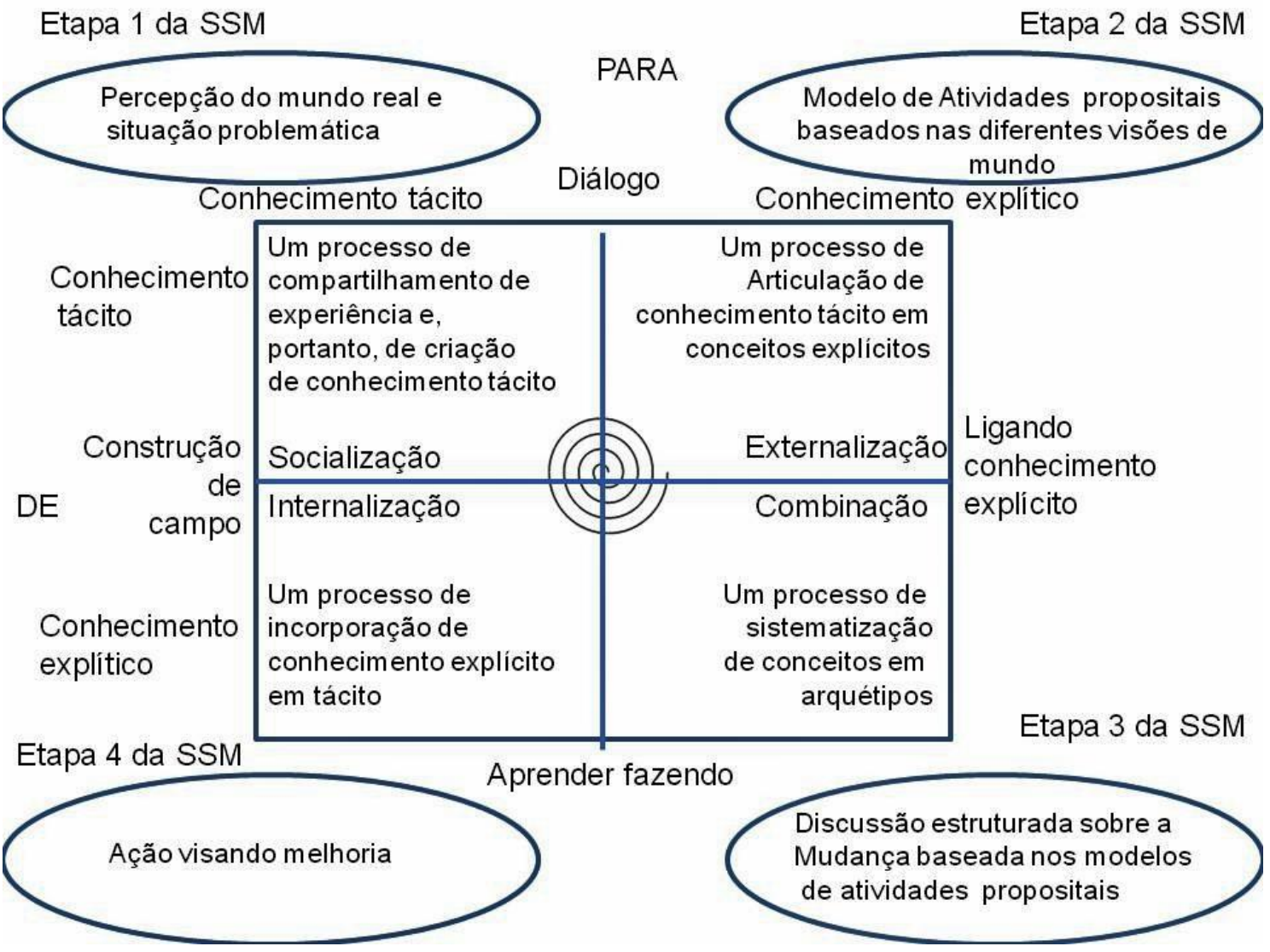

Figura 22 Criação do conhecimento oriundo das etapas do SSM Fonte: Adaptado de Yoshida (2002) apud HOSS(2002)

Assim sendo, fez-se a proposição de condução de uma pesquisa-ação, na qual o pesquisador traria o conhecimento sobre a SSM e as demais metodologias necessárias para a resolução do problema e a organização, o conhecimento sobre o contextos em que está inserida e outros conhecimentos tácitos que deveriam ser explicitados e documentados. A metodologia com as características da SSM foi adotada para a aprendizagem evolucionária, uma vez que a aprendizagem coletiva era um requisito para a resolução do problema. Deste modo, a pesquisa-ação foi realizada para, de acordo com Hult e Lennung (1980), aprimorar as competências dos atores sociais, de forma a incorporar o conhecimento sobre as metodologias adotadas. Neste, e nos demais contextos onde se realiza a pesquisa-ação, ela apresenta uma natureza dual, segundo McKay e Marshall (2001), com a justaposição e interdependência de ação (prática) e de pesquisa (teoria), o que 
significa que o pesquisador tem um duplo objetivo: introduzir melhorias por meio de mudanças em uma situação problemática e gerar novos conhecimentos como resultados das suas atividades. Conceitualmente, os dois ciclos que representam essa natureza dual operam em paralelo, mas com entradas e saídas em momentos distintos conforme representado na Figura 23.

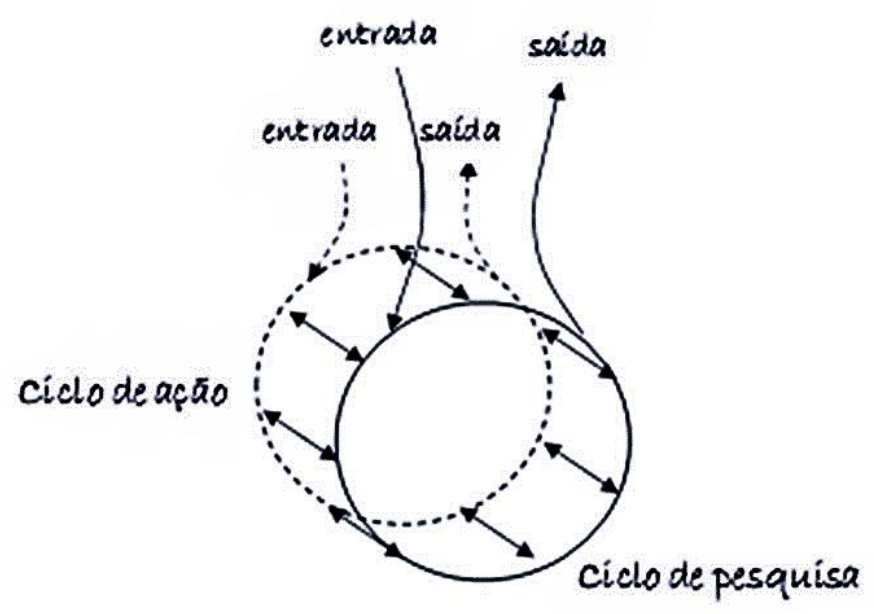

Figura 23 Natureza dual dos ciclos de pesquisa-ação Fonte: Adaptado de McKay e Marshall (2001)

O primeiro ciclo diz respeito aos interesses da organização em melhorar o conhecimento do ecossistema - introduzir questões de qualidade -, decidindo se é ou não necessário gerar outro ciclo, em função dos resultados obtidos. O segundo diz respeito aos interesses do pesquisador - verificar a possibilidade de elaborar um referencial teórico para um modelo de maturidade para ecossistemas digitais de produção de software, utilizando o PRO2PI-MFMOD como meio de conduzir o desenvolvimento das referências necessárias para a construção de um framework de capacidade/maturidade para ESP.

\subsection{PROJETO DE PESQUISA-AÇÃO E TESE}

O trabalho de Perry e Zuber-Skerritt (2002) tem como objetivo apresentar de forma clara os conceitos-chave que distinguem o núcleo de um projeto de pesquisa-ação e uma tese de projeto de pesquisa-ação. $O$ núcleo de um projeto de pesquisa-ação pode ser integrado a um projeto de pesquisa que tem como produto final uma tese. 
A pesquisa-ação é, essencialmente, uma forma de conduzir uma pesquisa em uma organização que aprende e que traz benefícios para a organização e para o corpo de conhecimento que é tema de estudo da tese. Os autores partem do pressuposto de que não há uma definição de consenso ou que claramente distinga os conceitos complexos de aprendizado organizacional e organização que aprende (learning organization). Assim sendo, a definição de organização que aprende pressuposta é a de uma forma ideal de organização definida pelas cinco disciplinas de Senge (1990): domínio pessoal, modelos mentais, visão compartilhada, aprendizado em equipe e pensamento sistêmico. Com a visão do pensamento sistêmico, todos os membros da organização entendem o todo e não somente partes fracionárias da estrutura, dos processos e da cultura da organização. Essa visão significa também que a colaboração e o aprendizado em grupo são essenciais e mais efetivos devido à sinergia resultante no grupo. Essa sinergia é explicada por Kanter (1990) que afirma que o valor gerado pelo todo é maior que o valor gerado pela soma das partes. Para Perry e Zuber-Skerritt (2002) a pesquisa-ação tem três aspectos fundamentais: a) um grupo de pessoas trabalhando juntas, b) envolvidas em ciclos de planejamento, ação, observação e reflexão com o trabalho desenvolvido de forma mais sistemática que a usual e c) a produção de um documento público da experiência (uma tese, por exemplo).

No paradigma dominante da pesquisa tradicional, há uma fronteira que separa o pesquisador do sistema que está sendo pesquisado. O sistema é reduzido a uma ou a algumas partes e as suas outras partes são assumidas como constantes. Esta abordagem de pesquisa é, segundo os autores, apropriada para algumas circunstâncias, especialmente nas ciências naturais, como por exemplo, na análise do efeito de um determinado fertilizante em uma determinada planta. Por outro lado, a pesquisa-ação reconhece e envolve o sistema social do qual o pesquisador é uma parte. Ou seja, trata de sistemas flexíveis (soft) sem fronteiras ou bordas claramente definidas entre o pesquisador e o sistema. A pesquisa tradicional é adequada para os hard systems, enquanto que a pesquisa-ação é adequada para os sistemas flexíveis de gestão e aprendizado organizacional. Segundo o conceito dos autores, é possível identificar dois tipos de projeto de pesquisa-ação. O primeiro deles é o projeto de pesquisa núcleo da ação na qual o pesquisador está envolvido e participa, como membro, de um grupo de trabalho na organização. O relato do 
projeto será então como um relatório de pesquisa-ação, que é escrito na primeira pessoa do plural, na forma de narrativa e que compara as situações antes e depois de cada ciclo de planejamento, ação, observação e reflexão.

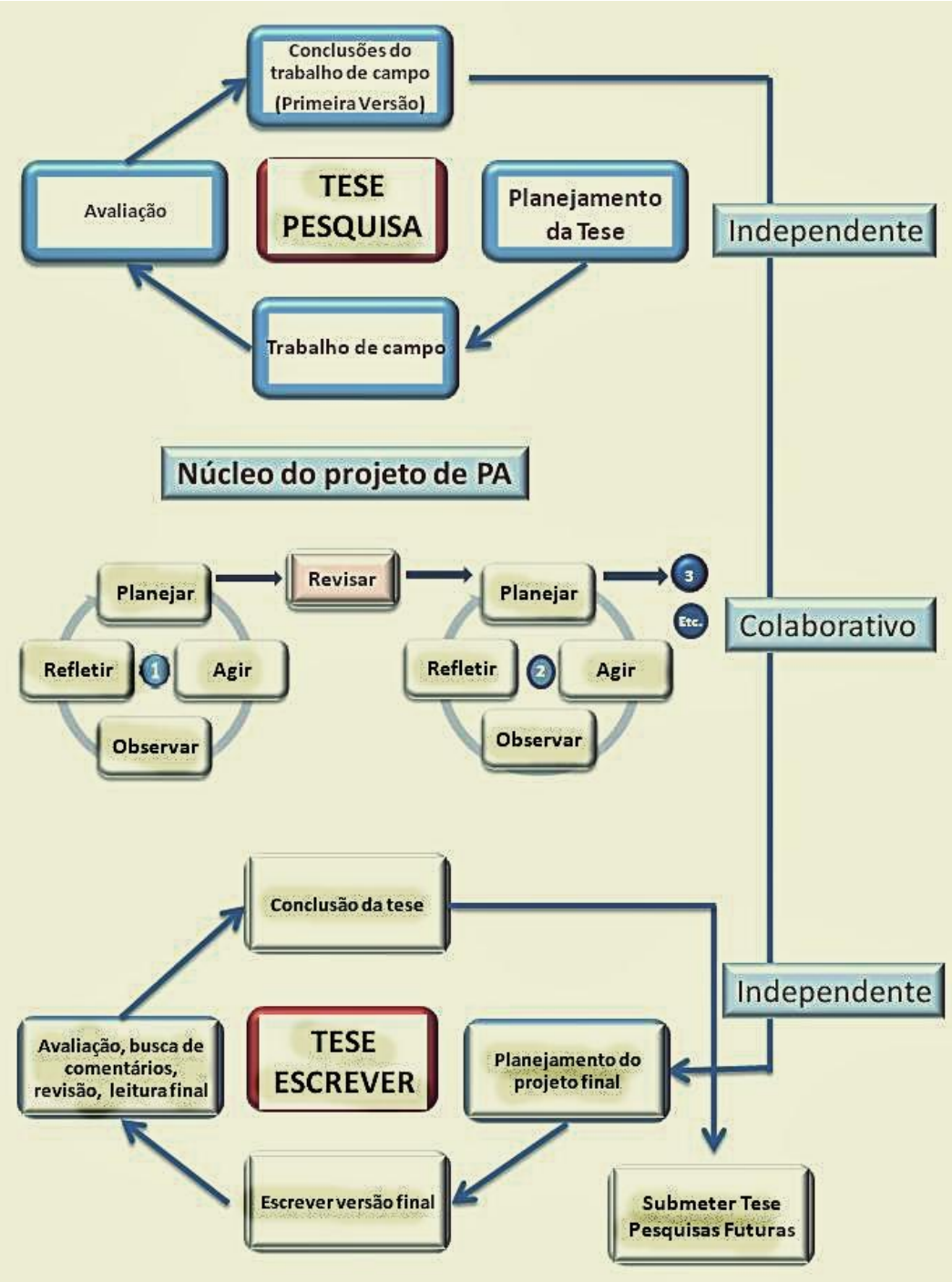

Figura 24 Relacionamento entre núcleo de ação e pesquisa Fonte: Adaptado de Perry e Zuber-Skerrit (1991)

Para esta tese foi feita uma adaptação do modelo de Perry e Zuber-Skerritt (2002), que apresenta um framework para a realização de um trabalho de pós-graduação com a implementação de um projeto de pesquisa-ação. Esse modelo utiliza os conceitos de tese de pesquisa-ação, a ser desenvolvida pelo pesquisador, e projeto de pesquisa núcleo da ação,que são utilizados na organização como a fase de ação da tese de pesquisa-ação.

O processo da pesquisa-ação é mais complexo do que os modelos lineares usados para descrevê-la. A pesquisa-ação é um processo em espiral, que olha para frente e 
para trás. Esse modelo espiral é congruente com o modelo sugerido por Dick (1999a). Perry e Zuber-Skerritt (1991) afirmam que é necessário acrescentar dois ciclos ao núcleo da ação para iniciar e concluir o projeto de pesquisa: um primeiro ciclo de pesquisa-ação para identificar o projeto e um segundo ciclo para escrever a tese. Esses dois ciclos são diferenciados dos ciclos do núcleo da ação da pesquisaação. A Figura 24 mostra os ciclos da espiral da pesquisa-ação, incorporando a relação entre os ciclos da tese e os ciclos de pesquisa do núcleo da ação.

\subsection{O PROJETO DE PESQUISA}

Para Kemmis e McTaggart (2005), fazer pesquisa-ação significa planejar, observar, agir e refletir de maneira mais consciente, mais sistemática e mais rigorosa o que fazemos na nossa experiência diária. Em geral, duas ideias definem um bom trabalho de pesquisa: a) que se possa reivindicar que a metodologia utilizada é adequada à situação, e b) que se possa garantir, de certa forma, um acréscimo no conhecimento que existe sobre o assunto tratado.

Para Dick (1992, 2002), um projeto de pesquisa-ação que tenha como resultado uma tese deve deixar claras as escolhas do paradigma, da metodologia e dos métodos utilizados. Por paradigma entende-se a abordagem global. $O$ autor entende a família de métodos experimentais e quase experimentais como um paradigma. As abordagens etnográficas são um segundo paradigma e a pesquisa-ação é o terceiro deles. A metodologia é uma subfamília utilizada em um paradigma. Por exemplo, existem variedades de pesquisa-ação: ciência da ação e metodologia de sistemas flexíveis são dois exemplos. Já os métodos são os processos utilizados para a coleta de dados. Entrevistar é um método, por exemplo, (ou vários, se são consideradas as diferentes variedades de entrevista). Grupos focais constituem outro. Análise de documentos é um terceiro.

\subsubsection{O MÉTODO SELECIONADO}

Para a escolha do método de pesquisa-ação utilizado nesta pesquisa foram consideradas as seguintes questões: o objetivo da pesquisa, o envolvimento do pesquisador no ambiente onde a pesquisa se realiza e a identificação de um problema nesse ambiente específico. A pesquisa-ação é uma metodologia de pesquisa qualitativa, o que é uma característica adequada para os objetivos desta tese. Nesta pesquisa busca-se investigar de maneira aprofundada, em conjunto com 
uma organização que deseja acrescentar o recorte de qualidade de processos em sua estrutura, a possibilidade de aplicar em ecossistemas digitais de produção de software o conhecimento acumulado e utilizado pela área de melhoria de processo de software.

A pesquisa-ação é um método que fornece bases para que o pesquisador faça parte do ambiente onde a pesquisa ocorre, como é caso desta pesquisa. A autora desta tese trabalhou até 2009, quando teve início este projeto, como pesquisadora na área de melhoria de processo de software na Divisão de Melhoria de Processo de Software do CTI-DMPS/CTI no qual acumulou experiência em pesquisa sobre melhoria de processo, sempre aplicada a empresas intensivas em desenvolvimento de software. Faz parte desse trabalho a utilização e a adaptação de modelos de referência e de métodos de avaliação para aplicação em empresas intensivas em software, de portes variados, com o objetivo de implementar a melhoria de processo de software segundo os modelos convencionais de capacidade/maturidade. A autora foi designada como coordenadora executiva do projeto FINEP - Modelo de Referência do Software Público Brasileiro, cujo objetivo é introduzir em um ambiente de produção descentralizado, distribuído e compartilhado as questões de qualidade de software, considerando qualidade de processo de desenvolvimento, qualidade para prestadores de serviço, qualidade de produto, interoperabilidade e qualidade no ecossistema. O desafio apresentado pela solicitação do cliente (SLTI/MPOG) mostrou-se pouco estruturado e com alto grau de complexidade. Nas primeiras interações para entendimento do projeto, verificou-se que o cliente conhecia apenas parcialmente a estrutura, as relações, os problemas, a cena de chegada e as restrições de ordem técnica e política da organização em estudo. A fase de diagnóstico para a preparação para a pesquisa e para a resolução do problema consumiu um esforço considerável. Quando são desconhecidos os problemas, é necessário um esforço grande para a realização do diagnóstico inicial. Nesse diagnóstico o problema deve ser identificado, assim como o campo de pesquisa e os interessados potenciais, além do levantamento das expectativas dos interessados sob uma perspectiva holística.

Era de conhecimento da autora que um entendimento mais aprofundado sobre a estrutura de funcionamento do ambiente em foco emergiria durante a aplicação da pesquisa. Havia também uma limitação de prazo para a execução do projeto que é 
regrado por um contrato de prestação de serviços. Em face dessas premissas, para a execução do projeto fez-se necessária a utilização de metodologias eficientes. Além disso, um requisito demandado pelo cliente era o de que houvesse um aprendizado coletivo durante o desenvolvimento do projeto e que todos os atores fossem envolvidos e participassem do processo de resolução do problema. Para atender as restrições impostas pela natureza do projeto - as expectativas do cliente de fazer com que durante 0 desenrolar do projeto os atores da organização participassem do processo, de que houvesse troca de conhecimento e, amadurecimento no entendimento do ambiente, de que o conhecimento tácito fosse explicitado, de que houvesse um nivelamento dos saberes na organização, de que o modelo fosse construído de forma colaborativa e compartilhada foi necessário procurar entre as abordagens de pesquisa disponíveis aquela que tivesse a capacidade de proporcionar os resultados esperados e, dentre os tipos de pesquisas disponíveis na Engenharia de Produção, foi selecionada a abordagem da pesquisaação.

Para reforçar as questões consideradas para a escolha da abordagem selecionada para a pesquisa, serão utilizados os itens citados por Thiollent (2005), Gummensson (2000) e Altrichter et. al (2002) para verificar se a pesquisa proposta atende a todos os requisitos considerados por esses autores.

O Quadro 18 apresenta as características principais de uma pesquisa-ação comparando com as características do trabalho executado para o desenvolvimento da tese. 


\begin{tabular}{|c|c|c|}
\hline \multicolumn{2}{|r|}{ Característica } & \multirow[b]{2}{*}{$\begin{array}{l}\text { Na pesquisa } \\
\text { O projeto de pesquisa tem como objetivo a resolução de um problema específico } \\
\text { de um cliente. O problema tem características inovadoras e sem precedentes } \\
\text { conforme comprovou a revisão bibliográfica. Para solucionar o problema, foi } \\
\text { necessária a realização de uma pesquisa com objetivo de avançar o } \\
\text { conhecimento na área de domínios dos modelos de capacidade/maturidade. }\end{array}$} \\
\hline 1 & Pesquisa com ação & \\
\hline 2 & Participativa & $\begin{array}{l}\text { A forma, os conceitos e os pressupostos da organização cliente induzem às } \\
\text { intervenções participativas e colaborativas. Além disso, a colaboração e a } \\
\text { participação são requisitos contratuais. }\end{array}$ \\
\hline 3 & Simultânea com a ação & $\begin{array}{l}\text { O trabalho de resolução do problema foi realizado simultaneamente às } \\
\text { pesquisas, com equipes de trabalho do cliente e do pesquisador. Com o cliente } \\
\text { ocorriam ações para a resolução do problema e com o pesquisador a busca de } \\
\text { referências teóricas que pudessem informar as construções necessárias para } \\
\text { ancorar as soluções propostas. }\end{array}$ \\
\hline 4 & $\begin{array}{l}\text { Sequência de eventos e uma } \\
\text { abordagem para a solução de } \\
\text { problemas }\end{array}$ & $\begin{array}{l}\text { Uma sequência de eventos foi planejada e executada para que seus resultados } \\
\text { fossem utilizados para auxiliar na solução do problema e obter aprendizados } \\
\text { intencionais ou não que poderiam contribuir para a teoria e para o conhecimento } \\
\text { científico. Para a abordagem cíclica foi utilizada a metodologia SSM e para } \\
\text { conduzir o trabalho teórico foi utilizado o PRO2PI-MFMOD. }\end{array}$ \\
\hline 5 & Pesquisadores como atores & $\begin{array}{l}\text { A autora como coordenadora técnica do projeto e servidora da DMPS/CTI, com } \\
\text { competências em Engenharia de Software e melhoria de processos de software, } \\
\text { teve participação ativa na condução da pesquisa-ação e da SSM e, a partir dos }\end{array}$ \\
\hline
\end{tabular}




\begin{tabular}{|c|c|c|}
\hline \multirow{2}{*}{\multicolumn{2}{|c|}{ Característica }} & \multirow{2}{*}{$\begin{array}{l}\text { Na pesquisa } \\
\text { resultados obtidos, na implementação de ações alinhadas com a visão de futuro } \\
\text { do sistema. }\end{array}$} \\
\hline & & \\
\hline & Meta dual & $\begin{array}{l}\text { O projeto envolve a solução de um problema que tem como objetivo estabelecer } \\
\text { um modelo de referência e elementos de acompanhamento para a melhoria do } \\
\text { sistema. As contribuições teóricas esperadas referem-se à utilização da lógica de } \\
\text { desenvolvimento dos modelos de capacidade/maturidade em uma outra } \\
\text { dimensão que não seja a de capacidade de processo. }\end{array}$ \\
\hline 7 & Interativa & $\begin{array}{l}\text { A pesquisa desenvolvida trabalhou com interação contínua, ao longo de } 24 \\
\text { meses, com representantes da macro organização do sistema, coordenadores, } \\
\text { membros das comunidades e grupos de interesse. No início do trabalho o } \\
\text { sistema contava com } 22 \text { comunidades e } 80 \text { mil usuários. Os pesquisadores e } \\
\text { especialistas utilizaram as experiências concretas da equipe do cliente para a } \\
\text { solução do problema e para a captação de dados para utilização na pesquisa. }\end{array}$ \\
\hline & Sistêmica & $\begin{array}{l}\text { A realização do projeto proporcionou um entendimento abrangente do problema. } \\
\text { Sob o ponto de vista teórico, viabilizou uma ampla revisão bibliográfica. Sob o } \\
\text { ponto de vista empírico ofereceu condições de entender a natureza do sistema, } \\
\text { sua missão, visão e complexidade. Foi possível desenvolver, em conjunto com o } \\
\text { cliente, um entendimento holístico, da visão estratégica, operacional e técnica } \\
\text { do sistema bem como a ligação entre o teórico e o empírico }\end{array}$ \\
\hline & Agente de mudança & $\begin{array}{l}\text { A pesquisa-ação proporcionou ao sistema o entendimento de sua natureza } \\
\text { epistemológica. Foi possível definir a visão, missão e projetar um futuro para o }\end{array}$ \\
\hline
\end{tabular}




\begin{tabular}{|c|c|c|}
\hline \multirow{2}{*}{\multicolumn{2}{|c|}{ Característica }} & \multirow{2}{*}{$\begin{array}{l}\text { Na pesquisa } \\
\text { qual ações do presente foram definidas e incorporadas em um Plano de Ação. }\end{array}$} \\
\hline & & \\
\hline & Entendimento da ética & $\begin{array}{l}\text { Para os pesquisadores e para a equipe técnica do projeto ficou bem claro, desde } \\
\text { o início, que a ética vigente no ambiente em estudo era diferente. Existia um forte } \\
\text { comprometimento com uma nova forma de organizar a propriedade do } \\
\text { conhecimento gerado pelo software ali disponibilizado. Assim sendo durante toda } \\
\text { a pesquisa houve uma preocupação com o respeito a essa ética. Não poderia ser } \\
\text { diferente. Qualquer tentativa de intervenção neste aspecto provocaria uma } \\
\text { quebra de confiança e um consequente rompimento de contrato. }\end{array}$ \\
\hline & Multi técnicas de coleta de dados & $\begin{array}{l}\text { Os métodos de coleta de dados foram efetuados das mais diversas formas. } \\
\text { Como a pesquisa é do tipo combinado houve coleta de dados quantitativos e } \\
\text { qualitativos. Foram utilizados entrevistas abertas, semiabertas, estruturadas, } \\
\text { surveys via web, workshops, reuniões, investigações de documentos, dados de } \\
\text { série históricas e publicações na mídia. }\end{array}$ \\
\hline & Entendimento sistêmico & $\begin{array}{l}\text { Para a condução da pesquisa-ação foi necessária uma fase inicial para } \\
\text { levantamento dos dados em publicações, na mídia e entrevistas exploratórias } \\
\text { com diferentes atores do sistema bem como um exercício estruturado de } \\
\text { construção de visão e missão para o sistema. }\end{array}$ \\
\hline & Tempo real ou retrospectiva & $\begin{array}{l}\text { A pesquisa-ação compreendeu um período de } 24 \text { meses (2009-2010). Os dados } \\
\text { e eventos relevantes para esta pesquisa foram captados durante esse período. }\end{array}$ \\
\hline & Parâmetros de qualidade próprios & Os critérios de avaliação da qualidade da pesquisa-ação tomaram como base os \\
\hline
\end{tabular}




\begin{tabular}{|c|c|c|}
\hline \multirow{2}{*}{\multicolumn{2}{|c|}{ Característica }} & \multirow{2}{*}{$\begin{array}{l}\text { Na pesquisa } \\
\text { critérios propostos por Croom, Thiollent e Thompson e Perry }(2005,2005,2004) \text { e } \\
\text { o rigor metodológico foi verificado considerando os elementos propostos por } \\
\text { Bermejo (2000). }\end{array}$} \\
\hline & & \\
\hline 15 & $\begin{array}{l}\text { Pessoas refletindo e melhorando } \\
\text { seu trabalho em um contexto } \\
\text { específico }\end{array}$ & $\begin{array}{l}\text { Para a aplicação dos ciclos da pesquisa-ação foi utilizada a metodologia soft } \\
\text { SSM cuja característica é promover o aprendizado coletivo. }\end{array}$ \\
\hline 16 & $\begin{array}{l}\text { Forte inter-relação entre reflexões e } \\
\text { ações envolvidas }\end{array}$ & $\begin{array}{l}\text { Os passos da SSM são compostos pelos blocos planejar,agir, observar e refletir. } \\
\text { As reflexões são realizadas em grupo, com pesquisadores e atores do sistema. A } \\
\text { consolidação dessas reflexões é agregada ao próximo planejamento, e caso } \\
\text { necessário, ações são executadas, como por exemplo, a criação de um Grupo de } \\
\text { Interesse para tratar as questões de qualidade no sistema. }\end{array}$ \\
\hline 17 & $\begin{array}{l}\text { Permissão para que as experiências } \\
\text { das pessoas envolvidas se tornem } \\
\text { públicas dentro e fora do grupo }\end{array}$ & $\begin{array}{l}\text { O sistema tem como premissa e elemento aglutinador o acesso livre ao } \\
\text { conhecimento. As experiências e o conhecimento gerado foram disponibilizados } \\
\text { na plataforma do sistema. }\end{array}$ \\
\hline 18 & $\begin{array}{l}\text { Coleta de dados sobre as questões } \\
\text { dos participantes, com ou sem a } \\
\text { ajuda de terceiros }\end{array}$ & Característica avaliada no item 11 desta tabela. \\
\hline 19 & Processo decisório participativo & $\begin{array}{l}\text { A decisão participativa sobre questões relativas ao sistema é um dos princípios } \\
\text { básicos do sistema em estudo. É um requisito necessário para as intervenções } \\
\text { que nele ocorrem. }\end{array}$ \\
\hline
\end{tabular}




\begin{tabular}{|l|l|l|}
\hline \multicolumn{2}{|c|}{ Característica } & Na pesquisa \\
\hline $\begin{array}{l}\text { Divisão de poder, suspensão relativa } \\
\text { de hierarquia e democracia }\end{array}$ & $\begin{array}{l}\text { O sistema SPB é estruturado em rede e o poder decisório é distribuído entre os } \\
\text { coordenadores da comunidade, a comunidade e a coordenação do ecossistema. }\end{array}$ \\
\hline $\begin{array}{l}\text { Membros do grupo colaborando uns } \\
\text { com os outros em uma "comunidade } \\
\text { crítica" }\end{array}$ & $\begin{array}{l}\text { A colaboração é principio básico do SPB. A colaboração inter e intra } \\
\text { comunidades e seu entorno é um requisito para entrada no sistema. }\end{array}$ \\
\hline $\begin{array}{l}\text { Prática autônoma da auto-reflexão, } \\
\text { auto-avaliação e autogestão }\end{array}$ & $\begin{array}{l}\text { Durante a execução do projeto/pesquisa os pesquisadores e os demais atores } \\
\text { autorreflexão, autoavaliação e autogestão. Os constrangimentos que ocorreram } \\
\text { foram naturais por conta do grande número de envolvidos no sistema e pelo } \\
\text { ineditismo da proposta. }\end{array}$ \\
$\begin{array}{l}\text { Aprendizado incremental por meio } \\
\text { de ação e erro, numa espiral auto- } \\
\text { reflexiva de planejamento, ação, } \\
\text { observação, reflexão e } \\
\text { replanejamento. }\end{array}$ & $\begin{array}{l}\text { Devido ao uso da metodologia soft SSM o aprendizado se deu sempre por meio } \\
\text { da espiral desejada de reflexão sobre o planejamento, ação, observação e } \\
\text { replanejamento. }\end{array}$ \\
\hline
\end{tabular}

Quadro 18 Características principais da pesquisa-ação versus Tese 


\subsubsection{A PESQUISA-AÇÃO, O MÉTODO CIENTíFICO TRADICIONAL E A TESE}

Para evidenciar as vantagens e limitações do método de pesquisa adotado, este item apresenta uma comparação do método da pesquisa-ação com o método científico tradicional. No contexto desta pesquisa, o método científico tradicional é entendido como aquele predominantemente utilizado em ciências naturais: o método de verificação de hipóteses (método hipotético-dedutivo) realizado por meio de um experimento controlado em laboratório.

A comparação é representada por meio do Quadro 19 na qual foi acrescentada a coluna "Tese" com o objetivo de apontar o posicionamento desta pesquisa em relação às características apresentadas. Em seguida são feitos alguns comentários sobre a referida tabela. 


\begin{tabular}{|c|c|c|c|}
\hline Característica & Método Científico & Pesquisa-ação & Tese \\
\hline $\begin{array}{l}\text { Objetivo da } \\
\text { pesquisa }\end{array}$ & $\begin{array}{l}\text { Ampliar o } \\
\text { conhecimento } \\
\text { científico por meio } \\
\text { da busca de leis e } \\
\text { teorias gerais }\end{array}$ & $\begin{array}{l}\text { Ampliar o conhecimento científico } \\
\text { por meio de ações que busquem } \\
\text { soluções para um problema } \\
\text { identificado numa determinada } \\
\text { organização }\end{array}$ & $\begin{array}{l}\text { Introduzir parâmetros de qualidade de software no } \\
\text { SPB } \\
\text { Problema: Com o crescimento do ecossistema em } \\
\text { número de soluções, de membros, de comunidades e } \\
\text { de diferentes tipos de usuários, o recorte de melhoria } \\
\text { de processo de software e qualidade se tornou } \\
\text { mandatório para garantir a robustez das soluções } \\
\text { disponibilizadas e para garantir o entendimento do } \\
\text { ecossistema por seus membros, usuários e } \\
\text { stakeholders. } \\
\text { Solução:- Obtida por meio da utilização do } \\
\text { arcabouço teórico de melhoria de processo de } \\
\text { software e dos frameworks de modelos de } \\
\text { capacidade/maturidade e ferramentas de tratamento } \\
\text { de problemas complexos. }\end{array}$ \\
\hline Foco & $\begin{array}{l}\text { Verificação de } \\
\text { hipóteses }\end{array}$ & $\begin{array}{l}\text { Investigação de questões de } \\
\text { pesquisa para compreensão do } \\
\text { problema/soluções dentro de seu } \\
\text { contexto }\end{array}$ & $\begin{array}{l}\text { Compreensão do ecossistema e de sua visão de } \\
\text { futuro e introdução de mecanismos capazes de } \\
\text { acompanhar sua evolução e proporcionar correção de } \\
\text { trajetória, quando necessário, utilizando elementos de } \\
\text { um framework de modelos de capacidade/maturidade }\end{array}$ \\
\hline
\end{tabular}




\begin{tabular}{|c|c|c|c|}
\hline Característica & Método Científico & Pesquisa-ação & Tese \\
\hline Ambiente & Laboratório & Ambiente real (realismo) & $\begin{array}{l}\text { Ecossistema SPB (realismo). Reflexões com ações } \\
\text { durante a execução do projeto. }\end{array}$ \\
\hline Pesquisador & $\begin{array}{l}\text { Observador externo } \\
\text { ao ambiente }\end{array}$ & $\begin{array}{l}\text { Atuam no ambiente colaborando } \\
\text { com pesquisados: o grau de } \\
\text { envolvimento varia }\end{array}$ & $\begin{array}{l}\text { Participação da autora como coordenadora/executora } \\
\text { do projeto que deu origem à pesquisa-ação e também } \\
\text { como membro da equipe de trabalho junto ao } \\
\text { ecossistema }\end{array}$ \\
\hline Etapas & $\begin{array}{l}\text { Lineares: observar } \\
\text { fatos, identificar } \\
\text { problema, formular } \\
\text { hipótese, deduzir } \\
\text { consequência, } \\
\text { falsear hipótese, } \\
\text { corroborar }\end{array}$ & $\begin{array}{l}\text { Circular: refletir sobre problema, } \\
\text { agir sobre problema }\end{array}$ & $\begin{array}{l}\text { A circularidade das etapas foi garantida pelo uso da } \\
\text { pesquisa-ação, reforçada pelo uso da metodologia soft } \\
\text { SSM para implementar os ciclos bem como das } \\
\text { etapas da PRO2PI-MFMOD para a definição do } \\
\text { método para construção dos elementos do framework } \\
\text { de modelo. }\end{array}$ \\
\hline Planejamento & $\begin{array}{l}\text { Prévio e direcionado } \\
\text { pela teoria }\end{array}$ & $\begin{array}{l}\text { Inicial (primeiro ciclo) e } \\
\text { direcionado pela teoria e/ou pelos } \\
\text { dados obtidos no ciclo anterior }\end{array}$ & $\begin{array}{l}\text { Inicial com o levantamento teórico para caracterizar o } \\
\text { sistema e escolher as abordagens a serem utilizadas } \\
\text { para tratar o problema do cliente e as questões de } \\
\text { pesquisa. Replanejamento de novos ciclos em função } \\
\text { dos resultados teóricos e dos dados coletados nos } \\
\text { ciclos anteriores }\end{array}$ \\
\hline
\end{tabular}




\begin{tabular}{|c|c|c|c|}
\hline Característica & Método Científico & Pesquisa-ação & Tese \\
\hline Variáveis & $\begin{array}{l}\text { Variáveis } \\
\text { conhecidas, poucas } \\
\text { e controláveis }\end{array}$ & $\begin{array}{l}\text { Identificação de variáveis, muitas } \\
\text { e controle reduzido }\end{array}$ & $\begin{array}{l}\text { Grande número de variáveis, diversas sem série } \\
\text { histórica, sem registro no sistema, coletadas a partir } \\
\text { dos logs da plataforma ou ao longo dos ciclos da } \\
\text { pesquisa-ação. }\end{array}$ \\
\hline $\begin{array}{l}\text { Fonte dos } \\
\text { dados }\end{array}$ & $\begin{array}{l}\text { Bem definida: } \\
\text { medições de } \\
\text { variáveis }\end{array}$ & $\begin{array}{l}\text { Diversificada: entrevistas, } \\
\text { documentos, vídeos, observação } \\
\text { direta, medições, questionários, } \\
\text { anotações do pesquisador }\end{array}$ & $\begin{array}{l}\text { Material da mídia, entrevistas com usuários, com } \\
\text { coordenadores de comunidade, com empresários e } \\
\text { com representantes tecno-políticos, surveys, e dados } \\
\text { oriundos dos ciclos da SSM. }\end{array}$ \\
\hline $\begin{array}{l}\text { Análise dos } \\
\text { dados }\end{array}$ & Estatística & Análise do discurso & Estatística e análise de discurso \\
\hline $\begin{array}{l}\text { Validade } \\
\text { Interna (Rigor } \\
\text { do processo) }\end{array}$ & $\begin{array}{l}\text { Procedimentos bem } \\
\text { planejados, controle } \\
\text { de variáveis, } \\
\text { medição e análise } \\
\text { dos dados } \\
\text { confiáveis, } \\
\text { consistência dos } \\
\text { resultados, revisão } \\
\text { por terceiros }\end{array}$ & $\begin{array}{l}\text { Ciclos iterativos bem planejados e } \\
\text { discutidos pelo grupo, } \\
\text { identificação das variáveis } \\
\text { envolvidas, fontes múltiplas de } \\
\text { dados e triangulação, adequação } \\
\text { da solução e revisão por terceiros }\end{array}$ & $\begin{array}{l}\text { Controle de variáveis, ciclos da SSM planejados e } \\
\text { discutidos pelo grupo, triangulação de dados coletados } \\
\text { e publicação de artigos científicos }\end{array}$ \\
\hline
\end{tabular}




\begin{tabular}{|l|l|l|l|}
\hline Característica & Método Científico & Pesquisa-ação & Tese \\
\hline $\begin{array}{l}\text { Repetição da } \\
\text { pesquisa }\end{array}$ & $\begin{array}{l}\text { Repetibilidade: } \\
\text { experimento tem } \\
\text { que poder ser } \\
\text { repetido por outros } \\
\text { pesquisadores }\end{array}$ & $\begin{array}{l}\text { Recoverability: repetição por } \\
\text { outros pesquisadores restrita a } \\
\text { contextos similares, } \\
\text { procedimentos devem estar bem } \\
\text { definidos para possibilitar } \\
\text { repetição }\end{array}$ & $\begin{array}{l}\text { A pesquisa está conformada de modo a permitir a } \\
\text { generalização para outros ecossistemas de produção } \\
\text { de software considerando as restrições inerentes ao } \\
\text { processo de pesquisa-ação. }\end{array}$ \\
\hline $\begin{array}{l}\text { Validade } \\
\text { externa }\end{array}$ & $\begin{array}{l}\text { Generalização: } \\
\text { pesquisa se } \\
\text { interessa- por } \\
\text { princípios gerais }\end{array}$ & $\begin{array}{l}\text { Transferability: comparação com } \\
\text { ações similares e uso da } \\
\text { pesquisa e seus produtos em } \\
\text { outros contextos; pesquisa como } \\
\text { fonte para outra pesquisa }\end{array}$ & $\begin{array}{l}\text { A pesquisa e seus produtos foram utilizados para o } \\
\text { tratamento de outros projetos com questões pouco } \\
\text { estruturadas no âmbito da DMPS/CTI bem como para } \\
\text { a criação o laboratório de políticas públicas - POLITIC, } \\
\text { que terá como metodologia de trabalho a pesquisa- } \\
\text { ação. }\end{array}$ \\
\hline $\begin{array}{l}\text { Aplicação do } \\
\text { conhecimento }\end{array}$ & $\begin{array}{l}\text { Após a finalização } \\
\text { da pesquisa }\end{array}$ & $\begin{array}{l}\text { Ao longo da pesquisa } \\
\text { pesquisa e em todos projetos com problemas não } \\
\text { estruturados do laboratório POLITIC da DMPS/CTI }\end{array}$ \\
\hline
\end{tabular}

Quadro 19 Método Científico\&Pesquisa-ação\&Tese

Fonte: adaptado de Filippo (2008) 
Foco: O método científico tradicional está apoiado numa visão objetiva da realidade, onde objeto de pesquisa e mensuração são independentes do pesquisador. Essa abordagem é denominada visão positivista. Na pesquisa-ação e em outros métodos qualitativos, assume-se uma visão subjetiva da realidade, em que diferentes indivíduos, incluindo o pesquisador, interpretam um mesmo fato de diferentes maneiras e em função do seu contexto. Esta abordagem é denominada visão interpretativista. No caso da pesquisa-ação, o raciocínio hipotético é mais brando, ou seja, considera-se que as soluções investigadas para o problema particular são geradas pelo pesquisador a partir de suposições, ou quase-hipóteses, embasadas num quadro de referência teórico. Essas suposições guiam o pesquisador no seu raciocínio e são avaliadas em função do êxito que as soluções implementadas têm em resolver o problema específico que está sob investigação (THIOLLENT, 1986).

Ambiente: Em relação às dimensões de precisão e realismo dos métodos de pesquisa (DENNIS e VALACICH, 2001), o experimento em laboratório privilegia a precisão em detrimento do realismo, enquanto a pesquisa-ação no ambiente real privilegia o realismo em detrimento da precisão.

Posicionamento do pesquisador: $\mathrm{Na}$ pesquisa-ação o pesquisador deve posicionar-se em relação ao seu nível de envolvimento com a pesquisa e com o ambiente onde ela é desenvolvida. Nesta pesquisa, o posicionamento da autora foi de pesquisador externo investigando as práticas de qualidade do objeto de estudo. Além de pesquisadora a autora foi coordenadora executiva do projeto em desenvolvimento. A atuação da autora se deu ao longo de todo o projeto que teve a duração de 24 meses (2009, 2010).

Planejamento: Na pesquisa-ação, o pesquisador admite que seu planejamento possa ser alterado em função dos resultados obtidos ciclo a ciclo (data-driven). A pesquisa-ação também pode privilegiar questões teóricas para orientar um novo ciclo (theory-driven) (DICK, 1993, HERR e ANDERSON, 2005). Nesta pesquisa foram utilizados os dois direcionamentos.

Variáveis: $O$ ecossistema SPB tem uma estrutura que não se mantém fixa. Comunidades de desenvolvimento de aplicação de software podem ser criadas ou desativadas, e mesmo extintas, ao longo do tempo; o número de membros por comunidade, e mesmo no sistema, varia diariamente; o número de dowloads das aplicações é conhecido somente no âmbito do ecossistema e diferentes outras 
variáveis estão fora do controle do pesquisador. Para coletar as variáveis foram utilizadas as séries históricas disponíveis no ambiente, além de outros mecanismos disponíveis na plataforma que abriga o ecossistema.

Validade interna: A validade interna trata do rigor do processo. Enquanto no método científico tradicional é feita a verificação da consistência dos resultados obtidos, na pesquisa-ação avalia-se se a ação realizada é considerada uma solução adequada para o problema inicial, ou se avança nessa direção.

Repetição da pesquisa: No método científico tradicional a pesquisa tem que ter repetibilidade ${ }^{10}$ para constituir-se como tal. Já na pesquisa-ação, onde se estuda um caso único e não se tem controle das variáveis, a repetição é substituída pelo que é chamado de recoverability (CHECKLAND e HOWELL, 1998): dentro de determinados limites, pode-se repetir as ações num ambiente similar ao utilizado pela pesquisa original (HARRISON et al., 1999). Para que isto aconteça, é fundamental que o pesquisador descreva detalhadamente os procedimentos realizados e o contexto em que a pesquisa se aplica.

Validade externa: No método científico tradicional, o foco de estudo concentra-se em tipos e classes de objetos ou eventos, sendo a generalização inerente ao método. Na pesquisa-ação, estuda-se um caso particular e a generalização não pode ser feita da mesma forma. Herr e Anderson (2005), citando Lincoln e Guba (1985), apresentam o conceito de transferabilidade (transferability), no qual o conhecimento não é generalizado, mas transferido de um contexto emissor para um contexto receptor. Neste caso, é o leitor da pesquisa que determinar até que ponto ela se aplica ao seu caso e o quanto ele pode dizer que ela lhe é útil. A generalização dentro do contexto da pesquisa-ação também é obtida em outras situações: a tese pode ser usada como um estudo de caso sobre o processo de pesquisa e sobre a solução encontrada; novos conceitos, produtos e instrumentos gerados pela pesquisa podem ser usados em outros contextos; a pesquisa passa a ser fonte de documentos sobre pesquisa-ação ou de conhecimento sobre a prática profissional que ela relata (HERR e ANDERSON, 2005).

\footnotetext{
${ }^{10}$ Graus de concordância entre os resultados de medições sucessivas, de uma mesma grandeza, efetuadas nas mesmas condições: método de medição, observador, instrumento de medida, local, condições de utilização e em intervalo de tempo curto entre medições. A repetibilidade pode ser expressa quantitativamente em termos da dispersão dos resultados.
} 
Observa-se, por último, que as questões abordadas sobre rigor da pesquisa, repetibilidade e generalização também se aplicam a outros métodos qualitativos. Mesmo nos métodos qualitativos em que 0 pesquisador coloca-se como imperceptível, a possibilidade de viés, ainda que menor, deve ser considerada.

\subsubsection{AS QUESTÕES DE PESQUISA}

A temática desta pesquisa diz respeito à introdução de parâmetros de qualidade no ecossistema SPB. O SPB é um ecossistema digital de produção de software, com características específicas, diferentes daquelas das organizações convencionais. Nesta pesquisa faz-se necessário procurar elementos capazes de compor um framework de maturidade/capacidade que seja adequado para representar a evolução para a melhoria desse tipo de ecossistema. A problemática principal em que a presente pesquisa está envolvida será abordada com a questão primária apresentada a seguir.

\section{Como introduzir questões da qualidade em ecossistemas digitais públicos de produção colaborativa de software?}

Para responder esta pergunta, é necessário responder também outras questões secundárias.

Pergunta 1 É viável que o processo de construção de uma visão de qualidade para redes virtuais incorpore a complexidade desses sistemas?

Pergunta 2 Os modelos de maturidade/capacidade que tradicionalmente visam aprimorar a qualidade de um processo linear e bem delimitado são adequados para redes virtuais com papéis que se alteram e configurações mutantes?

Pergunta 3 É possível avançar nos modelos de maturidade/capacidade para sistemas complexos utilizando os conceitos oriundos da Teoria do Pensamento Complexo (TPC)?

Pergunta 4 É possível, com a abordagem sistêmica, identificar algum tipo de estrutura/padrão (do tipo ciclo de aprendizado) que abrigue e defina a dinâmica interna desse tipo de estrutura?

Pergunta 5 Quais são os elementos que compõem esse tipo de estrutura/padrão? Qual é a dinâmica resultante da interação, do compartilhamento e do aprendizado destes ecossistemas? 
Pergunta 6 Quais são os elementos essenciais para uma possível avaliação de capacidade de ecossistemas complexos como o SPB?

Pergunta 7 Quais são os elementos essenciais para uma possível determinação da maturidade de ecossistemas complexos como o SPB?

Pergunta 8 Qual é o arcabouço teórico que deve ser utilizado para a estruturação dos elementos de um framework de um modelo de capacidade/maturidade para ecossistemas complexos como o SPB?

Pergunta 9 É possível pensar em uma generalização dos conceitos elaborados para o framework de um modelo de capacidade/maturidade desenvolvido para o SPB, considerando o SPB somente um caso de Ecossistema de Software Público (ESP)?

Por outro lado, para responder a estas questões secundárias é necessário incluir nos objetivos da pesquisa a construção de uma estrutura teórica que apoie a incorporação dos conceitos da complexidade à teoria e prática de melhoria de processos, em especial àquela relacionada com modelos de capacidade de processo e maturidade de sistemas.

\subsubsection{DELINEAMENTO DA PESQUISA}

\subsubsection{Características da pesquisa}

No Quadro 20 são apresentadas as principais características desta pesquisa. Esse conjunto de características é proposto por Gil (1991). Após a caracterização, será apresentado no item 3.4.3.2 o modelo proposto para a realização da pesquisa.

\begin{tabular}{|c|l|}
\hline Característica & Na tese \\
\hline \multirow{2}{*}{ Natureza } & $\begin{array}{l}\text { A pesquisa é de natureza aplicada, já que almeja gerar } \\
\text { conhecimento tanto para os atores envolvidos quanto para a } \\
\text { comunidade científica, ao investigar um caso real. }\end{array}$ \\
\hline \multirow{2}{*}{$\begin{array}{l}\text { A abordagem é combinada pois a pesquisa adota a abordagem } \\
\text { qualitativa para os fenômenos e as relações sociais no mundo } \\
\text { real, que são interpretados e têm uma significação atribuída e a } \\
\text { abordagem quantitativa, que traduz em números opiniões e } \\
\frac{\pi}{0}\end{array}$} & informações com a finalidade de analisá-las e classificá-las. \\
\hline$\frac{0}{4}$ &
\end{tabular}




\begin{tabular}{|c|c|}
\hline Característica & ese \\
\hline Objetivos & $\begin{array}{l}\text { Do ponto de vista de seus objetivos, a pesquisa realizada é } \\
\text { explicativa porque tem como finalidade relatar a estruturação de } \\
\text { elementos de um referencial teórico para tratar a capacidade/ } \\
\text { maturidade de ecossistemas digitais de produção de software }\end{array}$ \\
\hline 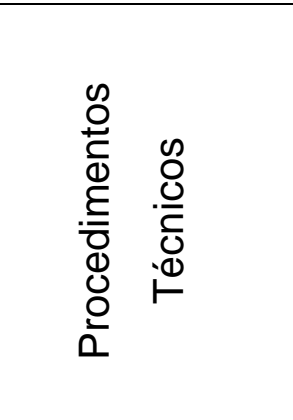 & $\begin{array}{l}\text { A metodologia de pesquisa é a pesquisa-ação, utilizada para } \\
\text { guiar questionamentos e ações sobre a realidade que se deseja } \\
\text { alterar. Como suporte à pesquisa-ação, utiliza-se a SSM, } \\
\text { ferramenta para tratar problemas complexos e o PRO2PI-MFMOD } \\
\text { que é um framework de métodos para a construção de modelos } \\
\text { de capacidade de processo. }\end{array}$ \\
\hline
\end{tabular}

Quadro 20 Características da pesquisa

\subsubsection{O modelo para a realização da pesquisa}

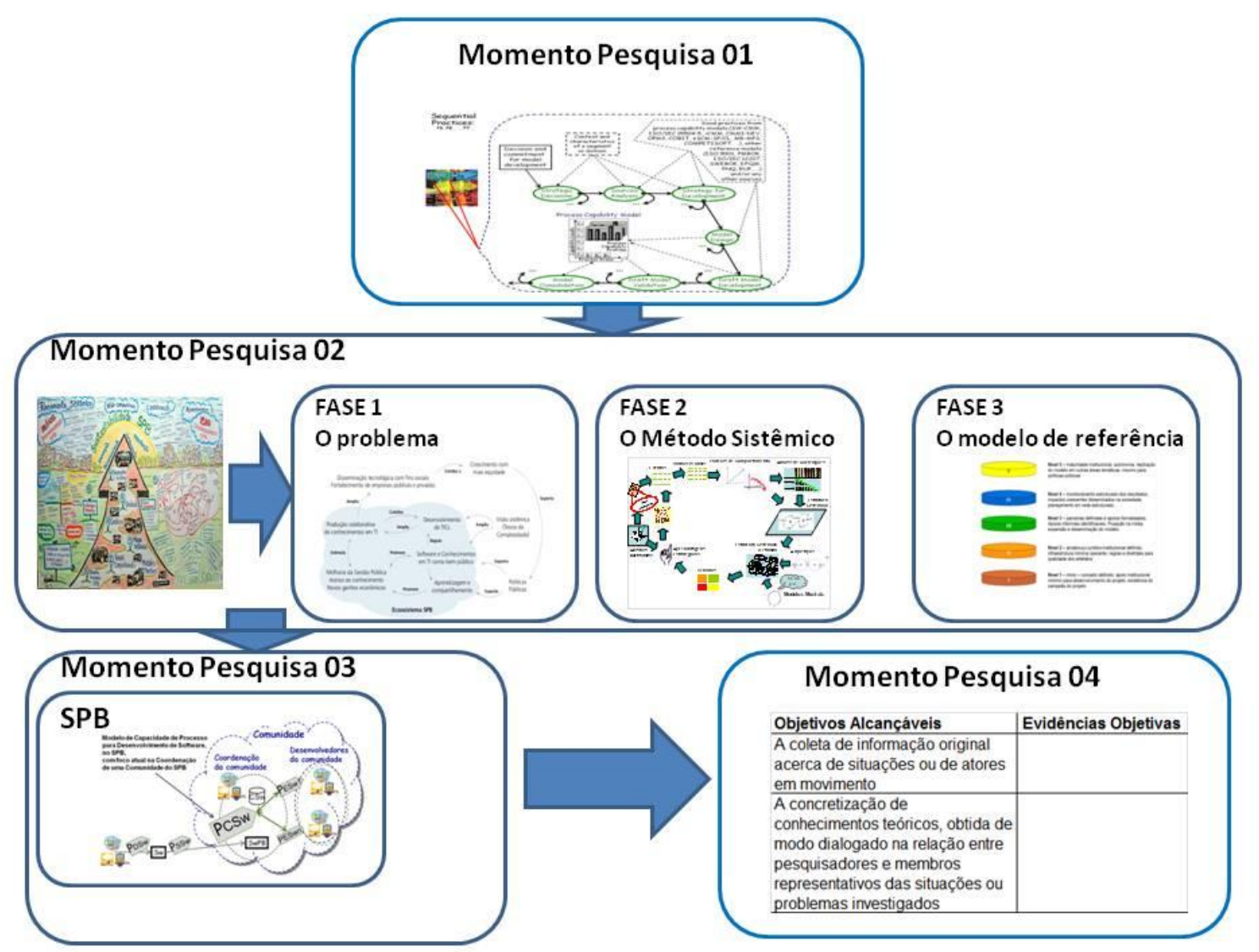

Figura 25 Os quatro momentos da pesquisa

Esta pesquisa está organizada de forma a gerar como resultado a obtenção de referências para um framework de modelos de capacidade/maturidade para ecossistemas públicos de produção de software. Essas referências devem permitir 
que a partir do framework de modelos de capacidade/maturidade, sejam instanciados modelos para o acompanhamento e a evolução de ecossistemas com as características do SPB. O framework deve ser desenvolvido a partir de um modelo de referência e ser robusto o suficiente para estabelecer, avaliar e monitorar o desenvolvimento, a gestão e o acompanhamento de ambientes desta natureza. $\mathrm{O}$ modelo de condução desta pesquisa é constituído de quatro momentos principais. Por meio da realização das atividades contidas nestes momentos torna-se possível atingir os objetivos específicos da pesquisa. Os momentos estão representados na Figura 25.

\section{Momento 01}

No primeiro momento o pesquisador relaciona-se com a situação problemática vivenciada pelo ecossistema SPB, ou seja, a questão da introdução da qualidade em seus processos e no ecossistema como um todo. Neste momento, é executada uma revisão bibliográfica abrangente e são definidas as metodologias, os métodos, os frameworks,e as técnicas a ser utilizados para a condução da pesquisa, são também identificados os principais atores do ecossistema bem como algumas possíveis ações de melhoria.

Nesse momento, definiu-se a abordagem aplicada para a realização da pesquisaação. Essa abordagem procura garantir que o problema do cliente seja resolvido e que as questões de pesquisa, apresentadas na seção - 3.4.4, sejam respondidas. Para atender os requisitos desse momento, foram selecionadas as metodologias e os métodos a ser utilizados. Para responder à questões de pesquisa, utilizou-se o framework PRO2PI-MFMOD.

\section{Momento 02}

O segundo momento relaciona-se à pesquisa aplicada: uma pesquisa-ação foi conduzida em conjunto com um framework de métodos para a construção de modelos de capacidade de processo, o PRO2PI-MFMOD, e de um método de tratamento de problemas complexos e desestruturados, a SSM. Esta última ferramenta foi utilizada como forma de operacionalizar uma capacidade de aprendizagem similar à evolucionária. Esse momento é de aplicação do ferramental selecionado no primeiro momento. Nele, há um entendimento sistemático do problema a ser resolvido, ocorre a aplicação do método sistêmico, com a finalidade 
de conhecer a situação real, e fazer emergir a situação ideal, e acontece a busca da dimensão que deve ser observada para que o movimento do real ao ideal aconteça.

Nesse momento, tem a início a execução da pesquisa-ação com suas fases e ciclos. As fases pressupõem que o trabalho do pesquisador é realizado em conjunto com o cliente, com o objetivo de resolver o problema por ele especificado. Essas fases são: Fase 01 - Entendendo o problema; Fase 02- Aplicando o método sistêmico e Fase 03 - Elaborando o modelo de referência. A primeira e a última fase são, respectivamente, de preparação e de finalização da pesquisa-ação, enquanto que a fase 02 hospeda os ciclos da pesquisa-ação. $\mathrm{O}$ segundo momento molda 0 terceiro momento.

\section{Momento 03}

Nesse momento são realizadas as provas de conceito considerando os níveis de capacidade resultantes da fase anterior, que dão origem a níveis de maturidade.

Para a realização dessa prova, é utilizado o Modelo de Capacidade de Processo para Desenvolvimento de Software no SPB - V.3.0 (ZOUCAS, 2011) que foi desenvolvido no âmbito do Projeto SPB no subprojeto SP04- Qualidade para desenvolvedores de Software.

\section{Paradigmas e Modelos de Capacidade e Processo de uma Comunidade SPB}

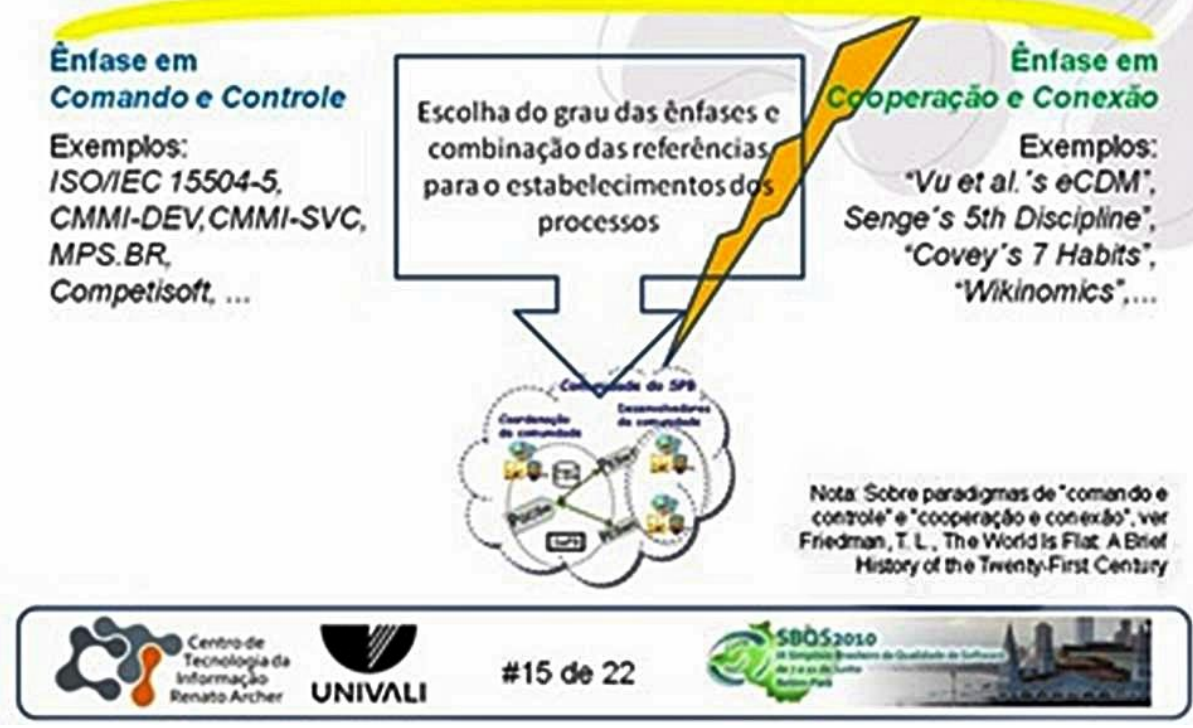

Figura 26 Novos paradigmas dos modelos de capacidade Fonte: Zoucas (2010) 
O modelo desenvolvido por Zoucas, embora tenha no próprio nome a palavra capacidade, foi gerado para abrigar tanto a dimensão capacidade como outra que fosse considerada mais adequada. Esta questão está tratada no texto do artigo "Modelo de Capacidade de Processo para o Software Público Brasileiro" (SBQS, 2010) e representado na Figura 26, que é um dos slides de apresentação do artigo no SBQS. (ZOUCAS, 2010).

Nesse momento é realizada uma verificação sistemática, cujo objetivo é verificar se o elemento da dimensão vertical ao eixo dos processos, no caso do SPB, níveis sistêmicos, é válido para outro ecossistema de natureza semelhante como, por exemplo, o SourceForge.

\section{Momento 04}

Por fim, o quarto momento relaciona-se com a validação da pesquisa efetuada considerando os critérios definidos no item 3.2.5. Foram utilizados critérios propostos por Bermejo, Thiollent, Coughlan e Coghlam e Thompson e Perry (2000, 2005, 2002, 2004).

\subsubsection{PROTOCOLO DE PESQUISA}

O protocolo de pesquisa é uma estrutura operacional, um framework, por meio da qual se pode desenvolver um roteiro de procedimentos que traduz de forma específica, um padrão de análise em movimento, de acordo com as características da pesquisa-ação. A padronização visa garantir a tipificação e a especificação das informações que se deseja colher, analisar e então seguir para a fase seguinte, conforme o modelo predefinido estabelece. O protocolo, neste caso, é um roteiro expresso em segmentos denominados fases/momentos, decorrentes da necessidade de explorar todas as dimensões que orientam a execução das atividades das fases/momentos padronizados, como já foi explicado no modelo de pesquisa. Em outras palavras o protocolo de pesquisa define a relação entre pesquisador e equipe de trabalho da unidade de pesquisa e os entregáveis para um modelo de pesquisa definido.

O protocolo de pesquisa deve ser utilizado para informar a unidade de pesquisa selecionada sobre a intenção e o conteúdo das técnicas de coleta de dados a serem utilizadas na pesquisa. $O$ protocolo tem como objetivo principal direcionar a execução da pesquisa. Todavia, a fase aqui descrita é a primeira quando se 
considera a aplicação da pesquisa, mas não quando se considera o seu contexto, pois o protocolo detalha a forma pela qual o modelo para a realização da pesquisa será seguido, e cumpre o objetivo de permitir uma macrovisão e uma abordagem processual conferindo objetividade e praticidade. O Quadro 21 resume o método descrito anteriormente, mostrando as fases propostas para o desenvolvimento completo desta pesquisa, com as ferramentas e técnicas aplicadas para desenvolver as atividades previstas.

\begin{tabular}{|c|c|c|c|}
\hline Momento & Objetivo & Subfase & Técnicas utilizadas \\
\hline \multirow{10}{*}{1} & \multirow{10}{*}{$\begin{array}{l}\text { Mergulho na } \\
\text { situação } \\
\text { problemática }\end{array}$} & & Revisão bibliográfica \\
\hline & & & Observação \\
\hline & & & Entrevistas \\
\hline & & & Reuniões \\
\hline & & & Seminários \\
\hline & & & Workshops \\
\hline & & & Análise de publicações na mídia \\
\hline & & & Análise de documentos formais \\
\hline & & & Análise de casos similares \\
\hline & & & Pesquisas semi estruturadas \\
\hline 2 & $\begin{array}{c}\text { Solução do } \\
\text { problema } \\
\text { Avanço no } \\
\text { conhecimento }\end{array}$ & $\begin{array}{l}\text { O Problema } \\
\text { O Método } \\
\text { O Modelo }\end{array}$ & $\begin{array}{l}\text { Pesquisa-ação } \\
\text { SSM } \\
\text { PRO2PI-MFMOD }\end{array}$ \\
\hline 3 & Verificação & & Prova de conceito \\
\hline 4 & Validação & & $\begin{array}{l}\text { Critérios propostos por Bermejo, Thiollent, } \\
\text { Coughlan e Coghlam e Thompson e Perry } \\
(2000,2005,2002,2004)\end{array}$ \\
\hline
\end{tabular}

Quadro 21 Fases e técnicas da pesquisa

\subsubsection{DA COLETA E ANÁLISE DE DADOS NESTA PESQUISA}

Nesta pesquisa, foram utilizadas diferentes fontes de dados para observar o ecossistema SPB, a infraestrutura que o suporta, os atores que o compõem as relações entre esses atores e a infraestrutura e, a dinâmica resultante, que se expressa pela interação, pelo compartilhamento e pela aprendizagem. Entre os dados considerados, estão séries históricas coletadas pela plataforma do ecossistema, registros disponibilizados pelas comunidades, resultados de entrevistas, surveys, workshops e reuniões. Deve-se observar que, sendo uma 
pesquisa-ação, entre os participantes da pesquisa está a própria autora, que também relata suas observações e vivências.

O uso de múltiplas fontes de dados, que possibilitam a triangulação desses dados (PATTON, 1990) tem pelo menos três vantagens. Uma delas é a de obter diferentes pontos de vista sobre o que está sendo observado e de contextualizar os diferentes dados coletados. Nesta pesquisa em particular, optou-se por usar tanto dados quantitativos, mensuráveis, tais como o número de membros de uma comunidade e o número de commits dos membros, quanto dados qualitativos, tais como os obtidos por meio de entrevistas semi estruturadas em que os participantes descrevem livremente a sua percepção sobre o ecossistema como um todo, a qualidade da plataforma na qual está disponibilizado o ecossistema e, o nível de cooperação, comprometimento e compartilhamento intra e inter comunidades. A contextualização de dados quantitativos e qualitativos possibilitou, por exemplo, obter as diferentes visões dos atores do ecossistema, ou seja, a percepção de que a visão do todo não é uniforme para todos os seus membros. A visão depende do ponto a partir do qual se olha para o restante do sistema e o arcabouço teórico resultante do trabalho de pesquisa incorporou este aspecto (ALVES, 2011), além de possibilitar a distinção entre as comunidades atuantes e ativas aquelas menos ativas. Também possibilitou conhecer, o uso pelas comunidades, da plataforma de desenvolvimento das soluções disponibilizadas pelo ecossistema, além de dados quantitativos indicando a utilização de critérios de qualidade para o ecossistema, a comunidade e as soluções.

Uma segunda vantagem de se usar a triangulação dos dados é a de identificar discrepâncias entre os dados coletados e, conforme o caso, desconsiderar esses dados. Uma outra vantagem da triangulação dos dados é a de evitar ou minimizar o efeito de visões tendenciosas do pesquisador. Esse procedimento é especialmente importante quando se utiliza o método da pesquisa-ação, já que o pesquisador participa e está diretamente envolvido no ambiente em que a pesquisa ocorre (HERR e ANDERSON, 2005). A coleta de dados quantitativos e passíveis de análise estatística também foi utilizada, com o intuito de diminuir a subjetividade inerente à coleta e à análise de dados qualitativos.

\subsubsection{A VALIDAÇÃO DA PESQUISA}

Westbrook (1995) considera que, na pesquisa-ação, o processo de pesquisa por si só necessita ser proativamente gerenciado. Para ele, a qualidade dos resultados 
pode depender tanto da gestão do projeto de pesquisa quanto do próprio projeto de pesquisa ou da análise dos resultados. Portanto, a avaliação dos resultados merece ter como bases os objetivos da pesquisa (científico e técnico) e as proposições estabelecidas no início dessa pesquisa.

Coughlan e Coghlan (2002) consideram que a avaliação envolve uma reflexão sobre os resultados da ação, tanto os intencionais quanto os não intencionais, e uma revisão do processo, para que o próximo ciclo de planejamento e ação possa se beneficiar do ciclo completado. A avaliação é a chave para o aprendizado. Sem ela, as ações são implementadas ao acaso, independentemente de sucesso ou fracasso, e os erros proliferam, gerando um aumento da ineficácia e da frustração.

Algumas das formas de avaliação dos resultados da pesquisa-ação citadas e utilizadas por diversos pesquisadores são as reuniões do pesquisador com colaboradores da empresa/organização pesquisada (CARVALHO, 2009), as apresentações para a direção e grupos interessados na pesquisa (MIGUEL, 2010) e as comparações com critérios/indicadores definidos na fase de coleta de dados, antes e depois da intervenção do pesquisador (MIGUEL, 2010; CARVALHO, 2009), e entre projetos similares, com e sem a intervenção do pesquisador (CARVALHO, 2009).

Uma vez coletados todos os dados, e considerando a triangulação desses dados, - pesquisador necessita elaborar uma narrativa da pesquisa realizada. Especificamente para a pesquisa-ação, devido à sua natureza cíclica, os pesquisadores podem sentir certa dificuldade em registrar no relatório esses desdobramentos. Na pesquisa-ação, é necessário fazer uma redução dos dados coletados, para torná-los apresentáveis e facilitar sua análise e posterior discussão. Para tal, propõe-se a elaboração de um quadro-resumo, onde cada ciclo de pesquisa-ação realizado é descrito resumidamente, com informações sobre o seu período de realização, a fase da pesquisa à qual corresponde, os critérios para avaliação adotados para cada ciclo, as atividades realizadas com a indicação dos participantes, os resultados da avaliação realizada e os aprendizados e melhorias que podem ser empregados nos ciclos seguintes. Os trabalhos de Carvalho (2009) e Miguel (2005) apresentam uma proposta de quadro-resumo, que contem as tratativas da condução da pesquisa em ciclos bem definidos. O Quadro 22 apresenta o formato de um quadro-resumo. Quadros com esse formato serão 
utilizadas nesta pesquisa, no final de cada Momento de Pesquisa e no final de cada ciclo da pesquisa-ação.

O Quadro 23 e Quadro 24, apresentam, respectivamente, os requisitos quanto aos objetivos de conhecimento alcançáveis e os requisitos de avaliação que serão analisados com relação a este projeto de pesquisa na fase avaliação da pesquisaação.

\begin{tabular}{|l|l|}
\hline Ciclo & \\
\hline Período & \\
\hline Fase de Pesquisa & \\
\hline Critério de avaliação & \\
\hline Atividades executadas & \\
\hline Avaliação \\
\hline Melhoria e aprendizagem & \\
\hline
\end{tabular}

Quadro 22 Quadro-resumo para pesquisa-ação

\begin{tabular}{|c|c|}
\hline Validade & Aspectos do trabalho \\
\hline Interna & $\begin{array}{l}\text { Compreende o nível de confiança em relação a causa e efeito entre } \\
\text { as variáveis (um exemplo é a constatação se as conclusões são } \\
\text { resultados das evidências) }\end{array}$ \\
\hline Externa & $\begin{array}{l}\text { Significa o grau de generalização das conclusões da pesquisa (ou } \\
\text { seja, a verificação de quão aplicáveis são os resultados para outros } \\
\text { objetos de análise }\end{array}$ \\
\hline $\begin{array}{l}\text { Do } \\
\text { constructo }\end{array}$ & $\begin{array}{l}\text { Consiste na extensão pela qual uma observação mede o conceito } \\
\text { que se pretende medir por meio do estabelecimento das medidas } \\
\text { operacionais corretas em relação a esse conceito }\end{array}$ \\
\hline Descritiva & $\begin{array}{l}\text { É expressa pelo grau pelo qual o relatório da pesquisa é exato, ou } \\
\text { seja, representa a situação pesquisada }\end{array}$ \\
\hline Interpretativa & $\begin{array}{l}\text { Compreende a extensão pela qual a interpretação dada representa o } \\
\text { que está sendo estudado, como no caso na pesquisa empírica. }\end{array}$ \\
\hline Teórica & $\begin{array}{l}\text { Consiste no grau pelo qual os dados estão de acordo com a teoria } \\
\text { postulada, ou seja, trata-se da constatação se a explanação teórica } \\
\text { do pesquisador é coerente com os dados apresentados. }\end{array}$ \\
\hline
\end{tabular}

Quadro 23 Validade da pesquisa

Fonte: Croom (2005) 


\begin{tabular}{|l|l|}
\hline Aspectos Gerais Alvo de Avaliação & Evidências Objetivas \\
\hline Pontos estratégicos & \\
\hline Capacidade de mobilização & \\
\hline Capacidade de propostas & \\
\hline Continuidade do projeto & \\
\hline Participação & \\
\hline Qualidade do trabalho em equipe & \\
\hline Efetividade das atividades de formação & \\
\hline Conhecimento e informação & \\
\hline Comunicação & \\
\hline Atividade de apoio & \\
\hline
\end{tabular}

Quadro 24 Referência para avaliação versus tese

Fonte: adaptado de Thiollent (2005)

\subsubsection{CONCLUSÃO}

Este capítulo apresentou os conceitos de pesquisa, de pesquisa na Engenharia de Produção e da pesquisa-ação. Tratou de alguns aspectos referentes à qualidade e à validação do projeto de pesquisa-ação e apresentou, por meio de tabelas, o protocolo a ser utilizado para essas avaliações. Apresentou também o projeto de tese a partir da pesquisa-ação, justificou a metodologia selecionada, fez um delineamento da pesquisa e indicou o modelo a ser utilizado nessa pesquisa. Por fim apresentou as características da pesquisa e o protocolo a ser utilizado na execução desta pesquisa. 


\section{PROBLEMA E AMBIENTE REAL DA PESQUISA}

Este capítulo apresenta o problema geral desta pesquisa, que é a introdução da dimensão da qualidade no ecossistema SPB, considerando a qualidade do ecossistema como um todo integrado. A dimensão da qualidade será também aplicada a desenvolvimento de software, à prestação de serviços de software, aos testes de software, à interoperabilidade e à qualidade de produto. O problema específico que dá início à pesquisa-ação é a necessidade de modelar o ecossistema, com o objetivo de estabelecer referências para um framework de modelos de capacidade/maturidade que seja capaz de promover sua melhoria. Como a metodologia da pesquisa é a pesquisa-ação, o problema é apresentado no contexto em que ocorre, o ecossistema SPB.

A seção 4.1 apresenta o contexto do ambiente real da pesquisa. A seção 4.2 explicita o problema ou situação problemática que dá início à pesquisa-ação. $\mathrm{Na}$ seção 4.3, são feitas considerações sobre os recursos necessários para a realização desta pesquisa.

\subsection{CONTEXTO DO AMBIENTE REAL}

O Software Público Brasileiro - SPB é um ambiente resultante do projeto Software Público Brasileiro, coordenado pela SLTI/MPOG. Esse projeto introduz novos conceitos e uma nova estrutura operacional para a produção de software, com a finalidade de aprimorar a eficiência da gestão governamental. O projeto foi oficialmente iniciado em 2006, quando o Governo Federal priorizou o software livre como opção estratégica para o desenvolvimento de software no âmbito do Governo e implementou políticas públicas para software com licença livre. Um dos desdobramentos dessas políticas é a percepção do potencial de participação da sociedade no desenvolvimento do software, o que levou a SLTI a formular o conceito de "software público". A partir da formulação desse conceito, foi necessário definir uma base jurídico-institucional que permitisse a criação de um ambiente virtual para a disponibilização das soluções de software na modalidade de licença "software público".

O conceito e o respectivo arcabouço do SPB também admitem a inclusão de software produzido e originalmente distribuído sob licença proprietária, mas cuja abertura de código evidencie a apropriabilidade pública do conhecimento associado. 
O software público é viabilizado por meio do Portal do Software Público Brasileiro (http://goo.gl/aUpeM). Esse portal conta com aproximadamente 60 soluções de software e com mais de 150 mil usuários cadastrados. O modelo do Software Público Brasileiro é replicado no âmbito internacional como Software Público Internacional, que é financiado pelo Programa das Nações Unidas para o Desenvolvimento - PNUD e tem iniciativas na Colômbia, Cuba, Costa Rica, Honduras, Trinidad e Tobago, Uruguai, Paraguai, Chile, Equador, Peru e Venezuela. No Brasil o portal é disponibilizado em quatro idiomas: português, espanhol, alemão e inglês.

Embora o SPB tenha adotado o modelo de produção de software livre, os resultados obtidos na criação de comunidades virtuais levaram à formação de um sistema com dinâmica própria, com mais identidade e autonomia em relação à indução governamental do que inicialmente era previsto. Esse sistema se auto-organiza, incorpora novos atores, novas parcerias e enseja inteligência e padrões de comportamento sistêmicos.

Muito embora a realização de negócios esteja inserida entre os objetivos do SPB, seu principal foco é a melhoria da gestão pública e do acesso público ao conhecimento de $\mathrm{TI}$, direcionados para o desenvolvimento sustentável do país.

O ecossistema SPB é composto por atores com diferentes características: a comunidade de desenvolvedores das soluções de software (ambiente de produção), a comunidade do setor empresarial, a comunidade dos prestadores de serviços (empresas ou usuários interessados), a comunidade de usuários das soluções, as comunidades de prática, as organizações públicas e outros. No ambiente do SPB, é usual seus membros participem de várias comunidades simultaneamente e que tenham diferentes papéis em cada uma delas. Nesse cenário, esses atores são prosumers (TAPSCOTT \& WILLIAMS, 2006) ou seja, caracterizam-se de forma simultânea como produtores e consumidores.

As características desse ecossistema são a descentralização, a auto-organização e a retroalimentação oriundas das comunidades virtuais, dos usuários finais participantes, assim como da rede de grupos de interesse que vem se ampliando desde a sua criação. 
Após as primeiras liberações de soluções no Portal SPB, as comunidades adotaram rapidamente um perfil ativo nos relacionamentos com o Governo e entre si, constituindo um comportamento semelhante ao de um sistema vivo. Percebeu-se que as interações eram diferentes em cada comunidade, mas apresentavam padrões de comportamento comuns. Algumas comunidades apresentavam um intenso fluxo de contribuições de diversas naturezas, inclusive a correção e a melhoria de código, enquanto que outras tiveram contribuições marginais, geralmente centradas em problemas na utilização da solução de software. No entanto, todas as comunidades tinham um processo similar de aprendizagem: aprendizagem coletiva dos problemas comuns (infraestrutura, segurança, interoperabilidade) e a troca de diferentes tipos de conhecimento.

O desenvolvimento do SPB se deu majoritariamente em bases não lineares, em função das diversas interações com as comunidades e com seu entorno. Diferentes ações surgiram para resolver problemas operacionais ou para implementar novas comunidades que atendessem a demandas imediatas como a prestação de serviços de suporte. Algumas dessas novas comunidades foram criadas por meio de novos subsites lançados com o objetivo de fornecer serviços de apoio a soluções de software do SPB ( Mercado Público Virtual - http://goo.gl/eOSJv) ou para atender a demandas específicas dos municípios (4CMBr - http://goo.gl/sAQHp).

Os diferentes componentes e atores descritos anteriormente assumem valores e papéis muito diversos dentro do SPB. Por exemplo, entre os atores estão membros da comunidade de software livre, empresários da industria de software, funcionários de empresas estatais, pesquisadores acadêmicos, policy makers, entre outros. Há ainda entidades que não são diretamente mantenedoras do SPB, mas que têm uma importante influência no seu desenvolvimento e trajetória, como os agentes da mídia, as universidades e, as prefeituras municipais. O próprio Portal SPB também tem instâncias diferenciadas para a participação da comunidade. Além do ambiente para a liberação das soluções de software público, o portal dispõe de um mercado livre virtual, onde prestadores de serviços dos software nele disponibilizados podem ser contatados para a realização de negócios. Existe também um local específico para o atendimento das necessidades de software de gestão das prefeituras. Assim, as fronteiras do SPB são tênues e transcendem a infraestrutura física do portal. 0 SPB tem uma natureza complexa, que por definição, implica alta horizontalidade, 
auto-organização, relacionamentos em redes e possuem muitos círculos de retroalimentação entre suas comunidades. Uma primeira aproximação do formato do SPB pode ser vista na Figura 27, na forma de uma representação de um mapa conceitual, que busca sistematizar todas as possibilidades de interação de um ator no portal. Para os membros, os usuários e demais stakeholders, o SPB era uma plataforma que proporcionava condições de desenvolvimento e disponibilização de soluções de software. A questão do novo tipo de licença de distribuição e, as alterações que essa nova forma traria nos formatos dos negócios não eram entendidas pela maioria.

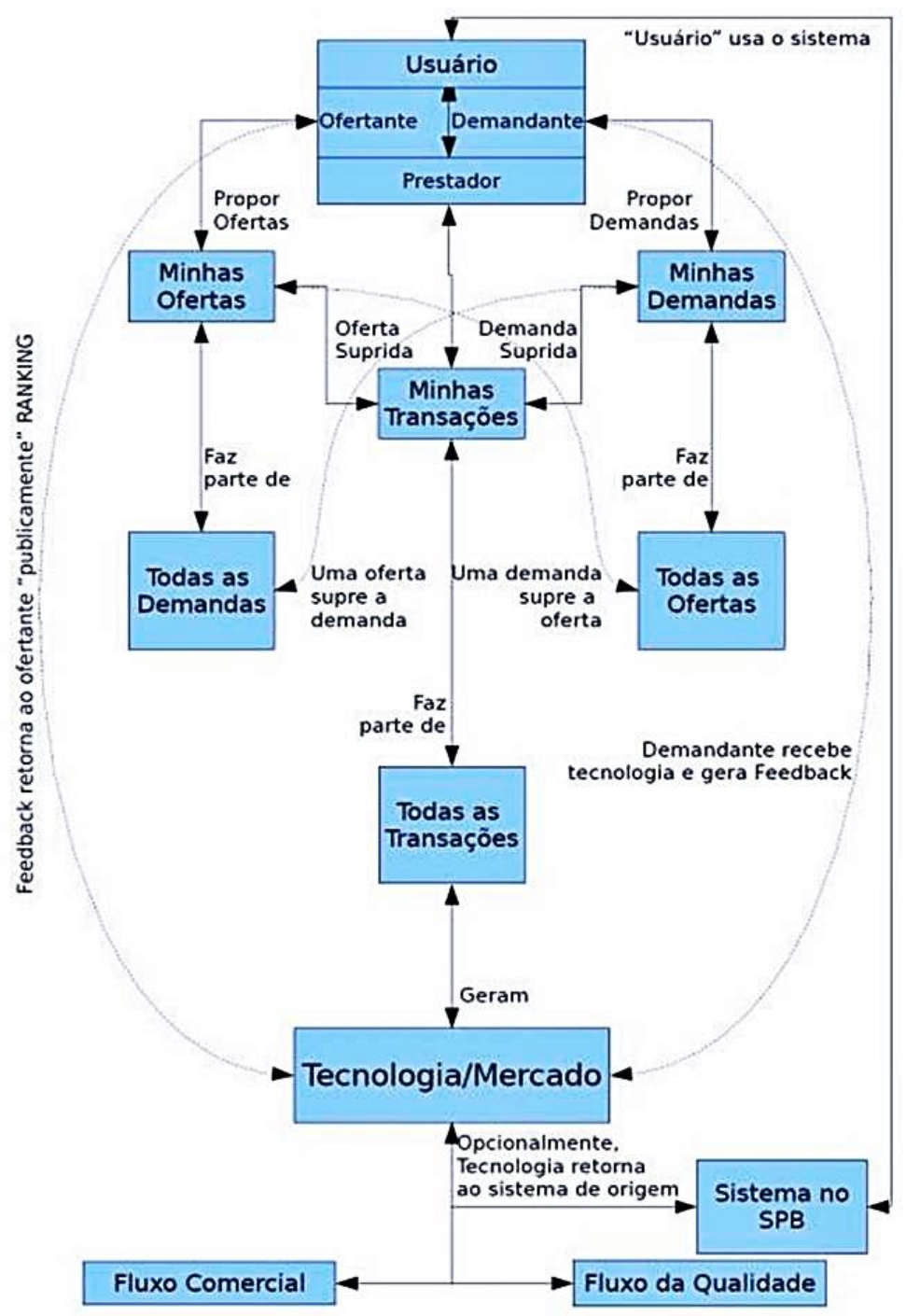

Figura 27 Representação do fluxo do sistema SPB

A coordenação do SPB reconhece a representação do mapa da Figura 27 como sendo a sua representação, mas sua limitação é percebida. No mapa não estão representados todos os stakeholders do sistema. A representação é unidimensional 
e apresenta somente a dimensão operacional. Nesse mapa não estão representadas as dimensões de infraestrutura, do arcabouço jurídico institucional, dos artefatos, dos relacionamentos, dos impactos internos e externos e da qualidade, de seus artefatos e do próprio sistema.

É importante relatar que o SPB seguiu um caminho contrário ao da maioria dos projetos de política pública. Ele foi primeiro implementado e só então seus coordenadores foram em busca de financiamento para o mapeamento e a consolidação do ecossistema. Com a obtenção do financiamento, foi contratado o CTI para criar ou procurar as bases teóricas que explicassem o fenômeno.

Foi essa busca que deu origem ao projeto Modelo de Referência do Software Público Brasileiro, cujo objetivo geral era pesquisar o modelo adequado para representar o conceito em prática. Os objetivos específicos desse projeto estão descritos a seguir:

1. SP01 - Vetor Ecossistema: estabelecer um plano de ação e uma estratégia para o desenvolvimento de arranjos institucionais que possam garantir a sustentabilidade do SPB;

2. SP02 - Vetor Interoperabilidade: definir a arquitetura e a interoperabilidade de software por meio de modelo de maturidade de interoperabilidade;

3. SP03 - Vetor Qualidade de Produto de Software: definir os critérios de admissibilidade de produto/serviço no sistema do SPB;

4. SP04 - Vetor Qualidade de Processos de Desenvolvimento de Software: . definir os os critérios e os procedimentos para admissão de solução de software no SPB desenvolver um modelo de capacidade para o desenvolvimento que contemple um método de avaliação de maturidade e um conjunto de orientações para o estabelecimento e a utilização do modelo e do método pela comunidade de interesse;:

5. SP05 - Vetor Qualidade de Prestadores de Serviço definir os os critérios e os procedimentos para admissão de um prestador de serviços no SPB desenvolver um modelo de capacidade para a prestação de serviços que contemple um método de avaliação de maturidade e um conjunto de orientações para o estabelecimento e a utilização do modelo e do método pela comunidade de interesse;. 
6. SP06 - Vetor Teste de Qualidade: definir uma estrutura tecnológica de teste de software para o SPB;.

7. SP07 - Disseminação e Sustentabilidade: desenvolver um plano de disseminação dos resultados, com ações de disseminação previstas e avaliação de impacto do SPB.

Cada um dos objetivos específicos foi considerado como um vetor de qualidade que contribui para a qualidade do todo. A utilização do termo "vetor" para designar cada um dos subprojetos associados a um objetivo específico decorreu da consideração que, cada vetor que atua no ecossistema com a dimensão da qualidade, promove a qualidade no ecossistema. A representação dessa ideia é mostrada na Figura 28.

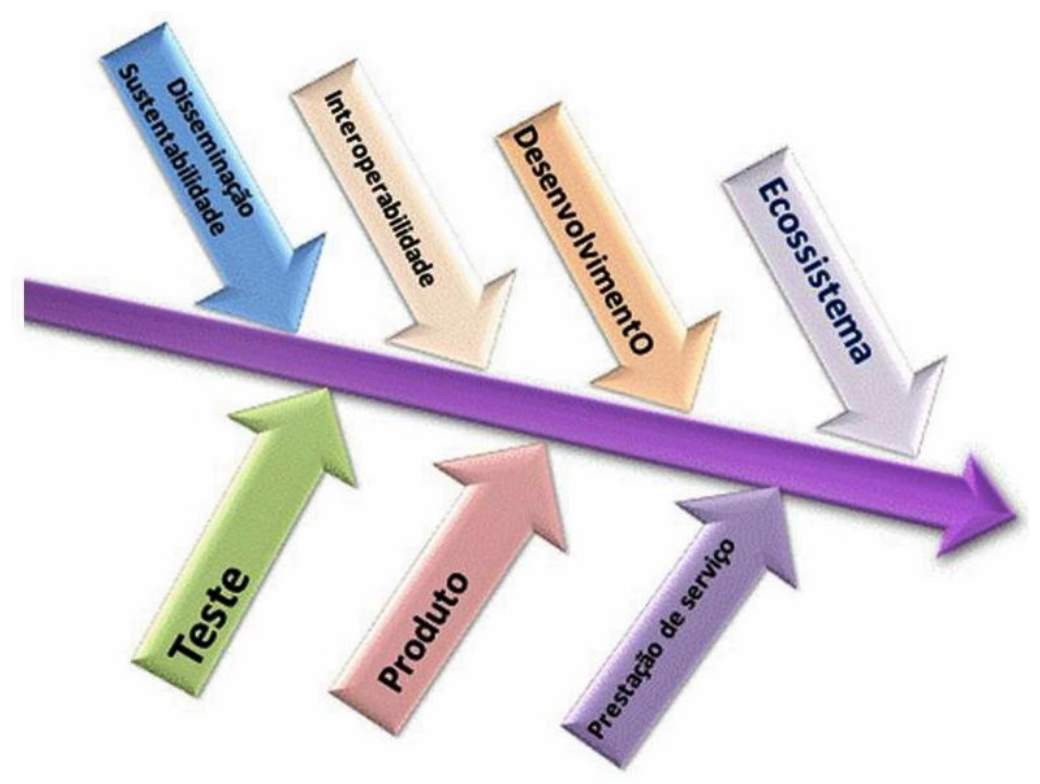

Figura 28 Vetores de qualidade do SPB

\subsection{PROBLEMA DE PARTIDA DA PESQUISA}

Estabelecidos os objetivos citados na seção anterior, a autora desta pesquisa foi designada como coordenadora do subprojeto cujo objetivo era definir o arcabouço estrutural/gerencial do sistema SPB: o vetor SP01 - Ecossistema. No início do projeto, a equipe de trabalho designada considerou que os vetores começariam a ser desenvolvidos paralelamente.

Após a primeira reunião de alinhamento do projeto verificou-se que os vetores SP02, SP03, SP04, SP05, SP06 e SP07 eram fortemente dependentes das definições, das estruturações e das modelagens que seriam realizadas no vetor SP01. Além disso, ficou clara para a equipe de trabalho a ausência de definições de propósito e de 
visão de futuro do ecossistema. Também não estava claro quem eram os seus stakeholders, quais eram os relacionamentos, e qual a dinâmica do sistema. Os stakeholders conhecidos tinham visões e entendimentos diferentes da missão, dos valores e dos objetivos básicos do ecossistema.

A ausência de requisitos básicos definidos e conhecidos por todos os envolvidos com o ecossistema tornou impossível o início dos trabalhos especificados no projeto. A decisão foi, então, ampliar o escopo do subprojeto SP01- Vetor Ecossistema. Além da responsabilidade de estabelecer um plano de ação e uma estratégia de desenvolvimento dos arranjos institucionais que garantissem a sustentabilidade do sistema, além de analisar os inter-relacionamentos dos atores do sistema e de propor um modelo que o representasse, o SP01 deveria elaborar referências para um modelo de maturidade/capacidade que tivesse a capacidade de reconhecer o sistema no seu estado atual e proporcionar o seu desenvolvimento futuro.

Nesse momento, ficou definido o problema de partida ou a situação problemática desta pesquisa, que pode ser expresso da seguinte forma: - inexistência de um modelo de referência, em diferentes níveis, para os stakeholders do sistema e a ausência de uma dimensão de qualidade para o ecossistema como um todo e para as suas partes.

Esta pesquisa introduz o recorte da qualidade no ecossistema como um todo. A qualidade para as suas partes, a qualidade para o desenvolvimento das soluções de software, a qualidade para prestadores de serviço e a qualidade nas comunidades estão tratadas em Zoucas (2010), Zoucas (2011) e Martinez (2011). A dimensão da qualidade, como um conjunto de vetores, com domínios próprios, tem como resultante a qualidade do ecossistema e a qualidade em suas partes.

A Figura 29 apresenta três "estados de mundo" em diferentes momentos no início do projeto. A visão do momento $\mathrm{T} 1$, a mais hard, mais linear, imagina o mundo do SPB como um ambiente controlado e controlável, onde as relações são predefinidas. No momento T2, percebe-se um contorno não tão rígido, mais fluido, com várias espécies no seu interior interagindo ainda dentro do sistema. Essa visão é mais flexível que a primeira, T1, mas desconsidera o ambiente externo ao sistema. No momento T3, existe uma visão soft do sistema. Nele, são notados propriedades, comportamentos e dinâmicas próprio de um ecossistema. 
Nesse estado de mundo T3, considera-se que os requistos de qualidade desenvolvidos pelos vetores, antes pensada de maneira individual e fechada, deve ser repensada com a visão do ecossistema, ou seja, as partes devem levar em consideração seu relacionamento quando de sua estruturação.

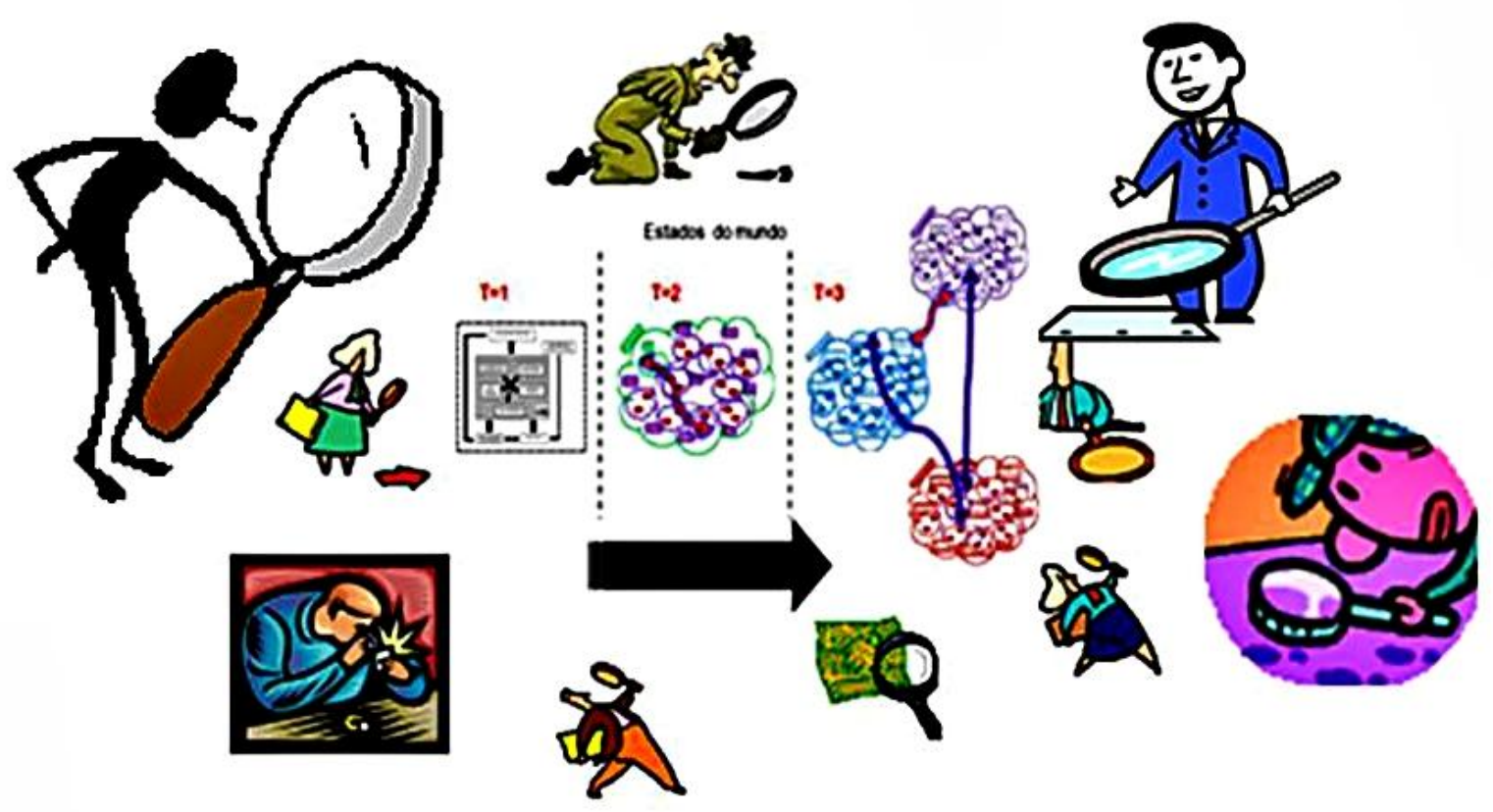

Figura 29 Estados de mundo no SPB

A Figura 30 representa essa visão das partes (sub projetos), existindo de forma individual, sem preocupação com o todo e, no segundo momento, alinhadas com o objetivo de qualidade do ecossistema.

\section{Qualidade no SPB}

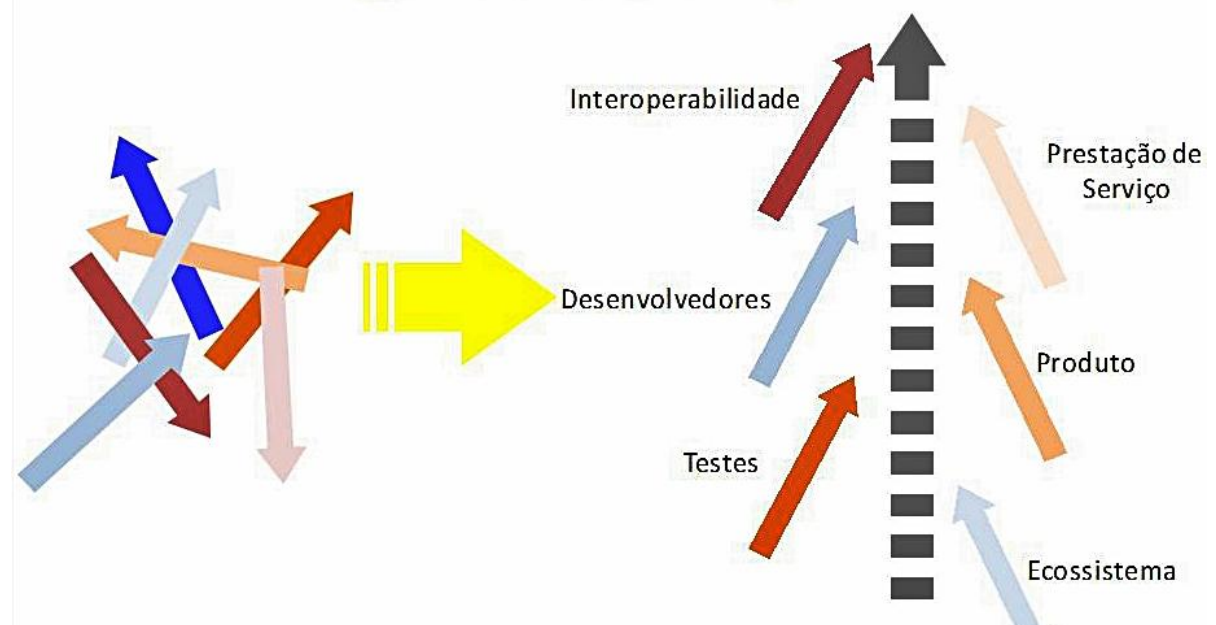

Figura 30 Qualidade no ecossistema SPB 
A partir das questões expostas acima teve início a estruturação desta pesquisa. A primeira fase está relacionada com a situação problemática vivenciada pelo SPB , ou seja, a percepção da necessidade de introduzir critérios de qualidade para as diversas espécies do ecossistema. Essa fase é a motivação da pesquisa. $\mathrm{Na}$ segunda fase, é realizada a aplicação da metodologia SSM e, além dela, é utilizada a metodologia para construção de frameworks de modelo, o PRO2PI-MFMOD. Na terceira fase, são realizadas as provas de conceito coma finalidade de verificar se os resultados obtidos na fase anterior estão em conformidade com as referências teóricas de construção de modelos de maturidade. A quarta fase trata da verificação e da validação da pesquisa.

\subsection{RECURSOS PARA A REALIZAÇÃO DA PESQUISA}

O projeto "Modelo de Referência para o Software Público Brasileiro" é desenvolvido de forma cooperada e compartilhada, para garantir a utilização de experiências anteriores bem sucedidas dos parceiros envolvidos.

Participam dessa iniciativa: Centro de Tecnologia da Informação Renato Archer (CTI/MCTI), Secretaria de Logística e Tecnologia da Informação (SLTI/MPOG), Centro de Tecnologia da Informação e Comunicação do Estado do Rio de Janeiro (PRODERJ), Secretaria de Política de Informática (SEPIN/MCTI) e Associação Brasileira de Entidades Estaduais de Tecnologia da Informação e Comunicação (ABEP). Os parceiros contam com importante suporte financeiro da Financiadora de Estudos e Projetos, FINEP. No final do mês de dezembro de 2008, o contrato CTI/FACTI/FINEP, de apoio financeiro ao projeto foi assinado entre as partes e os recursos financeiros chegaram na segunda semana de janeiro de 2009.

O projeto foi estruturado com sete coordenações. A autora é a coordenadora do Vetor SP01- Ecossistema. Esse vetor tem como característica básica a utilização da dinâmica de trabalho cooperada e compartilhada, mediada por ferramentas de cooperação e colaboração. Além da cooperação e do compartilhamento, a preocupação com a gestão do conhecimento gerado pela equipe é uma constante. Foram utilizados wikis, blogs, web conferências e outras ferramentas para desenvolvimento, armazenamento e recuperação do conhecimento gerado.

Nas primeiras interações com o cliente, as premissas básicas para 0 desenvolvimento do projeto foram apresentadas, analisadas, discutidas e aceitas 
pelas partes. Existe um alinhamento das ideias inovadoras do cliente com a disposição para procurar novos caminhos teóricos por parte da equipe do Vetor SP01. Os acordos entre as instituições e os coordenadores, membros e stakeholders foram muito simples e de fácil alinhamento. A equipe do Vetor SP01 teve amplo acesso à plataforma de suporte do ecossistema, aos coordenadores de comunidade, aos coordenadores do ecossistema e, aos membros da comunidade. A plataforma foi disponibilizada para surveys via web, notícias, divulgação e outros fins. Todas as bases de dados do ecossistema foram disponibilizadas para a equipe do Vetor SP01.

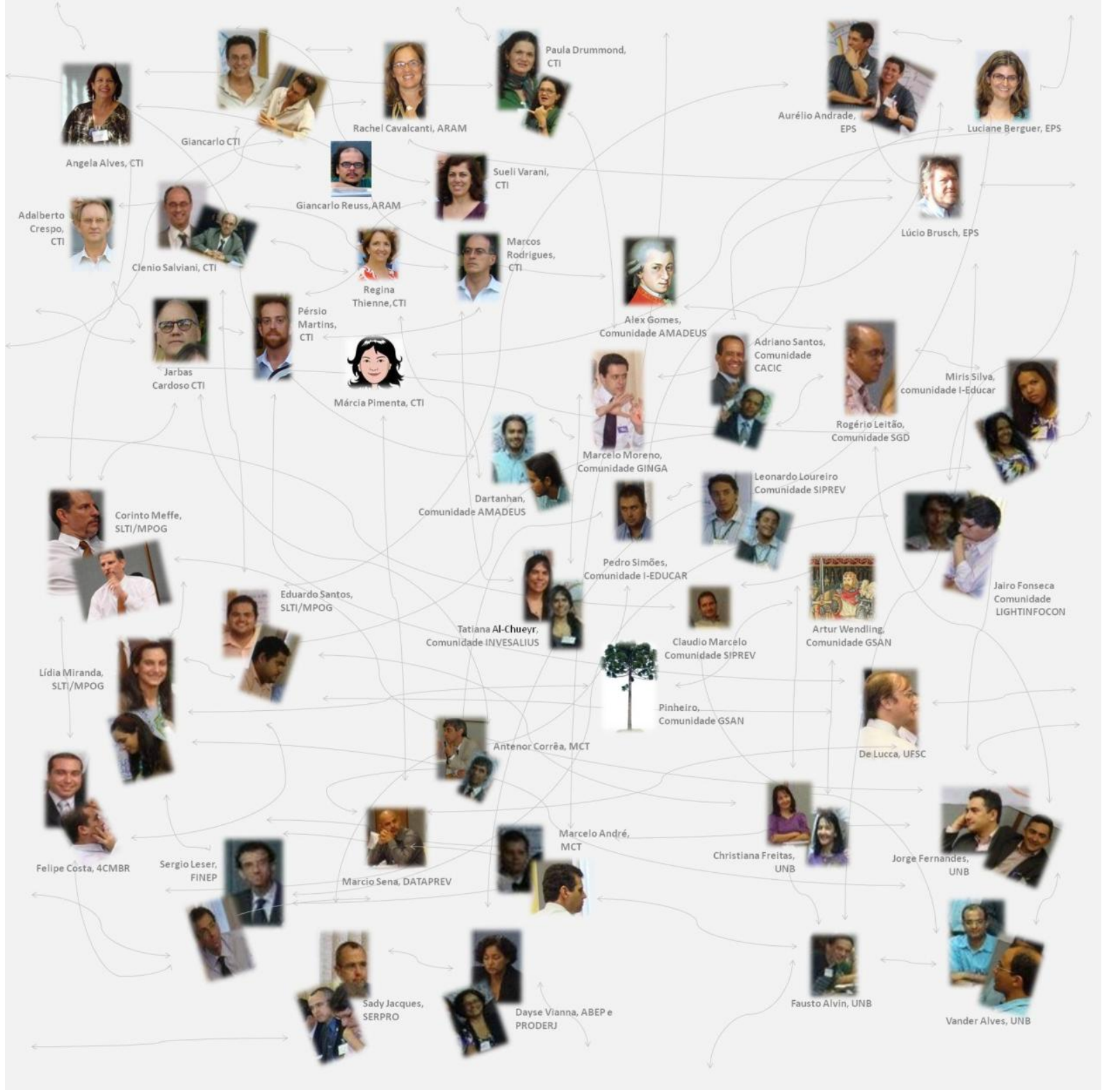

Figura 31 Membros da equipe do SPB baseados no CTI/Campinas 
Da mesma forma, todos os demais recursos técnicos, tais como servidores, laboratórios, ecossistema SPB, ambiente OpenACS (Open Architecture Community System), wikis, salas de web conferência, redes e redes wireless foram disponibilizados para a execução do projeto e da pesquisa-ação. A Figura 31, mostra as equipes dos sete vetores (sub projetos) do projeto.

Nela, estão pesquisadores do CTI, pesquisadores contratados e, pessoal de apoio do CTI e da FACTI. Ao todo são sessenta e duas pessoas que, com maior ou menor dedicação, de alguma maneira participaram diretamente no projeto. A este número deve ser acrescentado um conjunto de pessoas, direta e indiretamente envolvidas, do CTI, da FACTI, da SLTI/MPOG, do PRODERJ, da ABEP, e da SEPIN/MCT , membros das comunidades do Portal SPB, membros de publicações especializadas, além de professores e pesquisadores de universidades, no país e no exterior. 


\section{MOMENTOS DESSA PESQUISA-AÇÃO}

Este capítulo descreve as etapas da pesquisa cujo objetivo é utilizar a lógica de desenvolvimento dos modelos de maturidade para elaborar elementos de um framework de modelo de capacidade/maturidade para um ecossistema de produção de software. Por ecossistema de produção de software entende-se o ecossistema Software Público Brasileiro, ambiente colaborativo, cooperativo e compartilhado de produção de software com características diferenciadas dos ambientes de produção de empresas de desenvolvimento intensivas em software, que são ambientes controlados e com limites definidos e conhecidos. A pesquisa foi segmentada em partes denominadas "momentos de pesquisa". A Seção 5.1 apresenta um panorama geral dos quatro momentos de pesquisa realizados, e que são detalhados nas seções de 5.2 a 5.5. O Momento de Pesquisa 02 desdobra-se em três ciclos: o problema, o método sistêmico e o modelo de referência. Os momentos e ciclos são apresentados em ordem cronológica. A seção 5.6 concluiu esse capítulo, apresentando as reflexões da pesquisa.

Cada ciclo da pesquisa-ação é descrito em quatro partes, que correspondem às etapas Planejar, Agir, Observar e Refletir, típicas da pesquisa-ação. Na aplicação dos ciclos são apresentados o problema e a solução que foram investigadas, bem como as razões que levaram à escolha proposta. Na etapa Planejar também é feito o planejamento das etapas Agir, Observar e Refletir. A etapa Agir apresenta as ações realizadas para investigar as proposições, descrevendo sua implementação no decorrer do projeto. Na etapa Observar são descritas as fontes de dados utilizadas, bem como a forma de realização da coleta dos dados. Nessa etapa Refletir são apresentadas a análise dos dados e as reflexões das contribuições para a etapa seguinte.

\subsection{UMA VISÃO GERAL DOS MOMENTOS DESTA PESQUISA-AÇÂO}

Nos quatro momentos que compõem esta pesquisa foram investigados aspectos relativos à utilização do arcabouço teórico dos modelos de maturidade em um ecossistema de produção de software com características específicas, conforme descritas em 4.1. O objeto de estudo é o Ecossistema SPB com suas comunidades, seus grupos de interesse e seu mercado público. A pesquisa em campo teve a duração de um ano. Durante esse tempo, o objetivo foi a busca de evidências que 
pudessem ser utilizadas para verificar a viabilidade da construção de um modelo de referência baseados em maturidade, mesmo que para isso fosse necessária a redefinição de alguns conceitos como, por exemplo, "capacidade". A Figura 32 representa o modelo inicial do objeto de pesquisa.

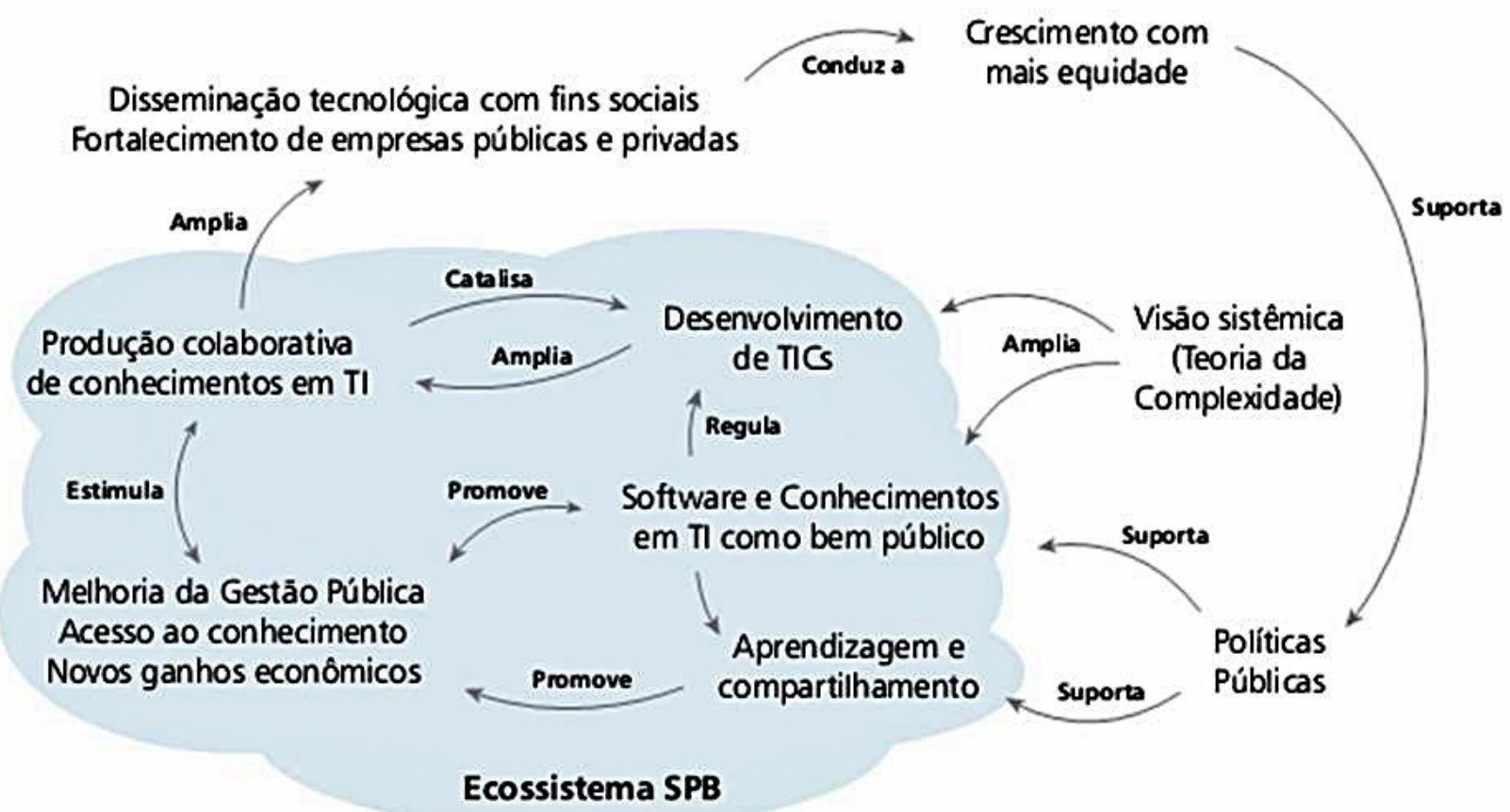

Figura 32 Representação do Ecossistema SPB e seu entorno

Inicialmente, investigou-se como a pesquisa seria e quais suportes metodológicos seriam utilizados. Por se tratar de um problema desestruturado e complexo, foi necessário utilizar algumas abordagens apropriadas para a confirmação das "quase hipóteses" levantadas pelas questões de pesquisa especificadas na seção 4.4.2. Para a condução da pesquisa foi utilizado o paradigma da pesquisa-ação. Para entender o problema, coletar os dados necessários e obter subsídios para a elaboração de aspectos do modelo de maturidade que contemplasse a visão sistêmica foi utilizada a metodologia SSM descrita na seção 2.3.4.1 e para conduzir a elaboração dos aspectos do modelo de capacidade/maturidade foi utilizado o framework de método para construção de modelos de capacidade PRO2PI-MFMOD, descrito na seção 2.6 . 
O fluxo seguido ao longo da pesquisa tem como pressuposto que, para a construção de referências de um método para elaborar um modelo de maturidade para o Ecossistema SPB, deve-se considerar seus elementos fundamentais: a solução de software desenvolvida e a comunidade que a abriga, mantém e atualiza. A pesquisa está estruturada conforme mostra a Figura 33.

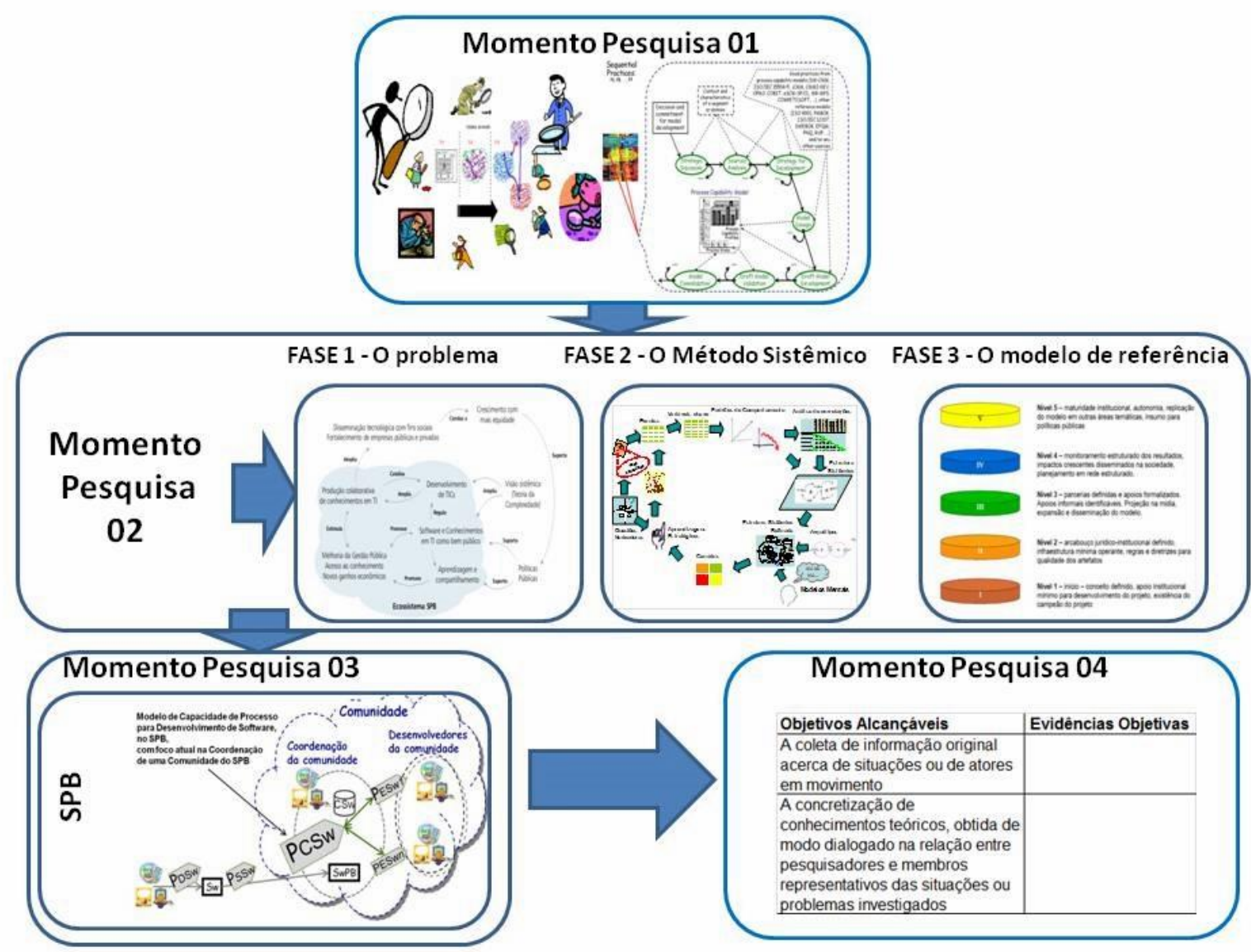

Figura 33 Os quatro momentos da pesquisa

No Momento de Pesquisa 01, foi definida a abordagem aplicada para a realização da pesquisa. Essa abordagem deveria garantir que as questões de pesquisa apresentadas na seção 3.4.2 fossem respondidas. Para atender os requisitos desse momento, foram selecionados as metodologias e os métodos que seriam utilizados. Para responder as questões de pesquisa, foram utilizados o PRO2PI-MFMOD como framework de método e a SSM para estruturar o problema e coletar dados.

Em seguida, teve início o Momento de Pesquisa 02, com suas fases e ciclos. As fases pressupunham que $o$ trabalho da autora seria realizado em conjunto com $o$ cliente, com o objetivo de resolver o problema por ele especificado, além de atender as questões de pesquisa identificadas. Essas fases são: Fase 01 - Entendendo o 
problema, Fase 02- Aplicando o método sistêmico e Fase 03 - Elaborando os elementos do modelo de referência. A primeira e a última fases são, respectivamente, de preparação e de finalização da pesquisa-ação, enquanto que a Fase 02 hospeda seus ciclos. Os ciclos foram estruturados conforme os ciclos sugeridos pela SSM. Ao finalizar o Momento de Pesquisa 02, teve início o Momento de Pesquisa 03. Nesse momento, foram realizadas as provas de conceito, a partir dos resultados gerados na fase anterior. Em seguida, foi realizado o Momento de Pesquisa 04, cujo objetivo era demonstrar a qualidade e a validade da pesquisa. Para isso, foram utilizados os frameworks definidos na seção 3.2.5. Os quatro momentos da pesquisa estão detalhados nas próximas seções.

\subsection{MOMENTO DE PESQUISA 01}

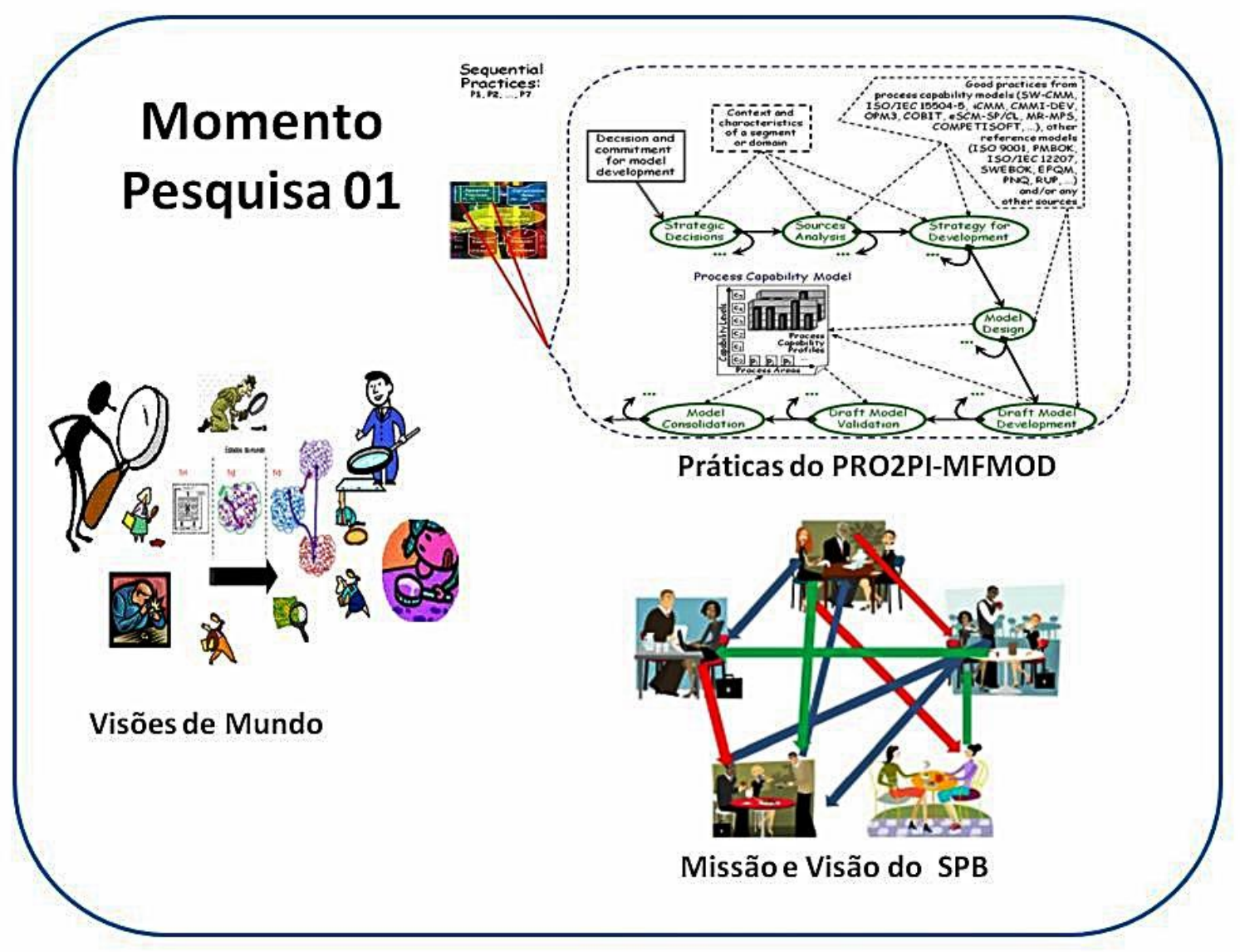

Figura 34 Representação do momento 01 da pesquisa

O Momento de Pesquisa 01, representado na Figura 34, é, essencialmente,um primeiro diagnóstico da situação problemática. Nele, os pesquisadores mergulham no objeto de estudo para classificá-lo conforme sua natureza, procurar os 
referenciais teóricos que o representam e selecionar as ferramentas adequadas para tratá-lo.

Após a análise do projeto Modelo de Referência do Software Público Brasileiro, verificou-se que não existia uma definição consolidada, documentada e disseminada do significado do Software Público Brasileiro. Não existiam também, de uma forma apropriada pela comunidade do SPB, pelos seus stakeholders e pela sociedade em geral, o conceito e o significado desse modelo. Na verdade não existia um modelo de referência explícito definido. Existia um entendimento tácito do conceito nos diferentes níveis do SPB. A coordenação tinha um entendimento mais sofisticado, abrangente e estratégico, que ela não conseguia comunicar para as demais camadas de stakeholders. Nesse primeiro momento, não havia sequer uma forma homogenia para se referir ao objeto. Uma observação relevante para a solução do problema foi o diagnóstico de que a comunidade não possuía um entendimento uniforme sobre o Software Público Brasileiro. Para alguns, era um portal, para outros, uma comunidade e, para outros ainda, uma iniciativa ideológica ou algo relacionado com o software livre

Para avançar na pesquisa foi necessário realizar entrevistas semiestruturadas com um conjunto de stakeholders representativos do sistema. Essas entrevistas, cujo roteiro encontra-se no ANEXO III, deveriam fazer um mapeamento preliminar do sistema. As primeiras entrevistas ocorreram em fevereiro de 2009. Os entrevistadores foram dois pesquisadores da equipe do vetor SP01 e os grupos entrevistados foram:

- Equipe SLTI, composta por: a) administrador do portal, coordenador da comunidade OpenACS e b) administradora do portal, responsável pela criação de comunidades, pelo atendimento ao usuário, além da supervisão das atividades nas comunidades;

- Gerente de Inovações Tecnológicas da SLTI: campeão ${ }^{11}$ do SPB, mentor das ideias do novo modelo econômico e de produção do SPB;

- Administradores e membros de comunidades: a) administrador da comunidade GSAN $^{12,}$ b) membro da comunidade OpenACS, c) administrador

\footnotetext{
${ }^{11}$ Líder com alta motivação

${ }^{12}$ As comunidades aqui referidas estão disponíveis em http://www.softwarepublico.gov.br
} 
da comunidade I3GEO, d) administrador da comunidade e-Proinfo e e) administrador da comunidade SIGATI;

- Grupo de interesse: coordenador do grupo de interesse $4 \mathrm{CMBr}$;

- Empresários: representantes de empresas com soluções disponibilizadas no portal;

- Universidade: pesquisador da Universidade de Brasília (UNB) e

- SPI/PNUD: responsável pela criação do SPB-SPI - Software Público Internacional (América Latina).

Após a coleta, a tabulação e a agregação dos dados das entrevistas, foi feita a reflexão crítica sobre os resultados obtidos. Com isto, ficou comprovado que o entendimento do SPB não era homogênio para seus stakeholders. Os entendimentos dependiam da posição ocupada no sistema. Não havia uma visão do todo e essa carência era também sentida no grupo de coordenação do SPB. Além disso, os entrevistados tinham expectativas díspares com relação ao resultado do projeto SPB, incluindo os stakeholders (SLTI, PNUD) e os líderes de comunidades.

Internamente ao projeto SPB, no CTI, a situação era a mesma. Não havia um alinhamento de entendimento das expectativas para cada um de seus vetores (SP01, SP02, SP03, SP04, SP05, SP06 e SP07). Desta forma, concluiu-se que existia um conjunto de diferentes concepções do projeto, tanto interna quanto externamente. Em dados momentos, o horizonte era o projeto Modelo de Referência; em outros momentos, o Portal do SPB, e, ainda em outros, a referência era o conceito SPB. A partir dessa conclusão, o vetor SP01 promoveu ações cujo objetivo era nivelar o entendimento de visões sobre o projeto. Foi necessária uma intervenção com o objetivo de definir, para os coordenadores, os coordenadores de comunidade, os police makers, os parceiros e os colaboradores, um propósito e uma visão para o SPB que fosse construída e compartilhada por todos.

Para conseguir uma abrangência capaz de cobrir toda a diversidade de atores e de, visões e interesses sobre o mesmo objeto, optou-se por adotar a abordagem do pensamento sistêmico, que possui a robustez necessária para tratar a heterogeneidade dos modelos mentais presentes. A partir dessa decisão, o SP01 convocou reuniões com os demais vetores para apresentar os resultados das 
entrevistas citadas anteriormente (visão de stakeholders e de atores envolvidos com software público), promoveu palestra sobre pensamento complexo e sistêmico, ministrou exercícios de construção de mapa sistêmico com a equipe do projeto do CTI e assessorou a elaboração e a implementação de ambientes colaborativos virtuais (criação de wikis para cada um dos vetores e para o projeto) e de, um ambiente para guarda e recuperação dos conhecimentos gerados.

Todavia, ficou demonstrada pelo resultado da pesquisa preliminar a inexistência de uma compreensão compartilhada do propósito e da visão de futuro para o SPB. Uma etapa era, portanto, imprescindível: a construção conjunta desse propósito e dessa visão. Para essa tarefa foi utilizada uma abordagem metodológica com os seguintes objetivos:

\section{Construção do propósito comum entre os participantes do projeto SPB e todos seus stakeholders}

\section{Compartilhamento da visão do SPB entre seus atores}

O objetivo do vetor SP01 era buscar definições aderentes aos diferentes interesses dos stakeholders do projeto e uma unidade de posturas e metas para o Software Público Brasileiro no âmbito do CTI, do MCT, da ABEP, da Proderj e da SLTI. O exercício foi desenvolvido com 28 participantes, entre pesquisadores do CTI e representantes da SLTI, da SEPIN/MCT e das Universidades.

\section{Metodologia e Resultados da Intervencão}

O exercício foi desenvolvido por meio da metodologia "Café Mundial" (BROWN, 1999). Essa metodologia é inspirada nos momentos de coffee break de eventos, pois especialistas perceberam que essas pausas eram um momento produtivo e rico, quando vários diálogos eram estabelecidos. A essência da metodologia é estabelecer uma rede de diálogos entre diferentes atores e, ao final, construir um resultado comum, com a colaboração de todos. Essa prática propicia a emergência de uma inteligência coletiva.

O "Café Mundial" consiste na separação dos participantes em grupos pequenos e heterogêneos, cada grupo organizado em torno de uma mesa, que têm como meta responder a uma questão ampla e pertinente a todos os grupos. Após um tempo predeterminado, cada grupo é mesclado com os participantes de outras mesas, permanecendo em cada mesa o anfitrião, aquele que tem o papel de relatar para o 
novo grupo a discussão do grupo anterior. Essa dinâmica pode ser repetida inúmeras vezes. No exercício realizado no $\mathrm{CTI}$, ela foi repetida três vezes. Ao término, cada mesa apresenta para as demais a resposta final da pergunta colocada. O facilitador do exercício busca integrar as respostas das mesas e gerar uma única, que contemple todas as demais. A Figura 35 representa pictoricamente a formação de um exercício da metodologia.

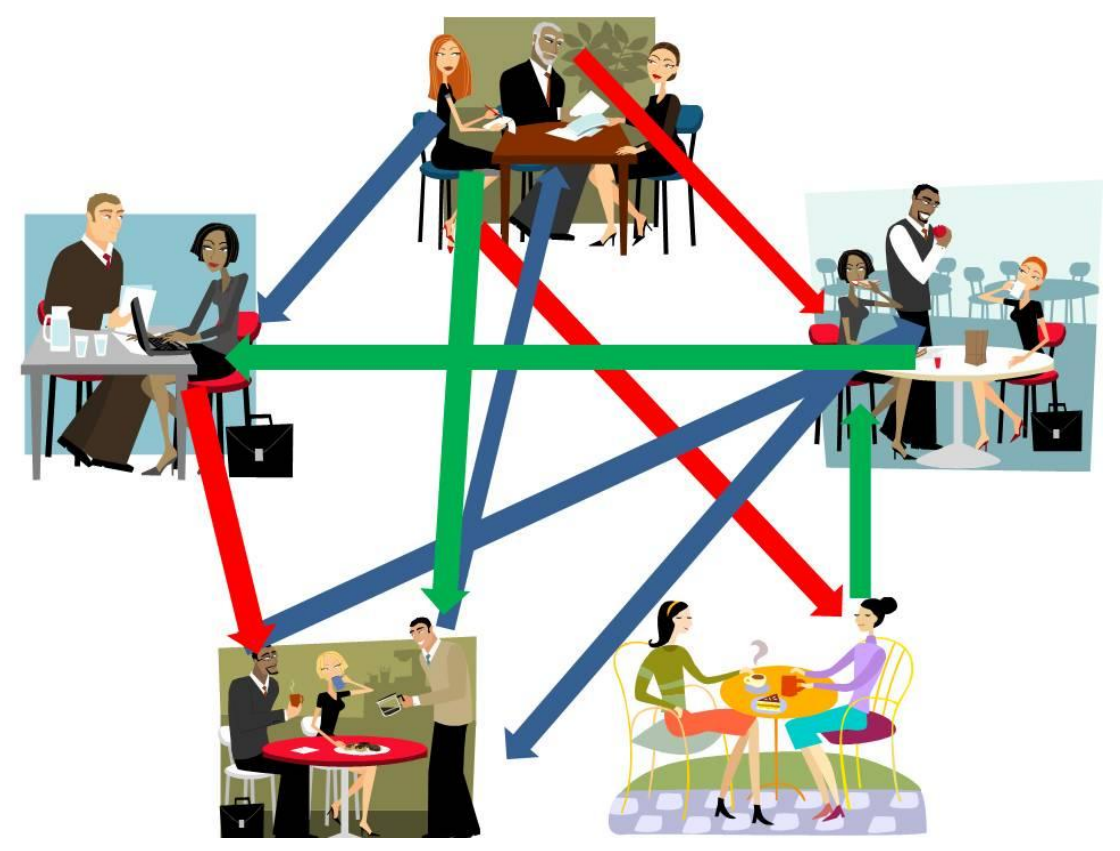

Figura 35 Representação do esquema da dinâmica do "Café Mundial"

Outro ponto importante a ser destacado na metodologia é que o ambiente deve permitir descontração, de forma que as pessoas se sintam à vontade para criar e expor o que pensam para o grupo. Assim, em cada mesa, deve haver a disponibilidade de papel à vontade, diversos tipos de lápis e canetas coloridas (quando possível, até alguns "brinquedos"), para que as pessoas possam criar suas ideias em um clima lúdico e deixando de lado o formalismo. O coffee break é servido simultaneamente. Após a aplicação da metodologia, foram definidos o propósito e a visão do SPB, que são apresentados a seguir:

\section{PROPÓSITO DO SPB}

"Construir e aprimorar continuamente uma rede de produção colaborativa de conhecimento para desenvolver, em ambiente público, soluções informatizadas de Tl direcionadas ao desenvolvimento sustentável (social, econômico e ambiental)." 
O propósito acima enunciado enfatiza três aspectos distintivos do SPB: rede de produção, colaboração e conhecimento. O fato de o SPB definir-se como "rede de produção" evidencia a tendência mundial de organização em rede, que visa potencializar cada ponto da rede e promover de forma eficaz a disseminação de ideias. $O$ aspecto colaborativo confirma a essência de uma rede não hierárquica que se alimenta pela atividade cooperativa entre os atores envolvidos. Um avanço no conceito do SPB é entender o propósito dessa rede colaborativa tomado como algo mais amplo e abrangente do que exclusivamente a produção de software, ou seja, como a produção de conhecimento agregado à criação de soluções informatizadas de Tecnologias da Informação. Essa expressão traz em si uma compreensão maior dos resultados dessa produção. A inovação que o conceito de Software Público carrega em seu propósito é o fato de ser desenvolvido em um ambiente público. Nestes termos, o ambiente SPB proporciona a oportunidade de desenvolver conhecimento relacionado a TI que viabiliza o desenvolvimento sustentável do país.

\section{VISÃO DO SPB}

"Ter o modelo de produção colaborativa em rede do SPB apropriado pela sociedade e ser referência internacional."

A visão corresponde ao conjunto de compreensões para o qual se devem direcionar as ações e os anseios. São as aspirações futuras. Assim sendo, o SPB pretende se consolidar não apenas como um ambiente de produção colaborativa em rede, mas ir além e ser um modelo de sucesso que permita replicar o conceito de software público em outras instâncias, no país e no mundo, evidenciando, por fim, que esse modelo foi verdadeiramente apropriado pela sociedade.

\section{Aplicando o PRO2PI-MFMOD}

Neste momento da pesquisa, após a coleta de dados, foi aplicado o PRO2PIMFMOD para relacionar as atividades com as práticas sequenciais do framework. $O$ resultado da aplicação é descrito na Quadro 25 e no Quadro 26.

\begin{tabular}{|c|c|c|c|c|}
\hline Atividade & Descrição & Regras & Práticas & Técnicas \\
\hline $\mathrm{A} 1$ & $\begin{array}{l}\text { Análise do projeto, formação de } \\
\text { equipes, estratégia de } \\
\text { execução do projeto, forma de }\end{array}$ & 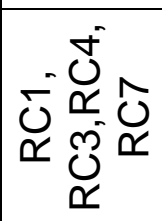 & P1 & $\begin{array}{c}\mathrm{T} 3, \mathrm{~T} 11, \mathrm{~T} 9, \\
\mathrm{~T} 12\end{array}$ \\
\hline
\end{tabular}




\begin{tabular}{|c|c|c|c|c|}
\hline Atividade & Descrição & Regras & Práticas & Técnicas \\
\hline & acompanhamento & & & \\
\hline A2 & $\begin{array}{l}\text { Pesquisas em publicações na } \\
\text { mídia, papers e documentação } \\
\text { do projeto }\end{array}$ & & P2 & $\mathrm{T} 12, \mathrm{~T} 9, \mathrm{~T} 3$ \\
\hline A3 & $\begin{array}{l}\text { Aplicação de entrevistas semi } \\
\text { estruturadas e do Café Mundial }\end{array}$ & & P1 & $\begin{array}{c}\text { T3, T11, T9, } \\
\text { T12 }\end{array}$ \\
\hline A4 & $\begin{array}{l}\text { Definição de propósito, de visão } \\
\text { de futuro e treinamento da } \\
\text { equipe }\end{array}$ & & $\mathrm{P} 2$ & $\mathrm{~T} 12, \mathrm{~T} 9, \mathrm{~T} 3$ \\
\hline
\end{tabular}

Quadro 25 Atividades, Regras, Práticas e Técnicas do MFMOD para o SPB

O Quadro 25 apresenta as atividades, as práticas sequenciais, as regras de customização e as técnicas empregadas nessa primeira fase de aplicação do PRO2PI-MFMOD. O Quadro 26 apresenta as atividades definidas e executadas e as relaciona com as práticas do PRO2PI-MFMOD e com aplicações das regras de customização. Ele demonstra que as atividades do método podem ser expressas com o emprego de duas das práticas sequenciais e de quatro regras de customização.

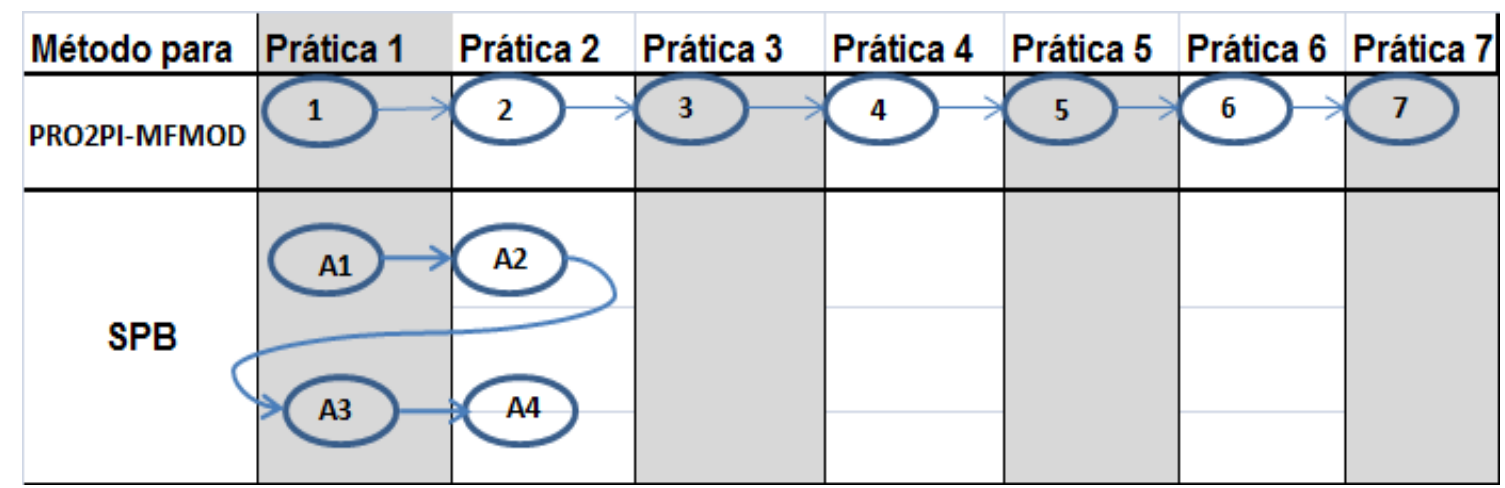

Quadro 26 Práticas e atividades do PRO2PI-MFMOD para o SPB - 01

RC1 é aplicada uma vez porque a atividade 2 corresponde à prática 2;

RC3 é aplicada uma vezes porque a aplicação do método termina antes das práticas 3,4,5,6 e 7;

RC4 é aplicada uma vez porque a prática 1 executa as atividades 1 e 3; 
$\mathbf{R C 7}$ é aplicada quatro vezes porque, durante cada uma das práticas 1 e 2, as atividades usam diferentes técnicas específicas para apoiar a sua execução. A seleção e a aplicação das técnicas específicas são discutidas a seguir.

Um subconjunto das quatro técnicas específicas do PRO2PI-MFMOD foi definido para apoiar a execução do método nesta fase inicial do projeto. As técnicas são apresentadas a seguir, na mesma sequência em que foram aplicadas durante a execução do método.

T3: Revisão de literatura - a revisão de literatura foi planejada para adquirir conhecimento sobre o sistema SPB, o projeto SPB e as publicações relativas ao sistema e aos casos e domínios similares.

T11: Entrevista - foi planejada uma entrevista semiestruturada com os principais representantes de todos os stakeholders do SPB. Seu objetivo foi coletar dados que permitissem o correto entendimento do ecossistema, bem como a sua correta caracterização e o seu domínio.

T9: Um primeiro brainstorm foi planejado e estruturado com a metodologia Café Mundial, com o objetivo de construir de forma compartilhada o propósito e a visão de futuro do SPB. Um segundo aconteceu na prática 2, com o objetivo de vislumbrar padrões de aprendizagem no SPB.

T12: O workshop foi planejado para disseminação e obtenção de comprometimento da comunidade SPB seu propósito e visão de futuro.

A aplicação do PRO2PI-MFMOD nesse momento de pesquisa foi detalhada para que a lógica de sua construção fosse explicitada. Nas próximas aplicações serão apresentados somente a tabela de "Atividades, Regras, Práticas e Técnicas do PRO2PI-MFMOD para o SPB" e o quadro de "Práticas do PRO2PI-MFMOD e atividades de um método para o SPB".

\section{Conclusão}

Os resultados do Momento de Pesquisa 01 são descritos no Quadro 27.

\begin{tabular}{|l|l|}
\hline Momento & 01 \\
\hline Período & Janeiro a abril de 2009 \\
\hline $\begin{array}{l}\text { Fase de } \\
\text { Pesquisa }\end{array}$ & Momento de Pesquisa 01: Diagnóstico da situação problemática \\
\hline
\end{tabular}




\begin{tabular}{|c|c|}
\hline $\begin{array}{l}\text { Critério de } \\
\text { avaliação }\end{array}$ & $\begin{array}{l}\text { Análise dos dados coletados na pesquisa semi estruturada e dos } \\
\text { dados oriundos da aplicação da metodologia Café Mundial, } \\
\text { execução das duas primeiras práticas sequenciais do PRO2PI- } \\
\text { MFMOD. }\end{array}$ \\
\hline $\begin{array}{l}\text { Atividades } \\
\text { executadas }\end{array}$ & $\begin{array}{l}\text { Revisão de literatura, pesquisa semi estruturada, aplicação da } \\
\text { metodologia Café Mundial, aplicação do framework de métodos } \\
\text { PRO2PI-MFMOD. }\end{array}$ \\
\hline Aval & $\begin{array}{l}\text { Dados das entrevistas coletados e analisados, missão e visão do } \\
\text { SPB definidas, práticas sequenciais } 1 \text { e } 2 \text { do PRO2PI-MFMOD } \\
\text { executadas. }\end{array}$ \\
\hline $\begin{array}{l}\text { Melhoria e } \\
\text { aprendizagem }\end{array}$ & $\begin{array}{l}\text { O SPB é um ambiente colaborativo e cooperativo de produção em } \\
\text { rede. É inovador, pois é desenvolvido em ambiente público. Deve } \\
\text { ser abordado com as referências teóricas dos sistemas complexos e } \\
\text { do pensamento sistêmico. O entendimento do sistema é } \\
\text { heterogêneo entre seus stakeholders. É possível utilizar o PRO2PI- } \\
\text { MFMOD para definir um método para construir os elementos de um } \\
\text { modelo para o SPB. }\end{array}$ \\
\hline
\end{tabular}

\section{Quadro 27 Resumo do Momento de Pesquisa 01}

Da reflexão sobre os resultados obtidos com as aplicações das entrevistas, a revisão bibliográfica, a aplicação do exercício de missão e visão, concluiu-se que o SPB deveria ser, antes da continuação do projeto, melhor compreendido pelos seus stakeholders. Percebeu-se também que, além de existir um entendimento heterogêneo do sistema, os stakeholders eram eles próprios heterogêneos, com modelos mentais diferentes, o que dificulta o desenvolvimento e o alinhamento de ideias que possam se transformar em estratégias.

Outras reflexões foram feitas durante o Momento 01. A primeira delas diz respeito à caracterização do objeto em estudo. Confirmou-se, com as características encontradas no sistema, que se tratava de um sistema complexo, o que exigiria um maior aprofundamento na teoria dos sistemas complexos, para que a capacidade de compreensão do problema fosse ampliada. A segunda reflexão refere-se à dinâmica e à relação dos elementos do sistema. Confirmou-se, com as características encontradas no campo, tratar-se de um ecossistema, conforme a definição de ecossistemas disponível na seção 2.4. Foram observadas diferentes espécies, 
diferentes relacionamentos entre elas, clusters de espécies, espécies oportunistas, em suma, todos os elementos de um ecossistema, conforme o referencial teórico utilizado na pesquisa. Uma terceira reflexão emergiu desse momento, relacionada com a teoria de frameworks de modelo de capacidade/maturidade e melhoria de processo. Os frameworks, como CMMI, ISO/IEC 15504 e MPS-Br, foram desenvolvidos para um domínio conhecido por toda a comunidade de software desde os anos 1950. O domínio é um dado do problema. Também são conhecidas as melhores práticas e, o objeto da melhoria são as empresas desenvolvedoras de software, com organização e processos bem conhecidos. No caso desta pesquisa, o domínio, o objeto, as melhores práticas, a visão de futuro, o propósito, as relações e a estrutura são desconhecidos ou fazem parte do conhecimento tácito do ecossistema e, por isso, devem ser explicitados ou conhecidos.

\subsection{MOMENTO DE PESQUISA 02}

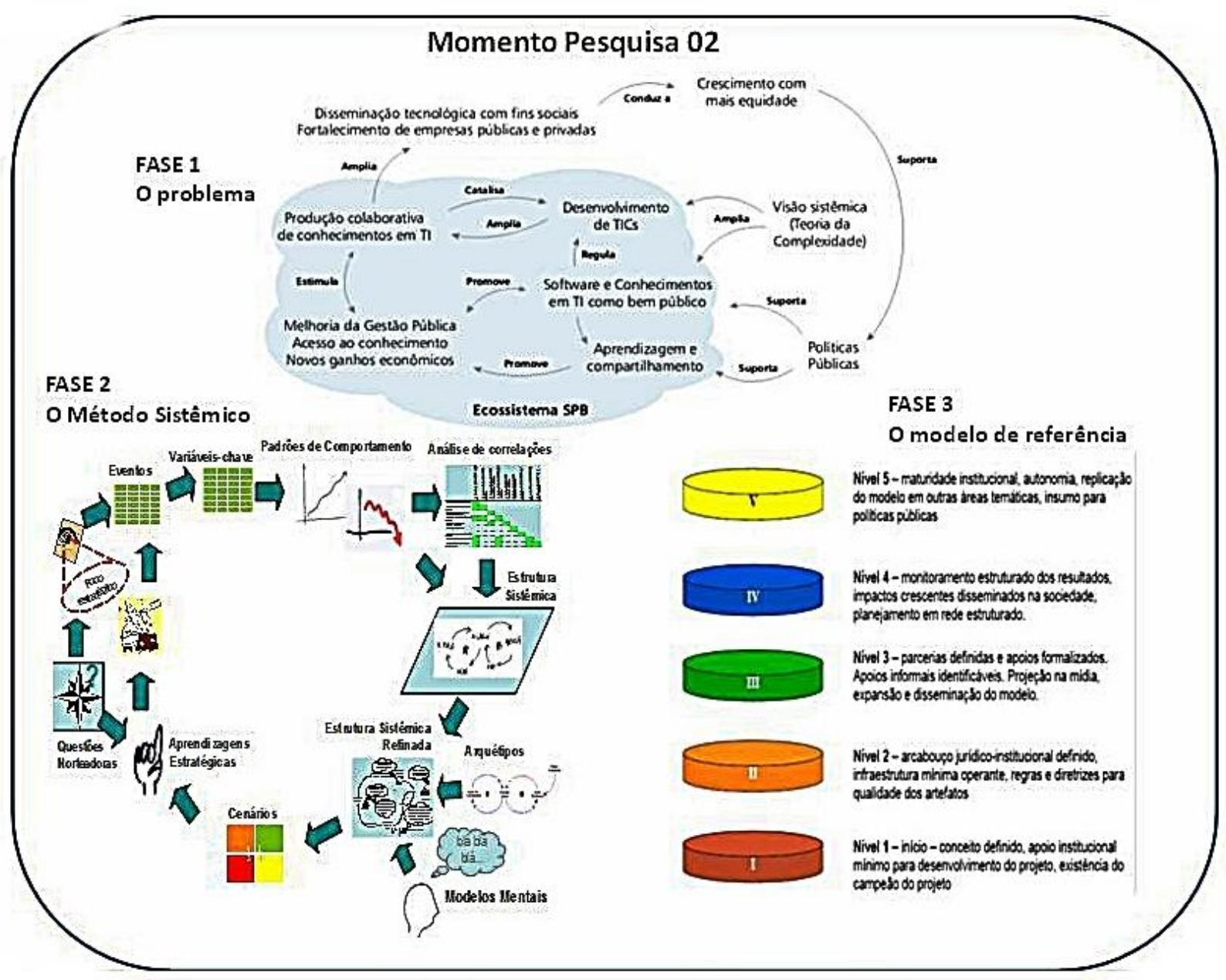

Figura 36 Representação do Momento 02 da pesquisa 
Com o resultado do Momento de Pesquisa 01, é possível delinear as abordagens apropriadas para tratar a situação problemática do Ecossistema SPB. O Momento de Pesquisa 02 contém três fases: Fase 01 - Entendendo o problema, Fase 02 Aplicando o método sistêmico e Fase 03 - Elaborando o modelo de referência. Essas fases não tiveram inicio, fim e contornos claramente definidos. O processo foi em espiral, com avanços e retrocessos, como é usual na pesquisa-ação. A divisão feita neste texto tem o objetivo de tornar o processo inteligível, de forma que possa ser repetido em outros ambientes, por outros pesquisadores, caso seja útil.

A pesquisa, e, portanto, as suas fases, pressupõem o trabalho conjunto do cliente, da equipe CTI e da autora e têm como objetivos resolver a situação problemática do cliente e responder as questões de pesquisa descritas na seção 3.5.3. A primeira e a última fases são, respectivamente, de preparação e de finalização, enquanto que a fase 02 hospeda os ciclos da pesquisa-ação. A Figura 36 representa graficamente os Momentos de Pesquisa 02. Nela estão representadas: a Fase 1, quando da definição do problema e da seleção das metodologias a serem utilizadas; a Fase 2, quando é aplicado o SSM e a Fase 3 quando é elaborada as versões dos modelos de referência para maturidade sistêmica.

\subsubsection{MOMENTO DE PESQUISA 02 - FASE 01- ENTENDENDO O PROBLEMA}

Nesta fase já existe um conhecimento prévio mínimo da natureza do SPB, proporcionado pelo Momento de Pesquisa 01. O SPB é mais que uma plataforma, um conjunto de comunidades ou uma nova forma de produzir software. Ele contém todos os aspectos citados anteriormente e mais a sociedade, a comunidade de software, as empresas de software e o ambiente jurídico-institucional, entre outros, conformando então um ecossistema de produção de software público. O SPB tem características que o tornam único: é um ambiente público de produção de software e a responsabilidade por uma solução nele disponibilizada é da comunidade que

a desenvolve e a mantém. É um sistema complexo, que tem um comportamento não linear, não previsível e dialético. Para abordá-lo, é necessário utilizar referências das teorias de ecossistemas, dos sistemas complexos e do pensamento sistêmico. Outros referenciais necessários para dar forma ao modelo de referência do sistema são a área de melhoria de processo de software e os frameworks de modelos de maturidade. Neste momento, é necessário selecionar as metodologias que serão utilizadas no processo para, em seguida, estruturar os ciclos da pesquisa-ação. Para 
conduzir a pesquisa-ação, é necessário escolher a metodologia adequada para acompanhar os ciclos e coletar dados para a construção de elementos para os modelos de maturidade. Para estruturar os ciclos da pesquisa-ação foi selecionada a metodologia SSM, conforme justificativa apresentada na seção 3.2.6, e para estruturar os elementos para o modelo de referência foi utilizado o framework PRO2PI-MFMOD, cuja adequação à pesquisa é demonstrada na seção 2.6. A seguir, apresenta-se um resumo da aplicação da metodologia na Fase 02 e na Fase 03.

\subsubsection{Atividades da Fase ENTENDENDO O PROBLEMA}

Após a escolha das metodologias SSM e PRO2PI-MFMOD, são desenvolvidas as atividades cujo objetivo é aumentar o grau de entendimento sobre o problema. Essas atividades estão discriminadas no Quadro 28, que é composto por três colunas. A primeira coluna descreve uma atividade-mãe, grafada em negrito, e as suas atividades-filhas. A segunda coluna contém o identificador da atividade no processo de construção do método (o número da atividade é formado pela letra $A$, seguida do número da sequência da atividade no processo do framework). A terceira coluna contém o número da Prática Sequencial que é atendida pela atividade. Tanto a atividade quanto a prática são apontadas somente na linha das atividades principais. 


\begin{tabular}{|c|c|c|}
\hline ATIVIDADES DA FASE ENTENDENDO O PROBLEMA & ATIVIDADE & PRÁTICA \\
\hline 1. Decisões iniciais & A5 & P1 \\
\hline \multicolumn{3}{|l|}{ 1.1.Formação de equipe } \\
\hline \multicolumn{3}{|l|}{ 1.2. Negociação de cronograma } \\
\hline \multicolumn{3}{|l|}{ 1.3. Comprometimento com prazos } \\
\hline \multicolumn{3}{|l|}{ 1.4. Plano de trabalho } \\
\hline \multicolumn{3}{|l|}{ 1.5. Estratégia para início de trabalho } \\
\hline \multicolumn{3}{|l|}{ 1.6. Estratégia para condução dos trabalhos } \\
\hline \multicolumn{3}{|l|}{ 1.7. Estratégia para a condução da pesquisa para os SP's } \\
\hline \multicolumn{3}{|l|}{ 1.8. Criação de ambiente colaborativo (wiki) para o SP01 e SPB_CTI } \\
\hline \multicolumn{3}{|l|}{ 1.10. Seminários conceituais (Sistemas Complexos e Pensamento Sistêmico) } \\
\hline \multicolumn{3}{|l|}{$\begin{array}{l}\text { 1.11. Construção de ambiente virtual para a organização e sistematização do conteúdo bibliográfico } \\
\text { utilizado pelo SP01 }\end{array}$} \\
\hline \multicolumn{3}{|l|}{ SAIDA } \\
\hline \multicolumn{3}{|l|}{$\begin{array}{l}\text { Equipe formada, cronograma negociado, prazos negociados e aceitos. Plano de trabalho, documento } \\
\text { de estratégia para início dos trabalhos, documento para estratégia de condução dos trabalhos, } \\
\text { documento de estratégia de condução da pesquisa elaborados. Ambiente colaborativo criado. Vetores } \\
\text { alinhados com a demanda do cliente. Seminários conceituais ministrados. Biblioteca do vetor SP01 e } \\
\text { do projeto criadas e disponibilizadas para uso. (http://goo.gl/0GvSM ) }\end{array}$} \\
\hline 2. Revisão de Literatura SPB & A6 & P2 \\
\hline 2.1. Revisão da literatura sobre o SPB (leis, instruções normativas) & & \\
\hline
\end{tabular}




\begin{tabular}{|c|c|c|}
\hline ATIVIDADES DA FASE ENTENDENDO O PROBLEMA & ATIVIDADE & PRÁTICA \\
\hline \multicolumn{3}{|l|}{ 2.2. Análise do Portal do SPB } \\
\hline \multicolumn{3}{|l|}{$\begin{array}{l}\text { 2.3. Revisão da literatura dos papers e artigos escritos e publicados pelo coordenador do SPB e } \\
\text { coordenadores das comunidades do SPB }\end{array}$} \\
\hline \multicolumn{3}{|l|}{$\begin{array}{l}\text { 2.4. Formulação, aplicação e análise de questionário semi estruturado para capturar a situação atual } \\
\text { do SPB bem como identificar os problemas na percepção dos stakeholders. }\end{array}$} \\
\hline \multicolumn{3}{|l|}{ SAIDA } \\
\hline \multicolumn{3}{|l|}{$\begin{array}{l}\text { Relatório de análise do conteúdo do Portal do SPB, position paper das publicações feitas pela } \\
\text { coordenação do SPB e coordenadores de comunidade do SPB, Consolidação dos dados do } \\
\text { questionário no Documento de Situação atual do SPB (base fevereiro de 2009) }\end{array}$} \\
\hline 3. Revisão de literatura dos quatro eixos teóricos do SPB & A7 & P2 \\
\hline \multicolumn{3}{|l|}{ 3.1. Revisão de literatura de Pensamento Sistêmico } \\
\hline \multicolumn{3}{|l|}{ 3.2. Revisão de literatura de Ecossistemas Digitais } \\
\hline \multicolumn{3}{|l|}{ 3.3. Revisão de literatura de Sistemas Complexos } \\
\hline \multicolumn{3}{|l|}{ 3.4. Revisão de literatura de Modelos de Maturidade } \\
\hline \multicolumn{3}{|l|}{ SAIDA } \\
\hline \multicolumn{3}{|l|}{$\begin{array}{l}\text { Position papers da revisão das disciplinas de Pensamento Sistêmico, Sistemas Complexos, } \\
\text { Ecossistemas Digitais e Modelos de Maturidade; alinhamento conceitual da equipe do projeto, } \\
\text { documento de aprofundamento teórico sobre a abordagem do Pensamento Sistêmico para a sua } \\
\text { utilização no SPB (base março de 2009); }\end{array}$} \\
\hline 4. Disseminação dos conceitos básicos dos eixos teóricos & A8 & P1 \\
\hline
\end{tabular}




\begin{tabular}{|c|c|c|}
\hline ATIVIDADES DA FASE ENTENDENDO O PROBLEMA & ATIVIDADE & PRÁTICA \\
\hline \multicolumn{3}{|l|}{ 4.1. Primeiro Seminário Conceitual (Pensamento Complexo e Pensamento Sistêmico) } \\
\hline \multicolumn{3}{|l|}{ 4.2. Segundo Seminário Conceitual (exercício de simulação de mapa sistêmico) } \\
\hline \multicolumn{3}{|l|}{ 4.3. Terceiro Seminário Conceitual (Questão do copyright no portal do 5CQualiBr) } \\
\hline \multirow{2}{*}{\multicolumn{3}{|c|}{$\begin{array}{l}\text { SAIDA } \\
\text { Alinhamento conceitual da equipe de trabalho com relação às teorias do Pensamento Sistêmico e do } \\
\text { Pensamento Complexo, construção de mapas sistêmicos, licença de uso para os artefatos do } \\
\text { 5CQualiBr. }\end{array}$}} \\
\hline & & \\
\hline 5. Identificação do Domínio e do Escopo & A9 & P1 \\
\hline \multicolumn{3}{|l|}{ 5.1. Apresentação do Plano de Trabalho do SP01 para líderes e stakeholders } \\
\hline \multicolumn{3}{|l|}{$\begin{array}{l}\text { 5.2.Carta de apresentação do projeto (em inglês) para o Lero (Irish Software Engineering Research } \\
\text { Centre) para inicio de intercâmbio na área de engenharia de software. }\end{array}$} \\
\hline \multicolumn{3}{|l|}{$\begin{array}{l}\text { 5.3. Desenvolvimento do arcabouço teórico de sustentação da abordagem do SPB por meio do } \\
\text { Pensamento Sistêmico }\end{array}$} \\
\hline \multicolumn{3}{|l|}{ 5.4 Construção compartilhada do propósito e da visão do SPB. } \\
\hline \multicolumn{3}{|l|}{$\begin{array}{l}\text { SAIDA } \\
\text { Relatório técnico do processo de construção coletiva do propósito e da visão do SPB. Disseminação } \\
\text { da visão e do propósito do SPB para os seus stakeholders e a sociedade. Relatório técnico das } \\
\text { discussões das alternativas de licença de uso para os artefatos do SPB. }\end{array}$} \\
\hline 6. Interação com as comunidades & A10 & P1 e P2 \\
\hline 6.1.Formulação do plano de trabalho para a construção do mapa sistêmico do SPB & & \\
\hline 6.2. Elaboração da apresentação integrada e apresentação do projeto Mc & & \\
\hline
\end{tabular}




\begin{tabular}{|c|c|c|}
\hline ATIVIDADES DA FASE ENTENDENDO O PROBLEMA & ATIVIDADE & PRÁTICA \\
\hline \multicolumn{3}{|l|}{ na reunião dos coordenadores de comunidade do Portal SPB em Brasília } \\
\hline \multicolumn{3}{|l|}{$\begin{array}{l}\text { 6.3. Interação com a comunidade Invesalius para esclarecimentos de dúvidas e elaboração de } \\
\text { abordagem nas comunidades do Portal. }\end{array}$} \\
\hline \multicolumn{3}{|l|}{ SAIDA } \\
\hline \multicolumn{3}{|l|}{$\begin{array}{l}\text { Plano de trabalho para a aplicação do Pensamento Sistêmico, apresentação do projeto Modelo de } \\
\text { Referência do SPB para os coordenadores de comunidade efetuada e Relatório técnico com dados } \\
\text { resultantes da interação com a comunidade Invesalius }\end{array}$} \\
\hline 7. Estratégia de desenvolvimento do modelo de referência & A11 & P3 \\
\hline \multicolumn{3}{|l|}{$\begin{array}{l}\text { 7.1. A estratégia para a construção do modelo de referência foi planejada pelo SP01, com as seguintes } \\
\text { diretrizes: a) utilização dos dados coletados até esse momento de pesquisa para elaborar o primeiro } \\
\text { desenho/projeto do modelo de referência, b) o desenvolvimento da versão do modelo deve ser coletiva } \\
\text { e cooperada e validada com o Grupo Consultivo }\end{array}$} \\
\hline \multicolumn{3}{|l|}{ 7.2. Utilização de referências sobre modelos de maturidade na estratégia de construção. } \\
\hline \multicolumn{3}{|l|}{ SAÍDA } \\
\hline \multicolumn{3}{|l|}{ Relatório técnico de estratégia para o desenvolvimento do modelo de referência versão 1.0} \\
\hline 8. Desenvolvimento do primeiro esboço dos níveis de maturidade do SPB & A12 & P4 \\
\hline \multicolumn{3}{|l|}{ 8.1. Elaboração do modelo de referência pelo Grupo Executivo } \\
\hline \multicolumn{3}{|l|}{ 8.2. Workshop sobre o modelo com o Gr upo Consultivo } \\
\hline \multicolumn{3}{|l|}{ SAÍDA } \\
\hline erência versão 1.0 & & \\
\hline
\end{tabular}

Quadro 28 Entendendo o problema (FASE01) 


\subsubsection{Aplicando o PRO2PI-MFMOD}

Neste momento da pesquisa, após a coleta de dados, foi aplicado o MFMOD para relacionar as atividades com as práticas sequenciais do método. O resultado da aplicação está descrito no Quadro 29 e no Quadro 30.

\begin{tabular}{|c|c|c|c|c|}
\hline Atividade & Descrição & Regras & Práticas & Técnicas \\
\hline A5 & Decisões iniciais & \multirow{8}{*}{ 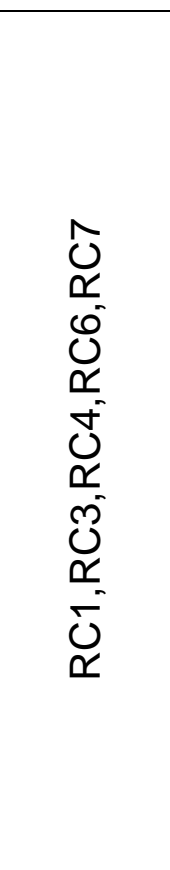 } & P1 & $\mathrm{T} 12, \mathrm{~T} 9, \mathrm{~T} 11$ \\
\hline A6 & Revisão de literatura & & P2 & T3 \\
\hline A7 & $\begin{array}{l}\text { Aprofundamento da revisão de } \\
\text { literatura dos quatro eixos teóricos }\end{array}$ & & P2 & T3 \\
\hline A8 & $\begin{array}{l}\text { Disseminação dos conceitos } \\
\text { básicos dos eixos teóricos }\end{array}$ & & P1 & $\mathrm{T} 12, \mathrm{~T} 9, \mathrm{~T} 11$ \\
\hline A9 & Identificação de Domínio e Escopo & & P1 & $\mathrm{T} 12, \mathrm{~T} 9, \mathrm{~T} 11$ \\
\hline A10 & Interação com as comunidades & & P1 e P2 & $\mathrm{T} 12, \mathrm{~T} 9, \mathrm{~T} 11$ \\
\hline A11 & $\begin{array}{l}\text { Estratégia de desenvolvimento do } \\
\text { Modelo de Referência versão } 1.0\end{array}$ & & P3 & T9 \\
\hline A12 & $\begin{array}{l}\text { Desenvolvimento do Modelo de } \\
\text { Referência versão } 1.0\end{array}$ & & P4 & T12 \\
\hline
\end{tabular}

Quadro 29 Atividades, Regras, Práticas e Técnicas do MFMOD para o SPB

O Quadro 29 apresenta as atividades, as práticas sequenciais, as regras de customização e as técnicas empregadas nessa fase do MFMOD. O Quadro 30 apresenta as atividades definidas e executadas do método e as relaciona com as práticas do framework e com as regras de customização. As atividades do método são expressas pelo emprego de quatro práticas sequenciais, a aplicação de cinco regras de customização, com o apoio de quatro técnicas específicas. Durante a aplicação do PRO2PI-MFMOD, observou-se que algumas técnicas não constavam do conjunto sugerido pelo framework. A opção para essa pesquisa foi enquadrar as técnicas novas como método para estruturar os workshops ou brainstorms. Uma outra opção seria acrescentar as novas técnicas ao conjunto de técnicas sugeridas pelo framework.

Assim termina a aplicação da segunda fase do PRO2PI-MFMOD, com quatro atividades na prática sequencial $\mathrm{P} 1$, duas na prática $\mathrm{P} 2$, uma em $\mathrm{P} 3$ e uma em $\mathrm{P} 4$, o que caracteriza grande atividade nas práticas sequências iniciais do framework, 
práticas estas, responsáveis por decisões sobre o projeto e pelo levantamento de informações para a confecção do método (seção 2.6.2).

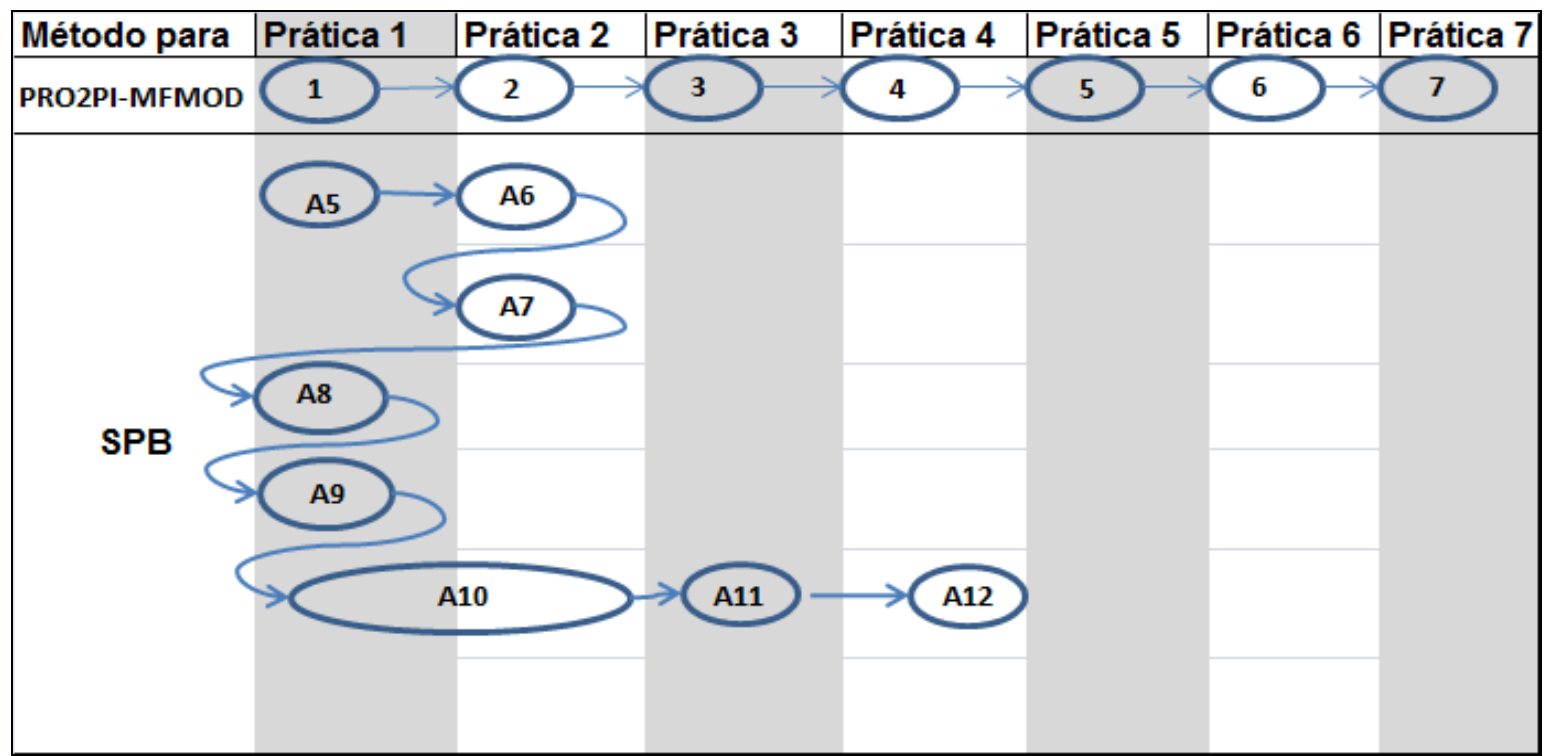

Quadro 30 Práticas e atividades do PRO2PI-MFMOD para o SPB 02

\subsubsection{Primeira versão do Modelo De Referência}

Com a realização das atividades da Fase 01 são coletadas informações e dados que permitem a construção do primeiro esboço de elementos do modelo de maturidade/capacidade para o SPB.

Nesse momento, o termo ecossistema, bem como seu significado no escopo do SPB, foi apropriado pelos stakeholders. Este termo foi utilizado com o intuito de descrever os ambientes virtuais compreendidos pelo SPB, pois faz referência a um conjunto de atores e suas inter-relações, não estabelecendo limites à variedade desses atores ou à intensidade ou formas dessas relações. $O$ termo indica a existência de um sistema, que é uma porção da realidade que comporta uma dinâmica própria. Assim, o sistema SPB tem sua própria dinâmica de produção, que, por sua vez, é uma somatória das dinâmicas das comunidades que o compõem.

Nesse momento da pesquisa, alguns aspectos do SPB estão mais explícitos e são compartilhados pela comunidade. Assim, entende-se que o Ecossistema SPB é composto por elementos que dizem respeito à infraestrutura que o suporta, pelos componentes que 0 integram e pelas relações, entre este e destes com a infraestrutura. A dinâmica resultante, que se expressa pela interação, pelo compartilhamento e pela aprendizagem, é o que caracteriza esse ecossistema. $O$ 
arcabouço estrutural do ecossistema é composto por camadas, cada uma das quais expressando um nível de funcionalidade, que se integram e interagem entre si. A Figura 37 ilustra a camada básica, a camada de componentes e duas visões sistêmicas.

A camada com a cor azul, mais interna, representa a infraestrutura necessária para suporte e hospedagem do ecossistema, que, por sua vez, necessita de um conjunto de regras, normas e instruções normativas, que fornece o suporte legal e institucional ao ecossistema. Nas camadas superiores, estão representados os componentes e as suas relações. A figura ilustra a visão que cada camada tem do ecossistema. Na camada de infraestrutura, a visão é de computadores, roteadores, softwares. Na camada de componentes, a visão é de uma rede formada por atores, entidades e artefatos. Nas camadas superiores, as relações começam a ser representadas, primeiro no formato não sistêmico e, depois com o componente sistêmico presente.

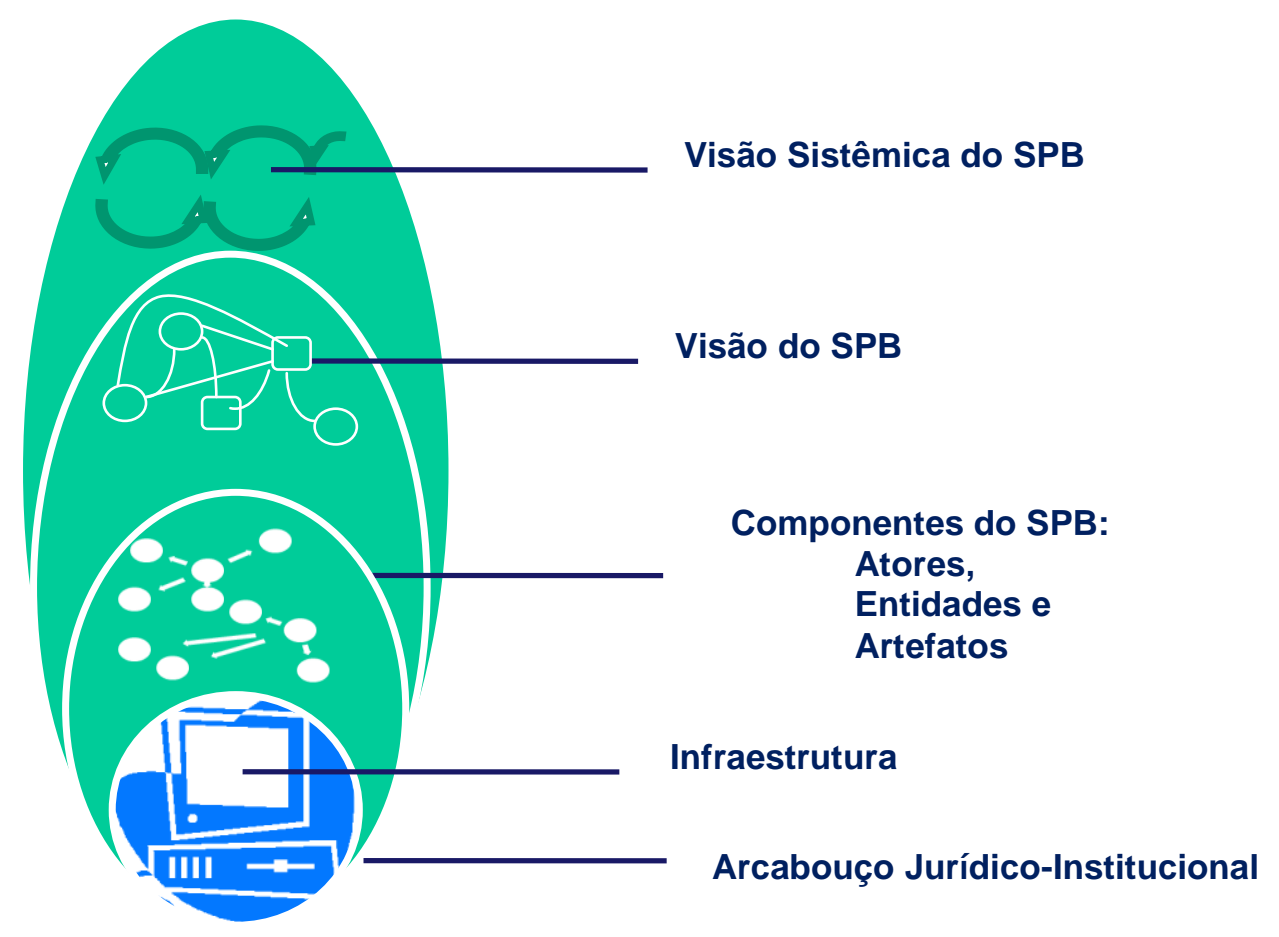

Figura 37 Arcabouço estrutural do Ecossistema SPB

O entendimento das características de cada camada e de sua interação com as demais auxilia a compreensão do todo complexo que é o SPB. O entendimento se dá por camadas e também por suas inter-relações, sendo que as camadas mais externas refletem as mais internas, mas as camadas externas também 
retroalimentam e influenciam as camadas internas e todas essas camadas interagem e promovem mudanças entre si. Estas são, portanto, características que evidenciam que o sistema é dinâmico, complexo, está em constante evolução e tem padrões de auto-organização. As camadas reconhecidas no ecossistema até esse momento são descritas a seguir.

Arcabouço Jurídico-Institucional - compreende o conjunto de conceitos, definições, normas e instrumentos legais que dá sustentação ao conceito de Software Público Brasileiro. O arcabouço jurídico-institucional é que define os limites e o fluxo de interação do SPB. Ao criar o conceito de software público, a SLTI construiu um espaço institucional, as regras e mesmo os valores que orientaram e fizeram com que a instalação do ambiente virtual se tornasse uma instanciação do conceito do SPB. Esse arcabouço continua evoluindo e trazendo novos elementos, que são consequência do próprio funcionamento e do amadurecimento do SPB. Nessa dimensão, estão incorporados e formalizados os objetivos do Software Público Brasileiro, bem como os valores que norteiam o seu crescimento.

Infraestrutura - diz respeito à infraestrutura das TICs que suportam o SPB, desde as plataformas de hardware e de software que o abrigam, até os canais de acesso, a segurança e a interoperabilidade. Porém, o que se destaca neste item é que a utilização de plataformas e ferramentas livres atende não somente as necessidades operacionais (de custos, não aprisionamento tecnológico), mas também os processos de geração e atualização tecnológica, que são inerentes a essas ferramentas. Ou seja, ferramentas criadas e mantidas por comunidades virtuais, que estimulam o compartilhamento e a aprendizagem coletiva, são mais aderentes e alinhadas com a infraestrutura do SPB do que ferramentas proprietárias. Isto não exclui estas últimas, mas entende-se que, para se ter uma evolução contínua do SPB, deve-se possibilitar que sua própria comunidade atue na infraestrutura que o suporta. A infraestrutura, assim como a dimensão anterior, também influencia os limites de atuação do SPB. Desta forma, por exemplo, os limites físicos de acesso, as ferramentas de gestão do conhecimento, entre outros aspectos, têm impacto direto na atuação da comunidade.

Componentes do SPB ${ }^{1}$ - esta dimensão diz respeito à natureza dos principais elementos que compõem o ambiente virtual do SPB: atores, entidades e artefatos. Ou seja, qualitativamente, há três tipos de elementos que compõem o SPB: 
- Atores - são os membros da comunidade virtual que participa do Portal do SPB, em seus mais diversos âmbitos;

- Artefatos - são, simultaneamente, os elementos que promovem a interação entre os atores e as entidades, e os resultados dessa interação. Na sua origem, O SPB possuía somente o artefato software. A liberação de um software no Portal SPB é que dava origem a uma comunidade em seu entorno. Durante o desenvolvimento do SPB, outros tipos de artefatos foram surgindo, como documentos conceituais, guias de testes de software, guias de qualidade de processo e outros.

- Entidades - são as instituições que dão suporte à existência do SPB. São elas que construíram e continuam construindo o arcabouço jurídicoinstitucional, que propiciam a existência de uma infraestrutura para o Portal SPB e que buscam e investem recursos para sua manutenção e desenvolvimento.

Conclui-se, nessa fase, que o SPB é um ecossistema complexo, dinâmico, composto por um arcabouço jurídico institucional, por uma infraestrutura de hardware e software e por componentes, que são os atores, as entidades e os artefatos. Ele é ainda composto por relações entre os seus elementos, as camadas internas e 0 ambiente externo. As relações não são percebidas da mesma forma pelas várias camadas. Na camada de componentes, elas são vistas de forma unidimensional, contendo somente os componentes do ecossistema; na camada seguinte, já é possível perceber a visão sistêmica.

A próxima fase deve continuar a coleta de dados, para ampliar o entendimento das características do domínio e subsidiar a construção dos elementos para 0 framework de maturidade/capacidade para o SPB.

\subsubsection{Conclusão do Momento de Pesquisa 02 - Fase 01}

Os resultados da aplicação das metodologias ao longo dessa fase estão descritos no Quadro 31.

\begin{tabular}{|l|l|}
\hline Momento 02 & Fase 01 \\
\hline Período & Durante o ano de 2009 \\
\hline Fase de Pesquisa & Fase 01- Entendendo o problema \\
\hline
\end{tabular}




\begin{tabular}{|l|l|}
\hline Momento 02 & Fase 01 \\
\hline $\begin{array}{l}\text { Critério de } \\
\text { Atividação } \\
\text { executadas }\end{array}$ & $\begin{array}{l}\text { Revinição de escopo, domínio e estratégia de desenvolvimento } \\
\text { semi estruturadas, workshops }\end{array}$ \\
\hline Avaliação & $\begin{array}{l}\text { Escopo, domínio e estratégia de desenvolvimento definidos } \\
\text { possível elaborar um primeiro esboço dos elementos de um } \\
\text { modelo de referência para o SPB. Neste momento já é possível } \\
\text { verificar que o caminho da qualidade pode ser estabelecido por } \\
\text { meino dos níveis de maturidade. Aparecem os primeiros indícios }\end{array}$ \\
\hline $\begin{array}{l}\text { me que a capacidade de processo não será o vetor de qualidade } \\
\text { e melhoria no sistema. Com o aprendizado sobre o ecossistema } \\
\text { neste momento é possível elaborar uma estratégia preliminar } \\
\text { para a elucidação dos elementos que devem compor o modelo } \\
\text { de maturidade para o SPB. }\end{array}$ \\
\hline
\end{tabular}

\section{Quadro 31 Resumo da Fase 01}

\subsubsection{MOMENTO DE PESQUISA 02-FASE 02-APLICANDO A SSM}

Nessa fase da aplicação das metodologias, a autora exerce as duas funções inerentes a um processo de pesquisa-ação: enquanto ação, aplica a SSM para desenvolver a compreensão do Ecossistema SPB; enquanto pesquisa, realiza a coleta dos dados necessários. Na seção "A SSM NO SPB - AÇÃO", é descrita a aplicação da metodologia, com as saídas necessárias para a ação, e na seção "A SSM NO SPB - PESQUISA", é descrita a seleção e a coleta dos dados necessários para a pesquisa.

A seção "A SSM NO SPB - AÇÃO" apresenta um resumo dos ciclos da SSM que foram executados durante um ano de trabalho em campo. Nela, são registrados as entradas para o ciclo, o processo utilizado para o seu desenvolvimento, bem como as suas saídas. A seção "A SSM NO SPB - PESQUISA" apresenta os bastidores de cada um dos ciclos. Nela, são apresentadas as atividades executadas, as técnicas utilizadas para executá-las e, os resultados registrados de forma a serem úteis para a pesquisa. Nos sete ciclos, foram executadas 187 atividades de diversas naturezas. 
Todas elas foram registradas. A Quadro 34 apresenta os sete ciclos, com a seguinte estrutura: a) número e nome do ciclo; b) planejamento; c) execução e observação; d) avaliação e e) resultados. A estrutura cobre as quatro fases fundamentais de um ciclo de pesquisa-ação: Planejar, Agir, Observar e Refletir.

\subsubsection{A SSM no SPB -Ação}

As etapas do método sistêmico foram aprimoradas e adaptadas para a aplicação no SPB. Foram realizados sete encontros híbridos, com parte presencial e parte virtual (conferências web), com a participação de quarenta pessoas, em média. Destas, cerca de trinta pessoas integravam o que se chamou de Grupo Consultivo, um conjunto de pessoas com diferentes envolvimentos com o SPB. Um segundo grupo, responsável pela preparação das reuniões, pela consolidação de resultados e pelos trabalhos de bastidores, foi chamado de Grupo Executivo e era formado por sete pessoas do grupo de pesquisa (a lista completa dos membros dos grupos Consultivo e Executivo é apresentada no Anexo V). Como sistematização dessas etapas, que estão documentadas no Portal do 5CQualiBR, foram obtidos os seguintes produtos:

\section{Desafio visionário do SPB}

\section{Mapa sistêmico}

5. Cenários e modelagem

\section{Variáveis-chave}

\section{Modelos mentais}

\section{Aprendizagens com a modelagem} computacional

\section{Plano de desenvolvimento sistêmico}

\section{Aplicacão do Método Sistêmico no SPB}

Para iniciar a análise sistêmica é necessário entender a razão de ser da organização, bem como a situação de interesse que motiva a aplicação dessa análise. O desenvolvimento da missão/propósito e da visão compartilhada do futuro foi realizado no Momento de Pesquisa 01, e a partir dele, foram realizados os trabalhos posteriores. A Figura 38 apresenta os passos da metodologia SSM. As figuras apresentadas neste momento da pesquisa são registros das reuniões, que utilizam a metodologia Rich Picture (AVISON, 1992) (CHECKLAND e SCHOLE, 
1999). A Rich Picture consiste na representação gráfica de uma situação de interesse na qual são explorados os atores, os processos, os relacionamentos e as questões centrais. Utiliza-se o artifício de ícones para expressar esses elementos. Pode-se, inclusive, explorá-la para melhor identificar o tipo de relacionamento entre as entidades (relacionamentos conflitantes ou relacionamentos de parceria). Segundo Checkland e Scholes (1999), a Rich Picture apresenta-se como a ferramenta mais indicada para explorar os relacionamentos, em contraste com a linguagem linear. Essa vantagem deve-se ao fato dessa ferramenta estimular o pensamento holístico sobre uma determinada situação de interesse. A Rich Picture foi utilizada durante o trabalho em campo para criar a documentação das sete reuniões de aplicação da SSM. Com a aplicação dessa ferramenta as reuniões são representadas graficamente em painéis dispostos no ambiente onde ocorrem as reuniões. As representações devem ser claras, mnemônicas e vívidas para que o conteúdo seja facilmente retomado na reunião seguinte.

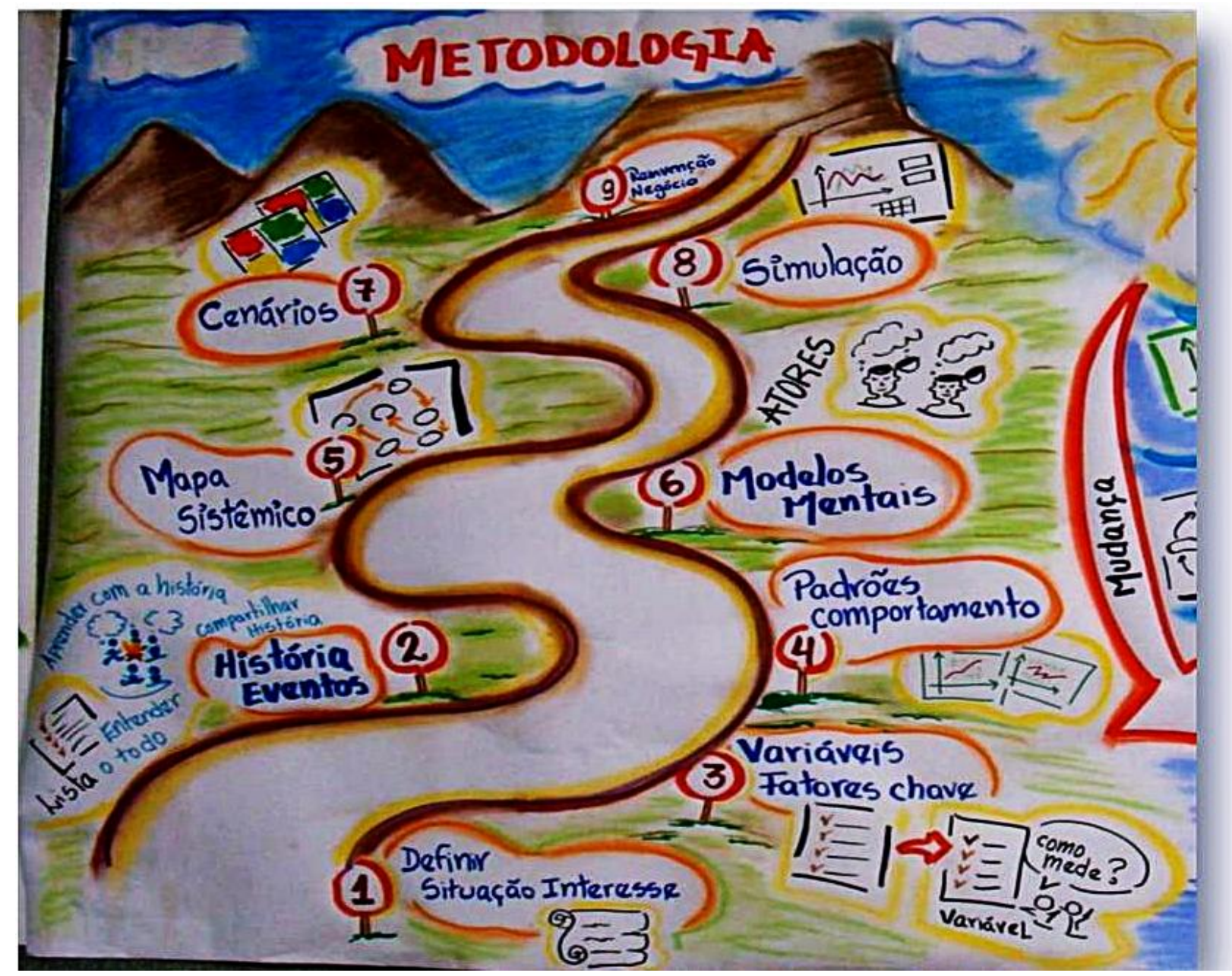

Figura 38 Representação da reunião sobre a metodologia SSM Fonte: Luciane Bergue (EPS) 


\section{Primeiro Ciclo - Desafio Visionário}

No Método Sistêmico, o primeiro passo é a definição do desafio visionário a ser desenvolvido pelo grupo de trabalho. O desafio visionário do SPB definiu a situação de interesse a partir da qual foram construídas as relações existentes em seu entorno. A Figura 39, apresenta o registro da construção do desafio visionário. $O$ desafio resultante da aplicação das metodologias correspondentes ao primeiro ciclo da SSM foi: "Compreender e aprimorar o modelo do Software Público de modo a torná-lo sustentável".
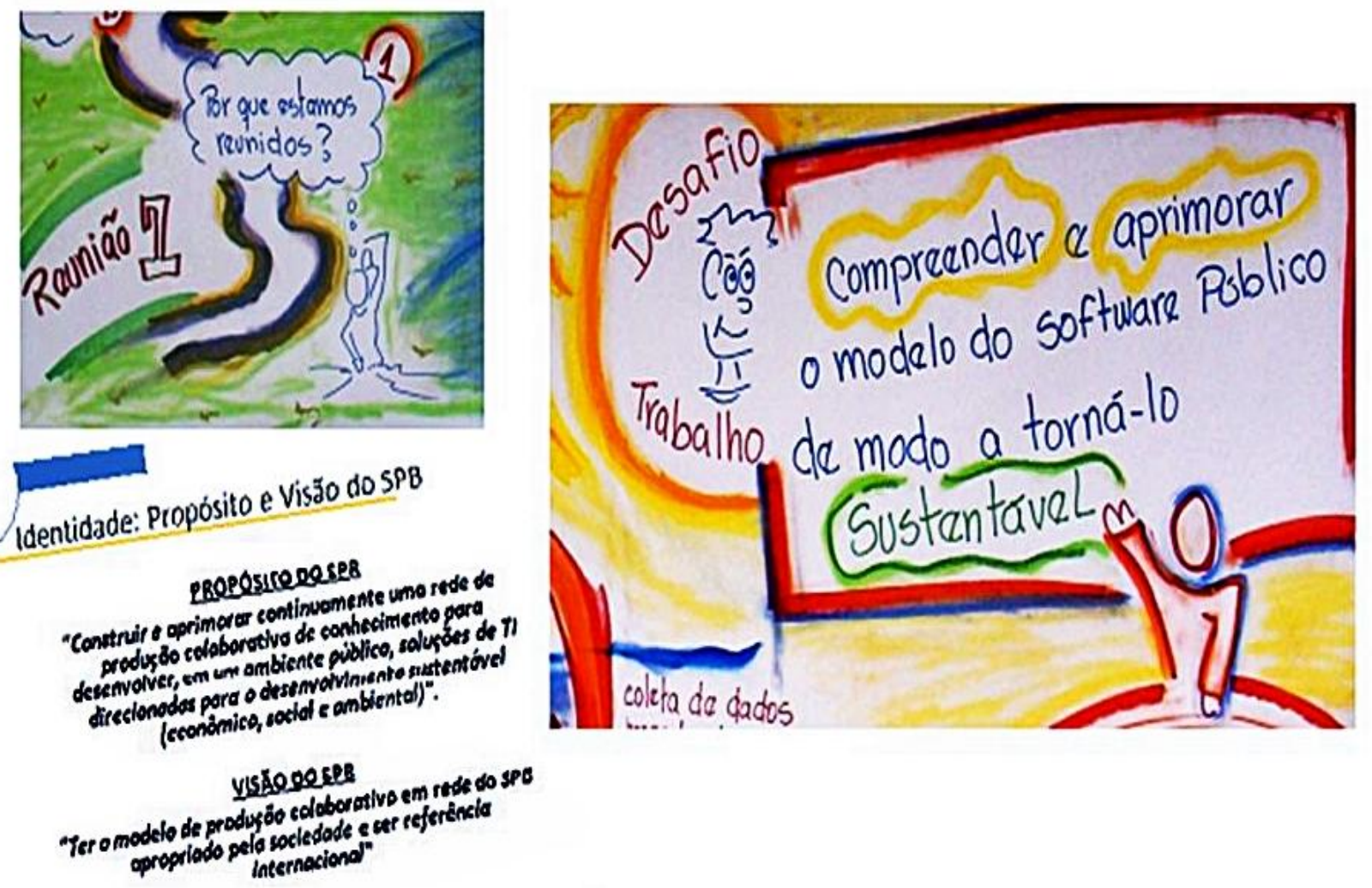

Figura 39 Representação da reunião de desafio visionário Fonte: Luciane Bergue (EPS)

\section{Sequndo Ciclo - Variáveis-Chave do SPB}

A história dos desafios do Ecossistema SPB foi narrada pelos membros do Grupo Consultivo, por meio de eventos. O registro dessa reunião está representado na Figura 40.

A partir desses eventos, foram identificadas as variáveis-chave que descrevem 0 SPB e que são descritas no Quadro 32. Estas variáveis-chave representam algumas 
das forças importantes na configuração do que é o SPB. Para cada variável, foi gerado um gráfico com dados coletados a partir do ano de 2006, quando se iniciou o SPB. Os gráficos auxiliaram a descrever o padrão de comportamento do SPB desde a sua criação ${ }^{13}$.

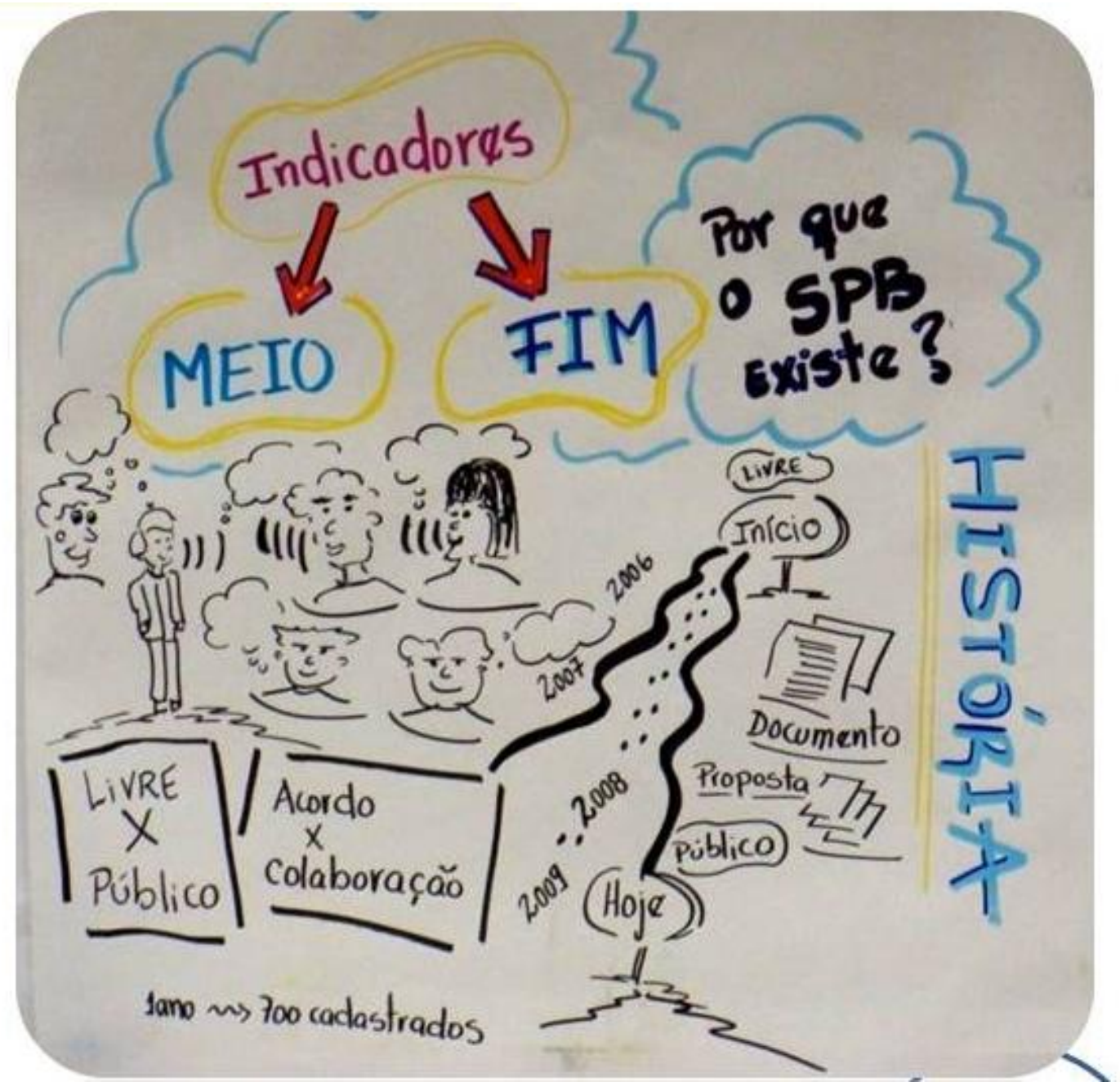

Figura 40 Representação da reunião sobre a história e os indicadores Fonte: Luciane Bergue (EPS)

\begin{tabular}{|c|l|l|}
\hline Num & \multicolumn{1}{|c|}{ Variável-chave } & Descrição \\
\hline $\mathbf{1}$ & $\begin{array}{l}\text { Número total de usuários do } \\
\text { Portal, incluindo seus sub-sites }\end{array}$ & $\begin{array}{l}\text { Número de visitas (=acessos) ao site } \\
\text { (Portal). }\end{array}$ \\
\hline $\mathbf{2}$ & $\begin{array}{l}\text { Número de acessos nacionais } \\
\text { ao Portal SPB }\end{array}$ & $\begin{array}{l}\text { Número de visitas (=acessos) ao site } \\
\text { (Portal) com origem no do BRASIL }\end{array}$ \\
\hline
\end{tabular}

\footnotetext{
${ }^{13}$ Veja os gráficos no Vetor Ecossistema do 5CQualiBr - http://goo.gl/Q9ZQh.
} 


\begin{tabular}{|c|c|c|}
\hline Num & Variável-chave & Descrição \\
\hline 3 & $\begin{array}{l}\text { Número de acessos } \\
\text { internacionais ao Portal SPB }\end{array}$ & $\begin{array}{l}\text { Número de visitas (=acessos) ao site } \\
\text { (Portal) demais países (EXCETO BRASIL) }\end{array}$ \\
\hline 4 & $\begin{array}{l}\text { Número absoluto de visitantes } \\
\text { únicos (pessoas) }\end{array}$ & Número de pessoas que visitaram o site \\
\hline 5 & $\begin{array}{l}\text { Tempo médio no site do Portal } \\
\text { SPB }\end{array}$ & $\begin{array}{l}\text { Tempo médio que o visitante permaneceu } \\
\text { no Portal }\end{array}$ \\
\hline 6 & $\begin{array}{l}\text { Capacitação: número de } \\
\text { commiters }\end{array}$ & $\begin{array}{l}\text { Evolução do número de pessoas que } \\
\text { estão autorizadas a fazer commit ano a } \\
\text { ano }\end{array}$ \\
\hline 7 & $\begin{array}{l}\text { Capacitação: número de } \\
\text { patchers }\end{array}$ & $\begin{array}{l}\text { Evolução do número de pessoas que } \\
\text { estão autorizadas a fazer patch, ano a ano }\end{array}$ \\
\hline 8 & $\begin{array}{l}\text { Número de commits nas } \\
\text { soluções de software do Portal } \\
\text { SPB }\end{array}$ & $\begin{array}{l}\text { O envio das modificações feitas pelo } \\
\text { usuário ao repositório CVS }\end{array}$ \\
\hline 9 & Número de parcerias formais & $\begin{array}{l}\text { Parcerias entre a comunidade e entidades, } \\
\text { estabelecidas por convênios e outros } \\
\text { mecanismos formais entre as instituições }\end{array}$ \\
\hline 10 & Número de parcerias informais & $\begin{array}{l}\text { Estimativa de apoios ou trocas entre } \\
\text { instituições e a comunidades SPB, sem } \\
\text { instrumentos de formalização (cursos, } \\
\text { palestras, visitas, apoio para divulgação e } \\
\text { outros) }\end{array}$ \\
\hline 11 & $\begin{array}{l}\text { Produção científica relacionada } \\
\text { ao SPB }\end{array}$ & $\begin{array}{l}\text { TCC's, mestrados, doutorados, artigos } \\
\text { científicos em periódicos (nacionais e } \\
\text { internacionais), resumos de congressos } \\
\text { (nacionais e internacionais) }\end{array}$ \\
\hline 12 & $\begin{array}{l}\text { Capacitação: número de } \\
\text { cadastros (pessoas físicas e } \\
\text { pessoas jurídicas) no Mercado } \\
\text { Público Virtual }\end{array}$ & $\begin{array}{l}\text { Número de cadastros no MPV; } \\
\text { prestadores de serviço em soluções } \\
\text { disponíveis no Portal }\end{array}$ \\
\hline 13 & $\begin{array}{l}\text { Número de soluções de } \\
\text { softwares abertas disponíveis }\end{array}$ & $\begin{array}{l}\text { Soluções cujos cadastros estão } \\
\text { disponíveis para qualquer usuário }\end{array}$ \\
\hline
\end{tabular}




\begin{tabular}{|c|c|c|}
\hline Num & Variável-chave & Descrição \\
\hline & no Portal & \\
\hline 14 & $\begin{array}{l}\text { Número de soluções de } \\
\text { softwares fechadas disponíveis } \\
\text { no Portal }\end{array}$ & $\begin{array}{l}\text { Soluções em fase de incubação e que, } \\
\text { portanto, têm seu acesso restrito; esse tipo } \\
\text { de solução não é visível para o usuário } \\
\text { comum }\end{array}$ \\
\hline 15 & Taxa de fidelidade ao site & $\begin{array}{l}\text { Visitantes leais ao site, ou seja, os } \\
\text { mesmos visitantes que voltam várias } \\
\text { vezes ao site }\end{array}$ \\
\hline 16 & Taxa de rejeição ao site & $\begin{array}{l}\text { A taxa de rejeição é a porcentagem de } \\
\text { visitas a uma única página (visitas em que } \\
\text { uma pessoa sai do site na mesma página } \\
\text { em que entrou) }\end{array}$ \\
\hline 17 & $\begin{array}{l}\text { Número de instalações de } \\
\text { soluções de software do Portal }\end{array}$ & $\begin{array}{l}\text { Estimativa do número de dowloads da } \\
\text { solução e teste (mesmo que mínimo) da } \\
\text { mesma pelos participantes da comunidade }\end{array}$ \\
\hline 18 & $\begin{array}{l}\text { Número de adoções de } \\
\text { soluções de software do Portal }\end{array}$ & $\begin{array}{l}\text { Estimativa do número de soluções } \\
\text { baixadas, testadas e adotadas por } \\
\text { entidades participantes ou visitantes do } \\
\text { Portal }\end{array}$ \\
\hline 19 & Economia de custo & $\begin{array}{l}\text { Valor financeiro estimado da redução de } \\
\text { custo da organização que adotou a } \\
\text { solução disponibilizada no Portal. Ou seja, } \\
\text { o quanto a organização economizou em } \\
\text { função da adoção da solução. Aqui deve } \\
\text { ser estimado um somatório dos valores de } \\
\text { todas as organizações }\end{array}$ \\
\hline 20 & Atos do poder público & $\begin{array}{l}\text { Portarias, instruções normativas, } \\
\text { resoluções, decretos, leis e outros. }\end{array}$ \\
\hline 21 & $\begin{array}{l}\text { Número de países que } \\
\text { demonstraram interesse } \\
\text { (formal ou informal) pelo SPB. }\end{array}$ & $\begin{array}{l}\text { Palestras, convênios, visitas, e países } \\
\text { relacionados ao Software Público } \\
\text { Internacional - SPI (PNUD) }\end{array}$ \\
\hline
\end{tabular}


A análise dos padrões de comportamento das variáveis-chave apontou dois aprendizados-síntese:

\section{APRENDIZADO 1}

O SPB está em crescimento, uma vez que o seu número de acessos, de usuários, de comunidades e outros indicadores crescem acentuadamente.

\section{APRENDIZADO 2}

Existe a necessidade da geração regular de dados de monitoramento, uma vez que variáveis representativas não puderam ser coletadas por falta de registro.

\section{Terceiro Ciclo - Mapa Sistêmico}

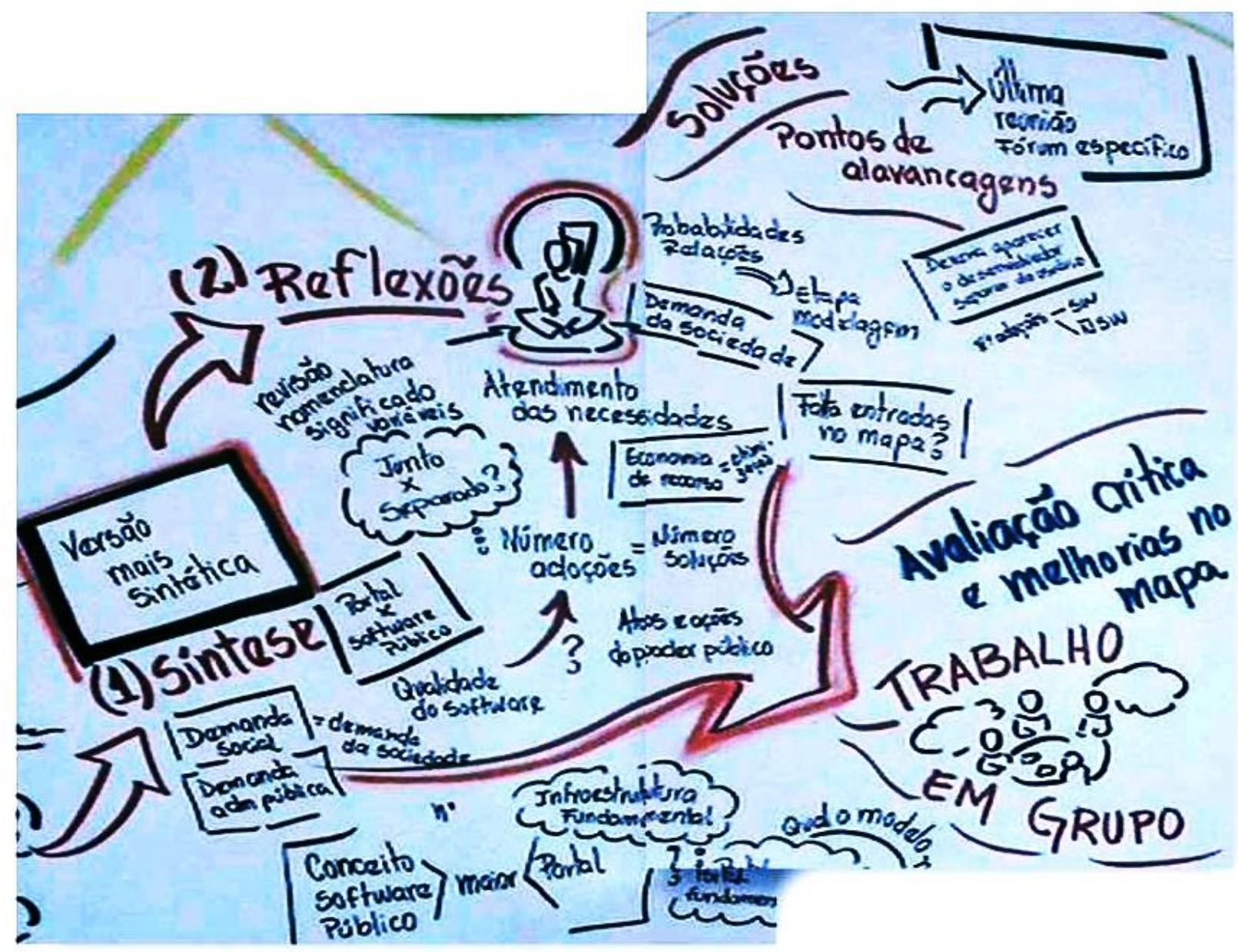

Figura 41 Representação da reunião de construção do mapa sistêmico Fonte: Luciane Bergue (EPS)

As relações entre as variáveis-chave que direcionam o SPB são representadas visualmente por um recurso chamado de mapa sistêmico. O mapa sistêmico busca 
relações causais entre as variáveis, além de incorporar resultados dos comportamentos dessas variáveis-chave, hipóteses preliminares, conhecimento especializado a respeito das influências recíprocas e também a experiência dos atores envolvidos. Dessa forma, a estrutura sistêmica do SPB vai sendo revelada. A Figura 41, apresenta o registro da reunião de construção do mapa sistêmico. $O$ mapa sistêmico final está representado na Figura 42. A leitura desse mapa é feita da seguinte forma:

Partindo-se da variável Número de Acessos ao Portal e seguindo pela seta mais externa do mapa, observa-se que o número de acessos conduz uma Necessidade de Infraestrutura e RH (Recursos Humanos) dedicados ao Portal. Com isso é gerada a necessidade de Investimentos em Infraestrutura e RH. Com o tempo, esse investimento torna-se Capacidade de Infraestrutura e $\mathrm{RH}$ que, por sua vez, gera Qualidade de Coordenação da Comunidade. Desta forma, os coordenadores podem confiar plenamente na infraestrutura do Portal. Com isso a Qualidade da Interação e dos Objetos (software e manuais, disponibilizados) é beneficiada, também como decorrência da capacidade de infraestrutura e $\mathrm{RH}$. Isto gera Qualidade de Governança da Rede SPB, que realimenta a qualidade de interação. A qualidade de governança também interfere positivamente na coordenação da comunidade (e nas atividades de divulgação, como será visto adiante, representadas pelo número 1 no mapa) o que fecha um enlace reforçador. Esse enlace é do tipo ganha-ganha. Todos ganham. Acompanhando o enlace mais externo do mapa nota-se que a qualidade da interação e dos objetos igualmente favorece o número de acessos ao Portal. Com isso, a qualidade da interação e dos objetos destaca-se como um ponto estratégico no mapa.

Voltando novamente ao ponto inicial (número de acessos), e seguindo pela volta mais interna, observa-se que o número de acessos naturalmente aumenta a Divulgação, bem como a qualidade da governança da rede SPB. A divulgação reforça o número de acessos. Entretanto, se houver Expectativa não Atendida, o número de acessos cai, gerando o que se chama de "enlace balanceador" no mapa. A expectativa não atendida reduz a divulgação, e novamente o número de acessos. A divulgação leva ao aumento no Número de Oportunidades no Portal. Aqui se entende por oportunidades no SPB as Novas Soluções, o Número de Adoções, o Interesse da Indústria de Software (que, com o tempo levam ao aumento no 
volume de negócios) ou, de uma maneira ampla, ações governamentais, empresariais, e naturalmente, ações de divulgação. Cabem também como oportunidades as ações de oportunismo existentes no Portal, como o Efeito "Carona", que será visto adiante. Ainda seguindo os efeitos da Divulgação, observa-se o aumento do número de Parcerias, o que favorece o aumento de Novas Soluções (que, com o tempo, levam ao aumento no número de adoções), Negócios (financiadores, por exemplo) e Capacitação (universidades, por exemplo).

A capacitação no SPB também é promovida pela qualidade da interação e dos objetos. E a recíproca é verdadeira. A capacitação gerada no SPB também favorece o crescimento no Número de prestadores no MPV (Mercado Público Virtual) que aumenta o número de adoções e de negócios no SPB que, por sua vez aumenta o número de prestadores no MPV, reforçando assim a capacitação, que por sua vez reforça as adoções de software público, que novamente reforça a capacitação. Veem-se, então, vários enlaces reforçadores. O aumento no número de prestadores também leva a um efeito não desejado, o "Efeito Carona", que se refere àquele perfil de usuário que somente extrai informações do Portal, sem retribuir com seus conhecimentos, estabelecendo uma relação unidirecional que diminui a confiança entre os membros. A consequência disto é a redução no número de parcerias.

Voltando-se ao número de adoções, observa-se que ele incentiva o Atendimento das Necessidades da Sociedade pelo SPB, que também recebe influência da capacidade de infraestrutura e $\mathrm{RH}$ do SPB. $\mathrm{O}$ atendimento das necessidades da sociedade pelo SPB gera efeitos na Otimização de Recursos e na Satisfação e Fidelização ao SPB. Com o tempo, o efeito é uma melhoria da qualidade da interação e dos objetos.

Retomando o ponto "interesse do setor de software" no mapa, nota-se que pode haver uma Competição com o modelo SPB. Ou seja, modelos convencionais de produção de software (ditos "proprietários") e mesmo outros modelos podem ver no SPB um modelo concorrente, uma ameaça. A competição pode levar a uma redução do Apoio Político. Entretanto, se houver um Alinhamento Intragovernamental, ou seja, um esclarecimento no âmbito do governo sobre os objetivos a que propriamente se propõe o SPB, essa competição pode ser amenizada e novamente haver um fortalecimento do apoio político ao SPB, que novamente leva ao aumento no número de oportunidades. 
Por fim, o Entendimento do Modelo SPB, isto é, o entendimento de como se comporta o SPB, seus pontos críticos, seus propósitos e sua configuração própria reforça no mapa dois fatores estratégicos: a qualidade de interação e dos objetos do SPB e o número de oportunidades. Esses dois pontos desencadeiam diversos outros pontos no mapa sistêmico.

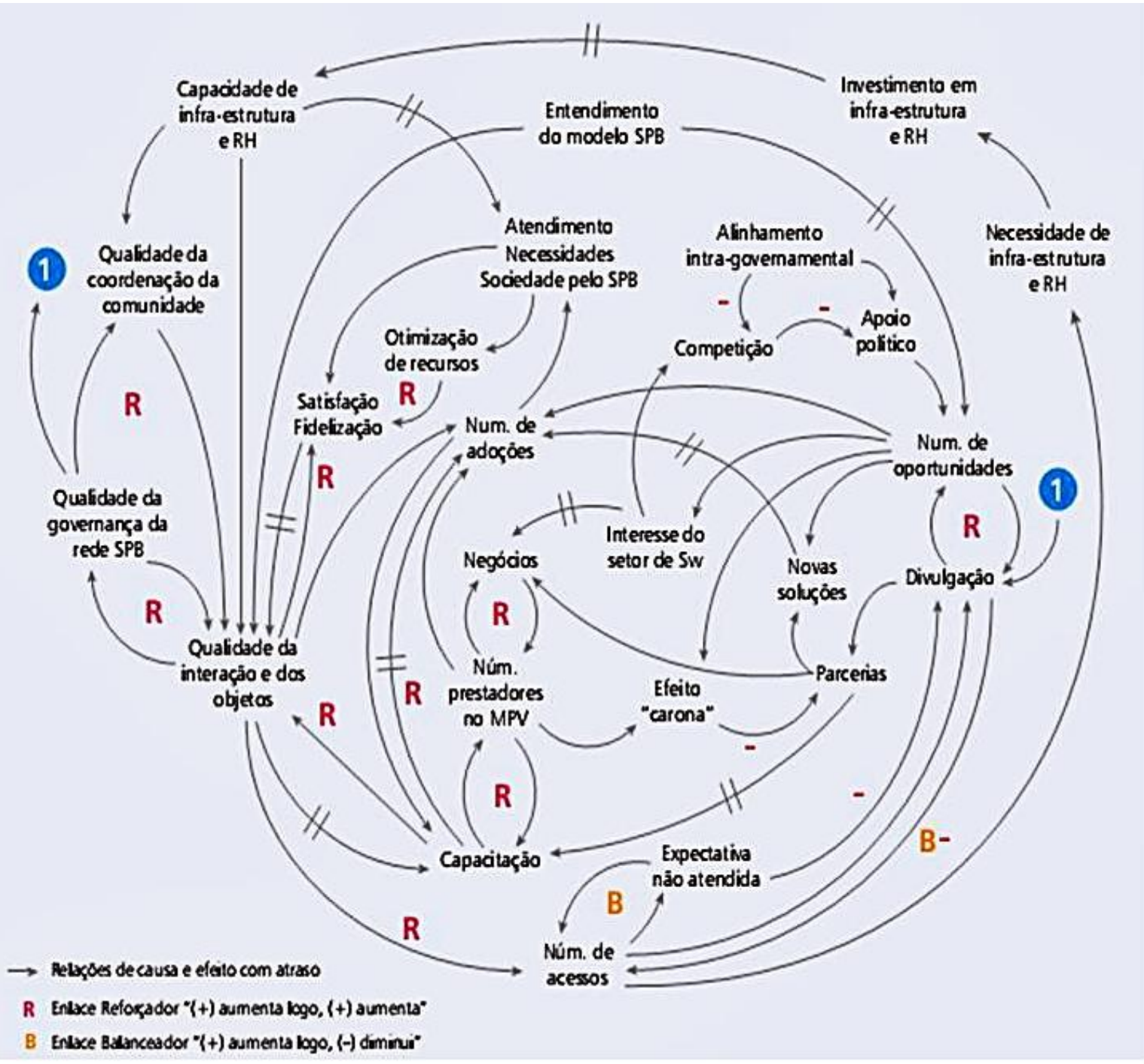

Figura 42 Mapa Sistêmico do SPB

\section{Quarto Ciclo - Modelos Mentais}

A identificação dos modelos mentais revela as crenças ou os pressupostos que os atores-chave mantêm em suas mentes, que influenciam seus comportamentos e, consequentemente, criam as estruturas do mundo real. Trata-se de uma etapa reveladora, pois dela podem emergir modelos mentais conflitantes ou 
complementares. A Figura 43, apresenta a memória da reunião do quarto ciclo, no qual os modelos mentais foram elaborados.

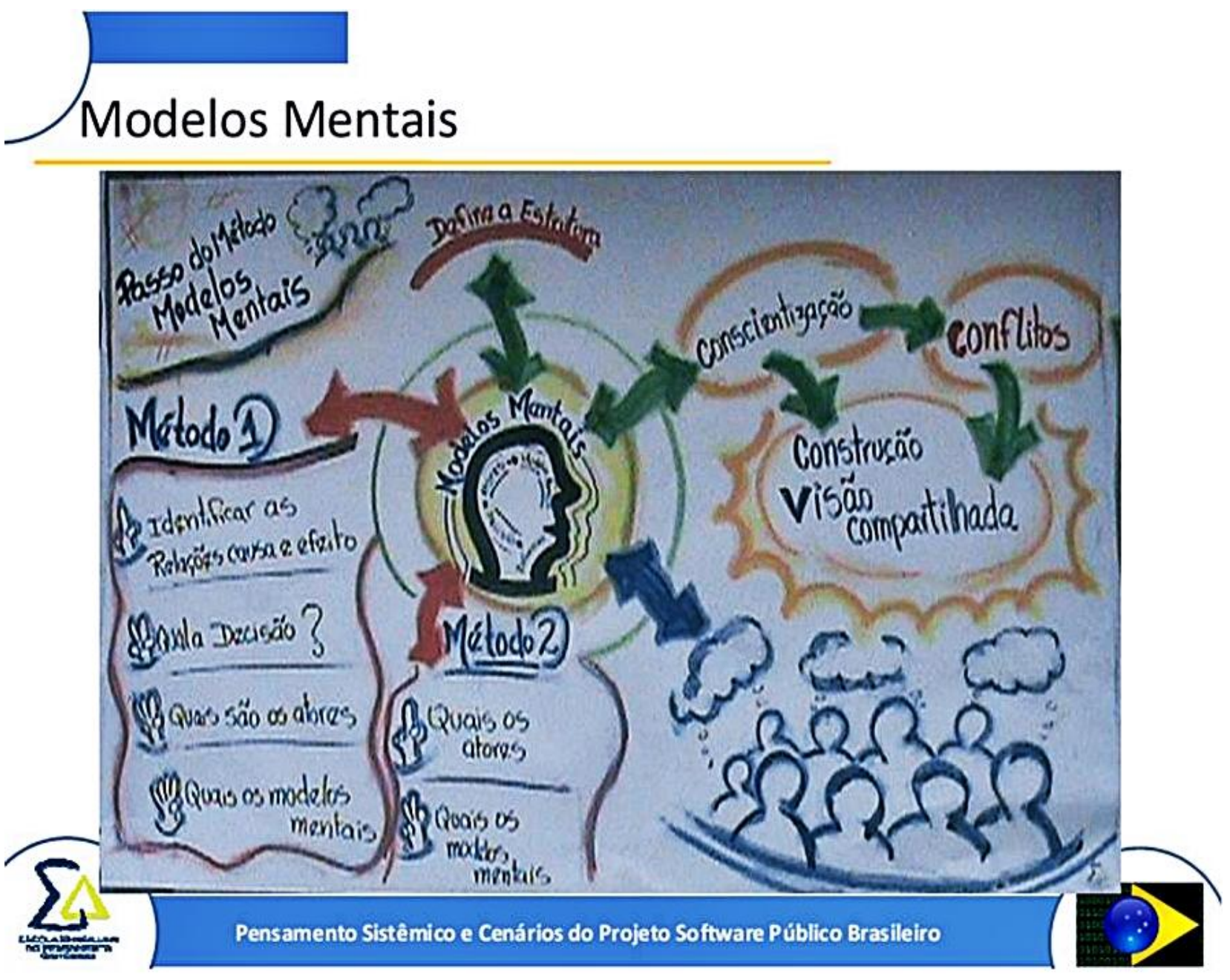

Figura 43 Representação da reunião sobre modelos mentais no SPB Fonte: Luciane Bergue (EPS)

Os modelos mentais identificados no SPB dizem respeito ao seguinte grupo de atores:

- Coordenadores - coordenadores de comunidades e coordenação geral do Portal.

- Desenvolvedores - colaboradores de desenvolvimento das soluções do ecossistema. Este grupo inclui os membros de comunidade mais ativos e conectados.

- Governo - refere-se ao Governo Federal, especialmente o Ministério de Planejamento Orçamento e Gestão. 
- Parceiros - financiadores, universidades, etc.

- Prestadores de serviço - pessoas físicas ou jurídicas cadastradas no Mercado Público Virtual.

- Setor de Software - comunidade de software livre e a indústria de software.

- Usuários finais - prestadores de serviço, prefeituras e órgãos públicos que utilizam soluções do ecossistema.

Os atores foram classificados conforme seu modelo mental como mostra o Quadro 33.

\begin{tabular}{|l|l|}
\hline \multicolumn{1}{|c|}{ Atores } & \multicolumn{1}{c|}{ Modelo mental } \\
\hline Coordenadores & "Sustentabilidade e aumentar o número de colaboradores" \\
\hline Desenvolvedores & "Ampliar minhas possibilidades profissionais." \\
\hline Governo & $\begin{array}{l}\text { "Combater monopólios na área de TI e gerar visibilidade } \\
\text { para a ação do Governo" }\end{array}$ \\
\hline Parceiros & "Quero projetos que gerem resultados efetivos e maior \\
interação com outras entidades" \\
\hline Srestadores de & "Como ampliar meu negócio?" \\
\hline Setor de Software & $\begin{array}{l}\text { "Software Público? O que é isso? É uma ameaça ou uma } \\
\text { oportunidade?" }\end{array}$ \\
\hline Usuários Finais & "Quero resolver meu problema e reduzir custos“ \\
\hline
\end{tabular}

Quadro 33 Modelos mentais do SPB

\section{Quinto Ciclo - Cenários e modelagem}

Se o método sistêmico inicialmente focou no passado (eventos e, padrões de comportamento) e no presente (mapa sistêmico e modelos mentais), a preocupação deste ponto em diante é com o futuro. Neste sentido, foram desenvolvidos os cenários e os modelos computacionais. A etapa dos cenários exercita a manutenção do contexto atual, a decisão de mudar a realidade ou ainda a falência de um projeto. Os cenários desafiam modelos mentais instituídos e seus possíveis desdobramentos. A Figura $\mathbf{4 4}$ apresenta o registro da quinta reunião. 
Para construir os cenários de futuro foram escolhidas duas variáveis críticas para o futuro do SPB:

\section{Apoio político-institucional}

\section{Alinhamento do Ecossistema SPB com novos} modelos que reconfigurarão o mercado e a indústria de software.

A partir do cruzamento dos eixos associados às variáveis citadas, configuraram-se quatro cenários representados na Figura 45. Para cada cenário, foram trabalhadas as seguintes questões:

Que mundo é este?

Quais são as suas

características?
Quais as

consequências

para o SPB?
Quais são as

estratégias criativas

para o cenário?

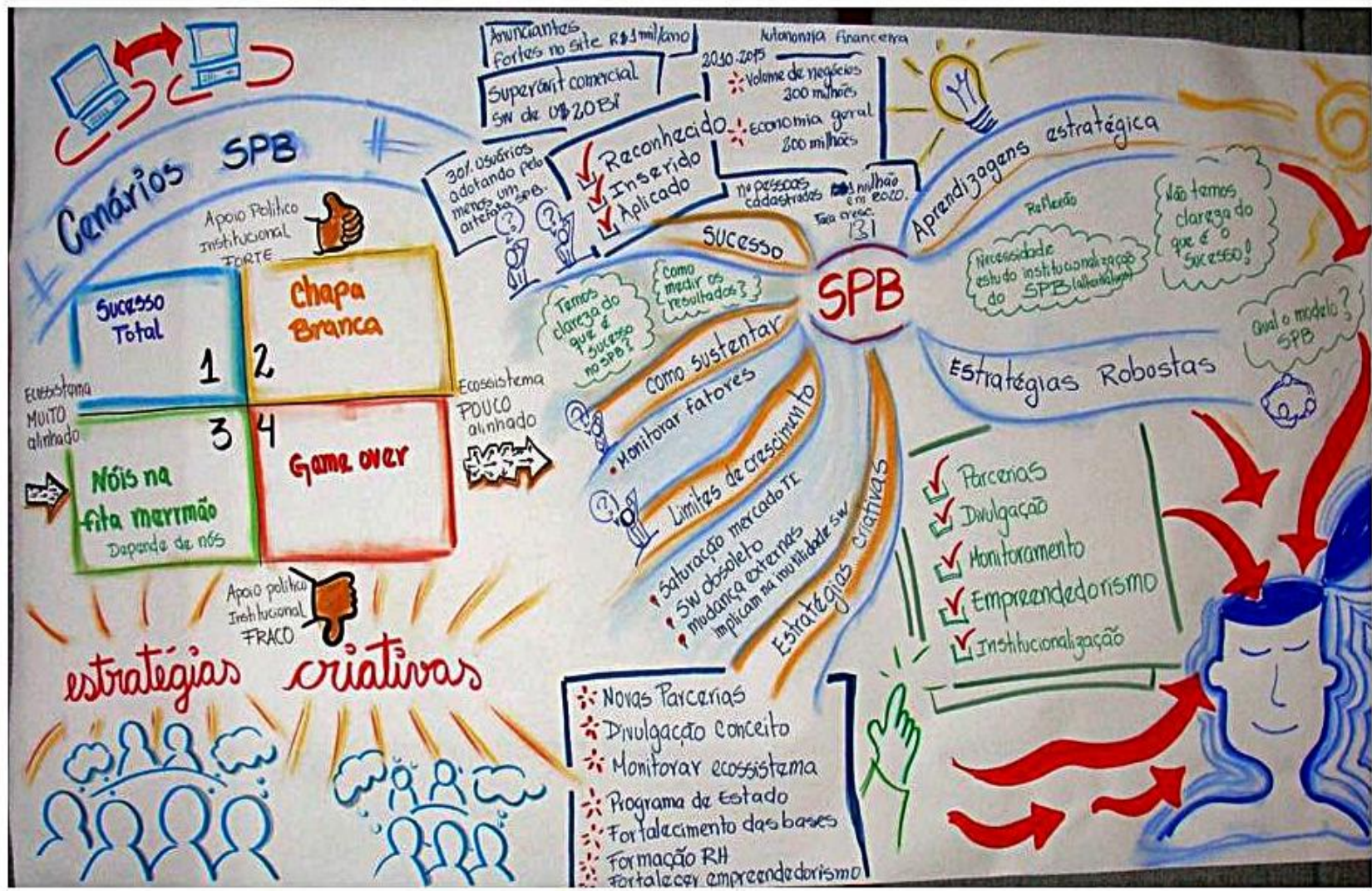

Figura 44 Representação da reunião de cenários do SPB Fonte: Luciane Bergue (EPS)

No cenário Sucesso Total, o modelo SPB foi reconhecido, inserido e aplicado em todas as esferas da sociedade. O sucesso do modelo SPB inspirou outros modelos 
de produção colaborativa de conhecimento, inclusive no âmbito internacional. Nesse ambiente, a sociedade utiliza corriqueiramente as soluções do SPB, há um aumento da transparência do governo, da eficiência no uso de recursos públicos e da cidadania. A gestão do SPB dispõe de infraestrutura e recursos humanos que atendem a alta demanda. $O$ governo $e$ as empresas mobilizaram linhas de financiamento para incentivar o investimento no aprimoramento e expansão do modelo SPB, o que capacitou prestadores de serviço do Mercado Público Virtual e estimulou a inovação tecnológica. Consequentemente, aumentou o volume de negócios diretos e indiretos. Com isso, o SPB tornou-se um protagonista da evolução da autonomia tecnológica da indústria de software brasileira.

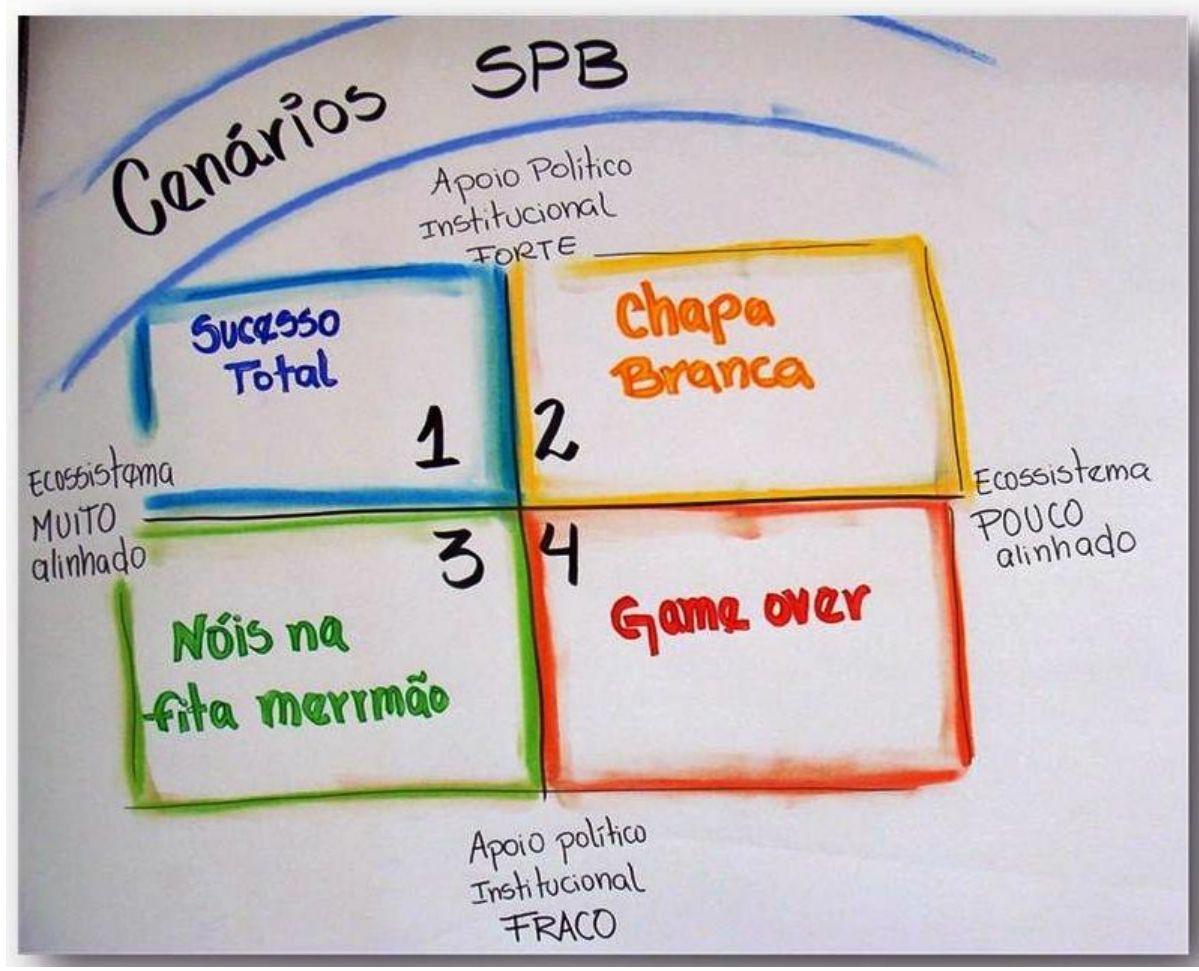

Figura 45 Cenários do SPB

Fonte: Luciane Bergue (EPS)

O cenário Chapa Branca é aquele que tem a mão forte do governo. O ecossistema só existe porque há um forte apoio do governo, que não reflete, necessariamente, as demandas da sociedade. Isso provoca uma inadequação tecnológica das soluções disponibilizadas. O baixo nível de colaboração resulta em baixo grau de inovação, desperdício de recurso público e perda da credibilidade. Para se evitar esse descolamento entre governo e demandas sociais, destaca-se a necessidade da condução do SPB de forma suprapartidária ou como um programa de Estado. Além 
disso, evidentemente, é preciso um esforço na divulgação e no envolvimento de atores-chave.

No cenário "Nóis na fita, merrmão!" ou modelo autossustentável, o apoio políticoinstitucional é fraco e o ecossistema alinhado. Neste caso, o panorama pende para a necessidade de pressão da sociedade e demonstração de maturidade do modelo. Assim, o motor do SPB neste cenário são as comunidades virtuais, que acabam adquirindo outro formato em decorrência do pouco apoio do Estado. Com isso, a sustentabilidade do ecossistema está condicionada a novas parcerias (projetos, recursos para infraestrutura, etc.) e ao atendimento das demandas da sociedade. Embora as comunidades virtuais deste cenário sejam fortes, há um evidente descolamento do Estado que não se beneficia do modelo e, tampouco promove a transparência, a eficiência no uso de recursos e a cidadania, como derivados da produção colaborativa conhecimento. Para evitar este cenário, é fundamental fortalecer a articulação com todos os participantes do ecossistema do software público, para realizar a pressão político--institucional necessária para engajar 0 Governo nesse processo.

Por fim no último cenário, "Game Over", o apoio político-institucional é fraco e o ecossistema é pouco alinhado. O Modelo do SPB foi pouco apropriado pela sociedade e pelo Estado. Cresceram forças de oposição ao SPB dentro do Estado. Com isso, as comunidades foram esvaziadas, os principais apoiadores do SPB foram desarticulados ou apartados do processo. A infraestrutura de TI do Portal não atende a demanda, as soluções anteriormente disponibilizadas no Portal estão estagnadas e já não há depósito de novas soluções. O usuário percebe o risco no uso de software público, com relação à descontinuidade de suporte e à segurança. Para que este cenário não ocorra, as estratégias desenhadas consideram a importância de se estabelecer a legislação e a institucionalização do SPB enquanto o Estado está favorável à instituição da governança no SPB e garantir fontes de recursos perenes. Além disso, é necessário incluir o SPB nas linhas de fomento do Governo (linhas de financiamento forte). O planejamento e a gestão estratégicocolaborativos ligados à governança também auxiliam a evitar o encaminhamento deste cenário. A parceria com novas entidades e a divulgação do modelo SPB fortalecem o alinhamento do ecossistema e o apoio político-institucional. 
Além do exercício de projeção de diferentes futuros, a discussão de estratégias criativas auxilia na preparação para as incertezas vindouras. As estratégias criativas são analisadas em conjunto e aquelas que se repetem destacam-se pela versatilidade diante de diferentes futuros. A elas dá-se o nome de estratégias robustas.

No caso do SPB, foram traçadas cinco estratégias robustas:

1. Divulgação: Interna, para os usuários do Portal SPB, a fim de ampliar o conhecimento sobre as atividades em andamento no modelo e, com isso, fortalecer a unidade e a identidade do ecossistema; e externa, visando captar novos usuários e potenciais parceiros.

2. Parcerias: As parcerias aumentam as ligações externas do SPB e com isso, a sua capacidade de atender as demandas da sociedade, além de diversificar os mecanismos de apoio institucional.

3. Monitoramento: O monitoramento advém da necessidade de conhecer os caminhos que o SPB está tomando e identificar os efeitos das tomadas de decisão no âmbito do próprio modelo.

4. Empreendedorismo: Tanto em âmbito nacional quanto no internacional, o empreendedorismo reflete a ousadia e a qualidade dos serviços e das soluções disponibilizadas em busca de novos mercados. Esta estratégia visa amparar os empresários de software no Brasil.

5. Institucionalização: Mecanismo que fortalece o próprio conceito do SPB. Decorre de um amadurecimento do modelo que, cada vez mais, requer sua autonomia de gestão e financeira.

\section{Sexto Ciclo - Modelos Computacionais}

A aplicação da modelagem computacional, é, de acordo com Andrade et al (2006): "O processo de construir modelos em software de Dinâmica de Sistemas, visando o desenvolvimento de micromundos gerenciais. Neles, pode-se testar estratégias e obter aprendizagens, o que, de outra forma, seria mais arriscado e mais demorado." (p. 99). A Figura 46, apresenta o registro da reunião de modelagem e a Figura 47, representa o aprendizado com a modelagem computacional. As aprendizagens foram: 
O empreendedorismo leva a um crescimento semelhante àquele decorrente de parcerias, pois aumenta a divulgação, embora a uma taxa relativamente pequena (10 a $20 \%)$.

A entrada de novos objetos também é crítica, embora de menor impacto em adoções e disseminação.
Monitoramento, disseminação e proatividade promovem um crescimento mais intenso que empreendedorismo e parcerias, mas menor que aquele obtido através de divulgação.

Nem toda entrada de nova solução representa entrada de novos usuários

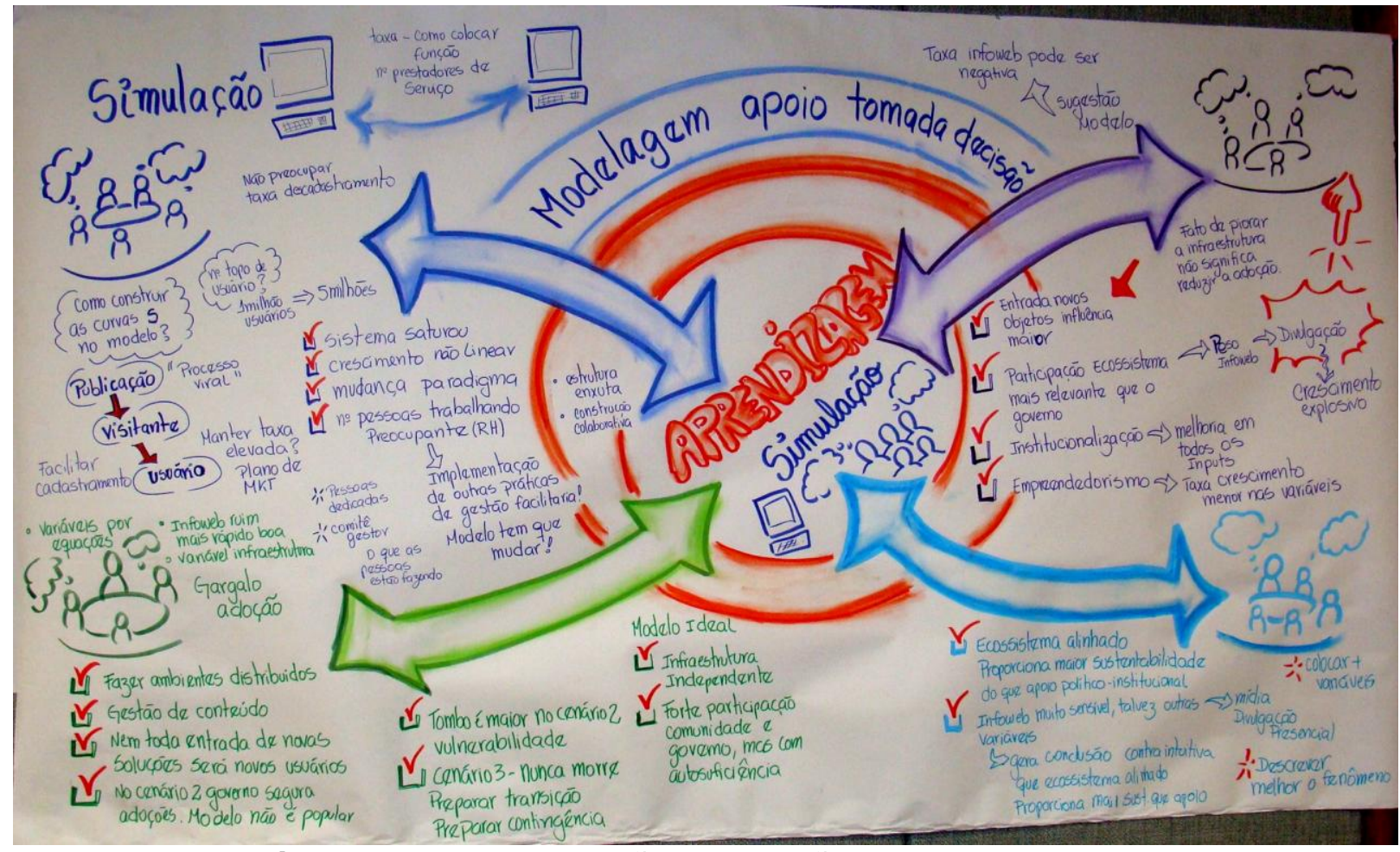

Figura 46 Representação da reunião de aprendizagem

Fonte: Luciane Bergue (EPS)

O ecossistema alinhado, aparentemente, proporciona uma sustentabilidade mais eficiente que um apoio político-institucional pleno Há necessidade de gerar estratégia de marketing viral (para trazer visitantes)
A taxa de geração de infoweb (emails, fóruns, notícias, etc.), é uma variável que potencializa 0 cadastramento de usuários. A taxa de infoweb também pode ter efeito negativo (pode gerar descadastramento). 
Todavia, a taxa de descadastramento não se altera. 0 descadastramento na prática se traduz como inatividade

A institucionalização leva ao crescimento e influencia todo o Ecossistema SPB. Entretanto, disso depende um alinhamento entre 0 Governo e o entendimento do SPB como um bem público

O fato de piorar a infraestrutura, aparentemente, não diminui o número de adoções
O modelo de crescimento tende a ser exponencial nas diversas simulações.

Os principais pontos fracos são a divulgação das soluções do SPB na sociedade e a sua adoção. A simulação mostrou que estas variáveis exercem forte influência em todo o sistema

Parcerias no SPB levam ao seu crescimento, mas de maneira branda.

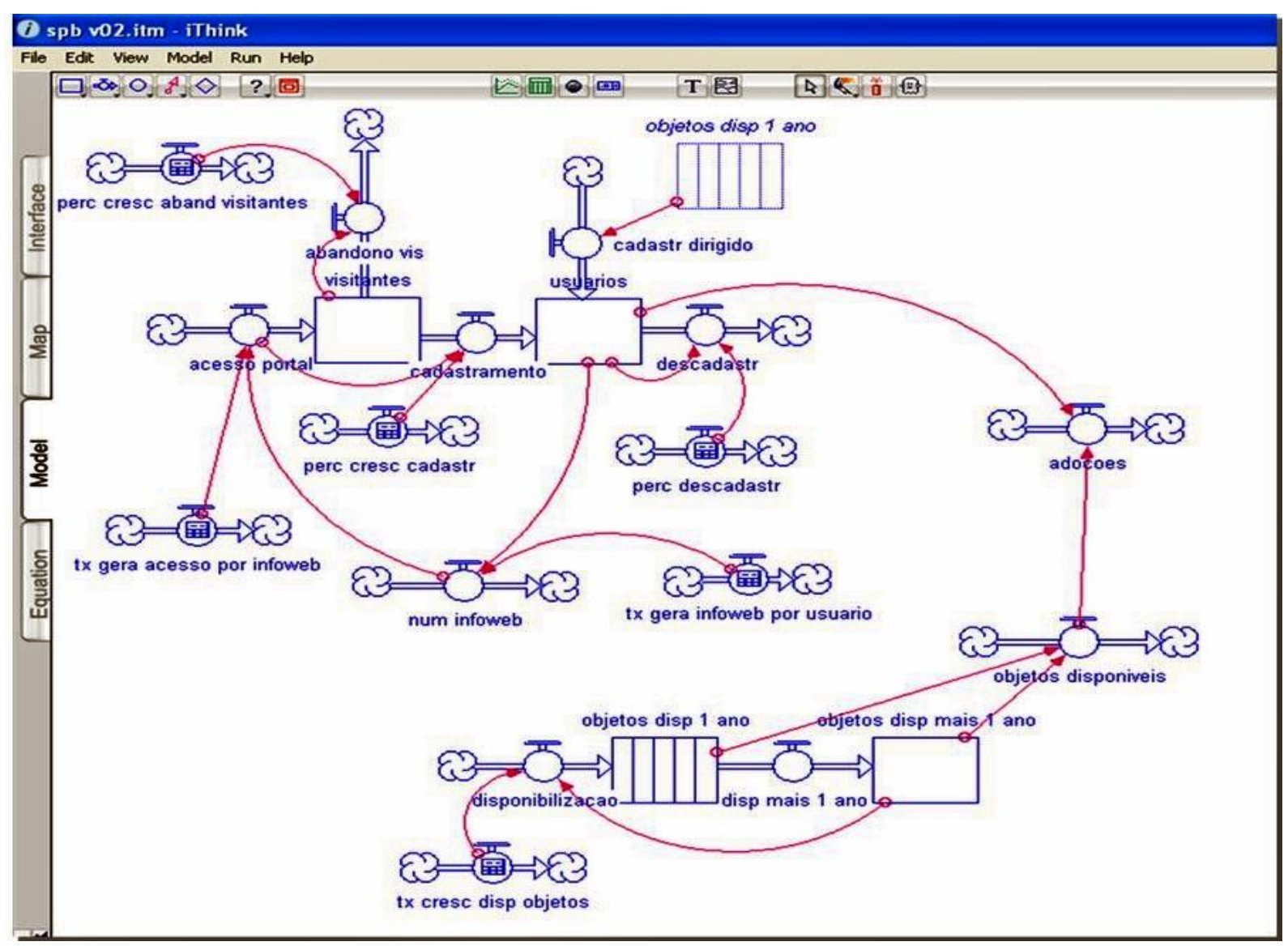

Figura 47 Aspecto geral do modelo do SPB no ITHINK 


\section{$\underline{\text { Sétimo Ciclo - Plano de Desenvolvimento Sistêmico }}$}

O processo de aplicação da SSM gerou grande quantidade de aprendizado. A fim de colocar em prática todo o conhecimento adquirido, propôs-se sistematizar e operacionalizar esse aprendizado. Trata-se do plano de desenvolvimento sistêmico da organização. A ideia central foi definir direcionadores e elaborar caminhos estratégicos úteis para serem usados como entrada no planejamento estratégico. Planejar ações significa elaborar um plano de projetos e ações visando alavancar o sistema e direcioná-lo para um alvo desejado (ANDRADE et al, 2006).

A sistematização do conhecimento foi elaborada na forma da proposição de uma Política do SPB e de sugestões de programas. A proposta de Política do SPB foi baseada em um objetivo geral, que procurou descrever o propósito do SPB a partir das discussões da aplicação do método sistêmico, ou seja, "construir e aprimorar continuamente uma rede de produção colaborativa de conhecimento para desenvolver, em ambiente público, soluções informatizadas de TI direcionadas ao desenvolvimento sustentável (social, econômico e ambiental)."

Isto posto, foram definidas cinco diretrizes para traçar caminhos estratégicos úteis para serem usados futuramente no planejamento do SPB e para sustentar seu objetivo geral. Essas diretrizes são:

Pesquisa, desenvolvimento e inovação

Fortalecimento da rede SPB

\section{Conhecimento, avaliação e monitoramento do SPB}

Cada diretriz relaciona um conjunto de objetivos que contém ações específicas no seu respectivo tema. O Plano de Desenvolvimento Sistêmico do SPB está disponível no ANEXO VI.

Ao longo do processo de aplicação do método sistêmico, foram geradas diferentes aprendizagens. Os resultados não se resumiram à consolidação do método no Planejamento Sistêmico (com sua política e suas diretrizes), mas a abertura para uma leitura sistêmica do SPB influenciou a geração de outros produtos relacionados 
ao entendimento desse ecossistema digital. A Figura 48 apresenta um desenho sobre o caminho percorrido ao longo dos sete ciclos da SSM.

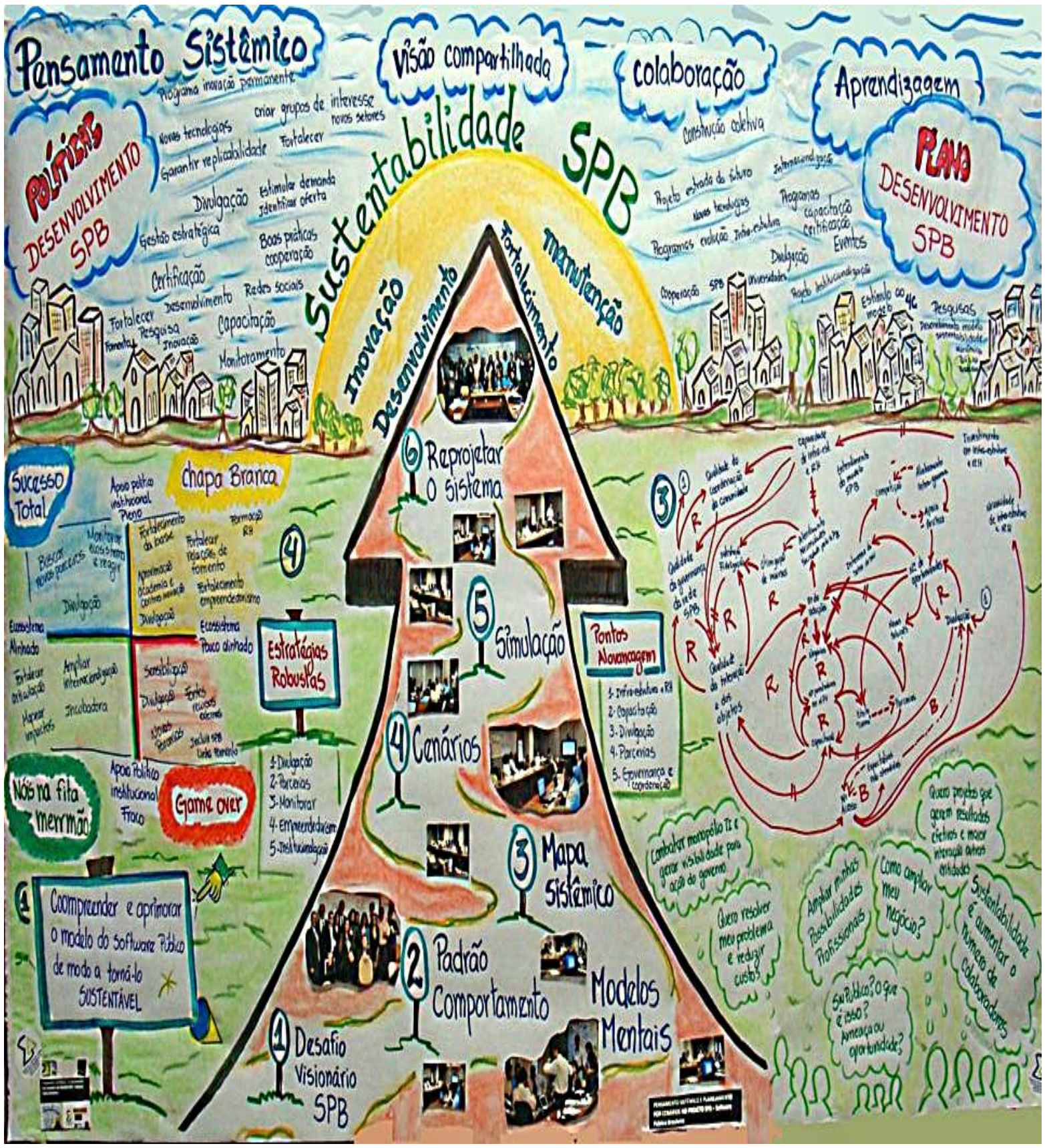

Figura 48 Representação da sétima reunião SSM Fonte: Luciane Bergue (EPS)

\subsubsection{A SSM no SPB - Pesquisa}

A aplicação da metodologia SSM apresentada na seção 5.3.2.1 percorreu todos os ciclos definidos dessa metodologia e, ao longo do processo construiu, com todos os stakeholders do ecossistema, um entendimento do presente, uma visão 
compartilhada do futuro desejado e estabeleceu as estratégias para atingir esses objetivos ou metas.

Ao longo dos ciclos, a autora coletou dados para desenvolver as referências para o modelo de capacidade/maturidade do SPB. Dessa forma, os dados coletados foram classificados, simultaneamente, conforme a tipologia definida pelo PRO2PI-MFMOD: práticas sequenciais e técnicas. As regras serão explicitadas quando da aplicação do framework. Os dados coletados estão representados no Quadro 34, que é composto por três colunas. A primeira coluna descreve uma atividade-mãe, grafada em negrito, e as suas atividades- filhas. A segunda coluna contém o identificador da atividade no processo de construção do método (o número da atividade é formado pela letra $A$, seguida do número da sequência da atividade no processo do framework). A terceira coluna contém o número da Prática Sequencial que é atendida pela atividade. Tanto a atividade quanto a prática são apontadas somente na linha das atividades principais. 


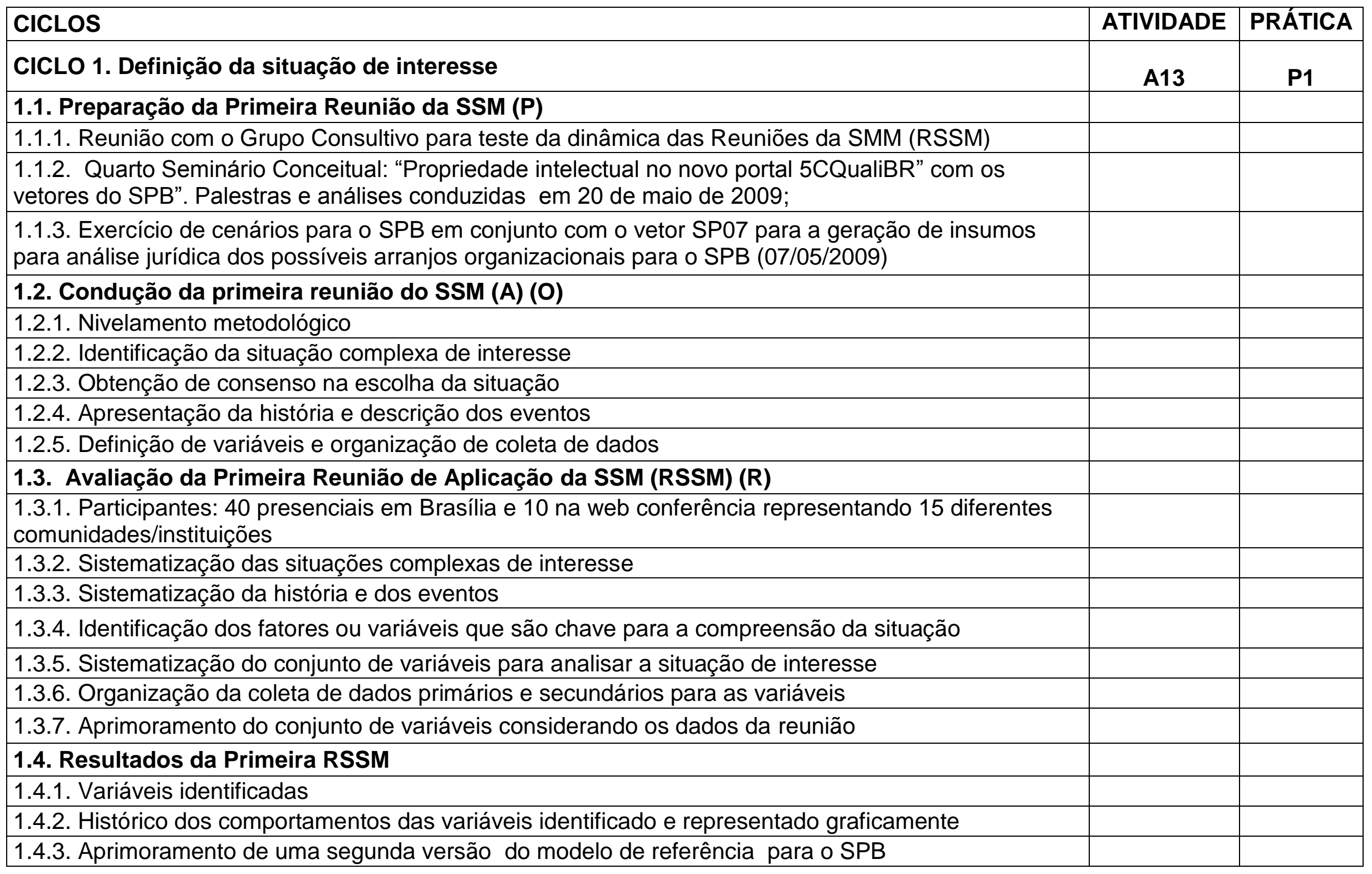




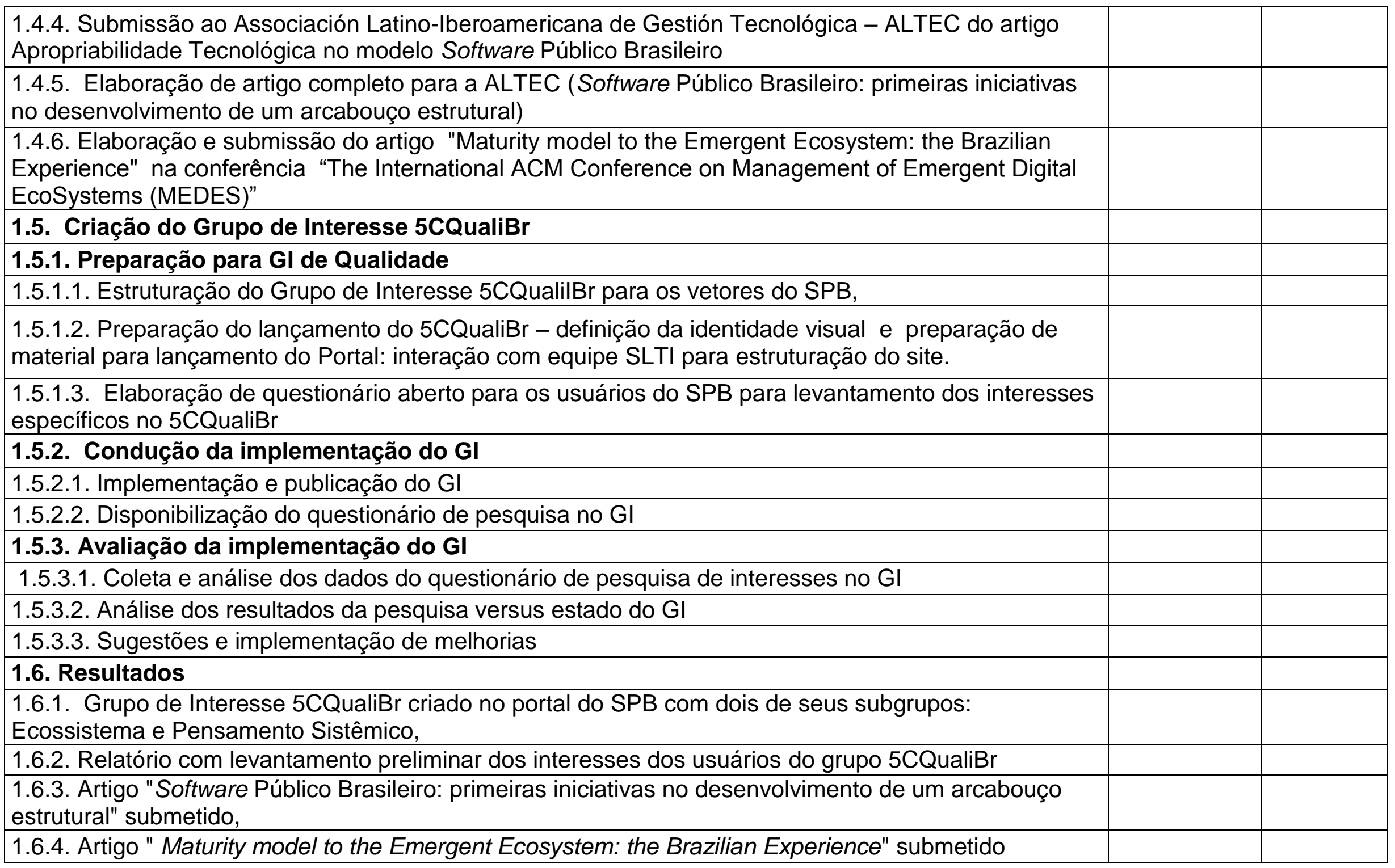




\begin{tabular}{|c|c|c|}
\hline CICLO 2 - Aprendizagem com padrões de comportamento e construção de mapa sistêmico & A14 & P2 \\
\hline \multicolumn{3}{|l|}{ 2.1. Preparação da Segunda RSSM } \\
\hline \multicolumn{3}{|l|}{$\begin{array}{l}\text { 2.1.1 Preparação e envio de literatura sobre padrões de comportamento, técnicas de arquétipos e } \\
\text { mapeamento sistêmico. }\end{array}$} \\
\hline \multicolumn{3}{|l|}{ 2.1.2. Preparação de material de apoio à reunião } \\
\hline \multicolumn{3}{|l|}{ 2.1.3. Elaboração e remessa de convites } \\
\hline \multicolumn{3}{|l|}{ 2.1.4. Elaboração da agenda de trabalho (08.07.2009) } \\
\hline \multicolumn{3}{|l|}{ 2.2. Condução da Segunda RSMM } \\
\hline \multicolumn{3}{|l|}{ 2.2.1. Posicionamento metodológico } \\
\hline \multicolumn{3}{|l|}{ 2.2.2. Apresentação dos resultados da coleta de dados com vistas à construção dos indicadores } \\
\hline \multicolumn{3}{|l|}{ 2.2.3. Aprendizado com o padrão de comportamento das variáveis-chave } \\
\hline \multicolumn{3}{|l|}{ 2.2.4. Mapeamento sistêmico considerando as variáveis-chave pelos grupos (quatro grupos) } \\
\hline \multicolumn{3}{|l|}{ 2.2.5. Direcionadores estratégicos } \\
\hline \multicolumn{3}{|l|}{ 2.3. Avaliação da Segunda RSSM } \\
\hline \multicolumn{3}{|l|}{ 2.3.1. Reunião presencial/web conferência com a participação de 30 pessoas } \\
\hline \multicolumn{3}{|l|}{ 2.3.2. Consolidação do mapa sistêmico a partir dos mapas gerados pelos grupos de trabalho. } \\
\hline \multicolumn{3}{|l|}{$\begin{array}{l}\text { 2.3.3. Artigo "A new approach of E-Gov processes development: the use of complex thinking theory } \\
\text { approach" aceito no evento "International Conference on Eletronic Government". }\end{array}$} \\
\hline \multicolumn{3}{|l|}{ 2.4. Resultados da Segunda RSSM } \\
\hline \multicolumn{3}{|l|}{ 2.4.1. Variáveis críticas do SPB } \\
\hline \multicolumn{3}{|l|}{ 2.4.2. Mapa sistêmico consolidado } \\
\hline Ciclo 3 - Aprendizagem com Mapa Sistêmico & A15 & P3 \\
\hline \multicolumn{3}{|l|}{ 3.1. Preparação da Terceira RSSM, } \\
\hline \multicolumn{3}{|l|}{ 3.1.1. Preparação e envio de literatura - teoria dos modelos mentais e mapeamento sistêmico } \\
\hline \multicolumn{3}{|l|}{ 3.1.2. Preparação de material de apoio à reunião } \\
\hline \multicolumn{3}{|l|}{ 3.1.3. Elaboração e remessa de convites } \\
\hline 3.1.4. Elaboração da agenda de trabalho (29.07.2009) & & \\
\hline
\end{tabular}




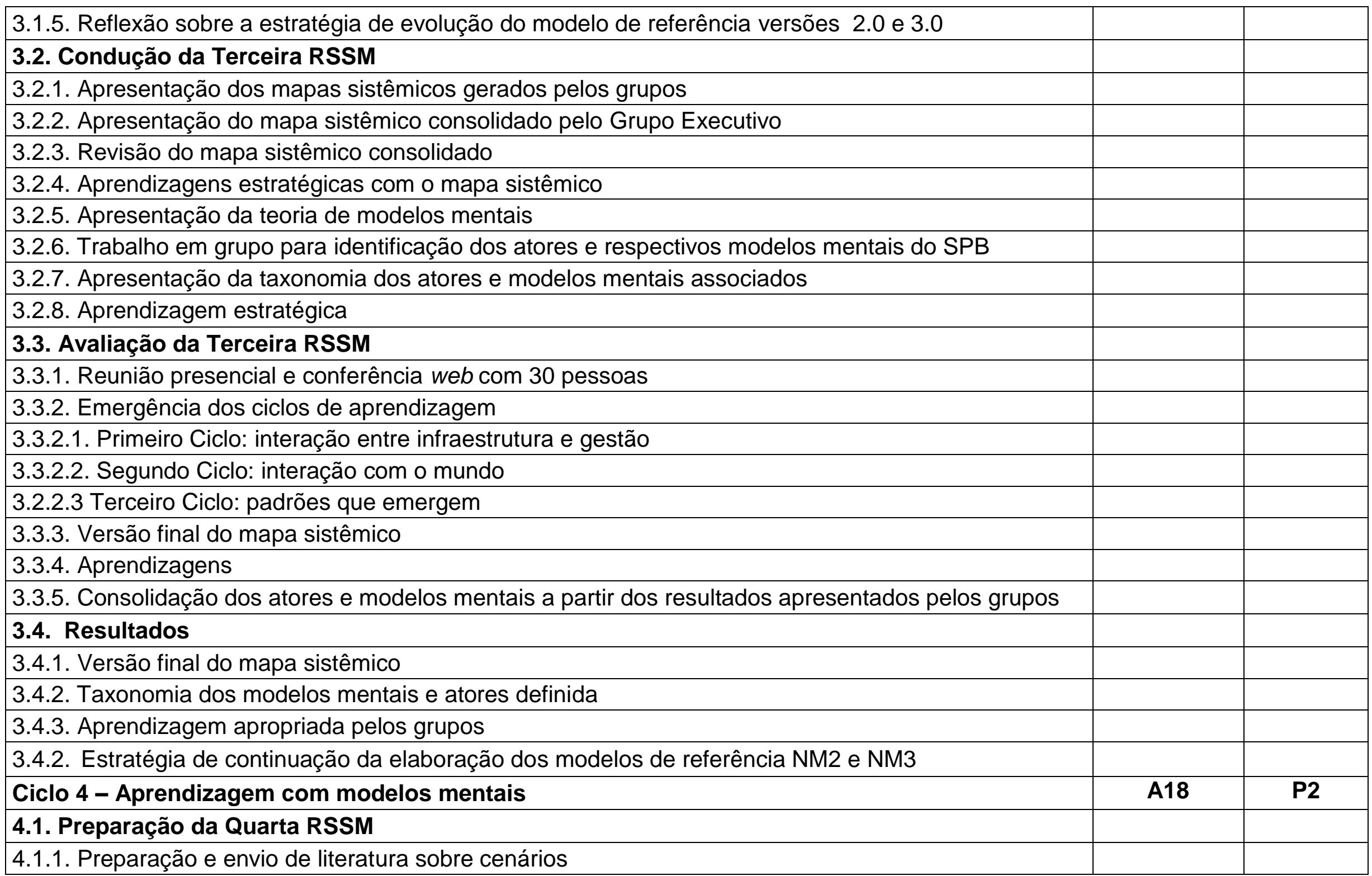




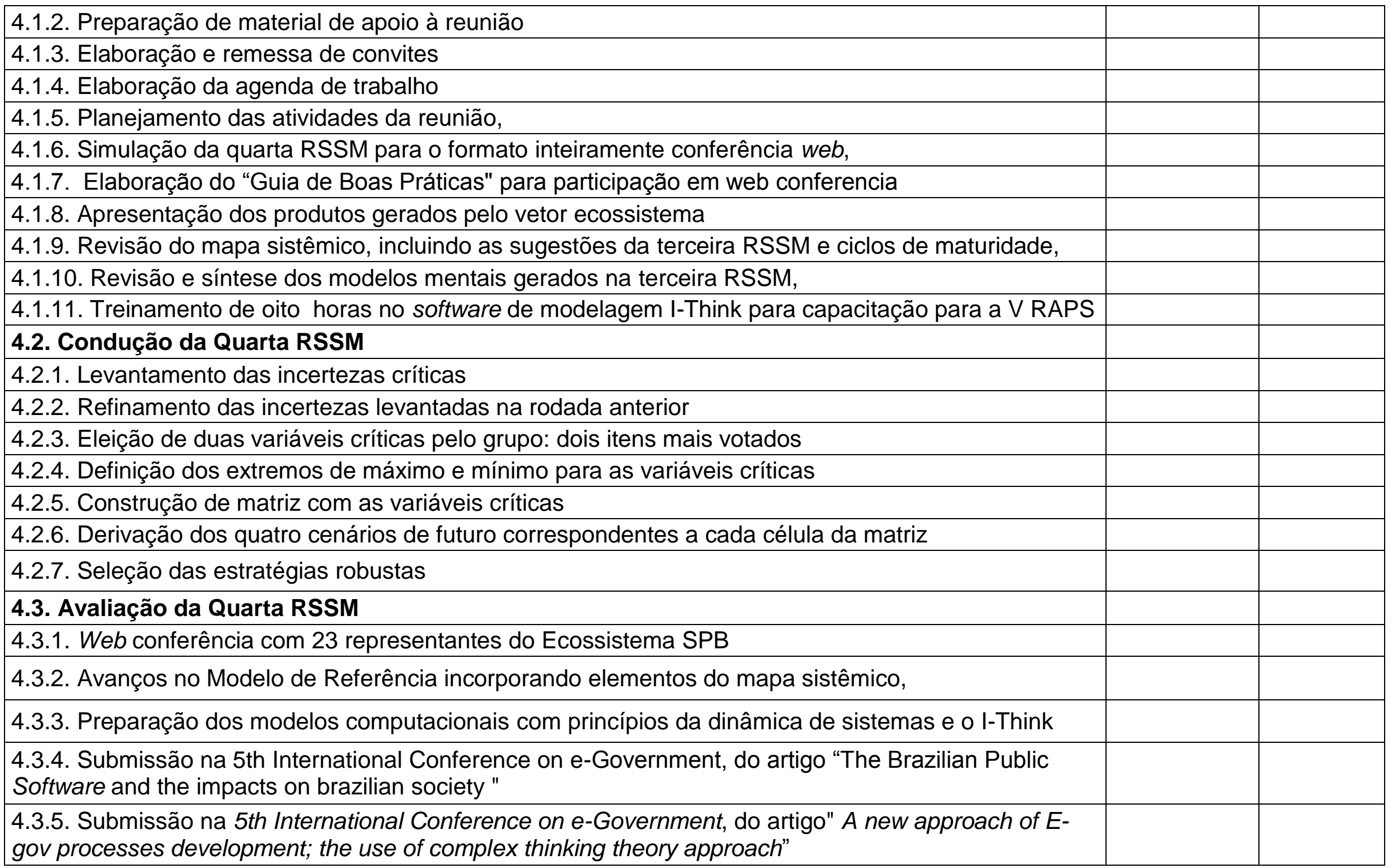




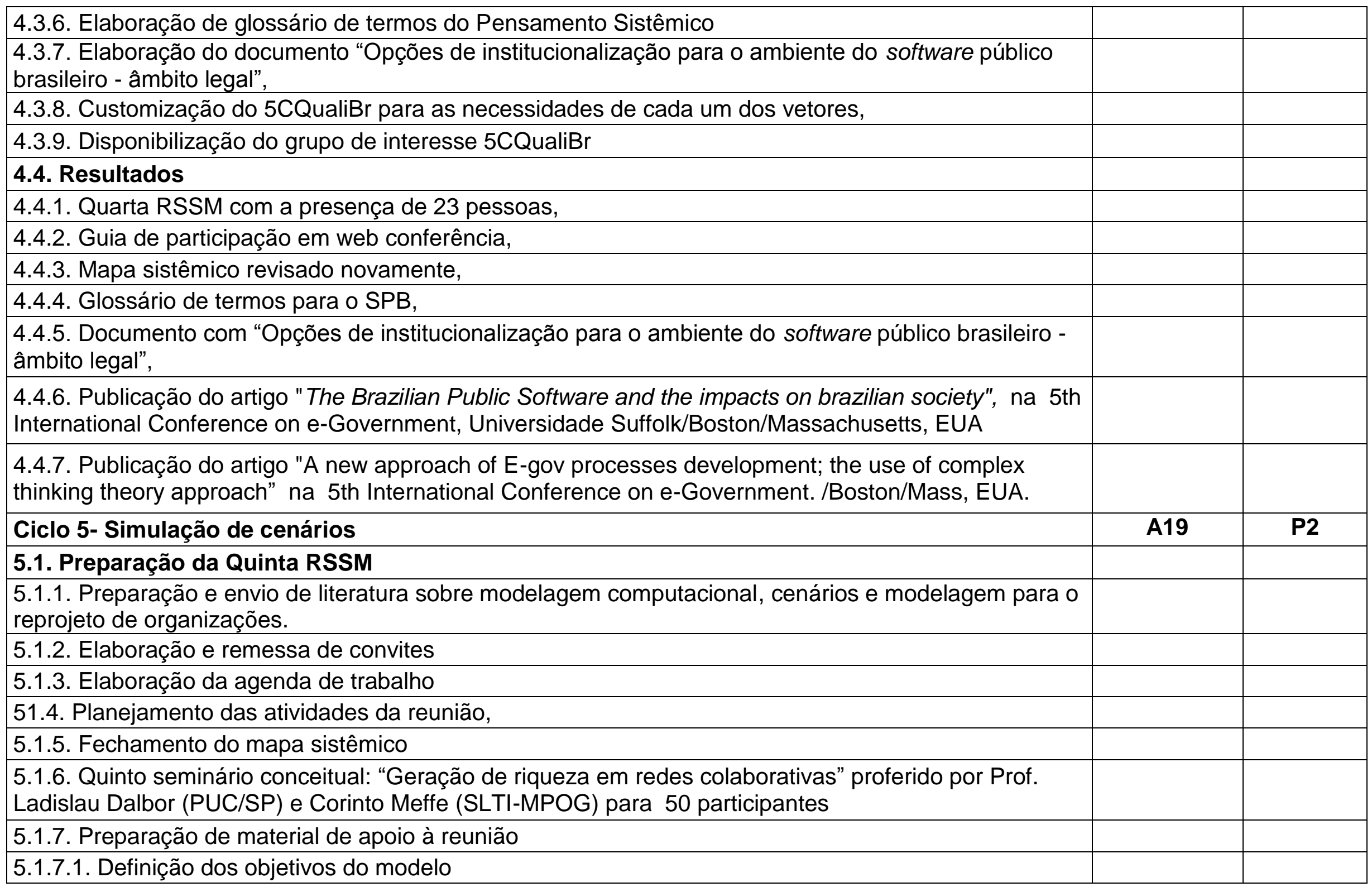




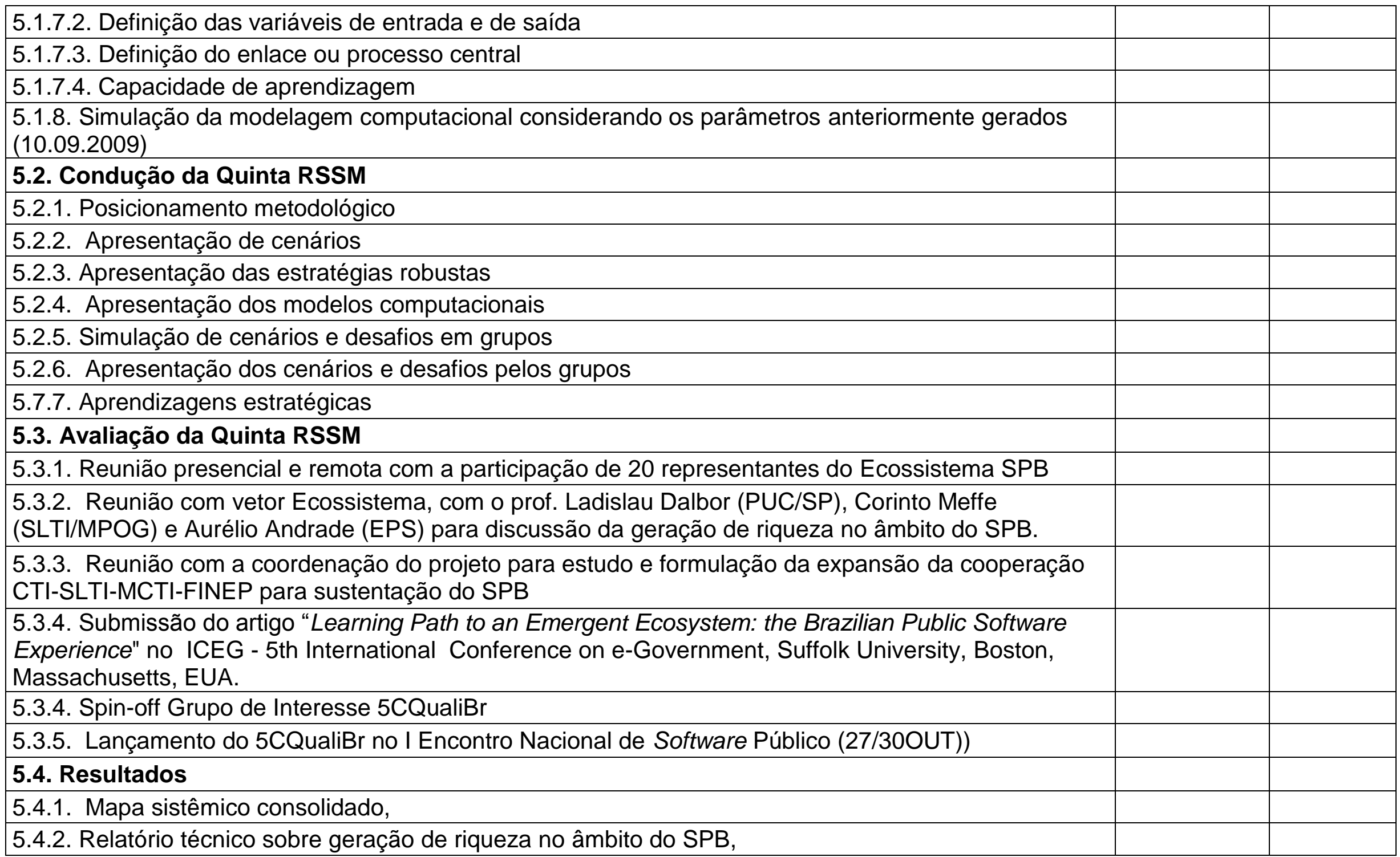




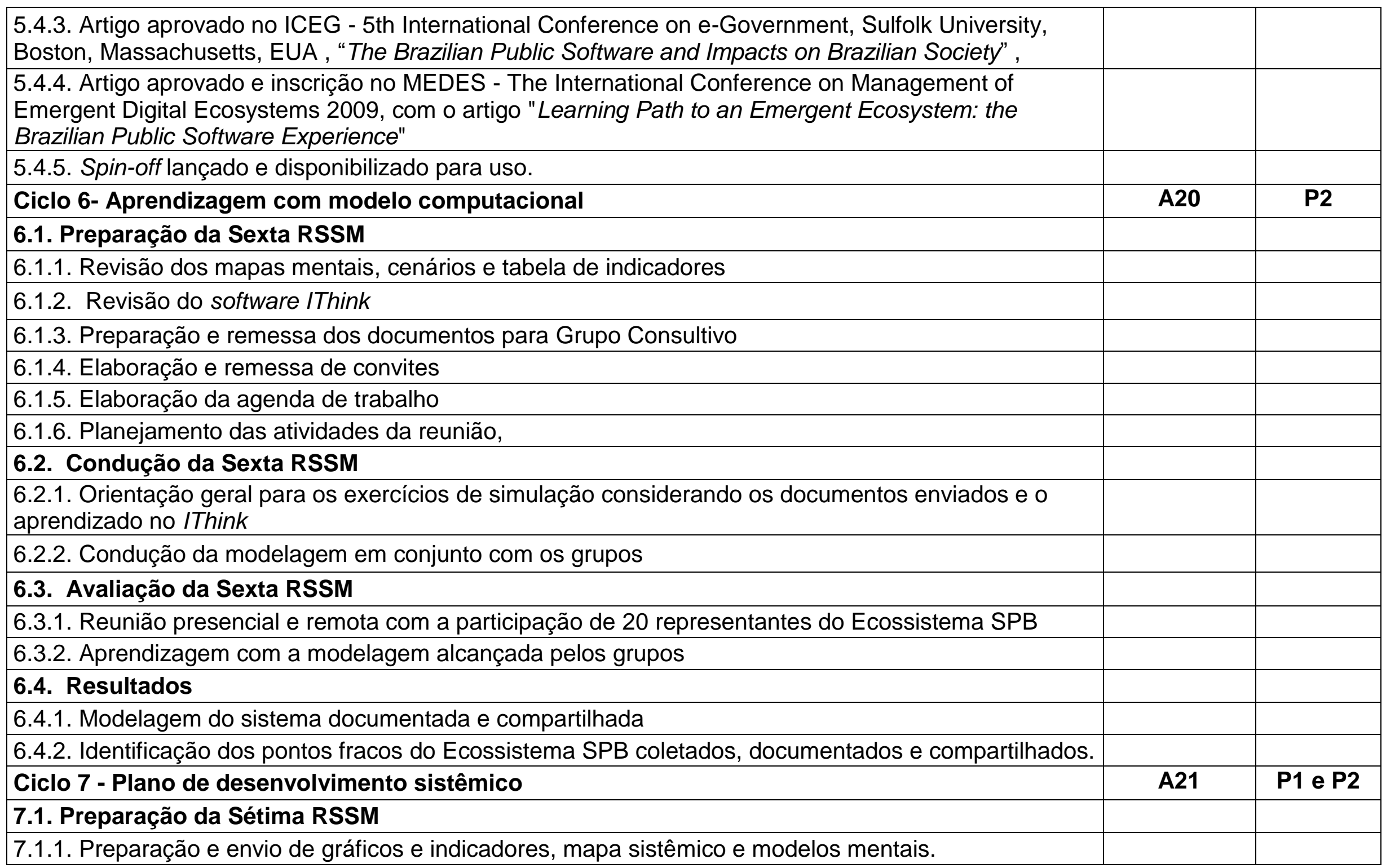




\begin{tabular}{|c|c|}
\hline \multicolumn{2}{|l|}{ 7.1.2. Elaboração do Roteiro do Plano de desenvolvimento sistêmico do SPB } \\
\hline \multicolumn{2}{|l|}{ 7.1.3. Elaboração e remessa de convites } \\
\hline \\
\hline \multicolumn{2}{|l|}{ 7.1.5. Planejamento das atividades da reunião } \\
\hline \multicolumn{2}{|l|}{ 7.1.6. Início da preparação da finalização das atividades relativas à aplicação da SSM } \\
\hline \multicolumn{2}{|l|}{ 7.2. Condução da Sétima RSSM } \\
\hline \multicolumn{2}{|l|}{ 7.2.1. Posicionamento metodológico } \\
\hline \multicolumn{2}{|l|}{ 7.2.2. Orientação geral para o exercício de plano de desenvolvimento sistêmico do SPB } \\
\hline \multicolumn{2}{|l|}{ 7.2.3. Condução das tarefas de elaboração do plano de desenvolvimento sistêmico do SPB } \\
\hline \multicolumn{2}{|l|}{ 7.2.4. Divisão dos representantes em dois grupos } \\
\hline \multicolumn{2}{|l|}{$\begin{array}{l}\text { 7.2.5. Orientação para elaboração do documento de políticas e diretrizes de desenvolvimento com a } \\
\text { seguinte estrutura: a) itens, b) ideias norteadoras. }\end{array}$} \\
\hline \multicolumn{2}{|l|}{ 7.2.6. Consolidação do item 7.2.5 } \\
\hline \multicolumn{2}{|l|}{$\begin{array}{l}\text { 7.2.7. Orientação para elaboração do documento Plano de Desenvolvimento com a) programa; b) } \\
\text { projetos; c) Gantt e d) Pertt }\end{array}$} \\
\hline \multicolumn{2}{|l|}{ 7.2.7. Detecção dos pontos de alavancagem } \\
\hline \multicolumn{2}{|l|}{ 7.3. Avaliação da Sétima RSSM } \\
\hline \multicolumn{2}{|l|}{ 7.3.1. Reunião presencial/web com a participação de 30 representantes do Ecossistema SPB } \\
\hline \multicolumn{2}{|l|}{ 7.3.2. Documento de políticas e diretrizes para desenvolvimento do SPB semi acabado } \\
\hline \multicolumn{2}{|l|}{ 7.3.3. Documento de plano de desenvolvimento do SPB semi acabado } \\
\hline \multicolumn{2}{|l|}{ 7.3.4. Pontos de alavancagem do ecossistema definidos } \\
\hline \multicolumn{2}{|l|}{$\begin{array}{l}\text { 7.3.5. Preparação para a participação dos vetores do Projeto Modelo de Referência no I Encontro do } \\
\text { Software Publico Brasileiro (Brasília 30.10.2009) }\end{array}$} \\
\hline \multicolumn{2}{|l|}{ 7.3.6. Revisão do Modelo de Maturidade considerando os achados dos ciclos anteriores } \\
\hline \multicolumn{2}{|l|}{$\begin{array}{l}\text { 7.3.7. Reunião entre CTI e parceiros do SLTI e SEPIN/MCT para alinhamento sobre o projeto Modelo } \\
\text { de Referência e deliberação sobre as próximas etapas do projeto }\end{array}$} \\
\hline \multicolumn{2}{|l|}{ 7.3.8. Elaboração de proposta de continuidade do Projeto Modelo de Referência } \\
\hline 7.3.9. Reunião com parceiros em Brasília para deliberar sobre a continuidade do & \\
\hline
\end{tabular}




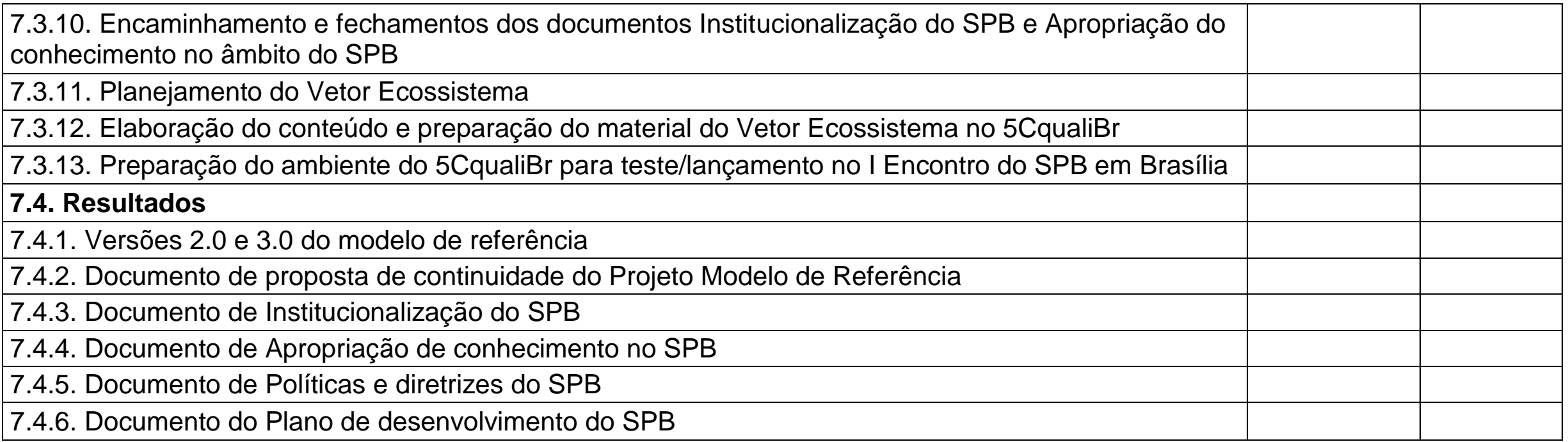

Quadro 34 Dados e informações coletados durante os ciclos da SSM 


\subsubsection{Aplicando o MFMOD}

A partir da aplicação da metodologia SSM, apresentada na seção 5.3.2.1 obteve-se um conjunto de dados que está registrados no Quadro 34. O passo seguinte foi a aplicação do PRO2PI-MFMOD, para estabelecer a relação das atividades com as práticas e demais componentes do framework. O resultado da aplicação é descrito no Quadro 35.

As práticas sequenciais de definição de estratégia e elaboração das três versões do modelo de referência, as regras de customização e as técnicas para execução das atividades estão discriminadas no Quadro 36. Essas atividades foram realizadas especificamente para desenvolver o modelo de referência do SPB.

\begin{tabular}{|c|c|c|c|c|}
\hline Atividade & Descrição & Regras & Práticas & Técnicas \\
\hline A13 & $\begin{array}{l}\text { Definição da situação de } \\
\text { interesse }\end{array}$ & \multirow{7}{*}{ 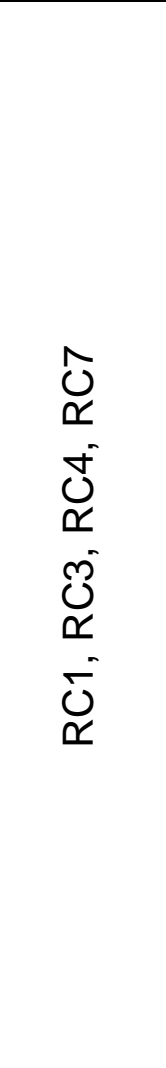 } & P1 & \multirow{7}{*}{$\begin{array}{l}\cong \\
F \\
E \\
F \\
F \\
0^{\circ} \\
F \\
D^{\circ}\end{array}$} \\
\hline A14 & $\begin{array}{l}\text { Aprendizagem com padrões de } \\
\text { comportamento e construção de } \\
\text { mapa sistêmico }\end{array}$ & & P2 & \\
\hline A15 & $\begin{array}{l}\text { Aprendizagem com mapa } \\
\text { sistêmico }\end{array}$ & & P3 & \\
\hline A18 & $\begin{array}{l}\text { Aprendizagem com modelos } \\
\text { mentais }\end{array}$ & & $\mathrm{P} 2$ & \\
\hline A19 & $\begin{array}{l}\text { Construção e simulação de } \\
\text { cenários }\end{array}$ & & P2 & \\
\hline A20 & $\begin{array}{l}\text { Aprendizagem com modelo } \\
\text { computacional }\end{array}$ & & $\mathrm{P} 2$ & \\
\hline A21 & $\begin{array}{l}\text { Plano de desenvolvimento } \\
\text { sistêmico }\end{array}$ & & $\mathrm{P} 1, \mathrm{P} 2$ & \\
\hline
\end{tabular}

Quadro 35 Atividades, Regras, Práticas e Técnicas do MFMOD para o SPB

A partir do Quadro 34, e com utilização do PRO2PI-MFMOD para a elaboração do método para a construção de elementos para o modelo de referência do SPB, foi obtida a formação descrita no Quadro 37. Para a aplicação do PRO2PI-MFMOD, foram tomadas algumas decisões. Foi considerado, para as práticas sequenciais, 0 ciclo como um todo e não cada atividade do ciclo. O objetivo do ciclo é atingido com 
a execução das atividades nele contidas. Portanto, a prática sequencial pode conter o conjunto de atividades discriminadas pelo ciclo a ela associado.

\begin{tabular}{|c|c|c|c|c|}
\hline Atividade & Descrição & Regras & Práticas & Técnicas \\
\hline A16 & $\begin{array}{l}\text { Desenvolvimento do modelo de } \\
\text { referência, versão } 2.0\end{array}$ & \multirow{6}{*}{ 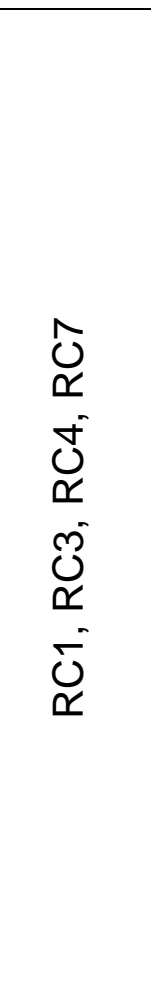 } & P4 & \multirow{6}{*}{$\begin{array}{l}\stackrel{N}{F} \\
\stackrel{0}{F} \\
\dot{\sigma} \\
\stackrel{F}{\vdash}\end{array}$} \\
\hline A17 & $\begin{array}{l}\text { Desenvolvimento do modelo de } \\
\text { referência, versão } 3.0\end{array}$ & & P4 & \\
\hline A22 & $\begin{array}{l}\text { Estratégia para o } \\
\text { desenvolvimento do modelo de } \\
\text { referência, versão sistêmica }\end{array}$ & & P3 & \\
\hline A23 & $\begin{array}{l}\text { Elaboração do modelo de } \\
\text { referência, versão sistêmica }\end{array}$ & & P4 & \\
\hline A24 & $\begin{array}{l}\text { Elaboração da versão para teste } \\
\text { do modelo de referência, versão } \\
\text { sistêmica }\end{array}$ & & P5 & \\
\hline A25 & $\begin{array}{l}\text { Validação do modelo de } \\
\text { referência, versão sistêmica. }\end{array}$ & & P6 & \\
\hline
\end{tabular}

Quadro 36 Atividades, Regras, Práticas e Técnicas do MFMOD para o SPB

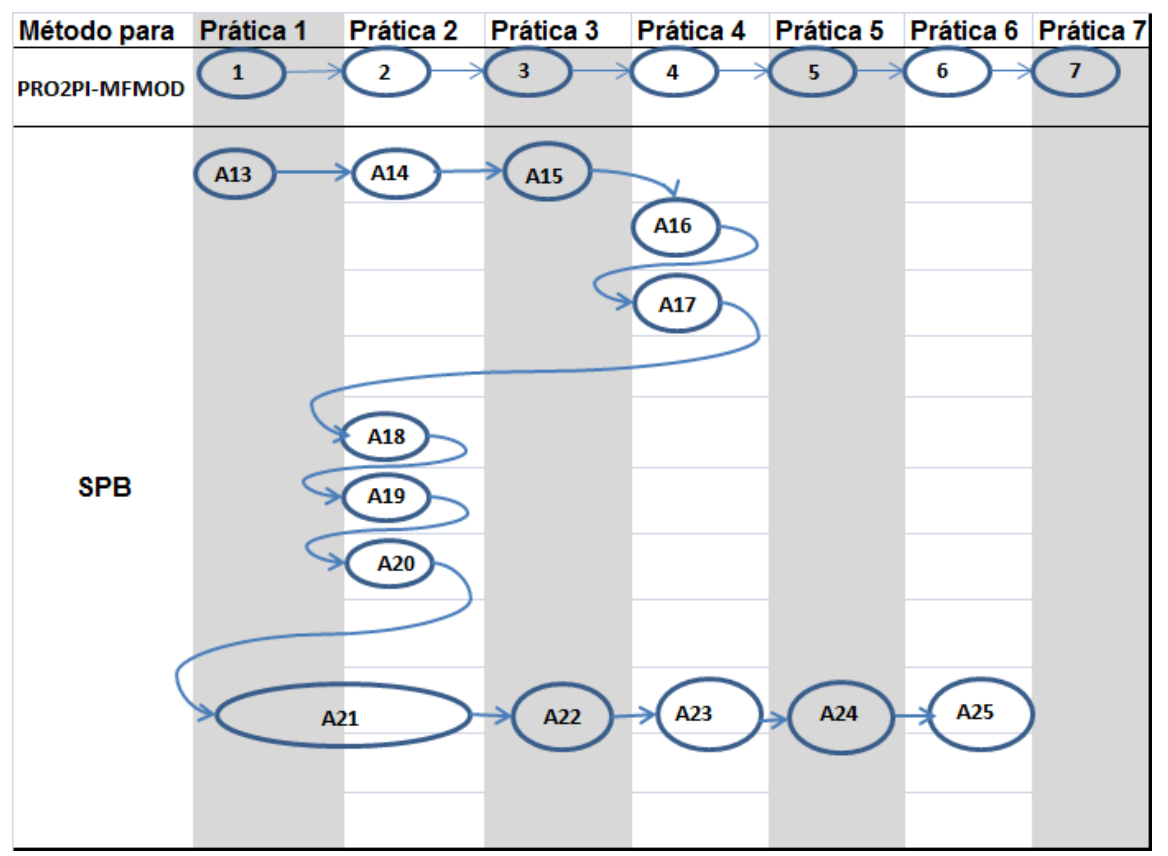

Quadro 37 Práticas e atividades do PRO2PI-MFMOD para o SPB - 03 
O Quadro 36 apresenta as atividades desse método definidas e executadas e as relaciona com as práticas do PRO2PI-MFMOD e com aplicações das regras de customização. O Quadro 37 apresenta a relação das atividades com os elementos do framework PRO2PI-MFMOD. O quadro foi elaborado a partir do Quadro 34 e do Quadro 35, que são, respectivamente, quadros com as atividades realizadas durante a aplicação da metodologia SSM e tabela com as atividades relacionadas com a construção e a evolução dos modelos de referência (versões, 2.0, 3.0 e sistêmica).

Assim termina a aplicação da segunda fase do PRO2PI-MFMOD, com duas atividades na prática sequencial $\mathrm{P} 1$, quatro na prática $\mathrm{P} 2$, duas em $\mathrm{P} 3$, três em $\mathrm{P} 4$, uma em P5 e uma em P6,0 que caracteriza que, após as definições iniciais como domínio e escopo, as atividades avançam para as próximas práticas, dando continuação à construção do modelo.

\subsubsection{Conclusão do Momento de Pesquisa 02 -Fase 02}

Os resultados da aplicação das metodologias ao longo dessa fase estão descritos no Quadro 38.

\begin{tabular}{|c|c|}
\hline Momento 02 & Fase 02 \\
\hline Período & Ano de 2009 \\
\hline $\begin{array}{l}\text { Fase de } \\
\text { Pesquisa }\end{array}$ & Fase 02- Aplicando a SSM e o PRO2PI-MFMOD \\
\hline $\begin{array}{l}\text { Critério de } \\
\text { avaliação }\end{array}$ & $\begin{array}{l}\text { 1.Situação de interesse definida } \\
\text { 2. Variáveis-chave } \\
\text { 3. Mapa sistêmico } \\
\text { 4. Modelos } \\
\text { 5. Cenários e modelagem computacional } \\
\text { 6. Criação de micro mundos com modelagem computacional } \\
\text { 7. Plano de desenvolvimento sistêmico } \\
\text { 8. Estratégia de desenvolvimento do Modelo de Referência } \\
\text { 2.0 definida; desenvolvimento do Modelo de Referência } 2.0 \text {; } \\
\text { estratégia de desenvolvimento do Modelo de Referência } 3.0 \\
\text { definida; desenvolvimento do Modelo de Referência } 3.0\end{array}$ \\
\hline
\end{tabular}




\begin{tabular}{|c|l|}
\hline $\begin{array}{c}\text { Momento } 02 \\
\text { Atividades } \\
\text { executadas }\end{array}$ & Fase $\mathbf{0 2}$ \\
\hline Avaliação & $\begin{array}{l}\text { Produtos de cada ciclo finalizados e apropriados pela } \\
\text { comunidade do SPB. }\end{array}$ \\
\hline $\begin{array}{c}\text { Melhoria e } \\
\text { aprendizagem }\end{array}$ & $\begin{array}{l}\text { Os componentes que serão utilizados para a construção do } \\
\text { entre eles. Nessa fase foi possível aumentar a granularidade } \\
\text { dos componentes do ecossistema, bem como entender como } \\
\text { se dá o aprendizado em seu interior. }\end{array}$ \\
\hline
\end{tabular}

Quadro 38 Resumo da Fase 02

\subsubsection{MOMENTO DE PESQUISA 02 - FASE 03 - OS MODELOS DE REFERÊNCIA}

Nesta fase são detalhadas as atividades relacionadas com a construção do modelo de referência. Os elementos utilizados para o detalhamento estão na seção 5.3.2, no Quadro 36 e no Quadro 37. São a seguir detalhadas as atividades A16, A17, A22, A23, A24 e A25.

\subsubsection{Atividade 16 -Projeto de Modelo - Níveis de Maturidade versão 2}

O modelo de referência do Ecossistema SPB é construído para permitir que um novo usuário consiga formar uma visão integrada dos diversos elementos que o compõem, bem como situar-se em relação a cada uma das dimensões associadas. Nesse sentido, os delineamentos do propósito, da visão e do modelo de referência complementam-se. Além da utilidade anteriormente apontada, é sobre o modelo de referência que são estruturados os níveis de maturidade e o método de avaliação que vão auxiliar na melhoria e na evolução do SPB.

A partir dos resultados da aplicação do método sistêmico, desenhou-se o modelo resultante, entendendo o SPB como uma rede que responde a processos cíclicos. Com esta perspectiva, O SPB foi interpretado em três camadas que buscam expressar os principais ciclos que o compõem. O modelo não é estático. $O$ entendimento das características de cada camada e de sua interação com as demais apenas auxilia a compreensão de um todo complexo e que permite sua avaliação e evolução. 
Para a construção do modelo de referência busca-se o entendimento por camadas e a compreensão das relações entre elas, sendo que as camadas mais externas refletem as mais internas. As camadas externas, por sua vez, também retroalimentam e influenciam as camadas mais internas. $E$ todas interagem e promovem mudanças entre si. Portanto, trata-se de um sistema dinâmico e complexo, que evolui e que tem padrões de auto-organização.

O modelo descrito decorre de observações feitas ao longo do ano de 2009. Nos anos posteriores, será natural a mudança na estrutura e mesmo na conceituação de cada camada. No futuro, por exemplo, a camada de infraestrutura pode ser composta por estruturas de rede e de recursos humanos diferentes das de 2009. E mesmo a conceituação do significado da infraestrutura do SPB pode sofrer reformulações.

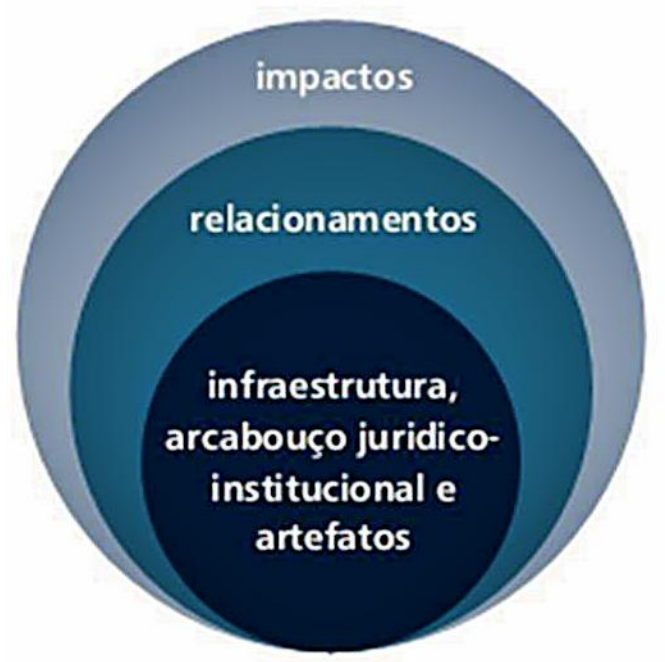

Figura 49 Modelo de referência do Ecossistema SPB

A Figura 49 ilustra a versão 2.0 do modelo de referência.Essa versão é construída considerando os dados e informações gerados e coletados durante a aplicação da SSM. Existem diferenças entre a versão 1.0 (Figura 37) e a versão 2.0 (Figura 49). As camadas acima da camada de componentes da versão 1.0 são difusas. Não especificam os componentes que fazem parte delas. Apresentam apenas uma visão da natureza dos seus componentes.

Na versão 2.0, há uma definição mais concreta das camadas do ecossistema. Houve um aprendizado sobre esse ecossistema, proporcionado pela aplicação da metodologia SSM. Agora é possível definir uma camada básica, composta pelo 
arcabouço jurídico institucional, pela infraestrutura e pelos artefatos. Os artefatos, na versão 1.0, estavam alocados na camada de componentes, depois da aplicação da SSM,percebeu-se que eles são a razão de existir do ecossistema e que, portanto, devem estar na sua camada básica. A camada de relacionamento foi melhor definida e dela agora fazem parte as entidades e os atores do ecossistema. Com os dados coletados, foi possível definir nove tipos de atores. As entidades foram tratadas de forma agregada, como um conjunto. A camada de impactos começa a ser delineada. Até essa versão, de acordo com os dados coletados, fazem parte dela variáveis relacionadas a sete tipos de impacto. As camadas do ecossistema são detalhadas a seguir.

A Infraestrutura, arcabouço jurídico-institucional e artefatos, - compreende os elementos que sustentam a operacionalização do conceito de Software Público Brasileiro. São eles que dão forma e regulam os processos básicos, que definem os limites e o fluxo de interação do SPB. Os elementos desta camada estão agrupados em três tipos:

1. Arcabouço jurídico-institucional - diz respeito ao aparato legal que suporta o conceito de software como bem público (instruções normativas, decretos e outros). Ao criar o conceito de software público, a SLTI construiu um espaço institucional, as regras e mesmo os valores que orientaram e fizeram com que a instalação do ambiente virtual se tornasse uma instanciação do conceito do SPB. Este arcabouço continua evoluindo e trazendo novos elementos que são decorrentes do próprio funcionamento e no amadurecimento do ecossistema. $O$ conceito de software público está em evolução, incorporando novas dimensões de modo a se tornar efetivo para atingir os objetivos para os quais foi criado. São exemplos dessa evolução os aspectos relativos ao direito da imagem vinculados ao software, as questões de propriedade intelectual vinculadas à produção colaborativa de modelos conceituais, de guias de qualidade, de tecnologia de teste, de marca vinculada ao software e outros e os aspectos de produção de software em ambientes virtuais e públicos. Nestes elementos estão incorporados e formalizados os objetivos do Software Público Brasileiro, bem como os valores que norteiam o seu crescimento. 
2. Infraestrutura - diz respeito à infraestrutura das TICs que suportam o SPB, desde as plataforma de hardware e de software que o abrigam, até os canais de acesso, a segurança e a interoperabilidade, entre outros itens. Atualmente, essa estrutura pode ser resumida pelo uso da ferramenta OpenAcs, suportada pelo banco de dados PostgreSQL, sobre uma plataforma Debian GNU/Linux, canais com largura de banda de 6MB. Estes elementos de infraestrutura, não são elementos estáticos. A infraestrutura de TICs de um ecossistema, deve ser aberta e flexível, de modo a permitir sua reconfiguração pelos participantes do ecossistema. Deve também incorporar novas tecnologias que facilitem a interatividade, a produção de conteúdo digital e a apropriação dos conhecimentos. A utilização de plataformas e ferramentas livres atende não somente as necessidades operacionais (custos, não aprisionamento e outros), mas também os processos de geração e atualização tecnológica que estão imbricados com essas ferramentas. Ou seja, ferramentas criadas e mantidas por comunidades virtuais, que estimulam o compartilhamento e a aprendizagem coletiva, são mais aderentes e alinhadas com a infraestrutura do SPB, do que ferramentas proprietárias. Isto não exclui estas últimas, mas entende-se que, para se ter uma evolução contínua do SPB, deve-se ter a possibilidade de que sua própria comunidade atue na infraestrutura que o suporta. A infraestrutura, assim como a dimensão anterior, também influencia os limites de atuação do SPB. Por exemplo, os limites físicos de acesso e, as ferramentas de gestão do conhecimento têm impacto direto na atuação da comunidade.

3. Artefatos - são, simultaneamente, os elementos que tanto promovem a interação entre os atores e as entidades, quanto expressam concretamente o resultado de sua interação. Na sua origem, o SPB só possuía o artefato software. A liberação de um software no Portal SPB é que dava origem a uma comunidade em seu entorno. No desenvolvimento do SPB, outros tipos de artefatos foram surgindo, como: documentos conceituais, guias de testes de software, guias de qualidade de processo e outros. Atualmente o portal contém 62 artefatos. São os artefatos os elementos que registram os conhecimentos produzidos no âmbito das comunidades. A sua natureza (software, diretrizes) define o processo de construção dos conhecimentos. Para soluções de software, o processo se dá através da produção de código (linhas de programação), que, 
após avaliação, pode ser incorporado ao código-fonte. Caso o artefato seja uma diretriz, pode ser liberada uma versão preliminar sua para consulta às comunidades e posterior seleção e agregação das contribuições (consulta pública).

4. Relacionamentos - esta camada compreende os elementos que conduzem as ações do SPB. São os membros da comunidade virtual que participam do Portal $\mathrm{SPB}$, em seus mais diversos âmbitos. É através da sua interação que o conhecimento é construído colaborativa e interativamente. Esses elementos também promovem a disseminação do SPB, através da sua conexão com outros âmbitos (empresas, governo e outros) e outras redes. Os elementos desta camada estão agrupados em dois tipos:

a. Atores - são os participantes individualizados das comunidades SPB. Apesar de pertencerem a diferentes instituições, ao participar da comunidade SPB, o fazem assumindo um ou mais papéis, por vezes distintos de sua atuação nas instituições de origem. Há uma extensa gama de papéis que podem ser assumidos por esses atores. Por vezes, estes papéis se sobrepõem. Os principais papéis identificados são apresentados a seguir.

I. Acadêmicos - são pesquisadores, alunos e outros que participam das comunidades virtuais com 0 intuito de colher informações e buscar conhecimentos que possam ser utilizados em trabalhos acadêmicos;

II. Coordenadores de Comunidade SPB - são os responsáveis pela condução das comunidades virtuais do SPB. Esses atores são os pontos focais de cada comunidade, responsáveis pela gestão do conhecimento nas comunidades, pela evolução dos artefatos e pelo desempenho da sua comunidade.

III. Comunidade de Software Livre - são usuários, e desenvolvedores que têm forte ligação com o movimento do software livre. Geralmente, são líderes de outras comunidades e formadores de opinião. 
IV. Desenvolvedores - são técnicos, muitas vezes sem educação formal na área de Tecnologia da Informação, que contribuem com o desenvolvimento do software. Propõem melhorias por meio de pequenos trechos de código que são submetidos às comunidades e ao seus coordenadores.

V. Fomentadores - são os atores que viabilizam recursos para o desenvolvimento do SPB, não somente financeiros, mas também econômicos e humanos.

VI. Governo - são atores que participam das diferentes esferas de atuação governamental: policy makers, políticos, Secretários de Estado, tecno-políticos e outros.

VII. Parceiros - são atores que apoiam o SPB, mas não aportam recursos financeiros. Apoiam o conceito, disseminam as ideias, dão apoio logístico e outros tipos.

VIII. Prestadores de Serviço - são atores que estão cadastrados no Mercado Público Virtual, oferecendo serviços diversos relacionados às ferramentas de software público. Podem ser pessoas físicas ou jurídicas.

IX. Usuário final - é o ator que participa do Portal SPB, de maneiras distintas: integrando as comunidades ou fóruns, fazendo download de soluções, implantando soluções, entre outras.

b. Entidades - são as instituições que dão suporte à existência do SPB. São elas que construíram e continuam construindo o arcabouço jurídicoinstitucional do SPB, que propiciam a existência de uma infraestrutura para o Portal SPB, que buscam e investem recursos para sua manutenção e seu desenvolvimento.

5. Impactos - é a camada que diz respeito aos impactos que o SPB gera interna e externamente ao seu ecossistema. Os principais impactos observados atualmente no SPB são:

a. Melhoria da gestão governamental a partir da introdução de novas ferramentas e processos - a disponibilização de ferramentas de software sob 
licença livre, possibilita às instituições governamentais alternativas à informatização de seus processos. Também possibilita 0 acesso a novas tecnologias e novos processos embutidos nestas ferramentas. A variedade de aplicações em camadas diversas, permite um uso amplo das ferramentas. Por outro lado, a possibilidade de participação em comunidades virtuais dos usuários da ferramenta abre a oportunidade de um processo mais intenso e rápido de aprendizagem dessa ferramenta;

b. Redução de custos de informatização, decorrentes da utilização de software do SPB - espera-se que, em certos casos, a utilização do software público contribua para diminuir os custos com informatização;

c. Capacitação tecnológica em TICs - a formação de comunidades virtuais, de maneira espontânea (emergente) em torno das ferramentas de software, leva à ocorrência de interações diversas para solucionar problemas (bugs) e dúvidas de uso, criar novas funcionalidades e buscar a evolução da solução. Essas interações levam a um processo de capacitação (learning by using), no qual o coordenador da comunidade tem um papel central, tanto solucionando questões como estimulando o surgimento de novas reflexões;

d. Inovações tecnológicas em produtos - os resultados das contribuições no código-fonte das soluções de software (patches e commits) levam a inovações tecnológicas, em sua maioria marginais, mas com algumas delas modificando radicalmente a solução. Esse processo de melhoria, leva ao alongamento do ciclo de vida das soluções, retardando sua obsolescência;

e. Geração de novas oportunidades profissionais e aumento da empregabilidade - a participação em comunidades virtuais amplia significativamente a rede de contatos dos desenvolvedores e usuários. A participação dos desenvolvedores, produzindo novos códigos, coloca-os em evidência, na proporção direta da qualidade do código desenvolvido. E, por consequência, é comum esses profissionais serem contatados para trabalhos ou mesmo para oportunidades de emprego. É também comum que vários desses profissionais se cadastrem no Mercado Público Virtual como fornecedores de serviços, ampliando as possibilidades de geração de novas oportunidades profissionais e de geração de renda; 
f. Geração de negócios - o software disponibilizado no SPB também gera negócios para empresas que direciona energia para o seu aprendizado e melhoramento. Algumas empresas privadas já oferecem serviços de implantação das soluções no Mercado Público Virtual. Porém, acredita-se que o número desses negócios possa ser bastante significativo, pois ainda há poucas informações a respeito do uso que essas empresas têm feito das soluções SPB.

g. Produção de conteúdo científico-tecnológico: papers, livros e outros - desde a sua criação, o Ecossistema SPB tem despertado a atenção de diversos pesquisadores e, profissionais da mídia, interessados no caráter inédito da experiência. Diversos artigos, científicos e não científicos, foram publicados, assim como alguns livros estão sendo escritos e publicados para o registro dessa experiência.

A configuração apresentada anteriormente foi mais uma vez analisada considerando os dados coletados com a SSM. Como exposto na seção 5.3.2.1, no ciclo 2 da SSM foram obtidas as variáveis-chave ou críticas do SPB e, a partir delas, foi estabelecida uma relação de causalidade, e tornou possível obter o desenho do mapa do ecossistema. O mapa sistêmico está representado na Figura 50. Da leitura do mapa, com suas variáveis e relacionamentos, é possível identificar agrupamentos de variáveis em ciclos. Cada ciclo, formado por um conjunto de variáveis e laços, apresenta uma característica e um significado.

A camada mais externa, na cor verde, diz respeito às variáveis críticas focadas em aspectos da infraestrutura e dos artefatos. A camada interna na cor amarela, diz respeito aos aspectos de relacionamento do SPB com seu entorno (divulgação na mídia, formação de parcerias) e a camada de cor rosa diz respeito a aspectos relacionados aos impactos obtidos pelo SPB (capacitação, negócios). Dessa forma, foram inicialmente identificados três ciclos de aprendizados no Ecossistema SPB.

Observou-se também que os modelos mentais, as variáveis críticas e o direcionamento das ações se davam em temas específicos, relacionados com etapas de evolução e amadurecimento do SPB. A partir da resolução de determinados gargalos ou da definição de novas metas, o foco de atenção e do 
desenvolvimento de atividades mudou, não eliminando, porém, a atenção sobre temas anteriores.

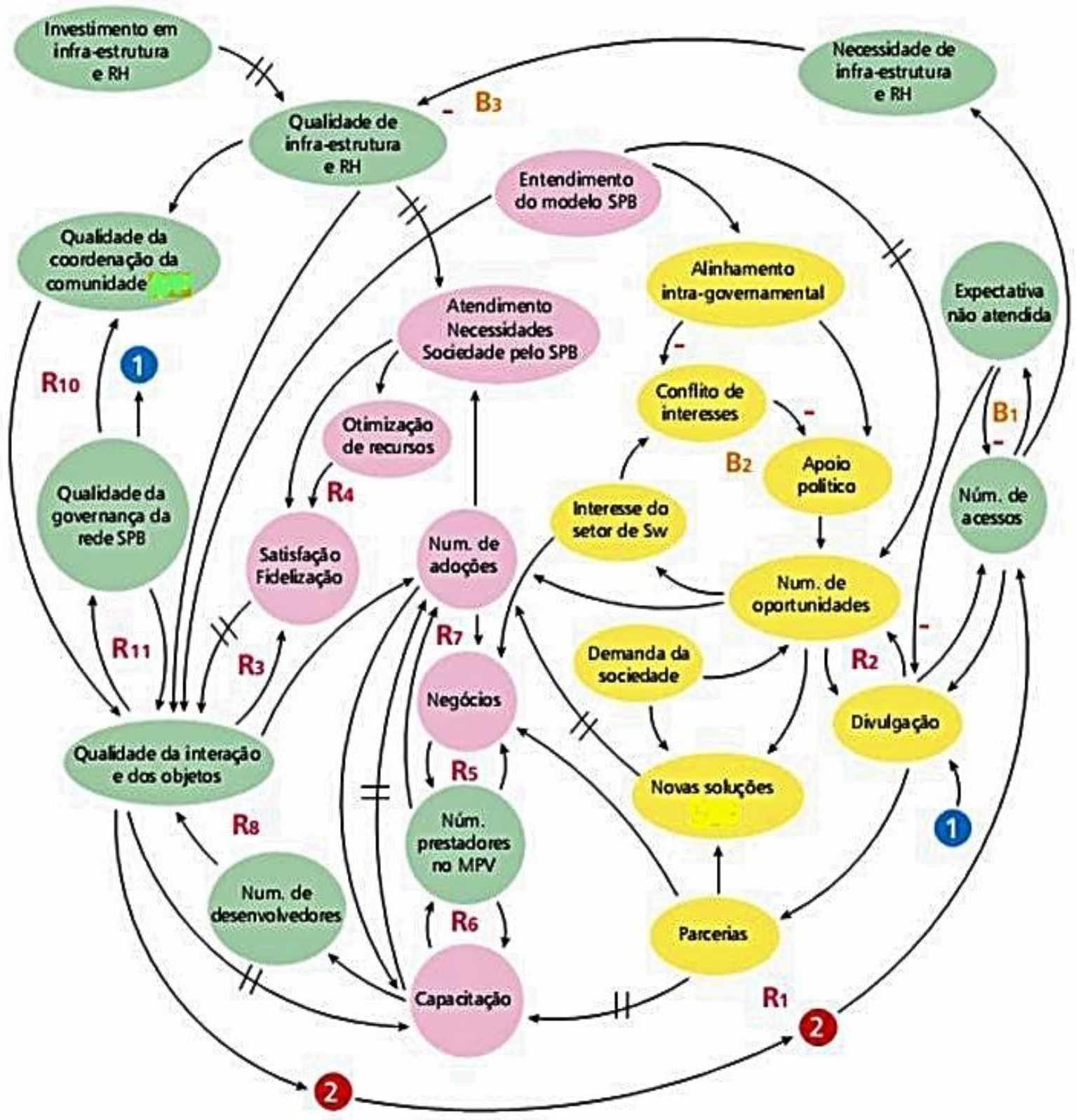

Figura 50 Agrupamentos de variáveis críticas do SPB

Os ciclos ocorrem em uma sequência, porém eles não são desconectados ou descontínuos. O primeiro ciclo continua a ocorrer no segundo ciclo, mas em uma intensidade menor. E o terceiro ciclo ocorre no primeiro e no segundo ciclos, mas não é o foco do aprendizado da maioria das comunidades do SPB. Foi acrescentado um quarto ciclo, que não estava presente no mapa sistêmico. É o ciclo 4, que deverá conter aprendizagens sobre o crescimento sustentado do SPB, 
conforme define o enunciado do propósito do ecossistema (seção 5.2). A Figura 51 expressa estas considerações.

Os ciclos não estão separados, mas inseridos em círculos de causalidade. Eles estão presentes em cada comunidade ou, grupo de trabalho, bem como no ecossistema como um todo. Os ciclos de aprendizagem são inspirados nas contribuições teóricas de Peter Senge (seção 2.3.4.2). Assim, considerando a experiência do SPB, foram verificados quatro ciclos de aprendizagem:

\section{I. aprendizagem com os elementos II. aprendizagem com as relações estruturais e artefatos do SPB do ecossistema}

\section{III. aprendizagem dos impactos e IV. aprendizagens do crescimento padrões de comportamento do SPB sustentado do SPB.}

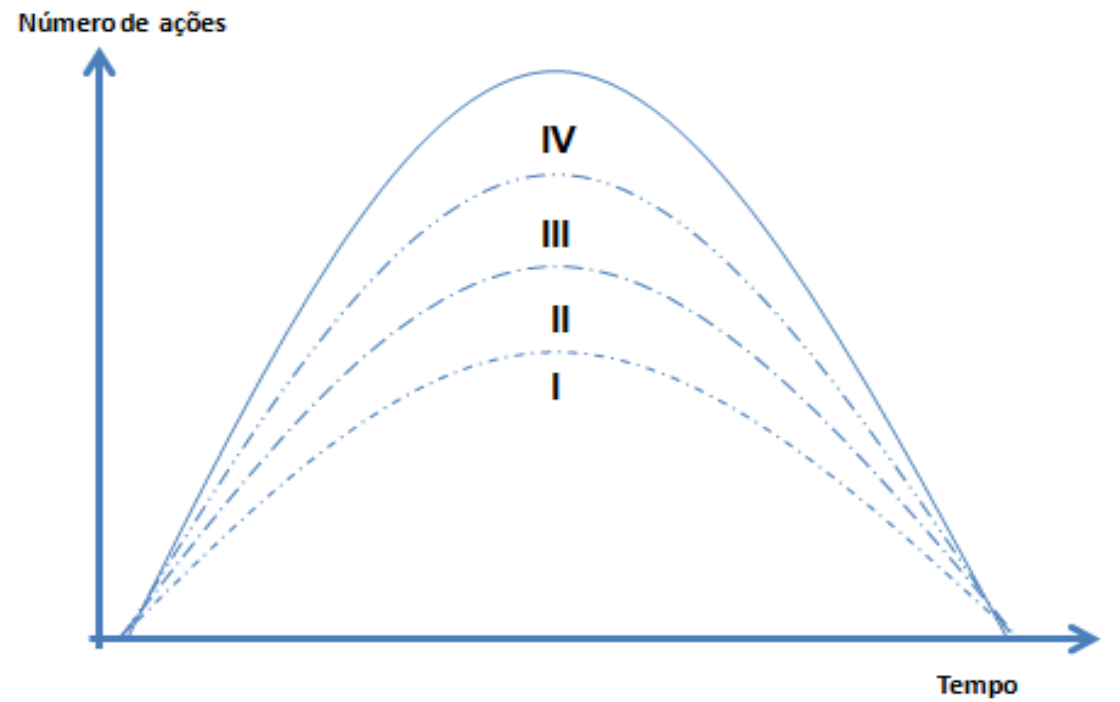

Figura 51 Ciclos de aprendizado do SPB

O primeiro ciclo diz respeito à aprendizagem com a infraestrutura e as rotinas básicas de funcionamento do portal. Ele está relacionado com a eficiência e a, segurança do ecossistema e com a estabilidade da estrutura de TI. Ele abriga também a compreensão profunda do ecossistema, o aperfeiçoamento de rotinas de cadastramento, as contribuições para o software e para a gestão de conflitos. Há também muita experimentação dos limites das ferramentas da plataforma e existem muitas melhorias nas rotinas básicas, causada pelas contribuições dos participantes das comunidades. Neste ciclo, os focos são a qualidade do funcionamento do portal 
e a qualidade dos artefatos (software, guias, manuais). Os artefatos são os produtos do SPB. Até agora, os artefatos principais são as soluções de software. As contribuições para os artefatos se dão, majoritariamente, por meio das comunidades virtuais. Existem esforços para analisar e melhorar os artefatos, como é característico das comunidades de software livre. Esforços para melhorar a qualidade, a usabilidade, as atividades e o apoio são feitos. Além de novos artefatos de software são também gerados guias de qualidade, diretrizes de interoperabilidade e, novos modelos de negócio. Como mencionado anteriormente, neste ciclo já se percebe uma conscientização das relações do ecossistema ou o comportamento do SPB como um todo.

O segundo ciclo tem como focos a compreensão das interações do SPB com seu entorno, sua divulgação, a conquista de novas parcerias, a interação com outros atores. Os atores são os participantes individuais do portal. As entidades são as organizações que dão suporte à existência do SPB ou os parceiros que participam do seu desenvolvimento. Depois de conseguir mais estabilidade no nível operacional, o foco concentra-se em ações para atrair novas entidades e, novos atores, para entender o perfil, as necessidades e as motivações dos atores e para a busca de novas parcerias. Há um movimento para expandir as fronteiras do ecossistema, unindo esforços com as universidades, e com outros ministérios. Nesta fase, também são criados spin-offs do ecossistema, ou seja, comunidades virtuais específicas ou outros ambientes dentro do portal para atender demandas da sociedade. Este foi o caso do $4 \mathrm{CMBr}$ (grupo de interesse criado para atender a necessidade de ferramentas automatizadas de gestão para pequenas prefeituras), do Mercado Virtual (para fornecer serviços relacionados aos software SPB) e do $5 \mathrm{CQualiBr}^{14}$ (para criar e melhorar métodos e metodologia de qualidade para os artefatos do portal). Este ciclo também expressa a maturidade de relacionamentos do ecossistema. Devido ao crescimento da participação e das parcerias, as relações dentro do ecossistema tornam-se mais complexas. Neste ciclo, há a aprendizagem sobre a rede de relacionamentos, sua intensidade e sua linearidade, ou não linearidade, e a ampliação de relacionamentos. Neste ciclo, o foco é melhorar a qualidade dos relacionamentos

${ }^{14}$ O 5CQualiBr é um spin off do Projeto Modelo de Referência do SPB. 
Com a infraestrutura mais estável, a rede de parcerias ampliada, e a divulgação de suas potencialidades, o foco se desloca para o entendimento mais amplo do ecossistema, seus resultados, impactos, padrões de comportamento e evolução. 0 aumento da diversidade de atores e das variáveis que devem ser gerenciadas provoca um aumento da complexidade do sistema e entender e gerenciar essas variáveis passa a ser fundamental para a continuidade do ecossistema. A compreensão das potencialidades do ecossistema amplia-se e ocorre um processo de expansão da sua identidade. O foco do terceiro ciclo é o monitoramento de seus resultados, de suas variáveis críticas, de seus impactos, bem como ampliação da compreensão de sua dinâmica de crescimento, seus riscos e potencialidades. $O$ ciclo envolve a aprendizagem da inteligência sistêmica do ecossistema. São feitos esforços para mapear as variáveis críticas e padrões de comportamento. O mapa indica com mais precisão, os pontos nos quais uma ação pode causar melhores impactos para o sistema ou, pelo menos, os pontos que promovem o crescimento minimizando os danos ao sistema. São pontos de alavancagem. Podem, então, ser realizados estudos de cenários e simulações computacionais, que oferecem reflexões sobre as melhores soluções a serem adotadas e os domínios estratégicos a considerar.

O quarto ciclo está relacionado à visão de longo prazo do ecossistema e ao seu crescimento em bases sustentáveis. O conhecimento da própria dinâmica de crescimento, das ameaças e das potencialidades, amplia a capacidade do ecossistema como instrumento de política pública. Neste ciclo, são realizadas ações para consolidar a ação do ecossistema e torná-la sustentável. O ecossistema passa a influir e atuar em conjunto com instrumentos de política pública, a direcionar ações para a autonomia orçamentária, a construir um modelo de gestão com maior representatividade da sociedade e a, replicar a experiência do SPB em outros países e em outras áreas temáticas. Analisando-se a evolução do ecossistema, percebe-se que, para os ciclos ocorrerem, há uma condição inicial, que é a constituição do arcabouço conceitual, legal e organizacional do ecossistema, o que se deu, no caso do SPB, a partir de um arranjo de atores específicos que implementaram a infraestrutura de suporte para o projeto. Essa estrutura foi criada e continua a manter o ambiente que permite que ocorram as interações no âmbito do SPB. O peso dos atores também é relevante. O campeão do projeto, o ator que 
une capacidade, conexões e conhecimentos para viabilizá-la e fazê-lo acontecer é essencial. O momento que antecede os ciclos de aprendizado é fundamental e nele também ocorrem aprendizados, porém esse momento se distingue dos demais pelo grau de incertezas presente, pela intensidade e instabilidade das definições. Portanto, não é ainda um ciclo de aprendizado, mas a construção de condições para que os ciclos possam ocorrer.

Os ciclos são recorrentes. A partir do quarto ciclo, pode-se retomar o primeiro ciclo, porém em outro estágio. Assim, cada conjunto de ciclos contribui para a evolução da estrutura do SPB, melhora a sua visão estratégica e incorpora novas variáveis. É um caminho natural olhar esses ciclos como um processo de maturação, que pode indicar uma base para o estabelecimento de níveis de maturidade para o ecossistema.
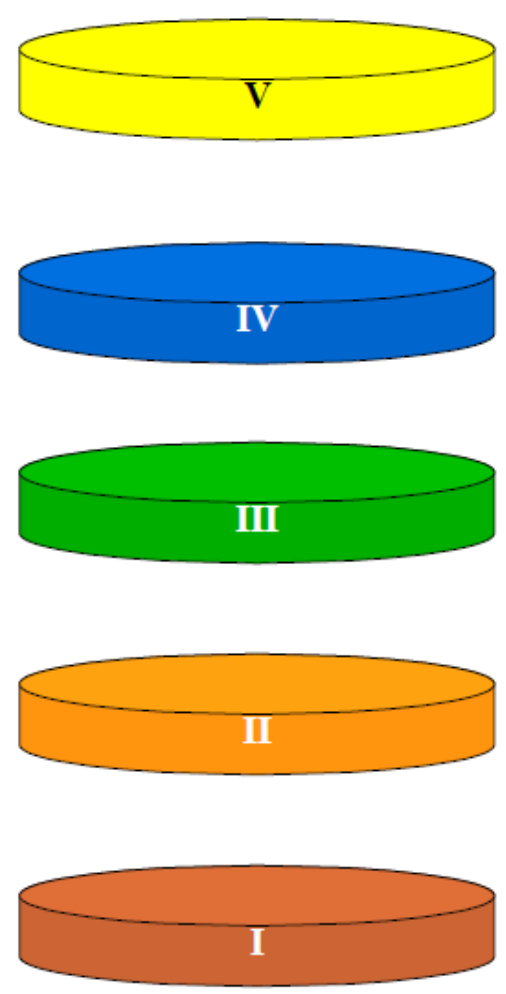

Nível 5 - maturidade institucional, autonomia, replicação do modelo em outras áreas temáticas, insumo para políticas públicas

Nível 4 - monitoramento estruturado dos resultados, impactos crescentes disseminados na sociedade, planejamento em rede estruturado.

Nível 3 - parcerias definidas e apoios formalizados. Apoios informais identificáveis. Projeção na mídia, expansão e disseminação do modelo.

Nível 2 - arcabouço jurídico-institucional definido, infraestrutura mínima operante, regras e diretrizes para qualidade dos artefatos

Nível 1 - início - conceito definido, apoio institucional mínimo para desenvolvimento do projeto, existência do campeão do projeto

Figura 52 Níveis de maturidade do SPB

Assim, a formulação dos níveis de maturidade do SPB se deu a partir da percepção dos ciclos de aprendizado. Essa percepção foi ratificada após a aplicação e a análise do mapa sistêmico. Foi então realizada uma primeira tentativa de definir os níveis de maturidade, utilizando os quatro ciclos de aprendizado identificados. A esses quatro níveis foi adicionado um quinto nível, inferior aos demais, que diz 
respeito ao estágio de formação do ecossistema. A partir das considerações, com as informações proporcionadas pelo mapa sistêmico, foi então formulado um modelo de maturidade com cinco níveis. Esses níveis são parte da versão 2.0 do modelo de referência. A Figura $\mathbf{5 2}$ ilustra os níveis de maturidade e os atributos relacionados para cada um desses níveis.

O resultado da alocação dos atributos do ecossistema a cada nível de maturidade está mostrado no Quadro 39. 


\begin{tabular}{|c|c|c|}
\hline & Variável & Descrição \\
\hline \multirow{6}{*}{$\frac{\pi}{\grave{z}}$} & Definição conceitual & $\begin{array}{l}\text { Indica a existência de um arcabouço conceitual que orienta o desenvolvimento do } \\
\text { ecossistema. Indica também a precisão com a qual esse arcabouço é definido. No caso } \\
\text { do SPB, esse arcabouço define o software como bem público. }\end{array}$ \\
\hline & Arcabouço Jurídico & $\begin{array}{l}\text { Indica a existência de um arcabouço jurídico que dá suporte ao arcabouço conceitual. No } \\
\text { caso do SPB, estabelece o sistema de licenciamento do software público, os deveres } \\
\text { das empresas que disponibilizam software no SPB, as instruções normativas que } \\
\text { definem o SPB, a regulamentação das marcas públicas e, as condições de entrada no } \\
\text { ecossistema. }\end{array}$ \\
\hline & Infraestrutura computacional & $\begin{array}{l}\text { Diz respeito à infraestrutura de suporte computacional do ecossistema: plataformas de } \\
\text { software, banda de transmissão, equipamentos. }\end{array}$ \\
\hline & Portal & $\begin{array}{l}\text { Diz respeito à existência e ao grau de sofisticação do portal, disponibilizado via Web, } \\
\text { que dá suporte ao ecossistema. }\end{array}$ \\
\hline & Recursos humanos de suporte & $\begin{array}{l}\text { Indica a quantidade e a qualidade dos recursos humanos que dão suporte ao } \\
\text { ecossistema. }\end{array}$ \\
\hline & Líder do projeto (campeão) & $\begin{array}{l}\text { Indica a existência de um líder do projeto e a sua capacidade de articulação, definida por } \\
\text { suas competências, conhecimentos e conexões. }\end{array}$ \\
\hline \multirow{4}{*}{$\frac{N}{\grave{Z}}$} & Número de acessos & $\begin{array}{l}\text { Indica o número de acessos do Portal SPB por visitantes, cadastrados e não } \\
\text { cadastrados. }\end{array}$ \\
\hline & Expectativas não atendidas & $\begin{array}{l}\text { Indica o número e a descrição das expectativas não atendidas dos visitantes do Portal } \\
\text { SPB. }\end{array}$ \\
\hline & $\begin{array}{l}\text { Necessidade de infraestrutura e } \\
\text { Recursos humanos }\end{array}$ & $\begin{array}{l}\text { Indica as necessidades quantitativas e qualitativas de infraestrutura e de } \mathrm{RH} \text { para o } \\
\text { funcionamento adequado do Portal SPB e para o atendimento às comunidades virtuais. }\end{array}$ \\
\hline & $\begin{array}{l}\text { Qualidade da infraestrutura e } \\
\text { recursos humanos }\end{array}$ & $\begin{array}{l}\text { Diz respeito à relação entre a qualificação existente da infraestrutura e de RH disponíveis } \\
\text { no portal e a qualificação mínima para a operação adequada do portal. }\end{array}$ \\
\hline
\end{tabular}




\begin{tabular}{|c|c|c|}
\hline & $\begin{array}{l}\text { Investimento em infraestrutura e } \\
\text { recursos humanos }\end{array}$ & $\begin{array}{l}\text { Indica o montante de recursos necessários para suprir a infraestrutura e o } \mathrm{RH} \text { do portal } \\
\text { de modo a tornar sua operação adequada. }\end{array}$ \\
\hline & $\begin{array}{l}\text { Qualidade da coordenação da } \\
\text { comunidade e de grupos de } \\
\text { interesse }\end{array}$ & $\begin{array}{l}\text { Indica a qualificação dos profissionais que compõem a coordenação das comunidades } \\
\text { virtuais e dos grupos de interesse, vis-à-vis as qualificações necessárias. }\end{array}$ \\
\hline & $\begin{array}{l}\text { Qualidade da governança do } \\
\text { ecossistema SPB }\end{array}$ & $\begin{array}{l}\text { Indica a qualidade da governança do Ecossistema SPB como um todo. Indica a } \\
\text { existência de monitoramento de resultados, planejamento estruturado, definição de } \\
\text { diretrizes e capacidade de resolução de conflitos. }\end{array}$ \\
\hline & $\begin{array}{l}\text { Qualidade da interação e dos } \\
\text { artefatos }\end{array}$ & $\begin{array}{l}\text { Indica a qualidade dos produtos e processos de software, das guias e dos documentos } \\
\text { disponibilizados no SPB. }\end{array}$ \\
\hline & Satisfação e fidelização & $\begin{array}{l}\text { Diz respeito ao grau de satisfação dos usuários do SPB com o portal, os artefatos, a } \\
\text { participação nas comunidades bem como ao seu retorno periódico e à sua participação } \\
\text { no portal. }\end{array}$ \\
\hline & Número de desenvolvedores & Indica o número de desenvolvedores de software participantes do portal. \\
\hline & $\begin{array}{l}\text { Novas soluções e Grupos de } \\
\text { Interesse }\end{array}$ & $\begin{array}{l}\text { Indica o número e o escopo das soluções de software disponibilizadas no portal, bem } \\
\text { como dos Grupos de Interesse participantes do portal. }\end{array}$ \\
\hline & Divulgação & $\begin{array}{l}\text { Diz respeito à caracterização das atividades de divulgação do SPB, em formatos (mails, } \\
\text { panfletos, livros), mídias (Internet, televisão) e eventos (seminários, congressos.) } \\
\text { diversos. }\end{array}$ \\
\hline$\frac{m}{\grave{D}}$ & Número de oportunidades & $\begin{array}{l}\text { Indica o número e a caracterização de oportunidades de negócios, profissionais, de } \\
\text { melhoria da gestão pública e de capacitação, proporcionadas pelo SPB. }\end{array}$ \\
\hline & Demanda da sociedade & $\begin{array}{l}\text { Indica o número e a caracterização dos diversos tipos de demandas da sociedade para o } \\
\text { SPB:- demandas por soluções, informações, contatos e serviços. }\end{array}$ \\
\hline
\end{tabular}




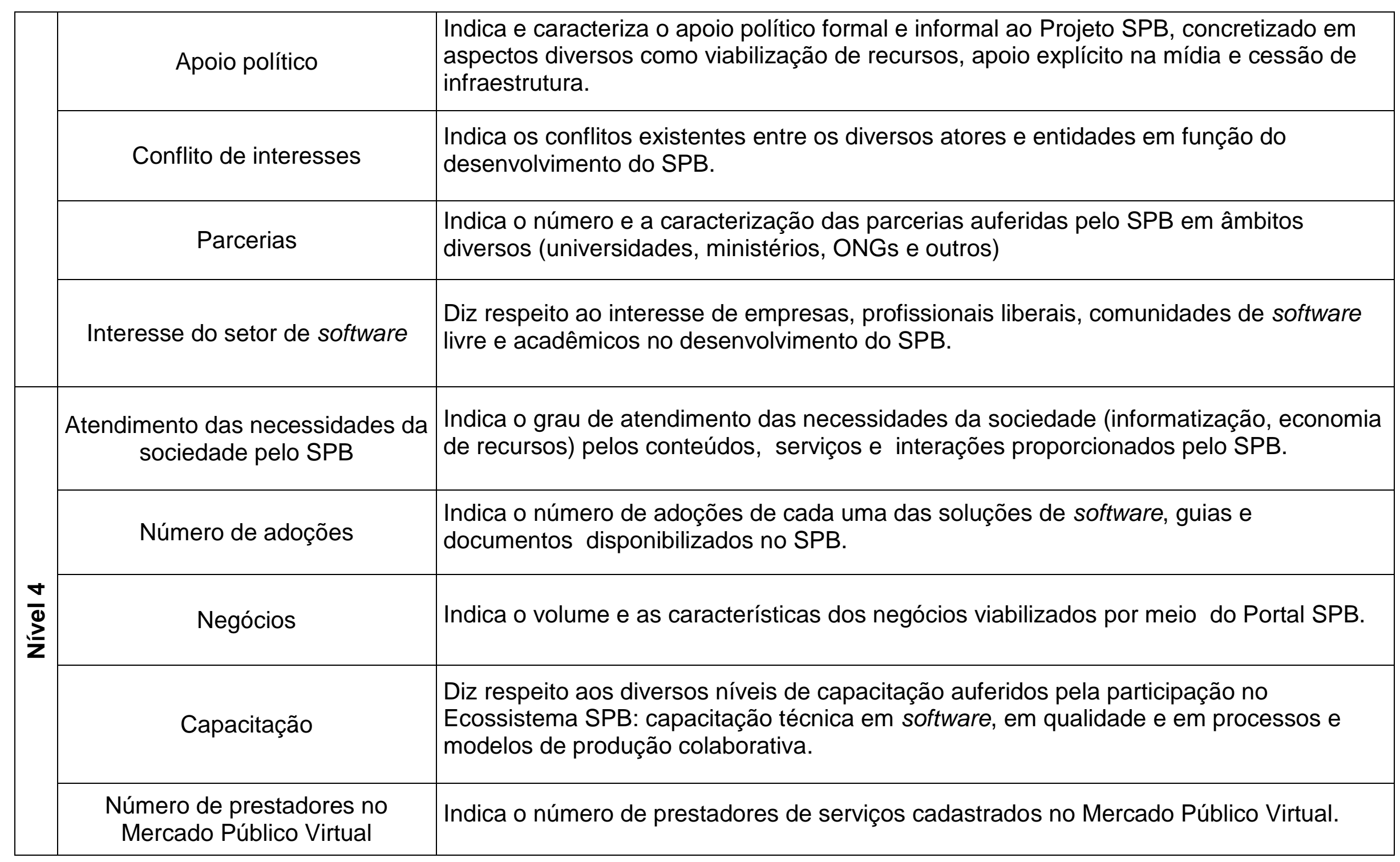




\begin{tabular}{|c|c|c|}
\hline & Otimização de recursos & $\begin{array}{l}\text { Indica o quanto uma entidade que adotou artefatos do SPB conseguiu otimizar seus } \\
\text { recursos. }\end{array}$ \\
\hline & Entendimento do modelo SPB & $\begin{array}{l}\text { Indica o grau de entendimento de sistemas complexos, modelos sistêmicos, redes } \\
\text { emergentes e outros operadores cognitivos relacionados ao modelo SPB. }\end{array}$ \\
\hline \multirow[b]{5}{*}{ 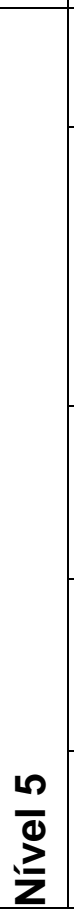 } & Replicação do SPB & $\begin{array}{l}\text { Indica o número e a caracterização de replicações do modelo SPB em outros países e } \\
\text { em, outras áreas temáticas. }\end{array}$ \\
\hline & Componente de políticas públicas & $\begin{array}{l}\text { Indica o uso do SPB como instrumento de políticas públicas, em níveis diversos como } \\
\text { rota alternativa para desenvolvimento ou aquisição de software por entidades públicas, } \\
\text { diminuição de custos operacionais de entidades públicas com TICs e melhoria da } \\
\text { qualidade da gestão governamental. }\end{array}$ \\
\hline & Autonomia orçamentária & $\begin{array}{l}\text { Indica o grau em que o orçamento mínimo necessário para a manutenção do SPB é } \\
\text { definido, disponibilizado e operacionalizado pelos órgãos gestores do SPB. }\end{array}$ \\
\hline & Gestão colegiada & $\begin{array}{l}\text { Indica a existência, a capacidade e o impacto de um órgão de gestão colegiada e o grau } \\
\text { de participação dos principais atores da sociedade nesse órgão. }\end{array}$ \\
\hline & Alinhamento intra-governamental & $\begin{array}{l}\text { Indica o quanto o Projeto SPB consegue se constituir em um projeto intra-governamental } \\
\text { de melhoria da gestão pública, que usa como base as ferramentas de } \mathrm{TI}\end{array}$ \\
\hline
\end{tabular}

Quadro 39 Variáveis para a definição dos níveis de maturidade do SPB 


\subsubsection{Atividade 17 - Projeto de Modelo - Níveis de maturidade versão 3}

$\mathrm{Na}$ seção anterior foi proposto um modelo para os níveis de maturidade, com base nos atributos cuja origem é o mapa sistêmico, e que representam o caminho percorrido pelo SPB até o presente momento. Os níveis têm como origem os ciclos de aprendizado identificados com a aplicação da metodologia do pensamento sistêmico. Esses níveis, na forma proposta não representam uma capacidade de mobilidade no sentido ascendente. Não é possível, a partir da leitura dos atributos e da denominação do nível, perceber qual é o vetor que eleva a maturidade de um determinado nível para o seu superior.

Neste momento da pesquisa, já é possível utilizar a analogia com os modelos de capacidade/maturidade desenvolvidos pelo SEI (família CMM) e pela ISO/IEC 15504 para Engenharia de software.

Porém, como a natureza dos ecossistemas digitais de produção de software revelou uma estrutura diferente das estrutura proposta pela Engenharia de software, foi realizada uma revisão no Modelo de Referência 2.0 à luz das analogias com os modelos convencionais. A apresentação do nível de maturidade, nessa terceira versão do modelo de referência se dá pelo significado do conjunto dos atributos que o compõem.

A terceira versão do modelo proposto é composta por cinco níveis sequenciais e cumulativos. No nível 1 de maturidade são criadas as condições e a infraestrutura básica para o ecossistema. No nível 2 as soluções desenvolvidas são disponibilizadas no ecossistema, as comunidades são criadas para manter e evoluir as soluções e estas são utilizadas. No nível 3 o processo de comunicação entre a demanda e a oferta é consolidado e soluções são induzidas pelas demandas. Nos níveis 4 e 5, ocorre a inovação social.

O nível I da versão 2.0 do modelo de referência não é mantido na versão 3.0 do modelo. O nível II da versão 2.0 torna-se o nível inicial na versão 3.0 ficando nele abrigados a infraestrutura básica, o arcabouço jurídico-institucional e os artefatos. Nesse nível, as soluções são disponibilizadas e existem comunidades que as suportam. O nível 2 da versão 3.0 tem como base o nível III da versão 2.0. Nesse nível - disponibilização de soluções - ocorrem, devido aos acordos institucionais, a projeção na mídia, a disseminação do ecossistema e, uma forte disponibilização de 
soluções de software nesse ecossistema. O nível 3 da versão 3.0 - indução de soluções - tem origem no nível IV da versão 2.0, que trata dos impactos do e no ecossistema. A partir da análise dos resultados e dos impactos é possível estabelecer uma estratégia para a indução de soluções no ecossistema que venham a contribuir para a melhoria dos indicadores de resultado e de impacto Os níveis 4 - inovação social e 5 - inovação social sistêmica têm origem no nível $V$ da versão 2.0, que trata da maturidade institucional, da geração de insumos para as políticas públicas e da autonomia do ecossistema. Nesses dois níveis da versão 3.0 ocorrem a inovação social e a inovação sistêmica, respectivamente. A versão 3.0 do modelo de referência, na sua forma final, está representado na Figura 53.

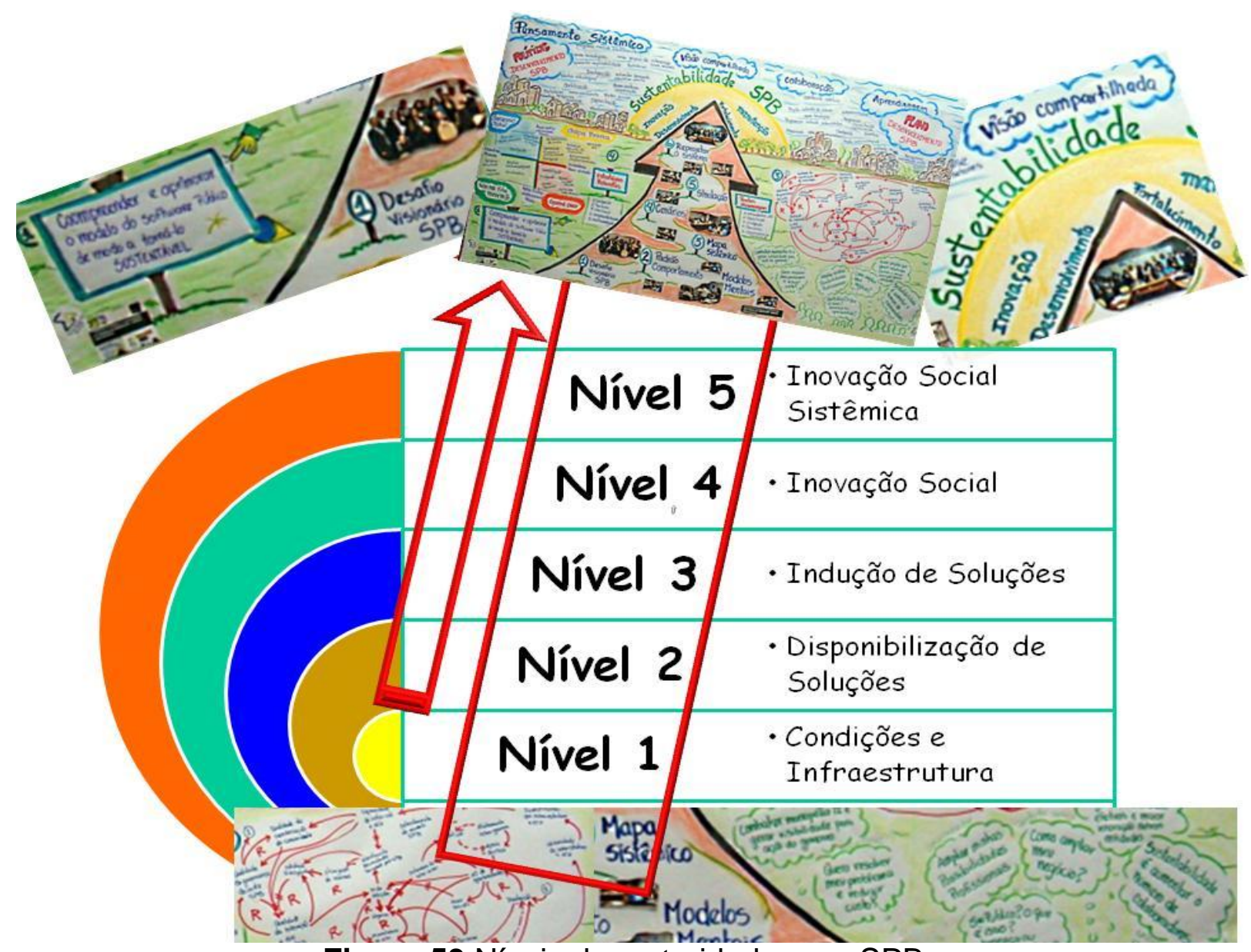

Figura 53 Níveis de maturidade para SPB

Fonte: (SALVIANO, 2010)

\subsubsection{Atividade 22 - Estratégia de Desenvolvimento - Nível Sistêmico}

Nessa atividade são estabelecidas as estratégias para o desenvolvimento da versão sistêmica do modelo de referência. Embora a versão anterior, mostrada na seção 5.3.3.2, apresente os níveis organizados a partir dos ciclos de aprendizado da 
versão 2.0, esses níveis não transmitem a ideia-força de movimento para a melhoria considerando os principais vetores de qualidade do sistema que emergiram durante a pesquisa em campo.

O Ecossistema SPB possui, tacitamente e explicitamente, como atributos: confiança, cooperação,comunidade, conhecimento e compartilhamento. Esses atributos definem os valores, a ética, o comportamento e os objetivos do ecossistema e são as ideias-força que o caracterizam. Essas ideias-força são conhecidas e compartilhadas no ecossistema. Um exemplo da presença constante dessas ideias pode ser observado na denominação dos Grupos de Interesse que compõem o ecossistema: esses grupos carregam em seus nomes as ideias-força: $4 \mathrm{CMBr}$ (comunidade, conhecimento, cooperação e compartilhamento) e 5CQualiBr (confiança, comunidade, conhecimento, cooperação e compartilhamento).

Essas ideias aparecem também na missão e na visão de futuro do ecossistema: missão - "Construir e aprimorar continuamente uma rede de produção colaborativa de conhecimento para desenvolver, em ambiente público, soluções informatizadas de Tecnologia da Informação direcionadas ao desenvolvimento sustentável (social, econômico e ambiental)"; visão de futuro - "Ter o modelo de produção colaborativo em rede do SPB apropriado pela sociedade e ser referência internacional." A aplicação da SSM explicitou concretamente essas ideias-força. Dessa forma, o vetor de qualidade do ecossistema deve traduzir essas ideias.

O desafio do ecossistema é trabalhar os aspectos de qualidade como um elemento impulsionador de uma transformação social o que implica a necessidade de criar um ambiente capaz de oferecer à comunidade tanto um repositório de conhecimentos para consulta quanto ferramentas de interatividade e de produção colaborativa desses conhecimentos.

A norma ISO/IEC 15504 encontra-se em processo de revisão. A norma revisada receberá o nome de ISO/IEC 33.000 e deverá ter caráter normativo em todas as suas partes. A norma atual, ISO/IEC 15504-2 - Realizando uma Avaliação, em sua seção 5 - Uma Estrutura de Medição para a Capacidade de Processo, define a estrutura de medição e detalha a métrica a ser utilizada. Ela define os níveis de capacidade, os atributos do processo e a escala padrão. 
A versão ISO/IEC 33.000 pretende que também a parte 2 da norma seja normativa, como as demais. Ela não deverá prescrever o conteúdo da estrutura de medição conforme sua antecessora. A nova parte 2 deverá informar os requistos necessários para a criação de uma estrutura de medição. A capacidade será tratada como um caso particular da estrutura de medição, considerando a capacidade dos processos. Isso significa que os níveis de capacidade hoje definidos pela norma - execução do processo, gerência de execução, gerência do produto de trabalho, definição do processo e inovação do processo - poderão se alterar conforme o atributo escolhido como adequado para avaliar e melhorar processos. As dimensões da norma ISO/IEC 15504-2 estão ilustradas na Figura 54, onde o eixo das ordenadas representa a dimensão da capacidade do processo (o quão bem se faz) e o eixo das abscissas representa a dimensão dos processos (o que se faz).

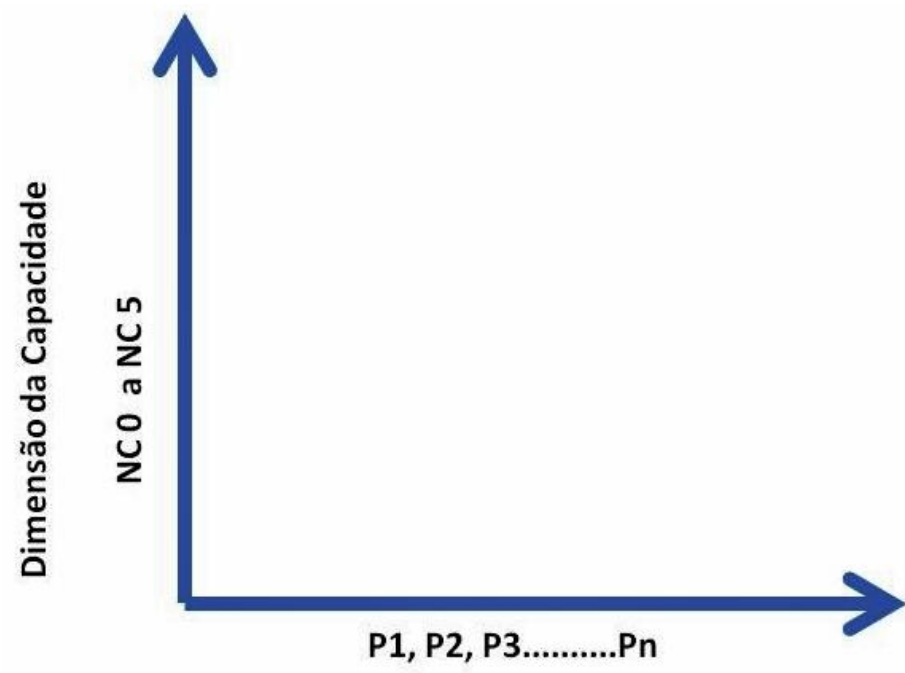

Dimensão do Processo

Figura 54 Dimensões da ISO/IEC 15504-2

Para a construção da estrutura de medição desta pesquisa foi considerada a alteração dessa estrutura. Esta alteração teve origem na análise das versões anteriores dos níveis de maturidade desenvolvidos ao longo da pesquisa (versão 1.0, versão 2.0 e versão 3.0). Os níveis de maturidade são conceituais, são abstrações feitas com o propósito de elaborar uma estrutura que permita que os processos principais de uma empresa de desenvolvimento de software sejam monitorados e melhorados. 
Nesta pesquisa, a dimensão de processo será mantida e a dimensão capacidade ${ }^{15}$ será substituída por uma outra dimensão que emergiu da análise dos conceitos dos níveis das versões anteriores, que é a dimensão sistêmica, representada na ordenada da Figura 55. A abscissa continua representando a dimensão de processo.

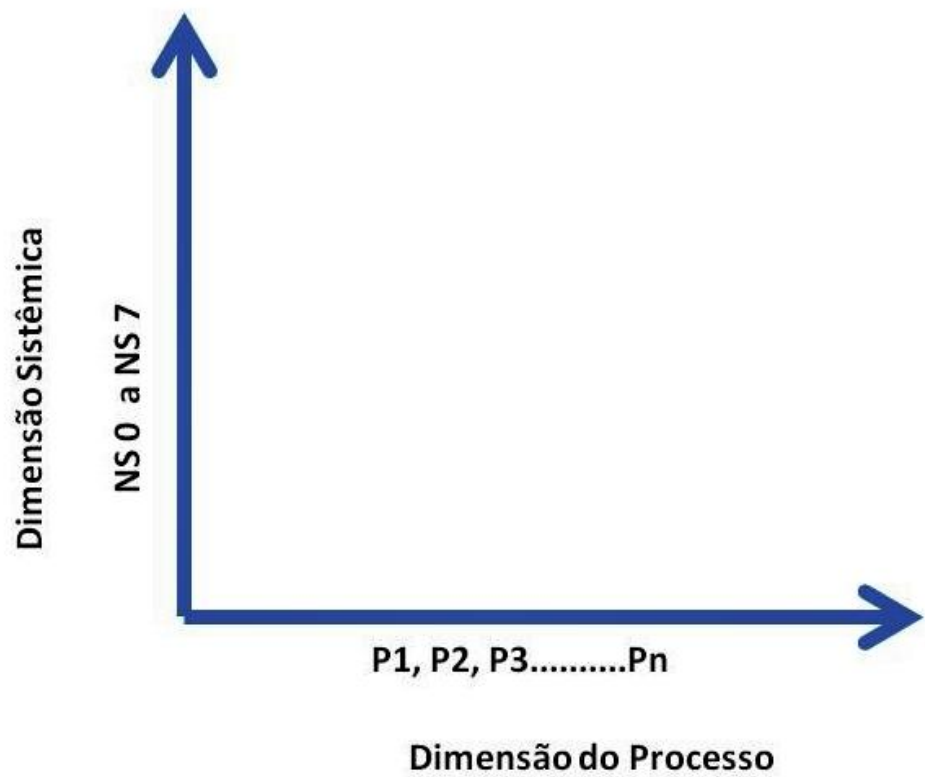

Figura 55 Nova dimensão para a estrutura de medição

A alteração se justifica porque as tentativas de utilizar a estrutura proposta pela norma ISO/IEC 15504-2 nos modelos de referência para o SPB não foram bem sucedidas.

As ações para melhorar e manter a capacidade dos processos, na forma dessa norma - executado, gerenciado, estabelecido e passível de otimização - não traduzem os vetores de melhoria que emergiram durante as versões anteriores do modelo de referência.

O ecossistema tem propósito, a visão de futuro e os valores diferentes dos de uma organização do tipo empresa de desenvolvimento de software. Nos ecossistemas as seguintes premissas estão fortemente presentes:

15 Capability dimension: the set of elements in a Process Assessment Model explicitly related to the Measurement Framework for Process Capability 
a forma de gestão com base em comando e controle é substituída pela ênfase em cooperação e conexão a possibilidade de avaliar os processos com base nos parâmetros atuais da norma não é factível, uma vez que esses processos estão em constante mudança e a sua estabilização não é uma meta;

as características emergentes durante o estudo do ecossistema são o compartilhamento, a conexão e a cooperação.

Considerando-se as características citadas anteriormente, é feita a tentativa de substituição da dimensão de capacidade por outra mais adequada e que represente de fato a dinâmica desejada para o ecossistema. Devido à característica sistêmica revelada durante a pesquisa em campo, a proposta de substituir a dimensão de capacidade pela dimensão sistêmica deve traduzir o quão sistêmicos são os processos do ecossistema. Portanto, no SPB, os vetores de melhoria no ecossistema serão aqueles que avaliam se os seus elementos agem e interagem sistemicamente.

\subsubsection{Atividade 23 - Projeto do nível de maturidade sistêmico}

A construção dos níveis de maturidade nesta pesquisa, segue a racionalidade observada nos modelos convencionais desenvolvidos para diferentes domínios. O nível de maturidade 1 abriga o conjunto de processos que são fundamentais para que a unidade organizacional execute o projeto de desenvolvimento de software. Nos níveis seguintes, seguindo a racionalidade de elevar o padrão de execução dos processos do nível 1 (que são considerados básicos) são acrescentados novos processos. Os novos processos têm a finalidade de dar suporte à elevação de capacidade dos processos que são considerados básicos para a organização. Os níveis são acumulativos como na família CMM e na ISO/IEC 15504. No nível n+1 estão presentes os processos do nível $\mathrm{n}$ e mais os seus próprios. Na proposta desta pesquisa, a relação entre o nível sistêmico do processo e o nível de maturidade sistêmica acontece de duas formas: 
1. O nível sistêmico é referente ao processo ou seja, 0 processo é a unidade a ser avaliada
2. O nível de maturidade sistêmica diz respeito à comunidade e à solução por ela disponibilizada e refere-se ao nível sistêmico de um conjunto de processos alocados em um determinado nível sistêmico.

Neste item 2, é feita uma analogia com os modelos de maturidade da capacidade representados pelo $\mathrm{CMMI}(\mathrm{SEl}, 2002)$, que apresenta na sua estrutura quatro categorias de processos: de gerência de projeto, de gerência de processo, de engenharia e de apoio. Para o caso do modelo de referência do SPB, a comunidade é considerada nas categorias de gerência de projeto e de gerência de processos, enquanto que a solução é alocada na categoria de processos de engenharia. Assim, o modelo do SPB teria em sua estrutura três categorias de processos: processos da comunidade, processos da solução e processos de apoio.

Para as empresas desenvolvedoras de software, existe a busca pela melhoria dos processos por meio de seu controle. A meta é que um processo esteja sob o controle estatístico de processo e, portanto, somente os processos de desenvolvimento estão sob avaliação. No caso do SPB, existe uma relação entre a linha de produção (comunidade) e o produto (solução) diferente das empresas convencionais. A solução tem processos autônomos, típicos de ambientes de desenvolvimento colaborativos, em rede e com um número não previsível de membros. Dessa forma, a proposta é que o modelo de referência do SPB tenha sempre como unidades de análise os processos da comunidade e os processos da solução. Portanto, as unidades de análise para os primeiros níveis são a solução de software disponibilizada e a comunidade que a mantém. A avaliação deve ser realizada internamente na comunidade, bem como na relação dela com as outras comunidades do ecossistema. Cada nível terá dois atributos: um para efeitos na solução de software e outro com efeito na comunidade. O algoritmo de descrição dos atributos deve sempre considerar a sistemática e a significância na unidade de análise. Ainda aqui não está presente a visão sistêmica demandada pelos últimos dois níveis. Considera-se que o nível de maturidade do sistema é determinado pelo conjunto de suas comunidades. 
Os dois últimos níveis tratam de aspectos que representam um rompimento com o paradigma anterior. O nível de abstração necessário para desenvolvê-los é alto, uma vez que eles estão distantes da realidade do SPB. Esses níveis não são detalhados nesta pesquisa. A questão relacionada aos dois últimos níveis de maturidade também ocorreu quando da construção do CMM. Os dois últimos níveis, 4 e 5, respectivamente, gerenciamento com métricas e otimização, não estavam detalhados como os demais. Recentemente, teve início o processo de definição desses níveis, existindo uma grande controvérsia sobre eles na comunidade de software.

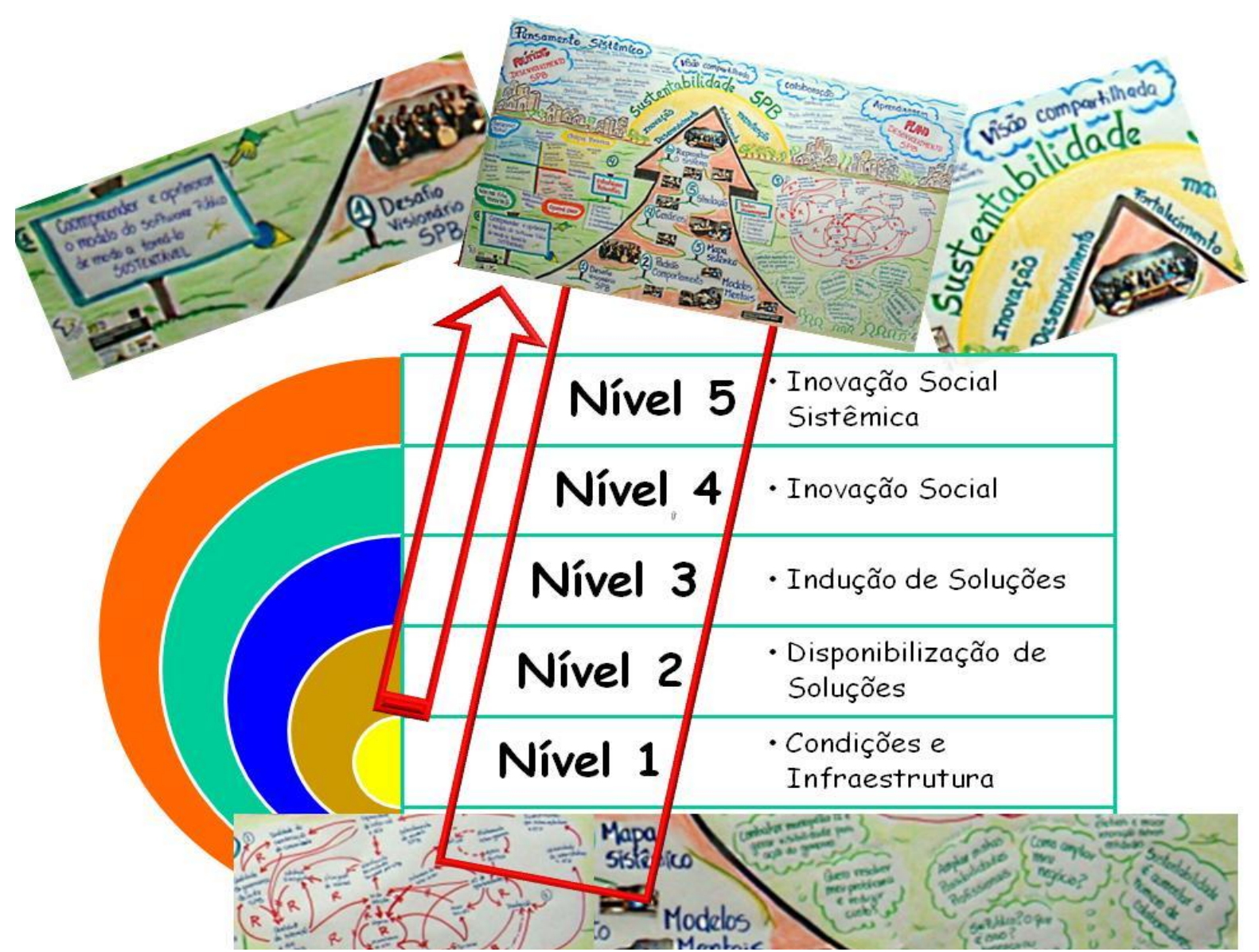

Figura 56 Níveis de maturidade para SPB

Fonte: (SALVIANO, 2010)

A construção dos atributos sistêmicos considera as ideias-força que norteiam o ecossistema. De alguma forma os conceitos de confiança, cooperação, comunidades e conhecimento devem estar contidos nos atributos sistêmicos. A base para a elaboração desses atributos sistêmicos foi a versão 3.0 do modelo de referência, desenvolvido na seção 5.3.3.2 e apresentado na Figura 56.

Os níveis dessa versão do modelo são: 
- Nível 1 - Condições e infraestrutura: são criadas as condições e a infraestrutura básica para o ecossistema;

- Nível 2 - Disponibilização de soluções: as soluções desenvolvidas são disponibilizadas no ecossistema, as comunidades são criadas para manter as soluções e buscar sua evolução e essas soluções são utilizadas;

- Nível 3 - Indução de soluções: o processo da comunicação entre demanda e oferta é consolidado e as soluções são induzidas pela demanda;

- Nível 4 - Inovação social (maturidade institucional) e

- Nível 5 - Inovação social sistêmica (geração de insumos para políticas públicas e de autonomia do ecossistema).

O mapeamento dos atributos do ecossistema, considerando suas ideias-força e os níveis da versão 3.0 do modelo de referência, são representados na Figura 57 . O nível 1 da versão 3.0, que é onde são criadas as condições e a infraestrutura básica para o ecossistema, foi mapeado no nível 1 da versão sistêmica. Nesse nível, são melhoradas as condições de infraestrutura básica para o ecossistema. Supõe-se que a infraestrutura tenha sido criada no nível 0 . No nível 1, a infraestrutura de hardware, software e o ambiente jurídico institucional estão preparados para abrigar as comunidades e as soluções por elas disponibilizadas. Nesse nível, a demanda pela disponibilização de soluções é interna ao ecossistema e decidida pelos coordenadores de comunidades. Esse nível abriga as comunidades que são, junto com as soluções, os componentes fundamentais para a existência e a manutenção do ecossistema. O nível 2 da versão 3.0, que trata especificamente da disponibilização de soluções e da criação de comunidades para a evolução e a manutenção dessas soluções internamente ao ecossistema, é mapeado também para o nível 1 da versão sistêmica. O nível 3 da versão 3.0, que abriga aspectos da consolidação da comunicação entre oferta e demanda e onde as soluções são induzidas pela demanda, foi mapeado para o nível 2 da versão sistêmica. Nesse nível sistêmico, também na versão sistêmica, existem mecanismos de comunicação entre o ecossistema e o ambiente exterior, de forma que as soluções são solicitadas ou sugeridas pela demanda.O ecossistema saiu do paradigma "ofertista" para o "paradigma guiado pela demanda". Os níveis 4 e 5 da versão 3.0, onde ocorrem a inovação social e a inovação social sistêmica foram mapeados para o nível 7 da 
versão sistêmica que abriga atributos de evolução sistêmica. Os níveis 4 e 5 da versão 3.0 e o nível 7 da versão sistêmica não são detalhados nesta pesquisa.

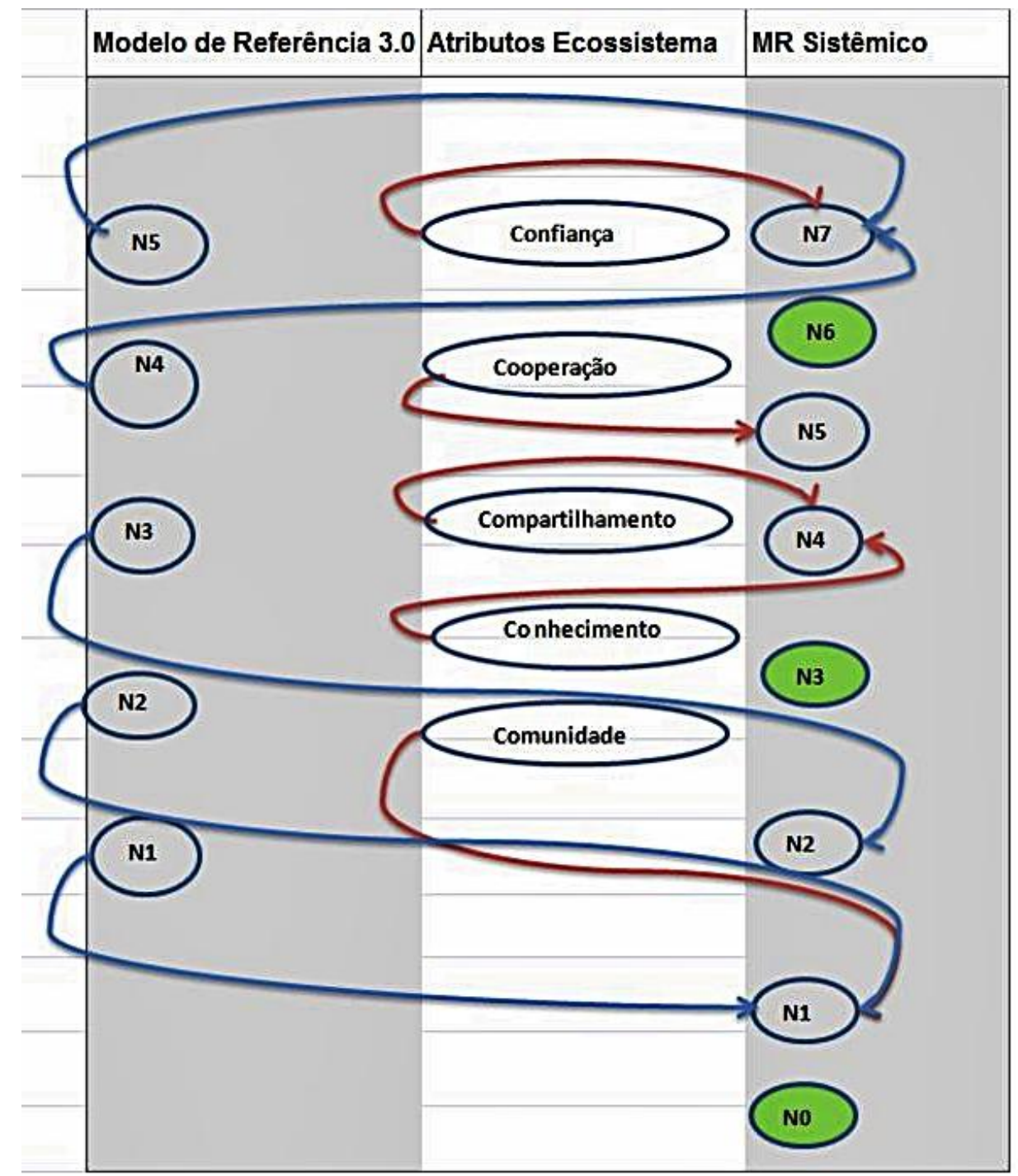

Figura 57 Percurso para construção dos níveis sistêmicos

Uma vez estabelecida a relação entre os níveis definidos na versão 3.0 e os níveis da versão sistêmica conclui-se que os atributos relevantes para a qualidade e a evolução do ecossistema não estão contemplados. São eles: confiança, cooperação, conhecimento e compartilhamento. Além dos atributos citados anteriormente, não está presente explicitamente o atributo relativo à conexão. Essa conexão é tanto física quanto social, ou seja, refere-se à situação em que os membros das comunidades estão conectados entre si e a outras comunidades. Dessa forma, o nível 3 da versão sistêmica trata da conexão. A análise feita a partir desse atributo deve considerar o quanto as comunidades e as soluções buscam e mantêm essa conexão. Para a solução, pode-se observar, por exemplo, se ela é desenvolvida 
levando em conta as questões de interoperabilidade com as demais soluções do ecossistema; para a comunidade, pode-se observar se ela utiliza a plataforma do ecossistema para o desenvolvimento da solução e se o seu coordenador participa de reuniões de coordenadores para observar e atuar nas estratégias das outras comunidades do ecossistema. O nível 4 do modelo de referência 3.0, contempla o atributo compartilhamento. A conexão propiciada pela infraestrutura no nível anterior provê condições de compartilhamento entre comunidades e soluções. No nível 3 da versão sistêmica, são observadas evidências de que as comunidades se preocupam em compartilhar com as demais comunidades do ecossistema os códigos das soluções que mantêm e desenvolvem e as estratégias de desenvolvimento de soluções compartilhadas; observa-se, ainda, se as soluções consideram, durante o seu desenvolvimento, o uso de técnicas de documentação de código que permitam o fácil compartilhamento, entre outros aspectos. $O$ nível 5 da versão sistêmica trata da questão da cooperação entre comunidades e soluções disponibilizadas. A cooperação, diferentemente da conexão e do compartilhamento exige que as partes envolvidas trabalhem juntas em prol de um objetivo comum. A estratégia para o compartilhamento exige considerar o trabalho cooperado. Nesse nível tanto as comunidades quanto as soluções devem possuir mecanismos que possibilitem e estimulem a cooperação no ecossistema. 0 níveis 6 - Monitoramento sistêmico e 7 - Evolução sistêmica não são abordados nesta pesquisa. Após essas reflexões foram definidos os atributos para o ecossistema.

\begin{tabular}{|l|}
\hline \multicolumn{1}{|c|}{ Níveis Sistêmicos } \\
\hline Do Início \\
\hline Da Oferta \\
\hline Da Demanda \\
\hline Da Conexão \\
\hline Do Compartilhamento \\
\hline Da Cooperação \\
\hline Do Monitorado sistêmico \\
\hline Do Evolucionário sistêmico \\
\hline
\end{tabular}

Quadro 40 Esboço dos atributos do ecossistema

O Quadro 40 mostra esses atributos e o Quadro 41 mostra o detalhamento dos níveis sistêmicos. 


\begin{tabular}{|l|l|}
\hline ESCALA & \multicolumn{1}{c|}{ DESCRIÇÃo DO ATRIBUTO } \\
\hline (0) Do Início & Ad hoc \\
\hline (1) Da Oferta & $\begin{array}{l}\text { As funcionalidades da solução são influenciadas sistemática e significativamente pela oferta. A } \\
\text { gestão da comunidade é influenciada sistemática e significativamente pela oferta. }\end{array}$ \\
\hline (2) Da Demanda & $\begin{array}{l}\text { As funcionalidades da solução são influenciadas sistemática e significativamente pela demanda. } \\
\text { A gestão da comunidade é influenciada sistemática e significativamente pela demanda }\end{array}$ \\
\hline (3) Da Conexão & $\begin{array}{l}\text { As funcionalidades da solução são influenciadas sistemática e significativamente pela gestão da } \\
\text { oferta e da demanda . A gestão da comunidade é influenciada sistemática e significativamente } \\
\text { pela gestão da oferta e da demanda . As funcionalidades da solução são influenciadas } \\
\text { sistemática e significativamente pelas conexões. A gestão da comunidade é influenciada } \\
\text { sistemática e significativamente pelas conexões }\end{array}$ \\
\hline (4) Do compartilhamento & $\begin{array}{l}\text { As funcionalidades da solução são influenciadas sistemática e significativamente pela gestão } \\
\text { de conexões. A gestão da comunidade é influenciada sistemática e significativamente pela } \\
\text { gestão de conexões . As funcionalidades da solução são influenciadas sistemática e } \\
\text { significativamente pelo compartilhamento. A gestão da comunidade é influenciada sistemática e } \\
\text { significativamente pelo compartilhamento }\end{array}$ \\
\hline
\end{tabular}




\begin{tabular}{|l|l|}
\hline ESCALA & \multicolumn{1}{c|}{ DESCRIÇÃO DO ATRIBUTO } \\
\hline (5) Da Cooperação & $\begin{array}{l}\text { As funcionalidades da solução são influenciadas sistemática e significativamente pela gestão } \\
\text { de compartilhamento A gestão da comunidade é influenciada sistemática e significativamente } \\
\text { pela gestão de compartilhamento As funcionalidades da solução são influenciadas sistemática e } \\
\text { significativamente pela cooperação intra e inter solução. A gestão da comunidade é influenciada } \\
\text { sistemática e significativamente pela cooperação intra e inter solução }\end{array}$ \\
\hline (6) Do Monitorado Sistêmico & Não detalhado \\
\hline (7) Do Evolucionário Sistêmico & Não detalhado \\
\hline
\end{tabular}

Quadro 41 Níveis sistêmicos 


\subsubsection{Conclusão do Momento de Pesquisa 02- FASE 03}

Os resultados obtidos com a execução dessa fase estão descritos no Quadro 42.

\begin{tabular}{|l|l|}
\hline Momento 02 & Fase 03 \\
\hline Fase de Pesquisa & $\begin{array}{l}\text { Fessa fase da pesquisa é possível verificar que os } \\
\text { níveis de maturidade do ecossistema devem conter as } \\
\text { ideias-força detectadas ao longo da aplicação da } \\
\text { SSM. } \\
\text { Melhoria e aprendizagem } \\
\text { Neste momento já se verifica que o caminho da } \\
\text { qualidade deve ser obtido por meio dos níveis de } \\
\text { maturidade. Aparecem os indícios de que a } \\
\text { capacidade de processo não é o vetor de qualidade e } \\
\text { melhoria no sistema. } \\
\text { Desta forma verificou-se que a estrutura de medição } \\
\text { da norma ISO/IEC 15504-2 não é adequada como } \\
\text { vetor de melhoria para o ecossistema. Foi então } \\
\text { proposta a substituição da dimensão capacidade pela } \\
\text { dimensão sistêmica. }\end{array}$ \\
\hline Quadro 42 Resumo da Fase 03
\end{tabular}

\subsubsection{CONCLUSÃO DO MOMENTO DE PESQUISA 02}

Esta seção contém a representação do ciclo completo de aplicação do PRO2PIMFMOD no Quadro 43 e no Quadro 44. Os resultados da aplicação das metodologias ao longo desse momento estão descritos no Quadro 45.

No Quadro 43 estão as ocorrências de oito atividades na prática $\mathrm{P} 1$, dez atividades na prática $\mathrm{P} 2$, três atividades na prática $\mathrm{P} 3$, quatro atividades na prática $\mathrm{P} 4$, uma atividade na prática $\mathrm{P} 5$ e uma atividade na prática $\mathrm{P} 6$. O maior número de atividades está na prática P2 que é a prática que trata da aprendizagem sobre o domínio e o escopo do objeto que se quer modelar, seguida de P1, que são as decisões iniciais que devem ser tomadas para continuidade da elaboração do método. Estão 
representadas quatro atividades em P4, que são as atividades das quatro versões do modelo de referência e, uma atividade em P5 e uma atividade em P6, representando respectivamente, a preparação do modelo do SPB (ZOUCAS, 2010) para a prova de conceito.

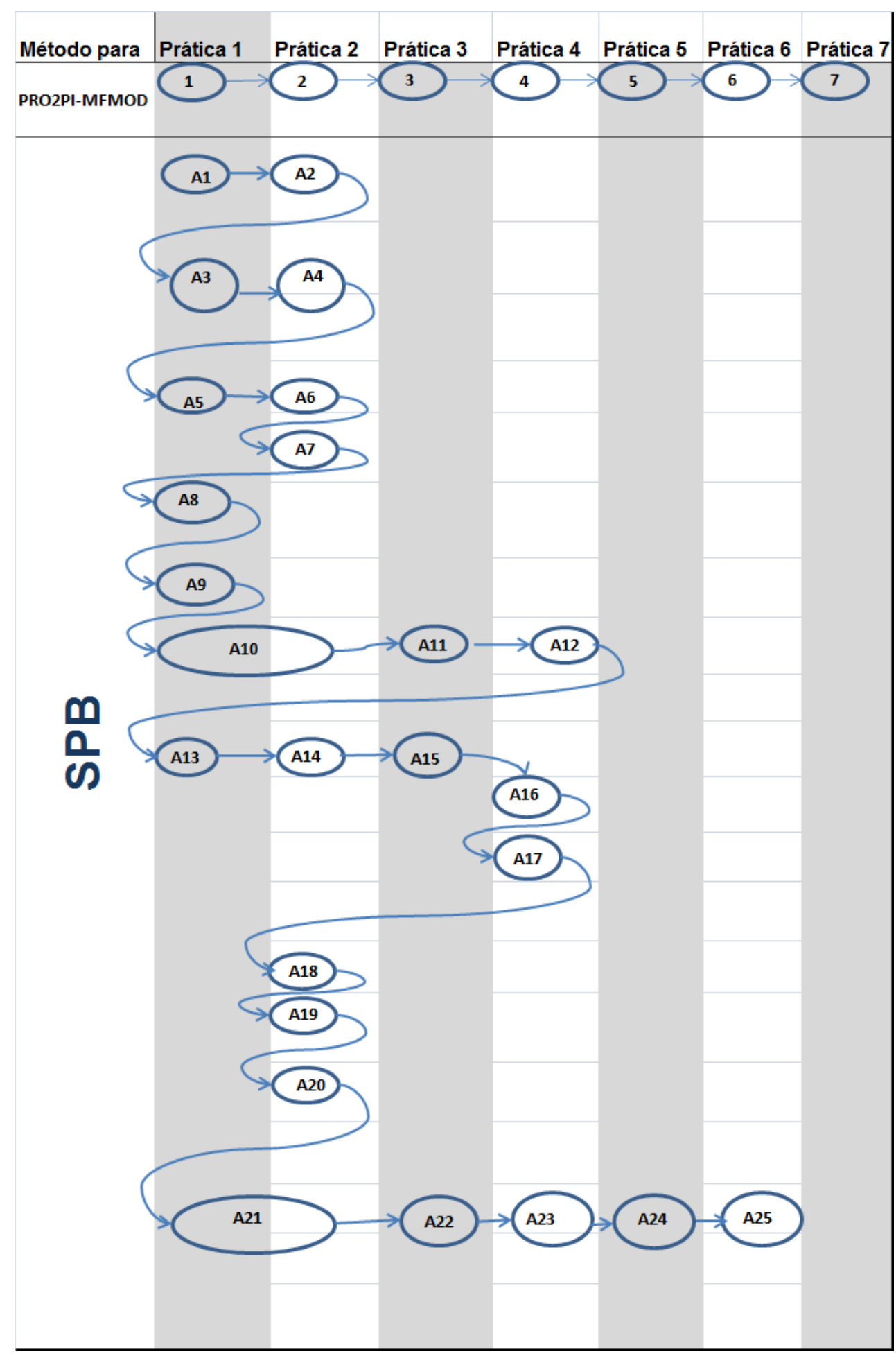

Quadro 43 Práticas e atividades do PRO2PI-MFMOD para o SPB 


\begin{tabular}{|c|c|c|c|c|}
\hline Atividade & Descrição & Regras & Práticas & Técnicas \\
\hline A1 & $\begin{array}{l}\text { Análise do projeto, formação de } \\
\text { equipes, estratégia de execução } \\
\text { do projeto, forma de } \\
\text { acompanhamento }\end{array}$ & \multirow{4}{*}{ 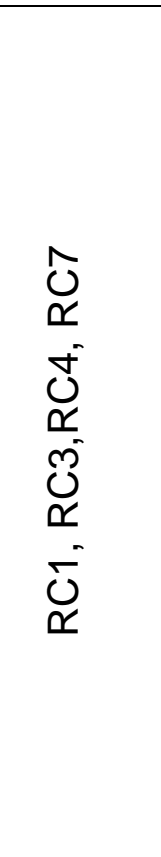 } & P1 & $\begin{array}{c}\text { T3, } \mathrm{T} 11, \mathrm{~T} 9, \\
\mathrm{~T} 12\end{array}$ \\
\hline A2 & $\begin{array}{l}\text { Pesquisas em publicações na } \\
\text { mídia, papers e documentação } \\
\text { do projeto }\end{array}$ & & P2 & T12, T9, T3 \\
\hline A3 & $\begin{array}{l}\text { Aplicação de entrevistas semi } \\
\text { estruturadas e do Café Mundial }\end{array}$ & & P1 & $\begin{array}{l}\text { T3, T11, T9, } \\
\text { T12 }\end{array}$ \\
\hline A4 & $\begin{array}{l}\text { Definição de propósito, de visão } \\
\text { de futuro e treinamento da } \\
\text { equipe }\end{array}$ & & P2 & T12, T9, T3 \\
\hline A5 & Decisões iniciais & \multirow{8}{*}{ 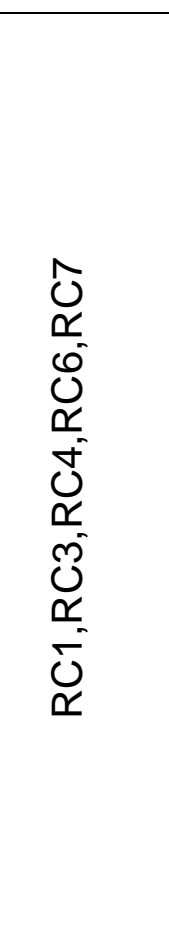 } & P1 & $\mathrm{T} 12, \mathrm{~T} 9, \mathrm{~T} 11$ \\
\hline A6 & Revisão de literatura & & P2 & T3 \\
\hline A7 & $\begin{array}{l}\text { Aprofundamento da revisão de } \\
\text { literatura dos quatro eixos } \\
\text { teóricos }\end{array}$ & & P2 & T3 \\
\hline A8 & $\begin{array}{l}\text { Disseminação dos conceitos } \\
\text { básicos dos eixos teóricos }\end{array}$ & & P1 & $\mathrm{T} 12, \mathrm{~T} 9, \mathrm{~T} 11$ \\
\hline A9 & Identificação de Domínio & & P1 & $\mathrm{T} 12, \mathrm{~T} 9, \mathrm{~T} 11$ \\
\hline A10 & Interação com as comunidades & & $\mathrm{P} 1, \mathrm{P} 2$ & $\mathrm{~T} 12, \mathrm{~T} 9, \mathrm{~T} 11$ \\
\hline A11 & $\begin{array}{l}\text { Estratégia de desenvolvimento } \\
\text { do modelo de referência } 1.0\end{array}$ & & P3 & T9 \\
\hline A12 & $\begin{array}{l}\text { Desenvolvimento do modelo de } \\
\text { referência } 1.0\end{array}$ & & P4 & T12 \\
\hline A13 & $\begin{array}{l}\text { Definição da situação de } \\
\text { interesse }\end{array}$ & \multirow{3}{*}{ 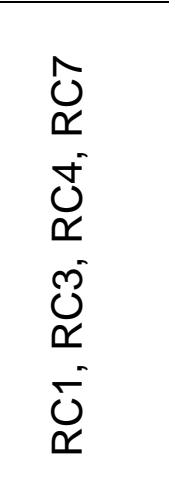 } & P1 & \multirow{3}{*}{ 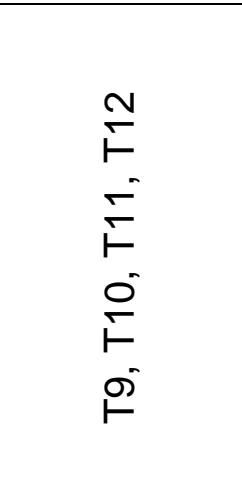 } \\
\hline A14 & $\begin{array}{l}\text { Aprendizagem com padrões de } \\
\text { comportamento e construção de } \\
\text { mapa sistêmico }\end{array}$ & & P2 & \\
\hline A15 & $\begin{array}{l}\text { Aprendizagem com mapa } \\
\text { sistêmico }\end{array}$ & & P3 & \\
\hline
\end{tabular}




\begin{tabular}{|c|c|c|c|c|}
\hline Atividade & Descrição & Regras & Práticas & Técnicas \\
\hline A16 & $\begin{array}{l}\text { Desenvolvimento do modelo de } \\
\text { referência versão } 2.0\end{array}$ & & P4 & \\
\hline A17 & $\begin{array}{l}\text { Desenvolvimento do modelo de } \\
\text { referência versão } 3.0\end{array}$ & & P4 & \\
\hline A18 & $\begin{array}{l}\text { Aprendizagem com modelos } \\
\text { mentais }\end{array}$ & & P2 & \\
\hline A19 & $\begin{array}{l}\text { Construção e simulação de } \\
\text { cenários }\end{array}$ & & P2 & \\
\hline A20 & $\begin{array}{l}\text { Aprendizagem com modelo } \\
\text { computacional }\end{array}$ & & P2 & \\
\hline A21 & $\begin{array}{l}\text { Plano de desenvolvimento } \\
\text { sistêmico }\end{array}$ & & P1, P2 & \\
\hline A22 & $\begin{array}{l}\text { Estratégia para o } \\
\text { desenvolvimento do modelo de } \\
\text { referência sistêmico }\end{array}$ & & P3 & \\
\hline A23 & $\begin{array}{l}\text { Elaboração do modelo de } \\
\text { referência sistêmico }\end{array}$ & & P4 & \\
\hline A24 & $\begin{array}{l}\text { Elaboração do draft para teste } \\
\text { do modelo de referência } \\
\text { sistêmico }\end{array}$ & & P5 & \\
\hline A25 & $\begin{array}{l}\text { Validação do modelo de } \\
\text { referência sistêmico }\end{array}$ & & P6 & \\
\hline
\end{tabular}

Quadro 44 Atividades, Regras, Práticas e Técnicas do MFMOD para o SPB

\begin{tabular}{|l|l|}
\hline Momento 02 & Fases 01, 02 e 03 \\
\hline Período & $2012-2013$ \\
\hline Fase de Pesquisa & Conclusão do Momento de Pesquisa 02 \\
\hline Critério de avaliação & $\begin{array}{l}\text { Desenvolvimento dos níveis de maturidade para o } \\
\text { ecossistema a partir de dados coletados durante a } \\
\text { aplicação da SSM. Proposta de alteração da estrutura de } \\
\text { medição da norma ISO/IEC 15504-2 }\end{array}$ \\
\hline
\end{tabular}




\begin{tabular}{|l|l|}
\hline Atividades executadas & Workshops, brainstorms, revisão do pares \\
\hline Avaliação & $\begin{array}{l}\text { Foram elaborados oito níveis de maturidade sistêmica (0-7) } \\
\text { e foram testadas em três áreas de processo do Modelo de } \\
\text { Capacidade de Processo para Desenvolvimento de } \\
\text { Software no SPB (solicitação de melhoria, gestão } \\
\text { estratégica e gestão da comunidade). }\end{array}$ \\
\hline $\begin{array}{l}\text { Os níveis de maturidade finais são melhorias e reflexões } \\
\text { aprendizagem }\end{array}$ & $\begin{array}{l}\text { Pobre as três versões geradas durante o projeto. } \\
\text { acrescentar atributos fundamentais para a qualidade do } \\
\text { ecossistema como compartilhamento, cooperação e } \\
\text { conexão. } \\
\text { Os níveis propostos alteram a estrutura de medição da } \\
\text { norma ISO/IEC 15504-2, seção 5. } \\
\text { Os níveis } 6 \text { e } 7 \text { representam uma quebra de paradigma } \\
\text { com relação aos níveis anteriores. }\end{array}$ \\
\hline
\end{tabular}

Quadro 45 Resumo do Momento 02

\subsection{MOMENTO DE PESQUISA 03}

Neste momento da pesquisa é realizada a prova de conceito considerando a estrutura de maturidade resultante do momento anterior. A prova de conceito é realizada utilizando o modelo de referência de processos "Modelo de Capacidade de Processo para Desenvolvimento de Software no SPB v.3.0" (ZOUCAS, 2010). A partir do modelo são selecionados os processos utilizados para a prova de conceito. O critério de seleção dos processos, bem como os processos selecionados são apresentados nas seções seguintes.

\subsubsection{Atividade 24 - Seleção de processos para a prova de conceito}

O Modelo de Capacidade de Processo para Desenvolvimento de Software para o Software Público Brasileiro, versão 3.0, é composto de nove áreas de capacidade de processo conforme descreve o Quadro 46. 


\begin{tabular}{|c|l|c|}
\hline ID & NOME & ACRÔNIMO \\
\hline 1 & Gestão Estratégica & GES \\
\hline 2 & Gestão da Comunidade & GDC \\
\hline 3 & Gestão do Conhecimento & GCH \\
\hline 4 & Gestão de Reutilização & GDR \\
\hline 5 & Gestão de Relacionamento com Clientes & GRC \\
\hline 6 & Solicitação de Melhoria & SDM \\
\hline 7 & Fornecimento de Melhoria & FDM \\
\hline 8 & Integração e Liberação da Solução & ILS \\
\hline 9 & Treinamento na Tecnologia e na Solução & TTS \\
\hline
\end{tabular}

Quadro 46 Áreas de capacidade de processo do SPB

As áreas de processo são compostas por objetivos e práticas. A Figura $\mathbf{5 8}$ apresenta a visão organizacional das áreas de capacidade de processo que compõem o modelo.

Foram selecionadas três áreas de capacidade de processo: Gestão Estratégica (GES), Gestão da Comunidade (GDC) e Solicitação de Melhoria (SDM). Para a seleção, utilizou-se o critério de escolha de processos que, representassem as três grandes áreas do modelo: operação, gestão e estratégia.

Gestăo

Estratégica

Geståo da Comunidade

Gestão do Conhecimento

Gestão de Reutilizaçăo

Gestäo de Relacionamento c/ Clientes

Solicitaçăo de Melhoria

Fornecimento de Melhoria

Integr ação e Liber ação da Solução

Treinamento na Tecnologia e na Solução

Figura 58 Visão organizacional das áreas de capacidade do Modelo

Fonte: Zoucas (2010) 


\subsubsection{1. Área Solicitação de Melhoria (SDM)}

O propósito da área de capacidade de processo SDM é orientar o estabelecimento dos processos para gerenciar a solicitação de melhoria para a solução disponibilizada na Comunidade do Software Público Brasileiro - SPB.

\section{Notas Introdutórias}

Esta área de capacidade de processo, por meio de um conjunto de boas práticas, tem a finalidade de auxiliar os responsáveis pelas comunidades a gerenciar de forma colaborativa e sustentável o recebimento, a análise e o tratamento das sugestões de melhorias da solução de software. Estas sugestões (solicitações) podem incluir: correções de defeitos, novas funcionalidades e evolução da solução. Cada comunidade define a forma de implementar essas práticas, tendo como base as orientações aqui apresentadas.

O gerenciamento das sugestões de melhorias abrange inicialmente a definição de uma estratégia que envolve o estabelecimento e a manutenção de um mecanismo para apoiar o gerenciamento das sugestões de melhoria, bem como a identificação, o registro e a aceitação dessas sugestões.

\section{Objetivos e Práticas}

\section{Objetivo SDM 1 - Solicitações de Melhoria Gerenciadas}

As solicitações de melhoria são gerenciadas com base em uma estratégia, com a adoção de um mecanismo para recebimento, identificação, registro e aceitação das sugestões de melhoria e para acompanhamento da lista de solicitações de melhoria.

Prática SDM 1.1 : Definir a estratégia para gerenciar as sugestões de melhoria

Prática SDM 1.2 : Estabelecer e manter um mecanismo para gerenciar as solicitações de melhoria

Prática SDM 1.3 : Receber, identificar e registrar solicitação de melhoria

Prática SDM 1.4 : Aceitar a solicitação de melhoria

Prática SDM 1.5 : Monitorar a lista de solicitações de melhoria 


\subsubsection{2. Área Gestão da Comunidade (GDC)}

\section{Propósito:}

O propósito da Área de Capacidade de Processo GDC é orientar o estabelecimento dos processos para gerenciar a Comunidade do Software Público Brasileiro SPB.

\section{Notas Introdutórias:}

Esta área de capacidade de processo, por meio de um conjunto de boas práticas, visa auxiliar o responsável por gerenciar a comunidade nas definições e no acompanhamento das atividades da comunidade do SPB para que ela atinja os seus objetivos de forma colaborativa e sustentável. Esse responsável pode ser o Coordenador e/ou Líder da Comunidade. Cada comunidade define a forma de implementar essas práticas, tendo como base as orientações aqui apresentadas.

A preparação das atividades para a gestão da comunidade inclui o estabelecimento e a manutenção dos objetivos dessa comunidade, de uma estratégia para alcançar esses objetivos, e de regras e um modo de operação da comunidade alinhada a sua estratégia. Envolve também estabelecer e manter um sistema para o funcionamento da Comunidade.

A realização e o acompanhamento das atividades de Gestão da Comunidade incluem a realização das atividades da Comunidade, monitoramento do dia a dia da Comunidade em relação à estratégia e o monitoramento da estratégia em relação aos objetivos. Se necessário, ações corretivas são definidas e acompanhadas para alinhar a estratégia da comunidade com seus próprios objetivos.

\section{Objetivos e Práticas:}

\section{Objetivo GDC 1: Gestão da Comunidade Preparada}

As atividades de Gestão da Comunidade são preparadas com base nos objetivos, na estratégia, nas regras, no modo de operação e na adoção de um mecanismo para apoiar o funcionamento da comunidade.

Prática GDC 1.1: Estabelecer e manter os objetivos da comunidade

Prática GDC 1.2: Estabelecer e manter uma estratégia para atingir os objetivos da comunidade. 
Prática GDC 1.3: Estabelecer e manter regras e modo de operação da comunidade alinhados à sua estratégia.

Prática GDC 1.4: Estabelecer e manter um mecanismo para apoiar o funcionamento da comunidade.

\section{Objetivo GDC 2: Atividades de Gestão da Comunidade Realizadas e Acompanhadas}

Executar ações na comunidade e acompanhá-las em relação ao seu alinhamento com a estratégia para atingir os objetivos dessa comunidade

Prática GDC 2.1: Realizar as atividades de Gestão da Comunidade
Prática GDC 2.2: Monitorar o dia a dia da Comunidade em relação à
estratégia
Prática GDC 2.3: Monitorar a estratégia em relação aos objetivos
Prática GDC 2.4: Definir e acompanhar ações corretivas para alinhar a
estratégia da comunidade com seus próprios objetivos.

\subsubsection{3. Área Gestão Estratégica (GES)}

\section{Propósito:}

O propósito da Área de Capacidade de Processo GES é orientar o estabelecimento dos processos para gerenciar a estratégia da Comunidade do Software Público Brasileiro - SPB.

\section{Notas Introdutórias:}

Esta área ajuda as comunidades, por meio de um conjunto de práticas, a atingir os objetivos do Software Público Brasileiro - SPB. Cada comunidade define a forma de implementar essas práticas, tendo como base as orientações aqui apresentadas.

Esta área de capacidade de processo envolve o alinhamento de objetivos da comunidade com os objetivos do SPB.

Alinhar objetivos da comunidade com objetivos do SPB inclui conhecer os objetivos do SPB, estabelecer e manter uma estratégia de alinhamento dos objetivos da comunidade (definidos na área de capacidade de processo GDC - Gestão da 
Comunidade) com os objetivos do SPB, definir e executar ações para induzir a comunidade ao atendimento dos objetivos do SPB, monitorar o alinhamento dos objetivos da comunidade com os objetivos do SPB, estabelecer e acompanhar ações corretivas para alinhar os objetivos da comunidade com os objetivos do SPB.

\section{Objetivos e Práticas:}

\section{Objetivo GES 1: Alinhamento dos Objetivos da Comunidade com Objetivos do} SPB

Os objetivos da comunidade são alinhados com os objetivos do SPB com base no conhecimento desses objetivos e em estratégia, ações, monitoração, estabelecimento e acompanhamento de ações corretivas para alinhar esses objetivos.

\section{Prática GES 1.1: Conhecer os objetivos do SPB}

Prática GES 1.2: Estabelecer e manter uma estratégia de alinhamento dos objetivos da comunidade com os objetivos do SPB

Prática GES 1.3: Definir e executar ações para induzir a comunidade ao atendimento dos objetivos do SPB

Prática GES 1.4: Monitorar o alinhamento dos objetivos da comunidade com os objetivos do SPB.

Prática GES 1.5: Definir e acompanhar ações corretivas para os objetivos da comunidade

Fonte: Zoucas (2010)

\subsubsection{ATIVIDADE 25 - PROVA DE CONCEITO DOS NÍVEIS SISTÊMICOS}

Para esta prova de conceito é utilizado o modelo de capacidade no SPB detalhado na seção anterior. Neste momento, é realizada a prova de conceito considerando os níveis de maturidade resultantes da fase anterior, apresentados na seção 5.3.2.

O modelo, embora tenha no seu nome a palavra "capacidade", foi desenvolvido para abrigar tanto a dimensão capacidade como outra, considerada mais adequada. Esta 
questão está tratada no texto do artigo "Modelo de Capacidade de Processo para o Software Público Brasileiro" (SBQS, 2010) e é representada na Figura 59, que ilustra o deslocamento da ênfase em comando e controle dos modelos convencionais para a ênfase em cooperação e conexão, adotada por novos modelos. O caso específico do SPB tem como premissa básica a ênfase em cooperação e conexão.

A prova de conceito consiste na aplicação, nos processos da comunidade e da solução, do algoritmo que considera o atributo do nível sistêmico. Os resultados da aplicação desse algoritmo nas áreas de processos selecionadas estão descritos nas seções 5.4.2.1, 5.4.2.2 e 5.4.2.3.

\section{Paradigmas e Modelos de Capacidade e Processo de uma Comunidade SPB}

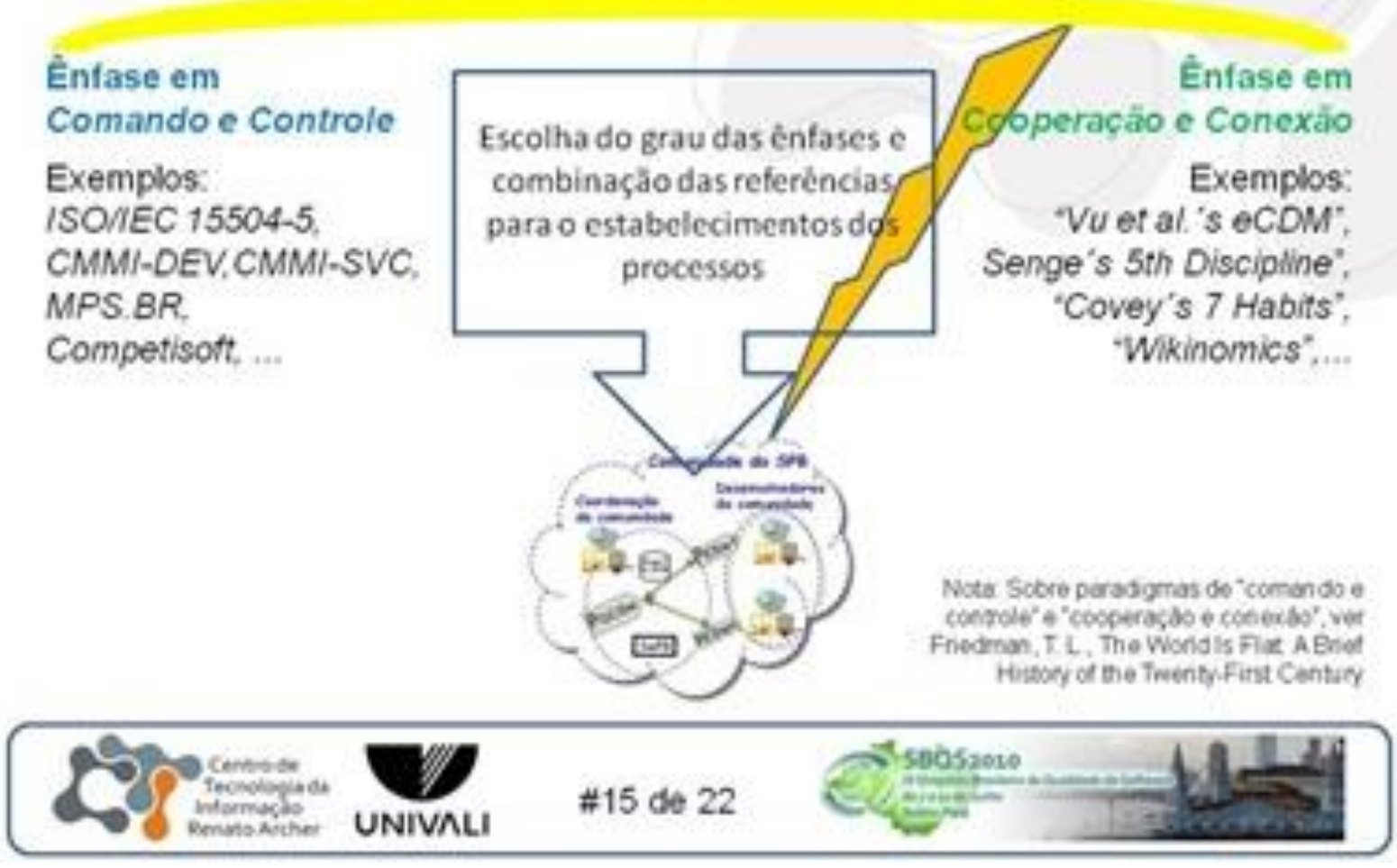

Figura 59 Paradigmas e modelos de capacidade

Fonte: Slide apresentado no SBQS (2010) 


\subsubsection{Validação da área Solicitação de Melhoria (SDM)}

\section{NÍVEL/ATRIBUTOS}

\section{Do INICIO}

As soluções de software recebem as solicitações de melhorias, modificações e mesmo manutenções de forma aleatória, sem separar as solicitações da oferta e da demanda e sem a sistematização de seu recebimento, avaliação e implementação. As comunidades uma vez estabelecidas no SPB atuam de forma isolada, sem coordenação e sem gestão.

\section{Da OFERTA}

As funcionalidades da solução disponibilizada por meio das comunidades são diretamente influenciadas pela oferta. $O$ coordenador da comunidade, juntamente com alguns desenvolvedores decidem, de forma ad hoc, quais alterações e melhorias serão implementadas. Da mesma forma, a gestão da comunidade é feita de forma personalística e depende da motivação, do interesse e das metodologias de gestão que são próprias de cada coordenador. Desta forma, as comunidades têm comportamentos, eficiência, e eficácia muito díspares. Neste nível, diferentemente do nível anterior, já existe uma preocupação com as solicitações da oferta que causam mudanças nas funcionalidades da solução. As solicitações podem ser de alterações, melhorias ou modificações nas características da solução ou relativas a funcionalidade, desempenho e outros aspectos. Esta oferta é oriunda do coordenador da comunidade bem como dos seus desenvolvedores mais atuantes. Considerando que o Ecossistema SPB é composto por acadêmicos, coordenadores de comunidade, comunidade de software livre, desenvolvedores, fomentador, governo, parceiros, prestadores de serviço e usuários finais, somente partes de duas dessas categorias influenciam de forma significativa a evolução da solução. Aqui, a gestão da comunidade é precária, uma vez que ela se dá a partir do coordenador dessa comunidade e de alguns de seus desenvolvedores mais atuantes. As evidências que comprovam esses atributos podem ser obtidas junto aos fóruns de discussão da ferramenta de desenvolvimento, nos chats e no histórico das alterações efetuadas no código da solução. 


\section{Da DEMANDA}

As funcionalidades da solução disponibilizada por meio das comunidades são ainda diretamente influenciadas pela oferta e a coordenação decide, juntamente com alguns desenvolvedores, as alterações que serão implementadas. Entretanto, neste nível já existe, embora de forma não estruturada, um tratamento das solicitações da demanda, ou seja, as solicitações dos outros atores que formam o Ecossistema SPB são consideradas e implementadas. A gestão da comunidade ainda é personalística e depende da motivação, do interesse e das metodologias de gestão que são próprias de cada coordenador, mas agora considera as questões colocadas pela demanda (por exemplo: a questão relativa a uma coordenação apagada, sem liderança). As comunidades continuam com comportamentos, eficiência e eficácia muito díspares. As evidências que comprovam esses atributos podem ser obtidas junto aos fóruns de discussão da ferramenta de desenvolvimento, nos chats e no histórico das alterações efetuadas no código da solução.

\section{Da CONEXÂO}

Neste nível, as solicitações referentes às funcionalidades da solução, tanto as da oferta quanto as da demanda, são agora tratadas de forma estruturada. Existem uma estratégia definida e a adoção de um mecanismo de recebimento, identificação, registro e aceitação das sugestões de melhoria e de acompanhamento da lista de solicitações de melhoria. A gestão da comunidade conta agora com um mecanismo de gerenciamento das sugestões de melhorias para as soluções. Neste nível, já se considera que as conexões entre os membros da comunidade são relevantes para a melhoria continua da solução, bem como para o fortalecimento da própria comunidade. Já existe uma preocupação com a razão entre o número de membros na comunidade e o número de contribuições efetivas para a melhoria da solução.

A participação em chats e fóruns de discussão é incentivada. Existe também uma preocupação quanto à disseminação do modelo de sustentação do SPB, que é ancorado em: 1) prover um software com documentação completa de instalação e preparado para funcionar; 2) disponibilizar um ponto focal ou uma equipe que possa fazer a interlocução com a sociedade e encaminhar suas demandas; 3) manter um ambiente virtual que operacionalize a comunicação 
com o usuário (fórum, ferramentas de controle de versão, etc.) e 4) comprometer-se com a gestão da colaboração: além da gestão da comunidade virtual associada ao software liberado, a entidade também se compromete a realizar ações para incentivar a colaboração e a gestão do conhecimento produzido (controle de versões, etc.). As ações referentes aos itens 2, 3 e 4 são incentivadas. As evidências que comprovam esses atributos podem ser obtidas junto aos fóruns de discussão da ferramenta de desenvolvimento, nos chats, no histórico das alterações efetuadas no código da solução, nas alterações na infraestrutura do ambiente e no aumento do número de membros na comunidade, do número de downloads da solução e do número de empresas que prestam serviços com a solução no Mercado Público Virtual.

\section{Do COMPARTILHAMENTO}

Neste nível, as conexões - que no nível anterior influenciavam tanto as soluções quanto a gestão da comunidade e eram tratadas de forma não gerenciada - passam agora a ser gerenciadas, ou seja, planejadas monitoradas e ajustadas, com seus produtos de trabalho estabelecidos, controlados e mantidos apropriadamente. O foco, neste nível, é a compreensão das interações do SPB com seu entorno, com vistas ao compartilhamento de conhecimento e trabalho. Existe uma preocupação com a divulgação, a busca de novas parcerias com entidades e a interação com outros atores, onde atores são os participantes individuais do portal e as entidades são organizações que dão suporte à existência do SPB ou parceiros que participam do seu desenvolvimento. Depois de mais estabilidade no nível operacional, o foco concentra-se em ações para atrair novas entidades e novos atores, para entender o perfil, as necessidades e as motivações dos atores e para a busca de novas parcerias. Há um movimento para expandir as fronteiras do ecossistema, unindo esforços com as universidades e com outros ministérios. Neste nível, já se considera a relevância do compartilhamento de conhecimento e de trabalho e, assim, emergem questões relativas a: aumentar a efetividade das diversas modalidades de compartilhamento de conhecimento e de trabalho que o ambiente oferece; como trabalhar de forma compartilhada com o setor público para redesenhar as práticas de governo de maneira que explorem todo o potencial do ecossistema e como reunir servidores e pesquisadores de 
diferentes organizações em equipes personalizadas para as demandas de governo. Tanto as funcionalidades das soluções das comunidades como a gestão da própria comunidade são influenciadas pelo resultado do tratamento das questões anteriormente colocadas. As evidências que comprovam esses atributos podem ser obtidas junto aos fóruns de discussão da ferramenta de desenvolvimento, nos chats, no histórico das alterações efetuadas no código da solução, nas alterações na infraestrutura do ambiente e no aumento do número de membros na comunidade, do número de downloads da solução, do número de empresas que prestam serviços com a solução no Mercado Público Virtual, do número de entidades do governo com soluções disponibilizadas, do número de universidades com comunidade no ambiente, entre outros.

\section{Da COOPERAÇÃo}

As funcionalidades da solução são influenciadas sistemática e significativamente pela gestão de compartilhamento. A gestão da comunidade é igualmente influenciada sistemática e significativamente pela gestão de compartilhamento. As funcionalidades da solução são influenciadas sistemática e significativamente pela cooperação intra e intersolução. A gestão da comunidade é igualmente influenciada sistemática e significativamente pela cooperação intra e intersolução. Neste nível, o compartilhamento de conhecimento e trabalho - que no nível anterior influenciava tanto as soluções quanto a gestão da comunidade e era tratado de forma não gerenciada - passa agora a ser gerenciado, ou seja, planejado, monitorado e ajustado, com seus produtos de trabalho estabelecidos, controlados e mantidos apropriadamente. Neste nível, também são criados spin-offs do ecossistema, ou seja, comunidades virtuais específicas ou outros ambientes dentro do ambiente de implementação do SPB, para atender demandas da sociedade. Este nível também expressa a maturidade de relacionamentos que são abrangidos pelo ecossistema. Devido ao crescimento da participação, das parcerias, etc., as relações dentro do ecossistema tendem a ser mais complexas. Neste nível há a aprendizagem sobre a rede de relacionamentos, sua intensidade, sua linearidade ou não linearidade, sobre a ampliação de relacionamentos, etc. Neste ciclo, o foco é melhorar a qualidade dos relacionamentos. 


\section{Do MONITORAMENTO SISTÊMICO}

Não desenvolvido nesta pesquisa

\section{Da EVOLUÇÃo SISTÊMICA}

Não desenvolvido nesta pesquisa

\subsubsection{Validação da área Gestão de Comunidade (GDC)}

\section{NÍVEL/ATRIBUTOS}

\section{Do INICIO}

As soluções e as comunidades são disponibilizadas no ecossistema sem que seus objetivos sejam estabelecidos e sem que exista sistematização de sua gestão.

\section{Da OFERTA}

A comunidade não possui objetivos definidos e não existe preocupação com a gestão. A gestão se dá a partir do seu coordenador e de alguns de seus desenvolvedores mais atuantes, sem que haja um alinhamento maior com seus membros. As soluções disponibilizadas são melhoradas e mantidas segundo as deliberações do coordenador da comunidade. Como a preocupação com a gestão é inexistente na comunidade, a solução pode não estar alinhada com os objetivos e as metas do ecossistema. As evidências que comprovam esses atributos podem ser obtidas junto aos fóruns de discussão da ferramenta de desenvolvimento, nos chats e no histórico das alterações efetuadas no código da solução.

\section{Da DEMANDA}

Se, no nível anterior, a comunidade estava voltada para si, nesse nível ela deve considerar as solicitações da demanda para as alterações na solução, na gestão da comunidade e na estratégia da comunidade em relação ao SPB.

Neste nível já existe, embora de forma não estruturada, uma preocupação com a gestão da comunidade e com o alinhamento entre gestão da comunidade e solução. As evidências que comprovam esses atributos podem ser obtidas junto aos fóruns de discussão da ferramenta de desenvolvimento, nos chats e no histórico das alterações efetuadas no código da solução. 


\section{Da CONEXÃO}

Neste nível, já existe uma forma estruturada de tratar a gestão da comunidade, com o objetivo de definir as atividades dessa comunidade para que ela atinja seus objetivos. A comunidade tem a gestão preparada, estabelecendo e mantendo seus objetivos, sua estratégia e seu modo de operação alinhados com sua estratégia. Ela também estabelece e mantém um mecanismo para apoiar o seu funcionamento. Neste nível já se considera que as conexões entre os membros da comunidade são relevantes para a melhoria continua da solução, bem como para o fortalecimento da própria comunidade. Já existe uma preocupação com a razão entre o número de membros na comunidade e 0 número de contribuições efetivas para a melhoria da solução. A participação em chats e fóruns de discussão é incentivada. Existe também uma preocupação quanto à disseminação do modelo de sustentação do SPB, que é ancorado em: 1) prover um software com documentação completa de instalação e preparado para funcionar; 2) disponibilizar um ponto focal ou uma equipe que possa fazer a interlocução com a sociedade e encaminhar suas demandas; 3) manter um ambiente virtual que operacionalize a comunicação com o usuário (fórum, ferramentas de controle de versão) e 4) comprometer-se com a gestão da colaboração: além da gestão da comunidade virtual associada ao software liberado, a entidade também se compromete a realizar ações para incentivar a colaboração e a gestão do conhecimento produzido (controle de versões, wikis). As ações referentes aos itens 2, 3 e 4 são inseridas no objetivo da comunidade. As evidências que comprovam esses atributos podem ser obtidas junto aos fóruns de discussão da ferramenta de desenvolvimento, nos chats, no histórico das alterações efetuadas no código da solução, nas alterações na infraestrutura do ambiente e no aumento do número de membros na comunidade, do número de downloads da solução e do número de empresas que prestam serviços com a solução no Mercado Público Virtual.

\section{Do COMPARTILHAMENTO}

Neste nível, a gestão da comunidade, que foi estruturada no nível anterior, agora é monitorada. São realizadas atividades de gestão da comunidade, a estratégia da comunidade é monitorada no dia a dia, as estratégias são monitoradas com relação ao objetivos da comunidade e são definidas e 
acompanhadas ações corretivas para alinhar a estratégia da comunidade com seus próprios objetivos. As conexões - que no nível anterior influenciavam tanto as soluções quanto a gestão da comunidade e eram tratadas de forma não gerenciadas - passam agora a contar com algum tipo de gerência. $O$ foco, neste nível, é a compreensão das interações do SPB com seu entorno, com vistas ao compartilhamento de conhecimento e trabalho. Depois de mais estabilidade no nível operacional, o foco concentra-se em ações para atrair novas entidades e novos atores, para entender o perfil, as necessidades e as motivações dos atores e para a busca de novas parcerias. Há um movimento para expandir as fronteiras do ecossistema, unindo esforços com as universidades e com outros ministérios. Neste nível, já se considera a relevância do compartilhamento de conhecimento e de trabalho e, assim, emergem questões relativas a: aumentar a efetividade das diversas modalidades de compartilhamento de conhecimento e de trabalho que o ambiente oferece; como trabalhar de forma compartilhada com o setor público para redesenhar as práticas de governo de maneira que explorem todo o potencial do ecossistema e como reunir servidores e pesquisadores de diferentes organizações em equipes personalizadas para as demandas de governo. Tanto as funcionalidades das soluções das comunidades como a gestão da própria comunidade são influenciadas pelo resultado do tratamento das questões anteriormente colocadas. As evidências que comprovam esses atributos podem ser obtidas junto aos fóruns de discussão da ferramenta de desenvolvimento, nos chats, no histórico das alterações efetuadas no código da solução, nas alterações na infraestrutura do ambiente e no aumento do número de membros na comunidade, do número de downloads da solução, do número de empresas que prestam serviços com a solução no Mercado Público Virtual, do número de entidades do governo com soluções disponibilizadas, do número de universidades com comunidade no ambiente, entre outros.

\section{Da COOPERAÇÃO}

Neste nível, o compartilhamento de conhecimento e trabalho - que no nível anterior influenciava tanto as soluções quanto a gestão da comunidades e era tratado de forma não gerenciada - passa agora a ser gerenciado. Neste nível também são criados spin-offs do ecossistema, ou seja, comunidades 
virtuais específicas ou outros ambientes dentro do ambiente de implementação do SPB, para atender necessidades da oferta e da demanda. Este nível expressa a maturidade dos relacionamentos que são abrangidos pelo ecossistema. Devido ao crescimento da participação, das parcerias, etc., as relações dentro do ecossistema tendem a ser mais complexas e a cooperação entre as comunidades e as soluções é incentivada.

As evidências que comprovam esses atributos podem ser obtidas junto aos fóruns de discussão da ferramenta de desenvolvimento, nos chats e no histórico das alterações efetuadas no código da solução.

\section{Do MONITORADO SISTÊMICO}

Não desenvolvido nessa pesquisa

\section{Da EVOLUÇÃO SISTÊMICA}

Não desenvolvido nessa pesquisa.

\subsubsection{Validação da área Gestão Estratégica (GES)}

\section{NÍVEL/ATRIBUTOS}

\section{Do INICIO}

As comunidades do SPB, que são responsáveis pelas soluções disponibilizadas, sua manutenção, sua melhoria e seu ciclo de vida, não possuem um processo para a gestão estratégica que diz respeito ao alinhamento da comunidade com os objetivos do SPB.

As evidências que comprovam esses atributos podem ser obtidas junto aos fóruns de discussão da ferramenta de desenvolvimento, nos chats e no histórico das alterações efetuadas no código da solução.

\section{Da OFERTA}

A comunidade desconhece os objetivos do SPB. Não existe uma preocupação com a gestão estratégica dessa comunidade Aqui, a gestão da comunidade é precária, uma vez que ela se dá a partir do seu coordenador e de alguns de seus desenvolvedores mais atuantes, sem que haja um alinhamento maior com os objetivos do SPB. As evidências que comprovam esses atributos podem ser obtidas junto aos fóruns de discussão da ferramenta de desenvolvimento, nos chats e no histórico das alterações efetuadas no código da solução 


\section{Da DEMANDA}

Se, no nível anterior, a comunidade estava voltada para si, neste nível ela deve considerar a existência da demanda (por alterações na solução, na gestão da comunidade e na estratégia da comunidade em relação ao SPB).

Entretanto, neste nível já existe, embora de forma não estruturada, uma preocupação com os objetivos do SPB e as ações são tomadas considerando o alinhamento com esses objetivos. As evidências que comprovam esses atributos podem ser obtidas junto aos fóruns de discussão da ferramenta de desenvolvimento, nos chats e no histórico das alterações efetuadas no código da solução.

\section{Da CONEXÃO}

Neste nível, já existe uma forma estruturada de tratar a estratégia da comunidade, com o objetivo de que ela esteja sempre alinhada com os objetivos do SPB. Agora a comunidade conhece os objetivos do SPB, estabelece e mantém uma estratégia de alinhamento dos objetivos da comunidade com os objetivos do SPB, define e executa ações para induzir a comunidade ao atendimento dos objetivos do SPB, monitora o alinhamento dos objetivos da comunidade com os objetivos do SPB e define e acompanha ações corretivas para os objetivos da comunidade. A gestão da comunidade conta agora com um mecanismo de gestão estratégica.

Neste nível, já se considera que as conexões entre os membros da comunidade são relevantes para a melhoria continua da solução, bem como para o fortalecimento da própria comunidade. Já existe uma preocupação com a razão entre o número de membros na comunidade e o número de contribuições efetivas para a melhoria da solução. A participação em chats e fóruns de discussão é incentivada. Existe também uma preocupação quanto à disseminação do modelo de sustentação do SPB, que é ancorado em: 1) prover um software com documentação completa de instalação e preparado para funcionar; 2) disponibilizar um ponto focal ou uma equipe que possa fazer a interlocução com a sociedade e encaminhar suas demandas; 3) manter um ambiente virtual que operacionalize a comunicação com o usuário (fórum, ferramentas de controle de versão) e 4) comprometer-se com a gestão da 
colaboração: além da gestão da comunidade virtual associada ao software liberado, a entidade também se compromete a realizar ações para incentivar a colaboração e a gestão do conhecimento produzido (controle de versões, wikis.). As ações referentes aos itens 2, 3 e 4 são incentivadas.

As evidências que comprovam esses atributos podem ser obtidas junto aos fóruns de discussão da ferramenta de desenvolvimento, nos chats, no histórico das alterações efetuadas no código da solução, nas alterações na infraestrutura do ambiente e no aumento do número de membros na comunidade, do número de downloads da solução e do número de empresas que prestam serviços com a solução no Mercado Público Virtual.

\section{DO COMPARTILHAMENTO}

Neste nível, as conexões - que no nível anterior influenciavam tanto as soluções quanto a gestão da comunidade e eram tratadas de forma não gerenciada passam agora a ser gerenciadas. O foco, neste nível, é a compreensão das interações do SPB com seu entorno, com vistas ao compartilhamento de conhecimento e trabalho. Existe uma preocupação com a divulgação, a busca de novas parcerias com entidades e a interação com outros atores. Depois de mais estabilidade no nível operacional, o foco concentra-se em ações para atrair novas entidades e para a busca de novas parcerias. Neste nível, já se considera a relevância do compartilhamento de conhecimento e de trabalho e, assim, emergem questões relativas a: aumentar a efetividade das diversas modalidades de compartilhamento de conhecimento e de trabalho que o ambiente oferece; como trabalhar de forma compartilhada com o setor público para redesenhar as práticas de governo de maneira que explorem todo o potencial do ecossistema e como reunir servidores e pesquisadores de diferentes organizações em equipes personalizadas para as demandas de governo. Tanto as funcionalidades das soluções das comunidades como a gestão da própria comunidade são influenciadas pelo resultado do tratamento das questões anteriormente colocadas. As evidências que comprovam esses atributos podem ser obtidas junto aos fóruns de discussão da ferramenta de desenvolvimento, nos chats, no histórico das alterações efetuadas no código da solução, nas alterações na infraestrutura do ambiente e no aumento do número de membros na comunidade, do número de downloads da solução, do número de empresas que 
prestam serviços com a solução no Mercado Público Virtual, do número de entidades do governo com soluções disponibilizadas, do número de universidades com comunidade no ambiente, entre outros.

\section{Da COOPERAÇÃO}

Neste nível, o compartilhamento de conhecimento e trabalho - que no nível anterior influenciava tanto as soluções quanto a gestão da comunidade e era tratado de forma não gerenciada - passa agora a ser gerenciado. Neste nível, também são criados spin-offs do ecossistema, ou seja, comunidades virtuais específicas ou outros ambientes dentro do ambiente de implementação do SPB, para atender demandas da sociedade. Este nível também expressa a maturidade dos relacionamentos que são abrangidos pelo ecossistema. Devido ao crescimento da participação, das parcerias, etc., as relações dentro do ecossistema tendem a ser mais complexas e passam a existir ações que estimulam a cooperação intra e extra as comunidades. Neste nível, há a aprendizagem sobre a rede de relacionamentos e sua intensidade e sobre a ampliação de relacionamentos.

\section{Do MONITORADO SISTÊMICO}

Não desenvolvido nesta pesquisa

\section{Da EVOLUÇÃO SISTÊMICA}

Não desenvolvido nesta pesquisa

\subsubsection{Conclusão do Momento de Pesquisa 03}

Os resultados da aplicação das metodologias ao longo desse momento estão descritas no Quadro 47.

\begin{tabular}{|c|c|}
\hline Momento 02 & Fase 03 \\
\hline Período & $2012-2013$ \\
\hline Fase de Pesquisa & Momento de Pesquisa 03 \\
\hline Atividades executadas & $\begin{array}{l}\text { Seleção do modelo de capacidade para a prova de } \\
\text { conceito. } \\
\text { Seleção dos processos do modelos para aplicação do } \\
\text { algoritmo dos níveis de maturidade }\end{array}$ \\
\hline
\end{tabular}




\begin{tabular}{|l|l|}
\hline Momento 02 & Fase 03 \\
\hline A aplicação da estrutura de medição sistêmica nas \\
áreas de processo do modelo de capacidade no SPB se \\
mostrou viável, pois conduz os processos à melhoria \\
alinhada aos objetivos do ecossistema. \\
A aplicação do algoritmo dos níveis de maturidade, \\
durante a realização da prova de conceito, foi mais \\
simples para o processo do nível operacional. Para os \\
dois outros níveis, gestão e estratégia, pelo fato de \\
ainda não ocorrerem no SPB, foi exigido um nível alto de \\
abstração, aumentando o grau de dificuldade da \\
aplicação do algoritmo.
\end{tabular}

Quadro 47 Resumo da fase 03

\subsection{MOMENTO DE PESQUISA 04}

Nesta seção são efetuadas as validações da pesquisa e do seu resultado. A validação da pesquisa é apresentada em 5.5.1, com a utilização das estruturas definidas em 3.4.7, e a validação do resultado da pesquisa é mostrada em 5.5.2.

\subsubsection{VALIDAÇÃO DA PESQUISA}

A abordagem da pesquisa-ação utiliza diferentes ênfases em diferentes comunidades científicas, nas diferentes áreas de pesquisa que adotam essa metodologia. Na abordagem empregada nesta tese, desenvolver uma pesquisa num ambiente real sob o ponto de vista do informante (insider) possibilita entender as entrelinhas das falas dos participantes, os problemas que eles vivenciam ou as ações que eles realizam. Por exemplo, nas entrevistas, nos workshops ou em qualquer outra forma de interação, ao identificar determinadas situações ou problemas não explicitados mas já vivenciados pela autora, Ihe foi possível elaborar rapidamente perguntas que oferecessem a possibilidade de abordar essas situações ou esses problemas. Quanto às possibilidades de viés e de não explicitação de conhecimentos tácitos, às quais os informantes (insiders) estão sujeitos, a triangulação dos dados e as discussões com os membros do grupo foram importantes meios para evitá-los ou reduzi-los. 


\section{Avaliação do processo de solução ou controle do problema.}

No início do projeto que abrigou a pesquisa-ação, tanto o seu escopo quanto a meta a ser alcançada não eram bem definidos e entendidos pelos grupos de trabalho. Para que fosse possível garantir que o projeto atendesse os seus objetivos e tivesse um fim definido, foi necessária uma primeira abordagem, que definiu claramente o problema e as grandes metas do projeto. Ao longo do desenvolvimento, foram necessários ajustes e alterações de rota que, entretanto, não comprometeram a resolução do problema e nem as metas definidas. O escopo, a meta e o problema a serem resolvidos foram amplamente compartilhados com os stakeholders do projeto. Durante a execução, emergiu um spin-off a partir do Vetor SP01: o Grupo de Interesse sobre qualidade de software 5CQualiBr.

\section{Avaliação da aprendizagem dos participantes.}

Participar de um projeto de pesquisa-ação leva o pesquisador e sua equipe a novas formas de trabalhar e pensar, desenvolvidas ao longo do processo de pesquisa. Existe uma dificuldade inicial para os envolvidos e, em especial, para o pesquisador, que tem um papel duplo no processo: ora pesquisador, usando o instrumental da pesquisa científica, ora membro do grupo, implementando ações e avaliando resultados.

Ao longo do projeto, o pesquisador aprende gradualmente a conhecer os membros do grupo, o que the permite avaliar seu desenvolvimento de pensamento, habilidades e atitudes. Com esse conhecimento desenvolvido, é possível avaliar o desenvolvimento da organização e, nessa ocasião, emergem algumas questões:

\section{A organização desenvolveu a} capacidade de enfrentar problemas semelhantes por conta própria?
E quanto a novos problemas, será a organização capaz de replicar os passos utilizados anteriormente?

As respostas para essas questões só poderão ser conhecidas em ações posteriores. No caso desta pesquisa, é possível observar empiricamente que houve um aprendizado por parte dos seus coordenadores, dos coordenadores de comunidade e dos seus membros mais atuantes, que se traduziu em ações realizadas sobre 0 ecossistema após o término da pesquisa. As evidências estão presentes na plataforma do SPB, na forma de notícias diárias sobre eventos relativos ao 
ecossistema, na mudança de coordenação sem traumas para o ecossistema (essa questão era um ponto fraco do ecossistema no momento da realização da pesquisa em campo), na alteração do formato do portal utilizando os mapas mentais como referência (http://goo.gl/K2wgP), no tráfego intensivo de mensagens entre os membros da comunidade e em outras formas. Observa-se também um crescimento no número de comunidades (de 22 para 60, disponíveis em http://goo.gl/dQnrz) e de membros do ecossistema (de 80 mil para $150 \mathrm{mil}$ ) no intervalo de quatro anos. A relação de causalidade possível é que, após o processo de aprendizado, a divulgação do ecossistema passou a ser feita sobre o modelo teórico construído. $O$ material de divulgação do ecossistema passou a ser elaborado com base em modelos e teorias bem definidas. Foram também gerados papers e artigos para revistas, que contribuíram para essa disseminação e divulgação.

Para os pesquisadores envolvidos, também houve um aprendizado tangível. Com a capacidade adquirida em pesquisar soluções para problemas difusos com a utilização do aparato teórico e de metodologias adequadas, o grupo passou a ser conhecido e requisitado por outros projetos, sempre com as mesmas características: sistemas complexos, problemas desestruturados, escopo não definido. A conclusão do grupo de pesquisadores é que a metodologia de trabalho do Laboratório de Políticas Públicas em TICs - Politic, que também é um spin-off do Projeto SPB, deverá ser a pesquisa-ação. Porque é isso que o grupo faz: resolve problemas e avança em uma área de conhecimento relacionada às TICs.

\section{Avaliação de resultados teóricos.}

É possível afirmar que as metodologias utilizadas podem ser, na maioria dos casos, utilizadas em outras situações com características semelhantes às do Ecossistema SPB. Considera-se que problemas de grupos diversos podem ser diferentes em cada processo de pesquisa-ação mas existem aspectos invariáveis que podem ser generalizados e aplicados em outras situações. A validade prática dos resultados, ou, em outras palavras, a sua aplicabilidade em situações semelhantes que apareçam em outros momentos, só será conhecida quando alguém tentar aplicá-los.

\section{O rigor na pesquisa-ação}

É importante destacar que o rigor da pesquisa-ação não se baseia nos princípios da pesquisa empírica e experimental tradicional. A sua natureza cíclica permite uma 
revisão constante das informações e interpretações realizadas. Assim, podem ser identificados quatro elementos que contribuem para o rigor científico da pesquisaação:

1. Participação:- Ainda na sua forma mais elementar (os informantes), é possível o uso de diversas fontes para a melhor compreensão de um fenômeno. As discussões em grupo podem resultar em um desafio para os participantes e os pesquisadores, que pode ter grandes benefícios para 0 processo.

2. Qualitativa:- As informações obtidas por meio do diálogo, desenvolvidas em um clima apropriado, podem contribuir para 0 aprofundamento do conhecimento acumulado. A qualidade permite chegar à essência do fenômeno.

3. A ação:- Considerando que a pesquisa é orientada para uma ação, os planos são testados imediatamente. Também os pressupostos podem ser testados. A ação e a pesquisa informam-se mutuamente.

4. Emergente:- De acordo com Dick (1999), este é um aspecto fundamental da pesquisa-ação. Na medida que aumenta o conhecimento, a ação está mais bem informada. O mesmo acontece com a metodologia utilizada. É essa sensibilidade às informações, à situação e às pessoas que dá à pesquisaação a possibilidade de mudar programas.

A seguir são apresentadas o Quadro 48 e ० Quadro 49 preenchidos com dados da pesquisa que demonstram o seu rigor. 


\begin{tabular}{|c|c|}
\hline $\begin{array}{l}\text { Aspectos Gerais Alvo de } \\
\text { Avaliação }\end{array}$ & Descrição \\
\hline Pontos estratégicos & $\begin{array}{l}\text { O problema a ser resolvido não era claro para o cliente e nem para o pesquisador. Foi necessária } \\
\text { a execução de uma etapa preliminar para definir e compartilhar o escopo do problema e as } \\
\text { possíveis soluções. A definição do problema originou a pesquisa. }\end{array}$ \\
\hline Capacidade de mobilização & $\begin{array}{l}\text { As instituições envolvidas, SLTI/MPOG e DMPS/CTI estavam comprometidas formalmente por } \\
\text { meio de um contrato de prestação de serviços. Entretanto houve entre as equipes um } \\
\text { engajamento que ultrapassou os limites do contrato formal. Durante um ano estiveram envolvidas } \\
\text { nesta pesquisa em média } 40 \text { pessoas/mês. }\end{array}$ \\
\hline Capacidade de propostas & $\begin{array}{l}\text { As propostas de aplicação de metodologias, exercícios de nivelamento de conhecimento, } \\
\text { entrevistas, ação e fundamentações teóricas foram aceitas pelos envolvidos no projeto. }\end{array}$ \\
\hline Continuidade do projeto & $\begin{array}{l}\text { O projeto teve a duração de dois anos, sendo que no primeiro deles foi executado o trabalho em } \\
\text { campo. Uma vez disseminada e compartilhada a dinâmica do trabalho não houve problema } \\
\text { durante sua execução. O projeto tem um spin-off que hoje é coordenado pela equipe do CTI e o } \\
\text { ecossistema continua em evolução conforme pode ser observado pelo tráfego de informações na } \\
\text { plataforma. }\end{array}$ \\
\hline Participação & $\begin{array}{l}\text { Houve participação, colaboração e cooperação ao longo de todo o desenvolvimento do projeto. } \\
\text { Todos os níveis do SPB estavam envolvidos. }\end{array}$ \\
\hline $\begin{array}{l}\text { Qualidade do trabalho em } \\
\text { equipe }\end{array}$ & $\begin{array}{l}\text { O projeto foi conduzido de forma cooperada e compartilhada. Todos tinham acesso a todo } \\
\text { conhecimento gerado e aos wikis de registros de atividades do projeto. }\end{array}$ \\
\hline
\end{tabular}




\begin{tabular}{|l|l|}
\hline $\begin{array}{c}\text { Aspectos Gerais Alvo de } \\
\text { Avaliação }\end{array}$ & Descrição \\
\hline $\begin{array}{l}\text { Efetividade das atividades } \\
\text { de formação }\end{array}$ & $\begin{array}{l}\text { Durante a execução do projeto, foram realizadas palestras para disseminação dos seus objetivos } \\
\text { e para entendimento do problema. Foram realizadas também palestras e workshops para difusão } \\
\text { dos eixos teóricos do projeto e para a disseminação da SSM e do pensar sistêmico. Percebe-se } \\
\text { que, hoje, tanto o ecossistema quanto a equipe do CTI mantêm e utilizam os conceitos } \\
\text { disseminados no próprio ecossistema e em outros projetos. }\end{array}$ \\
\hline Conhecimento e informação & $\begin{array}{l}\text { O conhecimento gerado pelo projeto foi publicado em anais de congressos e revistas. Foi } \\
\text { publicado também um livreto sobre a aplicação do pensamento sistêmico. O livreto é hoje o } \\
\text { material de divulgação do Ecossistema. A lista de publicações do Projeto SPB está disponível em: } \\
\text { http://goo.gl/FFSW2 }\end{array}$ \\
\hline Comunicação & $\begin{array}{l}\text { Foram realizados workshops, conferências web e reuniões. Os meios de comunicação foram } \\
\text { mensagens eletrônicas, wikis, chate a própria plataforma do SPB. }\end{array}$ \\
\hline Atividade de apoio & $\begin{array}{l}\text { Os dois grupos constituídos para a aplicação da SSM foram efetivos na capacidade de } \\
\text { processamento e análise das informações, bem como na utilização das ferramentas de TI } \\
\text { disponíveis. }\end{array}$ \\
\hline
\end{tabular}

Quadro 48 Aspectos gerais alvo de avaliação 


\begin{tabular}{|c|c|}
\hline Validade & spectos do trabalho \\
\hline Interna & $\begin{array}{l}\text { Para o levantamento de dados no SPB foi utilizada a metodologia SSM, que traz em seu conteúdo passos cuja } \\
\text { finalidade é o levantamento das variáveis criticas do sistema e posterior elaboração do mapa sistêmico. Com o } \\
\text { mapa sistêmico é estabelecida a relação entre as variáveis e seus efeitos sistêmicos (diagrama causal). Em } \\
\text { seguida é realizada uma modelagem usando um software específico IThink. Foram também analisadas as séries } \\
\text { históricas disponíveis. }\end{array}$ \\
\hline Externa & $\begin{array}{l}\text { Os elementos do modelo foram utilizados para avaliar a maturidade do próprio SPB. Em seguida, o SPB foi } \\
\text { convidado a fazer parte de um projeto europeu de disponibilização de plataformas para a gestão de cidades. Após } \\
\text { análise do estágio de maturidade do SPB e do ecossistema europeu, a equipe concluiu por não participar da } \\
\text { iniciativa. O SPB estava aquém do nível de maturidade necessário para o projeto europeu (chamada FP7-ICT- } \\
\text { 2011-UE-Brasil). A alteração da estrutura de medição foi aplicada no projeto CERTICS - Desenvolvimento de } \\
\text { um Modelo e Método para Avaliação de Tecnologia Nacional de Software (http://goo.gl/gJ7iX). No caso desse } \\
\text { projeto, o eixo de avaliação é a competência em desenvolvimento de tecnologia nacional para software. Nele, as } \\
\text { áreas de processo são avaliadas em relação à sua competência e não em relação à capacidade. }\end{array}$ \\
\hline Do construto & $\begin{array}{l}\text { Para a caracterização do objeto de estudo foram utilizados quatro recortes teóricos: pensamento sistêmico, } \\
\text { sistemas complexos, ecossistemas digitais e a teoria de modelos de maturidade. Foram realizadas provas de } \\
\text { conceito para comprovar que os níveis de maturidade propostos representam a evolução do objeto em relação a } \\
\text { um vetor sistêmico. Para as demais medidas necessárias utilizou-se a SSM com as devidas ferramentas de } \\
\text { coleta de dados. Os dados foram analisados e modelados. Nas modelagens, a relação entre os conceitos e a }\end{array}$ \\
\hline
\end{tabular}




\begin{tabular}{|l|l|}
\hline Validade & Aspectos do trabalho \\
\hline Descritiva & $\begin{array}{l}\text { medida se mostrou adequada na maioria dos casos. Para a coleta de dados também foram realizadas entrevistas } \\
\text { semiestruturadas e utilizadas as séries históricas disponíveis. } \\
\text { de exatidão do relatório da pesquisa, ou seja, sua capacidade de representar a situação pesquisada. }\end{array}$ \\
\hline Interpretativa & $\begin{array}{l}\text { A representação do objeto de estudo foi construída coletivamente com os seus principais stakholders, o que } \\
\text { aumenta a probabilidade de que a representação aqui descrita seja, de fato, uma das formas adequadas de } \\
\text { representar o ecossistema. }\end{array}$ \\
\hline Teórica & $\begin{array}{l}\text { Os eixos teóricos da pesquisa - sistemas complexos, pensamento sistêmico e ecossistema - permitiram as } \\
\text { caracterizações do objeto de estudo e, consequentemente, das metodologias e métodos adequados para abordá- } \\
\text { lo. O eixo de melhoria de processo e modelos de maturidade permitiu a percepção de um novo vetor para a } \\
\text { melhoria de processo no ecossistema e a norma ISO/IEC 15504-2 contribuiu para a elaboração de uma nova } \\
\text { estrutura de medição. }\end{array}$ \\
\hline
\end{tabular}

Quadro 49 Validade da pesquisa 


\subsubsection{VALIDAÇÃO DO RESULTADO DA PESQUISA}

A validação de um modelo de maturidade é uma atividade de difícil execução e de grande importância (Von WANGENHEIM, 2010), que requer um longo período de tempo. Esta pesquisa propõe referências para um modelo de maturidade sistêmico, utilizando uma perspectiva inovadora para modelos de maturidade: o pensamento sistêmico. Considerando esses aspectos, não é ainda viável a validação completa dos resultados dos elementos propostos para o modelo de maturidade. No entanto, a fim de obter confiança na qualidade do trabalho, foram identificadas e utilizadas uma validação considerada principal e cinco validações consideradas secundárias, descritas a seguir.

\section{Validação principal: uso da pesquisa-ação}

O trabalho de preparação do modelo de referência do SPB envolveu questões práticas e teóricas. As questões teóricas eram relacionadas com as dificuldades de compreensão da natureza e dinâmica do ecossistema SPB. Devido a essas peculiaridades, optou-se por utilizar a metodologia pesquisa-ação, que inclui as duas dimensões da situação problemática: a teórica e a prática. A pesquisa-ação é composta por fases sendo elas: a fase exploratória da pesquisa onde se realiza 0 diagnóstico das questões problemáticas do ecossistema; a fase de pesquisa onde são selecionados os modelos teóricos a serem utilizados e é elaborado o plano de ação da investigação; a fase da ação, onde o plano é implementado. Na fase de avaliação da pesquisa, verificou-se que as ações da pesquisa-ação atenderam às expectativas dos atores no ecossistema. O conhecimento gerado pelo processo de aplicação da pesquisa-ação é incorporado ao ecossistema. Os elementos do modelo de referência de maturidade, proposto no processo, é utilizado como referência pelo ecossistema. Do ponto de vista da pesquisa, foi gerado conhecimento suficiente para o desenvolvimento de um modelo de maturidade para os ecossistemas de software público. Desta forma é possível afirmar que o resultado da pesquisa foi construído, entendido, aceito e validado coletivamente, conforme a dinâmica da pesquisa-ação.

\section{Validação secundária 01: coincidência com a revisão da norma ISO/IEC 15504}

A primeira validação secundária refere-se a coincidência da necessidade de substituição, durante a execução da pesquisa-ação, do eixo da capacidade, 
conforme definido na ISO/IEC 15504-2, pelo eixo sistêmico e, a decisão do grupo responsável pela evolução e manutenção da norma ISO/IEC 15504, pela aprovação do desenvolvimento de uma nova série, aprovada em reunião da ISO, em Hyderabad, Índia, em 29 de maio de 2009. Todas as partes da norma serão revistas e produtos novos serão a ela anexados. A parte referente ao framework de medição será a norma ISO/IEC 33020 - Measurement Framework for assessment of process capability and organizational maturity. Esta norma da nova série deverá conter um framework para a elaboração de estruturas de medição, e a capacidade será considerada somente um caso possível, podendo existir outros, como o sistêmico, por exemplo. A proposta desta tese poderá ser considerada um caso do framework de elaboração de estruturas de medição.

\section{Validacão secundária 02: publicacãa de artigo em anais de conferência}

A aceitação, a apresentação e a posterior publicação do artigo "Towards a Systemic Maturity Model for Public Software Ecosystems" (ALVES, 2011) nos anais da Conferência SPICE, promovida pelo grupo que criou e desenvolve a série ISO/IEC 15504 e lançará sua revisão na série ISO/IEC 33000 - Series on Process Assessment (http://goo.gl/mAOhT), oferecem segurança de que a proposta da tese não está em desacordo com a norma utilizada como referência (ISO/IEC 15504-2).

\section{Validação secundária 03: uso de uma analogia}

Os modelos mais relevantes utilizados como referência para a melhoria de processos de software são: CMM, CMMI e ISO/IEC 15504. A maioria dos novos modelos é constituída por adaptações feitas aos modelos convencionais. Entretanto, existe uma abordagem alternativa para a construção de novos modelos: é a utilização do processo empregado, por exemplo, para o desenvolvimento do CMM. Essa abordagem é mais coerente com a melhoria de processo. Para o desenvolvimento dos níveis de maturidade sistêmica, foi identificado o processo fundamental de desenvolvimento utilizado no CMM.

$\mathrm{Na}$ década de 1980, Watts Humphrey (SEI) desenvolveu um framework com a finalidade de auxiliar as organizações a melhorar seus processos de desenvolvimento de software. Esse framework teve como base os grupos de software mais capazes que desenvolviam software para o governo federal americano. "Ao decidir como avaliar as organizações intensivas em desenvolvimento 
de software, primeiro foram listadas as características dos grupos mais capazes no desenvolvimento de software. Esse levantamento produziu um conjunto de 100 questões. Como esperávamos, essas avaliações seriam executadas pelo pessoal da Força Aérea e não por especialistas em software, o que levou as questões a terem como respostas atividades específicas do desenvolvimento que fossem facilmente compreendidas e verificadas pelos avaliadores. Uma vez que tínhamos as questões, enfrentamos outro problema: como pessoas que não eram especialistas em software poderiam usar o questionário para avaliar e classificar as organizações?. Era o início de outubro de 1986 e eu tinha tempo sobrando, então decidi trabalhar sobre o problema. Ocorreu-me listar essas 100 questões contra o quadro de maturidade de Crosby. [Em 1979, Philip B. Crosby propôs uma grade de maturidade da gestão da qualidade em cinco níveis, em termos de grau de maturidade dos processos de uma organização e de quão bem eles estão inseridos em sua cultura, com relação à gestão da qualidade do produto ou serviço]. Para minha surpresa, eles se encaixaram perfeitamente. Embora eu tivesse que redefinir os níveis de maturidade, não foi difícil classificar as perguntas na grade de maturidade." (HUMPHREY, 2002).

Ação similar com resultados semelhantes foi realizada no desenvolvimento do modelo de maturidade sistêmica. Os ciclos de aprendizagem propostos como uma primeira tentativa no sentido de um modelo de maturidade atuaram como a grade de maturidade de Crosby para a gestão da qualidade. O mapa sistêmico do SPB e suas variáveis críticas funcionam como as "100 questões" do SEI. O movimento que tem início no mapa sistêmico e segue na direção de um modelo de maturidade sistêmica é semelhante ao movimento ocorrido a partir das 100 questões do SEI em relação à grade de maturidade de Crosby. Também no caso do SPB, não foi difícil ajustar as variáveis e os ciclos de aprendizado aos níveis de maturidade.

Validação secundária 04: à dimensão de cooperacão de um modelo de

\section{desenvolvimento de software}

Foi também desenvolvido no projeto SPB um modelo de referência com base na cooperação para o desenvolvimento de software no seu contexto. A partir da análise das comunidades do SPB e de uma reflexão sobre a experiência anterior, conclui-se que há muitas abordagens para coordenar cada comunidade e que elas variam em um intervalo, da ênfase no "comando e controle" à ênfase na 
"cooperação e conexão". Assim sendo, o modelo de referência deve fornecer as melhores práticas e caminhos de melhoria que permitam a cada comunidade escolher um "ponto" nesse "intervalo" e orientar a melhoria com base nessa escolha. Quanto à ênfase no "comando e controle", já existem os níveis de capacidade estabelecidos pela norma ISO/IEC 15504 (SPICE), que foram incluídos no modelo como a dimensão de capacidade. O desenvolvimento do modelo de maturidade anteriormente citado incorporou em seus níveis de maturidade a dimensão da cooperação. O desenvolvimento desta dimensão cooperativa com base nos caminhos do modelo sistêmico de maturidade fornece alguma confiança sobre a qualidade desse modelo.

\section{Validação secundária 05: aplicação do modelo sistêmico}

Após a apresentação do trabalho "Brazilian Public Software: beyond Sharing" no ACM/MEDES 2010, The International ACM Conference on Management of Emergent Digital EcoSystems, a equipe do projeto SPB foi convidada para apresentar uma proposta para a chamada FP7-ICT-2011-UE-Brasil. O projeto tinha como objetivo principal replicar a experiência brasileira nas cidades europeias. Durante o processo de elaboração e discussão do projeto com os parceiros europeus, a equipe brasileira identificou uma incompatibilidade entre a estratégia da equipe e a dos parceiros. Com a utilização do modelo de maturidade para a compreensão sistêmica e com a indicação do foco do projeto, decidiu-se tentar compreender a posição do parceiro em termos do modelo de maturidade sistêmica. O resultado foi uma clara compreensão de quais eram e onde estavam as não-conformidades. As exigências colocadas pelos parceiros no que diz respeito ao ecossistema europeu estavam em um nível de maturidade muito além daquele em que o ecossistema se encontra hoje. O Ecossistema SPB está no nível 2 de maturidade. A meta da equipe CTI era levar esse ecossistema ao nível 3, por considerar que este objetivo era exequível mediante o orçamento e os prazos apresentados para o projeto. As exigências dos parceiros eram de levar o ecossistema para o nível 5, o que não era considerado viável. Portanto, a estrutura do modelo de maturidade sistêmica ajudou na construção de uma melhor compreensão sobre um problema referente à maturidade de ecossistemas. 


\section{CONSIDERAÇÕES FINAIS}

Os resultados desta tese, ratificam que é adequada a adoção da pesquisa-ação, como um mecanismo de realização de serviços de alto valor agregado com forte componente de pesquisa. Visando explorar a adoção da pesquisa-ação em situações, em que o problema e o escopo são indefinidos e, nas quais existe um alto grau de desestruturação, os resultados deste trabalho apontaram que essa é uma abordagem de pesquisa útil na condução das atividades, apesar das ameaças à sua validade, inerentes a esse tipo de investigação. A partir da busca constante do rigor metodológico, pode-se concluir que essa abordagem possibilitou $\mathrm{o}$ atendimento dos objetivos propostos, bem como o alcance dos resultados.

A realização da pesquisa trouxe contribuições para o Ecossistema SPB e, por tratarse de uma pesquisa-ação, essas contribuições são relevantes, pois um dos objetivos desse tipo de pesquisa é a maior aproximação entre o trabalho empírico e a teoria, na busca de solução para um determinado problema. Assim, a introdução de elementos de qualidade no ecossistema de produção de software trouxe uma maior capacitação desse ecossistema no que se refere à condução das atividades de desenvolvimento de aplicações de software de forma colaborativa e compartilhada, considerando o ecossistema como um corpo único que depende de suas partes para sua evolução e manutenção. Outro benefício obtido que pode ser citado é a criação de um grupo de interesse específico para tratar as questões de qualidade no ecossistema, o 5CQualiBr (http://goo.gl/2bP7N).

Para pensar sobre um modelo de maturidade para o SPB foi necessário utilizar conceitos teóricos que representam e explicam sua natureza. Os primeiros conceitos vêm da teoria do pensamento sistêmico. Essa abordagem sistêmica permitiu construir uma visão geral do Ecossistema SPB e entender como as suas variáveis se inter-relacionam e interagem. A análise do mapa sistêmico e a identificação das variáveis críticas nos ciclos de aprendizagem permitiram estabelecer suas dinâmicas internas. Os níveis de maturidade foram definidos com base nos ciclos de aprendizagem que emergiram do mapa sistêmico. Todo esse aprendizado foi transferido e apropriado pelo Ecossistema SPB.

O modelo de referência do Ecossistema SPB é um modelo construído para conduzir a evolução desse ecossistema, assim como para permitir que um novo usuário 
possa construir uma visão integrada dos vários elementos que o compõem. A estrutura conceitual do modelo de maturidade proposto é inovadora, uma vez que desloca o modelo de maturidade das empresas de desenvolvimento de software tradicionais para um outro tipo de arranjo produtivo: os ecossistemas digitais públicos, com produção de software cooperada e compartilhada.

Outro aspecto de diferenciação do modelo de referência proposto é que ele permite avaliar a maturidade dos ecossistemas com ênfase na cooperação e no compartilhamento, diferentemente dos modelos de maturidade convencionais que o fazem com ênfase em comando e controle. A caracterização do SPB é inspirada no conceito teórico mais amplo de ecossistemas e ecossistemas digitais. O SPB, assim como um ecossistema natural, é composto por elementos que se relacionam com a infraestrutura que os suporta, pelo relacionamento entre os atores e destes com a infraestrutura. A dinâmica resultante é expressa por meio da interação, do compartilhamento e da aprendizagem que são as características de um ecossistema. O SPB é um caso particular de um ecossistema público de produção de software. Assim é possível afirmar que o modelo construído para o Ecossistema SPB poderá ser generalizado tanto em escopo quanto em domínio.

Um aspecto importante do resultado dessa pesquisa são as validações realizadas e citadas anteriormente, que oferecem um nível de confiança suficiente de que a estrutura de medição proposta para o item 5 da norma ISO/IEC 15504-2 foi desenvolvida de forma aderente a essa norma. Para a comunidade SPICE o processo realizado e os resultados atuais podem ser usados como um caso de aplicação dos requisitos que serão definidos no framework de medição da norma ISO/IEC 33.000.

\subsection{CONCLUSÕES}

Esta seção tem quatro partes. A primeira responde a questão principal da pesquisa, a segunda responde as questões secundárias, a terceira examina se os objetivos gerais foram atendidos e a quarta verifica se os objetivos específicos foram atendidos. A qualidade, a avaliação e a validação do processo foram preocupações constantes durante todo o desenvolvimento desta pesquisa 


\subsubsection{QUANTO À QUESTÃO PRINCIPAL DA PESQUISA .}

O enunciado da questão principal é: "Como introduzir questões da qualidade em ecossistemas digitais públicos de produção colaborativa de software?"

O primeiro passo para responder esta questão foi descobrir a natureza do ambiente sobre o qual seriam feitas as intervenções com a finalidade de incorporar aspectos de qualidade. $O$ segundo passo foi entender o significado de qualidade para 0 ambiente da pesquisa. O que significa qualidade para o sistema? Que tipo de sistema deve ser melhorado? Qual a representação dele no mundo real? Quais são suas regras, dinâmicas, atores, enfim: o que é, como funciona e para quê? Qual a expectativa dos atores do sistema em relação ao projeto e ao ecossistema?

Com essas questões em mente, foi necessário procurar na literatura disponível o suporte teórico e metodológico que pudesse ser utilizado para responder a questão principal. As repostas foram encontradas nas teorias do pensamento sistêmico (a forma de abordagem), dos ecossistemas digitais (um ambiente com múltiplas espécies e capacidade de auto-organização), dos sistemas complexos (que metodologia utilizar para tratar um sistema soft) e de melhoria de processo e modelos de maturidade (afinal, o sistema produz aplicações de software). Com essa base teórica, foi possível construir os elementos utilizados como base para a construção do modelo de maturidade.

A dinâmica utilizada para a construção desses elementos foi bastante semelhante à usada por Humphrey quando da construção da primeira versão do CMM. Foi necessário utilizar ferramentas apropriadas para coletar dados que pudessem auxiliar na construção do modelo. No caso desta pesquisa, foi utilizada a SSM para coletar dados e informações e o PRO2PI-MFMOD para construir o método para gerar o modelo.

Durante a pesquisa ficou claro que a dimensão de capacidade de processo, da forma como é colocada na norma ISO/IEC 15504 e nos modelos da família CMM, que buscam o controle sobre os processos, não seria adequada. Outra dimensão deveria ser utilizada. A dimensão proposta nesta pesquisa é a "dimensão sistêmica", que deve avaliar os processos com o recorte sistêmico, da comunidade, da conexão, da cooperação, do compartilhamento e do conhecimento gerado em todo o ecossistema. Foram sugeridos oito níveis de maturidade, considerando a dimensão sistêmica para os processos. Os modelos convencionais possuem cinco níveis de 
maturidade cuja natureza difere dos oito níveis sugeridos que contemplam a dimensão sistêmica.

\subsubsection{QUANTO ÀS QUESTÕES SECUNDÁRIAS DA PESQUISA.}

A ordem das respostas às questões secundárias é diferente da ordem da seção 3.4.3. A numeração das questões foi mantida mas a sequência em que as perguntas foram respondidas é a que está representada a seguir.

Terceira: É possível avançar nos modelos de maturidade/capacidade para sistemas complexos utilizando os conceitos oriundos da Teoria do Pensamento Complexo (TPC)?

Sim, nesta pesquisa observou-se que o amparo teórico advindo da Teoria do Pensamento Complexo foi fundamental para indicar os elementos imprescindíveis para o modelo, bem como para garantir a robustez necessária para tratar as questões que esse tipo de sistema apresenta, conforme demonstrado na seção 5 , nos Momentos de Pesquisa 01 e 02.

Primeira: É viável que o processo de construção de uma visão de qualidade para redes virtuais incorpore a complexidade desses sistemas?

Para esta questão, a resposta é sim, com a ressalva de que, sem o auxilio das metodologias que incorporam essa complexidade, é impossível iniciar o processo de construção da visão de qualidade, uma vez que os elementos fundamentais para a construção são desconhecidos (Momentos de Pesquisa 01 e 02).

Segunda: Os modelos de maturidade/capacidade que tradicionalmente visam aprimorar a qualidade de um processo linear e bem delimitado são adequados para redes virtuais com papéis que se alteram e configurações mutantes?

Verificou-se que a capacidade, na definição dada pelos modelos de maturidade convencionais, não é apropriada. Foi então necessário buscar mecanismos que permitissem encontrar uma nova dimensão, diferente da capacidade, que fosse capaz de representar a maturidade desse tipo de sistema. No caso em estudo, a nova dimensão encontrada está relacionada aos ciclos de aprendizagem do sistema e à dimensão sistêmica (Momento de Pesquisa 03). 
Quarta: É possível, com a abordagem sistêmica, identificar algum tipo de padrão que abrigue e defina a dinâmica interna desse tipo de estrutura?

Sim, é possível. Com a aplicação da abordagem da Soft System Methodology foi possível coletar os dados necessários e com eles elaborar o mapa sistêmico ou diagrama causal. No mapa sistêmico foi possível analisar o comportamento das variáveis críticas do sistema e perceber padrões de comportamento, que foram denominados ciclos de aprendizagem e evoluíram para o modelo de maturidade.

Quinta: Quais são os elementos que compõem esse tipo de estrutura/padrão? Qual é a dinâmica resultante da interação, do compartilhamento e do aprendizado desses ecossistemas?

Com a aplicação da SSM e do PRO2PI-MFMOD foi possível desenvolver os elementos fundamentais para a elaboração da estrutura conceitual de modelos de maturidade para sistemas com as características do SPB. Esses elementos, que estão descritos no capítulo 5, são: os vetores fundamentais que promovem a melhoria do ecossistema, a unidade de avaliação composta por comunidade e solução, os níveis sistêmicos e o modelo de referência sistêmico.

Sexta: Quais são os elementos essenciais para uma possível avaliação de capacidade de ecossistemas complexos como o SPB?

Não foram propostos elementos de capacidade nesta pesquisa. A sua proposta refere-se a elementos de maturidade sistêmica. Para a avaliação da capacidade dos processos, poderá ser utilizada a estrutura proposta pela norma ISO/IEC 15504-2 ou desenvolvida uma nova estrutura a partir dos requisitos que serão definidos na série ISO/IEC 33000.

Sétima: Quais são os elementos essenciais para uma possível determinação da maturidade de ecossistemas complexos como o SPB?

A maturidade desses ecossistemas será determinada sempre com a avaliação dos processos que se referem à solução e à comunidade, conforme proposto na seção 5.

Oitava: Qual é o arcabouço teórico que deve ser utilizado para a estruturação dos elementos de um framework de um modelo de capacidade/maturidade para ecossistemas complexos como o SPB? 
O arcabouço teórico utilizado nesta pesquisa se mostrou adequado para tratar a questão da qualidade no SPB. Constituem esse arcabouço quatro eixos teóricos: sistemas complexos, pensamento sistêmico, ecossistemas digitais e modelos de maturidade.

Nona: É possível pensar em uma generalização dos conceitos elaborados para o framework de um modelo de maturidade desenvolvido para o SPB, considerando o SPB somente um caso de Ecossistema de Software Público (ESP)?

Sim, é possível pensar em generalização tanto de escopo quanto de domínio. 0 conjunto dos conceitos, metodologias e métodos utilizados nesta pesquisa podem ser replicados em outros ecossistemas com as características principais semelhantes às do SPB.

\subsubsection{QUANTO AO OBJETIVO DA PESQUISA.}

Primeiro: Criar uma estrutura de medição da qualidade do Software Público Brasileiro que considere as questões de maturidade e do pensamento sistêmico.

Este objetivo foi atingido ao longo da execução da pesquisa e, mais especificamente, durante a aplicação da pesquisa, descrita no capítulo 5.

\subsubsection{QUANTO AOS OBJETIVOS SECUNDÁRIOS.}

Primeiro: Proporcionar uma experiência que poderá ser usada como subsídio para os requisitos do framework de medição de processos para a nova norma ISO/IEC 33000 .

Como pode ser observado no capítulo 5, uma nova dimensão foi sugerida para o eixo de capacidade da norma ISO/IEC 15504-2. Essa nova dimensão pode ser um caso de estudo para a nova norma ISO/IEC 33000.

Segundo: Verificar a possibilidade de generalização do modelo, do caso particular, o Ecossistema SPB, para casos genéricos de ecossistemas digitais de natureza semelhante.

A generalização para outros ecossistemas semelhantes é possível, conforme mostra a validação dos resultados descrita no capítulo 5 . 
Terceiro: Avaliar a pertinência do uso dos conceitos e características das teorias de ecossistemas digitais, modelos de maturidade/capacidade, pensamento sistêmico e sistemas complexos.

A nona questão secundária, tratada anteriormente, responde esta questão.

Quarto: Aprender com a aplicação dos modelos conceituais SSM - Soft System Methodology e PRO2PI-MFMOD no processo de construção dos elementos do framework.

A utilização da SSM para estruturar o problema a ser resolvido foi fundamental para o avanço da pesquisa. Com ela, foi possível definir o escopo e estruturar o problema de forma que fosse possível a busca de uma solução adequada. A metodologia foi também útil para levantamento, coleta e análise de dados. O framework PRO2PIMFMOD guiou a pesquisa-ação na elaboração do método utilizado para definir os níveis de maturidade e deve ser utilizado para a construção do modelo de maturidade completo. Entretanto, para esse tipo de sistema, algumas recomendações de alteração serão feitas adiante, na seção "contribuições".

Quinto: Planejar, estruturar e executar uma pesquisa-ação concretizando os objetivos definidos.

A pesquisa-ação foi concluída e esta tese representa o seu produto de trabalho.

\subsection{CONTRIBUIÇÕES}

As contribuições desta pesquisa podem ser resumidas nos seguintes tópicos:

1. a alternativa dos modelos de maturidade, que podem agora optar em que posição devem ficar entre 0 intervalo comando/controle $e$ cooperação/conexão.

2. o deslocamento do objeto dos modelos de maturidade, de unidades organizacionais para redes públicas colaborativas de produção de software;

3. a disseminação e a apropriação do conceito de ecossistemas digitais pelo MCTI. A evidência objetiva dessa apropriação é a utilização do conceito na política "TI MAIOR- Programa Estratégico de Software e Serviços de Tecnologia da Informação" do MCTI. Essa política trata de doze ecossistemas. (http://goo.gl/UA3RZ); 
4. a emergência de um Laboratório de Políticas Públicas - POLITIC na Divisão de Melhoria de Processo de Software, DMPS/CTI. A execução da pesquisaação capacitou o grupo da DMPS no tratamento de problemas complexos e desestruturados, além de desenvolver competências no uso da pesquisaação, na metodologia SOFT e no PRO2PI-MFMOD;

5. os resultados dos trabalhos da pesquisa são utilizados pelo Ecossistema SPB, principalmente no relatório da perspectiva sistêmica que foi apropriado tecnologicamente por esse ecossistema;

6. a criação de um grupo de interesse específico para tratar as questões de qualidade no ecossistema, o 5CQualiBr (http://goo.gl/2bP7N) e, finalmente,

7. os níveis de maturidade propostos na pesquisa podem ser utilizados como um caso particular da dimensão capacidade da futura norma ISO/IEC 33000.

\subsection{TRABALHOS FUTUROS}

Uma vertente de investigação que pode ser abraçada a partir desta tese é o desenvolvimento completo do modelo e do método para avaliação da maturidade em ecossistemas digitais com características semelhantes às do SPB. Observou-se, durante o desenvolvimento desta pesquisa, que existe grande demanda para esse modelo, especificamente para avaliar esse tipo de organização.

Além da estruturação do modelo e do método de avaliação, é importante que eles sejam utilizados em outros ecossistemas, para evidenciar sua capacidade de aplicação em ecossistemas semelhantes ao SPB, como, por exemplo, o Sourceforge (http://sourceforge.net/) e outros ecossistemas de produção de software.

É importante também investigar os modelos de avaliação de produtos de software livre, como o Business Readiness Rating for Open Source (OpenBRR), Qualificação e Seleção de Software Open Source (QooS) e o QualiPSo OpenSource Maturity Model (OMM), para verificar a possibilidade de acrescentar a eles aspectos relativos ao ecossistema em que são produzidas as soluções de software. Outra vertente de investigação a ser explorada é a utilização das ferramentas empregadas nesta pesquisa em projetos do laboratório POLITIC, com o objetivo de elaborar uma metodologia genérica para o tratamento de problemas complexos. 
Outra possibilidade é a utilização da pesquisa-ação para conduzir todos os projetos do laboratório POLITIC, uma vez que eles sempre tratam da resolução de um problema e, a partir desse problema, ocorre uma pesquisa que leva a um avanço no conhecimento, como foi o caso deste trabalho.

Também podem ser conduzidas pesquisas para tornar as práticas sequenciais do PRO2PI-MFMOD adequadas para o caso de domínios e escopo desconhecidos, ou seja, executar as práticas sequenciais P1 e P2 várias vezes antes da definição da estratégia de desenvolvimento, de forma a definir as condições iniciais para a elaboração do método para o desenvolvimento do modelo de maturidade.

Outro assunto de pesquisa é a verificação da necessidade da existência da prática sequencial "P6 - validação da versão preliminar" em outros pontos do framework para validar, por exemplo, as condições iniciais para a construção do método. Com as alterações nas práticas sequenciais, faz-se necessário rever as regras de customização.

Finalmente, uma outra investigação sugerida é sobre o uso conjunto da SSM com a pesquisa-ação, de forma a potencializar os resultados dessas duas metodologias. 


\section{BIBLIOGRAFIA}

ABEP, Associação Brasileira das Entidades Estaduais de Tecnologia da Informação e Comunicação; 2007. Disponível em: http://goo.gl/OfsUx .

ABEPRO, Associação Brasileira de Engenharia de Produção. Referências de conteúdos da Engenharia de Produção. Disponível em: http://goo.gl/ove3S Acesso em: 25 jan. 2013.

ABNT: NBR ISO/IEC 15504 - Tecnologia de Informação - Avaliação de Processo, Parte 1 a Parte 5, Associação Brasileira de Normas Técnicas, 2008.

ABRAN ET AL. Guide to the Software Engineering Body of Knowledge SWEBOK, 2004 version, The Institute of Electrical and Electronics Engineers, Inc. - IEEE, 210 pages, 2004. Disponível em: http://goo.gl/TepGe. Ultimo acesso em 24/09/2013.

ACKOFF, RUSSELL L. Creating the Corporate Future. John Wiley \& Sons, 1981

AHERN, DENNIS M. et al. CMMI Distilled: A Practical Introduction to Integrated Process Improvement, SEI Series in Software Engineering, Addison-Wesley, 306 pg. 2001

ALTRICHTER, $\mathrm{H}$. et al. The concept of action research. The Learning Organization, v.9, n.3, p. 125-131, 2002.

ALVES, A. M.; et al .The Network Dynamics of the Brazilian Public Software. In: 3rd International Multi conference on Society, Cybernetics and Informatics, IMSCI, 2009, Orlando, FL. Proceedings of the 3rd International Multi-Conference 
on Society and Informatics, IMSCI. Winter Garden, FL, EUA: International Institute of Informatics and Systemics, IIIS, 2009. v. II. p. 31-36.

ALVES, A. M., et al. Towards a Systemic Maturity Model for Public Software Ecosystems. Published in: R.V. O'Connor et al. (Eds.): SPICE 2011, CCIS 155, pp. 145--156. Springer, Heidelberg (2011).

ANDRADE, Aurélio L. et al. Pensamento Sistêmico - Caderno de Campo. Porto Alegre: Bookman, 2006.

APPOLINÁRIO, F . Metodologia da ciência - filosofia e prática da pesquisa. São Paulo: Editora Pioneira Thomson Learning, 2006.

ARGYRIS C., PUTNAM, R., SMITH, D. Action Science: Concepts, Methods, and Skills for Research and Intervention. San Francisco, Jossey-Bass - 1985.

ASHBY, ROSS W. Uma Introdução à Cibernética. Ed Perspectiva S.A, São Paulo, SP, 1970.

AVISON, D.E.; GOLDER, P.A.; SHAH, H.U. Towards an SSM toolkit: rich picture diagramming. European Journal of Information Systems (1992) 1, 397-408. doi:10.1057/ejis.1992.17

AVISON, D. E.. Action Research, Communications of the ACM, Vol. 42, No. 1, January 1999, pp. 94-97.

BAR-YAM, Y. Dynamics of complex systems. Readings, Massachusetts: Addison-Wesley, 1997. 
BAR-YAM Y., Unifying Themes in Complex Systems: Proceedings of the International Conference on Complex Systems. Cambridge, MA: Perseus Press. 655 pages, 2000.

BASKERVILLE, R. Investigating Information Systems with Action Research Communications of the AIS, v.2, n.19, outubro. Disponível em: http://goo.gl/OfdtV. Ultimo acesso em março de 2012.

BEHRENS, M. A. O paradigma emergente e a prática pedagógica. Petrópolis/RJ: Vozes, 2005.

BENKLER, Yochai. The Battle over the Institutional Ecosystem in the Digital Environment. Communications of the ACM. Fevereiro, 2001. Vol.44. No. 2.

BENKLER, Yochai. La Economia Política Del Procomún. Novática (edição digital), n. 163, maio-junho de 2003. Disponível em http://goo.gl/jXeLAh.

BENKLER, Yochai. The Wealth of Nations: How Social Production Transforms Markets and Freedom. Yale University Press, 2006.

BERG, B. L. Qualitative Research Methods for Social Sciences. Editora Pearson Education, 2004, EUA

BERMEJO, J.. Arteologia. Disponível em http://goo.gl/k4cYG. Ultimo acesso em 24 de setembro de 2013.

BERTALANFFY, L. V.. Teoria geral dos sistemas. Editora Vozes Ltda, Petrópolis - RJ, 1975. 
BERTALANFFY, L. V.. Teoria geral dos sistemas, Petrópolis: ,Vozes, 1977.

BERTALANFFY, L. V.. General System Theory. New York: George Braziller, 1998.

BERTRAND, J. W. M.; FRANSOO, J. C. Modeling and simulation: operations management research methodologies using quantitative modeling. International Journal of Operations \& Production Management, v.22, n. 2, p. 241-264, 2002.

BORGATTI, R. Perspectivas da Complexidade Aplicadas a Gestão de Empresas. Tese de Doutorado apresentada no Programa de Pós-Graduação em Engenharia de Produção (PROD) na Escola Politécnica da Universidade de São Paulo (USP/POLI), São Paulo, 2008

BRERETON, Pearl et al. Lessons from applying the systematic literature review process within the software engineering domain. J. Syst. Softw. 80, 4 (April 2007), 571-583. DOl=10.1016/j.jss.2006.07.009 http://goo.gl/t2q9f

BRISCOE, G.; SADEDIN, S.; PAPERIN, G.. Biology of Applied Digital Ecosystems, Digital EcoSystems and Technologies Conference, 2007. DEST '07. Inaugural IEEE-IES, vol., no., pp.458-463, 21-23 Feb. 2007 DOI: 10.1109/DEST. 2007.372015

BROWN, J. et al. The World Café: Catalyzing Large-Scale Collective Learning. From Leverage Magazine, published by Pegasus Communications, Cambridge, MA, September 1999.

BRYMAN, A. Research methods and organization studies (contemporary 
social research). 1st edition, London: Routledge, 1989.

BUCKLEY, W..Sociologia e a Moderna Teoria de Sistemas. Editora da Universidade de São Paulo, SP, 1971.

BYRNE, DAVID. Complexity theory and social sciences: an introduction. New York: Routledge, 1998.

CAPRA, FRITJOF. O Ponto de Mutação. São Paulo, Cultrix, 1982.

CAPRA, FRITJOF. A Teia da Vida: uma nova compreensão científica dos sistemas vivos. Traduce: Newton Roberta Eichemberg. São Paulo: Cultrix, 1996. 256 p. Titular Original: the web of life: a new scientific understanding of living systems.

CARVALHO, B. V. Aplicação do método ágil Scrum no desenvolvimento de produtos de software em uma pequena empresa de base tecnológica. 2009. 100 f. Dissertação (Mestrado em Engenharia de Produção)-Universidade Federal de Itajubá, Itajubá, 2009.

CASTELLS, MANUEL. A Sociedade em Rede. São Paulo: Paz e Terra, 2008

CHANG, E.; WEST, M.. Digital Ecosystems: A Next Generation of Collaboration Environment for the Digital Networked Economy. The 8th International Conference on Information Integration and Web-based Application \& Services. December, Togyakarta, Indonesia (2006). Disponível em: http://goo.gl/M2hXn. Ultimo acesso em: 11/01/11

CHECKLAND, P.. The Shape of The Systems Movement. Journal of Applied 
Systems Analyses, (1979) 6, 129-135.

CHECKLAND, P.; Systems Thinking, Systems Practice. New York, John Willey \& Sons, 1981.

CHECKLAND, P. et al. The Systems Movement: Mappings and Conflicts. Journal of the Operational Research Society, (1983) 34, 661-675

CHECKLAND, P.. From Optimizing to Learning: A Development of Systems Thinking for the 1990s. Journal Operational Research Society. v. 36, n. 9, p. $757-767,1985$.

CHECKLAND, P. B.; HOWELL, S. E.. Action research: its nature and validity. Systemic Practice and Action Research, Vol, 11, No.1, p. 0-21. 1998.

CHECKLAND, P.; HOLWELL, S. Information, systems, and information systems: making sense of the field. Chichester: Wiley, 1988

CHECKLAND, P. Soft Systems Methodology: an overview. Journal of Applied Systems Analyses, (1988a) 15, 27-30.

CHECKLAND, P. Soft Systems Methodology. In: ROSENHEAD, Jonathan. Rational Analyses for a Problemátic World: Problems Structuring Methods for Complexity, Uncertainty and Conflict. John Wiley \& Sons, Chinchester, 1989.

CHECKLAND, P. \& SCHOLES Jim, Soft Systems Methodology in Action. Chichester, John Willey \& Sons, 1990

CHECKLAND, P. Systems theory and management thinking. American 
Behavioral Scientist, Vol. 38, No. 1, p. 75-91. 1994.

CHECKLAND, P. Varieties of Systems Thinking: the Case of Soft Systems Methodology. Systems Dynamic Review, (1994) 10, 189-197.

CHECKLAND, P. e SCHOLE, Jim. Soft System Methodology: a 30 year retrospective. John Wiley. Chichester, 1999.

CHRISSIS, MARY B. et al. CMMI: Guidelines for Process Integration and Product Improvement. 2nd edition, Addison-Wesley. 2003.

COUGHLAN, P.; COGHLAN, D.. Action research for operations management. International Journal of Operations \& Production Management, v.22, n. 2, p. 220-240, 2002.

CROOM, S.. Topic issues and methodological concerns for operations management research. In: Eden Doctoral Seminar on Research Methodology In Operations Management, Brussels, Belgium, 31st Jan.-4th Feb, 2005.

CROSBY, PHILIP. Quality is Free. McGraw-Hill. ISBN 0-07-014512-1.

CRYSTAL, David. Language and the Internet. Cambridge: Cambridge University Press, 2001.

CTI. CENTRO DE PESQUISAS RENATO ARCHER et al. Plano de Trabalho para o Projeto Modelo de Referência do Software Público Brasileiro - SPB. Campinas, SP. Versão 2.3, Maio 2007

CUSOMANO, M.A.; GAWER, A. The elements of platform leadership. Sloan 
management review, spring,. p. 51-58, 2007.

DAVISON, R.M. et al..Principles of canonical action research, Information Systems Journal (14), 2004, pp. 65-86.

DEMING, EDWARD W.. Out of the Crisis, Cambridge. MIT Center for Advanced Engineering Study, 1986

DEMO, PEDRO. Complexidade e Aprendizagem - a dinâmica não linear do conhecimento. São Paulo; Atlas, 2002.

DENNIS, A. R.; VALACICH, J. S. Conduction Research in Information Systems, CAIS - Communications of the Association for Information Systems, v. 7, artigo 5, julho. Disponível em: http://goo.gl/xoFbO Ultimo acesso em: maio de 2013..

DEST. Inaugural International Conference on Digital Ecosystems Technologies, Cairns, Austrália, 2007. Disponível em: http://goo.gl/abeJF , Ultimo acesso em: Fev 2011.

DICK, B., You want to do an action research thesis. Disponível em: http://goo.gl/dMNWc. Ultimo acesso em novembro de 2012.

DICK, B. You want to do an action research thesis? How to conduct and report action research, http://goo.gl/O2x14, 1992.

DICK, B. The Snyder evaluation process, http://goo.gl/nrSC3. Ultimo acesso em setembro de 2013. 
DICK, B.. Approaching an action research thesis: an overview. 1997. Disponível em http://goo.gl/V4iNt. Ultimo acesso em novembro de 2012.

DICK, B., Sources of rigour in action research: addressing the issues of trustworthiness and credibility. A paper presented at the Association for Qualitative Research Conference 'Issues of rigour in qualitative research' Disponível em: http://goo.gl/h3eEl. Ultimo acesso em agosto de 2012.

DICK, B., What is action research?. Disponível em : http://goo.gl/98s0lL. Ultimo acesso em setembro de 2013.

Dick, B. Postgraduate programs using action research, The Learning Organization, Vol. 9 No. 4, pp. 159-70, 2002..

DINI, P. et al. The Digital Ecosystems Research Vision: 2010 and Beyond. 2005. Disponível em: http://goo.gl/kD1gn. Ultimo acesso em julho de 2011.

DORLING, A.. Next Generation 15504 - the 33001 series of Standards UPDATE. Disponível em: http://goo.gl/J2h2G. Ultimo acesso em agosto de 2009..

EISENMANN, T. R.. Platform-mediated networks: Definitions and core concepts. Harvard Business School, Module Note No. 9-807-049, October, 2007.

ESCOBAR, Arturo. Welcome to Cyberia: Notes on the Anthropology of Cyberculture. Current Anthropology, Chicago, v. 35, n. 3, p. 211-231, jun. 1994 
FILIPPO, Denise Del Re. Suporte à Coordenação em Sistemas Colaborativos: uma pesquisa-ação com aprendizes e mediadores atuando em fóruns de discussão de um curso a distância. Tese de doutorado apresentada ao Programa de Pós-Graduação em Informática da PUCC-Rio. Rio de Janeiro. 2008.

FLOOD Robert L. \& CARLSON, Ewart R. Dealing With Complexity: Na Introduction to the Theory and applications of Systems Science. Plenum Press, New York, 1988.

FLORAC and CARLETON. Measuring the Software Process - Statistical Process Control for Software Process Improvement, 1999

FORRESTER Jay W.. Industrial Dynamics. New York, London. The MIT Press and John Willey \& Sons, 1961.

FORRESTER, Jay W. Principles of Systems. Productivity Press, Portland, 1990.

FORRESTER, Jay W. Principles of systems. Waltham, MA, EUA: Pegasus Com., 1999.

FREITAS, C. S. e MEFFE, Corinto. A Produção Compartilhada de Conhecimento: O Software Público Brasileiro. Informática Pública, ano 10, n. 2. p. 37-52, dez. 2008.

FUGGeTTA A. Software Process: A Roadmap, in Proceedings of Future of Software Engineering Workshop, In: ICSE, Limerick, Ireland, pp. 25-34. 2000. 
GIL, A. C. Como elaborar projetos de pesquisa. 3. ed. São Paulo: Atlas, 1991.

GLEICK, J. Caos: a criação de uma nova ciência. R. Janeiro: Campus, 1990.

GUBA, E. G., \& LINCOLN, Y. S. Competing paradigms in qualitative research. In N. K. Denzin \& Y. S. Lincoln (Eds.), Handbook of qualitative research (pp. 105117). London: Sage. 1994.

GUMMESSON, E. Qualitative Methods in Management Research. 2. Ed. Thousand Oaks: Sage Publications, 2000.

HARRISON, R.; BADOO, N.; BARRY, E.; BIFL, S.; PARRA, A.; WINTER B.; WUEST, J. Directions and Methodologies for Empirical Software Engineering Research. Empirical Software Engineering, v.4, n.4, p. 405-410(6), dezembro, 1999.

HAZDIC, M.; CHANG, E.; DILLONM Y. Methodology Framework for the Design of Digital Ecosystems. In Proceedings of the IEEE International Conference on Systems, Man and Cybernetics, 2007, pp. 7-12.

HERBSLEB, James et al. Software Quality and the Capability Maturity Model, in Communication of the ACM, Vol. 40, No. 6, pp. 30-40, June 1997.

HERR, K.; ANDERSON, G. L. The action Research Dissertation - A Guide for Students and Faculty.EUA: Sage Publications, 2005

HOSS, Marcelo. Soft Systems Methodology como forma de operacionalizar o processo de estruturação da transformação Lean sob a perspectiva da escola de pensamento evolucionária: uma pesquisa-ação. Tese de Doutorado apresentada no Programa de Pós-Graduação em Engenharia de 
Produção (PPGEP) da Universidade Federal do Rio Grande do Sul, UFRGS, 2011.

HULT, M. and LENNUNG, S-A. Towards a Definition of Action Research: A Note and Bibliography, Journal of Management Studies, May 1980, pp. 241-250.

HUMPHREY, Watts S., Managing the Software Process, Addison Wesley, Reading, Mass. USA, 1989.

IEEE: 610.12-1990 - IEEE Standard Glossary of Software Engineering Terminology.

IN01, BRASIL. Instrução Normativa no 1 de 17 de janeiro de 2011. Dispõe sobre os procedimentos para o desenvolvimento, a disponibilização e o uso do Software Público Brasileiro - SPB. Diário Oficial [da] República Federativa do Brasil (DOU), Poder Executivo, Brasília, DF, 17 jan. 2011. Seção1, p. 41

IN04, Instrução Normativa no 4 de19 de maio de 2008. Dispõe sobre o processo de contratação de serviços de Tecnologia da Informação pela Administração Pública Federal direta, autárquica e fundacional. Diário Oficial [da] República Federativa do Brasil (DOU), Poder Executivo, Brasília, DF, 20 maio 2008. Seçao1, p. 95-97.

INDRAWAN, M.; SEA, L.; SENG, L. Device Ecology: A Micro Digital Ecosystem. In Proceedings of the IEEE Inaugural Conference on Digital Ecosystems and Technologies, 2007, pp. 192-197, 2007.

ISO/IEC 20.000 2006, International Organization for Standardization and International Electrotechnical Commission. ISO/IEC 20000-1 Information Technology - Service Management, Part 1: Specification; ISO/IEC 20000-2 
Information Technology - Service Management, Part 2: Code of Practice, 2005. http://goo.gl/AFLSf

ISO/IEC 15504, Composed of seven parts (15504-1 to 15504-7) parts, under the general title Information technology — Process assessment, 2004-2008.

ISO/IEC 15504-1, The International Organization for Standardization and the International Electrotechnical Commission, ISO/IEC 15504 - Information Technology - Process Assessment - Part 1: Concepts and Vocabulary, 2004.

ISO/IEC 15504-2 2006, The International Organization for Standardization and the International Electrotechnical Commission, ISO/IEC 15504 - Information Technology - Process Assessment - Part 2: Performing an assessment. 2006.

ISO/IEC 15504-5 2006, The International Organization for Standardization and the International Electrotechnical Commission, ISO/IEC 15504 - Information Technology - Process Assessment - Part 5:An exemplar Process Assessment Model. 2006.

ISO 9001 2000. The International Organization for Standardization - Associação Brasileira de Normas Técnicas, NBR ISO 9001:2000 - Sistemas de gestão da qualidade - Requisitos, Rio de Janeiro, 2000.

ISO 9004 2000.The International Organization for Standardization - Associação Brasileira de Normas Técnicas, NBR ISO 9004:2000 - Sistemas de gestão da qualidade -diretrizes para melhorias de desempenho, RJ, 2000

ISO/IEC TR 15504-7 1998 The International Organization for Standardization and the International Electrotechnical Commission, ISO/IEC TR 15504-7 - Information Technology- Software Process Assessment - Part 7 : Guide for use in process 
improvement, Technical Report, 1998.

ISO/IEC 12207. Associação Brasileira de Normas Técnicas, NBRISO/IEC 12207 - Tecnologia de Informação - Processos de ciclo de vida de software, Rio de Janeiro, 1998.

IYER, B. E. A. Managing in a "Small world ecosystem": Lessons from the software sector. California Management Review, v. 48, n.3. Spring, p. 28-47, 2006.

JACKSON, Michael C. Systems Methodology for the Management Sciences. Plenum Press, New York, 1991.

JACKSON, Michael C. Social Theory and Operational Research Practice. Journal of the Operational Research Society, (1993) 44, 563-577.

JARRY RICHARDSON, R. Como fazer pesquisa-ação? 2009. Disponível em: http://goo.gl/kyq6N . Ultimo acesso em abril de 2012;

JOHNSON, A. P. A Short Guide to Action Research. 3.ed. USA: Ed. Pearson, ISBN-13: 978-0-205-50931-7;ISBN-10: 0-205-50931-2, 2008.

JONES, Steven G. Understanding Community in the Information Age. In: JONES, Steven G. (Org.). Cyber Society. Thousand Oaks (CA): Sage, 1995. p. 10-35.

JONES, Steven G. Introduction. In: JONES, Steven G. (Org). Cybersociety 2.0: Revisiting Computer-Mediated Communication and Community. Thousand Oaks 
(CA): Sage, 1998. p. 1-34.

JORDAN, Nehemiah. Temas de Psicología Especulativa. Editorial Troquel S.A., Buenos Aires, Argentina, 1974.

JURAN, Joseph M. Management of Quality Control, New York, New York:, 1967, OCLC 66818686

KANNAN, Rajkumar; Balasundaram, S.R. FREDERICK, Andres. The role of mulsemedia in digital content ecosystem design. MEDES'10 October, 26-29, Bangkok, Thailand, 2010.

KANTER, R.M.: When giants learn cooperative strategies. Planning Review, v.18, n.1, Jan/Feb, 1990.

KASPER, Humberto. O processo de Pensamento Sistêmico: Um Estudo das Principais Abordagens a partir de um Quadro de Referência Proposto. Dissertação de Mestrado apresentada no Programa de Pós-Graduação em Engenharia de Produção (PPGEP) da Universidade do Rio Grande do Sul (UFRGS), Porto Alegre, 2000.

KELTY, Christopher M. Two Bits: The Cultural Significance of Free Software. Durham: Duke University Press, 2008.

KEMMIS S.; MCTAGGART, R. Participatory Action Research: Communicative Action and the Public Sphere, Capítulo 23, The Sage Handbook of Qualitative Research Third Edition, Denzin, N. K.; Lincoln, Y. S. (eds) Sage Publication Inc, EUA, 2005. 
KITCHENHAM, B.A. Procedures for Performing Systematic Review.Tech.Report TR/SE-0401, Keele University, 2004.

KOCK, N.F. Can Action Research be Made More Rigorous in a Positivist Sense? The Contribution of an Iterative Approach, Journal of Systems and Information Technology, (1:1), 1997, pp. 1-24.

KREHER, H., Self-Organization and Soft Systems Methodology: And Inquiry in to Their Mutual Relationship and Relevance. Tesis Submitted for The Degree of Doctor of Philosophy. University of Lancaster, 1995.

KÜSTER, M.W.; LUDWIG, C.; ASCHENBRENNER. TextGrid as a Digital Ecosystem, in Inaugural IEEE International Conference on Digital Ecosystems and Technologies, Cairns Australia, 2007.

LAKATOS, E. M. Marconi, M. A. Fundamentos da Metodologia Científica. 4. ed. São Paulo: Atlas, 2006.

LANE, David. With a Little Help From our Friends: How System Dynamics and Soft OR Can Learn from each Other. Systems Dynamic Review, (1994) 10, 101- 134.

LANE, David. Can we Have Confidence in Generic structures? Journal of the Operational Research Society, (1998) 49, 936-947.

LEÓN, Lorena Rivera and DINI, Paolo. Digital Ecosystems in the EULAKS Project: Research context and strategies for the introduction of the Digital Ecosystem concept at the regional level. Department of Media and Communications. London School of Economics and Political Science. October 
2008 Licensed under Creative Commons 3.0.

LESSING, Lawrence. Code and Other Laws of Cyberspace. New York: Basic Books, 1999.

LESSIG, Lawrence. Free Culture: How Big Media Uses Technology and the Law to Lock Down Culture and Control Creativity. Penguin, 2004.

LESSING, Lawrence. Remix: Making Art and Commerce Thrive in the Hybrid Economy. New York: The Penguin Press, 2008.

LINCOLN, Y.; GUBA, E. Naturalistic Inquiry. Beverly Hills, EUA: Sage Publications, 1985.

MACHADO, ANGELA CRISTINA F., Definindo processos do ciclo de vida de software usando a Norma ISO/IEC 12207, publicação do curso de pósgraduação "Lato Sensu" / (Especialização) à distância em melhoria de processo de software, UFLA/FAEPE, 2003.

MARTINEZ, M. R. M. et al. Modelo de Capacidade de Processo para Serviços no Software Público Brasileiro. In: CONTECSI, 2011, São Paulo. Anais do 8. Congresso Internacional de Gestão da Tecnologia e Sistemas de Informação. São Paulo: FEA USP, 2011. p. 3383-3412.

MARUYAMA, Mogoroh. The Second Cybernetics: Deviating-Amplifying Mutual Causal Process. American Scientist, 1963.

MATURANA, H. R.; VARELA, Francisco J. A árvore do conhecimento: as 
bases biológicas da compreensão humana. São Paulo: Palas Athenas, 2001.

MCFEELEY Bob. IDEAL - A User's Guide for Software process Improvement, Handbook CMU/SEI-96-HB-001, 236 pages, 1996.

MCKAY J.; MARSHALL, P. The dual imperatives of action research. Information Technology \& People, v.14, n.1, MCB University Press, EUA, p. 46-59, 2001.

MCT: Projeto Modelo de Referência do Software Público Brasileiro, 2007

MCTAGGArt, R. Action Research: A Short Modern History, Deakin University Press, Geelong, 1991.

MEFFE, Corinto. A comunidade européia e o bem público software. Computerworld, 21 de dez. 2006.. Disponível em http://goo.gl/cDH9l. Publicada em 21 de dezembro de 2006.

MEFFE, Corinto.. O software público e a riqueza nacional. Computerworld, 11 de out. 2006b.

MEFFE, Corinto. Software Público: um novo ciclo econômico. 2009. Disponível em: http://goo.gl/msAvO

MEFFE, Corinto.. A Importância da Demanda e o Software Público. Computerworld, 30 de JUN. 2010. Disponível em http://goo.gl/fECth

MIGUEL, P. A. C. et al Metodologia De Pesquisa Em Engenharia De 
Produção E Gestão De Operações.1 ed. Rio de Janeiro: Elsevier, 99 p., 2010

MOGLEN, Eben.. Anarchism Triumphant: Free Software and the Death of Copyright. First Monday, v. 4, n. 8, 2 ago. 1999. Disponível em: http://goo.gl/JdXpP . Acesso em: 4 maio 2011.

MOORE, J. F. Business ecosystems and the view from the firm. Antitrust Bulletin, Vol. 51, No. 1, Spring 2006, p. 31-75, 2006.

MORECROFT, John e STERMAN, John. Modeling for Learning Organizations. Portland, Productivity Press, 1994

MORIN, Edgar. O método I: A Natureza da Natureza. Publicações EuropaAmérica Ltda, Portugal, 1977.

MORIN, Edgard. The Concept of System and the Paradigm of Complexity. In MARUYAMA, Mogoroh Context and Complexity: Cultivating Contextual Understanding. Springer-Verlag, New York, 1992.

MORIN, Edgard. Ciência com Consciência. BCD União de Editores S.A, Rio de Janeiro, RJ, 1996.

NACHIRA, F. Towards a Network of Digital Business Ecosystems Fostering the Local Development. European Commission Discussion Paper.2002.

NOMURA, Luzia. Definição e Estabelecimento de Processos de Fábrica de Software em uma Organização de TI do Setor Público. Tese de doutorado apresentada à Escola Politécnica da Universidade de São Paulo. Departamento 
de Engenharia de Produção. São Paulo-SP. 2008.

NAKANO, D. N.; Fleury, A. C. C. Métodos de Pesquisa na Engenharia de Produção. IN: XVI ENEGEP - Encontro Nacional de Engenharia de Produção, Anais. Piracicaba: UNIMEP/ABEPRO, 1996

NONAKA, I.; TAKEUCHI, H. Criação do conhecimento na empresa: como as empresas japonesas geram a dinâmica de inovação. Rio de Janeiro: Campus, 1997.

OSTERWEIL, L. Software processes are software too. In Proceedings of the 9th International Conference on Software Engineering (ICSE '87). IEEE Computer Society Press, Los Alamitos, CA, USA, 2-13, 1987.

OSTERWEIL L. Improving the Quality of Software Quality Determination Processes. In R. Boisvert, editor, The Quality of Numerical Software: Assessment and Enhancement. Chapman \& Hail, London, 1997.

O'TOOLE, PATRICK. Do's and Don'ts of Software Process Improvements, slides from tutorial presented at SIMPROS 2000 [Salviano e Santana 2000].

OQUIST, P. The epistemology of action research. Acta Sociológica, v.21, n. 2, 1978

PATTON, M. Q. Qualitative Evaluation and Research Methods. 2.ed. EUA: Sage Publications, 1990

PAULK, Mark C. et al. The Capability Maturity Model - Guidelines for Improving the Software Process, CMU-SEI, Addison-Wesley, 441 pages, 
1994.

PELTONIEMI, M. Business Ecosystem - a conceptual model of an organization population from the perspectives of complexity and evolution. e-Business Research Center, Research Reports 18,Tampere: Tampere University of Technology (TUT) and University of Tampere (UTA), 2005.

PERRY, C e ZUBER-SKERRITT, O. Action research within organizations and university thesis writing. The Learning Organization, vol. 9, no. 4, pp. 171-179. 2002.i

PERRY, C. e ZUBER-SKERRITT, O.. Action research in graduate management programs. First World Congress on Action Research and Process Management - Conference Proceedings, Brisbane: 1, 67-83. 1991.

Peterle, A.; MefFe, C.; CAStRo, C.; BRetAS, N.; SANTANNA, R. A Materialização do Conceito de Software Público: Iniciativa CACIC. Informática Pública, v. 07, set./2005 - fev/2006, Belo Horizonte, PRODABEL, 2006. p. $19-28$

PRIGOGINE, I., STENGERS, I. Order out of Chaos. - man's new dialogue with nature. New York: Bantam Books, 1984.

PROCERGS. Construindo uma plataforma tecnológica - Software Público Brasileiro. Documento interno da PROCERGS,2001.

PSPB. Portal do Software Público Brasileiro. Disponível em: http://www.softwarepublico.gov.br. 2011

RAYMOND, Eric S. The Cathedral and the Bazaar. 1997. Disponível em: 
http://goo.gl/QoEud. Acesso em: 2 maio 2011.

RAYMOND, Eric S.. Homesteading the Noosphere. 1998. Disponível em: http://goo.gl/o7lxB . Acesso em: 2 maio 2011.

RAYMOND, Eric S. How to become a hacker. 1999. Disponível em: http://goo.gl/zCim7 . Acesso em: 2 maio 2011.

RAYMOND, Eric S. O rei dos hackers. Revista do Linux, ano 1, no 9, set/2000, Curitiba: Conectiva S.A. p. 8-10

REIS, Christian Robottom. Caracterização de um Processo de Software para Projetos de Software Livre. Dissertação de Mestrado- ICMC/USP, 2003.

RESNICK, M. Thinking like a Tree (and other Forms of Ecological Thinking). International Journal of Computers for Mathematical Learning, 8, Kluwer Academic Publishers. Netherlands, pp 43-62, $2003 .$.

RESNICK, M. Sowing the Seeds for a More Creative Society. Learning and Leading with Technology, International Society for Technology in Education, Dec-Jan 2007-08, pp.18-22.

RICHARDSON, George. P. Introduction: Systems Thinkers, Systems Thinking. Systems Dynamics Review, (1994) 10, 95-98.

RIEL, M. Understanding Action Research, Center for Collaborative Action Research. 2007. Disponível em http://goo.gl/D0oAw . Acesso em: março de 2013. 
SALVIANO, C. F.: Uma proposta orientada a perfis de capacidade de processo para evolução da melhoria de processo de software (Portuguese) (A proposal oriented by process capability profiles for the evolution of Software Process Improvement), PhD thesis, FEEC Unicamp, 2006.

SALVIANO, Clenio F.; Tsukumo, Alfredo N.; Silva, L. P.; Santos, R. V. M.; Marinho, Wagner. Uma Estratégia para Melhoria de Processo de Desenvolvimento de Software Baseado em Componentes, in Anais do Quinto Simpósio Brasileiro de Qualidade de Software, Vitória, pp. 115-129 (2006).

SALVIANO, Clênio F. e SANTANA OZÉIAS V. (Editores), Anais e Slides das Apresentações do SIMPROS 2000: Segundo Simpósio Internacional de Melhoria de Processo de Software, São Paulo, 442 páginas, 2000

SEI, Software Engineering Institute, TR-24 e TR-25, 1993.

SEI, Software Engineering Institute, Capability Maturity Model @ Integration (CMMI SM ), Version 1.1, CMMI for Systems Engineering and Software Engineering (CMMI-SE/SW, V1.1) Staged Representation, Technical Report CMU/SEI-2002-TR-012 and ESC-TR-2002-012, 729 pages, March 2002.

SENGE, Peter M. A Quinta Disciplina - Arte, Teoria e Prática da Organização de Aprendizagem. São Paulo, Best Seller, 1990.

SENGE, Peter M.. KLEINER, Art, ROBERTS, Charlotte, ROSS, Richard \& SMITH, Brian. A Quinta Disciplina - Caderno de Campo. São Paulo, Qualitymark, 1995.

SHEARD, SARAH A., Evolution of the Frameworks Quagmire, IEEE 
Computer, July 2001.pp. 96-98.

SHEWHART, Walter A. Economic control of quality of manufactured product. Milwaukee: ASQ Quality Press, 1980. 501p.

SOMMERVILLE, I. Engenharia de Software. São Paulo: Pearson, $8^{\circ}$ edição, 2007

STACEY, R. D., Complexity and Creativity in Organizations, publicado em 1996.

STALLMAN, Richard. Palestra dada no I Fórum Internacional Software Livre Rio Grande do Sul, maio 2000. Vídeo completo incluído no CD-ROM da Revista do Linux, ano I, ำ 7, jul. 2000.

STALLMAN, Richard. The GNU Project, 1998. Disponível em: http://goo.gl/Ol45T. Acesso em: 5 maio 2011.

SUSMAN, G. I.; EVERED, R. D. An assessment of the scientific merits of action research. Administrative Science Quarterly, v. 23, December, 1978.

TAPSCOTT, Don. Wikinomics: Como a Colaboração em Massa pode mudar o seu Negócio. Rio de Janeiro: Nova Fronteira, 2007.

THIOLLENT, M.. Metodologia da pesquisa-ação. Coleção Temas Básicos de Pesquisa-ação, 2.ed. São Paulo: Editora Autores Associados, 1986.

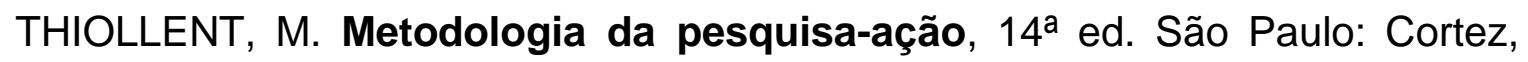


2005, Pósfacio, 1985, 132 p.

THIOLLENT, M. Metodologia da Pesquisa-Ação, Cortês Editora, 15ํeㄹçãa, 2007.

THOMPSON, F.; PERRY, C. Generalizing results of an action research project in one work place to other situations: principals and practice. European Journal of Marketing, v. 38, n. 3-4, p. 401-417, 2004.

TRONCALE, Len. The Systems Sciences: What Are They? Are They One or Many? European Journal of Operational Research 37 (1988) 8-33.

UDEN, L.; DAMIANI, E. The future of E-learning: E-learning ecosystem. Inaugural IEEE International Conference on Digital Ecosystems and Technologies, Cairns Australia, pp 113-117 (2007).

VILLIERS, M. R. Three approaches as pillars for interpretative information systems research: development research, action research and grounded theory. In: Proc. of SAICSIT - Annual Research Conference of the South African Institute of Computer Scientists and Information Technologists, 2005, p. 142-151.

WESTBROOK, R. Action Research, a New Paradigm for Research in Production and Operations Management, International Journal of Operations and Production Management, MCB University Press, UK, 15,2, 6-20, 1995.

WIENER, Norbert. Cibernética. Polígono e Universidade de São Paulo, São Paulo, SP 1970.

WIENER, Norbert Cibernética e Sociedade: o uso humano de seres 
humanos. Cultrix Ltda, São Paulo, SP, 1984.

YIN, R. K. Case study: design and methods. 3. Ed. Thousand Oaks: Sage Publications, 2002

YIN, R. K. Estudo de caso: planejamento e métodos. 3 ed. Porto Alegre: Bookman, 2005.

YOSHIDA, T. Soft Systems Methodology based on organizational knowledgecreation theory. In: RAGSDELL, G.; WEST, D.; WILBY, J. Systems theory and practice in the knowledge age. New York: Kluwer Academic - Plenum Publishers, 2002. p. 105-111.

ZOUCAS, A. C., THIRY, M., SALVIANO, C. F (2010)., Modelo de Capacidade de Processo para o Software Público Brasileiro, Anais do IX Simpósio Brasileiro de Qualidade de Software (SBQS), Belém, Pará, 8 a 11 de Junho de 2010. pp. 213-228.

ZOUCAS, A. C. ; THIRY, M. ; SALVIANO, C. F. . Modelo de Capacidade de Processo para o Software Público Brasileiro. In: Simpósio Brasileiro de Qualidade de Software, 2010, Belém, Pará. Anais do SBQS 2010. Belém, Pará: SBC, 2010. p. 213-228.

ZOUCAS, A.C. et al. Software Público Brasileiro: Rumo à Qualidade no Processo de Desenvolvimento de Software em Comunidades Virtuais. In: CONTECSI, 2011, São Paulo. Anais do 8. Congresso Internacional de Gestão da Tecnologia e Sistemas de Informação. São Paulo: FEA USP, 2011. p. 11931223. 


\section{ANEXO I LISTA DE PUBLICAÇÕES}

2011

ALVES, A. M., PESSÔA, M. S. P; SALVIANO, CLÊNIO F.. Towards a Systemic Maturity Model for Public Software Ecosystems. Published in: R.V. O'Connor et al. (Eds.): SPICE 2011, CCIS 155, pp. 145--156. Springer, Heidelberg (2011)

\section{0}

ALVES, A. M.,PESSÔA, M. S.; Brazilian Public Software and Quality.; IADIS/WWW/INTERNET 2010, International Association for Development of the Information Society -Timisoara, România, 12 a 19 de outubro, 2010, pp: 413-416.

ALVES, A. M,PESSÔA, M. S. P, Marcelo; STEFANUTO; Giancarlo; CASTRO, P. F. D. Paula F. D; Systemic Maturity Model and Brazilian Public Software; IEEE/PIC2010 - International Conference on Progress in Informatics and Computing Shanghai, China, 10-13 de dezembro de 2010. Digital Object Identifier: 10.1109/PIC.2010.5687921. Publication Year: 2010, Page(s): 1251 - 1256 IEEE CONFERENCES.

ALVES, A. M., STEFANUTO, Giancarlo N., CASTRO, P. F. D. ; PÊSSOA, M. S. P., Brazilian Public Software and Complexity, Published in proceedings of the BusCom 2010, Boston, Estados Unidos, from October 18 to 20.

ALVES, A.M. , PÊSSOA, M. S. P.; Brazilian Public Software: beyond Sharing.; ACM/MEDES 2010, The International ACM Conference on Management of Emergent Digital Eco Systems -Bangkok, Tailândia, 26 a 129 outubro, 2010, pp: 73 a 80.

AlVes, A. M.; Stefanuto, G.; CAStRo, P. F. D. ; EleutéRIO, S. V.; CARDOSO Jr., J. L.. Technological Appropriateness in the Brazilian Public 
Software Model. In: Electronic Proceedings of the 19th International Conference on Management of Technology (IAMOT), Cairo, Egypt, pp. 1-16, March 7-11 2010. IAMOT 2010 Proceedings of the 19th International Conference on Management of Technology. Miami, EUA: IAMOT, International Association for Management of Technology, 2010. v. 19

CARDOSO Jr., Jarbas L.; ALVES, A. M.; PAULA, A. L. L.; BARBIN, S. E. .The Certainty of Uncertainty, Managing Dynamic, Ambiguous and Non-linear Projects: the Brazilian Public Software Case. In: 19th International Conference on Management of Technology, IAMOT, 2010, Cairo, Egito. Proceedings of the 19th International Conference on Management of Technology. IAMOT 2010. Miami, EUA: IAMOT, International Association for Management of Technology, 2010. v. 19.

CARDOSO JR. Jarbas L., PAULA, André de, ALVES, A. M., BARBIN, Silvio; Congruência e Observância em Projetos Dinâmicos, Ambíguos e Não lineares. XVII SIMPEP, Simpósio de Engenharia da Produção - UNEP, Bauru, 8-10 de novembro, 2010. http://goo.gl/gFyBX . Ansis XVII (2010) ISSN 1809-7189

\section{9}

SALVIANO, C. F.; ZOUCAS, A. C.; SILVA, J. V. L.; ALVES, A. M.; WANGENHEIM, C. G. V. ; THIRY, M. . A Method Framework for Engineering Process Capability Models. In: European Systems \& Software Process Improvement and Innovation, 2009, Alcala de Henares. Industrial Proceedings 16th EuroSPI Conference. Copenhagen, Denmark: DELTA Series about Process Improvement, 2009. p. 6.256.36 .

ALVES, A. M.; CARVALHO, Marcius F. H.; CARDOSO Jr., Jarbas L.. The Network Dynamics of the Brazilian Public Software: the Managerial Aspects. In: 18th International Conference of the International Association for the Management of Technology, IAMOT, 2009, Orlando, EUA. Proceedings of the 18th International Conference of the International Association for the Management of Technology, 
IAMOT. Miami, EUA: IAMOT, International Association for Management of Technology, 2009. v. 18.

STEFANUTO, Giancarlo; ALVES, A. M.; CAVALCANTI, Rachel; CASTRO P. F. D. e ELEUTÉRIO, Sueli Varani. A new Approach of e-Gov Processes Development: the use of Complex Thinking Theory. In: International Conference on eGovernment, 5, 2009, Boston, EUA. Proceedings of 5th International Conference on e-Government.EUA: Academic Publishing Limited, 2009. P. 209 - 218.

ALVES, A. M et al. Brazilian Public Software and its Impact on Brazilian Society. In: International Conference on e-Government, 5, 2009, Boston, EUA. Proceedings of 5th International Conference on e-Government. EUA: Academic Publishing Limited, 2009. P. 187-191.

ALVES, A. M.; Carvalho, Marcius F. H.; CARDOSO Jr., Jarbas L. The Network Dynamics of the Brazilian Public Software. In: 3rd International Multiconference on Society, Cybernetics and Informatics, IMSCI, 2009, Orlando, FL. Proceedings of the 3rd International Multi-Conference on Society and Informatics, IMSCl. Winter Garden, FL, EUA: International Institute of Informatics and Systemics, IIIS, 2009. v. II. p. 31-36.

ALVES, A. M.; STEFANUTO, Gian; SALVIANO, Clenio; CASTRO, P. F. D. e MEFFE, Corinto Learning path to an emergent ecosystem: the Brazilian public software experience. In: Proceedings of the International Conference on Management of Emergent Digital EcoSystems (MEDES '09). ACM, New York, NY, USA, Article 71, 2 pages. DOI=10.1145/1643823.1643910. http://goo.gl//kPnk .

SALVIANO, Clenio F.; ZOUCAS, Alessandra; SILVA, Jorge V. L.; ALVES, A.M. ; WANGENHEIM, Christiane G. von and THIRY, Marcello. A Method Framework for Engineering Process Capability Models. EuroSPI 2009, The16th European 
Systems and Software Process Improvement and Innovation, Industry Proceedings, University of Alcala, Madri, Espanha, 2-4/9/2009

ALVES, A.M.; STEFANUTO, Giancarlo N.; CASTRO, P. F. D., VARANI, Sueli A.Software Público Brasileiro: muito além do compartilhamento de software. Revista INFOBRASIL, n. 7, Ano II, junho/agosto 2009, pp. 19-21.

CARDOSO, Jarbas L. Jr.; Rodrigues, Marcos Antonio; ALVES, A.M. Um modelo de referência para o Software Público Brasileiro, Revista INFOBRASIL, n. 7, Ano II, junho/agosto 2009, pp. 16-18.

2008

ALVES, A. M.; CARVALHO, Marcius F. H.; CARDOSO Jr., Jarbas L. A Dinâmica da Rede do Software Público Brasileiro. In: IADIS Ibero-Americana WWW/Internet, 2008, Lisboa, Portugal. Anais da Conferência IADIS Ibero-Americana WWW/Internet, 2008. Conferência IADIS Ibero-Americana WWW/Internet 2008 - ISBN: 978-9728924-72-0 @ 2008 IADIS

ALVES, A.M. Software Público Brasileiro: Reflexões. Anais da Conferência IADIS Ibero-Americana WWW/Internet 2008. Conferência IADIS Ibero-Americana WWW/Internet 2008 ISBN: 978-972-8924-72-0 @ 2008 IADIS

ALVES, A.M.; PÊSSOA, M. S. P.Gestão do Conhecimento e Melhoria de Processo de Software - Pesquisa-Ação. Conferência IADIS Ibero-Americana WWW/Internet 2008. ISBN: 978-972-8924-72-0 @ 2008 IADIS 
CARNEIRO, A. M.; ALVES, A. M.; STEFANUTO, G. N.; VEIGA, R.; SALLES FILHO, S..Propriedade intelectual na produção de software: um componente importante na equação de reuso. In: XII Seminário Latino-lberoamericano de Gestión Tecnológica - ALTEC 2007, 2007, Buenos Aires - Argentina. Gestión Tecnológica - ALTEC 2007, 2007. URL: (Carneiro et al., 2007: http://goo.gl/242Mw )

Os resultados da pesquisa-ação foram também publicados em duas revistas de Tecnologia da Informação:

O Software Público Brasileiro- Edição Especial. Revista Linux Magazine Especial \#6, Junho de 2011. URL:http://goo.gl/dWJzi

Software Público Brasileiro- Edição Especial. Revista INFOBRASIL, n. 7, Ano II, junho/agosto 2009 .URL: http://goo.gl/CQcyx

Os resultados também foram publicados no livreto Produtos do Vetor Ecossistema disponível em: http://goo.gl/KyeQO 


\section{ANEXO II REVISÃO SISTEMÁTICA DE LITERATURA}

\section{ASPECTOS CONCEITUAIS}

Este anexo busca, em um esforço de síntese, criar um arcabouço teórico que fundamente e oriente a pesquisa a ser desenvolvida nessa tese. Para tanto, são pesquisadas a teoria da complexidade, do pensamento sistêmico, dos ecossistemas digitais e dos modelos de maturidade, bem como seus principais conceitos e ideias.

\subsection{A METODOLOGIA}

Considerando que a revisão bibliográfica teria que dar conta de quatro temas conceituais, optou-se por dividir essa revisão em três passos: Passo 01- Visão Panorâmica, Passo 02 - Visão Focada e Passo 03 - Visão Detalhada.

O primeiro passo tem o objetivo de apresentar uma visão panorâmica dos recortes teóricos da pesquisa utilizando a metodologia de Revisão Sistemática de Literatura (RSL). A RS é utilizada na medicina e o seu uso no domínio da engenharia de software teve inicio em 2004 com Kitchenham (2004). Para a execução da RS foram levantadas as questões de pesquisa bem como uma primeira seleção das bases a serem pesquisadas. As bases e catálogos foram selecionados considerando as bases recomendadas por Kitchenham (2004) e Brereton (2006) para o domínio da engenharia de software. As questões de pesquisa têm o objetivo de apresentar a evolução e a tendência dos recortes teóricos considerando o conjunto de bases selecionado. Nesta fase foram elaboradas noventa sentenças de busca e foram pesquisadas onze bases e dois catálogos. Neste passo foi identificada uma revista específica para o tema "emergência" (Emergence: Complexity and Organization) e quatro para o tema "complexidade" (Journal of Systems Science and Complexity, Journal of Complexity, Computational Complexity e Complexity).

Com os resultados obtidos na RSL, executada no passo anterior este passo, Visão Focada, tem como objetivo selecionar as bases que são utilizadas para a continuação e o aprofundamento da pesquisa bibliográfica. Essas bases foram escolhidas considerando os seguintes critérios: 1) cobertura significativa em todos os temas e 2) publicações dos trabalhos relacionados a esta pesquisa. Foram selecionadas duas bases e nessas bases foram pesquisados os trabalhos relacionados aos temas da pesquisa e selecionados aqueles considerados mais 
relevantes. A relevância foi avaliada segundo o índice $\mathrm{h}^{16}$ do trabalho e a relevância do trabalho ou do autor no tema.

O passo Visão Detalhada consistiu na seleção dos trabalhos utilizados como referência para a elaboração do arcabouço teórico da pesquisa, considerando os passos anteriores. Também foram selecionados trabalhos considerados relevantes para o tema segundo o entendimento da autora. Neste passo, foi elaborado um formulário de análise para ser utilizado na leitura e avaliação dos trabalhos selecionados.

\subsection{O PROCESSO DE REVISÃO DE LITERATURA}

O objetivo deste item é apresentar os resultados obtidos com a aplicação da metodologia de revisão bibliográfica introduzida anteriormente.

\subsubsection{Visão Panorâmica}

\subsubsection{1 - Sem refinamento}

Para conhecer o comportamento do crescimento e as tendências dos trabalhos publicados nos quatro eixos teóricos foi feita uma primeira pesquisa, sem refinamentos no que se refere ao tipo de material pesquisado e área de concentração, nas bases Web Of Science, IEEEXplore, PROQUEST, Biblioteca Digital de Teses e Dissertações da USP e Microsoft Academic (Tabela 1)

Tabela 1 Bases utilizadas na pesquisa sem refinamento

\begin{tabular}{lll}
\hline Base & Característica & Endereço \\
Web Of Science & Grande volume de periódicos mundiais (8500) & $\underline{\text { http://isiknowledge.com }}$ \\
\hline IEEEXplore & $\begin{array}{l}\text { biblioteca digital do Institute of Electrical and } \\
\text { Electronics Engineers }\end{array}$ & $\underline{\text { http://ieeexplore.ieee.org }}$ \\
\hline PROQUEST & Vasta coleção de teses e dissertações & $\underline{\text { http://proquest.umi.com/i-std/pt/dis/contents.htm }}$ \\
\hline Bib Teses USP & Teses e dissertações da USP & $\underline{\text { http://www.teses.usp.br/ }}$ \\
Microsoft & Publicações em ciência da computação & $\underline{\text { http://academic.research.microsoft.com/ }}$ \\
Academic & &
\end{tabular}

\footnotetext{
${ }^{16} E$ uma proposta para quantificar a produtividade e o impacto de cientistas baseando-se nos seus artigos (papers) mais citados
} 
Foram utilizadas quatro sentenças de busca em cada uma das bases citadas, aplicadas nos campos de título e de resumo dos registros das bases. A Tabela 2 apresenta as sentenças utilizadas.

Tabela 2 Sentenças de busca sem refinamento

\section{Sentenças de Busca por Tema}

Complexity Theory OR Complexity OR Complex Thinking Theory

Systemic Thinking Theory OR Systemic Thinking OR Systems Thinking

Digital Ecosystems Theory OR Digital Ecosystems

Maturity Model Theory OR Maturity Model

O resultado da pesquisa nas bases de dados está apresentado na Tabela 3 e Gráfico 1 a seguir.

Tabela 3 Quantidade bruta de publicações por tema

\begin{tabular}{|l|c|c|c|c|c|}
\hline & WOS & IEEE Xplore & PROQUEST & Teses e Dissertações & Microsoft Academic \\
\hline Complexity & 100.000 & 93.353 & 180.239 & 11.811 & 9.670 \\
\hline Systemic Thinking Theory & 139 & 4 & 390 & 2073 & 2881 \\
\hline Digital ecosystems theory & 104 & 891 & 27 & 2258 & 307 \\
\hline Maturity model theory & 680 & 539 & 651 & 5600 & 2005 \\
\hline TOTAL & 100.923 & 94.787 & 181.307 & 21.742 & 14.863 \\
\hline
\end{tabular}

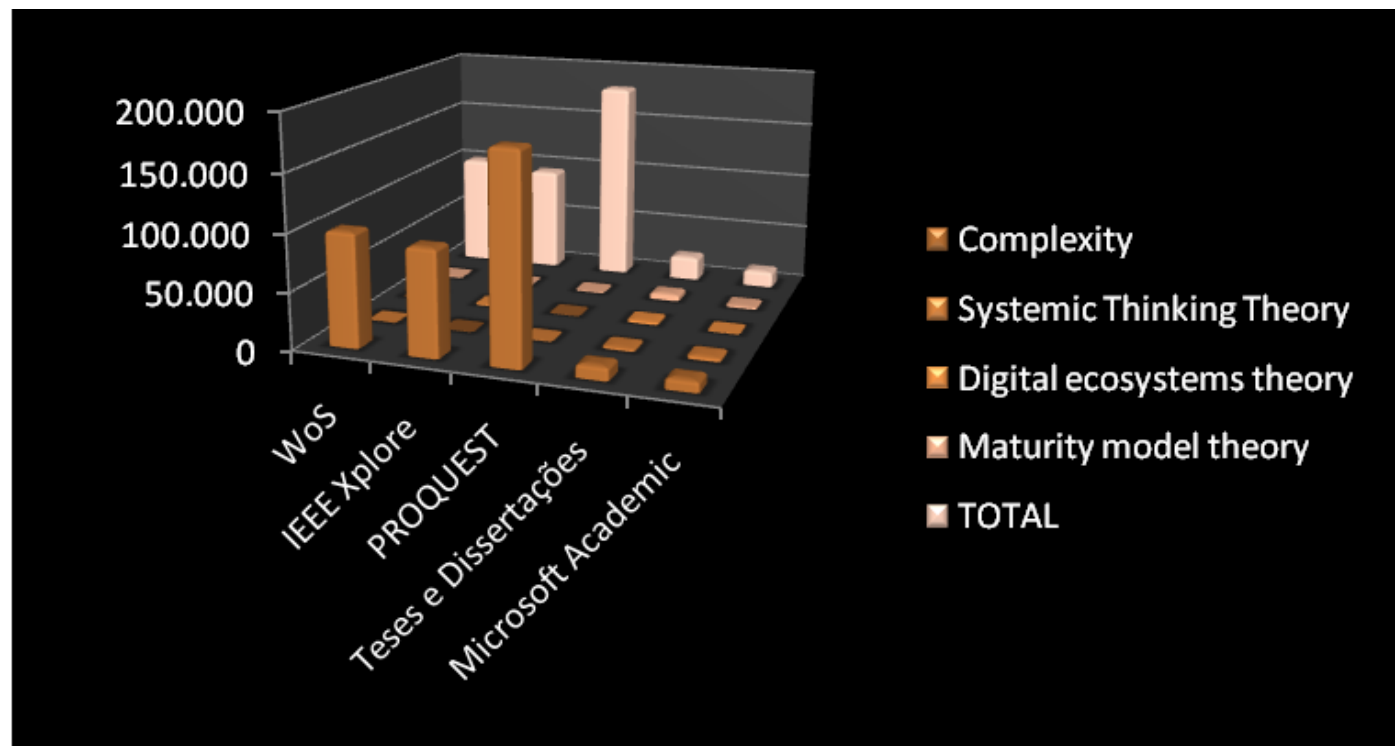

Gráfico 1 Quantidade bruta de publicações por tema

\section{CONCLUSÕES}

Esta primeira parte da pesquisa mostrou que, considerando todas as áreas do conhecimento disponíveis nas bases de busca, o eixo complexidade é o mais amplamente estudado, seguido pelos eixos modelos de maturidade, pensamento sistêmico e ecossistemas digitais. A diferença entre o primeiro e os três outros é 
significativa e da ordem de $10^{3}$. O eixo modelos de maturidade é mais referido na base de Teses e Dissertações.

É importante observar que o termo complexidade tem significados diferentes na Engenharia de Software. O primeiro significado está relacionado com o tamanho, a função, os casos de uso, etc. de um sistema de software. O segundo significado, que é utilizado nesta pesquisa, diz respeito à complexidade relacionada não apenas com o número de variáveis no sentido da extensão, mas com um conjunto de propriedades que permitem interpretar um fenômeno como complexo (DEMO, 2002).

\subsubsection{2 - Primeiro refinamento}

Nesse momento foram utilizadas as bases de dados nas quais seriam efetuadas as pesquisas. Foram consideradas as dez bases de dados que contêm trabalhos relativos ao domínio da Engenharia de Software. A pesquisa selecionou, dentro de cada base, as áreas das engenharias (ES) e da ciência da computação (CC). Foram selecionados somente os artigos. As bases pesquisadas foram: Web of Science, IEEEXplore, ACM Digital Library, Citeseer Library, INSPEC, Science Direct, EI Compendex, SCOPUS, WILLEY e SPINGER LINK (Tabela 4). As sentenças de busca utilizadas estão descritas na Tabela 5.

Tabela 4 Bases do primeiro, segundo e terceiro refinamentos

\begin{tabular}{|c|c|}
\hline Base & †t Endereço \\
\hline ACM Digital Library & http://portal.acm.org/ \\
\hline Bib Teses USP & http://www.teses.usp.br/ \\
\hline Citeseer Library & citeseer.ist.psu.edu \\
\hline El Compendex & uww.engineeringvillage2.org/Controller/Servlet/AthensService \\
\hline IEEEXplore & http://ieeexplore.ieee.org \\
\hline INSPEC & www.iee.org/Publish/INSPEC/ \\
\hline Microsoft Academic & http://academic.research.microsoft.com/ \\
\hline PROQUEST & http://proquest.umi.com/i-std/pt/dis/contents.htm \\
\hline Science Direct & www.sciencedirect.com \\
\hline SCOPUS & http://www.scopus.com/home.url \\
\hline SPRINGER LINK & http://www.springerlink.com/ \\
\hline Web Of Science & http://isiknowledge.com \\
\hline WILLEY & http://onlinelibrary.wiley.com \\
\hline
\end{tabular}


Tabela 5 Sentenças de busca do primeiro refinamento

\section{Ordem Sentença de Busca Primeiro Refinamento}

(Title ("complexity theory" OR complexity OR "complex thinking theory") OR

1 Abstract ("complexity theory" OR complexity OR "complex thinking theory")); model theory" OR "capability model" OR capability OR maturity)).

(Title ("systemic thinking theory" OR "systemic thinking" OR "systems thinking")

2 OR (Abs ("systemic thinking theory" OR "systemic thinking" OR "systems thinking"));

(Title ("digital ecosystems theory" OR "digital ecosystems") OR Abs ("digital

3 ecosystems theory" OR "digital ecosystems"));

(Title ("maturity model theory" OR "maturity model" OR "capability model

4 theory" OR "capability model" OR capability OR maturity) OR Abs ("maturity model theory" OR "maturity model" OR "capability model theory" OR "capability model" OR capability OR maturity)).

As sentenças foram elaboradas considerando os quatro eixos teóricos do trabalho separadamente. Cada um deles foi pesquisado nos campos de título e de resumo dos registros das bases.

As sentenças foram reescritas para cada uma das bases pesquisadas para atender os formatos exigidos para as sentenças de entrada para a pesquisa.

O resultado da pesquisa nas bases de dados está apresentado na Tabela 6 e no Gráfico 2 a seguir.

Tabela 6 Quantidade de publicações por tema na ES e na CC

\begin{tabular}{|l|c|c|c|c|c|c|c|c|c|c|}
\hline Primeiro Refinamento & WoS & IEEE & ACM & Citeseer & Inspec & Science Direct & Compendex & SCOPUS & Wiley & Springer \\
\hline Complexity & 4580 & 6297 & 220 & 9881 & 8632 & 2644 & 31850 & 416 & 2425 & 6045 \\
\hline Systemic Thinking & 37 & 0 & 0 & 0 & 0 & 0 & 0 & 195 & 0 & 0 \\
\hline Digital ecosystems & 267 & 0 & 0 & 0 & 0 & 0 & 0 & 113 & 0 & 0 \\
\hline Capability model theory & 974 & 0 & 0 & 0 & 0 & 0 & 0 & 9188 & 0 & 0 \\
\hline TOTAL & 5858 & 6297 & 220 & 9881 & 8632 & 2644 & 31850 & 9912 & 2425 & 6045 \\
\hline
\end{tabular}




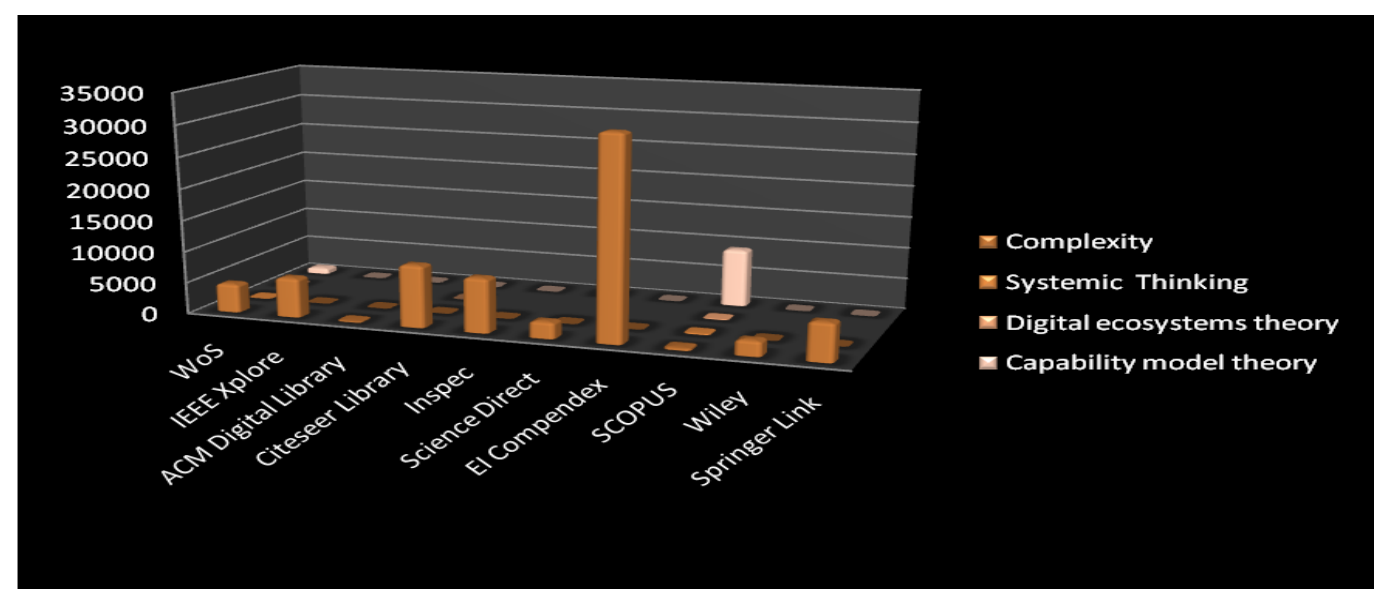

Gráfico 2 Quantidade de publicações por tema na ES e na CC

\section{CONCLUSÕES}

Nesta etapa, foram repetidas as sentenças de busca da etapa anterior e foram selecionadas somente as áreas do conhecimento engenharias e ciência da computação. O conjunto de bases foi maior e abrangeu bases indicadas para 0 domínio das engenharias.

A ordem verificada para a quantidade de trabalhos em cada eixo teórico, para este caso, foi: eixos complexidade, modelos de maturidade, ecossistemas digitais e pensamento sistêmico. A diferença das quantidades entre o primeiro e o segundo eixos e os demais é de ordem de $10^{3}$. É interessante das quantidades observar que na Web of Science foram encontrados 4580 artigos relativos à complexidade e 974 relativos a modelos de maturidade. Na SCOPUS foram encontrados 416 artigos sobre complexidade e 9188 sobre modelos de maturidade. O número de trabalhos recuperados em cada um dos eixos indica, neste caso, a maturidade do tema em termos de número de publicações. As ciências da complexidade antecedem os modelos de maturidade, o que era o esperado. Entretanto o eixo ecossistemas digitais, um tema mais recente, antecede o eixo pensamento sistêmico, este mais antigo.

\subsubsection{3 - Segundo refinamento}

Para este segundo refinamento foi utilizado o mesmo conjunto de bases e trabalhos utilizados no item anterior (Tabela 4). A sentença de busca utilizada encontra-se descrita na Tabela 7. 
Tabela 7 Sentença de busca do segundo refinamento Ordem $>$ Sentença de Busca Primeiro Refinamento

((((Document Title:("complexity theory" OR "complexity" OR "complex thinking theory")) AND (Document Title:("systemic thinking theory" OR "systemic thinking" OR "systems thinking")) AND (Document Title:("digital ecosystems theory" OR "digital ecosystems")) AND (Document Title:("maturity model theory" OR "maturity model" OR "capability model theory" OR "capability model" OR "capability" OR "maturity"))) OR ((Abstract:("complexity theory" OR "complexity" OR "complex thinking theory")) AND (Abstract:("systemic thinking theory" OR "systemic thinking" OR "systems thinking")) AND (Abstract:("digital ecosystems theory" OR "digital ecosystems"))

Para esta pesquisa a sentença de busca foi gerada considerando os quatro eixos teóricos e a busca foi realizada nos campos de título e de resumo dos registros das bases. A sentença foi reescrita para cada uma das bases pesquisadas para atender o formato exigido para a sentença de entrada para a pesquisa. O resultado da pesquisa nas bases de dados está apresentado na Tabela 8 e Gráfico 3 a seguir.

Tabela 8 Quantidade de publicações por tema na ES e CC

\begin{tabular}{|c|c|c|c|c|c|c|c|c|c|c|}
\hline Segundo Refinamento & WoS & IEEE & ACM & Citeseer & Inspec & Science Direct & Compendex & SCOPUS & Wiley & Springer \\
\hline $\boldsymbol{\Sigma}$ & 0 & 0 & 0 & 0 & 0 & 0 & 0 & 0 & 0 & 0 \\
\hline TOTAL & 0 & 0 & 0 & 0 & 0 & 0 & 0 & 0 & 0 & 0 \\
\hline
\end{tabular}

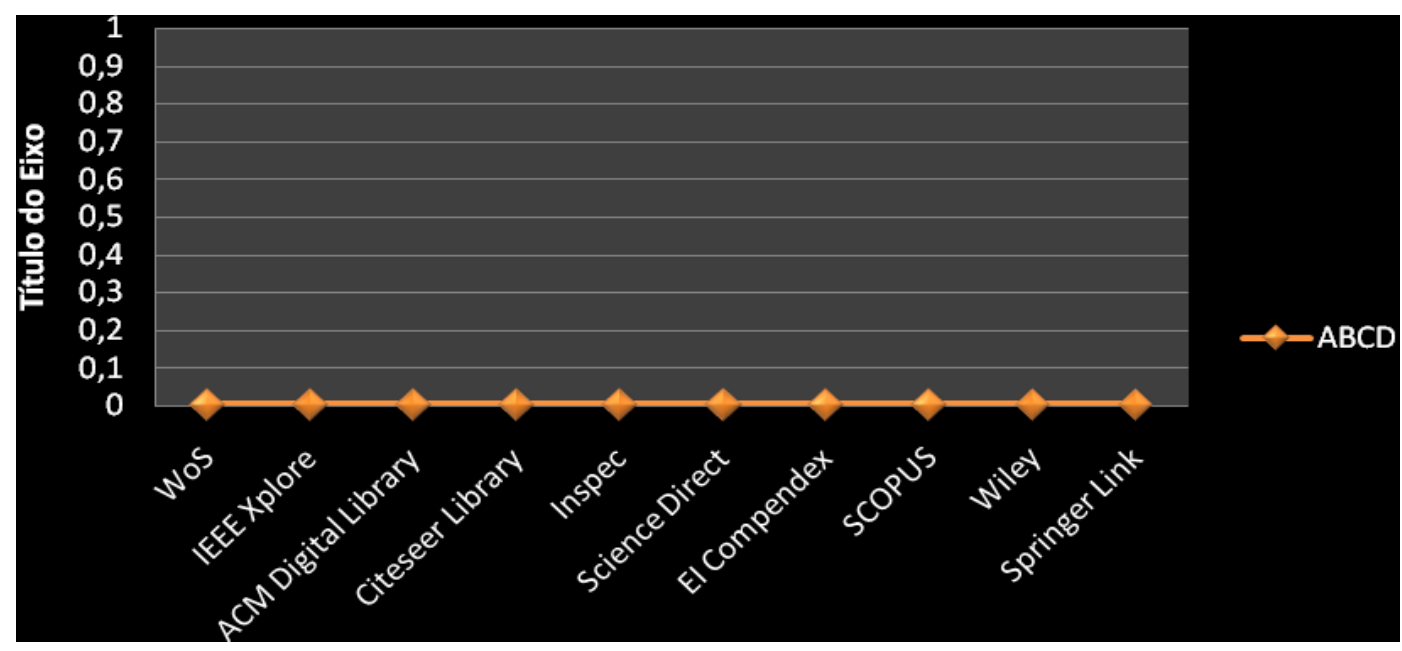

Gráfico 3 Quantidade de publicações por tema na ES e CC

\section{CONCLUSÕES}

Nesta etapa, em todas as dez bases, não foram encontrados artigos que tratassem dos quatro eixos teóricos conjuntamente. 
Com este resultado pode-se deduzir que a proposta deste trabalho de pesquisa, ou seja, utilizar os eixos teóricos da complexidade, do pensamento sistêmico, dos modelos de maturidade e dos ecossistemas digitais, em conjunto, para explicar um fenômeno emergente e elaborar um referencial teórico para o entendimento e o modelamento desse fenômeno, identificar as melhores práticas e percursos de aprendizagem, e organizá-los como ciclos de melhoria contínua é inovadora.

\subsubsection{4 - Terceiro refinamento}

Tabela 9 Sentença de busca do terceiro refinamento

\begin{tabular}{|c|c|}
\hline \multicolumn{2}{|c|}{ Ordem $\nabla$ Sentenças de Busca } \\
\hline 1 & $\begin{array}{l}\text { Tl=(("complexity theory" OR "complexity" OR "complex thinking theory") AND TI=("systemic thinking } \\
\text { theory" OR "systemic thinking" OR "systems thinking")) OR TS=(("complexity theory" OR "complexity" } \\
\text { OR "complex thinking theory") AND TS=("systemic thinking theory" OR "systemic thinking" OR } \\
\text { "systems thinking")) }\end{array}$ \\
\hline 2 & $\begin{array}{l}\text { Tl=(("complexity theory" OR "complexity" OR "complex thinking theory") AND TI=("digital ecosystems } \\
\text { theory" OR "digital ecosystems")) OR TS=(("complexity theory" OR "complexity" OR "complex } \\
\text { thinking theory") AND TS=("digital ecosystems theory" OR "digital ecosystems")); }\end{array}$ \\
\hline 3 & $\begin{array}{l}\text { (TI=("complexity theory" OR "complexity" OR "complex thinking theory") AND TI=("maturity model } \\
\text { theory" OR "maturity model" OR "capability model theory" OR "capability model" OR capability OR } \\
\text { maturity)) OR (TS=("complexity theory" OR "complexity" OR "complex thinking theory") AND } \\
\text { TS=("maturity model theory" OR "maturity model" OR "capability model theory" OR "capability model" } \\
\text { OR capability OR maturity)); }\end{array}$ \\
\hline 4 & $\begin{array}{l}\text { (Tl= ("systemic thinking theory" OR "systemic thinking" OR "systems thinking") AND Tl=("digital } \\
\text { ecosystems theory" OR "digital ecosystems")) OR (TS= ("systemic thinking theory" OR "systemic } \\
\text { thinking" OR "systems thinking") AND TS=("digital ecosystems theory"OR "digital ecosystems")); }\end{array}$ \\
\hline 5 & $\begin{array}{l}\text { ((Tl=("systemic thinking theory" OR "systemic thinking" OR "systems thinking") AND Tl=( "maturity } \\
\text { model theory" OR "maturity model" OR "capability model theory" OR "capability model" OR } \\
\text { "capability" OR "maturity")) OR (TS=("systemic thinking theory" OR "systemic thinking" OR "systems } \\
\text { thinking") AND TS=( "maturity model theory" OR "maturity model" OR "capability model theory" OR } \\
\text { "capability model" OR "capability" OR "maturity"))) }\end{array}$ \\
\hline 6 & $\begin{array}{l}\text { ((TI=("digital ecosystems theory" OR "digital ecosystems") AND TI=( "maturity model theory" OR } \\
\text { "maturity model" OR "capability model theory" OR "capability model" OR "capability" OR } \\
\text { "maturity")) OR (TS=("digital ecosystems theory" OR "digital ecosystems") AND TS=("maturity model } \\
\text { theory" OR "maturity model" OR "capability model theory" OR "capability model" OR "capability" } \\
\text { OR "maturity"))) }\end{array}$ \\
\hline
\end{tabular}

O terceiro refinamento foi executado em consequência dos resultados obtidos com a pesquisa no segundo refinamento. Conforme já se observou, o segundo refinamento não encontrou artigos que tratassem simultaneamente dos quatro eixos 
teóricos desta pesquisa. Considerando este resultado foi adotado um algoritmo de busca que realiza uma combinação dois a dois dos termos representativos dos eixos teóricos $\left(\mathrm{C}_{4,2}\right)$. As repetições foram desconsideradas. Para este terceiro refinamento foi utilizado o mesmo conjunto de bases e trabalhos utilizados no item anterior (Tabela 4). As sentenças de busca utilizadas na pesquisa às bases estão descritas na Tabela 9.

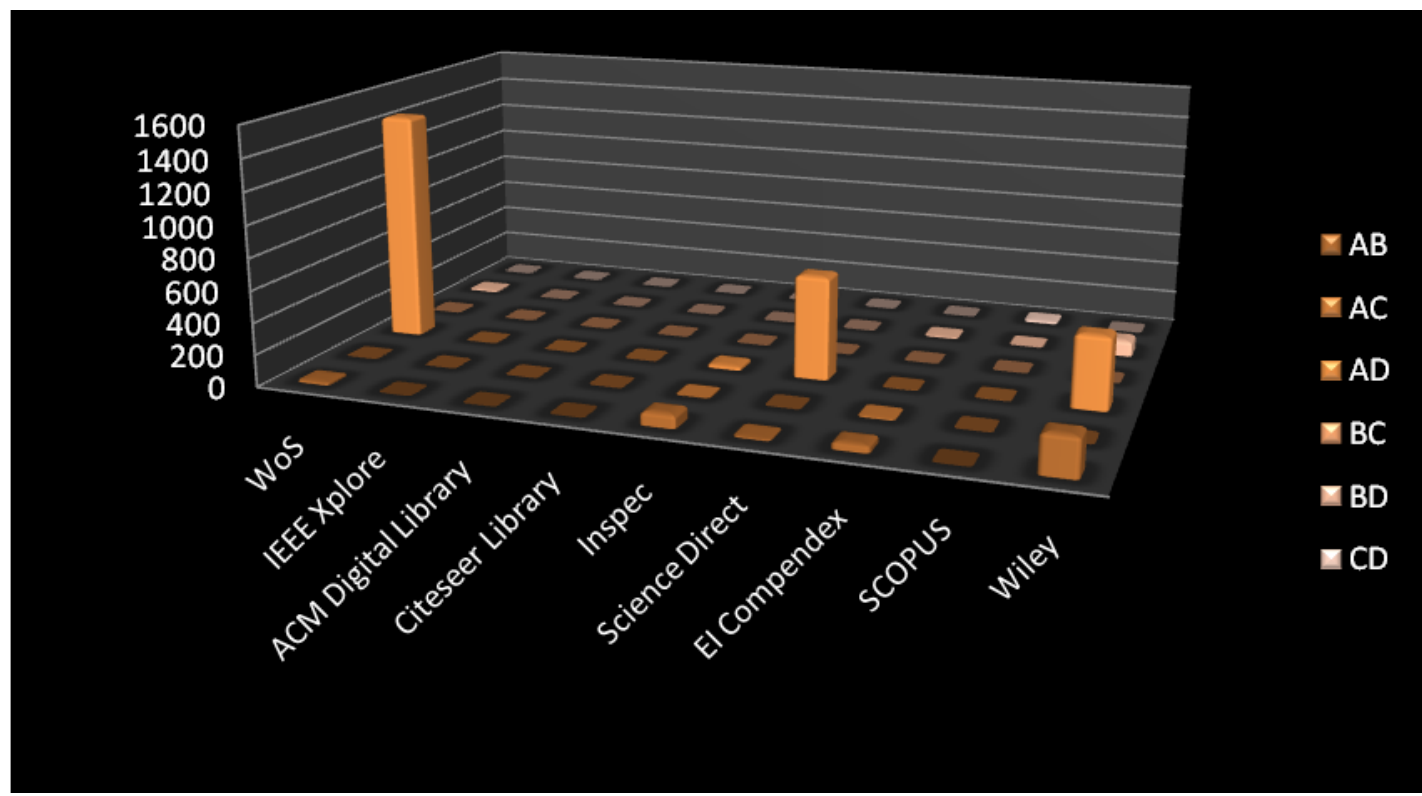

Gráfico 4 Quantidade de Publicações por Tema na ES e CC

\section{CONCLUSÕES}

Nesta etapa, em que foram utilizados pares de termos dos eixos teóricos, foram encontrados 2581 artigos que tratam simultaneamente dos eixos complexidade e modelos de maturidade, seguidos por 397 artigos que tratam simultaneamente dos eixos complexidade e pensamento sistêmico, 122 artigos que tratam simultaneamente dos eixos pensamento sistêmico e modelos de maturidade, 16 artigos que tratam simultaneamente dos eixos ecossistemas digitais e modelos de maturidade e 9 artigos que tratam simultaneamente dos eixos complexidade e ecossistemas digitais. Não foi encontrado nenhum artigo para os eixos pensamento sistêmico e ecossistemas digitais.

Este resultado aumenta a confiança nos resultados obtidos no item 1.2.1.2, que apontam uma baixa incidência de publicações dos eixos pensamento sistêmico e ecossistemas digitais, quando comparado com os demais. 


\subsubsection{Visão Focada}

Considerando os dados gerados nas várias etapas do passo anterior foram elaborados critérios para diminuir a amplitude e aumentar a profundidade da revisão.

O primeiro critério diz respeito à quantidade de bases a serem pesquisadas. Após a pesquisa nas dez bases do passo anterior identificou-se a existência de redundância de publicações e uma quantidade diferente de trabalhos por eixo teórico em cada base. Para definir as bases para o prosseguimento da revisão selecionaram-se aquelas com cobertura em todos os temas. As bases selecionadas foram Web of Science e SCOPUS.

O processo de pesquisa, utilizando as sentenças de busca apresentadas nos itens 1.2.1.2 e 1.2.1.4 foi realizado novamente nas bases escolhidas e os trabalhos recuperados foram selecionados considerando a sua aderência aos eixos teóricos da pesquisa. Para o eixo teórico ecossistema digital foi necessário realizar a pesquisa, em ambas as bases, nos Anais de Conferências e não somente em artigos como feito para os demais eixos teóricos. Nas bases pesquisadas não existiam artigos sobre esse eixo.

\subsubsection{Visão Detalhada}

Neste passo foram avaliadas as referências teóricas utilizadas em artigos escritos ao longo do período de 2005 a 2011 e com estrita relação com a pesquisa em desenvolvimento. Foram selecionados para utilização como referência teórica 53 artigos no eixo ecossistemas digitais, 28 artigos no eixo complexidade, 27 artigos no eixo modelos de maturidade e, 18 artigos no eixo pensamento sistêmico.

Ao conjunto de artigos selecionados foram agregadas duas dissertações de mestrado (KASPER, 2000) (GIOVANNINI, 2002) e uma tese de doutorado (BORGATTI, 2008), relativas aos eixos teóricos complexidade e pensamento sistêmico, respectivamente.

Além dos artigos citados, que estão relacionados com os eixos teóricos desta pesquisa, foram utilizados como referência para as metodologias empregadas no desenvolvimento do trabalho oito artigos sobre pesquisa-ação e catorze artigos para revisão sistemática de literatura. 


\section{CONCLUSÃO}

Os objetivos da revisão de literatura foram atingidos após a execução do processo. O primeiro objetivo, a verificação do caráter inédito do trabalho proposto, ficou demonstrado pelos resultados obtidos no item 1.2.1.3. Por sua vez o resultado das análises efetuadas no item 1.2.3 fornece subsídios para a elaboração do capítulo Revisão de Bibliografia desta pesquisa.

Com os resultados obtidos nesta revisão percebe-se que o tema complexidade é de longe, aquele com o maior número de publicações em journals, seguido pelo tema modelo de maturidade. O tema relativo ao pensamento sistêmico é o terceiro com maior número de publicações enquanto que o tema ecossistemas digitais é o que tem menor número de publicações e estas se encontram em anais de conferências.

A ausência de trabalhos que tratam os quatro eixos teóricos simultaneamente indica que a questão proposta por esta pesquisa é original e é um assunto de pesquisa. 


\section{ANEXO III ROTEIRO PARA ENTREVISTAS PRELIMINARES}

\section{Questões gerais}

1. Conhecer infraestrutura de apoio do SPB: pessoas, infra de TI, acesso, segurança, etc..

2. Realiar um tour virtual no SPB, visitando as comunidades, verificando quais os tipos de interações que aconteciam além de interagir com o pessoal técnico que coordena a comunidade, verificar os tipos de resultados obtidos, a intensidade do trabalho e a produtividade

\section{Questões específicas}

Estas questões devem auxiliar a indicar os contornos do modelo conceitual mais aderente a realidade do SPB. Nesse momento antes das entrevistas era possível identificar dois modelos capazes de explicar a realidade do SPB: a) Modelo 01 Atores-Entidades_Artefatos e b) Modelo 2 - Atratores e atores

Considerando os modelos foram feitas as seguintes perguntas:

\section{MODELO CONCEITUAL/INSTITUCIONALIDADE}

1. Como surge uma comunidade virtual? Surge a partir de demandas? De quem? Como se dá o processo?

2. Quais os fatores/motivações que parecem influenciar no surgimento/crescimento da comunidade virtual?

3. Houve comunidade que foi extinta? Que fatores levaram a isto?

4. Como se organiza a produção dentro da comunidade? Tem procedimentos pré-definidos pelo SLTI? Ela tem liberdade para criar seus próprios procedimentos?

5. Como se dá a coordenação das comunidades? Meritocracia? Quais os limites de poder do coordenador? Pode excluir membro da comunidade, por exemplo?

6. Quais os principais resultados positivos? Volume de interações? Produtos? Aprendizado? Aspectos sociais (capacitação, motivação, renda, etc.) - 
(existe uma taxonomia de classificação de perfil de usuário, dimensão econômica e dimensão social.)

7. Quais as principais motivações da comunidade, do MPOG/SLTI, MCT, empresas, pesquisadores, etc., na participação no SPB?

8. Qual a visão de futuro para a institucionalidade do SPB?

\section{TECNOLOGIA, QUALIDADE E PROCESSO/PRODUTO.}

1. - Quais os principais problemas ocorridos no âmbito do SPB em termos de infraestrutura, comportamento da comunidade, segurança, discordância de procedimentos, falhas de processo produtivo, etc.?

2. - quais os critérios de qualidade vigentes no SPB?

a. Teste de soluções

b. Substituição de versão - controle, necessidade, etc.;

c. Erros - como a comunidade se comporta?

d. Qual o tempo de resposta pra correção de um bug detectado pela comunidade?

e. Requisitos técnicos para entrada de um software

3. quais os tipos e intensidades de participações : desenvolvimento, usabilidade, troca de conhecimentos técnicos, etc.;

4. há um retorno da comunidade sobre a aceitação de uma solução? é viável e operacional fazer tal análise pela comunidade?

5. há algum controle de dowloads de soluções no sentido de identificar o perfil do usuário? Há algum feedback dos usuários? Os problemas identificados pelos usuários são repassados para a comunidade virtual? As dificuldades de implantação são recorrentes?

\section{MODELO DE NEGÓCIOS (prestação de serviços, modelos de negócios)}

1. - Quais os tipos de demandas de serviços/produtos que chegam e que podem chegar ao SPB? Como (Se) estas demandas se transformam em comunidades virtuais? 
2. - Como se dá a comercialização de serviços (mercado público) em termos de processo?

3. - Quais os resultados que vem sendo obtidos?

4. - Quais os limites de atuação do SPB como fornecedor de serviços? É só um espaço de agenciamento ou participa da negociação, garante qualidade, etc.?

5. - Há uma visão normativa a respeito da evolução de modelos de negócios para o SPB?

6. - No momento quais são os principais obstáculos jurídico-institucionais para evolução do modelo de negócios no SPB?

7. - Quais os principais impactos visíveis com a economia do conhecimento no SPB? Geração de renda? aumento de competitividade das empresas, criação de empresas, melhoria da imagem (visibilidade) da empresa e mesmo do MPOG?

8. - sobre as empresas criadas, qual o grau de mortalidade? Quantas pessoas aproximadamente são empregadas nestas empresas?

\section{CIÊNCIA, TECNOLOGIA E INOVAÇÃO}

1. -qual o grau de novidade das soluções encontradas no SPB? são novas para o país? Para o mundo?

2. -existe uma definição de parâmetro/escala do que representa o grau de novidade de uma solução?

3. quantas soluções já possuem registro no INPI? Outro tipo de registro/licença?

4. em relação à produção acadêmica? Há teses, dissertações, artigos (nacionais e internacionais) gerados no âmbito do SPB? Em caso positivo, quais as publicações?

5. o SLTI oferece cursos aos usuários? Quais e quantos?

\section{GESTÃO DO CONHECIMENTO}

1. -Como se dá efetivamente a apropriação do conhecimento gerado?

2. -Como se dá a gestão do conhecimento no SPB? Já há alguma estratégia, ferramentas, pensadas? 
3. Qual a estratégia de junção dos diferentes blocos do SPB (Catir, $4 \mathrm{CMBr}$, Mercado Público e o Portal SPB) no sentido de produção de conhecimento? Como se complementam? Qual a função de um para outro?

4. Há uma estratégia de atrais novos públicos para geração do conhecimento no SPB? Públicos menos especializado, policy makers, imprensa, terceiro setor, pequenas prefeituras? 


\section{ANEXO IV CONSTRUÇÃO DO PROPÓSITO E VISÃO DO SPB}

\section{METODOLOGIA}

O exercício foi desenvolvido por meio de uma metodologia conhecida como "Café Mundial". Essa metodologia foi inspirada nos momentos de coffee break de eventos, quando especialistas perceberam, que essas pausas eram um momento extremamente produtivo e rico e quando vários diálogos eram estabelecidos.

A essência da metodologia é estabelecer uma rede de diálogos entre diferentes atores e, ao fim, construir um resultado comum, com a colaboração de todos. Essa prática propicia a emergência de uma inteligência coletiva.

O Café Mundial consiste na separação dos participantes em grupos menores e heterogêneos, organizados em torno de uma mesa, que têm como meta responder a uma questão ampla e pertinente ao grupo. Após um tempo pré-determinado, este grupo é mesclado com os participantes de outras mesas, permanecendo na mesa 0 anfitrião, aquele que tem o papel de relatar para o novo grupo a discussão do grupo anterior. Esta dinâmica pode ser repetida inúmeras vezes. Neste exercício no CTI foi repetida três vezes. Ao final, a mesa apresenta para as demais a resposta final da pergunta colocada. O facilitador do exercício, busca integrar as respostas das mesas e gerar uma única, que contemple todas as demais.

Outro ponto importante a ser destacado na metodologia, é que o ambiente deve permitir bastante descontração, de forma que as pessoas se sintam à vontade para criar e colocar o que pensam para o grupo. Assim, em todas as mesas é disponibilizado papel à vontade, diversos tipos de lápis e canetas coloridas (quando possível, até alguns "brinquedos") para que as pessoas possam criar suas ideias em um clima lúdico e deixando de lado o formalismo. O coffee break também é servido ao mesmo tempo.

Construção do Propósito do SPB

Para a construção do propósito do SPB, a facilitadora colocou ao grupo a seguinte questão:

\section{"Qual o propósito do SPB?"}

Frisando que o propósito: 
- deve ser uma afirmação de intenções claras e simples;

- é mais do que a descrição do que acontece internamente

- é aquilo que as pessoas, em conjunto querem e podem realizar

- é a razão de existência do grupo

- é transparente e direto

Os participantes se reuniram em pequenos grupos, distribuídos em 5 mesas.

As respostas resultantes de cada mesa, para a questão formulada foram para cada mesa:

Mesa 1 - Anfitriã: Dra. Cristiana Freitas

"Promover um ambiente sustentável de produção de conhecimento compartilhado destinada a distribuir soluções de TI que favoreçam o desenvolvimento econômico brasileiro."

Mesa 2- Anfitriã: Paula Drummond

"Construir e aprimorar continuamente uma rede de competências para colaboração e compartilhamento de soluções de interesse público visando o desenvolvimento tecnológico, social e econômico."

Mesa 3 - Anfitrião: Miguel

"Construir na forma de conhecimento compartilhado e distribuir para comunidade soluções de TI para desenvolvimento tecnológico".

Ambiente que propicie soluções.

Rede pública e dinâmica desenvolvida de modo compartilhado visando o desenvolvimento econômico técnico e social.

"Nome impróprio do SPB."

Mesa 4-Anfitriã: Maria Antonia

"Construir de forma colaborativa soluções de TI e disponibilizá-los como bem público".

Mesa 5 - Anfitrião: Giancarlo Stefanuto

"Construir uma rede de produção colaborativa de conhecimentos (relacionados a software) para ampliar o uso eficaz de TI e gerar novos negócios."

Resultado final, após discussão com todos: 


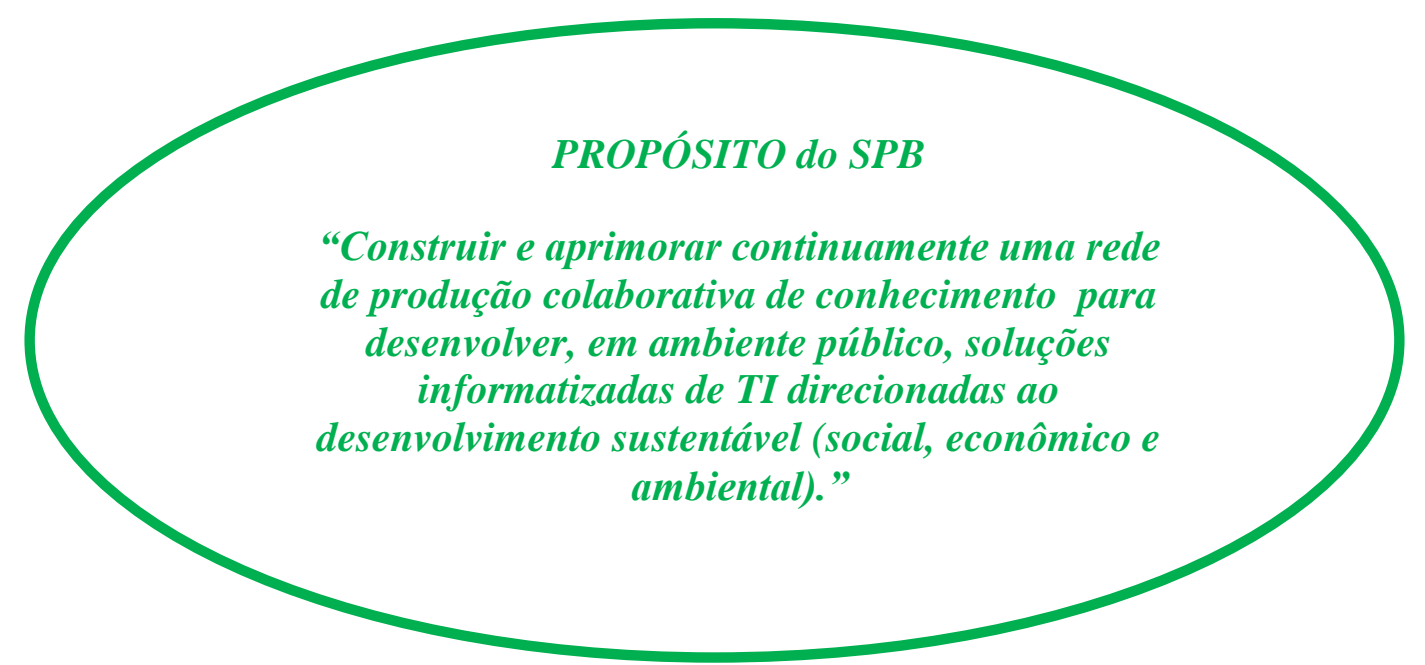

O propósito acima enunciado chama a atenção inicialmente para três aspectos do SPB: rede de produção, colaboração e conhecimento. O fato de o SPB definir-se como "rede de produção" evidencia a tendência mundial de organizar-se em rede visando potencializar cada ponto e promover de forma eficaz a disseminação de ideias. $O$ aspecto colaborativo confirma a essência de uma rede não hierárquica que se alimenta pela atividade cooperativa entre os atores envolvidos. Um avanço no conceito de SPB é entender esta rede colaborativa tomada em seu propósito como algo mais amplo e abrangente do que exclusivamente a produção de softwares, ou seja, como a produção de conhecimento agregado à criação de soluções informatizadas de tecnologias da informação. Essa expressão traz em si uma compreensão maior do que se deriva dessa produção.

A grande novidade que o conceito de Software Público carrega e evidentemente transparece em seu propósito é o fato de ser desenvolvido em um ambiente público. Este aspecto procura trazer para o ambiente de produção colaborativo a neutralidade e a segurança necessárias para um desenvolvimento fértil de ideias e não o comprometimento com interesses escusos.

Nestes termos, o ambiente SPB proporciona oportunidade de desenvolver conhecimento relacionado a TI que viabiliza o desenvolvimento sustentável do país. Sustentável em sua compreensão mais ampla que apreende as dimensões social, econômica e por extensão, ambiental. No âmbito social, ao facilitar o acesso gratuito ao conhecimento. Na esfera econômica, uma vez que promove a geração de renda e impacta com diferente intensidade o setor de TIC. E finalmente na dimensão 
ambiental o SPB possibilita, por meio de geração de ferramentas e interpretações de dados, a ampliação do conhecimento da atuação do homem no seu meio, logo a capacidade de transformá-lo. Com tudo isso, o propósito do SPB pode parece ambicioso, mas ele pretende ser uma afirmação clara e simples de suas intenções e reflete aquilo que realmente se deseja: um desenvolvimento verdadeiramente sustentável.

\section{Construção da Visão do SPB}

Para a construção coletiva da visão do SPB, a facilitadora colocou a seguinte questão:

\section{"Qual a visão do SPB para daqui a 5 anos?}

Entendendo que visão:

- é o conjunto de convicções e compreensões do grupo sobre a direção para qual a organização deve seguir;

- deve orientar o planejamento estratégico.

- é aquilo que queremos criar, é o sonho coletivo

Novamente os participantes se reuniram em pequenos grupos, distribuídos em 4 mesas.

As respostas resultantes de cada mesa, para a questão formulada acima, foram:

\section{Mesa 1 e 2:}

"O SPB como referência nacional e internacional promovendo continuamente a aprendizagem em redes colaborativas e criando novas oportunidades para pequenos desenvolvedores."

\section{Mesa 3:}

"Tornar o Brasil um centro de excelência internacional (de conhecimento) em produção colaborativa de soluções de TI para o ambiente público."

\section{Mesa 4:}

"Ter uma rede de produção colaborativa, ativa, bem populada, com muitas interações, produzindo soluções com alto impacto no bem estar da sociedade." 


\section{Mesa 5:}

"Conceito consolidado e o modelo apropriado pela sociedade, cultura e ação fluindo dinamicamente."

Resultado final após intensas discussões com todos:

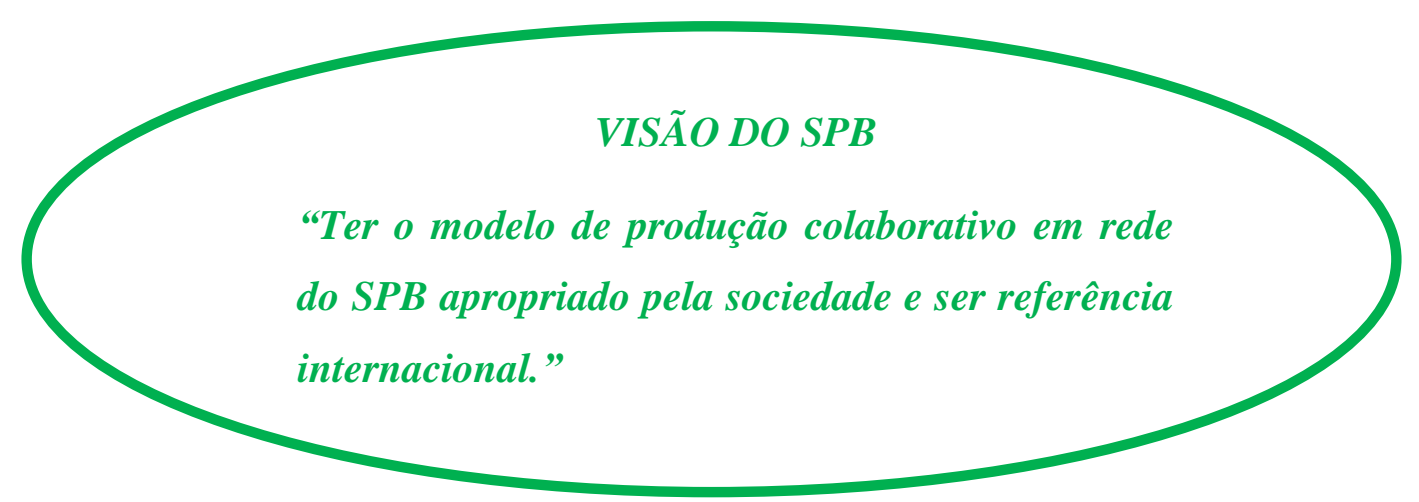

A visão corresponde ao conjunto de compreensões para qual se deve direcionar nossas ações e anseios. São as aspirações futuras. Assim sendo, o SPB pretende-se se consolidar não apenas como mais um ambiente de produção colaborativo em rede, mas ir além e ser um modelo de sucesso que permita replicar o conceito de software público em outras instâncias no país e no mundo, evidenciando por fim, que o modelo foi verdadeiramente apropriado pela sociedade. 


\section{ANEXO V GRUPO CONSULTIVO E EXECUTIVO}

\section{GRUPO EXECUTIVO}

Angela Alves

CTI

Aurélio L. Andrade

EPS

Giancarlo Stefanuto

CTI

Luciane X. Bergue

EPS

Lúcio Brusch

EPS

Paula Drummond de Castro

CTI

Sueli Varani

CTI

\section{GRUPO CONSULTIVO}

$\begin{array}{ll}\text { Adalberto Crespo } & \text { CTI } \\ \text { Adriano Santos } & \text { CACIC } \\ \text { Alex Sandro Gomes } & \text { UFPE } \\ \text { Antenor Cesar Vanderlei Corrêa } & \text { SEPIN } \\ \text { Christiana Soares de Freitas } & \text { UNB } \\ \text { Clenio Figueiredo Salviano } & \text { CTI } \\ \text { Corinto Meffe } & \text { MPOG } \\ \text { Daniel de Oliveira } & \text { DFJUG } \\ \text { Dayse Vianna } & \text { PRODERJ } \\ \text { Eduardo dos Santos } & \text { MPOG } \\ \text { Fausto Alvim } & \text { UNB } \\ \text { Giancarlo Reuss } & \text { ARAM } \\ \text { Gleibson Rodrigo (Amadeus) } & \text { UFPE } \\ \text { Jairo Fonseca } & \text { LIGHTINFOCON } \\ \text { Jarbas Lopes Cardoso Junior } & \text { CTI }\end{array}$




\begin{tabular}{|c|c|}
\hline Jorge Fernandes & UNB \\
\hline José Eduardo De Lucca & USFC \\
\hline José Maria Villac Pinheiro & Nexus Geoengenharia e Comércio \\
\hline Lídia Araujo Miranda & MPOG \\
\hline Luis Felipe Costa & SLTI \\
\hline Marcelo André de Barros Oliveira & MCT \\
\hline Marcelo Ferreira Moreno & PUC \\
\hline Marcius Fabius Carvalho & SP07 \\
\hline Miris Silva & COBRA \\
\hline Pérsio Penteado Pinto Martins & CTI \\
\hline Rachel Cavalcanti & ARAM \\
\hline Regina Thienne & CTI \\
\hline Rogério de Souza Leitão & SGD \\
\hline Sady Jacques & SERPRO \\
\hline Sérgio Leser & FINEP \\
\hline Sergio Saad & Lupa Treinamento \\
\hline Tatiana AI Chueyr Pereira Martins & CTI \\
\hline Vander Ramos Alves & UNB \\
\hline
\end{tabular}




\section{ANEXO VI PLANO DE DESENVOLVIMENTO SISTÊMICO DO SPB}

\section{POLÍTICA DO SPB}

\section{Introdução}

O presente documento é parte do Plano de Desenvolvimento Sistêmico do SPB. É resultado de um processo colaborativo entre coordenadores de comunidade do Portal SPB, SLTI/MPOG, CTI/MCT, EPS (Escola de Pensamento Sistêmico), representantes de universidades, PRODERJ,ABEP e empresas ao longo do ano de 2009. Trata-se de um documento propositivo que busca abranger os pontos considerados estratégicos para a sustentabilidade do SPB.

A Política do SPB é baseada em um objetivo geral, que descreve o propósito do SPB e cinco diretrizes. As diretrizes são focos de atuação que visam sustentar o objetivo geral. Cada diretriz relaciona um conjunto de objetivos que abarcam ações específicas no tema de cada diretriz.

Em seguida, é apresentada uma lista de temas de projetos focados nas diretrizes apresentadas.

\section{Objetivo Geral}

Construir e aprimorar continuamente uma rede de produção colaborativa de conhecimento para desenvolver, em ambiente público, soluções informatizadas de TI direcionadas ao desenvolvimento sustentável (social, econômico e ambiental).

1. Diretriz Conhecimento, Avaliação e Monitoramento do SPB - promover estudos e pesquisas periódicas para construção de uma base estruturada de conhecimentos sobre o SPB.

-objetivo 1.1.: levantar informações primárias e secundárias para a construção de indicadores que caracterizem o desenvolvimento do SPB.

-objetivo 1.2: monitorar os resultados e impactos do SPB e disseminá-los para a sociedade seus resultados

2. Diretriz Fortalecimento Operacional - facilitar a adequação física e operacional do SPB para suportar seu crescimento e manutenção.

-objetivo 2.1: implementar estudos para tornar a estrutura computacional e de recursos humanos mais autônoma. 
-objetivo 2.2: Aplicar novas tecnologias e métodos para melhoria do ambiente

3. Diretriz Fortalecimento da Rede SPB -construir um ambiente institucional que facilite a sustentação e operação da rede SPB.

-objetivo 3.1: definição de um modelo jurídico-institucional para o SPB que amplie sua sustentabilidade (social, econômico e ambiental)

-objetivo 3.2: aprimorar a qualidade da governança da Rede SPB

-objetivo 3.3: estimular a cooperação internacional

-objetivo 3.4: favorecer as oportunidades de negócios

-objetivo 3.5: promover a apropriação do modelo de software público pela rede de parceiros (universidades, empresas, órgãos de fomento, etc.), nas esferas de governo (municipal, estadual e federal) e pela sociedade.

4. Diretriz Divulgação - promover a divulgação do modelo SPB e seus conhecimentos, buscando contextualizar e alinhar com tendências e fatos portadores de futuro ( redes sociais virtuais, inteligência de redes, cultura digital etc.).

Objetivo 4.1 -implementar e gerenciar canais de informação intra-rede para viabilizar o alinhamento estratégico e a troca de melhores práticas

Objetivo 4.2 -implementar ações dinâmicas de disseminação baseadas nos objetivos estratégicos e direcionadas para web 2.0.

5. Diretriz de Pesquisa, Desenvolvimento e Inovação ${ }^{17}$ - fortalecer e pontecializar as atividades de PDI do SPB, buscando alinhamento com as demandas da sociedade.

\footnotetext{
${ }^{17}$ A dinâmica de pesquisa, desenvolvimento e inovação no SPB não obedece a uma sequencia de eventos que pressupõem uma lógica linear. Estas atividades aproximam- se de um modelo interativo de inovação baseados em designs e redesigns e feedback loop das etapas ou um redirecionamento de etapas de acordo com as respostas obtidas. Trata- se de um modelo mais fluido que é mais adequado à demanda. As relações entre as diferentes etapas são traçadas em várias combinações entre conhecimento científico e tecnológico, pesquisa e mercado, conferindo um caráter mais dinâmico e versátil ao processo inovativo (OCDE, 1992).

OCDE - Technology/Economy Programme (1992), Technology and Economy- The key Relationships. OCED, Paris. 2 Inovação é aqui entendida como o conceito amplo de inovação, ou seja, o processo de criação e apropriação social (pelo mercado ou não) de produtos, serviços, processos, métodos, e sistemas que não existiam antes, ou apresentam novas características, diferentes das já existentes (Bin e Salles, 2007)
} 
-objetivo 5.1: identificar e priorizar demandas de softwares de interesse público -objetivo 5.2: fomentar pesquisa e desenvolvimento destes software, no ecossistema SPB

-objetivo 5.3: Prospectar e aplicar novas tecnologias e métodos para melhoria do ecossistema SPB

BIN , A. ; SALLE FILHO, Sergio . Contributions to a Conceptual Framework of Technology and Innovation Planning at the Micro Level. In: 19th Annual Meeting on Socio- Economics - SASE, 2007, Copenhagen. NETWORK F Knowledge, Technology, and Innovation, 2007. v. 1. p. 1- 12. 


\section{PROGRAMAS E PROJETOS}

\section{- Programa de Monitoramento(objetivos 1.1 e 1.2)}

- Projeto para implantar monitoramento

- Projeto para identificar e estimular a demanda e a oferta

- Programa de Governança (objetivos $1.1 ; 1.2 ; 2.1 ; 2.2 ; 3.1 ; 3.2$ )

- Planejamento e gestão estratégica colaborativa

- Projeto para a definição da capacidade de infraestrutura

- Projeto de modelagem jurídico-institucional-financeiro do SPB

- Programa de incentivo à participação da Rede SPB (objetivo 3.3; 3.4; 3.5, 4.1 e 4.2)

- Projeto para o envolvimento do governo

- Projeto para atração de novos membros

- Projeto para identificar e estimular a demanda e a oferta

- Projeto de reconhecimento de contribuições de membros de comunidades

- Programa de empreendedorismo e inovação (objetivos 3.4; 3.5; 5.1; 5.2 e 5.3)

- Projeto para financiamento para entes públicos adotarem soluções livres (desde hardware até contratação de serviços)

- Projeto para incentivar a universidades para o aprendizado, cultura e empreendedorismo de software livre, aprimorar/desenvolver softwares públicos visar desenvolvimento colaborativo

- Projeto para criar certificação e selo para prestadores de serviço

- Projeto para criação da certificação de origem controlada de software do SPB

- Projeto para fortalecimento de cadeia de atores envolvidos

- Projeto para identificar e estimular oferta

- Projeto para estímulo ao compartilhamento de boas práticas de cooperação

- Programa de Divulgação (objetivos 4.1, 4.2, 1.1, 1.2, 1.3, 3.7, 5.1, 5.2) 
- Projeto para aprimorar a divulgação do modelo e promover novas formas de divulgação do modelo

- - Projeto para prover estrutura para divulgação

- Programa de Pesquisa, Desenvolvimento e Inovação (objetivos 5.1, 5.2, 5.3,

$3.5,1.1,1.2,1.3)$

- Projeto para incentivar a universidades para o aprendizado, cultura e empreendedorismo de software livre, aprimorar/desenvolver softwares públicos visar desenvolvimento colaborativo

- Projeto para estruturar Projeto estrada para futuro (FIXME)

- Projeto para fortalecer pesquisa, desenvolvimento e inovação com software livre(FIXME)

- Projeto para capacitar lista de atores 